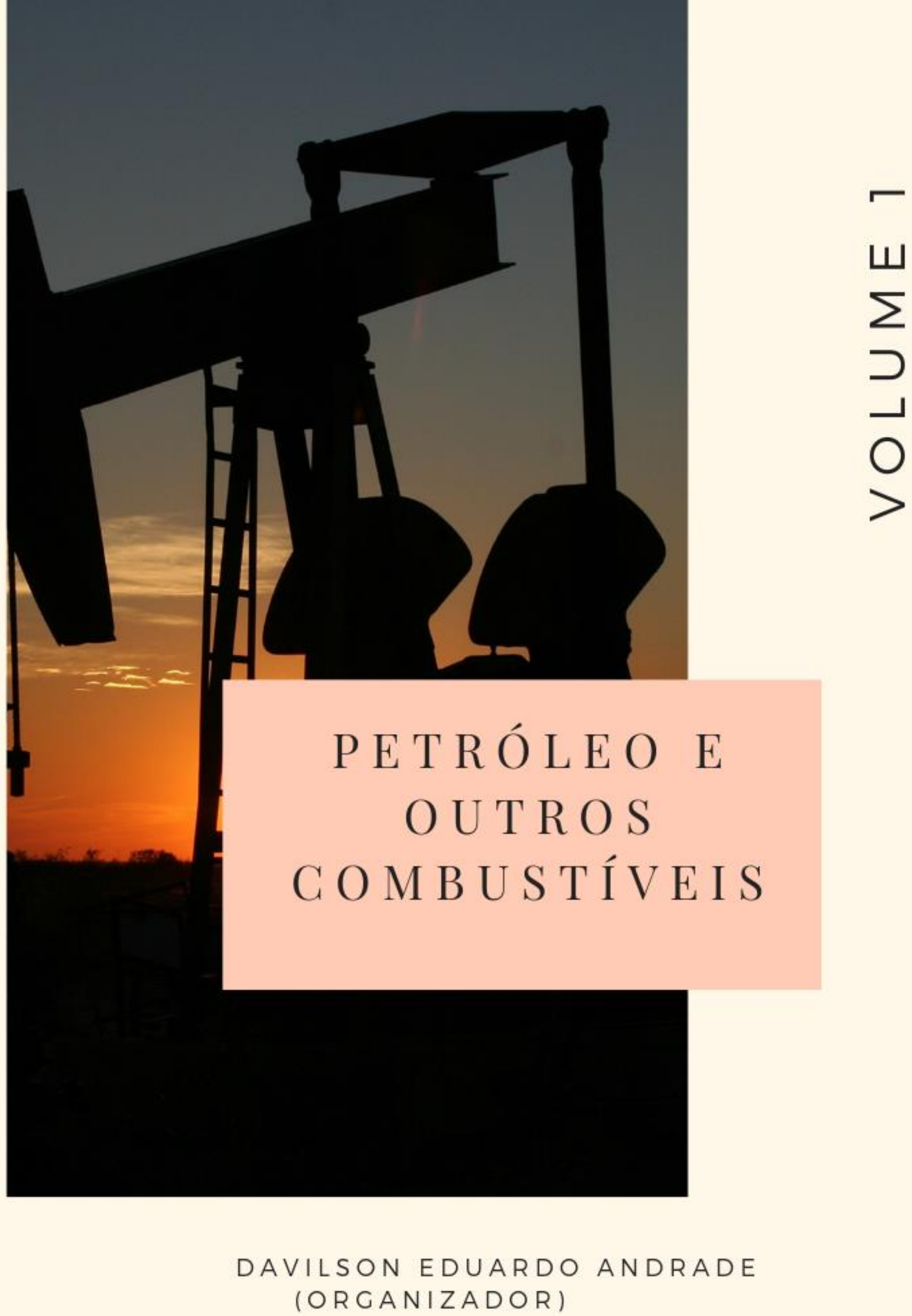

\title{
口被口
}

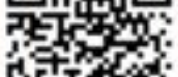


Davilson Eduardo Andrade

(organizador)

\section{Petróleo e outros combustíveis Volume 1}

1a Edição

Belo Horizonte

Poisson

2019 
Editor Chefe: Dr. Darly Fernando Andrade

\section{Conselho Editorial}

Dr. Antônio Artur de Souza - Universidade Federal de Minas Gerais

Msc. Davilson Eduardo Andrade

Msc. Fabiane dos Santos Toledo

Dr. José Eduardo Ferreira Lopes - Universidade Federal de Uberlândia

Dr. Otaviano Francisco Neves - Pontifícia Universidade Católica de Minas Gerais

Dr. Luiz Cláudio de Lima - Universidade FUMEC

Dr. Nelson Ferreira Filho - Faculdades Kennedy

Msc. Valdiney Alves de Oliveira - Universidade Federal de Uberlândia

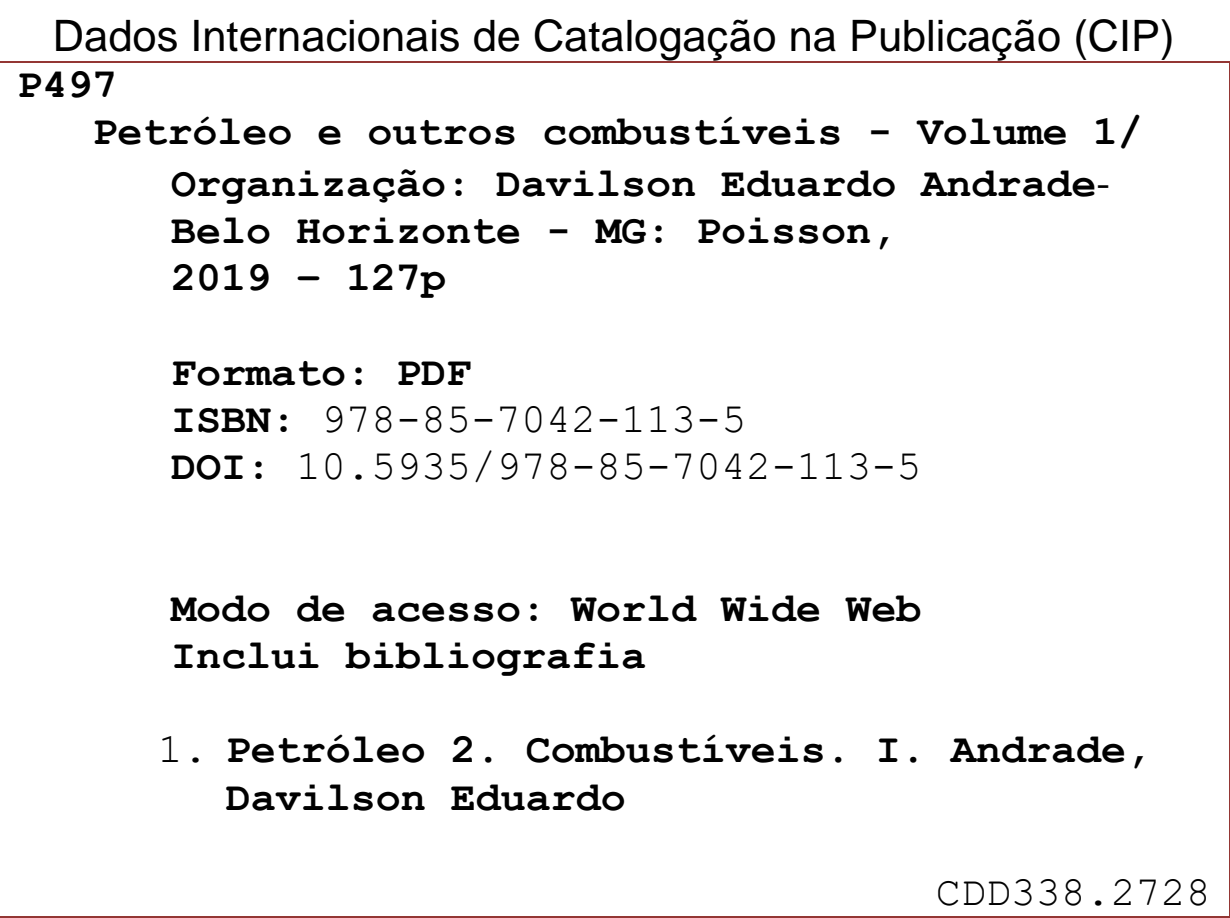

O conteúdo dos artigos e seus dados em sua forma, correção e confiabilidade são de responsabilidade exclusiva dos seus respectivos autores.

Baixe outros títulos gratuitamente em www.poisson.com.br

contato@poisson.com.br 


\section{SUMÁRIO}

Capítulo 1: 0 manejo do coral sol como espécie invasora no descomissionamento de ativos offshore

Lucas Mota de Lima, Isabelly Christinne Alves Bezerra Alencar dos Santos

Capítulo 2: Remoção de mercaptanas em corrente de butano líquido: Uma proposta inovadora, amigável ao meio ambiente, ótimo custo benefíco e elevada eficiência...... 13

Mário Augusto de Lopes de Almeida, Rosanne Graziele Vieira de Melo Santos

Capítulo 3: Estudo comparativo de características físico-químicas de resíduo oleoso da indústria de $\mathrm{E} \& \mathrm{P}$ de petróleo e diferentes tipos de cimento Portland para utilização em concreto 20

Yane Coutinho, Fernanda Cavalcanti Ferreira, Romildo Alves Berenguer, Rodrigo Mendes Patrício Chagas, Ana Maria Gonçalves Duarte Mendonça, Milton Bezerra das Chagas Filho

Capítulo 4: Caracterização dos produtos de corrosão e incrustação em equipamentos da indústria petrolífera 28

Jardel Dantas da Cunha, Fernando Nunes da Silva, Andréa Francisca Fernandes Barbosa

Capítulo 5: Formação de hidratos em perfurações de poços em águas profundas e ultra profundas 33

Vitória Camila Paixão dos Santos, Fabrícia Medeiros Santandrea, Marcos Alexandre Lopes Silva, Ilean José Ferreira Lima Verçosa, Lycia Carolinne Santos de Oliveira, Jaceguai Soares da Silva

Capítulo 6: Um estudo sobre a estrutura cristalina dos hidratos de metano. 39 José Antonio de Padua Neto, Victor Henrique Rocha Sales, Carolina Rocha Luiz Vianna

Capítulo 7: Modelagem do flowmeter para estimativa da vazão de fluidos 45

Sebastião Henrique Camilo da Silva, Márcio Roberto de Andrade Araújo, Claudiana Ferreira da Silva, Wellington dos Santos de Araújo, Ana Carolina Santos de Oliveira, Edilson Ponciano de Lima

Capítulo 8: Influência da temperatura no escoamento de petróleo em linhas de produção de fibra de vidro no campo petrolífero da cidade de Araças - BA.

Sandro Luís da Costa Alves, Luciana Rocha Alves, Luzia Aparecida Tofaneli, Turan Dias Oliveira

Capítulo 9: Oscilações log-periódicas em passeios aleatórios com perfil de memória de Cauchy-Lorentz. 60

Jair Rodrigues Neyra, Rafael Santos da Costa, André Keullen da Cunha Silva, Thiago Rafael da Silva Moura, Maria Liduína das Chagas

Capítulo 10: Capacidade de sorção da fibra de licuri na remoção de água oleosa proveniente do petróleo 66

Pedro Victor Bomfim Bahia, Thaís da Silva Bitencourt, Rosangela Regia Lima Vidal 


\section{SUMÁRIO}

Capítulo 11: Borra oleosa - Forma de mitigar acidentes e medidas alternativas de destinação final.

Rafaely Angelica Fonseca Bandeira; Antonio de Souza Araújo; Almir Mariano de Sousa Júnior; Ana Catarina Fernandes Coriolano; Regina Célia Pereira Marques; Everton Notreve Rebouças Queiroz Fernandes; Francisco Odair Filgueira Junior

Capítulo 12: Água produzida: Gerenciamento de efluente- revisão 79 Larissa Freitas Farias, Laíse Ramonny Oliveira Nunes

Capítulo 13: Interpretação do perfil fluid capacitance da ferramenta production logging tool. 85

Sebastião Henrique Camilo da Silva, Márcio Roberto de Andrade Araújo Filho, Claudiana Ferreira da Silva, Wellington dos Santos de Araújo, Ana Carolina Santos de Oliveira, Edilson Ponciano de Lima

Capítulo 14: Avaliação da gasolina aditivada utilizada na cidade de Campina Grande-PB através da determinação de parâmetros físico-químicos 92

Lauanda Albuquerque Queiroz, Yasmin Geissiana Marinho de Menezes, Marcos Mesquita da Silva, Divanira Ferreira Maia

Capítulo 15: Caracterização do querosene de aviação em mistura de pseudocomponentes e simulação do processo de hidrodessulfurização

Mateus Fernandes Monteiro, Mario Hermes de Moura Neto, Diêgo Vinícius Fernandes Bezerra, Paula Fabiane Pinheiro do Nascimento, Eduardo Lins de Barros Neto, Osvaldo Chiavone Filho

Capítulo 16: Simulação e Análise do Comportamento da Onda Eletromagnética de Dados GPR no Monitoramento de Postos de Gasolina.

Debora Abreu da Silva, Zoraida Roxana Tejada da Piedade, Anderson Almeida da Piedade

Capítulo 17: Royalties de petróleo e municípios paulistas confrontantes no contexto da sustentabilidade integral

Hirdan Katarina de Medeiros Costa, André Felipe Simões, Edmilson Moutinho dos Santos, Paulo Santos de Almeida, Homero Fonseca Filho, Ednílson Viana

Capítulo 18: Propriedades do biodiesel de sebo bovino e suas misturas bx a baixas temperaturas.

Maria Gabriela da Silva Cavalcanti, Luiz Antônio Pimentel Cavalcanti

Capítulo 19: Estudos comparativos no processo industrial de produção de bioetanol a partir do melaço e caldo de cana-de-açúcar.

Scarllet O'hara de Oliveira Moraes, Wellington da Silva Rodrigues, Kelson Carvalho Lopes, Fábio de Melo Resende

Capítulo 20: Síntese de catalisadores a base de cério e zircônio por decomposição térmica de nitratos 


\section{SUMÁRIO}

Capítulo 21: Avaliação da eficiência do extrato de alecrim na estabilidade oxidativa do biodiesel soja/sebo $80 / 20 \%(\mathrm{~m} / \mathrm{m})$.

Ingrid Rocha Teixeira, Daniel Freire Almeida, Selmo Queiroz Almeida, Iran Talis Viana Santos, Leila Maria Aguilera Campos

Capítulo 22: Análise de rendimento do catalisador heterogêneo óxido de alumínio (al2o3) na produção de biodiesel de soja (Glycine Max)

Rayanne Samara de Sousa Reinaldo, Leonardo Alcântara Alves, Maria Rosimar de Sousa, Klismeryane Costa de Melo

Capítulo 23: Escala piloto de produção da Nanoferrita Ni0,5 Zn0,5 Fe204: Avaliação da reprodutibilidade para aplicação como catalisador nanomagnético na obtenção de biodiesel

Joelda Dantas, Ana Cristina Figueiredo de Melo Costa

Capítulo 24: Avaliação Catalítica de Cerâmicas Magnéticas NiFe204 e Dopadas com

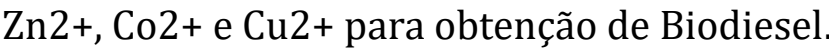

Daniela da Costa Barbosa, Adriano Lima da Silva, Ana Flávia Felix Farias, Joelda Dantas, Ana Cristina Figueiredo de Melo Costa, Simoni Margareti Plentz Meneghetti

Capítulo 25: Síntese de ferrita do tipo ni0,5 Zn0,5 Fe204 e utilização como catalisador em reação de esterificação do óleo de soja para obtenção de biodiesel. 204

Joelda Dantas, Elvia Leal, Nathalia Oliveira Araújo, Kleberson Ricardo de Oliveira Pereira, Pollyana Caetano Ribeiro Fernandes, Ana Cristina Figueiredo de Melo Costa

Capítulo 26: Produção de hidrogênio a partir da eletrólise do resíduo de frutas tropicais 221

Adriana Carla de Oliveira Lopes, Fabiane Caxico de Abreu Galdino

Capítulo 27: Análise de risco associada aos desafios da exploração do gás natural liquefeito em ambiente offshore por plantas FLNG. 230

Kaique Moreira Matos Magalhães, Geraldo José Belmonte dos Santos, Armando Sá Ribeiro Junior

Capítulo 28: Energia eólica: Perspectivas no Brasil e no mundo 237

Erica Werneck Duarte Melo, Isabela Pessanha Vilaça, João José de Assis Rangel

Autores: 


\section{Capítulo 1}

\section{O manejo do coral sol como espécie invasora no descomissionamento de ativos offshore}

\section{Lucas Mota de Lima}

\section{Isabelly Christinne Alves Bezerra Alencar dos Santos}

Resumo: No Brasil a maior parte da produção de petróleo e gás natural ocorre no ambiente offshore, na qual existe plataformas de produção que operam desde a década de 60. Isso significa que boa parte delas estão em processo de desativação, conhecido como descomissionamento. Um risco para a remoção desses ativos é que boa parte estão incrustados com a espécie bioinvasora do coral sol, que tem impacto na população e comunidade nativa marinha do Brasil, além do impacto negativo no âmbito econômico e social. 0 presente trabalho tem como objetivo tratar do manuseio, controle, e remoção da espécie invasiva do coral sol nos ativos offshore na etapa do descomissionamento, tendo em vista que o coral sol representa um potencial aumento de custos e complicações para o setor petrolífero. Para tanto realizou-se uma revisão da literatura especializada utilizando dados de órgãos da administração pública federal direta, relatórios de pesquisas ambientais, artigos científicos, estudos elaborados por grupos, fundações, confederações e conselhos relacionados à petróleo, gás natural e meio ambiente. A necessidade de identificação de tecnologias, subaquáticas ou sob aquáticas, de controle e/ou erradicação do coral-sol que considerem também a contenção da dispersão e a filtragem do efluente, bem como de empresas no mercado nacional que busquem disponibilizá-las para imediata atuação, são os elementos que tornam o manejo do coral sol na etapa de descomissionamento bem-sucedido. Portanto, qualquer medida de gestão do coral sol deve prever avaliações de custo-benefício envolvendo a valoração dos benefícios dessas atividades e dos passivos que estas determinam.

Palavras-chave: Descomissionamento, Coral Sol, Bioinvasão. 


\section{INTRODUÇÃO}

No Brasil a maior parte da produção de petróleo e de gás natural ocorre em campos marítimos. Há registro de plataformas de produção offshore desde a década de 60, atualmente totalizam cerca de 150 estruturas em funcionamento, destas $42 \%$ operam há mais de 25 anos. Essas estruturas são projetadas para durarem em torno de 20 a 25 anos, ou seja, as plataformas offshore nacionais passam por um expressivo cenário de desativação (ANP, 2017).

Segundo o Grupo de Economia da Energia e a Gerencia de Análise Econômica (IBP, 2017) a Petrobras é a empresa mais afetada pela desinstalação de equipamentos marítimos, já que, das 79 plataformas com idade acima de 25 anos no Brasil, 74 são operadas pela empresa.

0 abandono é a última etapa da vida útil das instalações de produção de petróleo e gás em que ocorre a desativação das instalações, tamponamento dos poços produtores e a remoção dos equipamentos, sendo esta denominada de descomissionamento.

A operação de descomissionamento é o conjunto de ações legais, procedimentos técnicos e de engenharia aplicados de forma integrada a um sistema offshore com o objetivo de assegurar que sua desativação ou cessação de produção atinjam as condições de segurança, condições de preservação ambiental, confiabilidade e rastreabilidade de informações e documentos (E\&P BRASIL, 2018 a).

Essas atividades são relativamente inovadoras nos campos brasileiros, pois só agora a indústria nacional está começando a lidar com o fim da vida produtiva de alguns campos e/ou fim da vida útil de suas plataformas nos campos exploratórios e produtivos de petróleo e gás (SANTOS, 2011).

Além disso há os riscos da remoção desses ativos, devido ao fato que durante o período de exploração, as Unidades Estacionárias de Produção (UEP) que ficam submersas tornam-se parte integrante do ecossistema submarino. As barras de aço verticais, horizontais e oblíquas dessas estruturas tem, rapidamente, uma vida marinha associada (TEIXEIRA e MACHADO, 2012).

Essas espécies têm determinadas características biológicas que potencializam seu sucesso como bioinvasoras.

A bionvasão pode ser definida com o processo de ocupação de ambiente natural por espécie exótica, provocando impactos ambientais negativos, como mudanças no meio abiótico, competição, hibridação, deslocamento de espécies nativas, entre outros (CARLTON, 1996; COLAUTTI e MACISAAC 2004).

o Coral-Sol é deslocado do seu habitat natural, através de águas de lastros ou organismos incrustados em cascos de navios e outras embarcações, como navios sondas e plataformas que se deslocam entre diferentes regiões do mundo e ancoram na costa brasileira (E\&P BRASIL, 2018 a). Assim, são espécies de outros lugares do mundo, ou seja, exóticas para o Brasil, trazidas por embarcações.

Segundo alguns autores as plataformas e outras estruturas associadas à exploração de petróleo são os principais vetores de introdução do coral-sol (FERREIRA et al, 2006; CREED et al, 2017). Estudos realizados por SAMMARCO et al. (2004) e FRIEDLANDER et al. (2014) mostraram que essa espécie era dominante em UEP no golfo do México e no leste africano. Contudo outros autores admitem a participação de navios como vetores de dispersão dessas espécies de corais, que ficam incrustadas nos cascos das estruturas (CASTRO \& PIRES, 2001; DE PAULA \& CREED, 2004).

Há também outra evidências que comprovam que a bioincrustação nessas estruturas seja o principal vetor de introdução da espécie na costa brasileira, de acordo com PSZCZOL et al. (2017): (a) os registros de ocorrência mais antigos estão em plataformas de petróleo; (b) foi observada uma ligação entre os registros de transporte de petróleo e gás por navegação e o registros de invasões em comunidades naturais; (c) os principais pontos de introdução costeiras estão sempre associados às instalações portuárias usadas pela indústria de petróleo e gás.

Esse bioinvasor causa impacto na população e comunidade nativa marinha do Brasil e de outras regiões afetadas pela sua introdução (CREED, 2006; LAGES et al., 2011; MIRANDA et al., 2016), as maiores consequências são a alteração de habitats, predação, deslocamento de espécies nativas, alteração na cadeia trófica e ciclagem de nutrientes, parasitismo, competição e aumento da capacidade de sobrevivência de novas espécies invasoras (CROOKS, 2002).

Além do impacto negativo no âmbito econômico e social, como problemas na saúde pública e na perda da 
produção de atividades relacionadas, como a pesca, aquicultura, turismo e infraestrutura (BRASIL, 2017). 0 reflexo social é visto na perda de emprego e do bem-estar das populações pela redução da qualidade do seu ambiente natural (BAX et al., 2003). Os custos relativos às ações de controle das espécies exóticas invasoras também são somados aos impactos econômicos das invasões biológicas (PIMENTEL et al. 2001).

Na exploração e produção as estruturas que ficam submersas tornam-se parte integrante do ecossistema submarino, alvo de atração e abrigo para as mais variadas espécies de peixes, com interação entre algas, corais e moluscos. Nesse contexto que o presente trabalho tem como objetivo tratar do manuseio, controle, e remoção da espécie invasiva do coral sol nesses ativos, tendo em vista que o coral sol representa um potencial aumento de custos e complicações para o setor petrolífero, tornando-se um desafio na etapa do descomissionamento.

\section{METODOLOGIA}

Este estudo constituiu-se de uma revisão da literatura especializadautilizando os dados e publicações de agências nacionais e internacionais de regulação de petróleo e gás natural, dados de órgãos da administração pública federal direta, relatórios de pesquisas ambientais, artigos científicos, estudos elaborados por grupos, fundações, confederações e conselhos relacionados à petróleo, gás natural e meio ambiente.

\section{RESULTADOS E DISCUSSÃO}

A fase de descomissionamento é inerente à atividade de extração de petróleo, seja por condições técnicas que inviabilizem o processo de extração do óleo, pelo próprio exaurimento do recurso ou por questões econômicas, com o objetivo principal de devolver a propriedade, mas livre de danos ambientais e restaurada nas condições originais, obedecendo regulamentações do Ibama, ANP e Marinha (MARTINS,2015).

As autoridades ambientais querem evitar que o coral-sol, considerado uma espécie bioinvasora, seja carregado para a superfície junto com os equipamentos substituídos ou que vão ser descartados. 0 objetivo é evitar que a retirada de equipamentos possa trazer para a superfície o invasor incrustado em uma plataforma ou linhas de produção instaladas há 30 ou 40 anos (VALOR ECONÔMICO, 2018). A preocupação da indústria é que ainda não há uma regra sobre como lidar com o coral-sol e outras questões envolvendo a desativação dos campos e plataformas.

A incrustação de coral-sol em plataformas de petróleo e outras estruturas e embarcações associadas à exploração de petróleo e gás natural tem levado à solicitação de ações de remoção de coral-sol em instalações, mudança de rota e extensão de permanência na locação e inspeção de unidades (E\&P BRASIL, 2018 b).

A atenção com os principais vetores pode ser uma importante medida para se tentar controlar a disseminação do coral-sol pela costa brasileira. Os vetores podem aumentar a propagação do invasor através de disseminação secundária, frustrando a gestão de contenção e facilitando o potencial invasor da espécie estabelecida (PSZCZOL et al.,2017).

A aparente relação com portos onde fundeiam-se ou fazem-se a manutenção de plataformas da indústria de petróleo e gás é um indício disso (BRASIL, 2017).

Assim, o monitoramento dos vetores em mobilização é uma medida importante, principlamete nas operações descomissionates. Medidas de gerenciamento de risco devem ser consideradas em relação à entrada de possíveis vetores de dispersão em locais onde ainda não se observa o coral sol.

Em relação ao do controle e/ou erradicação do coral-sol, apenas algumas estratégias estão documentadas. A limpeza subaquática mecânica completa de casco em ambiente offshore realizada por mergulho demandaria longos períodos (atualmente a taxa de remoção obtida com os métodos utilizados está em torno de $1,3 \mathrm{~m}^{2} / \mathrm{h}$, segundo dados da Petrobras). Por exemplo, para uma plataforma como um Floating, Production, Storage and Offloading (FPSO), com uma área submersa de aproximadamente $20.000 \mathrm{~m}^{2} .0$ tempo de mergulho efetivo seria de aproximadamente 15.000 horas, elevando o risco aos mergulhadores.

Cabe esclarecer que a realização de operações desse tipo deve ser feita em consonância com as atividades da plataforma (atenção com tomadas d'água, movimentação de carga, etc.) e possui restrições de recursos, tanto de acomodação das equipes e equipamentos na plataforma, quanto de disponibilidade de 
embarcações que realizam mergulhos a partir do próprio barco.

Outro método para o tratamento e erradicação do coral-sol é o envelopamento, onde o recobrimento de estruturas incrustadas com coral-sol por papel plástico ou folhas de ráfia se mostrou um método efetivo na eliminação dessas espécies. As tecnologias de encapsulamento utilizam tecidos impermeáveis (lona de polietileno) para envolver o casco de embarcações ou estruturas artificiais (pilares de píer), a fim de impedir o fluxo de água entre a área em torno da superfície revestida pelo invólucro e o ambiente, criando, assim, condições tóxicas para os organismos incrustados. Biocidas presentes no revestimento antiincrustante da embarcação também podem contribuir para a mortalidade dos organismos. 0 encapsulamento não remove a incrustação biológica, os organismos são mortos e permanecem no local (INGLIS et al., 2012).

Além dos métodos subaquaticos de remoção de bioincrustção, existem as técnicas de remoção sob aquática (fora da água). A técnica de dessecação, ou secagem ao ar, é uma técnica em que a embarcação é retirada da água e deixada sobre um suporte até que toda a bioincrustação seja eliminada. 0 tempo necessário para que os organismos bioincrustantes morram quando expostos ao ar varia com as condições ambientais locais, tais como temperatura, umidade, precipitação e luz solar direta, e com a quantidade de organismos incrustados presentes.

Em ambos os casos a técnica de hidrojateamento é mais eficiente de remoção de grandes quantidades de bioincrustação de cascos de navios do que a remoção manual.

Faz-se necessária a identificação de tecnologias de limpeza que considerem a contenção da dispersão e a filtragem do efluente, bem como de empresas no mercado nacional que busquem disponibilizá-las para imediata atuação.

COUTTS \& FORREST (2007) descreveram uma série de procedimentos para que uma erradicação seja bem-sucedida, e que estão elencados a seguir: (I) ter estudos de base; (II) determinações claras e resposta rápida das autoridades; (III) comprometimento de esforços e recursos para atender aos objetivos; (IV) colaboração de todas as partes interessadas; (V) tempo suficiente de quarentena para evitar a dispersão; (VI) adequado gestão de projeto; e (VII) procedimentos de garantia de qualidade.

A diferença na distribuição vertical das populações de coral-sol impacta seu controle e erradicação. A probabilidade de sucesso na erradicação do bioinvasor decresce com a dificuldade de acesso à população, ou seja, quanto maior a profundidade que uma espécie é encontrada, menor é a probabilidade de controlála ou erradicá-la. a mesma. Ademais, no ambiente marinho, o custo financeiro ao acesso à população está relacionado com a profundidade (SAMMARCO et al., 2013). Além da profundidade, outro fator limitante para o manejo desse coral é sua ocorrência em fendas e acidentes muito comuns nos costões rochosos, impedindo o acesso manual e até visual (CREED et al., 2016).

\section{CONCLUSÃO}

Através do estudo dos desafios do manuseio e remoção da espécie invasiva do coral sol nas etapas de descomissionamento de ativos offshore, foi possível inferir algumas conclusões:

- Tratar de medidas de controle da bioinvasão no ambiente marinho é uma questão complexa pelo fato de a maioria dos vetores de introdução de espécies aquáticas estar associada a atividades de grande importância econômica.

- Qualquer medida de erradicação e gestão do coral sol no processo de descomissionamento, deve prever avaliações de custo-benefício envolvendo a valoração dos benefícios dessas atividades e dos passivos que estas determinam. Além disso, qualquer medida deve considerar praticidade e probabilidade de êxito, e a duração dessas ações de resposta.

\section{REFERÊNCIAS}

[1] Anp. Descomissionamento de Instalações Offshore Visão do Regulador. Agência Nacional do Petróleo, Gás $\begin{array}{lll}\text { Natural e } & \text { Biocombustíveis, } & \end{array}$ $2017 . \quad$ Disponível em:<https://www.ibp.org.br/personalizado/uploads/2017/08/01_MarceloMafra_IBP_Descomissionamento_22_09_2017.pdf >. Acesso em: 20 Jun. 2018.

[2] Bax, N., Wiliamson, A., Aguero, M. Gonzales, E., Geeves, W. Marine Invasive 
[3] Alien Species: A Threat to Global Biodiversity. Marine Policy, v.27, n.4, p.313-323, 2003.

[4] Brasil. Ministério da Ciência, Tecnologia, Inovação e Comunicações. Grupo de Trabalho Coral-Sol. Relatório Final. Plano Setorial para os Recursos do Mar. Brasília, DF, 02 fev.2017. 77p. Disponível em: < https://www.slideshare.net/MCTI/grupo-de-trabalho-coral-sol-relatrio-final>. Acesso em: 07 jun. 2018.

[5] Carlton, J.T. Biological Invasions and Cryptogenic Species. Ecology, v. 77, n.6, p. 1653- 1655, 1 set.1996.

[6] Castro, C. B.; Pires, D. O.Brazilian Coral Reefs: What We Already Know and What is Still Missing. Bulletin of Marine Science, v. 69, n. 2, p. 357-371, 2001.

[7] Colautti, R.I., Macisaac, H.J. A neutral terminology to define 'invasive' species.

[8] Diversity and Distributions, Canadá, v.10, p.135-14, 2004.

[9] Coutts, A.D.M. \& Forrest, B.M. (2007). Development and Application of Tools for Incursion Response: Lessons Learned From the Management of the Fouling Pest Didemnum Vexillum . Journal of Experimental Marine Biology and Ecology, 342: 154-162

[10] Creed, J.C. Two Invasive Alien Azooxanthellate Corals, Tubastrea Coccinea and T. Tagusensis, Dominate the Native Zooxanthellate Mussimilia Hispida in Brazil. Coral Reefs, v.25, n.3, p. 350-350, 2006.

[11] Creed, J.C., Fenner, D., Sammarco, P., Cairns, S., Capel, K., Junqueira, A.O.R., Cruz, I., Miranda, R.J., Carlos-Junior, L., Mantelatto, M.C.,

[12] Oigman-Pszczol, S. The Invasion of The Azooxanthellathe Coral Tubastrea (Scleractinia: Dendrophyliidea) Throughout The World: History, Pathways and Vectors. Biol Invasions, v.19, p.283-305, 2017. Disponível em: <https://doi.org/10.1007/s10530-016- 1279-y>. Acesso em: 10 maio. 2018.

[13] Crooks, J.A. Characterizing Ecosystem-Level Consequences of Biological Invasions: The Role of Ecosystem Engineers. Oikos, v.97, p. 153-166, 2002.

[14] De Paula, A. F.; Creed, J. C. Two Species of the Coral Tubastraea (Cnidaria, Scleractinia) in Brazil: A Case of Accidental Introduction. Bulletin of Marine Science, v. 74, n. 1, p. 175-183, 2004.

[15] E\&P Brasil. Descomissionamento: unificando definições. 2018 Disponível em:<http://epbr.com.br/unificando-as-definicoes-sobre-descomissionamento/>. Acesso em: 15 Jun. 2018.

[16] E\&P Brasil. Descomissionamento: o Meio Ambiente e o Coral Sol. 2018. Disponível em:< http://epbr.com.br/descomissionamento-o-meio-ambiente-e-o-coral-sol/>. Acesso em: 01 Jul. 2018.

[17] Ferreira, C.E.L.; J.E.A. GONÇ ALVES, \& R. Coutinho. Ship hulls and oil platforms as potential vectors to marine species introduction. Journal of Coastal Research, n.39, p.1341-1346, 2006.

[18] Friedlander, A.M., Ballesteros, E., Fay, M., Sala, E. Marine Communities on

[19] Oil Platforms in Gabon, West Africa: High Biodiversity Oases in a Low Biodiversity Environment. PLoS ONE, v.9, n.8, 2014. Disponível em: < https://doi.org/10.1371/journal.pone.0103709>. Acesso em: 10 maio.2018.

[20] IBP. Instituto Brasileiro do Petróleo, Gás Natural e Biocombustíveis. Regulação do Descomissionamento e seus Impactos para a Competitividade do Upstream no Brasil. Cooperação e Pesquisa IBP - UFRJ. Ciclo de Debates sobre Petróleo e Economia. Rio de Janeiro, RJ, 2017. $62 \quad$ p. Disponível em:< https://www.ibp.org.br/personalizado/uploads/2017/10/TD-Regulação-do- Descomissionamento-site2.pdf>. Acesso em: 25 Jun. 2018.

[21] Inglis, G., Floerl O. \& Woods C. (2012). Scenarios of Vessel Biofouling Risk and their Management. An Evaluation of Options. MAF Technical Paper No: 2012/07. 126 p.

[22] Martins, C. F. O Descomissionamento de Estruturas de Produção Offshore no Brasil. 2015. 43 f. Monografia (Bacharelado em Engenharia Ambiental), Departamento de Engenharia Ambiental. Programa de Pós-Graduação em Engenharia Ambiental. Universidade Federal do Espírito Santo, Vitória.

[23] Pimentel, D.; Mcnair, S; Janecka, J.; Wightman, J.; Simmond, C.; O'connell, C.; Wong, E.; Russel, L.; ZERN, J.; Aquino, T.; Tsomondo,

[24] T.Economic and environmental threats of alien plant, animal, and microbe invasions.

[25] Agriculture, Ecosystems \& Environment, v.84, p.1-20, 2001.

[26] Pszczol, S.0; Creed, J.; Fleury, B. O Controle da Invasão do Coral-Sol no Brasil não é uma Causa Perdida. Sociedade Brasileira para o Progresso da Ciência. São Paulo, v.69, no.1, 2017. Versão On-line ISSN 2317-6660. 
[27] Sammarco, P. W.; Atchison, A. D.; Boland, G. S. 2004. Expansion of Coral

[28] Communities Within the Northern Gulf of Mexico Via Offshore Oil and Gas Platforms. Marine Ecology Progress Series, v.280, p.129-143, 2004.

[29] Sammarco, P.W. (2013). Corals on Oil and Gas Platforms Near the Flower Garden Banks: Population Characteristics, Recruitment, and Genetic Affinity. U.S. Dept. of the Interior, Bureau of Ocean Energy Management, Gulf of Mexico OCS Region, New Orleans, LA.

[30] Santos, L. F. D. Descomissionamento de sistemas offshore técnicas, potênciais problemas e riscos relacionados ao final da vida produtiva. Relatório de Projeto Final em Engenharia Naval - Universidade Federal do Rio de Janeiro, Escola Politécnica: Rio de Janeiro, 2011.

[31] Teixeira, B. M.; Machado, C. J. S. Marco Regulatório Brasileiro do Processo de Descomissionamento Ambiental da Indústria do Petróleo. Revista de Informação Legislativa, Brasília, a. 49, n. 196, p. 183-203, dez. 2012.

[32] Valor ECONÔMICO. Coral Sol Ameaça Renovação da Bacia de Campos. Disponível em: < https://www.valor.com.br/brasil/5449825/coral-ameaca-renovacao-da-bacia-de-campos>. Acesso em: 01 Jun. 2018. 


\section{Capítulo 2}

Remoção de mercaptanas em corrente de butano líquido: Uma proposta inovadora, amigável ao meio ambiente, ótimo custo benefíco e elevada eficiência

\section{Mário Augusto de Lopes de Almeida}

Rosanne Graziele Vieira de Melo Santos

Resumo: 0 estudo trata sobre uma forma alternativa de tratamento para remoção de mercaptanas presentes em corrente líquida de butano da Banagas (Bahrain National Gas). 0 objetivo foi desenvolver uma proposta eficiente e que substituísse o uso de KOH, gerador de resíduos desagradáveis. A tecnologia proposta tem várias vantagens sobre o $\mathrm{KOH}$, tais como: a reação entre o produto proposto " $\mathrm{A}$ " e as mercaptanas resulta no valioso produto " $\mathrm{C}$ " no qual pode ser aproveitado comercialmente; a possibilidade de recuperação de quase $15 \mathrm{~m}^{3} / \mathrm{d}$ da água usada no processo e o produto da reação B pode reaparecer como produto " $\mathrm{A}$ " mediante uma operação de regeneração muito simples e econômica. Dessa forma, os esforços são direcionados ao aproveitamento dos produtos das reações o que gera um cenário amigável ao meio ambiente, em termos de eliminação de descarte de resíduos, e lucratividade com sua comercialização. Os testes de laboratório comprovaram a eficiência da tecnologia proposta e os autores sugerem a realização de teste de campo, sob as condições reais de operação da planta da Banagas, como forma de comprovar os resultados obtidos.

Palavras-chave: butano líquido, mercaptanas, leito fixo reacional, regeneração, recuperação. 
Vários compostos sulfurados são geradores de odores desagradáveis tais como as mercaptanas (compostos orgânicos que contêm o grupo -SH).

"O nome mercaptana do latim mercurius captans, deriva da capacidade que o grupo -SH tem de ligar-se fortemente com o mercúrio, também denominados de tióis ou grupo sulfidrila." (SILVA FILHO 2013).

A etil-mercaptana [metil-mercaptana] é o composto de enxofre encontrado com maior frequência e teor no butano como matéria-prima. Entretanto, existem outros compostos como dissulfeto de carbono, sulfeto de carbonila e metil-mercaptana [etil-mercaptana] que por serem gasosos nas condições ambientais são difíceis no manuseio (RODRIGUES, 2016).

Pode-se destacar alguns processos conhecidos mundialmente no tratamento de mercaptanas, a saber:

- Tratamento Cáustico: consiste na utilização de uma solução aquosa de KOH ou NaOH e tem a capacidade de eliminar compostos ácidos de enxofre tais como H2S e mercaptanas de baixo peso molecular. Apresenta como aspectos negativos a baixa eficiência assim como a necessidade de usar grandes volumes de produto químico;

- Tratamento Merox: consiste no tratamento cáustico regenerativo seguida da oxidação a dissulfetos. A vantagem do processo consiste na regeneração da base consumida, reduzindo assim os custos operacionais;

- Tratamento Bender: consiste na transformação de compostos sulfurados corrosivos (mercaptanas) em outras formas poucos agressivas (dissulfetos). Nesse processo existe uma combinação entre lavagens cáusticas e reações com enxofre com ações de campos elétricos de elevada voltagem;

- Sulfatreat: consiste em um processo seco, ou seja, não usa líquidos. Trata- se da aplicação de óxido de ferro impregnado em material sólido poroso; (SOUZA, 2002).

- Leito fixo reacional: consiste no tratamento de mercaptanas através de leito fixo reacional impregnado por químicos apropriados.

\section{INTRODUÇÃO}

O objetivo principal do presente estudo foi apresentar uma solução técnica para o tratamento de remoção de mercaptanas em corrente de butano líquido da Banagas (Bahrain National Gas). Como consequência da referida solução técnica pretende-se eliminar o uso de $\mathrm{KOH}$ enquanto método de tratamento de remoção de mercaptanas e apresentar solução para a questão ambiental causada pelo descarte dos subprodutos reacionais decorrente do tratamento cáustico, evitando assim qualquer tipo de descarte de produtos gerados de odores. Além disso, os trabalhos foram direcionados de modo a desenvolver uma tecnologia na qual os aspectos regeneração e recuperação sejam tomados como requisitos importantes.

É necessário esclarecer alguns aspectos sobre regeneração e recuperação do leito fixo reacional. A regeneração é uma atividade operacional, isto é, não é necessário remover o leito para regenerar, uma vez que este procedimento é feito no próprio tratador durante a operação de tratamento para a remoção das mercaptanas. Na recuperação é necessário remover o leito fixo para um local adequado no qual a operação possa ser realizada.

\section{METODOLOGIA}

Os testes laboratoriais foram projetados de modo a simular as condições de campo da Banagas.

A proposta do estudo é a aplicação de um leito fixo reacional de areia impregnada com o produto "A". Em escala de laboratório não foi possível visualizar a eficiência dos leitos impregnados. Portanto, a maior parte dos testes foram realizados na solução do produto "A" de modo que foi possível obter dados qualitativos e quantitativos ${ }^{1}$ para posterior tratamento dos dados.

\footnotetext{
1 Todos os subprodutos gerados serão analisados em laboratório apropriado. O objetivo das análises será comprovar os dados estequiométricos gerados na simulação computacional, dados de literatura e informações qualitativas.
} 


\section{MATERIAIS E MÉTODOS}

No presente estudo optou-se realizar os testes com GLP, pois este contém 30 ppmw de etil mercaptana, < 5 ppmw de $\mathrm{H} 2 \mathrm{~S}$ e $<30$ ppmw de enxofre, ou seja, quantidades conhecidas de compostos de enxofre.

Foram usados os seguintes simuladores:

- WebQC - para o balanceamento das equações e cálculo estequiométrico.

- ChemSep e ChemCad - para simular o processo nas condições de operação da planta da Banagas.

Outros materiais: balança analítica (precisão de 3 casas decimais); produto "A"; conectores; rolhas; mangueiras; conexões; reatores; válvulas de controle; borbulhadores e bico de Bunsen.

\section{Leito Fixo}

A construção do leito fixo reacional se deu da seguinte forma: tomou-se 126 gramas de areia de 16- 30 mesh e impregnou-se com 30,8 mL com o produto "A". Em seguida, adicionou-se mais 126 gramas de areia seca com a mesma especificação (16 -30 mesh) sobre o leito já impregnado, com o objetivo de proporcionar selamento, reparando rachaduras e impedindo a formação de possíveis caminhos preferencias para o GLP. Ao final, foi dado tempo necessário para que a areia depositada na parte superior pudesse adsorver a o máximo de líquido depositado na parte inferior.

Esquema 1: descrição do aparato laboratorial referente ao leito fixo reacional.

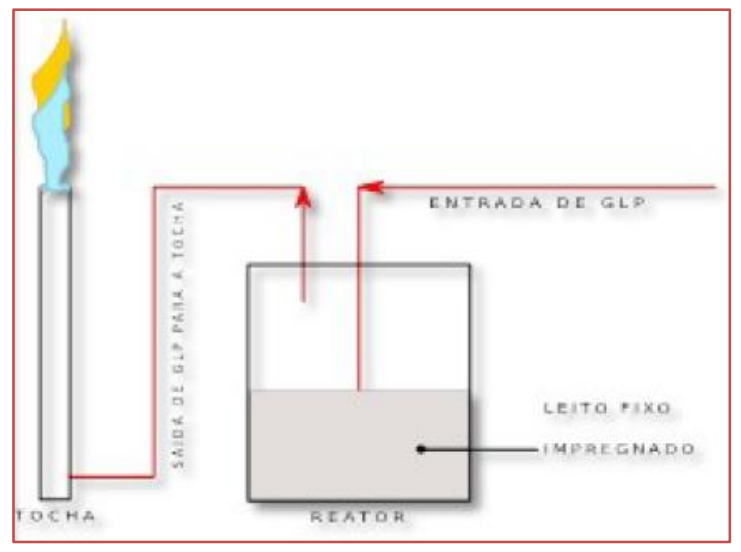

Foto 1: Aspecto dos reatores na prática antes de iniciar os testes.

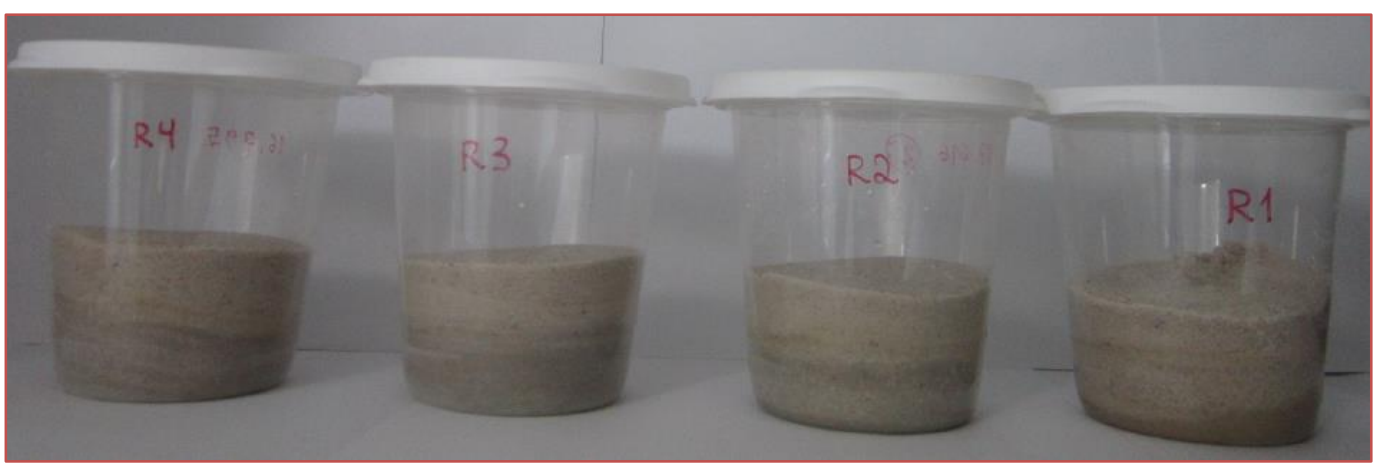


Dados:

- $\quad$ Reatores (1,2,3 e 4): local onde ocorrem as reações de sequestro das mercaptanas; altura útil: 85 mm; nível do líquido: $40 \mathrm{~mm}$ e diâmetro interno: $72 \mathrm{~mm}$.

- $\quad$ Condições laboratoriais: pressão: 1 atm e temperatura: $26^{\circ} \mathrm{C}$.

\section{Solução do Produto "A"}

Dados:

- $\quad$ Reatores $(1,2,3,4,5,6,7$ e 8$)$ : local de onde ocorrem as reações de sequestro das mercaptanas; altura útil: $85 \mathrm{~mm}$; nível do líquido: $63 \mathrm{~mm}$ e diâmetro interno: 25,4 $\mathrm{mm}$.

- $\quad$ Condições laboratoriais: pressão de 1 atm e temperatura $26^{\circ} \mathrm{C}$.

Esquema 2: descrição do aparato laboratorial referente ao teste em solução do produto "A".

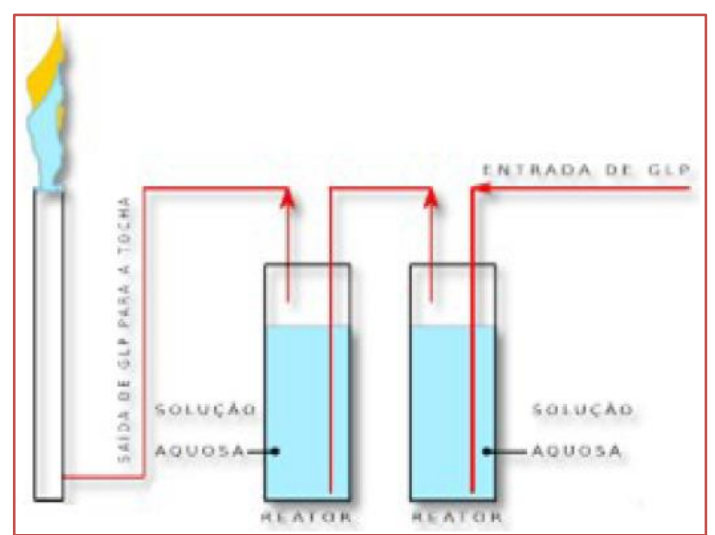

Foto 2: Aspecto da ST e reatores na prática antes de iniciar os testes.

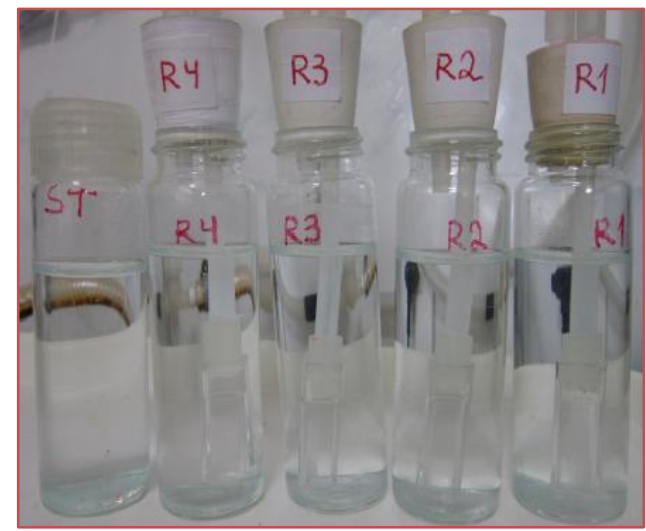

Todos os reatores contém a mesma solução igual a ST (solução de trabalho), com a mesma composição química e concentração, portanto, possuem a mesma aparência.

Ao total foram realizadas quatro bateladas de testes nas quais, em cada batelada, foram usados dois reatores, ou seja, os testes foram realizados em duplicatas.

\section{RESULTADOS E DISCUSSÃO}

\subsection{TESTE EM LEITO FIXO REACIONAL}

Os testes foram realizados no leito fixo reacional, porém, não foi possível interpretar os resultados por conta das limitações do aparato laboratorial. Por este motivo, os testes foram realizados apenas no R1 e em seguida os esforços foram direcionados para o teste em solução do produto A. Abaixo, seguem fotos representando os testes em leito fixo. 
Foto 3: Comparação do R1 com R2, R3 e R4 que não tiveram circulação de GLP.

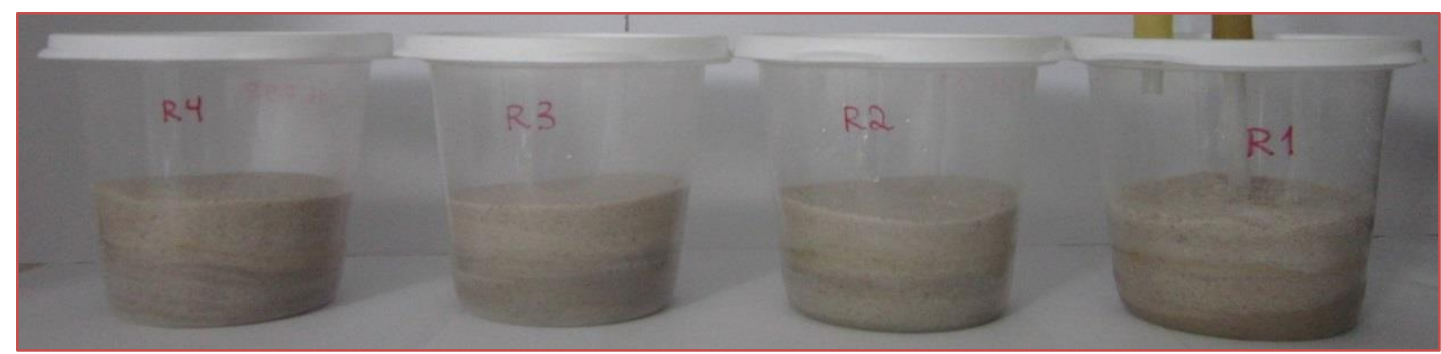

Percebe-se que o leito do R1 está mais seco. Provavelmente, quase toda solução do produto "A" foi consumida. Porém, nesta escala não há sensibilidade para determinar o consumo.

Tabela 1: matriz de testes com leito fixo reacional.

\begin{tabular}{|c|c|c|}
\hline \multicolumn{1}{|c|}{ Teste } & Reatores & Duração \\
\hline 1 & R1 & 2 horas \\
\hline 2 & R2 & 0 \\
\hline 3 & R3 & 0 \\
\hline 4 & R4 & 0 \\
\hline
\end{tabular}

\subsection{TESTE EM SOLUÇÃO DO PRODUTO “A”}

Como se pode observar na tabela 2 abaixo, foram realizadas quatro bateladas de testes, porém, a análise será voltada, especificamente, para o teste 4 mediante sua importância no contexto geral do trabalho.

Tabela 2: matriz de testes com solução do produto "A".

\begin{tabular}{|c|c|c|}
\hline \multicolumn{1}{|c|}{ Teste } & Reatores & Duração \\
\hline 1 & R1, R2 & 3 horas \\
\hline 2 & R3, R4 & 2 horas \\
\hline 3 & R5,R6 & $1: 20$ horas \\
\hline 4 & R7,R8 & 1 hora \\
\hline
\end{tabular}

\section{TESTE 4}

Foto 4: aspecto no início do teste e do borbulhamento gerado pela passagem de GLP.
Foto 5: aspecto ao final do teste. R7 turvo e R8 límpido sem indícios de reações.

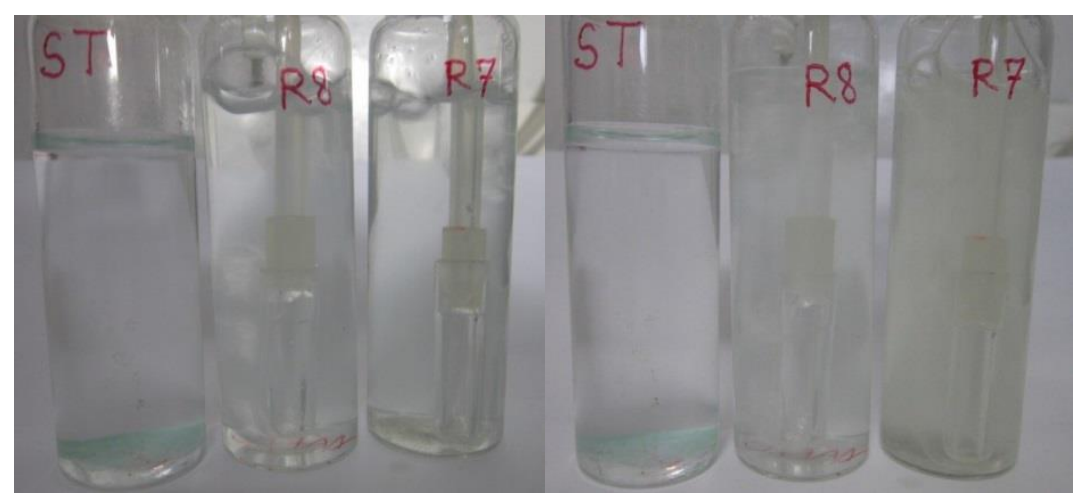


Pode-se perceber na foto 5, o R7 apresenta indícios da ocorrência de reações enquanto que no R8 a solução permaneceu praticamente intacta. A duração de 1 hora não foi suficiente para que ocorressem reações expressivas no R8.

Assim, verificou-se que com 1 1hora de teste e com uma solução de cloreto de cobre a 0,1582 g/L (ST) é possível abater todas as mercaptana, H2S residual e enxofre dos demais compostos sulfurados.

Foto 6: ST e todos os reatores juntos após finalização dos testes.

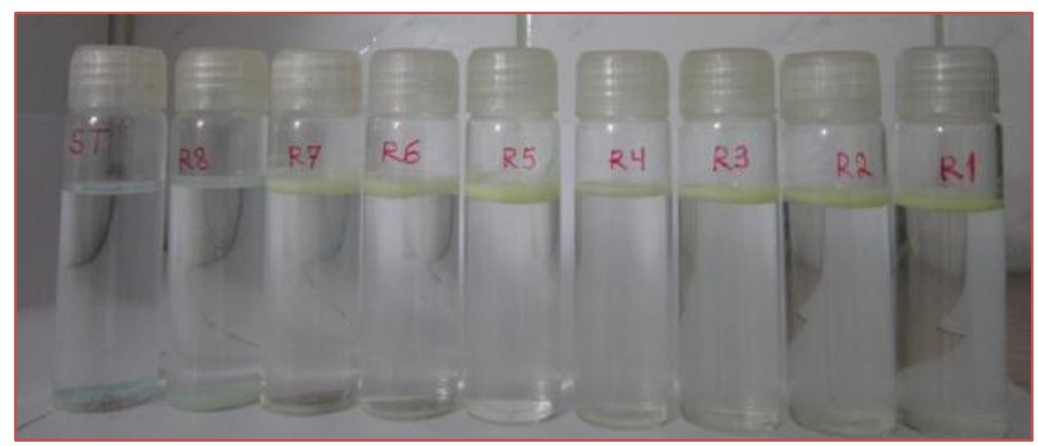

O processo de remoção das mercaptanas com o produto "A" ocorre conforme as reações: 4 RSH + 2 A = 2

$$
\begin{aligned}
& \mathrm{ApRS}+4 \mathrm{HAn}+\mathrm{RSSR} \\
& \mathrm{RSH}+\mathrm{B}=\mathrm{ApSR}+\mathrm{HAn} \\
& 2 \mathrm{ApSR}+2 \mathrm{~A}=\mathrm{RSSR}+4 \mathrm{~B}
\end{aligned}
$$

Como existem outros compostos sulfurados no butano, é necessário considerá-los. Entretanto são concentrações muito baixas, de modo que apresenta-se apenas o H2S, cuja a concentração é de 15 ppmw, ou seja, acima da tolerância permitida de < 5 ppmw:

$$
\mathrm{H} 2 \mathrm{~S}+\mathrm{A}=\mathrm{ApS}+2 \mathrm{HAn}
$$

$\mathrm{Na}$ foto 6 observa-se que na parte superior dos reatores (R1 a R7) existe uma espuma de dissulfeto dimetila (RSSR ou DMDS, de coloração amarelada e insolúvel em água) corroborando com os dados de literatura e com a reação 1 acima. O DMDS é volátil, de modo que a mistura repousada, algum tempo depois, não mais apresentará o colar.

Na mistura repousada também será possível observar o produto "B" formando um corpo de fundo de cor marrom.

A tecnologia proposta tem várias vantagens sobre o $\mathrm{KOH}$, tais como:

- $\quad$ a reação entre o produto proposto "A" e as mercaptanas resulta no valioso produto "C", o qual pode ser aproveitado comercialmente;

- $\quad$ a possibilidade de recuperação de quase $15 \mathrm{~m}^{3} / \mathrm{d}$ da água usada no processo;

- o produto da reação B pode reaparecer como produto "A" mediante uma operação de regeneração muito simples e econômica. 


\section{CONCLUSÕES}

Sabe-se que o leito fixo reativo é composto de partículas sólidas (areia) de 16-30 mesh. O processo é limitado a cerca de $0,06 \%$ de mercaptana $(600 \mathrm{ppm})$, pois seria necessário usar um grande volume de água para acima desse limite. No caso de Banagas, o teor de mercaptana a ser removida é de cerca de 85 ppm, ou seja, a tecnologia proposta no presente trabalho é perfeitamente adequada para o cenário da Banagas.

À luz do presente relatório, foi possível concluir que os testes em escala laboratorial corroboraram os dados da literatura e forneceram ao time técnico segurança na indicação baseada no uso o produto "A" para o tratamento de remoção das mercaptanas na Banagas. Para a continuidade desse estudo, sugere-se a realização de teste de campo de modo a verificar a eficácia da proposta de tratamento nas condições de campo da Banagas.

\section{AGRADECIMENTOS}

O time da Carioca Oil \& Gas Brazil agradece à Banagas e GPT pela colaboração no desenvolvimento desse trabalho.

\section{REFERÊNCIAS}

[1] SILVA FILHO L. F. - Avaliação e Modelagem da Absorção do H2S do gás natural em coluna de leito estagnado. Tese de Doutorado - UFRN, PPGQ. Natal. 2013. Disponível em: <https://repositorio.ufrn.br/jspui/bitstream/123456789/15926/1/LuizFSF_TESE.pdf> Acesso em: 06/07/2018.

[2] RODRIGUES, A. F. S. B. - Dessulfurização de butano líquido por adsorção mediante utilização de peneira molecular. Dissertação de Mestrado - Universidade de São Paulo, Escola Politécnica, Engenharia Química. São Paulo. 2016. Disponível em: <http://www.teses.usp.br/index.php? option=com_jumi\&fileid=17\&Itemid=160\&id=77A69AD4A9B7\&lang=pt-br $>$. Acesso em: 06/07/2018.

[3] SOUZA, José Roberto - Dessulfurização de Gás Natural usando Peneiras Moleculares. Dissertação de Mestrado - UFRN, Programa de Pós-graduação em Engenharia Química, Programa de Recursos Humanos da Agência Nacional do Petróleo, PRH 14, Engenharia de Processos em Plantas de Petróleo e Gás Natural. Natal. 2002. Disponível em: $<$ http://www.nupeg.ufrn.br/documentos_finais/dissertacoes_de_mestrado/dissertacoes/ joseroberto.pdf >, Acesso em: 06/07/2018. 


\section{Capítulo 3}

Estudo comparativo de características físico-químicas de resíduo oleoso da indústria de $E$ \& P de petróleo e diferentes tipos de cimento Portland para utilização

\section{em concreto}

Yane Coutinho

Fernanda Cavalcanti Ferreira

Romildo Alves Berenguer

Rodrigo Mendes Patrício Chagas

Ana Maria Gonçalves Duarte Mendonça

Milton Bezerra das Chagas Filho

Resumo: A construção civil gera produtos de impacto ambiental e consome grande quantidade de matéria prima, assim como a indústria petrolífera. Contudo, os resíduos da indústria petrolífera tendem a ser mais tóxicos e contaminantes, como, por exemplo, o cascalho de perfuração, também chamado resíduo oleoso. Este material é proveniente da Exploração e Produção (E\&P) de petróleo e contém fragmentos de rocha e resíduos de fluido de perfuração, o que torna seu descarte complicado. Estudos tem sido realizados para avaliar a incorporação deste resíduo na construção, como na construção de sub-base de pavimentação, materiais cerâmicos e a base de cimento. Um dos usos possíveis para este resíduo é o concreto, material amplamente usado neste setor. Dentre os vários aspectos que podem ser avaliados na utilização de um resíduo no concreto está sua reatividade potencial, referente à possibilidade de desencadeamento da reação álcali-agregado (RAA). Esta reação causa deterioração de estruturas, podendo levá-las à ruína e, uma vez desencadeada, não é possível mitiga-la. Desta forma, o presente trabalho objetivou realizar uma comparação ampliada de características físicas e químicas do resíduo oleoso e de cimentos CP I, CP II F 32, CP II F 40 e CP V. Além disso, para analisar a possibilidade de ocorrência da RAA em concretos produzidos com o resíduo oleoso em substituição a diferentes tipos de cimento, determinou-se o equivalente alcalino, indicativo do potencial reativo, destes materiais. Foi analisada a massa específica e granulometria, assim como a caracterização química dos materiais e calculados os valores de equivalente alcalino. A granulometria do resíduo é similar à do cimento, embora a massa específica seja inferior, o que deve ser considerado na dosagem do concreto. Com relação aos equivalentes alcalinos, estes se mostraram variáveis e acima do recomendado para a não ocorrência da reação. Desta forma, tem-se que, ao utilizar, seja o resíduo oleoso, seja cimentos comerciais, é necessária sua caracterização química. Para as amostras analisadas, recomenda-se a utilização de agregado não reativo para que não haja a ocorrência de RAA.

Palavras-chave: Resíduo Oleoso, Cimento Portland, Concreto, Reação Álcali-Agregado, Equivalente Alcalino. 


\section{INTRODUÇÃO}

O concreto é um dos materiais mais consumidos no mundo, uma vez que o desenvolvimento de um país está diretamente associado ao crescimento de sua infraestrutura urbana (DIAS, SILVA, POGGIALI, 2017). De acordo com Pedroso (2009), dados da Federación Iberoamericana de Hormigón Premesclado (FIHP) estimam o consumo anual mundial de 11 bilhões de toneladas de concreto.

O concreto é um material compósito, produzido pela mistura do aglomerante cimento, agregados graúdo e miúdo, aditivos e adições. Para atender a demanda de concreto, consome-se anualmente cerca de 4,1 bilhões de toneladas de cimento (USGS, 2017).

Worrell et al. (2001) apud Costa et al. (2013) explicam que a calcinação da rocha calcária, principal matéria-prima natural usada para fabricação do clínquer, é o principal fator responsável pela emissão de dióxido de carbono no processo de fabricação de cimento Portland. A cada $1.000 \mathrm{~kg}$ de calcita (CaCO3) calcinada são gerados $560 \mathrm{~kg}$ de $\mathrm{CaO}$ e $440 \mathrm{~kg}$ de CO2. A reação química de calcinação é responsável por aproximadamente $52 \%$ das emissões de $\mathrm{CO} 2$ no processo de fabricação do clínquer e o consumo de energia responde pelo restante. Acerca do consumo energético, a cada $1.000 \mathrm{~kg}$ de clínquer fabricados gera-se em média aproximadamente $815 \mathrm{~kg}$ de C02. De acordo com John (2000), o CO2 é considerado o principal gás do efeito estufa.

Neste contexto, verifica-se que a construção civil gera produtos de impacto ambiental e consome grande quantidade de matéria prima. Segundo com Sjöström (1996) apud John (2000), esta quantidade representa 14 a $50 \%$ do total de matérias primas naturais extraídas no planeta.

A indústria petrolífera também gera grandes volumes de resíduos líquidos e sólidos nocivos ao meio ambiente e à saúde pública. Entre esses resíduos, os cascalhos de perfuração ocupam posição de relevância (MENESES; PAULA, 2015). Cascalhos de perfuração são misturas de fragmentos pequenos de rochas impregnados com o fluido empregado para lubrificar e resfriar a broca durante a perfuração (FIALHO, 2012).

O fluido de perfuração tem o objetivo de manter a pressão ideal no poço, sustentar suas paredes evitando seu desmoronamento, remover os detritos da rocha perfurada e para lubrificar e resfriar a broca (BARROS, 2015). Geralmente, cerca de 10 a 15\% do volume do ?uido de perfuração permanecem aderidos aos cascalhos após o processo de separação (MORAES, 2010).

De acordo com Ganghis, Alarsa e Trentini (2009), estima-se que, na região nordeste do Brasil, exista uma quantidade de resíduos da ordem de $100 \mathrm{mil} \mathrm{m}^{3}$ provenientes do processo de perfuração de poços para produção de petróleo; e, que, em função do crescente número de poços que estão em fase de construção, estima-se uma geração anual de $50 \mathrm{mil} \mathrm{m}^{3}$.

Os autores ainda explicam que, embora, comumente, classificado pela legislação brasileira como classe II, a destinação de grandes quantidades desse tipo de resíduo, com as características físico-químicas encontradas, tem se mostrado um grande desafio para as empresas do setor e órgãos ambientais.

A acumulação desse resíduo demanda a urgente implementação de medidas ao menos atenuadoras de seus efeitos negativos ao meio ambiente, uma vez que não é possível cessar sua geração (MENESES; PAULA, 2015).

Os estudos para o reuso do cascalho em materiais de construção são recentes. Eles apontam alternativas para a construção de sub-base de pavimentação, materiais cerâmicos e a base de cimento (FIALHO, 2012). Page et al. (2003) fazem uma avaliação das opções de emprego deste material e uma das categorias apresentada foi concreto e produtos de cimento.

Fialho (2012) avaliou o comportamento de dois tipos de cascalhos em substituição e adição em concretos não armados. Os resultados apontaram que o uso dos cascalhos em materiais a base de cimento é vinculado a sua caracterização prévia.

A caracterização do resíduo deve compreender a análise química completa, caracterização de sua microestrutura, características físicas e ambientais (JOHN, 2000). Assim, pode-se selecionar o material com vista a determinada utilização (FIALHO, 2012).

A composição química dos cascalhos é muito variada e depende da composição das formações rochosas perfuradas e da composição química do ?uido de perfuração (FIALHO, 2012; PAULA; MENESES, 2015).

Neste contexto, a caracterização do material é de fundamental importância com objetivo de verificar a compatibilidade do resíduo na aplicação determinada e, neste caso, no concreto. Deve ter foco também na 
durabilidade do material. Um dos aspectos que deve ser verificado é a possibilidade de reação álcaliagregado (RAA).

A RAA é uma reação química que ocorre internamente na estrutura do concreto, que envolve hidróxidos alcalinos, principalmente do cimento, e alguns minerais reativos do agregado na presença de umidade, causando comprometimento da estrutura do concreto devido às fissurações, expansões ou deslocamentos (HASPARYK, 2005). Na falta de álcalis, agregado reativo e umidade, a RAA não ocorrerá (MEHTA; MONTEIRO, 2006).

0 teor de álcalis é representado através da porcentagem equivalente de óxido de sódio (Na2Oeq) e pode ser calculado de acordo com a Equação [1].

$$
\text { Na20eq }(\%)=\% \mathrm{Na} 20+0,658 \% \mathrm{~K} 20
$$

Onde \%Na2O é a porcentagem de óxido de sódio e \% K2O é a porcentagem de óxido de potássio presentes na amostra.

A ASTM C-150 (2019) tem como requisito químico opcional que o equivalente alcalino não exceda 0,60\% para ser caracterizado como cimento de baixo teor de álcalis. De acordo com ACI Committe 221 (1998) apud Hasparyk (2005), o limite recomendado é de 0,40\%. Entretanto, é importante salientar que a fonte de álcali pode ser externa e não somente oriunda do cimento (HASPARYK, 2005).

Coutinho et al. (2015) realizaram um estudo comparativo entre o cimento CP II F 32 e o resíduo oleoso, analisando sua constituição química e possível influência no desencadeamento da reação álcali-agregado, determinando que ambos possuíam componentes químicos semelhantes e equivalente alcalino superior ao valor de $0,6 \%$.

Neste contexto, o presente estudo visa a realizar uma análise ampliada das características físicas e químicas do resíduo oleoso proveniente da extração de petróleo e o cimento Portland, utilizando-se, para isto, de vários tipos de cimento, com vista à substituição parcial do cimento pelo resíduo em concretos. Além disso, será realizada a análise do teor de álcalis destes materiais, visando à avaliação da durabilidade quanto à possibilidade de ocorrência da reação álcali-agregado.

\section{MATERIAIS E MÉTODOS}

Neste trabalho foram analisados os materiais citados a seguir.

- Cimento: Cimento Portland CP I, CP II F 32 , CP II F 40 e CP V;

- Resíduo oleoso de E\&P de petróleo: cascalho de perfuração oriundo das atividades de Exploração \& Produção de petróleo do município de Carmópolis, Sergipe e São Sebastião do Passé, na Bahia (Figura 1).

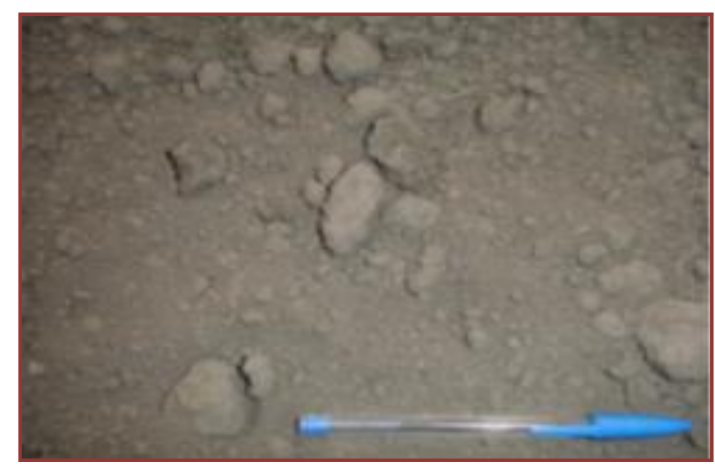




\subsection{MASSA ESPECÍFICA}

A massa especifica é a relação da massa e o seu volume, desconsiderando os vazios. A determinação da massa específica do resíduo oleoso foi realizada por meio do frasco de Lê Chatelier, segundo a norma DNER - ME 085/1994. A massa específica do cimento CP V foi determinada através do procedimento descrito na NBR 16605:2017. Demais massas específicas foram obtidas através de procedimentos descritos pelos respectivos autores.

\subsection{ANÁLISE GRANULOMÉTRICA POR DIFRAÇÃO A LASER (AG)}

Para realização deste ensaio, a amostra do resíduo foi beneficiada em peneira ABNT no $80(0,18 \mathrm{~mm})$, e dispersas em $250 \mathrm{~mL}$ de água destilada em agitador Hamilton Beach modelo N-5000 na velocidade de 17.000rpm, por 20 minutos; em seguida, a dispersão foi colocada em um equipamento CILAS modelo 1064, em modo úmido, até atingir a concentração ideal (150 unidades de difração/área de incidência).

\subsection{ANÁLISE QUÍMICA}

Depois de secas em estufa a $110 \mathrm{oC}$, as amostras do resíduo foram submetidas à análise química por fluorescência de raios X, conforme estabelece a ABNT NBR 14656:2001. Para isso, foi utilizado equipamento EDX 720 da Shimadzu.

Para análise do cimento, foi considerado o Boletim de Ensaios de Cimento datado em 03/03/2018, fornecido pela Votorantim Cimentos do produto tipo CP II F 40 Obras Estruturais da marca Poty, o trabalho de Souza (2007), utilizando CP II F 32, e análise realizada no Núcleo de Estudos Geoquímicos do Laboratório de Isótopos Estáveis - NEG LABISE, na Universidade Federal de Pernambuco, com o CP V. Tais cimentos foram escolhidos por serem mais usuais no mercado.

\section{RESULTADOS E DISCUSSÃO}

\subsection{CARACTERIZAÇÃO FÍSICA}

A tabela 1 apresenta dados de massa específica dos cimentos e do resíduo oleoso avaliados.

Tabela 1: Massa específica de cimentos e resíduo oleoso.

\begin{tabular}{|l|c|}
\hline \multicolumn{1}{|c|}{ Cimento } & Massa Específica $\left(\mathbf{g} / \mathrm{cm}^{\mathbf{3}}\right.$ ) \\
\hline CP I(i) & 3,19 \\
\hline CP II F 32(ii) & 3,04 \\
\hline CP II F 40(iii) & 3,11 \\
\hline CP V (iv) & 3,08 \\
\hline Resíduo Oleoso(v) & 2,34 \\
\hline
\end{tabular}

(i) Lins (2017), (ii) Souza (2007), (iii) Ficha técnica da empresa Poty, (iv) Fonte: Autores, (v) Mendonça (2013)

A partir da análise das massas específicas, nota-se que os cimentos estão variando entre 3,04 e 3,19 g/ $/ \mathrm{cm}^{3}$. Bauer (2011) menciona que a massa específica dos cimentos gira em torno de $3,15 \mathrm{~g} / \mathrm{cm}^{3}$, o que pôde ser observado nos resultados apresentados na Tabela 1.

0 resíduo oleoso apresentou massa específica de $2,34 \mathrm{~g} / \mathrm{cm}^{3}$. Lucena (2008), por sua vez, obteve 2,60 $\mathrm{g} / \mathrm{cm}^{3}$ e $2,38 \mathrm{~g} / \mathrm{cm}^{3}$, para resíduos provenientes de Sergipe e do Rio Grande do Norte, respectivamente, enquanto Fialho, Calmon e Pereira (2014) obtiveram o valor de $2,58 \mathrm{~g} / \mathrm{cm}^{3}$ para resíduo proveniente do Espírito Santo. Esta variedade está de acordo com o esperado se deve à diversidade de composição do resíduo oleoso, que depende da geologia local e fluido de perfuração utilizado.

Com relação ao uso do resíduo oleoso no concreto, devido à diferença entre massas específicas, caso a substituição seja feita em massa, o volume de resíduo oleoso utilizado será maior, o que pode comprometer a trabalhabilidade da mistura. Recomenda-se, pois, a substituição em volume.

A distribuição granulométrica do cimento CP II F 32 e resíduo oleoso, determinadas por Mendonça (2013), estão apresentadas na Figura 2. 
Figura 2: Resultados de granulometria a laser para o (a) cimento CP II F 32 e (b) resíduo oleoso, determinados por Mendonça (2013).

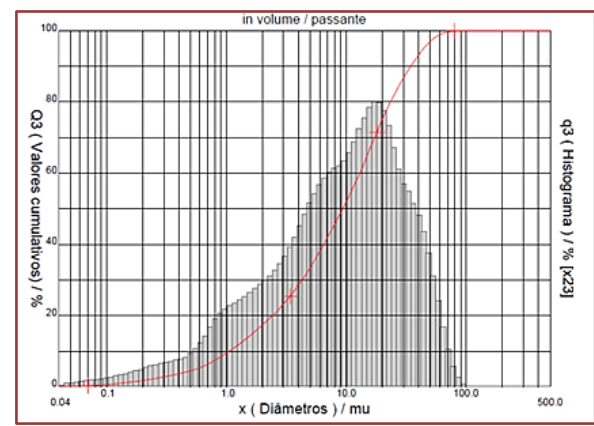

(a)

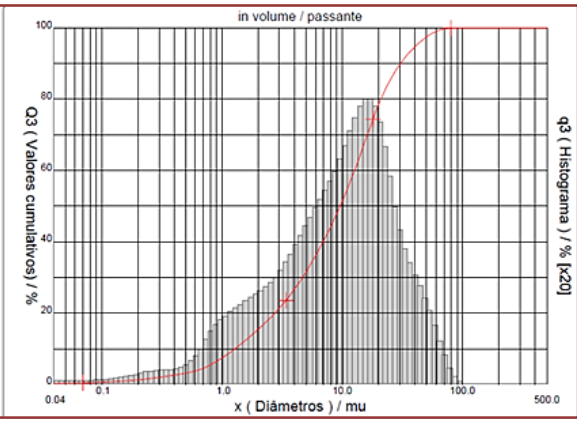

(b)

Analisando-se as distribuição granulométricas, tem-se que o diâmetro médio para o cimento foi de 13,97 $\mu \mathrm{m}$, enquanto que para o resíduo oleoso foi de 13,28 $\mu \mathrm{m}$. Para os valores característicos, tem-se: D10 de 1,05 $\mu \mathrm{m}$ para o cimento e 1,28 $\mu$ m para o resíduo oleoso, D50 de 9,33 $\mu \mathrm{m}$ para o cimento e 9,58 $\mu \mathrm{m}$ para o resíduo oleoso e D90 de 34,38 $\mu \mathrm{m}$ e 30,37 $\mu \mathrm{m}$ para o cimento e o resíduo, respectivamente. Tanto o cimento quanto o resíduo não apresentaram partículas com dimensão superior a $100 \mu \mathrm{m}$, como analisado por Mendonça (2013). Percebe-se, portanto, que o cimento tem uma porção maior de material com granulometria inferior a 1,28 $\mu \mathrm{m}$ e 9,58 $\mu \mathrm{m}$ em relação ao cimento. Contudo, os materiais possuem granulometrias semelhantes, o que é um indicativo de sua compatibilidade física.

\subsection{CARACTERIZAÇÃO QUÍMICA}

A Tabela 2 apresenta os resultados da análise química dos cimentos e do resíduo oleoso. Salienta-se que, para o CP I, os resultados foram obtidos por Lins (2017), para o CP II F 32 por Souza (2008), para o CP II F 40 em ficha técnica da empresa Poty, para o CP V pelos autores deste trabalho e para o resíduo oleoso por Mendonça (2013).

Tabela 2. Análise química do cimento e do resíduo oleoso

\begin{tabular}{|c|c|c|c|c|c|c|}
\hline Componente & CP I (i) & $\begin{array}{c}\text { CP II F } \\
\text { 32(ii) } \\
(\%)\end{array}$ & $\begin{array}{c}\text { CP II F } 40 \\
\text { (iii) } \\
(\%)\end{array}$ & CP V ARI (iv) & $\begin{array}{c}\text { Resíduo } \\
\text { oleoso (v) } \\
(\%)\end{array}$ & $\begin{array}{c}\text { Limites (NBR } \\
\text { 16697: 2018) } \\
(\%)\end{array}$ \\
\hline Perda ao fogo & 3,5 & 4,80 & 4,08 & 3,58 & $x_{0}$ & $\begin{array}{c}\mathrm{CP} \mathrm{I} \leq 4,5 \\
\mathrm{CP} \text { II F } \leq 12,5 \\
\mathrm{CP} \mathrm{V} \leq 6,5\end{array}$ \\
\hline Resíduo insolúvel & - & 0,58 & 1,77 & - & - & $\begin{array}{c}\mathrm{CP} \mathrm{I} \leq 5,0 \\
\mathrm{CP} \text { II } \mathrm{F} \leq 7,5 \\
\mathrm{CP} V \leq 3,5\end{array}$ \\
\hline $\mathrm{SiO}_{2}$ & 16,82 & 29,22 & 19,37 & 15,62 & 58,44 & - \\
\hline $\mathrm{Al}_{2} \mathrm{O}_{3}$ & 3,94 & 12,69 & 4,07 & 3,96 & 17,06 & - \\
\hline $\mathrm{Fe}_{2} \mathrm{O}_{3}$ & 3,74 & 2,32 & 3,53 & 2,82 & 7,02 & - \\
\hline $\mathrm{CaO}$ & 66,04 & 44,80 & 60,77 & 64,34 & 5,73 & - \\
\hline $\mathrm{Na}_{2} \mathrm{O}$ & - & 0,68 & 0,17 & 0,39 & - & - \\
\hline $\mathrm{BaO}$ & - & - & - & - & 3,26 & - \\
\hline $\mathrm{SO}_{3}$ & 3,76 & - & 2,72 & 5,83 & 2,53 & $\leq 4,5$ \\
\hline $\mathrm{MgO}$ & 4,25 & 2,40 & 2,53 & 1,20 & 2,24 & $\leq 6,5$ \\
\hline $\mathrm{K}_{2} \mathrm{O}$ & 0,91 & 1,51 & 0,72 & 1,12 & 1,82 & - \\
\hline $\mathrm{TiO}_{2}$ & 0,24 & - & - & 0,27 & 1,61 & - \\
\hline $\mathrm{SrO}$ & 0,21 & - & - & 0,07 & 0,12 & - \\
\hline $\mathrm{MnO}$ & - & - & - & - & 0,11 & - \\
\hline $\mathrm{ZrO}_{2}$ & - & - & - & 0,01 & 0,03 & - \\
\hline $\mathrm{ZnO}$ & - & - & - & 0,03 & 0,03 & - \\
\hline $\mathrm{Rb}_{2} \mathrm{O}$ & - & - & - & - & 0,01 & - \\
\hline $\mathrm{C}$ & - & - & - & - & 0,00 & - \\
\hline
\end{tabular}

(i) Lins (2017), (ii) Souza (2007), (iii) Ficha técnica da empresa Poty, (iv) Fonte: Autores, (v) Mendonça (2013) 
A partir da análise química dos cimentos, percebe-se que, no tocante à perda ao fogo e ao teor de óxido de magnésio (Mg0), todos atendem à exigência da NBR 16697 (2018). Com relação ao óxido de enxofre ( $\left.\mathrm{SO}_{3}\right)$, contudo, o CP V encontra-se acima do estabelecido em norma. 0 resíduo oleoso, por sua vez, atende ao requerido pela norma.

0 cimento possui como principais constituintes os óxido de cálcio ( $\mathrm{CaO})$, silício $\left(\mathrm{SiO}_{2}\right)$, alumínio $\left(\mathrm{Al}_{2} \mathrm{O}_{3}\right)$ e ferro $\left(\mathrm{Fe}_{2} \mathrm{O}_{3}\right)$. Analisando-se a constituição do resíduo oleoso, nota-se que este é composto majoritariamente pelos óxidos de silício e alumínio além de óxidos de ferro e cálcio em menores quantidades, podendo, portanto, ser classificado como um complexo silicoaluminoso. Observa-se, portanto, semelhança na composição química destes materiais. Desta forma, é possível estes compostos reajam similarmente quando em meios que favoreçam reações químicas, como mencionado por Coutinho et al. (2019).

Ao comparar as quantidades de componentes presentes nos dois materiais, verifica-se que a quantidade de sílica é significativa no resíduo oleoso, maior que no cimento: 58,44\% no resíduo e $16,82 \%, 29,22 \%$, 19,37\% e 15,62\% nos cimentos CP I, CP II F 32, CP II F 40 e CP V, respectivamente. Porém, a quantidade de óxido de cálcio é consideravelmente inferior no resíduo oleoso: 5,733\% no resíduo e $66,04 \%, 44,80 \%$, $60,77 \%$ e $64,34 \%$ nos cimentos, conforme ordem mencionada anteriormente.

Tem-se um equivalente alcalino de 1,20\% para o resíduo oleoso. Para os cimentos CP I, CP II F 32, CP II F 40 e CP V, tem-se valores de equivalente alcalino de $0,60 \%, 0,64 \%, 1,67 \%$ e $1,13 \%$, valores iguais ou superiores a $0,6 \%$. Assim como o cimento, o resíduo oleoso encontra-se acima do limite estabelecido para evitar o aparecimento da reação álcali-agregado. Desta forma, verifica-se que o resíduo oleoso não seria decisivo no desencadeamento da reação álcali-agregado, independentemente do cimento utilizado, o que também foi observado por Coutinho et al. (2015). Ao utilizar os materiais analisados, seria indicado utilizar agregados comprovadamente não-reativos, de modo a evitar o desencadeamento da reação (COUTINHO et al., 2019).

Com relação ao equivalente alcalino obtido para o resíduo oleoso, Lucena (2008) obteve para o resíduo de Sergipe equivalente alcalino de $1,85 \%$ e para o resíduo do Rio Grande do Norte equivalente alcalino médio de $0,96 \%$, obtido pela análise de três amostras. Fialho (2012), por sua vez, obteve equivalente alcalino de $0,99 \%$ (CAP III). Tal variabilidade se deve, novamente, às características da rocha perfurada e fluido utilizado, e, portanto, à geologia local.

É importante salientar, desta forma, que não há uma composição específica para o resíduo oleoso, sendo função da geologia local onde está sendo escavado o poço de extração de petróleo. Há influência, também, do fluido de perfuração utilizado. Assim, é de extrema importância a avaliação química da amostra antes de usar o material como matéria prima para produção do concreto, a fim de evitar a RAA.

\section{CONCLUSÃO}

Pode-se concluir que a granulometria do resíduo é similar à do cimento, embora a massa específica seja inferior, o que deve ser considerado na dosagem do concreto. As composições do resíduo oleoso e do cimento também são similares. Ademais, os equivalentes alcalinos obtidos a partir da concentração de óxido de sódio e potássio para os dois materiais são bastante variáveis, de 1,20\% para o resíduo oleoso e de $0,60 \%, 0,64 \%, 1,67 \%$ e 1,13\%, 1,67\% para os cimentos CP I, CP II F 32, CP II F 40 e CP V, todos valores iguais ou superiores ao valor indicado de $0,6 \%$ para evitar a ocorrência da reação álcali-agregado. Desta forma, pode-se inferir que o de resíduo oleoso analisado pode ser utilizado na produção de concreto em substituição ao cimento, independentemente do tipo de cimento utilizado, considerando o aspecto da reatividade potencial, desde que seja utilizado agregado não reativo.

\section{AGRADECIMENTOS}

Ao CNPq, pela bolsa concedida. 


\section{REFERÊNCIAS}

[1] ASSOCIAÇÃO BRASILEIRA DE NORMAS TÉCNICAS (ABNT).

[2] _ _ _ Cimento Portland - Requisitos. NBR 16697. Rio de Janeiro. 2018.

[3] _. Cimento Portland e outros materiais em pó - Determinação da massa específica._NM 23. Rio de Janeiro. 2001.

[4] _ _ Cimento Portland e matérias-primas - Análise química por espectrometria de raios X - Método de ensaio. NBR 14656. Rio de Janeiro. 2001.

[5] AMERICAN SOCIETY FOR TESTING AND MATERIALS. ASTM C 150: Standard specification for Portland cement. West Conshoho.

[6] BARROS, R. M. M. Incorporação do resíduo de cascalho de perfuração de poços de petróleo em formulações cerâmicas. Dissertação (mestrado). 107 f. Universidade Federal do Rio Grande do Norte. Natal, 2015.

[7] BAUER, L.A. Falcão. Materiais de Construção. LTC. 5ª Edição Revisada. Rio de Janeiro, 2011.

[8] COSTA, E. B.; KIRCHHEIM, A.P. ; MANCIO, M.; KIRCHHEIM, A. P.. Clínquer Portland com reduzido impacto ambiental. Ambient. constr. [online]. 2013, vol.13, n.2, pp.75-86. ISSN 1678-8621. http://dx.doi.org/10.1590/S167886212013000200007.

[9] COUTINHO, Y.; FERREIRA, F. C.; BERENGUER, R. A.; CHAGAS, R. M. P.; MENDONÇA, A. M. G. D.; CHAGAS FILHO, M. B. Análise do Equivalente Alcalino de Resíduo Oleoso da Indústria de E \& P de Petróleo e Cimento Portland para Utilização em Concreto. Impacto das Tecnologias nas Engenharias. Volume 4. Capítulo 19. 2019. Editora Atena. Disponível em: < https://www.atenaeditora.com.br/arquivos/ebooks/impactos-das-tecnologias-nas-engenharias-4>. Acesso em: 01 de maio de 2019.

[10] COUTinho, Y.; MENDONÇA, A. M. G. D., NASCMENTO, M. H. A., COSTA, D. B., CHAGAS FILHO, M. B. Análise do Equivalente Alcalino de Resíduo Oleoso da Indústria de E \& P de Petróleo e Cimento Portland para Utilização em Concreto. I Congresso Nacional de Engenharia de Petróleo, Gás Natural e Biocombustíveis - I Conepetro. 2015.

[11] DEPARTAMENTO NACIONAL DE ESTRADAS DE RODAGEM. Material finamente pulverizado - determinação da massa específica real. DNER-ME 085. 1994.

[12] DIAS, A. M.; SILVA, T. J. V.; POGGIALI, F. S. J. O concreto sustentável brasileiro. Revista Construindo, v. 9, p. 110, 2017.

[13] FIALHO, P. F. Cascalho de perfuração de poços de petróleo e gás. Estudo do potencial de aplicação em concreto. 2012. 217 f. Dissertação (Mestrado). Universidade Federal do Espírito Santo, Vitória, 2012.

[14] FIALHO, P. F.; CALMON, J. L.; PEREIRA, V. S. Resíduo de perfuração de petróleo como agregado miúdo em blocos de pavimentação. Congresso Luso-Brasileiro de Materiais de Construção Sustentáveis. Guimarães, Portugal. 2014.

[15] GANGHIS, Diógenes; ALARSA, Marcelo; TRENTINI, Sérgio. Alternativa para destinação fnal de cascalho de perfuração de poços de petróleo on shore gerados no Nordeste do Brasil. Congresso Internacional de Meio Ambiente Subterrâneo, 1 , $2009 . \quad$ Disponível em: <http://aguassubterraneas.abas.org/asubterraneas/article/view/21961/14330>. Acesso em 26 abril 2019.

[16] HASPARYK, N. P. Investigação de concretos afetados pela reação álcali-agregado e caracterização avançada do gel exsudado. 326 f. Tese (doutorado). Universidade Federal do Rio Grande do Sul. Porto Alegre, 2005.

[17] JOHN, V. M. Reciclagem de Resíduos na Construção Civil: contribuição para metodologia de pesquisa e desenvolvimento. 113 f. São Paulo, 2000. Tese (Livre Docência) - Departamento de Engenharia de Construção Civil, Universidade de São Paulo, São Paulo, 2000.

[18] LINS, D. N. Análise da Resistência à Compressão do Cimento LC $^{3}$ e a Influência das Adições Minerais em seu Desempenho. Dissertação de Mestrado. Universidade de Brasília. 2017.

[19] LUCENA, A. Utilização de Cascalhos de Perfuração Oriundos das Atividades de Exploração de Petróleo em Revestimentos Asfálticos de Estradas. Tese de Doutorado. Universidade Federal de Campina Grande. 2008.

[20] MEndonçA, A. M. G. D. Uso de Resíduos Oleosos de Petróleo (E\&P) em Obras Civis. RELATÓRIO FINAL Programa Nacional de Pós-Doutorado - PNPD 2007. Universidade Federal de Campina Grande, 2013.

[21] MEHTA, P. K.; MONTEIRO, P. J. M. Concrete: microstructure, properties, and materials. 3ª Edição. McGrawHill, 2006.

[22] MENESES, C. G.; PAULA, G. A. Avaliação do resíduo de cascalho de perfuração de poços de petróleo da Bacia Potiguar e alternativas para sua destinação e reaproveitamento. Revista Eletrônica de Petróleo e Gás. Ano 3, n. 1, p. 29-38, out.2014/mar.2015 ISSN 2316-668. 
[23] MORAES, Mariana Almeida de. Estudo Geoquímico, Ecotoxicológico do sedimento nas proximidades de um poço de perfuração na Bacia de Campos, Rio de Janeiro, Brasil. Dissertação (mestrado). 157 p. Universidade Federal Fluminense. Niterói, 2010.

[24] PAGE, P.W.; GREAVES, C.; LAWSON, R.;HAYES, S.; BOYLE, F. Options for the Recycling of Drill Cuttings. SPE/EPA/DOE Exploration and Production Environmental Conference, Texas, 2003.

[25] PEDROSO, F. L. Concreto: as origens e a evolução do material construtivo mais usado pelo homem. Revista Concreto e Construções. Ano XXXVII. 2009. ISSN 1809-7197. São Paulo, SP. Disponível em: www.ibracon.org.br. Acessado em: 10 mai.2017.

[26] USGS. U.S. Geological Survey. Mineral Commodity Summaries. Cement Statistics and Information. 2017. Disponível em: <https://minerals.usgs.gov/minerals/pubs/commodity/cement/mcs-2017-cemen.pdf>. Acesso em: 26 de abril de 2019. 


\section{Capítulo 4}

\section{Caracterização dos produtos de corrosão e incrustação em equipamentos da indústria petrolífera}

\section{Jardel Dantas da Cunha}

Fernando Nunes da Silva

Andréa Francisca Fernandes Barbosa

Resumo: Na indústria petrolífera a problemática da formação de corrosão e/ou incrustação provoca uma série de problemas, entre os quais: a redução na capacidade de escoamento, risco de acidentes e redução da produção. Medidas corretivas e preventivas devem ser tomadas para que problemas maiores não venham ocorrer na coluna de produção e seus componentes e em equipamentos de superfície. 0 estudo da formação de corrosão e/ou incrustação é de suma importância tanto no conhecimento do mecanismo de formação quanto na escolha do método de remoção desta. As técnicas: extração Soxhlet, espectrometria por fluorescência de raios X (EFRX) e difração de raios $\mathrm{X}$ (DRX) foram utilizadas na caracterização das amostras. Através da análise dos resultados foi possível identificar incrustação ferruginosa (amostra AM1), cuja sua formação está associada à presença de produtos de corrosão; e carbonática (amostras AM2, AM3), associadas, está associada à presença de íons de Ca+2 e bicarbonato (-HCO3) dissolvidos na água de formação.

Palavras-chave: Incrustação, corrosão, caracterização. 


\section{INTRODUÇÃO}

Durante a produção de petróleo, é comum o surgimento de processos de natureza corrosiva, depósitos inorgânicos e orgânicos, hidratos e formação de emulsão estável, podendo haver comprometimento no escoamento do petróleo e até mesmo, obstrução das colunas, tubulações e afetar o funcionamento dos equipamentos de superfície e sub-superfície [01, 02, 03].

As incrustações podem ser definidas como compostos químicos de natureza inorgânica que se encontram inicialmente solúveis em soluções salinas e podem ser encontradas: rocha reservatório; canhoneados; gravel packing; coluna de produção; equipamentos de superfície, tais como: caldeiras, condensadores, compressores e tubulações [08, 09]. Entre os produtos de incrustação podemos citar: o sulfato de bário ou Barita (BaSO4), sulfato de estrôncio ou celestina $\left(\mathrm{SrSO}_{4}\right)$ e o carbonato de cálcio ou Calcita $\left(\mathrm{CaCO}_{3}\right)$. Os respectivos mecanismos de formação, da Barita (Equação 01) e da Celestina (Equação 02), estão associados a incompatibilidade entre a água de injeção, rica em íons sulfatos $\left(\mathrm{SO}_{4}^{-2}\right)$, cloretos $\left(\mathrm{Cl}^{-}\right)$, bicarbonatos $\left(\mathrm{HCO}_{3}^{-}\right)$e a água de formação, rica em cátions como: magnésio $\left(\mathrm{Mg}^{+2}\right)$, cálcio $\left(\mathrm{Ca}^{+2}\right)$, sódio $\left(\mathrm{Na}^{+2}\right)$, bário $\left(\mathrm{Ba}^{+2}\right)$ e estrôncio $\left(\mathrm{Sr}^{+2}\right)$. A formação da Calcita (Equação 03) ocorre em decorrência de um desequilíbrio termodinâmico entre o dióxido de carbono $\left(\mathrm{CO}_{2}\right)$ e o bicarbonato $\left(\mathrm{HCO}_{3}^{-}\right)$.

$$
\begin{aligned}
& \mathrm{Ba}^{+2}+\mathrm{SO}_{4}^{2} \rightarrow \mathrm{BaSO}_{4} \downarrow \\
& \mathrm{Sr}^{+2}+\mathrm{SO}_{4}^{2} \rightarrow \mathrm{SrSO}_{4} \downarrow \\
& \mathrm{Ca}^{+2}+2 \mathrm{HCO}_{3} \rightarrow \mathrm{CaCO}_{3} \downarrow+\mathrm{CO}_{2} \uparrow+\mathrm{H}_{2} \mathrm{O}
\end{aligned}
$$

Produtos de corrosão insolúveis poderão formar depósitos sedimentares e/ou incrustantes, como os tubérculos em tubulações, a formação destes está associada composição do aço, do fluxo, condições do meio: como pH, temperatura, pressão, composição do eletrólito, existência de inibidores, dentre outros [14]. Produtos de corrosão ( $\mathrm{Fe}(\mathrm{OH}) 2$, $\mathrm{FeOOH}, \mathrm{Fe} 304, \gamma$-Fe2O3, Fe3C, $\mathrm{Fe}(\mathrm{OH}) \mathrm{CO} 3$, Fe2(OH)4CO3 e FeCO3 ) formam camadas passivas finas mais que em virtude da exposição prolongada com o meio corrosivo ficam mais espessas promovendo a redução da taxa corrosiva inicial [15]. A diversidade da escolha do tratamento adequado para a corrosão é dificultada em virtude da composição do fluido, bactérias, teor de dióxido de carbono/teor de H2S, teor de oxigênio dissolvido e presença de particulados $[04,05,06,07]$.

As estratégias para o gerenciamento dos problemas relacionados às incrustações, tradicionalmente são divididas em duas categorias, sendo métodos corretivos (acidificação, limpeza mecânica com pigs) e métodos preventivos (injeção de inibidor de corrosão e/ou incrustação) [11]. 0 tratamento das incrustações e afetado quando de forma corretiva pela formulação e o volume do ácido a ser utilizado na operação, das condições do poço, do tipo de fluido do reservatório e da temperatura da formação. Em ambos os casos o tratamento a ser escolhidos serão função da mineralogia e das propriedades dos produtos de corrosão e/ou incrustação. 0 presente trabalho tem como objetivo caracterizar os produtos de corrosão e/ou incrustação coletados em equipamentos na coluna de produção com auxilio das técnicas de difratometria de raios-X e flourescencia de raios-X.

\section{METODOLOGIA}

\subsection{COLETA DAS AMOSTRAS}

As amostras foram coletadas durante inúmeras intervenções em equipamentos da coluna de produção: a) Coluna de produção (AM1), b) Bomba de fundo (AM2) e c) Nipple de assentamento (AM3).

\subsection{EXTRAÇÃO SOXHLET}

A extração Soxhlet foi realizada utilizando como solvente na extração da amostra foi o clorofórmio, devido às seguintes características: possuir moléculas polares assim como o óleo presente no resíduo o que ajuda na remoção do mesmo; ser menos tóxico que os outros tipos de solvente; e ser de baixo custo [12]. 


\subsection{DIFRAÇÃO DE RAIOS-X (DRX) E ESPECTROMETRIA POR FLUORESCÊNCIA DE RAIOS X (EFRX)}

A difração de raios X foi realizada em um equipamento da marca Shimadzu modelo LabX XRD - 6000, com radiação CuK $\alpha(\lambda=1,5418 \AA ̊$ ). 0 difratograma obtido foi analisado pelos programas Search Match v.3.01 e Basic Process da Shimadzu com banco de dados do ICDD (International Center for Diffraction Data). Dessa forma, dependendo das fases cristalinas presentes têm-se o conhecimento dos produtos de incrustação e/ou corrosão. A análise de EFRX foi realizada num equipamento da marca Shimadzu modelo XRF-1800 no modo semi-quantitativo no qual é empregada a metodologia de dispersão por comprimento de onda (WD-XRF). 0 equipamento possui limite de deteç̧ão do sódio $(\mathrm{Na} \rightarrow \mathrm{Z}=11$ ) ao urânio $(\mathrm{U} \rightarrow \mathrm{Z}=92$ ) utilizando radiação $\operatorname{RhK} \alpha(\lambda=0,615 \AA ̊)$. Na preparação da amostra foi utilizada a prensagem da amostra com ácido bórico, utilizando uma proporção de 6:1 (ácido bórico:amostra) com dois ciclos de prensagem de 60 segundo com uma carga de $30 \mathrm{kPa}$. Os elementos analisados foram: Alumínio (Al), Bário (Ba), Cálcio (Ca), Cloro (Cl), Cobre (Cu), Cromo (Cr), Enxofre (S), Estrôncio (Sr), Ferro (Fe), Fósforo (P), Manganês (Mn), Molibdênio (Mo), Níquel (Ni), Potássio (K), Silício (Si), Sódio (Na) e Zinco (Zn).

\section{RESULTADOS E DISCUSSÃO}

\subsection{EXTRAÇÃO SOXHLET}

A Tabela 1, apresenta os teores de orgânicos e inorgânicos obtidos após a extração Sohxlet.

Tabela 1 - Teores de orgânicos e inorgânicos após extração Soxhlet

\begin{tabular}{|c|c|c|}
\hline & Teor de Orgânicos & Teor de Inorgânicos \\
\hline Amostra 01 & 2,67 & 97,27 \\
\hline Amostra 02 & 1,26 & 98,09 \\
\hline Amostra 03 & 1,84 & 98,48 \\
\hline
\end{tabular}

Em todas as amostras os teores de inorgânicos foram superiores a 97\%. A necessidade do processo de extração remota que a presença da fase orgânica comprometa a leitura interpretação dos espectros de raios-X e fluorescência de raios-X.

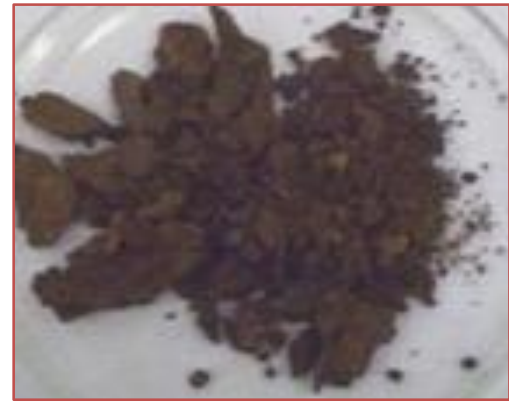

(a)

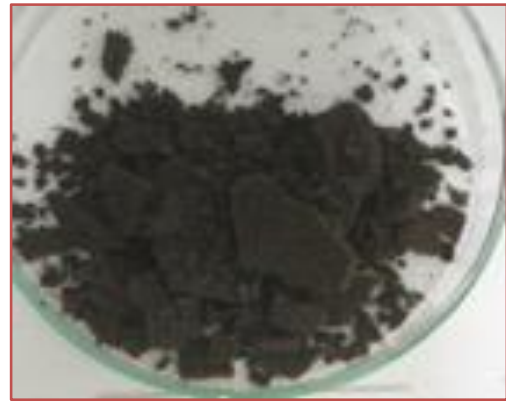

(b)

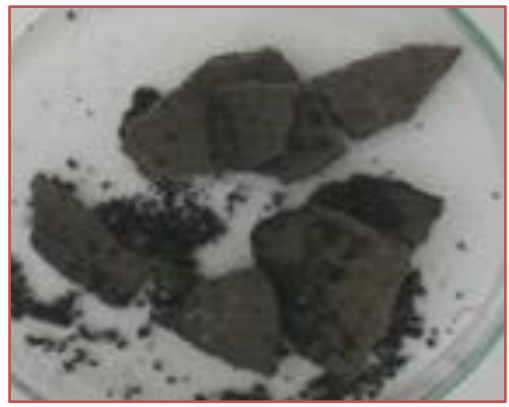

(c)

As amostras após extração apresentaram coloração: vermelha, cinza e cinza respectivamente para as amostras AM1, AM2 e AM3.

\subsection{DIFRAÇÃO E FLUORESCÊNCIA DE RAIOS-X}

A Tabela 2, apresenta os resultados de difratometria de raios-X dos produtos de corrosão e/ou incrustação. 
Tabela 2 - Resultado da difratometria de raios-X dos produtos após extração Soxhlet

\begin{tabular}{|l|l|}
\multicolumn{2}{|l}{ Fases/JCPDS } \\
\hline AM1 & Fe3S4/16-0713, Fe+30 $(\mathrm{OH}) / 29-0713, \mathrm{FeS} / 15-0037, \mathrm{Fe} 9 \mathrm{~S} 11 / 10-0437$ \\
\hline AM2 & $\mathrm{CaCO3/72-1652}$ \\
\hline AM3 & $\mathrm{CaCO3/85-1108}$ \\
\hline
\end{tabular}

Através da análise do difratograma (Tabela 2) foram detectadas quatro fases cristalinas, as quais apresentaram segundo banco de dados JCPDS a seguinte classificação: Greigita (Fe3S4), Goetita $(\mathrm{Fe}+3 \mathrm{O}(\mathrm{OH}))$, Mackinawita $(\mathrm{FeS})$ e Smitita (Fe9S11). As fases presentes confirmam o alto teor de ferro e enxofre detectados pela técnica de EFRX (Tabela 3) e a sua formação esta associada à ação do H2S e contaminação pelo oxigênio na coluna de produção. A Goetita é resultado da oxidação superficial da amostra quando esta entra em contato com a atmosfera fora do poço. Devido a sua estabilidade a Goetita é a fase predominante na popularmente chamada "ferrugem". Os produtos de corrosão originários da reação do H2S na superfície do aço, podem se apresentar sob as mais diversas formas. 0 tipo de sulfeto de ferro depende de inúmeras variáveis como: temperatura, salinidade, concentração de sulfeto presente, pressão parcial de $\mathrm{H} 2 \mathrm{~S}, \mathrm{pH}$, presença de bactérias redutoras de sulfato e de outros gases como $\mathrm{CO} 2$ e 02 . Produtos de corrosão de estruturas cúbicas como a Greigita (Fe3S4) e as estruturas tipo ortorrômbicas são formadas pelo aumento na concentração dos íons enxofre (CUNHA, 2008). Em sistemas dominados pelo $\mathrm{CO2}$, a presença de pequenas quantidades de $\mathrm{H} 2 \mathrm{~S}$ pode levar à formação de um depósito de sulfeto de ferro chamado Mackinawita, em temperaturas abaixo de $120^{\circ} \mathrm{C}$. Isto ocorrerá quando a razão entre a pressão parcial do $\mathrm{CO} 2$ e a pressão parcial do $\mathrm{H} 2 \mathrm{~S}(\rho \mathrm{CO} 2 / \rho \mathrm{H} 2 \mathrm{~S})$ for maior que 200. A Mackinawita é um depósito fino, que reduz a taxa de corrosão e sua estabilidade é ainda desconhecida. Esta tende a sofrer transformações na presença de oxigênio gerando Greigita.

Tabela 3 - Resultado de EFRX (modo semi-quantitativo) referente à amostras AM1, AM2 e AM3.

\begin{tabular}{|l|l|c|l|} 
& $\begin{array}{l}\text { Elemento } \\
\text { Majoritário }\end{array}$ & $\begin{array}{l}\text { Elemento } \\
\text { Majoritário }\end{array}$ & Elementos traços (Somatório) \\
\hline AM1 & $\mathrm{Fe}=80,00 \%$ & $\mathrm{~S}=18,70 \%$ & $\mathrm{Al}, \mathrm{Ca}, \mathrm{Cl}, \mathrm{Cr}, \mathrm{P}$ e $\mathrm{Mn}=1,28 \%$ \\
\hline AM2 & $\mathrm{Ca}=95,34 \%$ & - & $\mathrm{Cl}, \mathrm{Cu}, \mathrm{S}, \mathrm{Sr}, \mathrm{Fe}, \mathrm{P}, \mathrm{Mn}, \mathrm{Ni}, \mathrm{K}, \mathrm{Si}=4,65 \%$ \\
\hline AM3 & $\mathrm{Ca}=88,30 \%$ & - & $\mathrm{Al}, \mathrm{Cl}, \mathrm{S}, \mathrm{Sr}, \mathrm{Fe}, \mathrm{P}=11,69 \%$ \\
\hline
\end{tabular}

Nos difratogramas das amostras AM2 e AM3 (Tabela 2) foi detectada uma fase cristalina, a qual apresentou segundo o banco de dados JCPDS a fase Calcita (CaCO3), sendo esta confirmada pelo altos teores de cálcio apresentado no EFRX (Tabela 3). A formação da Calcita presente na amostra AM2 e AM3, que estava localizada na bomba de fundo, pode ter ocorrida devido à presença de íons de $\mathrm{Ca}+2 \mathrm{e}$ bicarbonatos (-HCO3) dissolvidos na água, sendo esta formação favorecida pela diminuição da pressão ou aumento da temperatura no reservatório.

\section{CONCLUSÕES}

AM1 é uma incrustação tipo ferruginosa, sendo esta resultante da ação corrosiva do H2S comumente encontrado em poços de produção, onde a sua origem está associada tanto à ação biogênica como à abiogênica;

A formação da Calcita ou carbonato de cálcio (CaCO3), identificados através da análise dos difratogramas, nas amostras AM2 e AM5, está associada à presença de íons de $\mathrm{Ca}+2$ e bicarbonato (-HCO3) dissolvidos na água, pois tal formação é comum em poços que apresentem teores elevados desses íons e sendo esta também favorecida pela diminuição da pressão ou aumento da temperatura no reservatório; 


\section{REFERÊNCIAS}

[1] Moiseeva, L. S. "Carbon Dioxide Corrosion of Oil and Gas Field Equipment" Protection of Metals, Vol. 41, (2005) 76-83.

[2] LI, J.; WANG, C.; LIU, J.; LIU, L.; YIN, Z.; ZHANG, Y.; LI, H.; HE, F. “Corrosion analysis, and use of an inhibitor in oil wells". Research Chemistry Intermed. v. 40, p. 649-660, 2014.

[3] CUNHA, J. D.; SILVA, F. N.; BARBOSA, A. F. F.; SILVA, D. R., Avaliação da Incrustação na bomba de fundo em poços produtores de petróleo e gás: Estudo de Casos. Holos (Natal. Online). , v.7, p.3 - 437, 2016.

[4] Shpiner, R., Vathi, S., StuckeY, D.C. "Treatment of oil well produced water by waste stabilization ponds: Removal of heavy metals", Water Research 43 (2009) 4258-4268.

[5] Tellez, G.T., Nirmalakhandan, N., Gardea-Torresdey, J. L., "Kinetic evaluation of a field-scale activated sludge system for removing petroleum hydrocarbons from oilfield-produced water" Environmental Progress 24 (2005) 96104.

[6] EDYVEAN, R. G. J. “Hydrogen sulphide - A corrosive metabolite” International Biodeterioration 27 (1991) $109-120$.

[7] HEMMINGSEN, T. and H. LIMA, "Electrochemical and Optical Studies of Sulphide Film Formation on Carbon Steel”, Electrochimica Acta 43 (1998) 35 - 40

[8] Wood, R. J. K. Erosion-corrosion interactions and their effect on marine and offshore materials. Wear, v. 261, p. $1012-1023,2006$.

[9] BOIM, J. M. Modelagem Semi-Analítica para Incrustação de Sulfato de Bário em Reservatórios Heterogêneos. Macaé, 2003. Tese de Doutorado-Universidade Estadual do Norte Fluminense - UENF, 2003.

[10] GENTIL, V. Corrosão. Editora LTC. 5a ed. Rio de Janeiro/RJ - Brasil, 2007.

[11] MILANEZ, A. Incrustações de Cálcio em Digestor Contínuo Tratamento com Antiincrustantes. Master of Scientiae. Suzano Papel e Celulose. Suzano/SP - Brasil. 2006.

[12] MOURA, D. M. A. ARAÚJO, B. A. T. MAChado, S. F. TÁVORA, M. P. SILVA, A. A. R. CUNHA, J. D. SILVA, D. R. Eficiência de Solventes Orgânicos Apolares na Extração de Produtos de Corrosão. In: LatinCorr 2006 - Congresso Latino Americano de Corrosão, Fortaleza - CE, Brasil, 2006.

[13] CUNHA, J. D. Tese - Avaliação de Heterociclo do Tipo Mesoiônico Solubilizado em Sistema Microemulsinado para Aplicação em Dutos. Universidade Federal do Rio Grande do Norte - UFRN, Natal/RN - Brasil, Dezembro, 2008.

[14] LINTER, B.R. e BURSTEIN, G.T. "Reactions of Pipeline Steel in Carbon Dioxide Solutions" Corrosion Science, 41, p.117-139, 1999.

[15] KINSELLA, Y. J.; TAN, Y. J.; BAILEY, S. “Electrochemical Impedance Spectroscopy and Surface Characterization Techniques to Study Carbon Dioxide Corrosion Product Scales”, Corrosion, v. 54, n. 10, p.835-842, 1998. 


\section{Capítulo 5}

\section{Formação de hidratos em perfurações de poços em águas profundas e ultra profundas}

\section{Vitória Camila Paixão dos Santos \\ Fabrícia Medeiros Santandrea \\ Marcos Alexandre Lopes Silva \\ Ilean José Ferreira Lima Verçosa \\ Lycia Carolinne Santos de Oliveira \\ Jaceguai Soares da Silva}

Resumo: Os hidratos são estruturas cristalinas com aparência de um cristal de gelo, que se formam na presença de água e, principalmente, de hidrocarbonetos de baixa massa molecular e sob condições de alta pressão e/ou baixa temperatura. As condições para a formação de hidratos são semelhantes àqueles presentes em operações de perfuração de poços e produção de óleo em águas profundas e ultra profunda e também em locais onde baixas temperaturas são frequentes. Esta pesquisa objetivou descrever as características, condições da formação e causas da presença de hidratos na exploração e produção de petróleo. Para tanto, a técnica metodológica usada foi a revisão bibliográfica em revistas/periódicos, livros e sites especializados, como o Portal de Periódicos CAPES, sobre a formação de hidratos dutos de óleo e gás em águas ultra profundas. Foram obtidos dados referentes a formação química dos hidratos, seus prejuízos à produção e formas de redução de sua formação como a utilização de inibidores que irão retardar a nucleação das moléculas. As pesquisas demostraram que, dentre as soluções usadas para a evitar a formação dos hidratos, seu uso pode minimizar ou até mesmo cessar os prejuízos caudados à indústria pela formação de hidratos.

Palavras-chave: Hidratos, Águas ultra profundas, Inibidores. 


\section{INTRODUÇÃO}

A prospecção de petróleo vem ocorrendo em áreas de acesso cada vez mais difícil, especialmente em águas profundas e ultra profundas. E nesse último caso, a necessidade de longos dutos por onde escoa o petróleo e a existência de baixa temperatura tornam a produção de petróleo mais complexa. Problemas como a deposição de parafinas e asfaltenos e a formação de plugs de hidratos dificultam bastante o escoamento do petróleo e, por muitas vezes, o impedem.

Os hidratos são estruturas cristalinas com aparência de um cristal de gelo, onde, conforme citado por Silveira (2016), existem dois ou mais componentes associados sem ligações químicas covalentes, essa associação ocorre por meio de um completo encapsulamento de um tipo de molécula por outra, os quais se originam através da junção da água com gases de baixo peso molecular ou hidrocarbonetos de cadeias curtas, submetidos a determinadas condições de pressão e temperatura de até $310 \mathrm{~K}$ ou $36,85{ }^{\circ} \mathrm{C}$. A estrutura básica do hidrato é uma molécula de metano aprisionada em armadilhas formadas por moléculas de água ligadas um às outras, em uma estrutura rígida, sendo muito semelhante ao gelo.

Trata-se de cristais formados pelos componentes de gás natural em presença de água. Os hidrocarbonetos ficam encapsulados em uma estrutura cristalina de hidratos, isto é, presos no interior da estrutura. Isso explica o favorecimento da formação de hidratos com moléculas de metano e etano (moléculas de pequeno tamanho) (FERREIRA; SARAIVA, 2011).

A formação dos hidratos é um mecanismo que depende basicamente do tempo, este conceito é importante quando se deseja evitar ou atrasar sua formação em risers, que são grandes tubos usados para encapsular equipamentos de perfuração durante operações submarinas de petróleo e gás ou num poço de petróleo. 0 tempo de iniciação da formação dos hidratos é a partir do momento em que há um contato entre a água e o gás até o instante de detecção da formação completa do hidrato no sistema. Ocorre uma supersaturação na interface água/gás, deste modo, esta interface é o local mais provável de haver a formação dos mesmos.

Os hidratos são formados durante o escoamento de gás ou óleo contendo, obrigatoriamente, gás e água dentro dos tubos. Para que ocorra a formação de hidratos é necessário que tenha alta pressão, baixas temperaturas, água e gás. A formação de hidratos ocorre quando a água, através de forças de ligação de hidrogênio, conforma-se de modo a formar um retículo cristalino que, para ser estabilizado, precisa englobar alguma molécula, geralmente gasosa. Sua formação se dá de forma diferente, seja através do escoamento de óleo, do escoamento de gás ou durante a perfuração, completação e em testes de poços. A aglomeração de gotas e de partículas de hidratos faz com que a viscosidade do óleo aumente de forma significativa. Com o aumento da viscosidade, ocorre uma perda de cargas, um aumento na pressão, assim ocorrendo um risco de plugueamento do duto.

As possibilidades de obstrução das linhas de transporte de fluidos ocorrem em praticamente todas as operações desde a perfuração à produção de petróleo e gás. Durante a perfuração, quando a trajetória do poço atravessa um reservatório de gás, parte do gás incorpora-se ao fluido de perfuração. Esta condição se torna mais crítica porque, além de absorver gás, o fluido tem capacidade de incorporar sólidos de granulometria fina gerados durante a perfuração (ANDRADE, 2009).

Por muitas vezes a produção é parada para remover plugs de hidrato de tubulações assim, consequentemente ocorrendo a perda da produção. Neste sentido, este trabalho objetiva apresentar as características, condições de formação e as causas da presença de hidratos em decorrência do seu surgimento.

\section{METODOLOGIA}

Nesse sentido, esta pesquisa propôs descrever as características, condições da formação e causas da presença de hidratos na exploração e produção de petróleo em águas profundas e ultra profundas. Para tanto, esse estudo ocorreu na forma de revisão bibliográfica por meio de revistas/periódicos voltados para esta linha de pesquisa, as quais foram obtidas em livros e sites especializados, como o Portal de Periódicos CAPES. 


\section{DESENVOLVIMENTO}

Dentre as formações de hidratos, pode-se observar a formação de hidratos no escoamento de óleo, onde a formação de hidratos se inicia na fase aquosa emulsionada no óleo. A água, ao entrar em contato com o gás forma uma película de hidrato, inicialmente não rígida, que isola a fase água da fase óleo. Com o decorrer do tempo está película vai ficando mais fina, essa aglomeração pode formar um plug de hidratos. Como mostra a Figura 1, a seguir.

Figura1: Esquema de plugueamento em escoamento de óleo e gás.

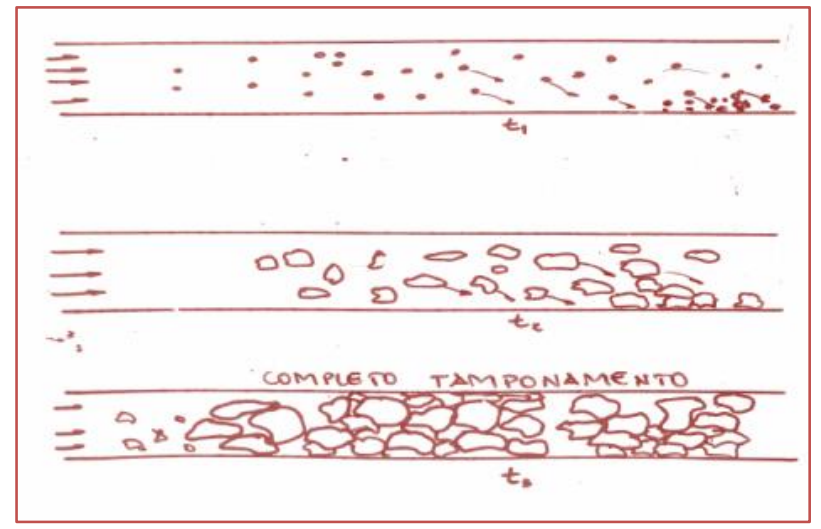

Fonte: CARVALHO, 2010.

Na fase líquida, são formados os cristais de hidratos individuais. Somente nesta fase, há concentração e nível de energia necessários para que a ligação de átomos de hidrogênio ocorra. Tais cristais possuem um tamanho muito pequeno, entretanto encontram a possibilidade de crescimento, compartilhando as faces compostas de 5 e 6 membros das moléculas de água. Apenas no momento em que esse processo de aumento continua até que ocorra a formação de um tampão é que os hidratos se tornam um problema (ANDRADE, 2009).

Já a formação de hidratos no escoamento de gás, se tem a água livre que se encontra na parte inferior do duto e é natural da água produzida e da água condensada do gás, dessa forma os hidratos começam a se formar na parede do duto, conforme a Figura 2, onde a temperatura é mais baixa. Com o aumento da deposição, a área de fluxo diminui, ressaltando que a deposição é irregular e se concentra na parte inferior do duto ou em regiões localizadas, provocando uma redução no diâmetro do duto, essa deposição aumenta as perdas de cargas, causando a perda de pressão do escoamento.

Figura 2: Exemplos de plugueamento em escoamento de gás.

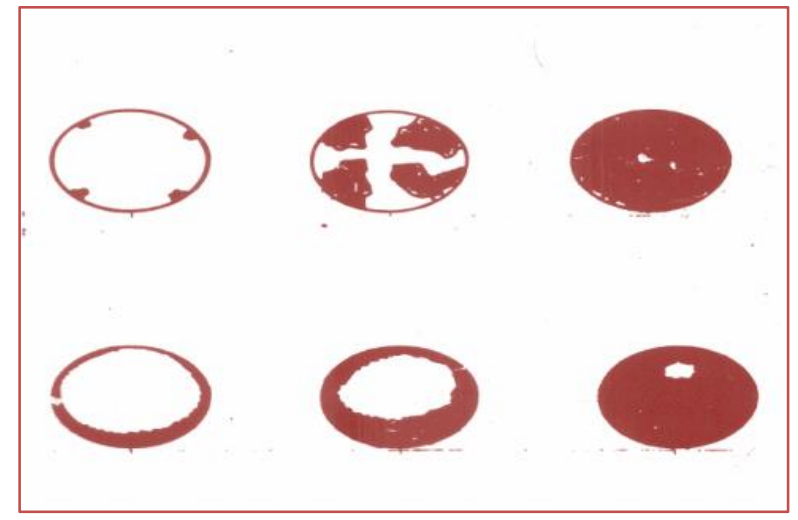

Fonte: CARVALHO, 2010. 
Durante a fase de perfuração, completação e nos testes de poços, é comum que tenha invasão de fluidos vindo da formação, dentre eles água e gás. E devido ao peso do fluido de perfuração ou completação, associando as baixas temperaturas da água ultra profundas, o risco de se formar hidratos é real.

Durante o processo de perfuração, completação e teste de poços podem ocorrer à invasão de fluidos vindo da formação, dentre eles água e gás. Devido ao peso da coluna hidrostática do fluido de perfuração ou completação, associado às baixas temperaturas de águas ultra profundas, pode-se ter a formação de hidrato (CARVALHO, 2010).

A formação de hidratos nessa fase é prejudicial porque pode impossibilitar a passagem de ferramentas, aumentando as perdas de cargas ou pode mesmo obstruir por completo as tubulações. 0 problema se torna maior à medida que a lâmina d'água que ocorre a operação é maior, portanto, quanto mais se perde calor para o meio maior é a possibilidade de fluido de entrar na região de hidratos.

Quanto a sua classificação os hidratos são qualificados pelo arranjo das moléculas de água no cristal e, por conseguinte, a estrutura de cristal. De acordo com Almeida (2015), dois tipos de hidratos são comumente encontrados nas áreas de atividades do petróleo: tipo I e tipo II, por vezes referido como a Estrutura I e II. Um terceiro tipo de hidrato que também pode ser encontrada é tipo $\mathrm{H}$ (também conhecido como estrutura H), mas é muito menos comum, como mostrado na Figura 3.

Figura 3: Representação dos modelos de estruturas de cristais de hidratos.

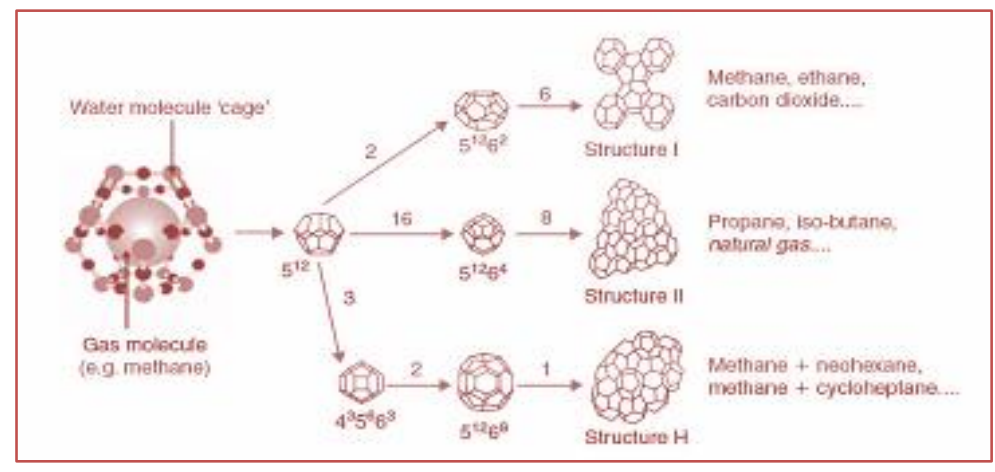

Fonte: ANDRADE, 2009.

Na indústria do petróleo, o termo hidrato é reservado às substâncias que são normalmente gasosos à temperatura ambiente. Estes incluem o metano, o etano, o dióxido de carbono, e o sulfureto de hidrogênio.

A aglomeração de gotas e de partículas de hidratos faz com que a viscosidade do óleo aumente de forma significativa. Com o aumento da viscosidade, ocorre uma perda de cargas, um aumento na pressão, assim ocorrendo um risco de plugueamento do duto.

As possibilidades de obstrução das linhas de transporte de fluidos ocorrem em praticamente todas as operações desde a perfuração à produção de petróleo e gás. Durante a perfuração, quando a trajetória do poço atravessa um reservatório de gás, parte do gás incorpora-se ao fluido de perfuração. Esta condição se torna mais crítica porque além de absorver gás o fluido tem capacidade de incorporar sólidos de granulometria fina gerados durante a perfuração. (DE ANDRADE, 2009).

Por muitas vezes a produção é parada para remover plugs de hidrato de tubulações assim, consequentemente ocorrendo a perda da produção. Dentre as soluções para a evitar a formação dos hidratos, pode-se a) aquecer as linhas de transmissão submarina de petróleo enquanto as mesmas não estiverem ativas e b) a utilização de inibidores de hidratos.

Para Flexim (2014), inibidores de formação de hidratos são substâncias solúveis em água, geralmente sais ou álcoois. Atuam por diversos mecanismos, tendo como objetivo principal evitar a formação de hidratos em sistemas de gás, o bloqueio de linhas de condução e as intervenções de manutenção dispendiosas. Os inibidores são injetados na boca do poço, normalmente por bombas de pistão de injeção, produzindo uma vazão pulsante e pressão altamente dinâmica. Os inibidores devem ser injetados na corrente gasosa antes que seja atingida a formação de hidrato, dispersando o gás com a utilização de bicos nebulizantes. 
Inibidores de baixa dosagem (cinéticos e antiaglomerantes) são polímeros de alto peso molecular, que podem prevenir nucleação ou crescimento de cristais durante tempo suficiente para que possa ser retomada da atividade. Também reduzem a quantidade de hidrato formado. Entretanto, não mudam a posição do envelope de hidratos, apenas atrasam o seu aparecimento (ANDRADE, 2009)

Os inibidores cinéticos atuam em período de tempo pré-determinado, dependendo basicamente do subcooling (sub-resfriamento) a que está exposto o fluido e o tempo de residência do fluido na zona de formação de hidratos (ALMEIDA, 2015).

Porém, dependendo das condições de operação, as quantidades de inibidores essenciais para evitar a formação de hidratos são excessivas, deste modo se faz necessário à utilização de inibidores de baixa dosagem. Basicamente, os inibidores de hidrato podem ser classificados em três tipos: inibidores termodinâmicos, inibidores cinéticos e anti-aglomerantes. A ação de cada um dos aditivos mencionados foi descrita de forma resumida por Drumond (2008) e pode ser observada na Figura 4.

Figura 4: Forma como agem os inibidores de formação de hidratos.

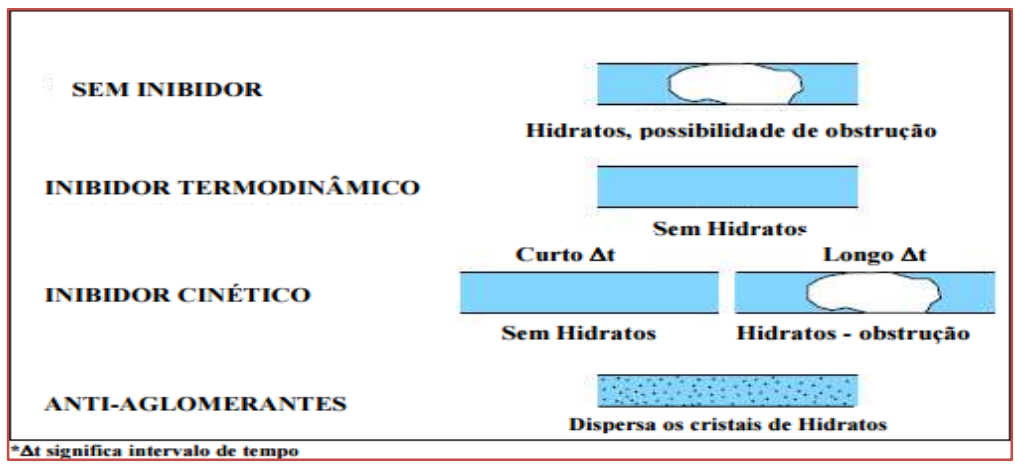

Fonte: ANDRADE, 2009.

Uma forma comum de utilizá-los é no caso do tempo de residência, ou seja, o tempo em que os fluidos ficarão submetidos às condições favoráveis à formação de hidrato, seja curto, mas não o suficiente para não formar hidrato. Desta forma, se utilizados, os inibidores de baixa dosagem podem atrasar a formação, permitindo a retomada da atividade (ANDRADE, 2009).

\section{CONSIDERAÇÕES FINAIS}

Diante das considerações apresentadas, a formação de hidratos durante a produção, tanto em águas profundas quanto em ultra profundas, pode levar a um aumento significativo da viscosidade do óleo, a interrupção de produção para remoção de plugues de hidratos causando, assim, prejuízos.

A literatura pesquisada demonstrou que, dentre as soluções para a evitar a formação dos hidratos, as alternativas mais utilizadas são: 1) o aquecimento das linhas de transmissão submarina de petróleo enquanto as mesmas não estiverem ativas; e, 2) a injeção de inibidores de formação de hidratos. 0 uso destas pode minimizar ou até mesmo cessar os prejuízos caudados pela formação de hidratos.

\section{REFERÊNCIAS}

[1] ALMEIDA, Lara Maria Toledo Reis. Prevenção de Hidrato com Adição de Inibidores. Rio de Janeiro, 2015. Disponível em: <https://app.uff.br/riuff/bitstream/1/777/1/Monografia\%20Final.pdf>. Acesso em: 23 Mar 2018.

[2] CARVALHO, R.B. Analise de métodos de controle de hidratos em aguas ultra profundas. Rio de Janeiro. Universidade Federal do Rio de Janeiro, 2010.

[3] ANDRADE, Alex R. Hidratos no âmbito da perfuração: Histórico, Mecanismos de Inibição e Técnicas para Análises de Hidrato. Rio de Janeiro, $2009 . \quad$ Disponível em: <http://www.ppgem.ct.utfpr.edu.br/lacit/publicacoes/monografias/monografia\%20Alex\%20\%20 de\%20Andrade\%20-\%20Vers\%E3o\%20Final. pdf>. Acesso em: 20, Mai, 2018. 
[4] DRUMOND et al, Fabiano Garcia. Analise econômica de campos marítimos de petróleo considerando a opção de substituição temporária de métodos de elevação de petróleo: um estudo de caso. Espirito Santo, 2008. Disponivel em: <http://www.portalalpg;org.br/PDPetro/3/trabalhos/IBP0473_05.pdf>. Acesso em: 10 Mai 2018.

[5] FERREIRA E SARAIVA, Alan Pinto, Marcelle Mendonça Rocha. Importância da prevenção de hidratos para o processamento de gás natural. Rio de Janeiro, 2011. Disponível em: http://pt.slideshare.net/engenheiroalanferreira/tcc-hidrato-alan-e-marcelle-9193567>. Acesso em: 21, Mar, 2016.

[6] FLEXIM. Instrumentos de Medição. Berlim, 2014

[7] SILVEIRA, Luana Caroline. Previsão De Formação De Hidratos Em Linhas De Escoamento De Petróleo E Gás. Rio Grande do Norte, $2016 . \quad$ Disponível em: <https://monografias.ufrn.br/jspui/bitstream/123456789/3062/1/TCC_2016.2_LuanaCaroline.pdf>. Acesso em: 5 Mar, 2018. 


\section{Capítulo 6}

\section{Um estudo sobre a estrutura cristalina dos hidratos de}

metano

\section{José Antonio de Padua Neto \\ Victor Henrique Rocha Sales \\ Carolina Rocha Luiz Vianna}

Resumo: Hidratos de metano vêm se mostrando uma futura fonte de energia promissora que, em quantidade, pode superar as reservas de petróleo já exploradas e que ainda devem ser exploradas. Tem uma estrutura cristalina semelhante ao gelo que pode variar de uma cor mais escura a outra tão clara quanto o gelo. Sua estrutura é formada por gaiolas que aprisionam o metano ou outros gases leves, em menor quantidade. As gaiolas existentes nas estruturas hidratantes variam em três tipos básicos, em que cada um deles apresentam suas particularidades, bem como a preferência em aprisionar gases com um tamanho maior ou menor em relação ao metano. Sabe-se que os hidratos apresentam ocorrência em grandes extensões do leito marinho bem como em regiões congeladas em um solo conhecido como permafrost. A grande quantidade de reservas deste recurso natural supera em grande vantagem os recursos de gás explorados e que ainda serão explorados no decorrer dos anos. 0 objetivo deste trabalho é apresentar as possíveis estruturas cristalinas dos hidratos e as características de cada uma delas. 


\section{INTRODUÇÃO}

Atualmente a principal fonte de energia no mundo é o petróleo e seus derivados. Já o gás natural tem tomado cada vez mais um lugar de destaque no que tange a sua utilização como fonte de energia tanto industrial como residencial, contudo o Brasil vem necessitando de importações cada vez maiores deste commodity para suprir sua demanda. Nesse contexto uma outra forma de exploração de hidrocarbonetos se torna interessante: a exploração das reservas de hidratos de gás, principalmente metano.

A distribuição de hidratos no planeta é heterogênea. Uma estimativa aponta que há em torno de 5000 GtC de carbono na forma de metano em hidratos, que representa uma significativa fração do carbono orgânico do mundo. A exploração de hidratos de gás poderia, então, suprir toda e qualquer necessidade existente de gás, visto que sua concentração no planeta é consideravelmente maior do que todas as reservas de petróleo convencionais já encontradas e estimadas no mundo.

Entretanto, como o metano exerce um impacto considerável no ambiente terrestre, observa-se a necessidade de pesquisas sobre o que são os hidratos, suas estruturas e características, bem como este recurso pode ser explorado, considerando que com suas estimativas de reserva, esta produção poderia no futuro substituir o petróleo como fonte principal de energia.

Com isso, o objetivo deste trabalho é realizar um estudo de revisão bibliográfica que possa descrever as características de estruturas cristalinas dos hidratos de gás, suas características e diferenças.

\section{METODOLOGIA}

\subsection{HIDRATOS DE GÁS}

Hidratos de gás ou clatratos, palavra vinda do latim que significa "gaiola", é um sólido cristalino formado por moléculas de águas ligadas por interações intermoleculares do tipo "pontes de hidrogênio" umas às outras, que encapsulam moléculas de gás, como o metano ( $\mathrm{CH} 4)$ e dióxido de carbono ( $\mathrm{CO} 2)$ (Sloan (1998)) apud (Clennell; (2000)). Sua estrutura é de grande semelhança á do gelo, entretanto, sua cor pode variar de uma cor mais clara a um cinza escuro (Frozen, 2014). Por sua estrutura cristalina ser estável permite que ele não venha a derreter em temperaturas acima de $0{ }^{\circ} \mathrm{C}$ desde que se mantenha a grande pressão (Clennell (2000)). Visões macroscópicas e microscópicas dos hidratos de metano podem ser vistas nas figuras 1 (a), (b), (c).

Figuras 1 - Hidratos de metano: (a) e (b) imagens macroscópicas; (c) fórmula estrutural.

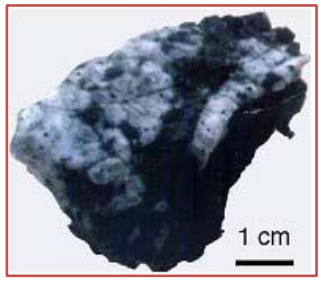

(a)

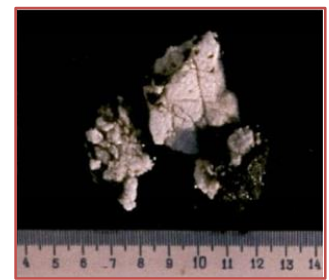

(b)

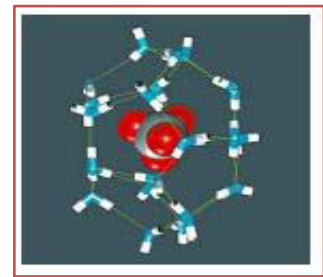

(c)

Fonte: (a) e (c) (Tanaka (2003) apud Barros (2009)); (b) (Clennell (2000)).

A figura 1 (a) mostra a visualização macroscópica de uma ocorrência natural de hidratos de gás metano em ambiente marinho. Já a figura 1(b) mostra cristais de hidrato de gás recuperados de $300 \mathrm{~m}$ embaixo do fundo marinho em sedimentos finos da margem da Costa Rica. A figura 1(c) demonstra a forma cristalina de um hidrato de gás metano.

De acordo com Paull et al (1999) apud Clennell (2000), o hidrato é formado quando há a decomposição da matéria orgânica por bactérias em profundidades menores que $1000 \mathrm{~m}$, ou pela desestruturação do material orgânico com temperaturas que variam de 80 a $100^{\circ} \mathrm{C}$, em profundidades superiores a $1000 \mathrm{~m}$ até $3000 \mathrm{~m}$.

Conforme Max (2003), para a formação dos hidratos, três condições devem ser atendidas: a combinação correta entre temperatura e pressão; a presença de gases formadores de hidratos (metano (CH4), etano 
(C2H6), e dióxido de carbono (CO2); suficiente quantidade de água. As camadas de gelo (permafrost) e regiões de subsolo marinho na margem continental, são as principais localidades que favorecem a formação do hidrato, pois proporcionam as condições já mencionadas de temperatura e pressão adequadas (MAX (2003)).

Os gases aprisionados nos hidratos são formados de modo biogênico ou termogênico. Contudo, o gás em maior evidência é o metano biogênico, em seguida o termogênico que pode apresentar uma mistura de outros hidrocarbonetos entre C2 até C5 (SLOAN; KOH; SUM, (2010)).

\subsection{A ESTRUTURA CRISTALINA DOS HIDRATOS DE GÁS}

Para se compreender melhor os hidratos em sua microestrutura, as possíveis estruturas cristalinas de uma unidade de hidrato estão dispostas na figura 2.

Figura 2 - Possíveis estruturas cristalinas dos hidratos.

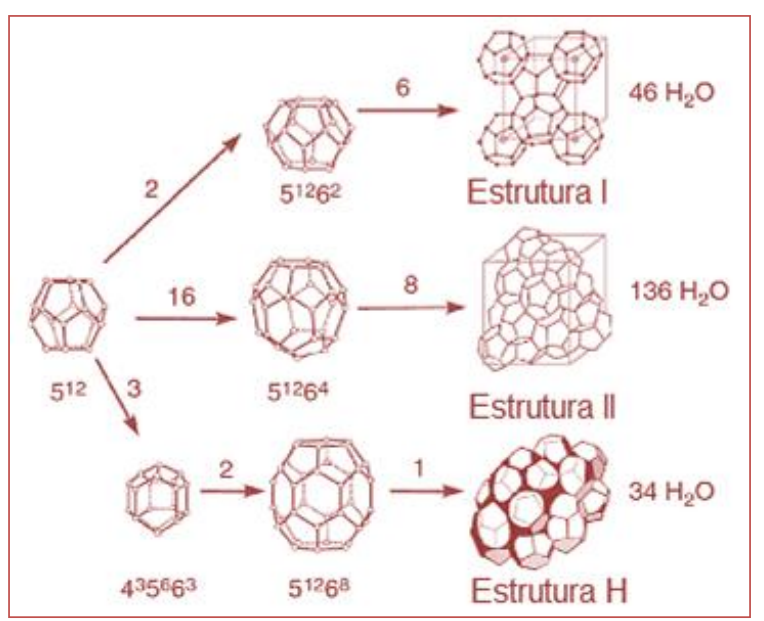

Fonte: Adaptada de Sloan; Koh; Sum, (2010).

De acordo com Sloan; Koh; Sum, (2010), a figura 2 mostra que os hidratos formados de acordo com a Estrutura I são compostos por gaiolas básicas com doze faces pentagonais, e sua capacidade se limita a abrigar moléculas menores, como o metano (CH4), sendo assim sua formação está associada a origem biogênica. Já os hidratos formados de acordo com a Estrutura II contêm 12 faces pentagonais e duas faces hexagonais, e por seu tamanho superior, pode abrigar moléculas maiores como o etano (C2H6), por isto sua formação está associada a origem termogênica. Já os hidratos formados de acordo com a estrutura $\mathrm{H}$ formam um icosaedro irregular, um poliedro de 20 lados, que tem 12 faces pentagonais e 8 faces hexagonais. Estas moléculas são encontradas também em processos artificiais.

Como existe mais de um tipo de estrutura e gaiola na formação dos hidratos de gás, o perfeito ajuste da molécula de gás que foi capturada dentro da gaiola determinará qual será o tipo de estrutura cristalina que será formada (Sloan; Koh; Sum, (2010)).

Segundo Holder; Hand (1982) e Circone et al., (2005) apud Frozen, (2014), para o hidrato de metano ser estável e necessário que penas $70 \%$ das gaiolas disponíveis estejam ocupadas por metano, embora tipicamente mais de $95 \%$ das gaiolas estejam completas.

0 arranjo mais simples de estrutura de hidrato é estrutura A (I). Esse arranjo é composto por dois tipos de gaiola, que podem ser vistos na figura 3:

Gaiola em formato de um dodecaedro, um poliedro de 12 lados onde cada face é um pentágono regular;

Gaiola em formato de um tetradecaedro, um poliedro de 14 lados com 12 faces pentagonais e 2 faces hexagonais. 
Figura 3 - Gaiolas das estruturas A (I).

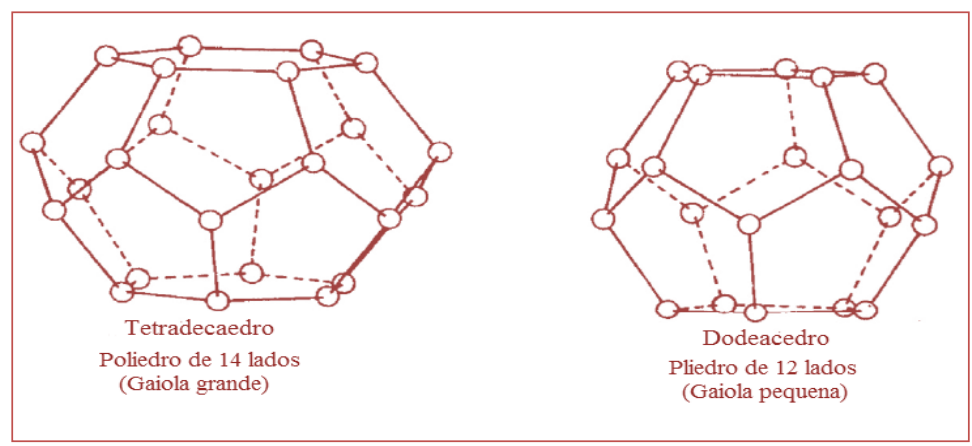

Fonte: Adaptada de Carroll (2014)

As gaiolas dodecaédricas são menores que as gaiolas tetradecaédricas; assim, os dodecaedros são frequentemente referidos como pequenas gaiolas, enquanto as gaiolas tetradecaédricas são referidas como grandes gaiolas.

O autor Sloan (1998) evidencia que hidratos tipo A (I), consistem de 46 moléculas de água. Considerando que cada molécula convidada (gás) ocupa cada uma das gaiolas existentes, a fórmula teórica apresentada por Carroll (2014) para a formação de hidratos do tipo A (I) é: X·53/4 H2O, em que X é o gás formador de hidrato.

Alguns dos formadores comuns da estrutura A (I) de hidrato incluem os gases metano (CH4), etano (C2H6) e dióxido de carbono (CO2). As moléculas convidadas podem ocupar tanto as pequenas quanto as grandes gaiolas. (ENGLISH; MACELROY, (2015)).

Observa-se que a estrutura dos hidratos tipo B(II) é significativamente mais complexa do que do tipo A (I). Os hidratos do tipo B (II) são também construídos a partir de dois tipos de gaiolas, como pode ser visto na figura 4. As estruturas unitárias de um hidrato tipo II são:

Gaiola em formato de um dodecaedro, um Poliedro de 12 lados onde cada face é um pentágono regular;

Gaiola em formato de um hexadecaedro, um poliedro de 16 lados com 12 faces pentagonais e 4 faces hexagonais.

Figura 4 - Gaiolas das estruturas B(II).

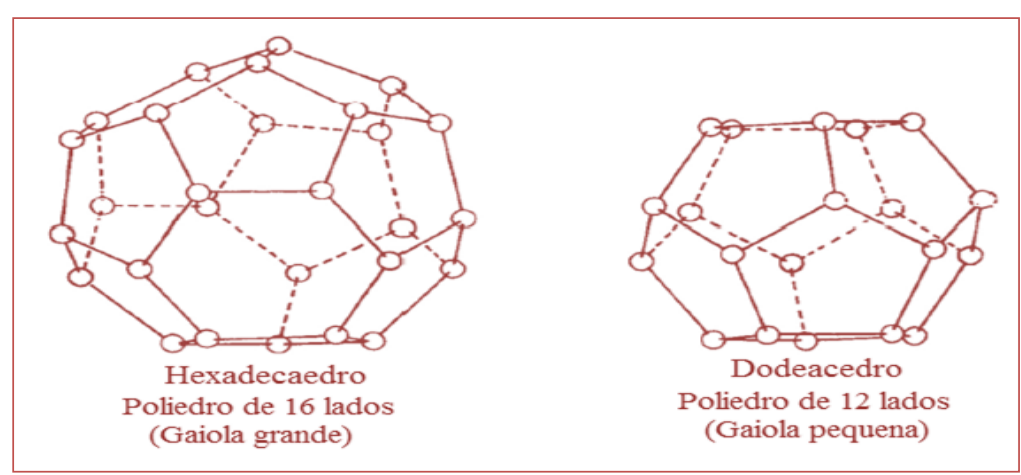

Fonte: Adaptada de Carroll (2014)

Observa-se que a estrutura I e a estrutura II possuem o arranjo dodeacedro, e o que irá diferencia-lo é o diâmetro da gaiola, que se mostra ligeiramente maior da gaiola B do que para a gaiola A. As gaiolas dodecaédricas são menores que as hexadecaédricas.

O hidrato formado pelas estruturas do tipo II consiste em 136 moléculas de água (SLOAN (1998)). Se um convidado da molécula ocupa todas as gaiolas, então a composição teórica é X·52/3 H2O, em que X é o formador de hidrato. Quando a molécula convidada ou hidratante ocupa apenas as gaiolas maiores, o que ocorre normalmente, então a composição teórica é X·17 H2O (CARROLL (2014)). 
Entre os formadores mais comuns de hidratos do tipo B (II) estão o nitrogênio (N2), propano (C3H8), e isobutano (C4H10). É interessante salientar que o nitrogênio pode ocupar tanto grandes quanto pequenas gaiolas do tipo B (II), (English e MacElroy (2015)). Entretanto, os hidratos do tipo I e os hidratos do tipo II não são estequiométricos, as composições dos hidratos reais diferem dos valores teóricos.

Outro tipo de estrutura para os hidratos são as estruturas do tipo $\mathrm{H}$, que pode ser visto na figura 5 . Os hidratos tipo $\mathrm{H}$ são muito menos comuns do que os tipos I ou II. Para formar este tipo de hidrato, é requerido uma molécula pequena, como o metano (CH4). Como tal, os hidratos do tipo H são sempre hidratos duplos (CARROLL, (2014)).

Figura 5 - Estrutura cristalina de hidrato do tipo $\mathrm{H}$.

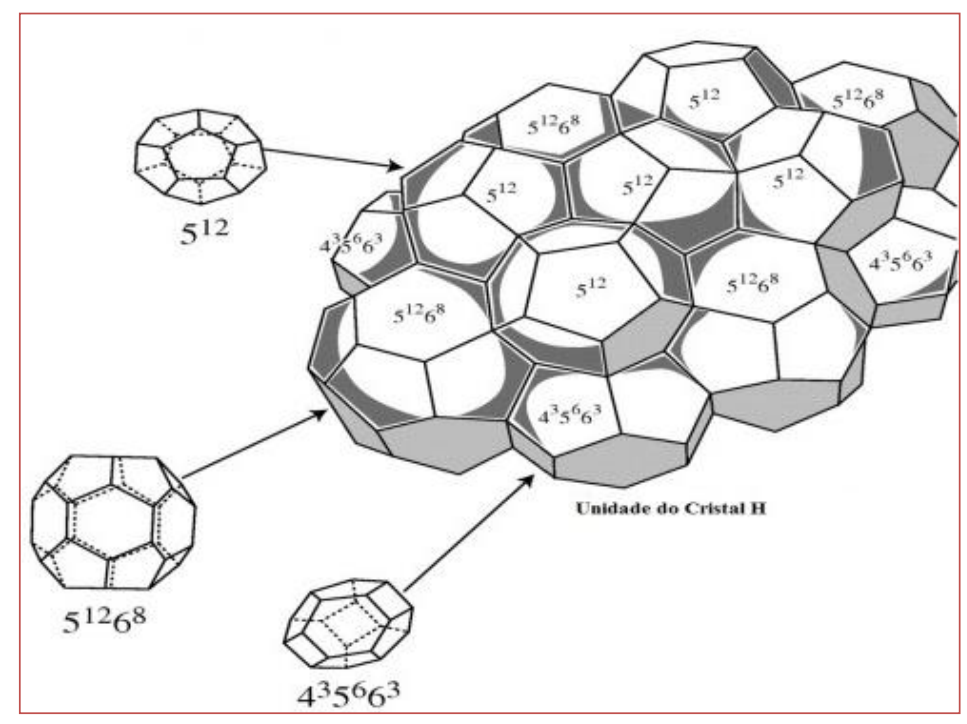

Fonte: Adaptada de Maslin et al, (2010).

A unidade cristalina é composta de 3 gaiolas dodecaédricas (pequenas), 2 gaiolas dodecaédricas irregulares (médio) e 1 gaiola icosaédrica, composto por vinte faces, (grande). Isto é, essa estrutura cristalina é composta por 34 moléculas de H20. Moléculas convidadas pequenas, tais como metano (CH4), ocupam as pequenas, médias e algumas das grandes gaiolas da estrutura, enquanto uma molécula maior ocupa somente a grande gaiola, os gases convidados também podem ser metano ou cicloheptano (SLOAN (1998)).

De acordo com Carroll (2014), por possuir dois tipos obrigatórios de formadores, um hidrato do tipo H, oferece uma maior dificuldade para se determinar uma fórmula molecular teórica. No entanto, se assumirse que as pequenas moléculas, $(\mathrm{X})$, só entraram nas duas gaiolas menores e que a grande molécula, (Y), só entra nas maiores estruturas, então a fórmula teórica é: Y·5X·34H20.

Os gases formadores do tipo $\mathrm{H}$ incluem as seguintes espécies de hidrocarbonetos: 2-metilbutano, 2,2dimetilbutano, 2,3-dimetilbutano, 2,2,3-trimetilbutano, 2,2-dimetilpentano, 3,3-dimetilpentano, metilciclopentano e mais pesados, ou seja, moléculas muito maiores do que as contidas nas estruturas I e II. A maioria desses componentes não são comumente encontrados no gás natural; ou talvez seja é melhor afirmar que a maioria das análises não testa esses componentes (CARROLL, (2014)); (ENGLISH; MACELROY, (2015))

É interessante salientar que os hidratos normalmente se formam em uma das três diferentes estruturas cristalinas que foram apresentadas (figuras 3, 4, 5). As estruturas I e II cristalizam-se em um sistema cúbico (isométrico), enquanto que a estrutura H cristaliza-se em um sistema hexagonal (SLOAN (1998), e Von STACKELBERG, MÜLLER (1954)) apud (ENGLISH; MACELROY, (2015)). 


\section{CONCLUSÕES}

Observa-se que os hidratos podem ser usados como fonte obtenção de energia, sabendo que sua ocorrência esta associada a regiões de margens continentais e bem como as regiões congeladas conhecidas como permafrost.

A estrutura cristalina dos hidratos pode ser de três tipos básicos: I, II e H. Cada uma dessas estruturas permite o aprisionamento de gases leves, como hidrocarbonetos cuja composição química varia de 1 a 4 carbonos, bem como $\mathrm{CO} 2$ e outros gases. Cada tipo de estrutura favorece o acumulo de determinados tipos de gases, contudo, a predominância para todas as estruturas é do aprisionamento de metano (CH4).

Cada estrutura possui uma particularidade, por exemplo, observando a estrutura I nota-se sua capacidade de conter somente gases leves, como o metano, devido ao raio da mesma ser relativamente pequeno, quando comparado com as duas outras estruturas. A estrutura de gaiolas II engloba gaiolas maiores como o hexadecaedro e seu raio interno maior permite a encapsulação de gases mais pesados como o propano, isobutano entre outros. A estrutura $\mathrm{H}$ se difere pelo fato de ser a única entre as duas a se cristalizar em um sistema hexagonal, contudo pela sua formação necessitar de 3 tipos diferentes de gaiolas ela pode armazenar gases de diferentes tamanhos.

\section{REFERÊNCIAS}

[1] BARROS, Caio de Souza Barros. Análise de Atributos Sísmicos Para Caracterização de Hidratos de Gás no Cone do Rio Grande. 2009. № 51. Trabalho de Conclusão de Curso de Graduação em Geofísica - Universidade Federal Fluminense, Niterói, 2009.

[2] CARROLL, John. Natural Gas Hydrates: A Guide for Engineers. 3. ed. Waltham U.S: Grupo Paulo Pimentel, 2014. $317 \mathrm{p}$.

[3] CLENNELL, M. B. Hidrato de gás submarino: natureza, ocorrência e perspectivas para exploração na margem continental brasileira. Revista Brasileira de Geofísica, v. 18, n.3, pp. 397-410, 2000.

[4] ENGLISH, Niall; MACELROY, Donal. Perspectives on molecular simulation of clathrate hydrates: Progress, prospects and challenges. 1. ed. [S.l.]: Elsevier, 2015. 133-156 p.v. 121.

[5] FROZEN HEAT A GLOBAL OUTLOOK ON METHANE GAS HYDRATES. Nairobi, Kenya: UNEP, 2014.

[6] PADUA, José A. Neto. ROCHA, Victor H. Sales. Um estudo sobre hidratos. 2018.59p. Monografia (Graduação em Engenharia de Petróleo)- Centro Universitário de Barra Mansa, Barra Mansa, RJ, 2018

[7] MASLIN, Mark et al. Gas hydrates: past and future geohazard. 1. ed. [S.l.]: The Royal Society, 1010. 2369$2393 \mathrm{p}$.

[8] MAX, D. , Michael. Natural Gas Hydrates : Oceanic and Permafrost Environments. 1. ed. [S.l.]: Kluwer Academic Publishers, 2003. 1 p. v. 1.

[9] SLOAN, E. Dendy. Clathrate Hydrates of Natural Gases, Second Edition, Revised and Expanded. 2. ed. New York: Marcel Dekker Inc, 1998. 709 p. v. 1

[10] SLOAN, E. Dendy; KOH, Carolyn; SUM, Amadeu K. Natural Gas Hydrates in Flow Assurance. Gulf Professional Publishing; Edição: 1, 23 de setembro de 2010. 


\section{Capítulo 7}

\section{Modelagem do flowmeter para estimativa da vazão de fluidos}

Sebastião Henrique Camilo da Silva

Márcio Roberto de Andrade Araújo

Claudiana Ferreira da Silva

Wellington dos Santos de Araújo

Ana Carolina Santos de Oliveira

Edilson Ponciano de Lima

Resumo: A ferramenta de perfilagem de produção (Production Logging Tool - PLT) é aplicada na produção e injeção de poços e se constitui de vários dispositivos. Um deles é chamado Continuous Flowmeter, equipamento responsável por monitorar as taxas de fluxo em cada zona produtora ou injetora. Desenvolvemos um protótipo do flowmeter para medir uma relação entre potencial elétrico, rotações por minuto (RPM) e vazão com ar e água. Os resultados mostraram que o potencial elétrico e as RPM são proporcionais à taxa de fluxo. Isso significa que, quanto maior é o potencial eléctrico e a rotação, maior é a taxa de fluxo. Com o modelo físico do flowmeter foi possível encontrar a relação entre os três parâmetros descritos, a fim de prever e calcular as taxas de fluxo. 


\section{INTRODUÇÃO}

O Continuous Flowmeter é um perfil de poço revestido que tem como objetivo monitorar as taxas de fluxo de fluido no poço. Este perfil consiste basicamente de uma ou mais hélices centralizadas, cuja velocidade de rotação é registrada continuamente dentro do poço. A rotação da(s) hélice(s) é função da velocidade de fluxo do fluido proveniente da zona produtora, da velocidade e do sentido de movimentação do cabo, descendo ou subindo, e da viscosidade dos fluidos (Thomas, 2001).

Se a velocidade relativa entre a ferramenta e o fluido produzido fosse igual à zero, não haveria movimento relativo entre eles e, portanto, a velocidade do cabo seria a própria velocidade do fluido. Como seria bastante trabalhoso ou até não operacional ficar alterando a velocidade do cabo em cada trecho de interesse para se encontrar a rotação da hélice igual à zero, é muito mais simples se efetuar três manobras de descida e subida, com velocidades diferentes do cabo entre cada manobra, e plotá-los em um gráfico da rotação da hélice (RPS) em função da velocidade do cabo (Vcabo). Traçando-se uma reta pelos pontos obtidos, pode-se extrapolar e encontrar a velocidade do cabo que resultaria em rotação zero para cada trecho de interesse.

A partir das velocidades de fluxo nos trechos de interesse, ou seja, entre os canhoneados abertos, determina-se, por diferença, a contribuição percentual de cada intervalo. Dessa forma, dependendo do modelo, o perfil flowmeter fornece medições de velocidade de fluido precisas, em situações complexas de completações e regimes de escoamento, e oferece flexibilidade para monitorar poços com diferentes ranges de velocidade. A Figura 1 apresenta uma seção mecânica do flowmeter, com o desenho das suas hélices, sendo aplicado de acordo com suas especificações quanto à pressão, temperatura, diâmetro, comprimento, peso, pontos do sensor, máxima velocidade do fluido e características do material (resistente à corrosão, por exemplo).

Figura 1: Seção mecânica (hélices) do Continuous Flowmeter da Empresa Halliburton.

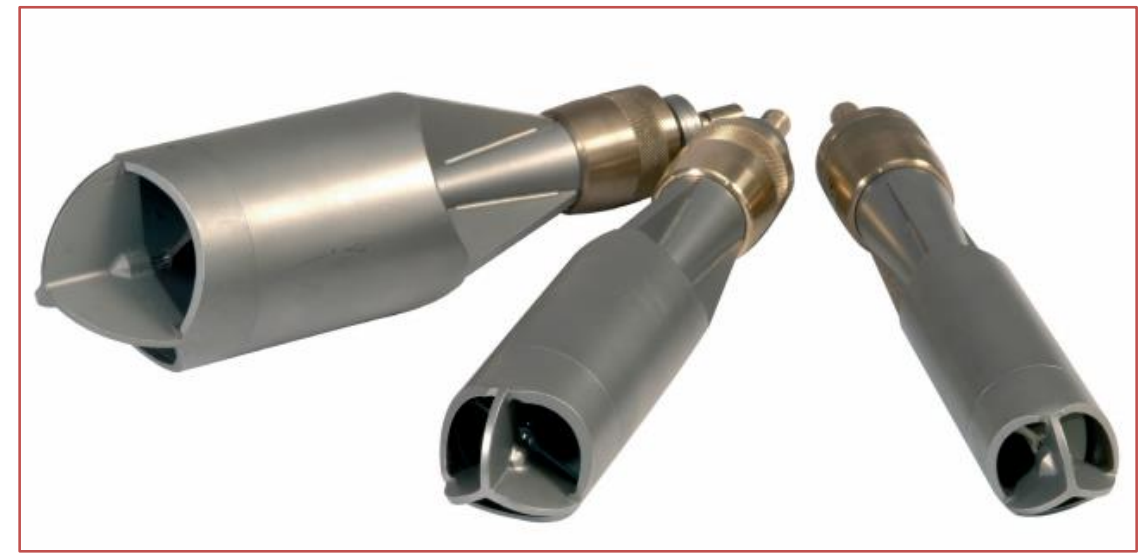

(Fonte: Halliburton, wireline \& perforating, 2014)

O propósito deste estudo foi:1) entender o princípio básico de funcionamento do flowmeter e desenvolver um modelo físico utilizando a modelagem icônica; 2)Encontrar a relação entre a rotação da hélice por minuto e do potencial elétrico utilizando como fluido o ar; 3) determinar a vazão por meio de um canal hidráulico através de um vertedouro e medir a voltagem; 4) estabelecer uma constante da ferramenta para estimar a vazão a diferentes voltagens.

Para tal, foram realizados dois testes. 0 primeiro usando ar para observar a relação entre a rotação da hélice versus a voltagem, e o segundo usando água para observar a relação entre a voltagem versus a vazão.

Os resultados mostraram que o potencial elétrico e a rotação por minuto (RPM) são proporcionais à vazão, ou seja, quanto maior o potencial elétrico e as RPM, maior será a vazão, podendo assim estimar a passagem do fluido no reservatório. Portanto, a principal contribuição deste trabalho foi encontrar a relação entre a rotação da hélice, voltagem e vazão baseada na prototipagem da ferramenta do flowmeter. 


\section{METODOLOGIA EXPERIMENTAL}

\subsection{MODELAGEM DA FERRAMENTA}

A modelagem do flowmeter baseou-se no Continuous Flowmeter Spinners da Empresa GE Oil \& Gas e o desenho, considerando as falhas na montagem e funcionamento, foi realizado no programa Solidworks, conforme a Figura 2.

Figura 2: Desenho técnico do flowmeter.

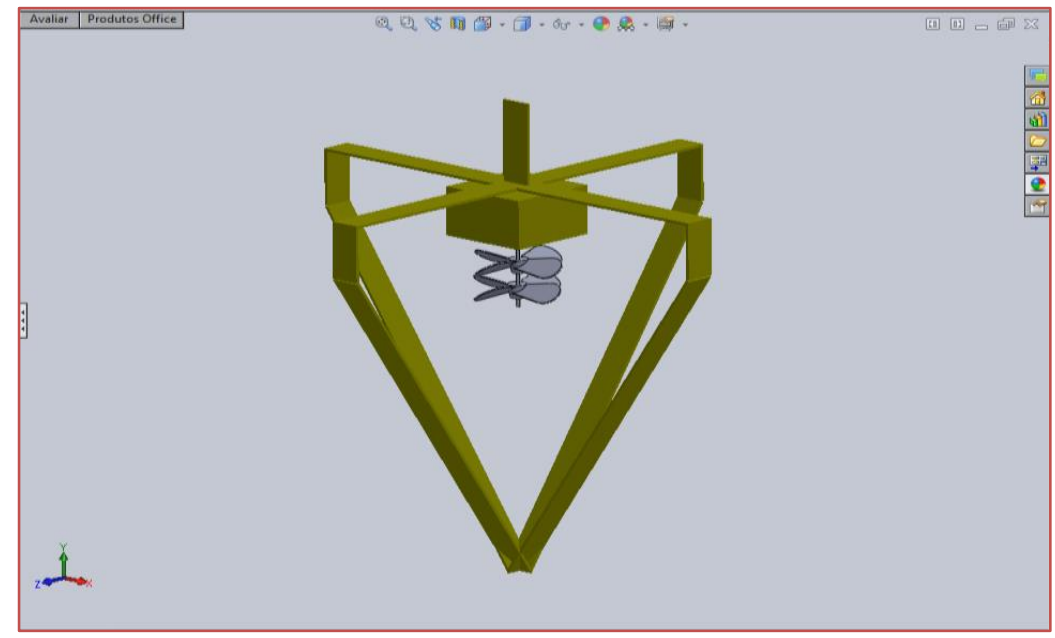

A Tabela 1 apresenta os materiais usados, os custos e as especificações. 0 Centro Universitário Tiradentes (Unit) forneceu parte dos materiais.

Tabela 1: Materiais e especificações para montagem do flowmeter

\begin{tabular}{|l|c|c|}
\hline Materiais & 10,00 & $1,5 \mathrm{~cm} \times 02 \mathrm{~mm}$ \\
\hline Hastes de ferro & 10,00 & - \\
\hline 01 Motor de Corrente Contínua (DC) & Unit & Diâmetro 7,5 cm \\
\hline 02 Hélices & Unit & - \\
\hline 01 Multímetro & - & - \\
\hline 02 Ímãs & 5,50 & - \\
\hline 01 Reed switch & Emprestado & - \\
\hline 01 Arduino & Unit & - \\
\hline 01 Protoboard & 16,50 & $15 \mathrm{~cm}$ \\
\hline 01 Tinta spray dourada metálica & Unit & \\
\hline 01 Vertedor Parede Delgada & & \\
\hline
\end{tabular}

Inicialmente, as hastes de ferro foram montadas simulando as hélices da ferramenta, onde foram anexadas a um motor de corrente contínua. Também foi feito um modelo de proteção para a hélice utilizando as hastes de ferro, sendo pintada com uma tinta dourada metálica. Dois ímãs foram inseridos na hélice em abas alternadas. Como o perfil de avaliação do poço é um sensor elétrico, foi necessário montar um circuito elétrico. Para isso, utilizou-se o sistema Reed Switch e Protoboard junto com o Arduino 1.6.6 (ver Figura 3), onde para que cada vez que a hélice girasse o ímã fechasse o contato com o reed switch e mandasse um sinal para o programa Arduino 1.6.6. Nele, as RPM ou rotação da hélice (RPS) são contabilizadas. 
Figura 3: Protoboard conectado ao Arduino 1.6.6.

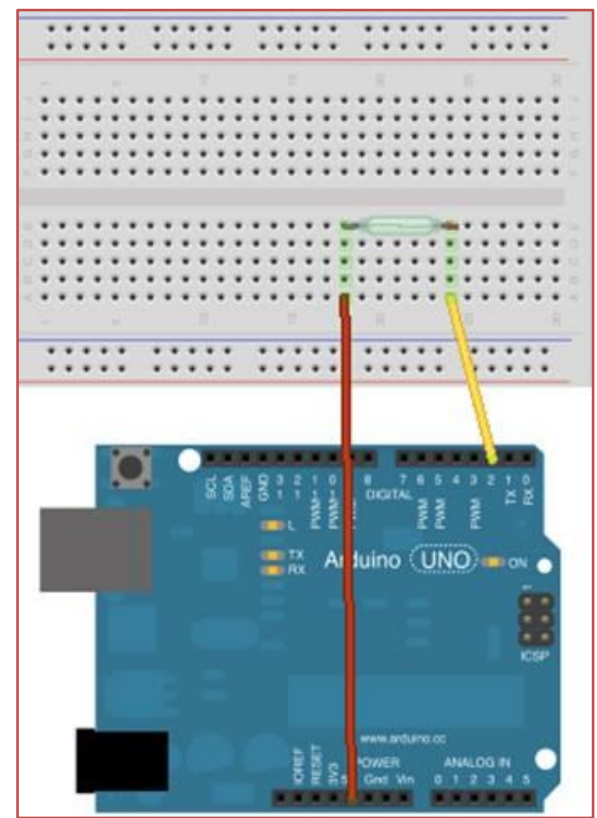

A Figura 4 apresenta o resultado final do modelo icônico do flowmeter para realização dos testes experimentais.

Figura 4: Modelo Icônico do flowmeter.
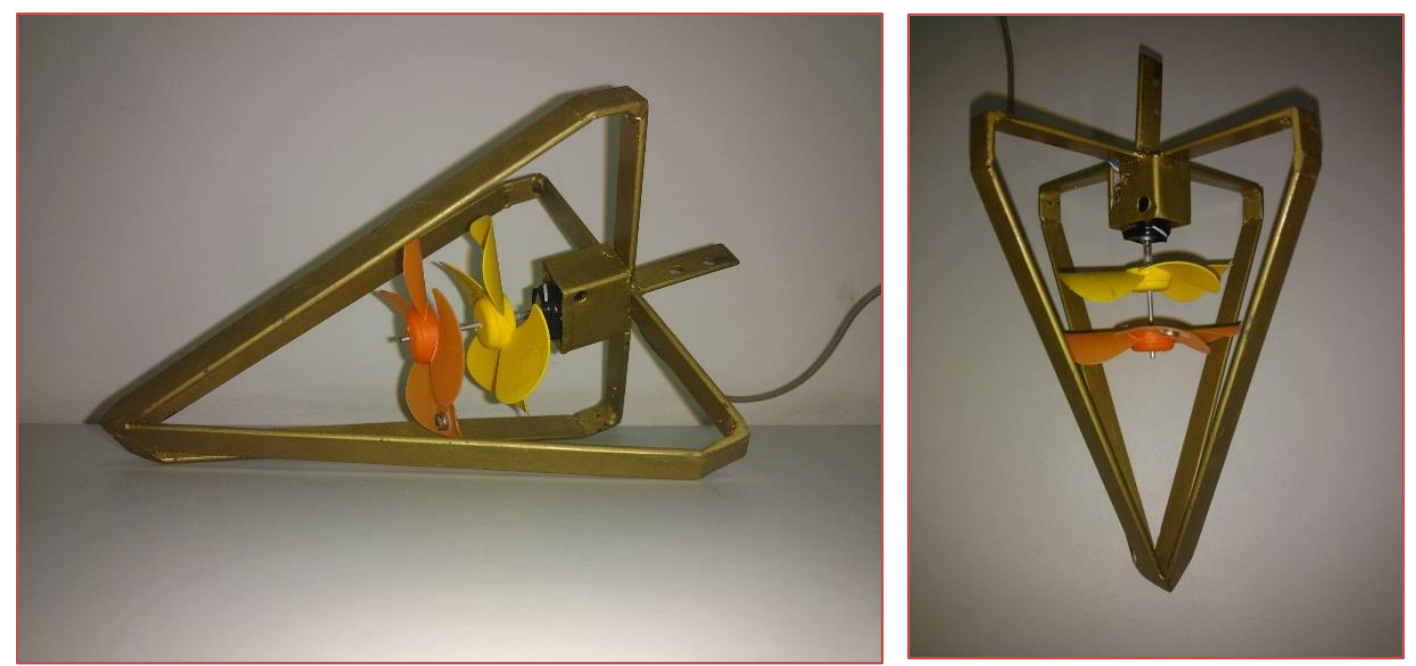

\section{TESTES EXPERIMENTAIS}

Dois testes com o flowmeter foram realizados para obter a relação entre a rotação da hélice por minuto e do potencial elétrico, logo após calibrar e medir a vazão.

0 primeiro teste foi utilizado como fluido o ar. Utilizando o protoboard e reed switch foram contabilizadas as RPM, usando o programa Arduino 1.6.6, conforme citado antes; e o multímetro que contabilizou a tensão elétrica. A tensão em termos técnicos é a "diferença de potencial elétrico entre dois pontos", medido em volts (Morimoto). Quanto mais volts, mais energia pode fluir.

No segundo teste foi utilizado como fluido a água em um canal hidráulico (Figura 5), onde foi obtida a tensão elétrica através do multímetro anexado ao flowmeter. 
Figura 5: Canal hidráulico utilizado nos testes de medição das vazões com o flowmeter.

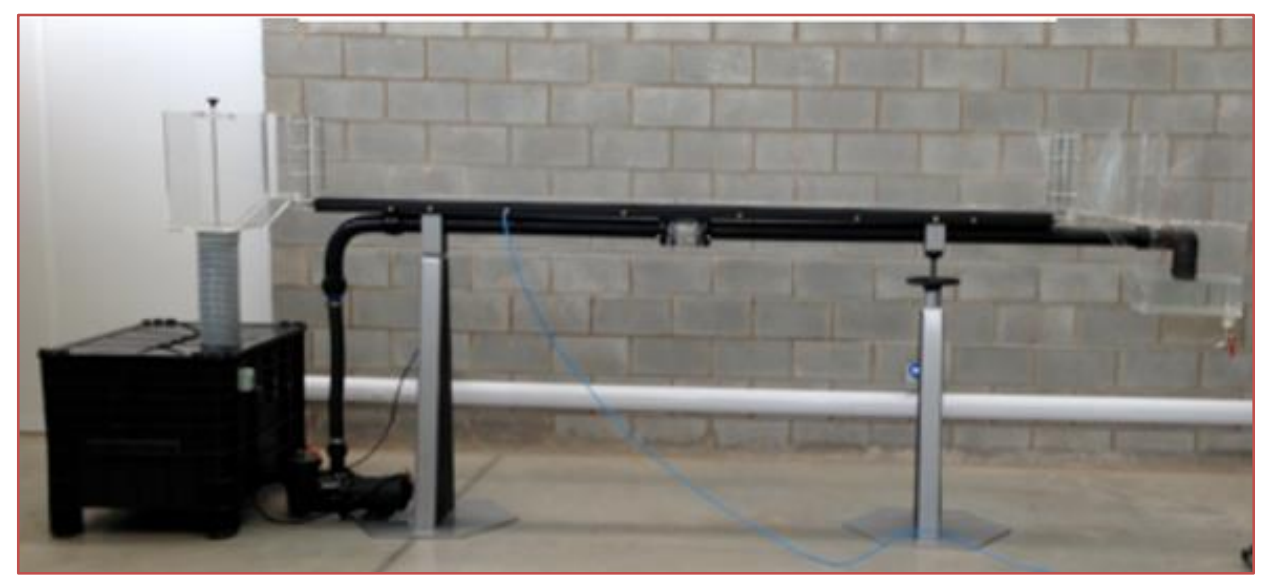

O canal hidráulico é um equipamento desenvolvido especialmente para apoiar o ensino das matérias que tratam dos fluidos e seus escoamentos, assim como para apresentar os fenômenos reais em forma visual, o que torna mais fácil o entendimento dos fenômenos hidráulicos. 0 objetivo do canal foi simular a chegada dos fluidos do reservatório até o fundo do poço e realizar a medição das vazões, através da ferramenta. Para isso, o flowmeter foi colocado no meio do canal hidráulico com um vertedor de parede delgada, conforme Figura 6. Observa-se que o flowmeter foi colocado acima do topo do vertedor que tem uma altura de $15 \mathrm{~cm}$ a partir da base do canal (datum). Seguidamente, após ligar a bomba, espera-se que o fluxo, ao longo do canal, estabilize. Isso pode ser acompanhado com a leitura do multímetro. Após observar a estabilização, é realizada a medição de altura do líquido a montante do vertedor.

Figura 6: Calibração do flowmeter.
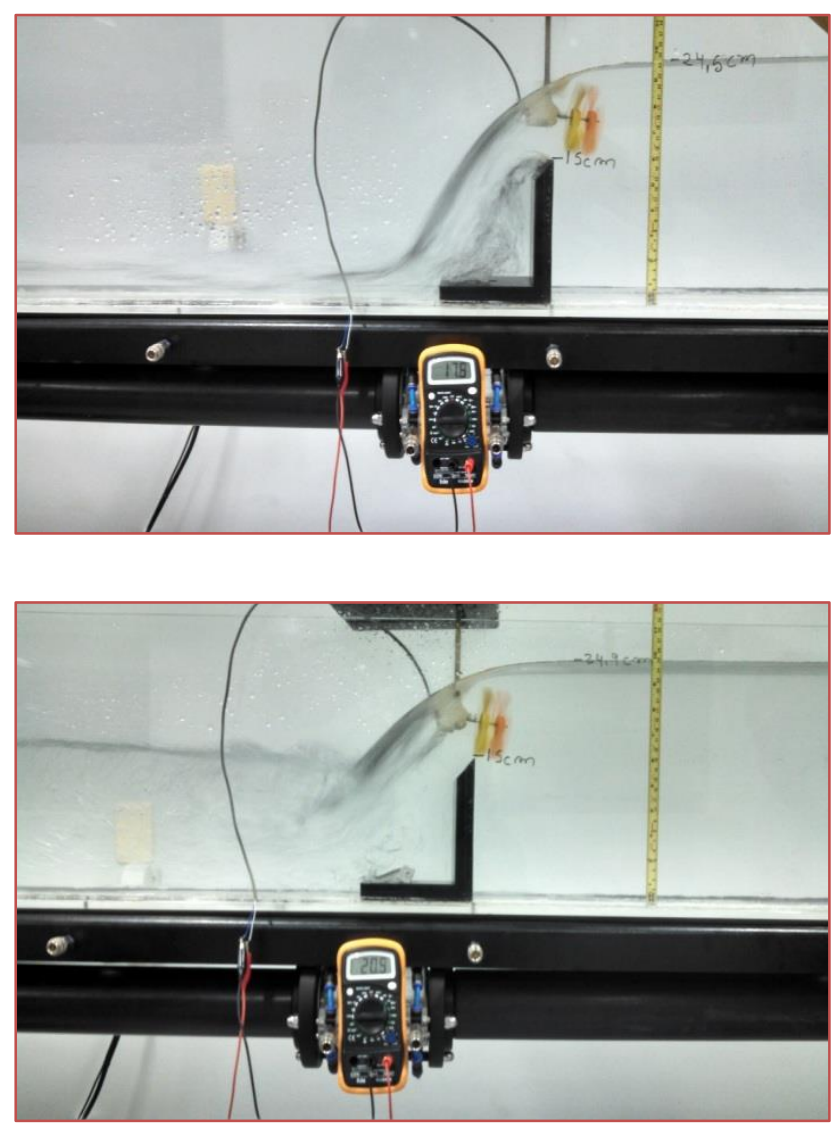
Os dados obtidos foram analisados com base na fórmula do vertedor retangular de parede delgada e sem contrações (Fernandez et al.,2005), ver Equação 1, para obtenção da vazão:

$$
Q=1,84 \times L \times H^{\frac{3}{2}} \text { (Equação 01) }
$$

Na qual: 1,84 é a constante utilizada para o vertedor tipo parede delgada; L é a largura do canal hidráulico em metros; H é a diferença da altura do vertedor com a lâmina d'água medida também em metros. A unidade da vazão resulta em litro por segundo (L/s).

A Tabela 2 mostra os dados obtidos no canal hidráulico.

Tabela 2: Dados obtidos do canal hidráulico (Tensão, H e L).

$$
\text { Vertedor de Parede Delgada }
$$

\begin{tabular}{|l|l|}
\hline $\mathbf{L}(\mathbf{m})$ & $\mathrm{H}(\mathrm{m})$ \\
\hline $\mathbf{0 , 1}$ & 0,095 \\
\hline $\mathbf{0 , 1}$ & 0,099 \\
\hline
\end{tabular}

\section{RESULTADOS E DISCUSSÕES}

\section{TESTE COM AR}

Os resultados do primeiro teste podem ser observados no gráfico 1. Este apresenta a tensão elétrica em função das RPM das hélices do flowmeter para o teste com ar. Observa-se que existe uma boa linearidade e proporcionalidade dos dados obtidos, ou seja, maior RPM da hélice, maior a tensão elétrica medida em milivolts $(\mathrm{mV})$. Portanto, acredita-se que esta relação seja válida para qualquer outro fluido que possa ser usado no flowmeter.

Observa-se também na Gráfico 1 que a equação da linha de tendência é confiável, já que, quando a rotação da hélice for zero, a tensão elétrica fica próximo de zero $(-0,9752)$. Na realidade, se não existir rotação na hélice, a tensão é zero. Portanto, com o intuito de calibrar (corrigir) a equação da curva, foi adicionado um quinto dado, ou seja, rotação zero para tensão zero como se mostra no Gráfico 2.

Gráfico 1: Gráfico da rotação da hélice em função da tensão elétrica utilizando ar.

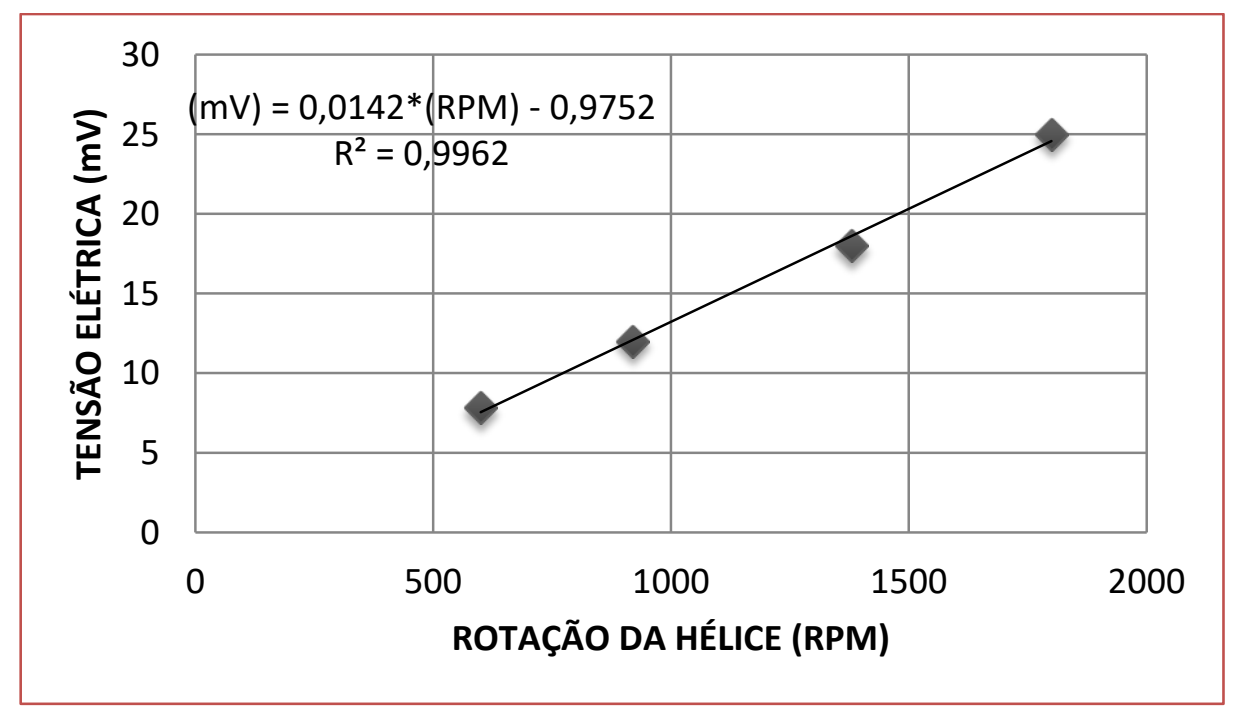


Observa-se também no Gráfico 2 que o coeficiente de Pearson (R2) melhora e para rotação zero, a tensão fica ainda mais próxima de zero $(-0,2775)$. 0 valor da inclinação da curva calibrada $(0,0137)$ indica que uma rotação da hélice que acontece em um minuto, provoca um potencial elétrico de 0,0137 $\mathrm{mV}$.

Gráfico 2: Gráfico da rotação da hélice em função da tensão elétrica - curva calibrada.

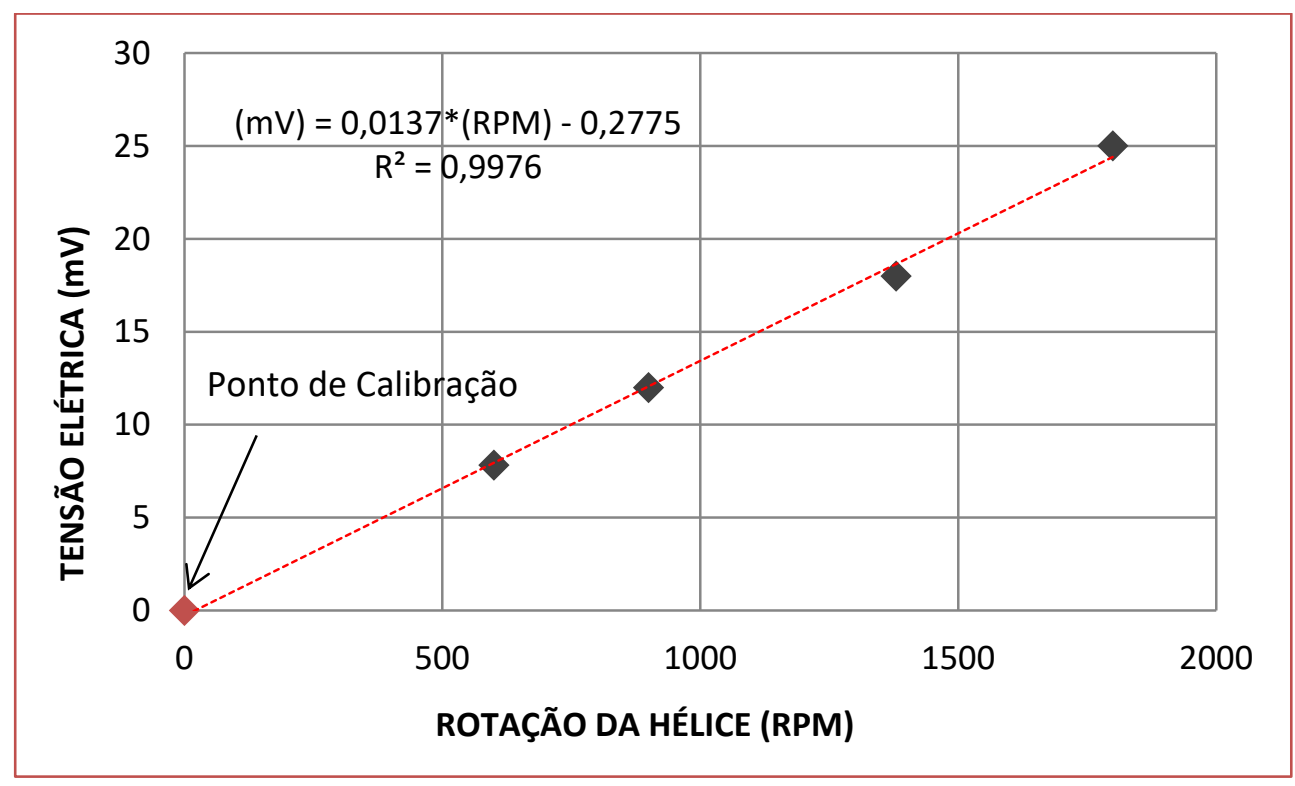

Uma limitação do primeiro teste foi estimar ou calcular a vazão do ar a partir dos dados obtidos (RPM e voltagem) de uma equação que esteja em função do tipo de fluido, tipo de hélice, RPM e tensão.

\section{TESTE COM ÁGUA}

No segundo teste, os resultados obtidos no canal hidráulico estão apresentados na Tabela 3. Observa-se que quanto maior é a tensão medida, igualmente maior é a vazão calculada. Portanto, existe também uma direta proporcionalidade entre estes dois parâmetros, assim como observado no primeiro teste entre RPM e tensão. Isto é, quanto maior é a rotação da hélice, maior é a tensão e consequentemente maior é a vazão que escoa através do flowmeter.

Com os dados da Tabela 3 se obteve uma constante, relacionando a vazão e a tensão elétrica. Observa-se que as constantes de proporcionalidade não foram iguais apesar de serem próximas. Isto indica que a linearidade existe, mas precisa ser calibrada.

Tabela 3: Resultados obtidos através da calibração.

\begin{tabular}{|c|c|c|}
\hline Tensão (mV) & $\mathbf{Q}(\mathbf{L} / \mathbf{s})$ & $\mathbf{Q} / \mathbf{V}(\mathbf{L . m V} / \mathbf{s})$ \\
\hline 17,50 & 5,39 & 0,31 \\
\hline 20,50 & 5,73 & 0,28 \\
\hline Média & 5,56 & 0,29 \\
\hline
\end{tabular}

Plotando os dados de vazão e tensão da Tabela 3, observa-se no gráfico 2 que a equação da reta precisa ser calibrada já que, se o potencial elétrico medido fosse zero, a vazão seria de $3,4 \mathrm{~L} / \mathrm{s}$. Isto fisicamente não teria sentido já que quando a tensão é zero significa que não acontece rotação na hélice, ou seja, não existe fluxo sobre a hélice do flowmeter. Portanto, esta condição foi adicionada como terceiro ponto para obter a calibração da curva da vazão em função da tensão. 
Observa-se no mesmo Gráfico 3 que a equação da curva calibrada apesar de ter um menor valor do R2 mostra que quando a tensão for zero, a vazão ficará em um valor muito próximo de zero $(0,0417$ L/s). 0 interessante é que a inclinação da curva coincida muito bem com a constante (relação da vazão/tensão) calculada na Tabela 3 - nela, o valor da constante oscila entre 0,28 a 0,31 L.mV/s e inclinação da curva calibrada no valor de 0,2893 L.mV/s, próximo ou igual ao valor médio da constante calculada na Tabela 3. Dessa forma, a equação da curva calibrada é confiável para predizer a vazão de água que flui pela hélice do flowmeter. A inclinação desta curva indica que por cada litro que flui sobre a hélice da ferramenta, é gerado um potencial de $0,29 \mathrm{mV}$ num segundo.

Gráfico 3: Dados de vazão em função da tensão e linearidade dos dados sem e com calibração.

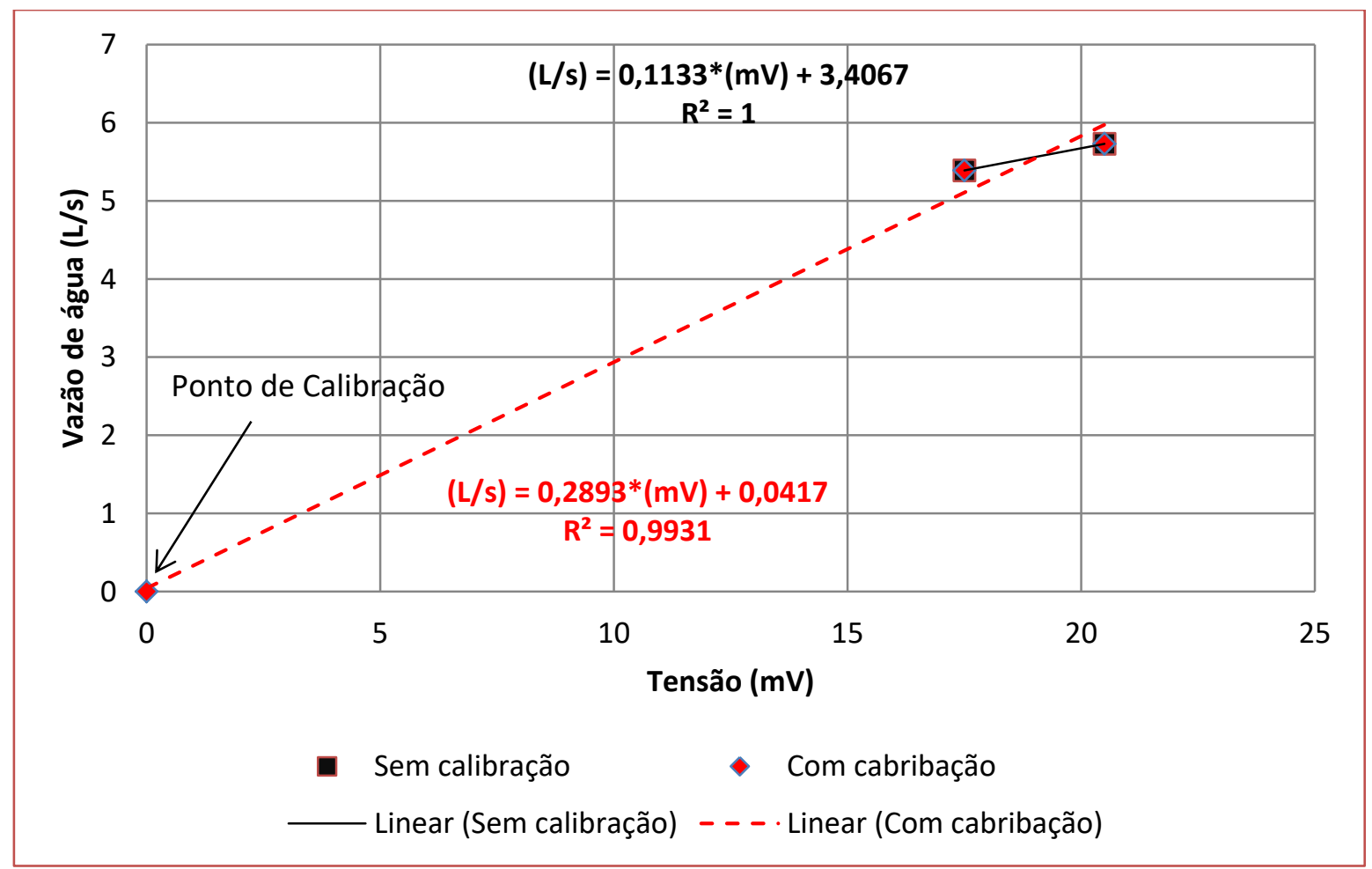

Uma limitação do segundo teste foi obter mais dados de vazão e tensão no canal hidráulico. Está limitação foi dada por se ter disponível um único vertedor e a dificuldade de variar a altura do líquido em relação ao topo do vertedor.

Os resultados mostraram que o potencial elétrico e as RPM são proporcionais à vazão, ou seja, quanto maior o potencial elétrico e as RPM, maior será a vazão, podendo assim estimar a passagem do fluido no reservatório. Portanto, a modelagem do flowmeter para estimativa da vazão de fluidos nos permitiu chegar a vazões para diferentes potenciais elétricos, possibilitando estimar as vazões em um mesmo poço.

O perfil flowmeter corrido isoladamente, sem outras informações, somente pode informar a contribuição de cada intervalo, se o fluxo for com um único fluido, conforme testes realizados com ar e água. Caso esteja presente a produção de dois fluidos, mais um perfil é necessário para informar, além da contribuição de cada intervalo, qual a percentagem de cada fluido.

\section{RECOMENDAÇõES}

A modelagem icônica da ferramenta flowmeter permitiu entender o princípio básico de funcionamento desse perfil de produção, o continuous flowmeter. Testes para determinação da vazão de fluidos foram realizados, quando foi observado que o potencial elétrico e as RPM são proporcionais à vazão, ou seja, quanto maior o potencial elétrico e as RPM, maior será a vazão. Além disso, após a calibração da ferramenta foi possível estimar a passagem do fluido no reservatório, atingindo o objetivo da ferramenta 
de medir a vazão total de produção (ou de injeção). E, por fim, através da ferramenta foi possível encontrar a relação entre a rotação da hélice, voltagem e vazão.

A calibração das curvas obtidas foi importante para dar maior confiabilidade no cálculo de valores preditivos no flowmeter.

Para futura melhoria deste trabalho se recomenda:

- Obter uma equação confiável para medir a vazão do ar e comparar com a vazão de água.

- Procurar alternativas para obter maior quantidade de dados de vazão e usar vários tipos de vertedores.

- Realizar uma análise de sensibilidade com diferentes geometrias de hélice e/ou número de hélices.

- Realizar a medição das RPM para líquidos.

- Realizar a medição de vazão, tensão e RPM para fluidos bifásicos e trifásicos.

\section{REFERÊNCIAS}

[1] Carlos, E. Morimoto, "Entendendo a eletricidade: tensão, corrente, watts e outros bichos". Disponível em: http://www.hardware.com.br/dicas/entendendo-eletricidade.html. Acesso em 06/06/2016.

[2] Fernandez, M. F., Araujo, R., Ito, A. E., Netto, A. (2005) “Vertedores”, in Manual de hidraúlica. São Paulo, Edgard Blucher Ltda.

[3] Paz, E. F. (2010) Sistema baseado em medidor de pressão diferencial para determinação em linha de vazões de produção em poços de petróleo, Dissertação de mestrado, Universidade de São Paulo.

[4] Thomas, J.E. (2001) Fundamentos de Engenharia de Petróleo. 2 $2^{\underline{a}}$ edição. Rio de Janeiro, Interciência. Disponível em: www.halliburton.com. Acesso em 05/06/2016. 


\section{Capítulo 8}

Influência da temperatura no escoamento de petróleo em linhas de produção de fibra de vidro no campo petrolífero da cidade de Araças - BA

Sandro Luís da Costa Alves

Luciana Rocha Alves

Luzia Aparecida Tofaneli

Turan Dias Oliveira

Resumo: 0 petróleo é considerado o recurso natural mais procurado e utilizado na sociedade moderna, no entanto a sua busca e extração tem sido extenso e árduo trabalho. Durante a exploração do petróleo em campos maduros, o mesmo deve ser levado do poço até a estação de pré-processamento afim de realizar a separação da emulsão óleo/água, sendo que o fluxo do petróleo durante esse trajeto é realizado pela linha de produção. Em campos maduro, a produção de petróleo está associada a uma grande produção de água, assim favorecendo a corrosão das tubulações, assim algumas empresas detentoras de blocos exploratórios tem substituído as linhas de produção fabricadas a partir de aço por fibra de vidro, essa mudança tem-se mostrado eficiente quanto ao problema da corrosão, no entanto poucos trabalhos têm sido realizados no sentido de avaliar a variação da temperatura do petróleo nessas tubulações de fibra de vidro, por isso se faz necessário a avaliação do comportamento da temperatura e por consequência da viscosidade e compará-lo com o fluxo em tubulações de aço carbono, para assim obter conclusões mais precisas sobre a troca dessas tubulações, até mesmo para servir de parâmetros para as empresas em futuras trocas das linhas de produções mais antigas por linhas de produção fabricadas a partir de fibra de vidro. Assim este trabalho tem como objetivo verificar a influência da temperatura na viscosidade do petróleo produzido através de linhas de produção fabricadas a partir de fibra de vidro em campos maduros.

Palavras-Chave: Condutividade térmica, Viscosidade, Hidrocarboneto líquido, Parafinação. 


\section{INTRODUÇÃO}

0 petróleo deriva do latim, onde petra significa pedra e oleum é óleo, assim este mineral foi denominado como óleo de pedra. Para Cruz (2011), o petróleo é uma mistura líquida formada por hidrocarbonetos, estes que por sua vez pode conter compostos orgânicos leves como metano ( $\mathrm{CH} 4)$ e compostos mais pesados como substâncias orgânicas naftênicas e aromáticas com cadeias carbônicas superior a C17.

0 petróleo é o recurso natural mais consumido pela sociedade moderna, sendo motivo de independência energética para os países. Esse hidrocarboneto pode ser utilizado de diversas formas, quando processado, que pode variar desde a utilização como combustíveis em automóveis até a química fina, na produção de medicamentos, perpassando pela indústria petroquímica que amplia seu leque de utilização em uma infinita gama de produtos fabricados a partir da nafta, principal derivado do petróleo.

A busca pelo petróleo tem se intensificado nos últimos anos, no entanto a sua busca é ainda muito complexa. De acordo com Thomas (2004), a realização dos trabalhos para que se possa encontrar um novo campo de petróleo exige um investimento inicial relativamente alto, uma vez que se faz necessário a delimitação das bacias sedimentares e um criterioso estudo para identificar dentro da bacia sedimentar o local que apresente maior indício para acumulação desse hidrocarboneto, para assim propor uma perfuração que comprove o prospecto desse mineral.

De acordo com Alves \& Tofaneli (2016), o petróleo após ser encontrado no reservatório deve ser encaminhado para estação de pré-processamento, para que o mesmo seja separado dos demais fluidos, uma vez que a emulsão que sai do reservatório é composta essencialmente por água, petróleo e gás.

Para Machado (2002), o escoamento de um fluido viscoso é definido como a deformação contínua e irreversível, sendo essa deformação realizada por um sistema de forças. Na indústria do petróleo, em especial no processo de extração, o escoamento de fluidos pode ocorrer em três tipos: monofásico, bifásico e multifásico.

Segundo Cruz (2011), o escoamento bifásico é aquele que apresenta duas fases distintas no mesmo fluxo em uma tubulação, sendo que em especial no caso da indústria do petróleo o escoamento pode se apresentar do tipo multifásico, envolvendo o transporte de fluidos na fase líquida (água e petróleo) concomitantemente com o fluxo na fase gasosa (gás natural), sendo que este gás pode ser associado ou não a fase líquida.

O escoamento monofásico na indústria do petróleo só ocorre em casos específicos, sendo estes limitados ao processo de injeção de água ou injeção de gás no reservatório de petróleo, com o objetivo de aumentar a pressão do reservatório ou diminuir a massa especifica do petróleo, respectivamente.

Porém em campos petrolíferos maduros, a produção de petróleo em sua maioria ocorre em escoamento bifásico (água e petróleo), uma vez que a produção de gás já ocorreu anteriormente na recuperação primária do reservatório.

Durante o escoamento do petróleo nas linhas de produção, algumas propriedades do fluido podem interferir no processo de escoamento, uma desta é a viscosidade. A viscosidade, também conhecida como módulo de Young, pode ser: dinâmica e cinemática, onde a viscosidade dinâmica é expressa pela razão entre a tensão de cisalhamento e a taxa cisalhante, já a viscosidade cinemática é descrita pela razão entre a viscosidade dinâmica e a massa específica do fluido em questão.

Segundo Machado (2002), a viscosidade é uma propriedade física do fluido muito importante para descrever a sua resistência ao fluxo, assim demonstrando a sua resistência necessária para que o mesmo possa realizar uma mudança posicional.

Durante o fluxo do petróleo nas linhas de produção, desde a cabeça do poço até a estação de processamento primário, a viscosidade do petróleo pode sofrer variações, sendo que os fatores que mais interferem nessas variações são: natureza físico química do fluido, temperatura, pressão, taxa de cisalhamento, tempo de escoamento e campo elétrico. No entanto Machado (2002), corrobora que o fator mais relevante para variações de viscosidade na indústria do petróleo é a temperatura.

A distância dos poços de petróleo até a estação de processamento primário pode variar bastante de acordo com localização da estação em relação aos poços produtores de petróleo, em alguns casos essa distância pode favorecer uma intensa troca de calor, assim proporcionando uma variação significativa na viscosidade do petróleo, que por sua vez terá uma dificuldade maior durante o escoamento.

A corrosão e a parafinação são consideradas os principais problemas para indústria do petróleo, sendo que a parafinação da linha de produção é conhecida como a deposição de cristais ao longo da parede 
interna do poço. Para Baldotto \& Figueiredo (2010), o processo de parafinação das linhas de produção pode resultar em intervenções não programadas da produção e condições inseguras nas operações, causando perdas na produção e possibilidade de danos irreparáveis, requerendo o abandono ou substituição de equipamentos.

De acordo com Alves \& Tofaneli (2016), o acúmulo de parafina ao longo da linha de produção ocasiona a redução interna das tubulações, que contribui para uma diminuição da vazão, aumento do atrito da parede da tubulação que por consequência exige uma maior capacidade da unidade de bombeamento e acima de tudo pode alterar o tipo de escoamento do petróleo ao longo da linha de produção.

Algumas empresas detentoras de blocos exploratórios na bacia do Recôncavo, vem substituindo suas linhas de produção fabricadas a partir de aço por linhas de produção de fibra de vidro.

De acordo com Young (2008), a condutividade térmica do aço é de 50,2 W/mK, enquanto que a fibra de vidro tem um valor de $0,048 \mathrm{~W} / \mathrm{mK}$, assim demonstrando que a fibra de vidro tem condutividade bem menor que o aço.

Essa mudança de material para fabricação das linhas de produção tem evitado a corrosão das linhas, no entanto poucos trabalhos vêm sendo realizado com objetivo de avaliar a deposição de parafinas ao longo da tubulação, que por sua vez é influenciada principalmente pela diminuição da temperatura.

Este trabalho tem como objetivo verificar a influência da temperatura na viscosidade do petróleo produzido através de linhas de produção fabricadas a partir de fibra de vidro no campo petrolífero de Fazenda Boa Esperança localizado no município de Araças - BA.

\section{METODOLOGIA}

O presente trabalho foi desenvolvido a partir de uma pesquisa bibliográfica sobre a influência da temperatura no escoamento do petróleo nas linhas de produção que vão da cabeça do poço até a estação de pré-processamento, além de pesquisa de campo, onde foram coletadas amostras de petróleo para verificação da temperatura do mesmo em dois pontos distintos: na cabeça de produção e na chegada da estação.

A pesquisa de campo foi realizada no campo petrolífero de Fazenda Boa Esperança - FBE, localizado no município de Araças - BA, cuja coordenadas geográficas são: latitude 12¹3’02"S e longitude 38¹2'11”W.

As amostras de petróleo foram coletadas em dois poços distintos, sendo um com linha de produção fabricada a partir de aço e o outro poço com linha de produção fabricada a partir de fibra de vidro, sendo que em cada poço foi retirada amostras na chegada do petróleo na superfície, na cabeça do poço, e outra no final da linha de produção, ou seja, na entrada da estação de pré-processamento. A amostragem foi realizada no mês março de 2016, sendo que em cada ponto de coleta foram retiradas duas amostras, cada uma contendo um volume de $500 \mathrm{~mL}$, sendo uma utilizada para realizar a análise da viscosidade e a outra foi guardada como contraprova, caso fosse necessária à sua utilização. No momento da retirada das amostras, foi medida a temperatura do petróleo com auxílio de um termômetro químico com escala interna, marca Incoterm modelo 5001, com faixa de medição de temperatura de $-30^{\circ} \mathrm{C}$ a $50^{\circ} \mathrm{C}$ e limite de erro de $\pm 1^{\circ} \mathrm{C}$.

As amostras após serem coletadas foram acondicionadas para retirada da água contida na amostra, uma vez que a emulsão produzida pelo reservatório é composta de água salobra e petróleo. Após a separação dos fluidos, o petróleo foi identificado e encaminhado para o laboratório da Carboflex para determinação da viscosidade em quatro temperaturas diferentes: T0, foi considerada a temperatura do fluido na cabeça do poço, T3, sendo a temperatura no final da linha de produção (entrada da estação de préprocessamento), sendo ainda considerada mais duas temperatura entre os valores obtidos na cabeça do poço e na entrada da estação (T1 e T2), de modo a garantir a realização da curva da viscosidade em função da temperatura, onde T1 foi definida como a temperatura média entre T0 e T2, já T2 sendo a temperatura média entre T1 e T3).

\section{RESULTADOS E DISCUSSÃO}

A estação de pré-processamento na qual foi realizada a amostragem, recebe produção de 18 poços de petróleo, sendo 4 injetores de água e 14 produtores de petróleo. A distância desses poços até a estação é demonstrada na tabela 1 , assim a escolha dos dois poços utilizados para coleta foi de acordo com a maior 
distância, pois a variação de temperatura é influenciada pelo tempo em que esse petróleo trocará calor com a tubulação.

Tabela 1: Distância dos poços até a estação.

\begin{tabular}{|l|c|c|}
\hline Poços & Distância $(\mathrm{m})$ & Material \\
\hline Poço 1 & 979,6 & Fibra de Vidro \\
\hline Poço 2 & 312,4 & Aço \\
Poço 3 & 426,8 & Aço \\
Poço 4 & 865,4 & Fibra de Vidro \\
Poço 5 & 786,4 & Aço \\
Poço 6 & 687,9 & Aço \\
\hline Poço 7 & 1028,1 & Aço \\
Poço 8 & 197,8 & Aço \\
Poço 9 & 1049,4 & Fibra de Vidro \\
Poço 10 & 1023,1 & Aço \\
Poço 11 & 1035,7 & Fibra de Vidro \\
\hline Poço 12 & 978,5 & Aço \\
Poço 13 & 687,4 & Aço \\
Poço 14 & 992,4 & Aço \\
\hline
\end{tabular}

Assim os poços escolhidos para realização da coleta foram o poço 7 com a linha de produção fabricada com aço e o poço 9 com a linha de produção fabricada com fibra de vidro. Com relação a temperatura, quando comparada entre os pontos de coleta, pode-se observar a diferença entre as linhas de produção fabricadas a partir de aço com a de fibra de vidro, como demonstra o gráfico 1.

Gráfico 1. Temperatura do petróleo.

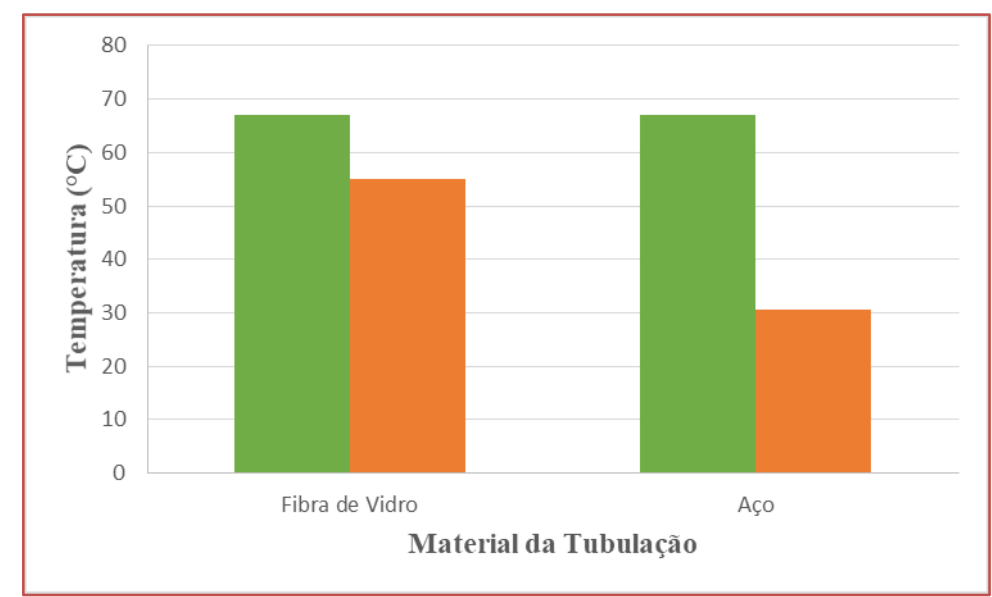

Fonte: Elaboração própria

Assim pode-se observar que a temperatura na cabeça do poço foi a mesma nos dois poços, no entanto ao final da linha de produção a temperatura entre os tipos de tubulações são diferentes, sendo que a temperatura do fluido na estação para tubulação de aço chegou com uma variação de 39,25\%, já o poço com a tubulação de fibra de vidro chegou ao final com uma variação de 17,91\%. 
Considerando a viscosidade do petróleo ao longo da linha de produção, houve variação em função da temperatura nos dois tipos de tubulações, como pode ser observado no gráfico 2.

Gráfico 2: Curva da viscosidade.

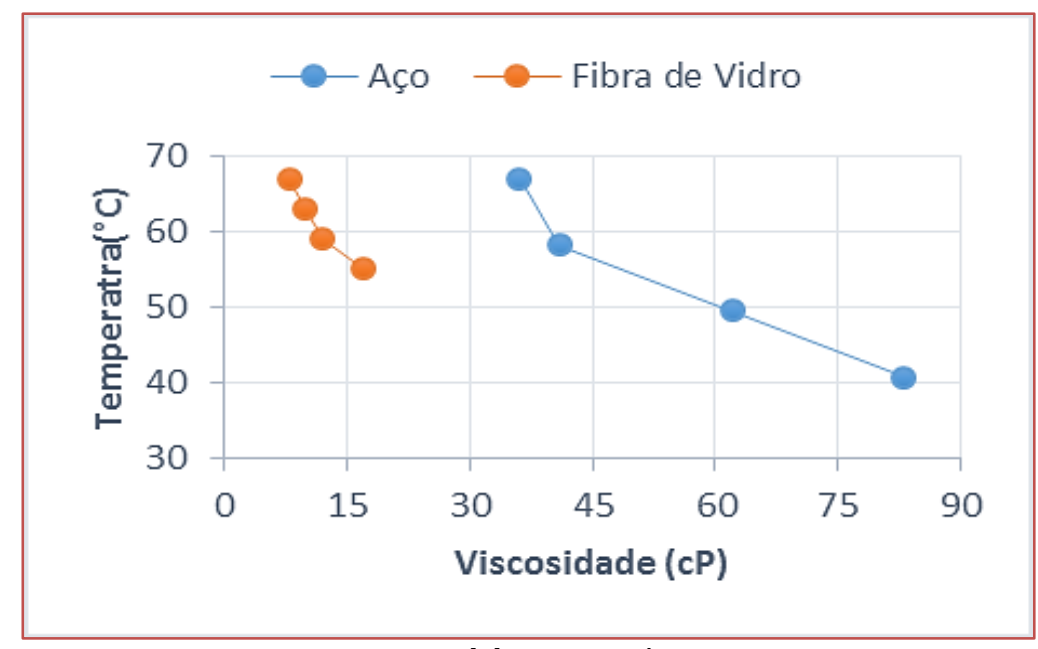

Fonte: Elaboração própria

Considerando a viscosidade Apesar da variação de temperatura na linha de produção fabricada com aço ter sido de $32,25 \%$ ao longo da linha de produção, a sua influência na viscosidade foi relativamente alta, uma vez que teve uma variação de $130,56 \%$, saindo do poço com uma viscosidade de 18cP e chegando na estação com uma viscosidade de $41,5 \mathrm{cP}$, já a linha de produção fabricada com fibra de vidro teve uma variação de temperatura de 17,91\%, influenciou na viscosidade com uma variação de $87,5 \%$, saindo da cabeça do poço com uma viscosidade de 8cP e no final da linha de produção chegou com uma viscosidade de $41,5 \mathrm{cP}$.

Apesar da grande variação da viscosidade em função do material de fabricação da linha de produção, não existe nenhuma norma para valores de viscosidade durante o escoamento, no entanto sabe-se que quanto menor a viscosidade do petróleo, melhor é o seu escoamento.

\section{CONCLUSÕES}

De acordo com os resultados obtidos, pode-se concluir que a substituição das linhas de produção fabricadas a partir de fibra de vidro tem se mostrado eficiente no que se refere a variação da viscosidade, assim mantendo a produtividade dos campos petrolíferos maduros e minimizando os custos operacionais com a desparafinação das linhas de produção, assim viabilizando a produção de petróleo em campos petrolíferos considerados maduros. Assim este trabalho pode servir de subsídio para pequenas empresas em suas tomadas de decisão no que se refere ao material de fabricação das linhas de produção.

\section{AGRADECIMENTOS}

Os autores são gratos a Faculdade de Tecnologia SENAI CIMATEC. Agradecem também a Alan Matos Teles pelo apoio operacional na coleta das amostras e a Lilian Vasconcelos Brandão pelo apoio nas análises das amostras. 


\section{REFERÊNCIAS}

[1] ALVES, S. L. da C. \& TOFANELI, L. A. Avaliação do fluxo de petróleo em linhas de produção fabricadas a partir de fibra de vidro. II Workshop de Gestão, Tecnologia Industrial e Modelagem Computacional. SENAI CIMATEC, Salvador - BA, 2016.

[2] BALDOTTO, L. E. B. \& FIGUEIREDO, A. B. Equipamentos de produção. Ática, 2010.

[3] CRUZ, S. R. Estudo da deposição de parafinas em escoamento multifásico em dutos. 2011, 113p. Dissertação de Mestrado, Pontifícia Universidade Católica do Rio de Janeiro, Programa de Pós Graduação em Engenharia Mecânica. Rio de Janeiro - RJ.

[4] MACHADO, J. C. V. Reologia e Escoamento de Fluidos - Ênfase na Indústria do Petróleo. Interciência, 2002.

[5] THOMAS, J. E. Fundamentos de Engenharia de Petróleo. Interciência, 2004.

[6] YOUNG, H. D. \& FREEDMAN, R. A. Física 1: Mecânica. 12ª edição. Addison Wesley, 2008. 


\section{Capítulo 9}

Oscilações log-periódicas em passeios aleatórios com perfil de memória de Cauchy-Lorentz

Jair Rodrigues Neyra

Rafael Santos da Costa

André Keullen da Cunha Silva

Thiago Rafael da Silva Moura

Maria Liduina das Chagas

Resumo: Propomos um modelo de passeios aleatórios, discretos e não-Markovianos para modelar dados de séries temporais associados ao fluxo de fluidos em meios porosos. Usamos a representação em termos de passeios aleatórios como aproximação de séries temporais. Construímos um modelo de passeios aleatórios com perfil de memória da Cauchy-Lorentz. Utilizamos simulações numéricas para obter os resultados das observáveis físicas. Reportamos que encontramos o fenômeno de difusão anômala, acompanhadas de oscilações log-periódicas do primeiro momento da posição, que mudam segundo as mudanças do parâmetro de escala $\beta$. Para $\beta<1$, a difusão é superdifusiva acompanhada de oscilações log-periódicas do primeiro momento da posição. Desaparecendo para valores típicos de $\beta>1$, com regime superdifusivo $(H>1 / 2)$. A superdifusão ocorre para ambas as regiões de anti-persistência $(p<1 / 2)$ e persistência $(p>1 / 2)$. Ocorre transição do regime de difusão, na região de persistência, do superdifusivo para o difusivo ordinário, quando $\beta$ >> 1 .

Palavras-chave: Séries temporais, passeios aleatórios, difusão anômala, meio poroso, distribuição de Cauchy-Lorentz. 


\section{INTRODUÇÃO}

A predição de quantidades observáveis relacionadas ao petróleo, utilizando séries temporais, é um dos desafios atuais da indústria do petróleo [1-5]. As séries temporais são representações de dados ordenados no tempo, tais como o preço do petróleo na bolsa de valores, a produção diária de óleo, as variações no fluxo de fluido, também podem representar grandezas utilizadas na previsão de falhas nos mais diversos tipos de peças mecânicas, dispositivos eletrônicos, etc. Estes dados podem ser usados para a otimização de desempenho da produção de petróleo em plataformas inshore ou offshore [1-2]. As técnicas que utilizam inteligência artificial (IA) na predição de séries temporais vem ganhando aceitação cada vez maior. Estas técnicas entram como integrante de um conjunto de ferramentas para a execução de operações interconectadas [1].

Uma maneira de modelar as séries temporais é por meio de sua representação através da técnica de passeios aleatórios [6]. Inspirados no desenvolvimento de novas ferramentas para a indústria de petróleo. Em particular, para análise de fluxo de fluidos em meios porosos, nós propomos a análise de séries temporais utilizando passeios aleatórios discretos (CAD). Cada elemento de fluido sendo aproximado à uma partícula, cada partícula difunde no meio poroso aleatoriamente como resultado da rugosidade do meio poroso, da geometria e do choque com outras partículas [7]. Um ingrediente adicional, que é incorporado em nossa modelagem, é a capacidade do caminhante aleatório recuperar uma decisão de sua dinâmica microscópica, i.e, recuperar uma decisão tomada no passado. Para realizar a análise estatística realizamos uma série de experimentações, via computador, para um conjunto de passeios aleatórios. A finitude das experimentações em termos da análise de espaço (meio poroso finito) e tempo (série temporal finita), nos induzem, convenientemente, à reportar nossos resultados para passeios aleatórios de tamanho finito.

Os regimes de difusão podem ser classificadas, através do expoente de Hurst $(\mathrm{H})$, em difusão anômala $(\mathrm{H}$ * $1 / 2)$ e ordinária $(H=1 / 2)$. Destacamos dois regimes de difusão anômala, que medimos em nossas experimentações numéricas, o regime subdifusivo $(H<1 / 2)$ e o regime superdifusivo $(H>1 / 2)$. Medidas típicas de $\mathrm{H}$, em outros intervalos, que classificam outros regimes de difusão podem ser encontrados em [8-11]. A análise das séries temporais podem ser feitas de dois modos. A primeira é dispondo de um banco de dados e precedendo com as técnicas de tratamento de dados. A outra é fazendo a modelagem da série temporal, como no modelo que estamos apresentando, em que a variável aleatória é do tipo CauchyLorentz. Cada medida da série temporal é representado por um passo de um caminhante aleatório com perfil de memória de Cauchy-Lorentz, em um instante de tempo t. Portanto, a dinâmica microscópica do conjunto de caminhantes aleatórios, na maneira como as informações são recuperadas, segue o perfil memória de Cauchy-Lorentz, que possui impacto nas medidas macroscópicas do expoente de Hurst $(\mathrm{H})$.

O nosso modelo foi construído com base no modelo de passeios aleatórios do elefante (PAE) - em inglês elephant random walks (ERW) [8]. Este modelo, com perfil de memória uniforme, proposto por G.M. Schütz and S. Trimper, possui o rótulo de "passeios aleatórios do elefante" utilizado, apenas, para enfatizar que esta é a melhor memória possível, que recupera cada decisão do passado de maneira equiprovável.

Escolhemos o modelo PAE como ponto de partida para a construção do nosso. Algumas características, herdadas pelo nosso modelo, que queremos destacar, possuem influencia direta na dinâmica microscópica. Para os PAE, que possui dois pontos de correlação, as soluções encontradas para as observáveis físicas macroscópicas são exatas; o PAE é o limite analítico para passeios aleatórios que possuem a característica de guardar na memória toda sua história. Sua generalização permite obter outros resultados fazendo a rápida mudança da função de distribuição de probabilidade [8]. No modelo PAE, o caminhante aleatório se move segundo a seguinte dinâmica microscópica: se move para dois pontos adjacentes da sua posição atual em passos unitários, para direita $(+1)$ ou para a esquerda $(-1)$. Generalizações e características adicionais podem ser encontrados nas referências [9-11].

\section{METODOLOGIA}

Inspirados no modelo Schütz e Trimper (PAE), nós propomos um modelo de passeios aleatórios com perfil de memória segundo a distribuição de Cauchy-Lorentz [12]. No modelo de passeios aleatórios com perfil de memória uniforme, discreta, cada incremento realizado no instante de tempo $t$ depende de toda a história do caminhante. Cada estado é recuperado de forma equiprovável. Esta característica é responsável por moldar um passeio aleatório com perfil de memória uniforme. A probabilidade de recuperar uma ação tomada do passado no instante de tempo $t+1$ é de $1 / t$. A caminhada é gravada a todo instante, o que atribui a característica não-Markoviana à caminhada. 
A dinâmica estocástica de cada caminhante ocorre da seguinte maneira: o caminhante anda um passo para a direita $(+1)$ ou um passo para a esquerda $(-1)$, tal como em um passeio aleatório unidimensional Markoviano, com a equação de evolução estocástica dada por

$$
X_{t+1}=X_{t}+\sigma_{t+1}
$$

para um tempo $t+1$. Quando o caminhante anda um passo para a direita, a variável $\sigma t+1$ assume o valor +1 e quando o caminhante anda para a esquerda, assume o valor -1 . A memória consiste de um conjunto de variáveis aleatórias $\sigma \mathrm{t}^{\prime}$ para o tempo $\mathrm{t}^{\prime}<\mathrm{t}$. $\mathrm{O}$ acesso à memória e a dinâmica microscópica ocorrem da seguinte maneira:

(a) no tempo $\mathrm{t}+1$ um número $\mathrm{t}^{\prime}$ do conjunto $1,2, \ldots, \mathrm{t}$ é escolhido aleatoriamente com probabilidade uniforme $1 / \mathrm{t}$.

(b) $\sigma \mathrm{t}+1$ é determinado estocasticamente por, $\sigma \mathrm{t}+1=\sigma \mathrm{t}^{\prime}$ com probabilidade $\mathrm{p}$ e $\sigma \mathrm{t}+1=-\sigma \mathrm{t}^{\prime}$ com probabilidade $1-\mathrm{p}$.

No instante $t=1$, o primeiro passo ocorre de acordo com a seguinte regra: o caminhante se encontra na posição X0 e se move para a direita com probabilidade q ou para a esquerda com probabilidade 1 - q, ou seja, $\sigma 1=+1$ com probabilidade q e $\sigma 1=-1$ com probabilidade 1 - q. Este processo é quantificado pela seguinte equação de evolução estocástica

$$
X_{t}=X_{0}+\sum_{t \prime=1}^{t} \sigma_{t \prime}(2)
$$

A quantidade p é o parâmetro de feedback. Ele quantifica a probabilidade do caminhante repetir uma ação do passado no instante de tempo $t^{\prime}$. Quando $(\mathrm{p}>1 / 2)$ o caminhante apresenta um comportamento persistente. 0 comportamento persistente é caracterizado pela repetição das mesmas ações passadas. Para $(\mathrm{p}<1 / 2$ ) o caminhante toma uma decisão contrária a decisão que foi selecionada, o caminhante apresenta, portanto, um comportamento anti-persistente. Para o valor de $(p=1 / 2)$ a caminhada aleatória é Markoviana. Nas regiões limítrofes de $(p=0)$ e $(p=1)$ surgem dois comportamentos extremos. No ponto $(\mathrm{p}=0)$, ocorre o máximo do comportamento anti-persistente, enquanto em $(\mathrm{p}=1)$ ocorre o máximo do comportamento persistente, onde o caminhante move-se de forma determinística. Este tipo de passeio aleatório apresenta característica de que o primeiro passo é macroscopicamente relevante, portanto, possui impacto nos regimes de difusão medidos pelo expoente de Hurst [8].

O primeiro momento da posição é

$$
\langle x(t)\rangle=\frac{\delta}{\Gamma(\lambda+1)} t^{2 p-1}(3)
$$

sendo $\delta=2 q-1, \lambda=2 p-1$ e $\Gamma$ a função gama. Os parâmetros $\delta$ e $\lambda$ estão definidos no intervalo $[-1,1]$.

Outra grandeza de interesse é o segundo momento da posição, que é dado pela equação 


$$
\left\langle x^{2}(t)\right\rangle=\begin{gathered}
\frac{t}{3 p-4}, p<3 / 4 \\
t \ln (t), p=3 / 4 \\
\frac{t^{4 p-2}}{(3 p-4) \Gamma(4 p-2)}, p>3 / 4
\end{gathered}
$$

Note que para ( $\mathrm{p}<3 / 4)$ o segundo momento, eq.(4) depende linearmente de t e a difusão é ordinária, para $(p>3 / 4)$ a difusão é caracterizada como superdifusiva. No ponto $(p=3 / 4)$ o segundo momento é descrito através de uma função logarítmica do tempo [8].

Nosso modelo é constituído por passeios aleatórios com uma memória associada, capazes de lembrar de eventos do passado segundo o perfil de memória descrita pela função de distribuição de probabilidade de Cauchy-Lorentz. A distribuição de probabilidade é usada para trazer da memória uma lembrança do passado do conjunto 1, 2, ..., t, neste caso, é a função de distribuição de Cauchy, verificada da seguinte maneira

$$
P\left(t^{\prime}\right)=\frac{P_{0}}{1+\left(\frac{t^{\prime}-\alpha}{\beta}\right)^{2}}(7)
$$

sendo P0 a constante de normalização, $\alpha=\mathrm{t} / 2$ o parâmetro de locação e $\beta$ o parâmetro de escala. Utilizamos a distribuição de Cauchy truncada no intervalo $[0,+\infty)$. A dinâmica é a mesma do modelo proposto por Schütz e Trimper exibido acima.

\section{RESULTADOS}

Nos passeios aleatórios o comportamento difusivo é classificado pelo expoente de Hurst. 0 comportamento difusivo pode ser classificado através da lei de escala assintótica do desvio quadrático médio da posição em relação ao tempo. 0 desvio quadrático médio é definido da seguinte maneira $<(\mathrm{x}-<$ $\mathrm{x}>)^{2}>=\mathrm{t}^{2 \mathrm{H}}$, sendo $\mathrm{H}$ o expoente de Hurst. Para os nossos passeios aleatórios de tamanho finito, $\mathrm{o}$ primeiro momento da posição cresce mais lentamente do que o segundo momento, segue-se que a aproximação $\left\langle\left(\mathrm{x}-\langle\mathrm{x}>)^{2}\right\rangle \sim\left\langle\mathrm{x}^{2}>\right.\right.$ é pertinente. Portanto, H pode ser avaliado através da seguinte relação $<\mathrm{x}^{2}>=\mathrm{t}^{2 \mathrm{H}}$

Nossos resultados apresentam difusão anômala nas regiões de persistência e anti-persistência. Lembramos que quando $\mathrm{p}>1 / 2$ o caminhante apresenta comportamento persistente, para $\mathrm{p}=1 / 2 \mathrm{o}$ comportamento é Markoviano e quando $\mathrm{p}<1 / 2$ o modo de comportamento é o anti-persistente. A difusão anômala pode ser classificada como superdifusiva e subdifusiva, segundo as medidas típicas de $\mathrm{H}$. Na região de anti-persistência $(\mathrm{p}<1 / 2)$, nosso modelo apresenta o comportamento superdifusivo, seguido de oscilações log-periódicas do primeiro momento de difusão, caracterizado por medidas de $\mathrm{H}>1 / 2$.

Estudamos como o parâmetro de escala, $\beta$, influencia na probabilidade do caminhante retomar suas ações passadas. Notamos com o crescimento de $\beta$, que o regime superdifusivo desaparece dando lugar ao comportamento difusivo na região de anti-persistência ( $p<1 / 2$ ). Na Figura 1 , menores medidas do expoente de Hurst são exibidas com o aumento do parâmetro de escala $\beta$. Quando o parâmetro assume valores da ordem de $\beta=10^{3}$, com $p=0$, obtemos $H \approx 1$ (regime superdifusivo); que passa para $H=1 / 2$ (regime difusivo) para valores típicos do parâmetro $\beta=10^{7}$ e parâmetro de feedback $\mathrm{p}=0$.

Na região de anti-persistência, para os valores de $\beta$ no intervalo $0 \leq \beta \leq 1$ o comportamento é superdifusivo. Notamos que o regime superdifusivo é acompanhado pelo comportamento log-periódico do primeiro momento da posição. Portanto, observamos que, para valores de $\beta$ no intervalo $0 \leq \beta \leq 1$, o primeiro momento da posição apresenta oscilações log-periódicas. A amplitude das oscilações diminuem com o aumento do parâmetro $\beta$. Na Figura 2, são exibidas medidas ordinárias, na região de antipersistência $\mathrm{p}=0$, do primeiro momento da posição para diversos valores de $\beta$. Foram escolhidos três valores de $\beta$ para mostrar a redução da amplitude das oscilações log-periódicas, que apresentam maiores amplitudes para valores de $\beta=10^{-3}$, que diminuem como pode ser visto, na Figura 2 , para os valores típicos de $\beta=10^{-1}$ e $\beta=10^{0}$, apresentando amplitudes cada vez menores. 
Figura 1: Medidas do expoente de Hurst $(\mathrm{H})$ em função da probabilidade (p) e o parâmetro de escala $\beta$. Observamos o transiente do regime superdifusivo para o difusivo ordinário com o aumento do parâmetro de escala $\beta$.

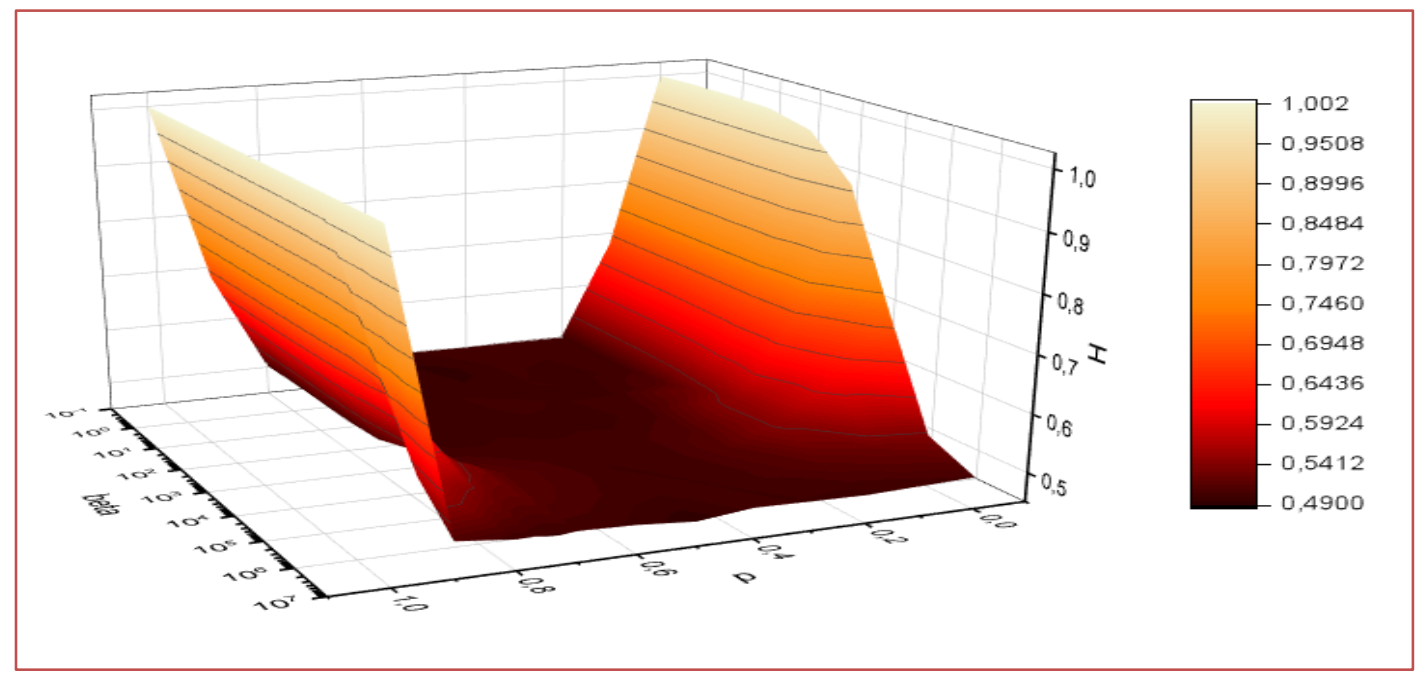

Figura 2: Comportamento do primeiro momento para os valores positivos de $\beta \leq 1$. É exibida redução das amplitudes das oscilações log-periódicas para valores típicos de $\beta$ da ordem de $10^{-3}, 10^{-1}$ e $10^{0}$.

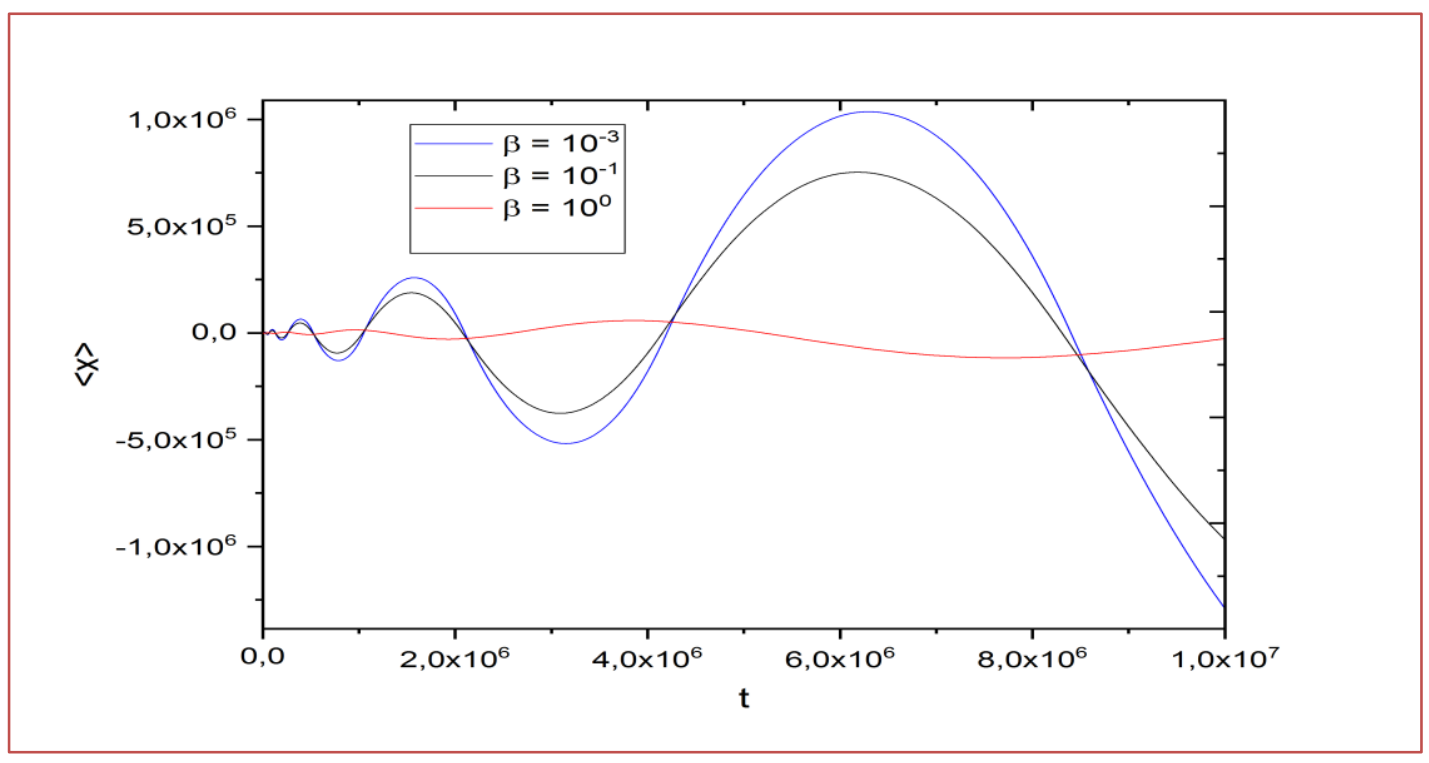

\section{DISCUSSÃO}

Em passeios aleatórios com perfil de memória uniforme, cada passo dependerá de toda a história do caminhante. $\mathrm{O}$ armazenamento de todos os passos na memória, que possam ser acessados de forma equiprovável é uma característica do modelo de passeios aleatórios com perfil de memória uniforme. A distribuição de Cauchy-Lorentz é usada como ingrediente fundamental o acesso à memória, i.e., para a construção do modelo de passeios aleatórios com perfil de memória de Cauchy-Lorentz. Nossos resultados obtém o primeiro momento e a variância em um passeio aleatório com perfil de memória de Cauchy.

Nos acréscimos de $\beta$, iniciando $\operatorname{com} \beta=10^{-3}$, observamos a transição do regime superdifusivo para o regime difusivo na região de anti-persistência. 0 comportamento superdifusivo do modelo é substituído totalmente pelo comportamento Markoviano. Em acordo com medidas quantitativas do expoente de Hurst, que passa de $\mathrm{H}=1$ para $\mathrm{H}=1 / 2$ no decorrer dos valores de $\beta$ da ordem de $10^{-3}$ a $10^{7}$, que são observações características dos regimes superdifusivo e difusivo ordinário, respectivamente.

Segundo os nossos resultados numéricos para passeios aleatórios finitos, as oscilações log-periódicas mostram que observações do primeiro momento da posição são maiores quão menores são os valores do 
parâmetro de escala. Em $\beta=10^{-3}$, são observadas as oscilações com as maiores amplitudes, que diminuem na medida que o parâmetro de escala $\beta$ aumenta, desaparecendo para valores típicos da ordem de $\beta=1$. Para valores de $\beta$ > 1, não há oscilações log-periódicas e o regime superfifusivo sofre transição para o regime difusivo para vários valores do parâmetro de feedback, que não correspondem aos valores ordinários do modelo ERW.

\section{CONCLUSÕES}

Em uma caminhada aleatória unidimensional Markoviana, o caminhante pode dar um passo para direita ou para esquerda sem que exista correlação entre os passos iniciais da caminhada com os passos dados após um longo tempo passado desde o inicio da caminhada. Com a construção da uma memória, a caminhada é gravada em todos os passos; seja o passo dado para a direita ou para a esquerda, modelando a capacidade do caminhante lembrar de toda a sua história. Cada passo do caminhante em um instante de tempo depende do seu percurso até aquele instante. 0 caminhante recupera qualquer ação do passado com probabilidade igual. A classificação dos regimes de difusão dos passeios aleatórios são determinadas segundo medidas do expoente de Hurst. Propomos um modelo de passeios aleatórios com perfil de memória conforme a distribuição de Cauchy-Lorentz, que possa agregar soluções para os desafios da industria do petróleo como, por exemplo; o estudo de correlações, a predição e o treinamento de series temporais utilizando técnicas de Big Data e Inteligência Artificial, respectivamente. As técnicas e os nossos resultados podem ser aplicados em áreas de interesse da industria petrolífera. Por exemplo, o comportamento de partículas, como estudado em nosso modelo, pode ser relacionado com a difusão das moléculas do petróleo em meios porosos, utilizados para treinar redes neurais supervisionadas ou não supervisionadas para a predição de séries temporais. Os resultados de passeios aleatórios com perfil de memória de Cauchy-Lorentz, nos permite compreender o comportamento do petróleo e diversas propriedades de transporte nos reservatórios.

\section{AGRADECIMENTOS}

Nós agradecemos a FAPESPA e a UFPA Campus Salinópolis pelo apoio a nossa pesquisa.

\section{REFERÊNCIAS}

[1] NYBØ, R. Time series opportunities in the petroleum industry. SINTEF Petroleum Research. Thormøhlensgate.

[2] LIEBOWITZ, J. The handbook of applied expert systems. FL: CRC Press. Boca Raton, 1998.

[3] AMARA, M. H. ; MARTIN, B. The Offshore Directional Drilling Advisor: An Expert System for Directional Drilling Optimization. In: SPE ANNUAL TECHNICAL CONFERENCE AND EXHIBITION, 1990, New Orleans, Louisiana.

[4] HAVREVOLD, L.; HYTTEN, N. ; PARIGOT, P. Getting More Out of Drilling Data byn Analysis-While-Drilling. In: OFFSHORE EUROPE, 1991, Aberdeen, United Kingdom.

[5] GOVIA, D. ; CARPENTER, K. Valuation Models for Intelligent Strategies. In: INTELLIGENT ENERGY CONFERENCE AND EXHIBITION, 2008, Amsterdam, The Netherlands.

[6] DINIZ, R. M. B. ; CRESSONI, J.C.; de SILVA, M. A. A.; MARIZ, A. M. ; de ARAÚJO, J. M. Narrow log-periodic modulations in non-Markovian in random walks. Phys Rev. E, 96,062143.

[7] [7] INGENHOUSZ, J. Nouvelles expériences et observations sur divers objets de physique. T. Barrois le jeune, 1785.

[8] [8] SHÜTZ, G. M.; TRIMPER, S. Elefants can always remember: Exact long-range memory effects in a nonMarkovian random walk. Phys. Rev. E, 70, 045101, (2004).

[9] [9] CRESSONI, J.C.; da SILVA, M. A. A.; VISWANATHAN, G. M. Amnestically Induced Persistence in Random Walks. Phys. Rev. Lett, 2007.

[10] [10] PARAAN, F.N.C.; ESGUERRA, J.P. Exact moments in a continuous time random walk with complete memory of its history. Physical Review E, 74, 032101, (2006).

[11] [11] HURST, H.E.; BLACK, R.P.; SIMAIKA, Y.M. Long-Term Storage: An Experimental Study, Constable, London, 1965.

[12] [12] FELLER, W. An Introduction to Probability Theory and Its Applications. 2.ed. John Wiley \& Sons Inc, NewYork. v. 2. 


\section{Capítulo 10}

\section{Capacidade de sorção da fibra de licuri na remoção de água oleosa proveniente do petróleo}

\section{Pedro Victor Bomfim Bahia}

Thaís da Silva Bitencourt

Rosangela Regia Lima Vidal

Resumo: Com o intuito de avaliar a capacidade de sorção da fibra da folha de licuri foram realizados experimentos de cinética e de isoterma de sorção em batelada, utilizando baixas concentrações inicias de óleo cru na água oleosa sintética em meio altamente salino. A cinética de sorção foi avaliada variando o tempo de contato e a isoterma de sorção foi obtida após $4 \mathrm{~h}$ de contato, ambos em diferentes concentrações iniciais de óleo na água oleosa sintética. Os sistemas foram avaliados utilizando 0,5 g/L de fibra, sob a rotação de $140 \mathrm{rpm}$ e a temperatura de $37{ }^{\circ} \mathrm{C}$, constantes. A cinética de sorção mostrou que o equilíbrio foi atingido a partir de $3 \mathrm{~h}$ de contado entre o óleo e a fibra, o equilíbrio foi facilmente observado para concentração inicial de óleo a partir de $40 \mathrm{mg} / \mathrm{L}$. 0 modelo que melhor se ajustou aos dados obtidos foi o de Freundlich, indicando que a adsorção óleo-fibra ocorre em multicamadas. 0 mecanismo de sorção foi atribuído a estrutura e a composição química da fibra, em que os processos de adsorção (óleo-licuri ou cera) e absorção (óleo-celulose) ocorrem simultaneamente. A fibra de licuri apresentou uma boa capacidade de remoção do óleo presente na água oleosa salina, podendo ser utilizada em águas oleosas com concentrações iniciais de óleo menores do que $100 \mathrm{mg} / \mathrm{L}$, com porcentagem máxima de remoção de $52 \%$ e descarte abaixo de $42 \mathrm{mg} / \mathrm{L}$, cumprindo o limite de descarte máximo diário estabelecido pelo CONAMA.

Palavras-chave: licuri, petróleo, água oleosa sintética, sorção. 


\section{INTRODUÇÃO}

O derramamento frequente de óleo em ambientes aquáticos pelas refinarias de petróleo tem chamado atenção aos riscos causados a vida marinha. 0 óleo quando é derramado na água do mar pode sofrer várias mudanças, dentre elas a formação da emulsão óleo-água. Por este motivo, as indústrias têm procurado alternativas para minimizar os danos causados pelo derramamento de petróleo, como por exemplo: skimming, queima controlada e o uso de adsorventes [1,2].

O óleo a ser descartado no mar deve seguir as normas da legislação ambiental vigente no país. O Conselho Nacional do Meio Ambiente brasileiro (CONAMA) estabelece um limite de contaminantes em efluentes para descarte, impondo que o descarte de água oleosa obedeça a concentração máxima mensal de óleo até $29 \mathrm{mg} / \mathrm{L}$ e a concentração máxima diária de óleo de $42 \mathrm{mg} / \mathrm{L}$ [3].

A biomassa é uma alternativa biodegradável a ser utilizada na remoção do óleo, presente na água do mar, após acidentes, problemas nas refinarias ou derramamentos de petróleo [4]. O licuri pode ser uma alternativa para este fim. Essa biomassa é uma fibra de baixo custo e encontrada em abundância nas regiões semi-áridas do país propicias ao seu crescimento [5].

A sorção compreende os processos de adsorção ou absorção que podem ocorrer na fibra vegetal simultaneamente. A adsorção ocorre devido à interação entre as moléculas do adsorvato com os sítios ativos presentes na superfície do material adsorvente. No caso da absorção, as moléculas do óleo podem penetrar no interior da biomassa. Os dois processos podem auxiliar na interação fibra-óleo, devido à estrutura e composição química da fibra [6].

A fibra de licuri tem como principais constituintes a celulose, hemicelulose e a lignina. A celulose e a lignina, formadas por estruturas tridimensionais, conferem a fibra pouca solubilidade na maioria dos solventes e rigidez, respectivamente. Além desses três principais constituintes, as fibras possuem uma pequena camada de cera superficial que cobre a sua estrutura [7]. A presença da lignina e da cera superficial na biomassa pode facilitar o processo de sorção entre a fibra e o óleo, visto que este processo ocorre mediante a interação da parte hidrofóbica da biomassa com as moléculas do petróleo, ambos de caráter hidrofóbico $[8,9]$.

O objetivo do trabalho foi avaliar a capacidade de sorção da fibra da folha de licuri na remoção do óleo presente na água oleosa sintética, obtida a baixas concentrações inicias de óleo cru em meio altamente salino, em sistemas em batelada, sob a rotação, temperatura e dosagem da fibra $\left(140 \mathrm{rpm}, 37^{\circ} \mathrm{C} \mathrm{e} 0,5 \mathrm{~g} / \mathrm{L}\right)$, constantes. A cinética de sorção foi avaliada variando o tempo de contato $(0,17$ a $5 \mathrm{~h})$, para diferentes concentrações iniciais de óleo cru presente na água salina (19, 30, 44 e $102 \mathrm{mg} / \mathrm{L})$ e a isoterma de sorção foi analisada após $4 \mathrm{~h}$ de contato óleo-fibra, a diferentes concentrações iniciais de óleo cru (em torno de $20,40,60,80$ e $100 \mathrm{mg} / \mathrm{L}$ ) na água oleosa sintética.

\section{METODOLOGIA}

\subsection{MATERIAIS}

Fibra da folha de licuri é proveniente da Região de Capim-Grosso no estado do Bahia e o petróleo foi gentilmente cedido pela Petrobrás (UO-SEAL). Esse óleo cru, com grau API de $37,3{ }^{\circ} \mathrm{API}\left(15,55{ }^{\circ} \mathrm{C}\right)$ e densidade de $0,84 \mathrm{~g} / \mathrm{cm} 3$, foi utilizado para preparar a água oleosa sintética. Os produtos químicos $\mathrm{n}$ hexano da Impex, cloreto de sódio e cloreto de cálcio do fabricante Synth foram utilizados sem tratamento prévio. A água Milli-Q foi utilizada no preparo da água salina.

\subsection{PREPARO DA ÁGUA OLEOSA SINTÉTICA}

A água oleosa sintética foi obtida a partir da adição de uma determinada quantidade de petróleo leve em água salina com concentração de sais de $55 \mathrm{~g} / \mathrm{L}$, contendo $50 \mathrm{~g}$ de cloreto de sódio e $5 \mathrm{~g}$ de cloreto de cálcio em 1 L de água Milli-Q. 0 sistema óleo-água salina foi mantida sob agitação constante de 12.000 rpm, por cerca de 40 minutos, utilizando um homogeneizador Turrax T25, da IKA. 


\subsection{PREPARO DA FIBRA}

A fibra da folha de licuri foi lavada com água destilada, para a eliminação de impurezas na superfície, seca ao sol e, posteriormente, cortada em pedaços menores e, então, moída em moinho. Em seguida, foi novamente lavada com água destilada e seca em estufa, por $48 \mathrm{~h}$, à temperatura constante de $60^{\circ} \mathrm{C}$.

\subsection{COMPOSIÇÃO QUÍMICA PELO MÉTODO VAN SOEST}

A composição química da fibra da folha de licuri foi determinada utilizando o método de van Soest. Esse método consiste na divisão dos componentes da amostra em conteúdo celular e material celular. Os ensaios realizados são da Fibra em Detergente Neutro (FDN) e a Fibra em Detergente Ácido (FDA) [10].

\subsection{EXPERIMENTOS DE SORÇÃO}

A eficiência de sorção de óleo pela fibra da folha de licuri foi avaliada a partir dos experimentos de cinética e isoterma de sorção em batelada. Os experimentos de cinética de sorção foram realizados, variando o tempo de contato fibra-óleo cru de 0,17 a 5 h, para diferentes concentrações iniciais de óleo cru $(19,30,44$ e $102 \mathrm{mg} / \mathrm{L}$ ) na água oleosa sintética. Os experimentos de isoterma foram avaliados após $4 \mathrm{~h}$ de contato fibra-óleo cru, a diferentes concentrações iniciais de óleo cru (em torno de 20, 40, 60, 80 e $100 \mathrm{mg} / \mathrm{L}$ ) na água oleosa sintética. Os dois experimentos ocorreram a rotação de140 rpm, a temperatura de $37{ }^{\circ} \mathrm{C}$ e a dosagem da fibra de 0,5 g/L, constantes. Após preparar a água oleosa sintética em diferentes concentrações, $45 \mathrm{~mL}$ dessa água foram adicionados em um tubo flacon, com capacidade de $50 \mathrm{~mL}$, e $5 \mathrm{~mL}$ de n-hexano, para promover a separação da fase orgânica. 0 sistema foi vigorosamente agitado e, em seguida, o sobrenadante foi coletado e lida a absorbância de cada uma das emulsões de óleo em água salina (água oleosa sintética) em um espectrofotômetro UV-VIS da Rigol Ultra 3560, utilizando uma curva de calibração, previamente construída, de absorbância versus a concentração inicial de óleo na água oleosa sintética. 0 comprimento de onda da fase orgânica foi $260 \mathrm{~nm}$. Os experimentos de sorção foram realizados pelo menos três vezes. A capacidade de sorção da fibra da folha de licuri foi determinada utilizando a Equação 1, em que q é a capacidade de sorção da fibra em mg/g, Ci e Cf são as concentrações inicial e final de óleo cru na emulsão respectivamente, em $\mathrm{mg} / \mathrm{L}$, $\mathrm{V}$ é o volume de água oleosa sintética e $\mathrm{m}$ é a massa da fibra da folha de licuri. A porcentagem de remoção do óleo pela fibra da folha de licuri foi obtida a partir da Equação 2.

$$
q=\frac{\left(C_{i-} C_{f}\right) V}{m} \text { (1) e \% Remoção de óleo }=\frac{C_{i}-C_{f}}{C_{i}} x 100 \text { (2) }
$$

Foram aplicados modelos de isoterma de adsorção (Langmuir, Temkin e Freundlich) no intuito de entender o comportamento de adsorção da fibra a partir dos dados obtidos. As equações linearizadas de Langmuir, Temkin e Freundlich são mostradas pelas Equações 3, 4 e 5 [11], em que Ce é a concentração do óleo cru na água oleosa sintética no equilíbrio (mg/g), qe é a quantidade da fibra da folha de licuri no equilíbrio (mg/g), qo é a capacidade máxima de adsorção da fibra (mg/g), b é uma constante relacionada a energia máxima de adsorção entre o óleo e a fibra (L/mg), B1 (adimensional) e $\mathrm{K}^{\circ} \mathrm{L}(\mathrm{L} / \mathrm{mg}$ ) são constantes, em que na relação $B_{1}=R T / b_{t}$, bt está relacionada ao calor de sorção $(\mathrm{J} / \mathrm{mol})$ e $\mathrm{K}^{\circ} \mathrm{L}$ a estabilidade da ligação [12], K e n são constantes que indicam a extensão da sorção e o grau de não linearidade entre a concentração inicial de óleo na água oleosa sintética e a adsorção, respectivamente.

Os valores de qo e b podem ser calculados por meio da linearidade entre Ce/qe e Ce, que fornece o coeficiente angular (1/qo) e o coeficiente linear (1/qob) (Equação 3) [13]. A partir do gráfico de ln qe versus o ln Ce é possível determinar o valor das constantes Kf e $\mathrm{n}$, utilizando os coeficientes linear e angular (1/n) respectivamente (Equação 5) [14].

$$
\frac{C_{e}}{q_{e}}=\frac{1}{q_{o} b}+\frac{C_{e}}{q_{o}}(3) \quad q_{e}=B_{1} \ln K_{L}^{\circ}+B_{1} \ln C_{e} \text { (4) } \quad \ln q_{e}=\ln K_{f}+\frac{1}{n} \ln C_{e} \text { (5) }
$$

Langmuir Temkin $\quad$ Freundlich 


\section{RESULTADOS E DISCUSSÃO}

\subsection{COMPOSIÇÃO QUÍMICA}

\subsubsection{MÉTODO VAN SOEST}

A capacidade de sorção da biomassa está diretamente relacionada à sua composição química, sendo necessária a sua caracterização. A composição química da fibra da folha de licuri foi determinada utilizando o método van Soest em que se obteve 10,99 \pm 0,18\% de lignina, 29,02 \pm 0,75\% de hemicelulose e $44,79 \pm 0,58 \%$ celulose, sendo $84,81 \pm 0,35 \%$ FDN e 55,78 $\pm 0,40 \%$ FDA. Em geral, as fibras naturais lignocelulósicas possuem uma pequena camada de cera superficial [7]. A presença dessa pequena camada de cera na superfície das biomassas confere a fibra da folha de licuri propriedades hidrofóbicas e oleofílicas. Além disso, a presença de lúmens ocos nas extremidades da celulose auxilia no armazenamento do óleo por ação capilar [9,11]. Como pode ser observado a partir dos valores citados acima, a lignina e a celulose correspondem mais da metade da composição química da fibra da folha de licuri, cerca de 56\%. 0 processo de sorção do óleo cru pelo licuri pode estar diretamente relacionado com a ocupação dos lúmens vazios da celulose pelas moléculas de óleo e com a interação do óleo com a sua fração hidrofóbica por forças de van der Waals, atribuída à lignina e à cera superficial, já que o óleo, a lignina e cera são majoritariamente hidrocarbonetos.

\section{EXPERIMENTOS DE SORÇÃO}

\subsection{CINÉTICA DE SORÇÃO}

O estudo da cinética de sorção possibilita a determinação do tempo de equilíbrio óleo cru-fibra. A Figura 1 mostra a capacidade de sorção do óleo cru pela fibra da folha de licuri na dosagem 0,5 g/L, em diferentes concentrações iniciais de óleo cru $(19,30,44$ e $102 \mathrm{mg} / \mathrm{L})$, a temperatura e rotação constantes $\left(37^{\circ} \mathrm{C}\right.$ e $140 \mathrm{rpm})$.

Figura 1: Cinética de sorção do óleo cru pela fibra da folha de licuri a 0,5 g/L, a diferentes concentrações iniciais de óleo cru na água oleosa sintética, a $140 \mathrm{rpm} \mathrm{e} 37^{\circ} \mathrm{C}$.

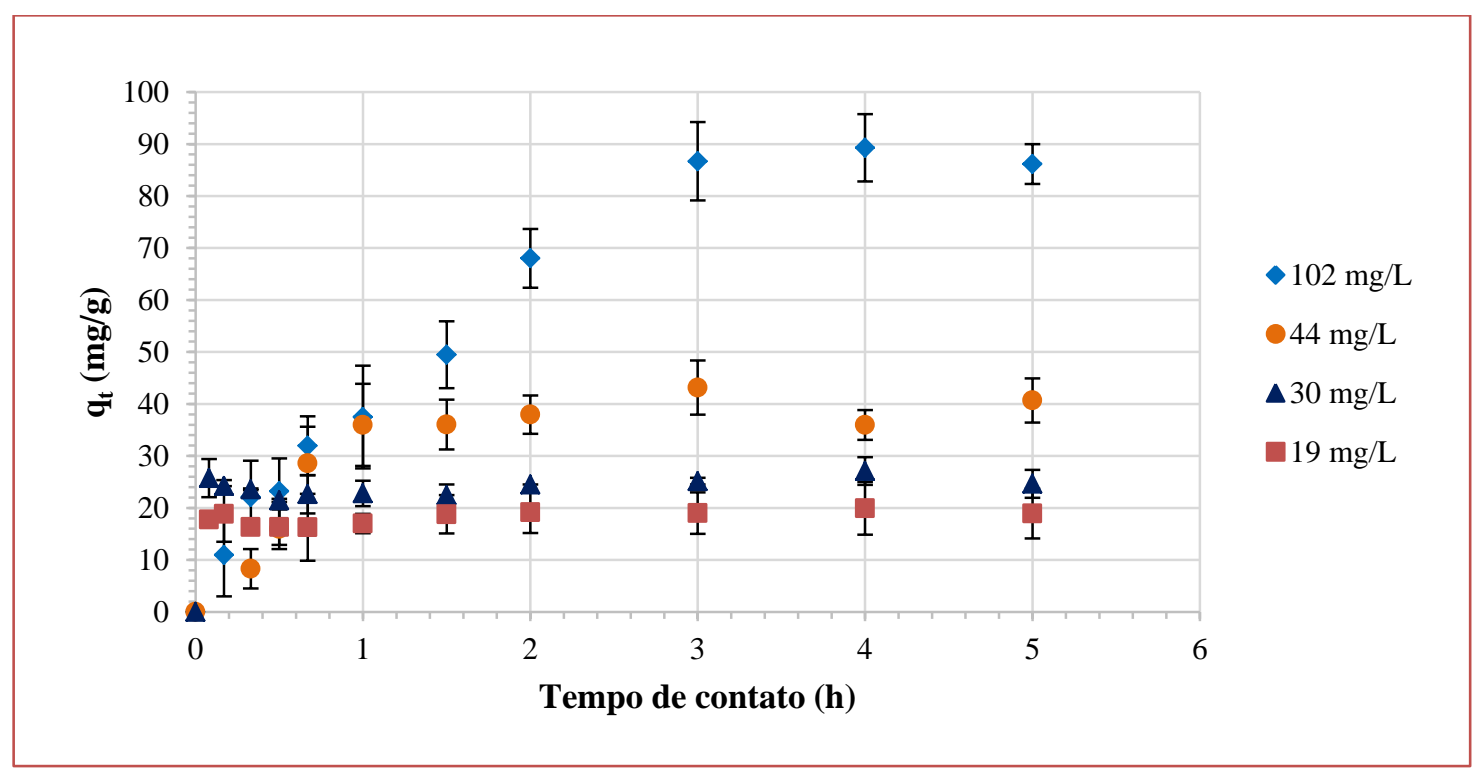

A partir da Figura 1, observa-se que a sorção do óleo pela fibra aumenta com o tempo de contato, até o equilíbrio ser alcançado. Por sua vez, o tempo de contato aumenta à medida que a concentração de óleo aumenta na água oleosa sintética. Para baixas concentrações iniciais de óleo cru na água oleosa sintética (19 e $30 \mathrm{mg} / \mathrm{L}$ ), é difícil observar o patamar de equilíbrio, provavelmente, devido à baixíssima concentração inicial de óleo cru na água oleosa sintética. A partir da concentração de $44 \mathrm{mg} / \mathrm{L}$, a formação do patamar de equilíbrio pode facilmente ser observado, sendo que o equilíbrio foi atingido após 3 horas de contato, atribuído à saturação dos sítios de sorção do óleo na biomassa. 


\subsection{ISOTERMA DE SORÇÃO DO LICURI}

A Tabela 1 e as Figuras 2 e 3 mostram a eficiência de sorção, em termos da concentração inicial de óleo cru (Co) e da concentração do óleo cru no equilíbrio (Ce), e da porcentagem de remoção do óleo cru pela fibra da folha de licuri, com dosagem de $0,5 \mathrm{~g} / \mathrm{L}$, tempo de contato 4 horas, à $140 \mathrm{rpm}$ e $37^{\circ} \mathrm{C}$. É possível observar que a partir da concentração de óleo de $60 \mathrm{mg} / \mathrm{L}$ a porcentagem de remoção permanece constante (52\%), apesar de não se observar a formação de um patamar de equilíbrio (Figura 2), devido à faixa de concentração inicial de óleo cru (em torno de 20-100 mg/L) utilizada. Também é possível observar que os valores de desvio padrão para qe e para a porcentagem de remoção de óleo cru pela fibra oscilam na faixa de concentração inicial de óleo cru utilizado. Os maiores valores de desvio padrão indicam que as medidas oscilam bastante em torno de um valor médio, sugerindo maior dificuldade de se trabalhar em um sistema heterogêneo, como é o caso do petróleo que é composto de uma mistura de hidrocarbonetos.

Tabela 1: Efeito da concentração inicial de óleo cru, presente na água oleosa sintética, na eficiência de sorção e na remoção do óleo, utilizando a fibra da folha de licuri na dosagem de $0,5 \mathrm{~g} / \mathrm{L}$, tempo de contado de $4 \mathrm{~h}$, a $140 \mathrm{rpm}$ e $37^{\circ} \mathrm{C}$

\begin{tabular}{c|c|c|c|c|c|}
$\begin{array}{c}\text { Co } \\
\text { (mg/L) }\end{array}$ & $\begin{array}{c}\text { Ce } \\
(\mathrm{mg} / \mathrm{L})\end{array}$ & $\begin{array}{c}\text { qe } \\
(\mathrm{mg} / \mathrm{g})\end{array}$ & $\begin{array}{c}\text { Remoção de } \\
\text { óleo }(\%)\end{array}$ & \multicolumn{2}{c|}{ Desvio Padrão } \\
\hline $\mathbf{2 0 , 3}$ & 13,2 & 14,2 & 35,0 & 1,28 & 0,14 \\
\hline $\mathbf{4 0 , 5}$ & 24,2 & 32,6 & 40,2 & 4,23 & 4,90 \\
\hline $\mathbf{6 0 , 1}$ & 35,9 & 48,4 & 40,3 & 2,84 & 2,91 \\
\hline $\mathbf{8 0 , 2}$ & 38,6 & 83,3 & 51,9 & 1,57 & 0,30 \\
\hline $\mathbf{1 0 5 , 3}$ & 50,3 & 106,3 & 52,2 & 4,23 & 1,77 \\
\hline
\end{tabular}

Figura 2: Capacidade de sorção no equilíbrio do óleo cru pela fibra da folha de licuri, dosagem de $0,5 \mathrm{~g} / \mathrm{L}$, em função da concentração de óleo cru no equilíbrio, a $37^{\circ} \mathrm{C}$.

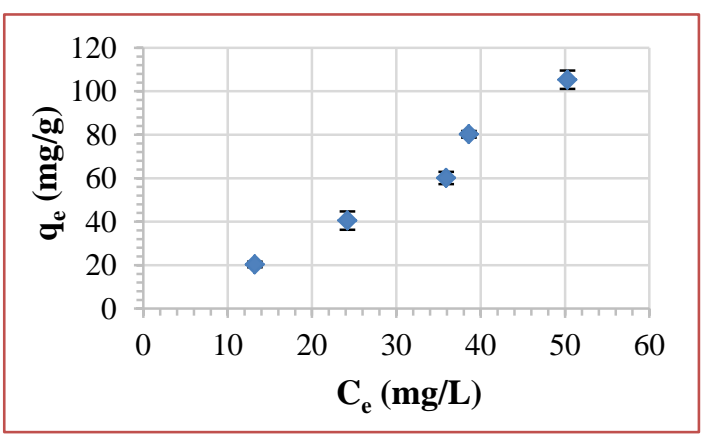

Figura 3: Percentagem de remoção do óleo pela fibra da folha de licuri, dosagem de $0,5 \mathrm{~g} / \mathrm{L}$, em função da concentração óleo cru no equilíbrio, a $37^{\circ} \mathrm{C}$.

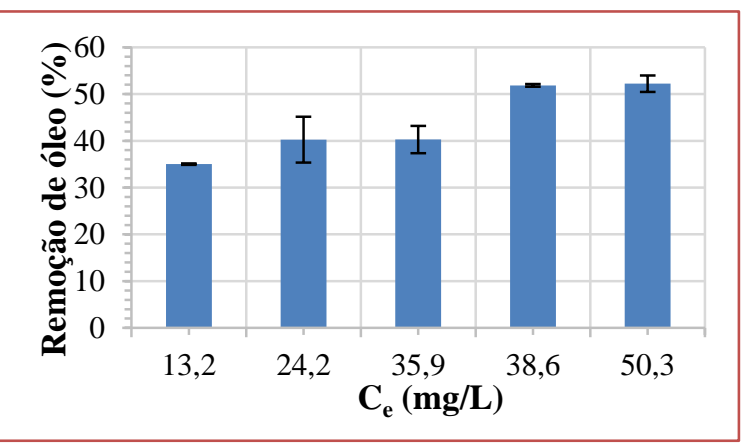

Na Figura 3 é possível observar que a partir da concentração de equilíbrio de 38,6 $\mathrm{mg} / \mathrm{L}$, a porcentagem máxima de remoção de óleo cru pela fibra da folha de licuri foi de $52 \%$. Os valores de concentração no equilíbrio indicam quanto de óleo não foi removido pela fibra. Os resultados evidenciam que a fibra da folha de licuri foi eficiente na remoção do óleo para concentração na faixa em torno de 20 a $80 \mathrm{mg} / \mathrm{L}$, correspondendo ao descarte de 13,2 a 38,6 mg/L, estando estes valores abaixo do valor máximo estabelecido pelo CONAMA que é de $42 \mathrm{mg} / \mathrm{L}$ de óleo diária. 


\subsection{APLICAÇÃO DOS MODELOS DE ISOTERMA DE ADSORÇÃO}

A Tabela 2 apresenta os parâmetros e os coeficientes de correlação obtidos a partir de cada equação linearizada para os modelos de isoterma de Langmuir, Temkin e Freundlich.

Tabela 2: Parâmetros e coeficientes de correlação $\left(\mathrm{R}^{2}\right)$ para os modelos de isoterma de Langmuir, Freundlich e Temkin.

\begin{tabular}{|l|c|c|}
\hline \multicolumn{1}{|c}{ Isoterma } & Parâmetros & Valores \\
\hline \multirow{3}{*}{ Langmuir } & $\mathrm{qo}(\mathrm{mg} / \mathrm{g})$ & 217,77 \\
& $\mathrm{~b}(\mathrm{~L} / \mathrm{mg})$ & 0,011 \\
& $\mathrm{R} 2$ & 0,072 \\
\hline \multirow{2}{*}{ Temkin } & $\mathrm{KL}^{\circ}(\mathrm{L} / \mathrm{mg})$ & 0,225 \\
& $\mathrm{~B} 1$ & 31,64 \\
& $\mathrm{R} 2$ & 0,706 \\
\hline \multirow{3}{*}{ Freundlich } & $\mathrm{Kf}(\mathrm{mg} / \mathrm{g})(\mathrm{mg} / \mathrm{L}) 1 / \mathrm{n}$ & 0,702 \\
& $\mathrm{n}$ & 0,808 \\
& $\mathrm{R} 2$ & 0,982 \\
\hline
\end{tabular}

Dentre os modelos de isoterma avaliados, o modelo de Freundlich foi o que apresentou coeficiente de correlação mais próximo de 1, ajustando-se melhor aos dados obtidos. Os modelos de Langmuir e Temkin apresentaram coeficientes de correlação igual a 0,094 e 0,765, respectivamente, ou seja, valores menores que 1, indicando esses modelos não se ajustaram de forma satisfatória aos dados experimentais. Sabe-se que, quanto menor o valor dos parâmetros relacionados à interação entre óleo cru-fibra da folha de licuri (B1 e n) para os modelos de Temkin e Freundlich, respectivamente, maior é a afinidade entre óleo e fibra de licuri. Desse modo, o modelo de Freundlich foi o que apresentou menor valor. E ao se comparar os parâmetros relacionados à capacidade de sorção do óleo pela fibra da folha de licuri para os modelos de Temkin e Freundlich (KLo e K), o de Freundlich foi o que apresentou o maior valor. Com base nos parâmetros observados, o modelo de Freundlich indica que a adsorção ocorre com formação de multicamadas, ou seja, as moléculas de petróleo ocupam os sítios de adsorção e a ocupação desses sítios interfere na energia dos demais, havendo a formação de mais de uma camada $[15,16]$.

A formação de multicamadas indica que a adsorção do óleo cru pela fibra da folha de licuri é favorecida pela interação hidrofóbica óleo-óleo sob a superfície irregular dessa fibra que possui em sua estrutura cerca de $10 \%$ de lignina e uma pequena camada de cera superficial. 0 óleo também pode ser absorvido por ação capilar através dos lúmens ocos na celulose que ocupa cerca de 45\% na estrutura química da fibra de licuri. A partir desse resultado, observa-se que o mecanismo de sorção do óleo cru pela fibra da folha de licuri é devido à contribuição dos processos de adsorção (óleo-lignina ou cera) e absorção (óleo-celulose), simultaneamente, e está diretamente relacionado à característica e a estrutura química da fibra, justificando a porcentagem máxima de sorção do óleo pela fibra da folha de licuri de $52 \%$.

\section{CONCLUSÕES}

O estudo de cinética de sorção indicou que o tempo de equilíbrio foi atingido a partir de 3 horas de contato óleo cru-água oleosa sintética, sendo o patamar de equilíbrio facilmente observado a partir de $40 \mathrm{mg} / \mathrm{L} .0$ estudo de isoterma de sorção mostrou que a porcentagem máxima de sorção da fibra foi de 52\%, para concentração inicial de óleo cru a partir de $80 \mathrm{mg} / \mathrm{L}$, podendo ser atribuída a presença da celulose e da lignina na fibra. Também foi observado que a fibra da folha de licuri foi eficiente na remoção de óleo cru com concentrações iniciais de óleo abaixo de $100 \mathrm{mg} / \mathrm{L}$, com valores de Ce menores do que o recomendado pelo CONAMA que é de $42 \mathrm{mg} / \mathrm{L}$ diário. 0 modelo de Freundlich foi o que melhor se ajustou aos dados obtidos, indicando que o processo de adsorção ocorre com formação de multicamadas, atribuído à interação óleo-óleo na superfície hidrofóbica/oleofílica da fibra. Portanto, o mecanismo de sorção do óleo cru pela fibra da folha de licuri ocorre tanto pela interação óleo-fibra (óleo-lignina ou cera e óleo-celulose, adsorção e absorção, respectivamente), quanto pela interação óleo-óleo (adsorção em 
multicamadas), justificando a porcentagem máxima de sorção de $52 \%$ de óleo cru pela fibra da folha de licuri.

\section{REFERÊNCIAS}

[1] KUNDU, P., MISHRA, I. M. Removal of emulsified oil from oily wastewater (oil-in-water emulsion) using packed bed of polymeric resin beads, Separation and Purification Technology 118 (2013) 519-529

[2] ABDELWAHAB, O. Assessment of raw luffa as a natural hollow oleophilic fibrous sorbent for oil spill cleanup. Alexandria Engineering Journal, 53 (2014) 213-218.

[3] CONAMA, http://www.mma.gov.br/port/conama/, Acessado em 01 de maio de 2018.

[4] PHUPHUAKRAT, T. Absorptive removal of biomass tar using water and oily materials. Bioresource Technology, 102 (2011) 543-549.

[5] OLIVEIRA, J. Síntese e caracterização de nanocompósitos poliméricos reforçados com whiskers de celulose da fibra de licuri. Dissertação apresentada ao Programa de Pós Graduação em Engenharia Química, Escola Politécnica, Universidade Federal da Bahia, Salvador, 2015.

[6] RIBEIRO, T. H.; RUBIO, J.; SMITH, R. W.; A dried hydrophobic aquaphyte as an oil filter for oil/water emulsions. Spill Science \& Technology Bulletin, 5-6 (2003) 483-489.

[7] WANG, J. ZHENG, Y., WANG, A. Effect of kapok fiber treated with various solvents on oil absorbency. Industrial Crops and Products, 40 (2012) 178-184.

[8] LI, X., TABIL, L. G., PANIGRAHI, S. C. Chemical treatments of natural fibre for use in natural fibre-reinforced composites: A review. Journal of Polymers and the Environment, 15 (2007) 25-33.

[9] CHOI, H.M., CLOUD, R.M., Natural sorbents in oil spill cleanup. Environmental Science \& Technology, 26 (1992) 772-776

[10] GOERING, H.K., VAN SOEST, P.J.; Forage fiber analysis (apparatus, reagents, procedures and some applications). Agricultural Handbook, 379 (1970).

[11] CHEU, S. KONG, H. SONG, S. Separation of dissolved oil from aqueous solution by sorption onto acetylated lignocellulosic biomass - equilibrium, kinetics and mechanism studies. Journal of Environmental Chemical Engineering, 4 (2016) 864-881.

[12] COULSON, J. M., RICHARDSON, J. F., Particle Technology and Separation Processes. Chemical Engineering, Fifth edition, Vol 2, 2002.

[13] FOO, K., HAMEED, B., Insights into the modeling of adsorption isotherm systems, Chemical Engineering Journal, 156 (2010) 2-10.

[14] NWADIOGBU, A., AJIWE, V.I.E., OKOYE, P.A.C., Removal of crude oil from aqueous medium by sorption on hydrophobic corncobs: Equilibrium and kinetic studies. Journal of Taibah University for Science, 10 (2016) 56-63.

[15] FREUNDLICH, HMF. Over the adsorption in solution. Journal of Physical Chemistry, 57 (1906) 385-471.

[16] THOMPSON, N.E., EMMANUE, G., ADAGADZU, K.J., YUSUF, N.B., Sorption studies of crude oil on acetylated rice husks, Archives of Applied Science Research, 2 (2010) 142-151. 


\title{
Capítulo 11
}

Borra oleosa - Forma de mitigar acidentes e medidas alternativas de destinação final

\author{
Rafaely Angelica Fonseca Bandeira \\ Antonio de Souza Araújo \\ Almir Mariano de Sousa Júnior \\ Ana Catarina Fernandes Coriolano \\ Regina Célia Pereira Marques \\ Everton Notreve Rebouças Queiroz. Fernandes \\ Francisco Odair Filgueira Junior
}

Resumo: Na busca de demonstrar maneiras adequadas para tratar o resíduo de petróleo (borra do petróleo ou borra oleosa) em casos de derramamentos ou mesmo de acidentes envolvendo pessoas ou o meio ambiente é que está sendo realizada essa revisão bibliográfica. A fonte principal de pesquisa foi obtida através de dados emitidos pela indústria petrolífera, principal responsável pela geração desse resíduo, provenientes de suas atividades. 0 objetivo principal é analisar os riscos que esses resíduos podem causar ao meio ambiente, estudar sua caracterização e seu destino final. Foram verificadas através de Ficha de Emergência emitida pela PETROBRAS, medidas cautelosas a serem adotadas em tais situações, bem como equipamentos a serem utilizados a fim de minimizar os danos aos envolvidos e ao meio ambiente. 0 possível dano ambiental decorrente da atividade petrolífera é de inteira responsabilidade da empresa geradora conforme se pode verificar na legislação vigente, onde preconiza que a responsabilidade civil e penal pelo impacto ambiental ocasionado, e pela segurança e saúde dos trabalhadores é da empresa. Na mediada que os produtos químicos são manuseados de forma adequada, respeitando as leis e normas vigentes no país, o impacto ambiental diminuirá consideravelmente.

Palavras-chave: Meio ambiente, PETROBRAS, Ficha de Emergência. 


\section{INTRODUÇÃO}

Qualquer atividade humana é por natureza geradora de resíduos sólidos. Estes por sua vez, são a denominações genéricas para determinados tipos de lixo produzido pelo ser humano e são representados por materiais que não possuem nenhum valor mais para o gerador; segundo o Instituto de Pesquisa Tecnológica (IPT), os resíduos sólidos podem ser classificados quanto à sua origem e natureza em domiciliar, comercial, serviços de saúde, industrial, radioativo, agrícola, entulhos, de portos, aeroportos, terminais rodoviários e ferroviários, (AMBIENTE BRASIL, 2004).

A fim de informar medidas que possibilitarão minimizar os impactos ambientais nas atividades de exploração do petróleo, em sua fase primária tratando o resíduo "Borra de petróleo" da maneira correta e indicada pela legislação vigente, é que essa pesquisa bibliográfica está sendo formalizada; indicando ainda medidas corretivas a serem adotadas em caso de situações emergenciais no manuseio do subproduto por meio de fichas de segurança emitidas pela PETROBRÁS (empresa que mais dispõe desse resíduo em seu complexo industrial em no Brasil).

Segundo a CNI- Conferência Nacional das Indústrias, o petróleo atualmente produzido no Brasil é utilizado essencialmente como matéria-prima nas refinarias, onde é processado para a obtenção de diversos tipos de derivados. Informa ainda que o país ocupa o nono lugar no mundo em termos de capacidade de refino e que atinge 2,1 milhões de barris/dia ou 2,3\% da capacidade mundial conforme dados coletados junto a ANP- Agência Nacional de Petróleo em 2011. (CNI, 2012).

Conforme preconiza a lei n 14248 que instituiu a Política Nacional de resíduos Sólidos, "resíduos sólidos são os resíduos que resultam de atividade humana em sociedade e que se apresentem nos estados sólido, semi- sólido ou líquido não passíveis de tratamento convencional". Nesta legislação, os resíduos sólidos são classificados de forma mais simplificada em urbanos, industriais, serviços de transporte, serviços de saúde e especiais.

Importante ressaltar que para a norma da ABNT (Associação Brasileira de Normas Técnicas), a NBR 10.004 resíduos sólidos são: Resíduos nos estados sólidos e semissólidos, que resultam de atividades da comunidade de origem: urbana, agrícola, radioativa e outros (perigosos e/ou tóxicos). Ficam incluídos nesta definição os lodos provenientes de sistemas de tratamento de água, aqueles gerados em equipamentos e instalações de controle de poluição, bem como determinados líquidos cujas particularidades tornem inviável seu lançamento na rede pública de esgoto ou corpos d'água, ou exijam para isso soluções técnicas e economicamente inviáveis, em face à melhor tecnologia disponível. (ABNTNBR 10.004, 2004)

Estes podem ser classificados quanto aos riscos potenciais de contaminação do meio ambiente em três categorias. classe I (perigosos), classe II (não inertes) e classe III (inertes).

Já na legislação ambiental, lei $\mathrm{n}^{\circ}$ 6.938/81 em seu artigo $8^{\circ}$ estabelece competências normativas ao CONAMA onde diz que esse deve estabelecer mediante proposta do IBAMA, normas e critérios para o licenciamento de atividades efetiva ou potencialmente poluidoras, a ser concedido pelos estados e supervisionado pelo IBAMA; regulamenta ainda que privativamente normas e padrões nacionais de controle da poluição por veículos automotores e outros tipos de veículos devem está parametrizado pelo CONAMA mediante audiência dos ministérios competentes, e o parágrafo 70 desse mesmo artigo estabelece normas, critérios e padrões relativos ao controle e a manutenção da qualidade do meio ambiente com vistas ao uso dos recursos ambientais principalmente hídricos.

Tendo em vista que um dos resíduos gerados nas indústrias petrolíferas (borras de petróleo ou borras oleosas), fruto do processamento primário dos fluidos na exploração e produção de petróleo e nos processos de refinamento do óleo cru é um grave problema a ser considerado devido à quantidade produzida que pode chegar a cerca de 30.000 toneladas a cada ano e que o tratamento e a disposição desse subproduto do processo de beneficiamento de petróleo se torna um grande desafio, por ser um resíduo de difícil tratamento e disposição final; são buscadas inúmeras soluções com novas tecnologias e tratamentos alternativos como: os tratamentos térmicos por pirólise, gaseificação e incineração, a reciclagem da borra com a sua incorporação à massa argilosa para a fabricação de blocos cerâmicos para a construção civil e a sua disposição em landfarming (técnicas de espalhamento das borras oleosas em grandes áreas, conforme figura 1). (SILVA, 2013). 
Figura 1: Dique alto do morro de Jericó/SE em 2002 (ALVES, 2003).

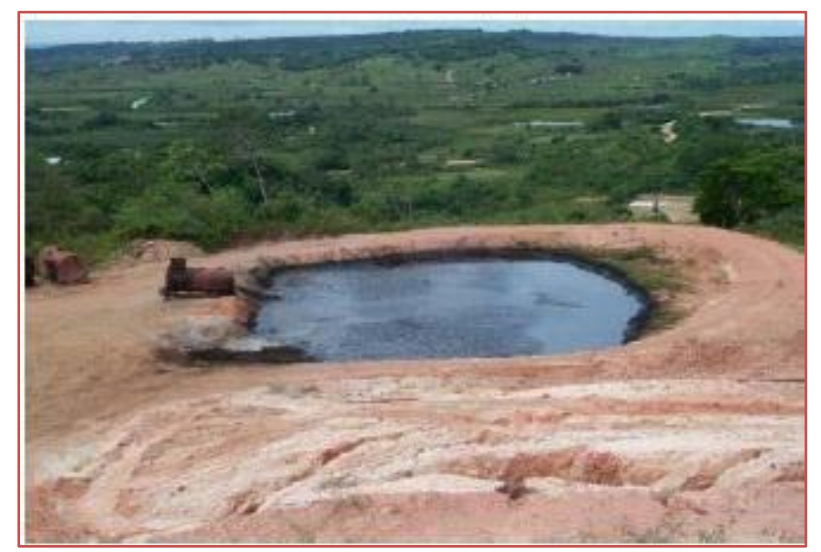

\subsection{ANÁLISE DE MÉTODOS DE TRATAMENTO E DISPOSIÇÃO FINAL DA BORRA OLEOSA}

A problemática resultante da geração dos resíduos é cada vez mais preocupante devido à necessidade de preservação do meio ambiente e de adequar-se as legislações vigentes.

Os aspectos ambientais são elementos das atividades, produtos e serviços de uma organização que pode interagir com o meio ambiente (ABNT/NBR/ISSO 14.001, 2004). Os impactos ambientais são qualquer modificação do meio ambiente, adversa ou benéfica, que resulte, no todo ou em parte, dos aspectos ambientais da organização (ABNT/NBR/ISO 14.001, 2004). A recuperação de áreas degradadas pode ser conceituada como um conjunto de ações - idealizadas e executadas por especialistas das mais diferentes áreas do conhecimento humano - que visam proporcionar o restabelecimento de condições de equilíbrio e sustentabilidade existentes anteriormente em um sistema natural (DIAS E GRIFFITH, 1998).

Realizando uma abordagem sobre o tema da análise de métodos de tratamento e disposição de produtos, resíduos e embalagens ocasionados no beneficiamento do petróleo através de estudos de casos reais, leva a uma direcionamento melhor de como dar destino ambientalmente correto a esse resíduo, sem comprometer o meio ambiente, e consequentemente, a saúde humana. Pois a forma de disposição final do resíduo químico gerado pelas instalações de uma empresa é de responsabilidade dela e interfere diretamente na relação do homem/meio- ambiente com questões que podem ser minimizadas e até sanadas quando se resolve investir em um descarte adequado, devendo ser seguidas leis, normas e regulamentos existentes e ainda podendo ser adotadas orientações dadas pelas FISPQ- Ficha de Informação de Segurança de Produtos Químicos, emitidas pelas empresas que fabricam, documento normalizado pela ABNT. Conforme norma, ABNT-NBR 14725, (promulga a Convenção no 170 da Organização Internacional do Trabalho- OIT), e deve ser disponibilizado junto com os produtos para os empresários que utilizem estes, tornando-se um documento obrigatório para a comercialização dos produtos; Essa fornece informações sobre vários aspectos dos químicos (substâncias ou misturas), segurança, à saúde e ao meio ambiente; transmitindo desta maneira, conhecimentos sobre produtos químicos, recomendações sobre medidas de proteção e ações em situação de emergência.

A FISPQ, documento dividido em 16 Seções, indica os perigos e possíveis riscos considerando o uso dos produtos químicos; o documento não abrange todas as situações que possam ocorrer em um ambiente de trabalho, indicando apenas parte da informação necessária para a elaboração de um programa de saúde, segurança e meio ambiente; O MSDS/SDS (Material Safety Data Sheet/ Safety) siglas conhecidas mundialmente referentes a essa ficha, o qual segue o modelo de cada país. Essa tem como objetivos indicar medidas emergenciais a serem adotadas em casos de acidente com o meio ambiente e ou com operadores no caso do manuseio da borra do petróleo a fim de evitar assim danos maiores ao meio ambiente. Modelo constante na figura 2 . 
Figura 2: FISPQ (fonte: PETROBRAS, 2014)

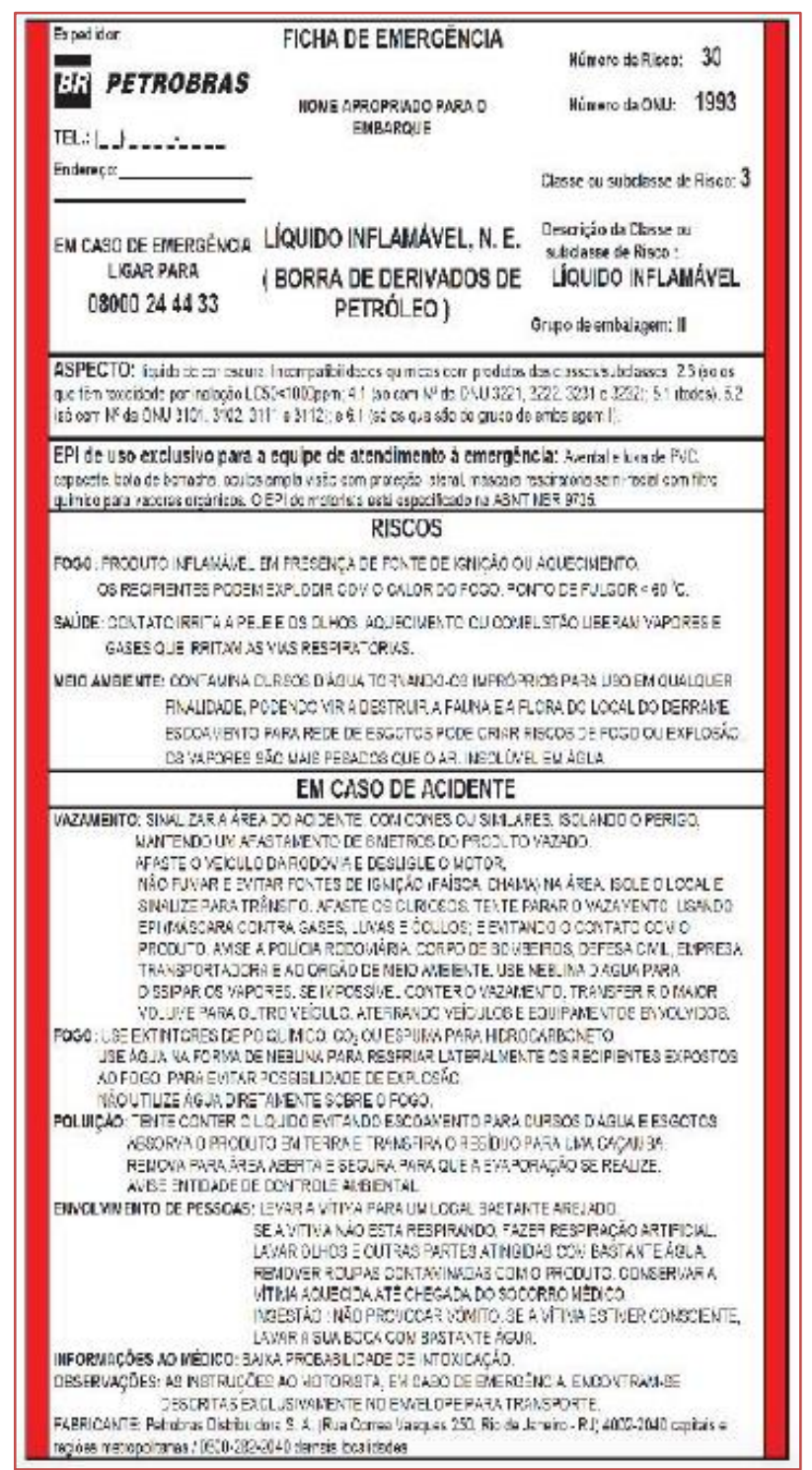

\section{METODOLOGIA}

A metodologia utilizada foi embasada em dados bibliográficas, buscando um contexto relacionado entre o petróleo, o meio ambiente e os respectivos impactos, indicando ainda medidas preventivas ou corretivas em caso de manipulação da borra oleosa. Qualquer ação proposta para diminuir impactos ocasionados pela ação humana sobre o meio ambiente contribui, para a sustentabilidade de todo o planeta.

Foi analisada a recomendação feita pela PETROBRAS por intermédio da ficha de emergência desse material onde estão informadas medidas sobre o meio físico (solo-alteração de propriedades físicas, químicas e biológicas, ar- poluição do ar e água- poluição das águas superficiais e subterrâneas), no meio biótico- interferência na fauna e flora e no meio antrópico, se altera saúde de operadores, se propicia risco a segurança e se causa danos a equipamentos. Uma vez estabelecida à significância dos aspectos e impactos ambientais serão indicadas medidas de controle para serem aplicadas nesses ambientes.

\section{RESULTADOS E DISCUSSÃO}

Em estudo realizado por Silva (2013), o processo de contaminação define-se como a adição no solo e no lençol freático de compostos, que qualitativa e/ou quantitativamente modificarão as suas características 
naturais e utilizações, produzindo inúmeros efeitos negativos, constituindo poluição e processo de degradação do meio ambiente.

Já para Paula (2014), a indústria petrolífera, em suas operações, geram grandes volumes de resíduos líquidos e sólidos que são patológicos ao meio ambiente e a saúde pública. No entanto, quando estes são adequadamente tratados, destinados e até reciclados, com balizamento em padrões internacionais inclusive, seus efeitos nefastos podem ser reduzidos a níveis aceitáveis.

Por fim, conforme ficha de emergência da borra oleosa demonstrada anteriormente e emitida pela PETROBRAS no ano de 1993, o líquido borra de derivados de petróleo é um líquido de cor escura inflamável em presença de fonte de ignição ou aquecimento, onde seus recipientes podem explodir com o calor do fogo e tem ponto de fulgor $<60^{\circ}$ c; se em contato irrita a pele e os olhos e quando sofre aquecimento ou combustão liberam vapores e gases que irritam as vias respiratórias. Essas quando derramadas no meio ambiente contaminam cursos d'água tornando-os impróprios para uso em qualquer finalidade, podendo destruir a fauna e a flora do local do derrame. Quando há o escoamento para rede de esgotos pode criar riscos de fogo ou explosão, seus vapores são mais pesados que o ar e esse produto é insolúvel em água. Em caso de acidente deverá conter o efluente, a fim de evitar escoamento para cursos d'água e esgotos; esse produto deve ser absorvido em terra e transferido o resíduo para uma caçamba onde deve ser levado para área aberta e segura para que a evaporação se realize e ainda deve ser informado aos órgãos ambientais da ocorrência. 0 seu manuseio deve ser realizado utilizando EPI (Equipamento de Proteção Individual) adequado tais como luvas impermeáveis do tipo nitrílicas, óculos de segurança, máscara de segurança do tipo peça semi facial com cartucho químico que proteja as vias aéreas contra inalação de vapores orgânicos e gases ácidos a fim de evitar intoxicação.

\section{CONCLUSÕES}

Os produtos químicos originados do processo industrial do petróleo, podem impactar significativamente o meio ambiente em caso de acidente, devido as suas características de formação e, sobretudo por serem insolúveis em água, podendo agredir severamente o lençol freático ocasionando prejuízos incalculáveis para a zona atingida; Por se tratar de um agente que pode causar danos ao meio ambiente, esse resíduo deve ser manuseado utilizando as normas como descrito na figura 2, por se tratar de um produto nobre, conforme composição pode ser vista na tabela 1, vemos que esse material pode ser reutilizado ou mesmo transformado em uma outra matéria, como no caso de reaproveitamento do resíduo utilizando técnicas de pirólise para dele extrair produtos como gasolina e diesel. (SILVA, 2013).

Tabela 1 - Composição típica da borra Oleosa (Oliveira, 2002).

\begin{tabular}{|cc|}
\hline Componente & Porcentagem \\
\hline Água & 21,91 \\
Sólido & 62,02 \\
Óleo & 16,67 \\
Enxofre & 1,46 \\
\hline
\end{tabular}

Para Melo et al., 2013, Em função da área específica e porosidade, os materiais catalíticos podem ser promissores para o processo de degradação catalítica de resíduos sólidos de petróleo, para obtenção de produtos de alto valor agregado, na faixa da gasolina e diesel. 


\section{REFERÊNCIAS}

[1] ASSOCIAÇÃO BRASILEIRA DE NORMAS TÉCNICAS. Informação e documentação - apresentação de citações em documentos: NBR 10520. Rio de Janeiro, 2001.

[2] ASSOCIAÇÃO BRASILEIRA DE NORMAS TÉCNICAS. NBR 10.004: Resíduos Sólidos - classificação. Rio de Janeiro: ABNT, 2004.

[3] ASSOCIAÇÃO BRASILEIRA DE NORMAS TÉCNICAS. NBR ISO 14.001: Sistemas de gestão ambiental Requisitos com orientação para uso. 2ª Edição. Rio de Janeiro: ABNT, 2004;

[4] ASSOCIAÇÃO BRASILEIRA DE NORMAS TÉCNICAS. NBR ISO 14.725- 1: Produtos químicos - Informações sobre segurança, saúde e meio ambiente. Parte 1: Terminologia . 1a Edição. Rio de Janeiro: ABNT, 2009;

[5] ALVES, M. R. F. V. Reciclagem de borra oleosa: uma contribuição para a gestão sustentável dos resíduos da indústria de petróleo em Sergipe. 2003. 191f. Dissertação (Mestrado em Desenvolvimento e Meio Ambiente). Núcleo de Estudos do Semi-árido da Universidade Federal de Sergipe, Programa de Pós-graduação em Desenvolvimento e Meio Ambiente, Universidade Federal de Sergipe, São Cristóvão.

[6] AMBIENTE BRASIL: Soluções para os resíduos sólidos. Disponível em: <http://ambientes.ambientebrasil.com.br/residuos/estatisticas_de_reciclagem/solucoes_para_os_residuos_solidos.ht ml>. Acesso em 13 de outubro de 2013.

[7] BRASIL. Lei n ${ }^{\circ} 6938$ de 31/08/1981. Dispõe sobre a política nacional de meio ambiente.

[8] BRASIL. Lei ${ }^{\circ} 14248$ de 29/07/2002. Dispõe sobre a política estadual de resíduo sólidos.

[9] CONGRESSO NACIONAL DE EXCELÊNCIA EM GESTÃO, 5, 2009, Niterói-Rio de Janeiro.

[10] SUSTENTABILIDADE DA INDÚSTRIA DE PETRÓLEO. Niterói- Rio de Janeiro.

[11] Figueiredo, Cristina Brunet de; Farias Filho, José Rodrigues de. 2009.

[12] CNI, CONFERÊNCIA RIO + 20, 2012, Brasília. A CONTRIBUIÇÃO DO SETOR BRASILEIRO DE PETRÓLEO, GÁS E BIOCOMBUSTÍVEIS PARA O DESENVOLVIMENTO SUSTENTÁVEL NO PAÍS. Brasília, 2012.

[13] DIAS, L.E.; GRIFFITH, J.J. Conceituação e caracterização de áreas degradadas. In:. Recuperação de áreas degradadas. Viçosa, MG, 1998.

[14] MELO, P. M. G.; CORIOLANO, A. C. F.;

[15] ARAUJO, A. S. Análise e proposta de destinação de resíduo de petróleo, borra oleosa e seu impacto no meio ambiente. Natal, RN, 2013.

[16] OLIVEIRA, S. H. Avaliação do uso de borra oleosa processada em sistemas de impermeabilização de aterros, 2002. 170f. Dissertação (Mestrado em engenharia Civil). Geotecnia, Departamento de Engenharia Civil, Pontificia Universidade Católica do Rio de Janeiro, Rio de Janeiro.

[17] PAULA, Geminson de Araújo. Avaliação do resíduo de cascalho de perfuração de poços de petróleo da bacia potiguar e alternativas para sua destinação e reaproveitamento. Natal, UNP- Universidade Potiguar, 2014. Dissertação, 18 p. Mestrado em Engenharia de Petróleo e Gás. Natal, 2014.

[18] PETROBRÁS distribuidora: Ficha de Emergência. Disponível em: <http://www.br.com.br/wps/wcm/connect/6 ea9ec0043b62bd9aa15bea490f2a4fd/fe- comb-outros-borraliquida.pdf?MOD=AJPERES $>$. Acesso em 04 de outubro de 2014.

[19] SILVA, Cristiano Guilherme da Câmara. A responsabilidade da indústria petrolífera frente a poluição ambiental gerada pelos resíduos (borra oleosa): uma exigência socioambiental. Natal, UNP- Universidade Potiguar, 2013. Dissertação, 21 p. Mestrado em Engenharia de Petróleo e Gás. Natal, 2013. 


\section{Capítulo 12}

\section{Água produzida: Gerenciamento de efluente- revisão}

\section{Larissa Freitas Farias}

\section{Laíse Ramonny Oliveira Nunes}

Resumo: Considerando a crescente demanda da indústria petrolífera, analisar os impactos gerados pelo maior dos efluentes produzidos é imprescindível do ponto de vista financeiro e ambiental. Para que os impactos ambientais envolvidos na destinação final da água produzida de petróleo sejam minorados e as indústrias consigam manter a produtividade, deve-se escolher o tratamento mais adequado e tecnicamente viável. 0 objetivo desse artigo é apresentar soluções para o gerenciamento desse efluente.

Palavras-chave: Efluente; Água produzida; Indústria petrolífera; Tratamento; Gerenciamento. 


\section{INTRODUÇÃO}

Durante a produção de petróleo e gás, um imenso volume de água de complexa composição é aprisionada nas formações subterrâneas [AMINI et al., 2012]. Esta água representa o principal resíduo ligado à extração de petróleo, de acordo com Silva [2000]. Dessa maneira, o gerenciamento desse efluente representa um custo extremamente relevante na indústria petrolífera.

De acordo com Motta [2013], a água produzida é um subproduto da separação do petróleo e do gás (processamento primário), conforme a Figura 1.

Figura 1: Produção de água a partir da separação do petróleo e gás

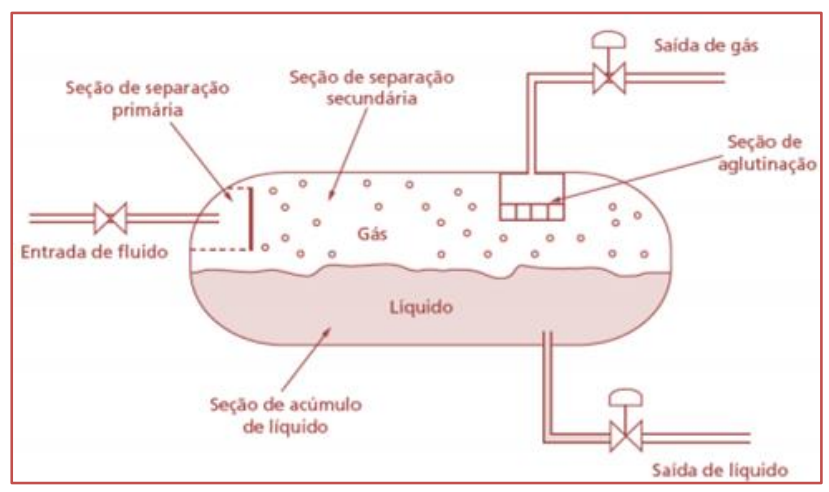

As alternativas comumente utilizadas para a destinação final desse efluente são: descarte, reuso e injeção. Estas alternativas precisam de tratamento específico para cumprir as normas ambientais, demandas produtivas e operacionais, segundo Motta [2013]. E destes, o mais econômico e é a injeção [SILVA, 2000], pois através da devolução da água produzida ao local de onde ela foi retirada, evita-se alguns problemas ambientais e gastos com tratamento preliminares.

\section{METODOLOGIA}

A metodologia adotada para o desenvolvimento deste trabalho de revisão bibliográfica foi pesquisa e análise de monografias, revistas de alcance internacional, jornais internacionais, leis e resoluções nacionais.

\section{RESULTADOS E DISCUSSÃO}

\subsection{IMPACTOS AMBIENTAIS}

Os impactos ambientais associados à água produzida se agravam em função da composição da água, das características do local em que ela ocorre e da sua disposição final. As potenciais causas de perigo são: alta salinidade; sólidos suspensos; presença de metais pesados; presença de orgânicos insolúveis; presença de orgânicos solúveis; presença de produtos químicos; radioatividade [SILVA, 2000].

O despejo de efluentes dessa natureza sem tratamento pode comprometer corpos hídricos e promover difusão de materiais pesados para os seres humanos que entrarem em contato com essa água. Além disso podem haver diversas complicações inesperadas, tendo em vista que a composição da água produzida é variável.

Stewart \& Arnold [2011], apresentam dois fatores que influenciam nas características físicas, químicas e biológicas da água produzida, são eles a localização do reservatório e a formação geológica deste lugar. Esses fatores dificultam o tratamento da água produzida, adicionando-se ao problema do grande volume a ser tratado.

A água produzida pode ser conata (quando existente no reservatório) apresentando alta salinidade e metais, ou água de injeção, que é aquela misturada com água subterrânea utilizada em processos de recuperação secundária [SILVA, 2000]. 


\subsection{GERENCIAMENTO DE ÁGUA PRODUZIDA}

0 tratamento e destinação final dos resíduos produzidos antropicamente precisam ser determinados de acordo com as leis ambientais vigentes no local da produção. Para a decisão, devem ser considerados: o custo, o volume produzido do resíduo em questão, a viabilidade técnica (no tocante a disponibilidade de equipamentos) e, no caso da água produzida de petróleo, ainda é imprescindível analisar a localização da base de produção.

O resíduo em questão é um efluente líquido de processo produtivo, e pode ser despejado em corpos hídricos. Em território brasileiro, a lei 9.433/97 versa sobre a gestão de recursos hídricos, incluindo os despejos em mananciais relativos a usos industriais. Um dos instrumentos da supracitada lei é o enquadramento do corpos hídricos e outro é a outorga de direitos.

Segundo a mesma lei, o enquadramento dos corpos de água em classes, segundo os usos preponderantes da água, visa a:

I - assegurar às águas qualidade compatível com os usos mais exigentes a que forem destinadas;

II - diminuir os custos de combate à poluição das águas, mediante ações preventivas permanentes.

E as classes de corpos de água serão estabelecidas pela legislação ambiental.

O enquadramento dos corpos hídricos é, portanto, a classificação das águas de um manancial quanto aos padrões de qualidade existentes. Esse enquadramento objetiva manter as características da água dos corpos hídricos, através da limitação dos despejos de efluente aos de padrões compatíveis com o do corpo hídrico que receberá estes despejos. Dessa forma, antes de haver qualquer lançamento de efluente, deve ser realizada uma análise de autodepuração do resíduo pelo corpo hídrico receptor. A partir dessa análise pode-se determinar qual o tratamento prévio adequado a ser aplicado ao despejo em questão. Nessa análise é considerado o volume a ser despejado, e para isso, o instrumento de outorga, da mesma lei, também entra em pauta.

A outorga de direitos libera as retidas de determinados volumes do corpo hídrico a ser analisado, de maneira que não haja comprometimento de sua vazão. Ela ainda é responsável por determinar o volume despejado no corpo hídrico, como no caso da água produzida. Esses volumes podem ser taxados, de acordo com a análise dos responsáveis técnicos do corpo hídrico.

Do ponto de vista do gerenciamento, nem sempre o despejo em corpos hídricos é adequado e nesse sentido a injeção torna-se muitas vezes uma alternativa viável. Pois consiste na devolução da água retirada de um local após sua utilização no processo produtivo.

\subsection{TRATAMENTO DE ÁGUA PRODUZIDA}

O petróleo e a água são praticamente imiscíveis, mas levando em conta o tempo de confinamento, bem como as condições de formação e migração do petróleo, pode haver solubilização de alguns hidrocarbonetos [SILVA, 2000].

Segundo Motta [2013], a presença de óleo na água produzida pode-se apresentar através de emulsão, óleo livre ou dissolvido, e a remoção do óleo na forma de emulsão é a mais complicada. Os métodos utilizados para separação dessas emulsões são flotação a ar [HONG; FANE; BURFORD, 2003], hidrociclones [SAIDI et al., 2012], coalescedores de leito [SOKOLOVIĆ; SOKOLOVIĆ; SEVIC, 2009] e separadores gravitacionais [STEWART \& ARNOLD, 2011]. Existem também os processos de separação por membranas, que trazem vantagens em relação aos demais por solucionar o problema de gotas com diâmetros na faixa de micrômetros ou submicrômetros [CHAKRABARTY; GHOSHAL; PURKAIT, 2008].

0 tratamento de água produzida não objetiva deixá-la em padrões de excelência, mas adequado ao local de destinação final (seja ele corpo hídrico - despejo, ou outros - injeção). Essa água pode ainda ser tratada para possibilitar o reuso. Dessa forma, o tipo de processo adotado, depende dos compostos que se deseja remover.

Os tratamentos adequados, segundo Motta [2013], para água produzida podem apresentar os seguintes objetivos: remoção de óleo de maneira dispersa; de compostos orgânicos solúveis; remoção de bactérias e algas; remoção turbidez e areia; remoção de gases dissolvidos; remoção de sais dissolvidos, sulfatos, nitratos e agentes de incrustação; remoção de dureza em excesso; remoção de compostos diversos. 
A água selecionada para injeção é tratada em geral por processo de flotação com adição de desemulsificantes e bactericidas [SILVA, 2000].

\subsection{REGULAMENTAÇÃO BRASILEIRA}

A Lei 6.938 instituiu, em 1981, a Política Nacional do Meio Ambiente, esse diploma legal prevê uma série de instrumentos de proteção e gestão ambiental para serem postos em pratica pelo Poder Público, tendo como objetivo organizar, disciplinar, controlar e fiscalizar atividades industriais e produtivas que podem causar danos ao meio ambiente e que exploram recursos naturais.

Porém mesmo com as possibilidades previstas por esta lei, os instrumentos de regulação mais comumente usados no nosso país são do tipo controle e comando, devido a relativa simplicidade e facilidade da aplicação desses. Os parâmetros estabelecidos pelo Poder Público para disciplinar condutas, quotas, padrões e limitações que devem ser atendidos pelos operadores são estabelecidos com base em critérios científicos que levam em conta condições naturais e fatores socioeconômicos e ambientais.

A respeito do tratamento, gerenciamento e padronização da água produzida e seus descartes no ambiente, não é possível encontrar muitas regulamentações especificas, mesmo este efluente gerando grandes volumes e possuindo grande potencial de danos ao meio ambiente.

Como a Lei do Petróleo [Lei 9.478/97] trata sobre a Política Energética Nacional e seus objetivos, institui o Conselho Nacional de Política Energética e Agência Nacional do Petróleo (ANP). Ela determina suas funções e objetivos, além de especificar o regime de concessão, editais de licitação, atividades de downstream, importações e exportações e biocombustíveis.

Esta lei ao estabelecer a ANP como o órgão regulador da indústria do petróleo e tem como função promover a regulação, contratação e fiscalização das atividades econômicas do setor. Em decorrência a seu poder de polícia administrativa, pode autuar e aplicar sanções administrativas.

Esta Lei do Petróleo também estabelece que a ANP deve fazer cumprir as boas práticas de preservação do meio ambiente, para garantir o cumprimento dessa determinação a agência criou uma Coordenadoria de Meio Ambiente (CMA). Porém a atuação da agencia nesta área é mais voltado para fornecer suporte e acompanhar ações de pesquisa, desenvolvimento e regulamentação concebidas pelos órgãos competentes, observando a responsabilidade e atuação dos mesmos.

A questão da água produzida é explorada pela ANP na Portaria ${ }^{\circ} 100 / 2000$, que aprova o Regulamento Técnico do Programa Anual de Produção (PAP) para os campos de petróleo e gás natural e trata a respeito das questões relacionadas com o acompanhamento e fiscalização das atividades de produção. 0 operador fica comprometido com o volume de água produzida que será descartado e com a reinjeção em poços para recuperação secundarizados hidrocarbonetos. Pode também comprometer-se com a reijeção em poços não produtores para descarte, e com o uso de outros meios de disposição tais como movimentação para disposição em outros campos ou para o tratamento da terra.

As regulamentações federais que tratam sobre a indústria petrolífera e o gerenciamento de agua produzida são as Resoluções CONAMA 357/2005, 430/2011 e 393/2007 e a Portaria 422/2011 do Ministério do Meio Ambiente.

A portaria do Ministério do Meio Ambiente dispõe sobre os procedimentos para o licenciamento ambiental federal de atividades e empreendimentos de exploração e produção de petróleo e gás natural no ambiente marinho e zona de transição terra-mar e teve como objetivo unificar as Resoluções CONAMA 01/86, 23/94, 237/97 e 350/04.

Na Resolução CONAMA 357/2005 define o padrão de qualidade das águas, que é estabelecido conforme sua classe, um conjunto de condições e padrões de qualidade da água necessários ao atendimento dos usos preponderantes, atuais ou futuros de um determinado segmento, além de dispor sobre as diretrizes ambientais para enquadramento dos corpos d'água nas suas diferentes classificações.

A Resolução CONAMA 430/2011, dispõe sobre as condições e padrões de lançamento de efluentes, complementando e promovendo algumas alterações na Resolução CONAMA 357/2005. A resolução de 2011 trata das condições, parâmetros, padrões e diretrizes para gestão do lançamento de efluentes em corpos de água receptores, ressaltando que o lançamento indireto de efluentes deve observar tal resolução na ausência de legislação ou normas específicas. 
Segundo esta resolução, os efluentes só poderão ser lançados diretamente nos corpos receptores depois de receberem o tratamento adequado e precisam obedecer às condições, aos padrões e às exigências dispostos pela própria Resolução CONAMA 430/2011, como também por outras normas aplicáveis. Também fica previsto que o órgão ambiental competente exigirá tecnologias ambientalmente adequadas e economicamente viáveis para o tratamento dos efluentes, compatível com as condições do respectivo corpo receptor. E é estabelecido o dever dos responsáveis pelas fontes poluidoras dos recursos hídricos de proceder com realização do automonitoramento para controle e acompanhamento periódico dos efluentes lançados nos corpos receptores, conforme disposto no Art. 24 da Resolução.

Os padrões de lançamento de efluentes definido pela resolução podem ser vistos na Tabelas 1 e 2:

Tabela 1: Padrões de lançamento de efluentes - Parte 1

\begin{tabular}{|l|l|}
\hline TABELA I & Valores máximos \\
\hline Parâmetros inorgânicos & $0,5 \mathrm{mg} / \mathrm{L} \mathrm{As}$ \\
\hline Arsênio total & $5,0 \mathrm{mg} / \mathrm{L} \mathrm{Ba}$ \\
\hline Bário total & $5,0 \mathrm{mg} / \mathrm{L} \mathrm{B}$ \\
\hline Boro total (Não se aplica para o lançamento em águas salinas) & $0,2 \mathrm{mg} / \mathrm{L} \mathrm{Cd}$ \\
\hline Cádmio total & $0,5 \mathrm{mg} / \mathrm{L} \mathrm{Pb}$ \\
\hline Chumbo total & $1,0 \mathrm{mg} / \mathrm{L} \mathrm{CN}$ \\
\hline Cianeto total & $0,2 \mathrm{mg} / \mathrm{L} \mathrm{CN}$ \\
\hline Cianeto livre (destilável por ácidos fracos) & $1,0 \mathrm{mg} / \mathrm{L} \mathrm{Cu}$ \\
\hline Cobre dissolvido & $0,1 \mathrm{mg} / \mathrm{L} \mathrm{Cr}+6$ \\
\hline Cromo hexavalente & $1,0 \mathrm{mg} / \mathrm{L} \mathrm{Cr}+3$ \\
\hline Cromo trivalente & $4,0 \mathrm{mg} / \mathrm{L} \mathrm{Sn}$ \\
\hline Estanho total & $15,0 \mathrm{mg} / \mathrm{L} \mathrm{Fe}$ \\
\hline Ferro dissolvido & \\
\hline
\end{tabular}

Tabela 2: Padrões de lançamento de efluentes - Parte 2

\begin{tabular}{|l|l|}
\hline Fluoreto total & $10,0 \mathrm{mg} / \mathrm{L} \mathrm{F}$ \\
\hline Manganês dissolvido & $1,0 \mathrm{mg} / \mathrm{L} \mathrm{Mn}$ \\
\hline Mercúrio total & $0,01 \mathrm{mg} / \mathrm{L} \mathrm{Hg}$ \\
\hline Niquel total & $2,0 \mathrm{mg} / \mathrm{L} \mathrm{Ni}$ \\
\hline Nitrogênio amoniacal total & $20,0 \mathrm{mg} / \mathrm{L} \mathrm{N}$ \\
\hline Prata total & $0,1 \mathrm{mg} / \mathrm{L} \mathrm{Ag}$ \\
\hline Selênio total & $0,30 \mathrm{mg} / \mathrm{L} \mathrm{Se}$ \\
\hline Sulfeto & $1,0 \mathrm{mg} / \mathrm{L} \mathrm{S}$ \\
\hline Zinco total & $5,0 \mathrm{mg} / \mathrm{L} \mathrm{Zn}$ \\
\hline Parâmetros Orgânicos & Valores máximos \\
\hline Benzeno & $1,2 \mathrm{mg} / \mathrm{L}$ \\
\hline Clorofórmio & $1,0 \mathrm{mg} / \mathrm{L}$ \\
\hline Dicloroeteno (somatório de 1,1+1,2cis + 1,2 trans) & $1,0 \mathrm{mg} / \mathrm{L}$ \\
\hline Estireno & $0,07 \mathrm{mg} / \mathrm{L}$ \\
\hline Etilbenzeno & $0,84 \mathrm{mg} / \mathrm{L}$ \\
\hline fenóis totais (substâncias que reagem com 4-aminoantipirina) & $0,5 \mathrm{mg} / \mathrm{L} \mathrm{C6H5OH}$ \\
\hline Tetracloreto de carbono & $1,0 \mathrm{mg} / \mathrm{L}$ \\
\hline Tricloroeteno & $1,0 \mathrm{mg} / \mathrm{L}$ \\
\hline Tolueno & $1,2 \mathrm{mg} / \mathrm{L}$ \\
\hline Xileno & $1,6 \mathrm{mg} / \mathrm{L}$ \\
\hline
\end{tabular}

\section{CONCLUSÕES}

De acordo com o exposto, percebe-se a necessidade de análise da composição da água produzida e da localização da base de produção. Esses fatores serão preponderantes para escolher o tipo de tratamento, levanto em conta também a viabilidade técnica e econômica.

Para situações nas quais é feita a opção por injeção de petróleo não há danos ao meio ambiente, desde que esse procedimento ocorra devolvendo esta água ao local de retirada. Como o procedimento nem sempre é 
possível o despejo torna-se mais viável alguma vezes e para isto são indicadas metodologia de separação por membranas flotação a ar, hidrociclones, coalescedores de leito e separadores gravitacionais. Outra opção é o reuso.

Percebe-se que as leis existentes dão suporte a metodologias ainda em processo de desenvolvimento, e por isso os estudos precisam ser refinados, apresentando propostas econômicas e viáveis.

\section{REFERÊNCIAS}

[1] AMINI, S.; MOWLA, D.; GOLKAR, M.; ESMAEILZADEH, F. (2012) Mathematical modelling of a hydrocyclone for the down-hole oil-water separation (DOWS). Chemical Engineering Research and Design, v. 90, p.2186-2195.

[2] ANP. Agência Nacional do Petróleo, Gás Natural e Biocombustíveis. 2016. Disponível em:< http://www.anp.gov.br/>. Acesso em: 10 de junho de 2016.

[3] BRASIL, 1997. Lei $n^{\circ} 9.433$ de 8 de janeiro de 1997. Institui a Política Nacional de Recursos Hídricos, cria o Sistema Nacional de Gerenciamento de Recursos Hídricos, regulamenta o inciso XIX do art. 21 da Constituição Federal, e altera o art. 1ํ da Lei no 8.001, de 13 de março de 1990, que modificou a Lei no 7.990, de 28 de dezembro de 1989.

[4] BRASIL, 1997. Lei n 9.478 de 6 de agosto de 1997. Dispõe sobre a Política Energética Nacional, as atividades relativas ao monopólio do petróleo, institui o Conselho Nacional de Política Energética e a Agência Nacional de Petróleo e dá outras providências. Brasília - Brasil.

[5] BRASIL, 1981. Lei n 6.938 de 31 de agosto de 1981. Dispõe sobre a Política Nacional de Meio Ambiente, seus fins e mecanismos de formulação e aplicação, e dá outras providências. Brasília - Brasil.

[6] BRASIL. Resolução CONAMA № 430, de 13 de maio de 2011. Dispõe sobre as condições e padrões de lançamento de efluentes, complementa e altera a Resolução no 357, de 17 de março de 2005, do Conselho Nacional do Meio Ambiente-CONAMA. Disponível em:<http://www.mma.gov.br/port/conama/legiabre.cfm?codlegi=646>. Acesso em 13 de junho de 2016.

[7] CHAKRABARTY, B.; GHOSHALAND A.K.; PURKAIT, M.K. (2008) Ultrafiltration of stable oil-in-water emulsion by polysulfone membrane. Journal of Membrane Science, v. 325, n. 1, p. 427-437.

[8] HONG, A.; FANE, A.G.; BURFORD, R. (2003) Factors affecting membrane coalescence of stable oil-in-water emulsions. Journal of Membrane Science, v. 222, p. 19-39.

[9] MINISTÉRIO DO MEIO AMBIENTE. Resolução CONAMA 357, de 17 de março de 2005. Dispõe sobre a classificação dos corpos de água e diretrizes ambientais para o seu enquadramento, bem como estabelece as condições e padrões de lançamento de efluentes, e dá outras providências. Ministério do Meio Ambiente, Brasil.

[10] MOTTA, A. R. P.; BORGES, C. P.; KIPERSTOK, A.; ESQUERRE, K. P.; ARAÚJO, P. M.; BRANCO, L. P. N. (2013). Tratamento de água produzida de petróleo para remoção de óleo por processos de separação por membranas: revisão. Eng Sanit Ambient, v.18 n.1, p. 15-26.

[11] SAIDI, M.; MADDAHIAN, R.; FARHANIEH, B.; AFSHIN, H. (2012) Modeling of flow field and separation efficiency of a deoiling hydrocyclone using large eddy simulation. International Journal of Mineral Processing, v. 112113, p. 84-93.

[12] SILVA, C. R .R. Água Produzida na Extração de Petróleo. 2000. Monografia (Curso de Especialização em Gerenciamento e Tecnologias Ambientais na Indústria) - Departamento de Hidráulica e Saneamento, Escola Politécnica, Universidade Federal da Bahia, 2000.

[13] SOKOLOVI, R.M.S.; SOKOLOVI, S.M; SEVIC, S. (2009) Oily water treatment using a new steady-state fiber-bed coalescer. Journal of Hazardous Materials, v. 162, n. 1, p. 410-415.

[14] SOUZA, L. A. Noções de processamento primário de petróleo. Apostila Petrobras. PUCRio- Pontifícia Universidade Católica do Rio de Janeiro, (2012).

[15] STEWART, M. \& ARNOLD, K. (2011) Produced Water Treatment Field Manual. Part 1 - Produced Water Treating Systems, p. 1-134. 


\title{
Capítulo 13
}

\section{Interpretação do perfil fluid capacitance da ferramenta production logging tool}

\author{
Sebastião Henrique Camilo da Silva \\ Márcio Roberto de Andrade Araújo Filho \\ Claudiana Ferreira da Silva \\ Wellington dos Santos de Araújo \\ Ana Carolina Santos de Oliveira \\ Edilson Ponciano de Lima
}

Resumo: A ferramenta de perfilagem de produção (Production Logging Tool - PLT) é muito utilizada na produção e/ou injeção de fluidos em poços de petróleo e gás natural. Esta ferramenta se constitui de vários perfis. Um deles é chamado de Fluid Capacitance, cujo objetivo é detectar a porcentagem de água do fluido que está produzindo, através da medição da capacitância/constante dielétrica do fluido que nada mais é a grandeza física que relaciona a quantidade de carga adquirida pelo capacitor em função do potencial elétrico. 0 objetivo desse trabalho foi desenvolver uma metodologia para interpretar os dados que são obtidos do perfil Fluid Capacitance e calcular a porcentagem de água que um ou vários reservatórios estão produzindo, através de um exercício de fluxo bifásico em função da capacitância. Este estudo se constituiu de uma revisão e consulta de livros e artigos em língua estrangeira. Foi observado que na literatura portuguesa não existem metodologias que mostrem a interpretação dos dados do perfil Fluid Capacitance. A contribuição deste trabalho foi mostrar uma metodologia simples de calculo para professionais da área que trabalham com este tipo de dados. Portanto, este estudo permitiu entender o princípio básico e o funcionamento da ferramenta de produção, onde, observa-se que apesar de uma grande porcentagem de água que o poço produz, ainda é viável economicamente continuar a produzir o mesmo, pois a vazão de óleo ainda é maior que a de água e através de métodos de recuperação pode-se diminuir essa porcentagem de água, assim aumentado à vazão de óleo.

Palavras-chave: Interpretação, Fluid Capacitance, Production Logging Tool. 


\section{INTRODUÇÃO}

O PLT (Production Logging Tool) é uma ferramenta muito utilizada na obtenção dos perfis de produção e injeção de fluidos. Permite determinar, por exemplo, o tipo de fluido e a vazão produzida em cada zona do poço (GOMES e ALVES, 2011). Estes perfis são realizados no início da completação e durante a produção do poço, para determinar as condições de produtividade. Seu objetivo é proporcionar informação sobre a natureza, o movimento dos fluidos durante a produção e injeção e diagnosticar problemas dentro do poço (MOTTOLA, 2014, p.1).

Segundo Thomas (2001, p.133) a ferramenta PLT pode fornecer os seguintes perfis: Continuous flowmeter, gradiomanômetro, densidade, hidrolog e temperatura. Neste trabalho desenvolveu-se uma metodologia para interpretar os registros que são obtidos pela ferramenta Hidrolog, para calcular a porcentagem de água que o reservatório está produzindo, através de um exercício de fluxo bifásico em função da capacitância/constante dielétrica que é grandeza física que relaciona a quantidade de carga adquirida pelo capacitor em função do potencial elétrico.

Se o poço estiver produzindo apenas dois fluidos (óleo e água, óleo e gás, ou gás e água) seria possível determinar a porcentagem de cada fluido em cada intervalo aberto para produção, descendo-se os perfis flowmeter e o gradiomanômetro. Porém, para petróleo bruto pesado e para poços que produzem pequenas quantidades de uma fase em relação à outra fase, a variação da densidade é baixa, por isso neste trabalho utilizou-se o hidrolog (MCKINLEY, 1982, p.572).

0 Hidrolog consiste em fazer passar o fluxo oriundo do reservatório pelo sensor através de um orifício, onde tem uma chapa que forma a ferramenta e um eletrodo de teflon, como pode ser visto na Figura 01. Os fluidos que passam pelo interior da ferramenta atuam como isolante ou dielétrico, um campo elétrico é aplicado à área de fluxo radial a partir da superfície. Por fim, é medida pelo capacitor e é convertida em frequência, ou seja, quanto mais fluido de diferentes constantes dielétricas estiver em contato ao campo elétrico na área de fluxo radial variará a frequência e será enviada e registrada em superfície.

Figura 01: Fluid Capacitance Logging Tool.

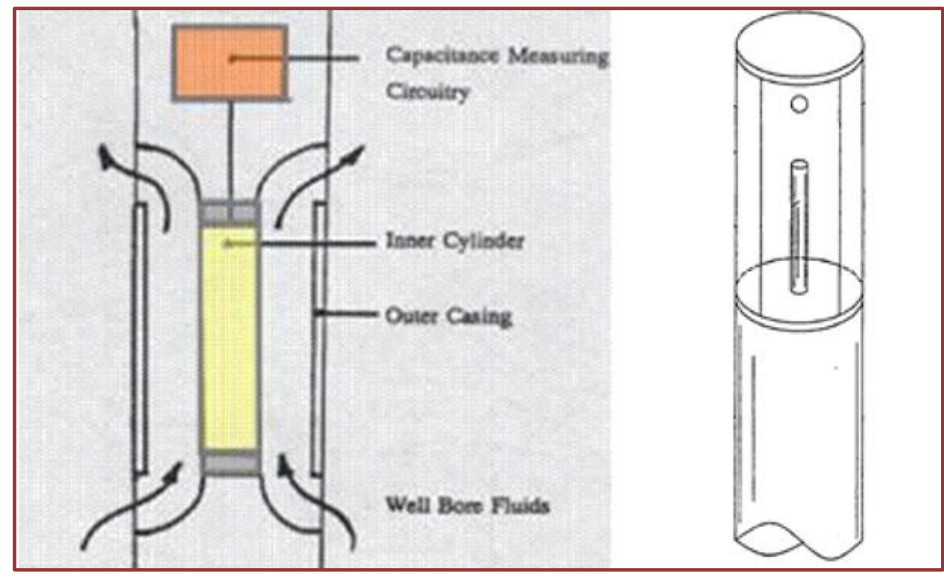

Para interpretar a ferramenta em fluxo bifásico, primeiramente é necessário conhecer as variáveis a seguir: $\mathrm{K}$ é a constante dielétrica do fluido, $\mathrm{K}_{\mathrm{w}}$ é a constante dielétrica da água, $\mathrm{K}_{\mathrm{o}}$ é a constante dielétrica do petróleo, $Y_{w}$ é a retenção de água e $Y_{o}$ é retenção de petróleo, e conhecer a Equação 1 a seguir:

$$
K=\sum \mathrm{Y}_{\mathrm{i}} \mathrm{K}_{\mathrm{i}}
$$


Na Equação 2 considera-se que a soma das retenções de todos os fluidos, neste caso óleo e água, no reservatório é de $100 \%$ igual a 1 , pode- se dizer que:

$$
\mathrm{Y}_{\mathrm{w}}+\mathrm{Y}_{\mathrm{o}}=1
$$

Então, conclui-se na Equação 3:

$$
\mathrm{Y}_{\mathrm{w}}=\frac{\mathrm{K}-\mathrm{K}_{\mathrm{o}}}{\mathrm{K}_{\mathrm{w}}-\mathrm{K}_{\mathrm{o}}}
$$

Considerando que as Equações 4 a 7 sejam:

$$
\begin{aligned}
\mathrm{V}_{\mathrm{o}} & =\mathrm{V}_{\mathrm{w}}+\mathrm{V}_{\mathrm{s}}(4) \\
\mathrm{Q}_{\mathrm{t}} & =\mathrm{Q}_{\mathrm{w}}+\mathrm{Q}_{\mathrm{o}}(5) \\
\mathrm{Q}_{\mathrm{o}} & =\mathrm{V}_{\mathrm{o}} \cdot \text { Área (6) } \\
\text { Área } & =\frac{\pi\left(\mathrm{D}^{2}-\mathrm{d}^{2}\right)}{4}
\end{aligned}
$$

Formulando, assim, a Equação 8 que será utilizada no exercício posteriormente.

$$
Q_{\mathrm{w}}=\mathrm{Y}_{\mathrm{w}} *\left[\mathrm{Q}_{\mathrm{t}}-1,4 * \mathrm{~V}_{\mathrm{s}} *\left(\mathrm{D}^{2}-\mathrm{d}^{2}\right)\right]
$$

$\mathrm{Na} \quad$ qual: $\quad \mathrm{V}_{\mathrm{o}}$ é a velocidade do petróleo em $\left(\frac{\mathrm{ft}}{\mathrm{min}}\right) ; \mathrm{V}_{\mathrm{w}}$ é a velocidade da água em $\left(\frac{\mathrm{ft}}{\mathrm{min}}\right)$; $\mathrm{V}_{\mathrm{s}}$ é a velocidade de deslizamento em $\left(\frac{\mathrm{ft}}{\mathrm{min}}\right) ; \mathrm{Q}_{\mathrm{t}}$ é a taxa de fluxo total em $\left(\frac{\mathrm{B}}{\mathrm{D}}\right) ; \mathrm{Q}_{\mathrm{w}}$ é a taxa de fluxo da água em $\left(\frac{B}{D}\right) ; Q_{o}$ é a taxa de fluxo de petróleo em $\left(\frac{B}{D}\right) ; D$ é o diâmetro interno do revestimento em polegadas e d é o diâmetro externo da ferramenta em polegadas.

0 Gráfico 01 mostra a variação das constantes dielétricas da água em função da temperatura e concentração de sal. E no Quadro 01 mostram-se as constantes dielétricas dos fluidos presentes no reservatório são:

Quadro 01: Constantes dielétricas dos fluidos (Água, petróleo e gás).

\begin{tabular}{|l|c|}
\hline \multicolumn{1}{|c|}{ Fluidos } & Constante Dielétrica \\
\hline Água & 60 a 80 \\
\hline Petróleo & 2,8 a 3,0 \\
\hline Gás & 1,0 \\
\hline
\end{tabular}




\section{METODOLOGIA}

Este estudo se constituiu de uma revisão e consulta de livros e artigos em língua estrangeira. Foi observado que na literatura portuguesa não existem metodologias que mostrem a interpretação dos dados do perfil de Fluid Capacitance e que a constante dielétrica dos fluidos utilizados não tem um valor fixo na bibliografia. Por isto, a contribuição deste trabalho foi mostrar uma metodologia simples do cálculo da porcentagem de água que a zona fornece para professionais da área que trabalham com este tipo de dados, como pode ser visto no Fluxograma 1.

Fluxograma 1: Passo-a-passo da resolução do exemplo do perfil Fluid Capacitance.

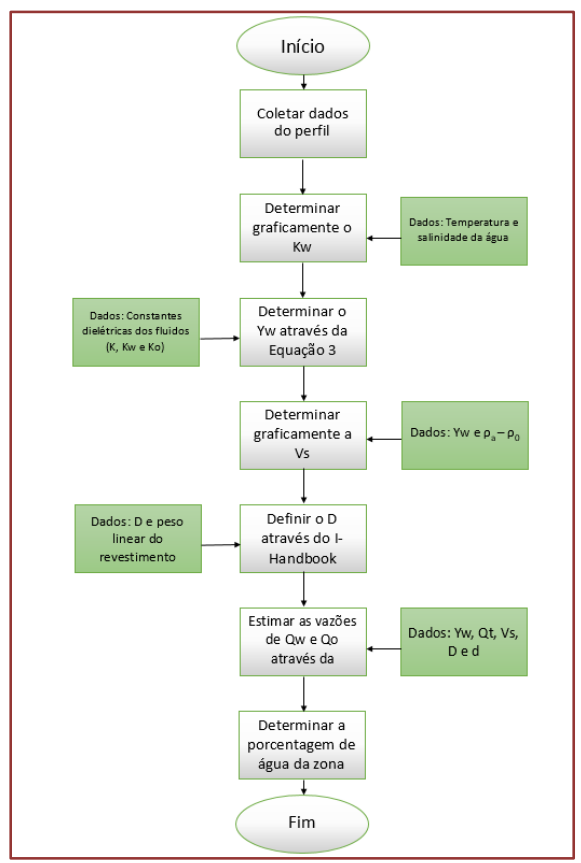

\section{RESULTADOS E DISCUSSÃO}

\subsection{EXEMPLO DE FLUXO BIFÁSICO}

Em um poço com revestimento de 7 polegadas e $23 \mathrm{lb} / \mathrm{ft}$, mede-se um valor de $\mathrm{K}=45$, com uma ferramenta HUM. Das medições tem-se uma taxa de fluxo de fundo de 1000 BPD. A temperatura do fundo é de $170^{\circ} \mathrm{F}$ e a salinidade da água é 18000 PPM. A diferença de densidade $\rho_{a}-\rho_{0}$ é de $0,15 \mathrm{~g} / \mathrm{cm}^{3}$. 0 petróleo bruto tem $20^{\circ}$ API. 0 diâmetro da ferramenta é 2,85 polegadas. Com base nos dados anteriores, calcule a porcentagem de água que fornece a zona.

1) No Gráfico 01 traça-se uma reta a partir do eixo $\mathrm{x}$, temperatura $\left(170{ }^{\circ} \mathrm{F}\right)$, até interpolar com a curva de salinidade da água (18000 PPM) e depois traça uma reta horizontal até tocar o eixo y, constante dielétrica da água, obtendo assim, a $\mathrm{K}_{\mathrm{w}}=84$. 
Gráfico 01: Variação da constante Dielétrica da água, em função da temperatura e concentração de sal.

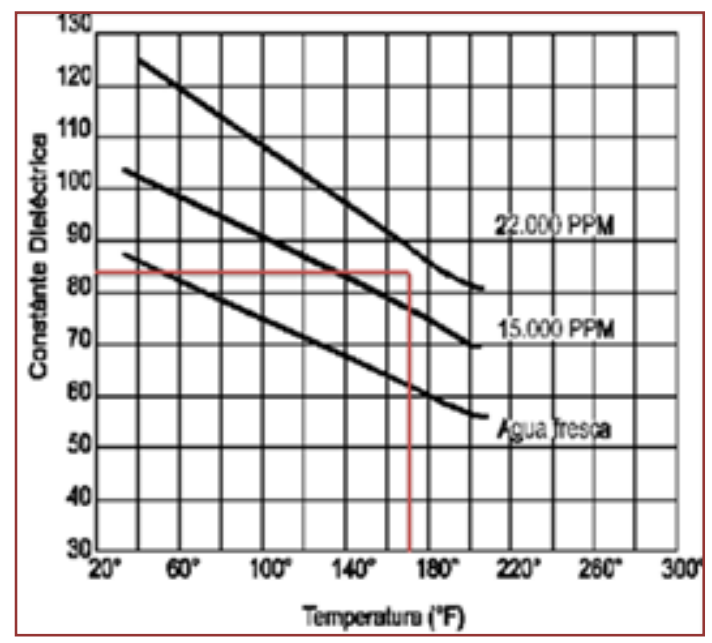

2) Considerando que o petróleo bruto é mediano de $20^{\circ} \mathrm{API}$, a partir do Quadro 01 que foi citado na introdução admite-se que o $K_{o}=2,8$. Para encontrar $Y_{w}$ aplica-se a Equação 3 a seguir:

3)

$$
\begin{gathered}
Y w=\frac{45-2,8}{84-2,8} \\
Y w=0,52
\end{gathered}
$$

4) No Gráfico 02 traça-se uma reta a partir do eixo x que representa a diferença das densidades dos fluidos $\left(\rho_{\mathrm{a}}-\rho_{\mathrm{o}}=0,15 \mathrm{~g} / \mathrm{cm}^{3}\right)$, até atingir a $\mathrm{Y}_{\mathrm{w}}$ encontrada anteriormente, depois traça-se uma reta horizontal até tocar o eixo y, logo, a $\left(\mathrm{V}_{\mathrm{s}}\right)$ é $9 \mathrm{ft} / \mathrm{min}$.

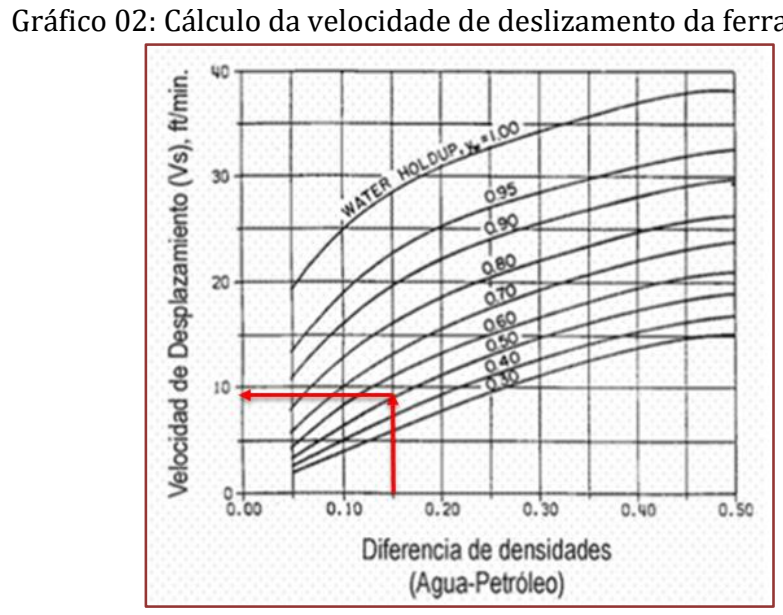

5) Na Figura 02 encontra-se o D (6,366 pol) a partir dos dados do revestimento. 
Figura 02: Programa I-Handbook - Disponível em:

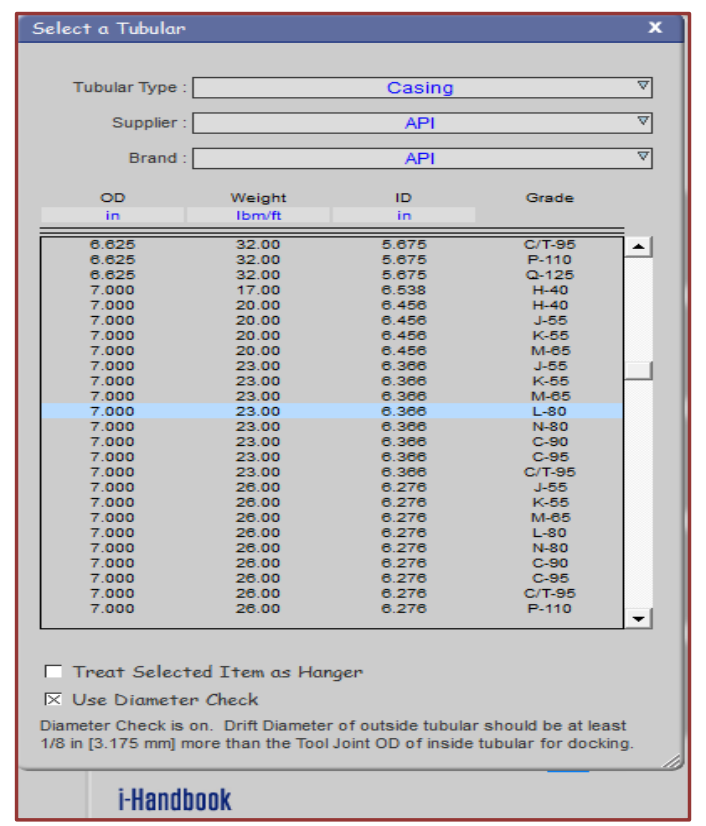

6) Logo, calculam-se as vazões $Q_{w}$ e $Q_{o}$ a partir da fórmula a seguir:

$$
\begin{gathered}
\mathrm{Q}_{\mathrm{w}}=\mathrm{Y}_{\mathrm{w}} *\left[\mathrm{Q}_{\mathrm{t}}-1,4 * \mathrm{~V}_{\mathrm{s}} *\left(\mathrm{D}^{2}-\mathrm{d}^{2}\right)\right](8) \\
\mathrm{Q}_{\mathrm{w}}=0,52 *\left[1000-1,4 * 9 *\left(6,366^{2}-2,85^{2}\right)\right] \\
\mathrm{Q}_{\mathrm{w}}=308 \frac{\mathrm{bbl}}{\mathrm{dia}} \\
\mathrm{Q}_{\mathrm{o}}=\left(\mathrm{Q}_{\mathrm{t}}-\mathrm{Q}_{\mathrm{w}}\right) \\
\mathrm{Q}_{\mathrm{o}}=(1000-308) \\
\mathrm{Q}_{\mathrm{o}}=692 \frac{\mathrm{bbl}}{\mathrm{dia}}
\end{gathered}
$$

7) Logo, a porcentagem de água é:

$$
\begin{aligned}
& \frac{Q_{w}}{Q_{t}}=\% \text { de água } \\
& \frac{308}{1000}=30,8 \%
\end{aligned}
$$

\section{CONCLUSÕES}

Portanto, o estudo do perfil de produção Fluid Capacitance permitiu entender o princípio básico e o funcionamento da ferramenta, onde, observa-se que apesar de uma grande porcentagem de água que o poço produz, ainda é viável economicamente continuar a produzir o mesmo, pois a vazão de óleo ainda é maior que a de água e através de métodos de reparação pode-se diminuir essa porcentagem de água, assim aumentado à vazão de óleo. Pode-se concluir que na perfilagem de produção o perfil Fluid Capacitance é de grande importância, pois através do mesmo é possível saber a porcentagem de água presente no reservatório e após esse estudo pode-se tomar uma decisão sobre o futuro do poço. 


\section{AGRADECIMENTOS}

Os autores agradecem ao Centro Universitário Tiradentes pelo fomento à pesquisa, ao corpo docente que colaborou no desenvolvimento desse trabalho e a Coordenação de Pesquisa, Pós-Graduação e Extensão (COPPE) pela bolsa concebida.

\section{REFERÊNCIAS}

[1] Gomes, J. S.; Alves, F. B. O Universo da Indústria Petrolífera - Da Pesquisa à Refinação. 2ª edição. Lisboa, Portugal: Fundação Calouste Gulbenkian, 2011.

[2] Mckinley R.M. Production Logging. International Petroleum Exhibition and Technical Symposium of the Society of Petroleum Engineers, Bejing-China, 1982.

[3] Mottola, Fabiola. Interpretación De Perfiles de Producción. Universidad de Oriente - Núcledo de Monagas, Venezuela, 2014.

[4] Thomas, J. E.; et al. Fundamentos de Engenharia de Petróleo. 2ª edição. Rio de Janeiro: Editora Interciência, 2001. 


\section{Capítulo 14}

\section{Avaliação da gasolina aditivada utilizada na cidade de Campina Grande-PB através da determinação de parâmetros físico-químicos}

\section{Lauanda Albuquerque Queiroz}

\section{Yasmin Geissiana Marinho de Menezes}

Marcos Mesquita da Silva

\section{Divanira Ferreira Maia}

Resumo: A gasolina é um combustível constituído basicamente por hidrocarbonetos e, em menor quantidade, por produtos oxigenados. Esses hidrocarbonetos são, em geral, formados por moléculas de menor cadeia carbônica (aproximadamente de 4 a 12 átomos de carbono) e a faixa de destilação varia de $30^{\circ} \mathrm{C}$ a $220^{\circ} \mathrm{C}$. A Agência Nacional de Petróleo, Gás Natural e Biocombustíveis (ANP) estabelece as especificações para as gasolinas automotivas e a sua composição influencia no consumo e no desempenho do motor. Neste contexto, o objetivo deste trabalho foi avaliar a gasolina aditivada para veículos automotores comercializada na cidade de Campina Grande-PB através da determinação de parâmetros físico-químicos. Foram feitos os seguintes ensaios: análise visual, densidade e teor de álcool dos postos de diferentes bandeiras e postos sem bandeira. Os resultados mostraram que os valores obtidos nestas análises encontram-se de acordo com os valores estabelecidos pelas especificações vigentes, com exceção do teor de álcool de $28 \%$ para a gasolina aditivada comercializada nos postos 1 e 4 e da densidade no posto 4 com valor de $0,7133225 \mathrm{~g} / \mathrm{mL}$.

Palavras-chave: Combustíveis, Gasolina, Análises físico-químicas. 


\section{INTRODUÇÃO:}

A gasolina é um dos principais combustíveis para veículos automotores, ficando em segundo lugar entre os combustíveis mais consumidos no Brasil. É uma substância volátil e inflamável proveniente da destilação fracionada do petróleo bruto, os hidrocarbonetos presentes pertencem, principalmente, às classes das parafinas (normal ou ramificadas), olefinas, naftênicos e aromáticos, formados por cadeias de 4 a 12 átomos de carbono, com temperaturas de ebulição entre $30^{\circ} \mathrm{C}$ a $220^{\circ} \mathrm{C}$. Sua composição dependerá da sua utilização, origem e dos processos de refino do petróleo, saindo da refinaria com composição balanceada para atender as especificações de comercialização. (BOAMAR, 2005)

Conforme O CONSELHO INTERMINISTERIAL DO AÇÚCAR E DO ÁLCOOL - CIMA, no uso das atribuições que lhe são conferidas pelo Decreto no 3.546, de 17 de julho de 2000, alterado pelo Decreto no 4.267, de 12 de junho de 2002, e Considerando que está garantido o abastecimento adequado de combustível em todo o território Brasileiro; Considerando a existência de etanol suficiente para o atendimento da demanda no período de entre safra da produção de cana-de-açúcar; e Considerando a importância de se elevar o uso do combustível renovável, resolve: Art. 1o Recomendar a fixação, a partir da zero hora do dia 16 de março de 2015, do percentual obrigatório de adição de etanol anidro combustível à gasolina, nos seguintes percentuais: I - 27\% na Gasolina Comum; e II - 25\% na Gasolina Premium. (MAPA - Resolução no 75 , de 5 de março de 2015)

0 uso de gasolina em não conformidade com especificações traz várias consequências que acarretam danos ao veículo e ao seu desempenho. A adição de solventes como o tolueno provoca danos em tubos e mangueiras constituídas de borracha. Uma gasolina com excesso de álcool anidro provoca a desregulagem do motor além do aumento do consumo de combustível. Portanto um combustível deve atender a todas as especificações para estar em conformidade e ser considerado de boa qualidade, tornando-se apto para o consumo(TAKESHITA, 2006)

Neste contexto, este trabalho tem como objetivo avaliar a gasolina aditivada para veículos automotores, comercializada nos mais diversos postos da cidade de Campina Grande - PB, por meio da determinação de parâmetros físico-químicos., buscando avaliar e comparar a qualidade deste combustível nos mais diversos postos de gasolina da cidade.

\section{METODOLOGIA}

\subsection{MATERIAL E REAGENTES:}

Provetas com rosca esmerilhada de $100 \mathrm{~mL}$; provetas com rosca esmerilhada de $50 \mathrm{~mL}$; pipetas volumétricas de $20 \mathrm{~mL}$; béqueres; Termômetro de laboratório; balança analítica com precisão de $0,0001 \mathrm{~g}$ e Gasolina aditivada comercializada em Campina Grande; Água destilada.

\section{Métodos:}

1 - Coleta das amostras: Coletar amostras de gasolina aditivada comercializada em diversos postos de combustíveis na cidade de Campina Grande - PB. Selecionar, por amostragem, postos de bandeiras diferentes.

2 - Ensaio de determinação de aspecto e cor: Numa proveta de $50 \mathrm{~mL}$, colocar $50 \mathrm{~mL}$ de gasolina a ser testada. Verificar o aspecto visual, a coloração e a presença de impurezas.

3 - Determinação do teor de álcool: Colocar $50 \mathrm{~mL}$ de gasolina aditivada em proveta de $100 \mathrm{~mL}$ e adicionar $50 \mathrm{~mL}$ de água destilada totalizando $100 \mathrm{~mL}$ de mistura. Tampar a proveta com rosca esmerilhada; mantendo a rosca firmemente segura, agitar. Após a agitação, manter a mistura em repouso para que ocorra a separação das fases. A camada superior será a gasolina e a inferior de água mais álcool.

0 teor porcentual de álcool na gasolina (T\%) pode ser calculado utilizando-se a expressão representada na Equação 1:

$$
\begin{gathered}
\mathrm{T} \%=(\text { Válcool } / \text { Vinicial gasolina }) \times 100 \% \quad \text { (Equação 1) } \\
\text { Onde: } \text { Válcool = Vfinal da solução aquosa }-50
\end{gathered}
$$

4. Determinação da densidade da gasolina: Utilizar uma proveta com rosca esmerilhada (a fim de evitar perdas por evaporação) de $50 \mathrm{ml}$; Pesar a proveta (MP), despejar $50 \mathrm{~mL}$ de gasolina aditivada na proveta e medir, por meio de uma balança analítica, a massa do produto final (proveta +gasolina)(MPG). 
Massa da gasolina (MG) $=$ MPG - MP $\quad$ Volume da gasolina $=50 \mathrm{~mL}$

Calcular a densidade (d) da gasolina utilizando o conceito físico-químico de densidade:

$$
\mathrm{d}=\mathrm{m} / \mathrm{V} \text { (Equação 1) }
$$

Assim, a densidade da gasolina foi calculada pela relação descrita na Equação 2:

$$
\mathrm{d}=\mathrm{MG} / 50 \quad \text { Equação } 2
$$

Comparar o valor obtido utilizando a Equação 2 com os valores determinados na Tabela 1

A temperatura ambiente foi controlada por meio ar-condicionado e aferida utilizando termômetro.

\begin{tabular}{|c|c|c|c|c|c|}
\hline \multirow{2}{*}{ Temperature ${ }^{\circ} \mathrm{C}$} & \multicolumn{2}{|c|}{ Densidode } & \multirow{2}{*}{ Temperatura ${ }^{\circ} \mathrm{C}$} & \multicolumn{2}{|c|}{ Densidode } \\
\hline & Minimo & Moximo & & Minimo & Moximo \\
\hline 0 & 0,7367 & 0,7753 & 25.5 & 0,7154 & 0.7558 \\
\hline 0,5 & 0,7362 & 0,7749 & 26.0 & 0.7151 & 0.7554 \\
\hline 1,0 & 0,7357 & 0,7745 & 26,5 & 0,7146 & 0,7550 \\
\hline i.s & 0.7353 & 0,7742 & 27.0 & 0,7142 & 0,7546 \\
\hline 2,0 & 0,7349 & 0.7738 & 27,5 & 0,7138 & 0,7543 \\
\hline 2.5 & 0.7345 & 0,7734 & 28,0 & 0,7134 & 0,7539 \\
\hline 3.0 & 0,7340 & 0.7730 & 20,5 & 0,7130 & 0.7535 \\
\hline 3.5 & 0,7336 & 0,7726 & 29.0 & 0,7125 & 0,7531 \\
\hline 4,0 & 0,7332 & 0.7723 & 29.5 & 0,7121 & 0.7327 \\
\hline 4,5 & 0,7326 & 0,7719 & 30.0 & 0.7177 & 0,7523 \\
\hline 5,0 & 0,7324 & 0.7715 & 30,5 & 0,7113 & 0.7519 \\
\hline 5,5 & 0,7320 & 0.7711 & 31,0 & 0.7109 & 0,7516 \\
\hline 6.0 & 0,7316 & 0.7707 & 31,5 & 0,7105 & 0,7512 \\
\hline 6.5 & 0,7312 & 0,7704 & 32,0 & 0.7100 & 0.7508 \\
\hline 7,0 & 0,7300 & 0.7700 & 32.5 & 0,7006 & 0.7504 \\
\hline 7,5 & 0.7305 & 0.7690 & 33.0 & 0.7092 & 0.7500 \\
\hline 8,0 & 0,7290 & 0.7692 & 33,5 & $0.708 \mathrm{~B}$ & 0,7497 \\
\hline e.5 & 0.7295 & $0,78 \mathrm{BB}$ & 34,0 & 0,7084 & 0,7493 \\
\hline 9.0 & 0,7291 & 0,7684 & 34,5 & 0,7000 & 0.7489 \\
\hline 9,5 & 0,7287 & 0.7680 & 35.0 & 0.7075 & 0.7485 \\
\hline 10,0 & 0,7283 & 0.7677 & 35,5 & 0,7071 & 0.7481 \\
\hline 10,5 & 0,7279 & 0,7673 & 36,0 & 0,7067 & 0,7477 \\
\hline 11.0 & 0.7275 & $0.7660^{\circ}$ & 36.5 & 0.7063 & 0,7473 \\
\hline 11,5 & 0,7270 & 0.7665 & 37.0 & 0.7059 & 0,7470 \\
\hline 12,0 & 0,7266 & 0,7661 & 37.5 & 0.7055 & 0,7466 \\
\hline 12,5 & 0,7262 & 0,7657 & 36,0 & 0,7051 & 0,7462 \\
\hline 13,0 & 0,7258 & 0.7654 & 38,5 & 0,7046 & 0,7458 \\
\hline 13.5 & 0,7254 & 0,7650 & 39,0 & 0,7042 & 0,7454 \\
\hline 14,0 & 0.7250 & 0.7646 & 30.5 & 0.7030 & 0.7450 \\
\hline 14.5 & 0,7246 & 0.7642 & 40,0 & 0,7034 & 0,7446 \\
\hline 15,0 & 0,7241 & 0.7636 & 40,5 & 0,7030 & 0,7443 \\
\hline 15.5 & 0.7237 & 0.7635 & 41.0 & 0,7025 & 0.7439 \\
\hline 16.0 & 0,7233 & 0.7631 & 41,5 & 0,7021 & 0,7435 \\
\hline 16.5 & 0,7229 & 0.7627 & 42.0 & 0,7017 & 0,7431 \\
\hline 17,0 & 0.7225 & 0,7023 & 42,5 & 0.7013 & 0,7427 \\
\hline 17,5 & 0.7221 & 0.7619 & 43,0 & 0,7009 & 0,7423 \\
\hline 18.0 & 0.7217 & 0.7615 & 43.5 & 0.7004 & 0.7420 \\
\hline 10,5 & 0,7212 & 0,7612 & 44,0 & 0,7000 & 0,7415 \\
\hline 19,0 & 0,7206 & 0.7808 & 44,5 & 0,6996 & 0,7412 \\
\hline 19,5 & 0,7204 & 0,7604 & 45,0 & 0,6992 & 0.7406 \\
\hline 20,0 & 0,7200 & $0.7000^{\circ}$ & 45, 5 & $0.69 \mathrm{es}$ & 0.7404 \\
\hline 20,5 & 0,7196 & 0,7598 & 46,0 & 0,6984 & 0,7400 \\
\hline 21,0 & 0,7192 & 0.7592 & 40,5 & 0,8980 & 0.7396 \\
\hline 21,5 & $0.71 \mathrm{a}$ & 0,7589 & 47,0 & 0.0975 & 0,7393 \\
\hline 22.0 & 0.7183 & 0.7585 & 47.5 & 0.6971 & 0,7386 \\
\hline 22,5 & 0.7179 & 0.7581 & 48,0 & 0.6967 & 0,73 s \\
\hline 23,0 & 0,7175 & 0.7577 & 48,5 & 0,6963 & 0,7381 \\
\hline 23.5 & 0,7171 & 0.7573 & 49.0 & 0,6959 & 0,7377 \\
\hline 24,0 & 0,7167 & 0.7569 & 49,5 & 0,6954 & 0,7373 \\
\hline 24.5 & 0,7163 & 0.7565 & 50,0 & 0,6950 & 0,7370 \\
\hline 25.0 & 0,7159 & 0,7562 & & & \\
\hline
\end{tabular}

Tabela 1 Valores de densidade da gasolina para diferentes temperaturas

Fonte: Manual para Testes de Combustíveis. 


\section{RESULTADOS:}

\subsection{COLETA DAS AMOSTRAS}

Foi feito um levantamento dos postos de combustíveis e verificou-se a existência de postos que recebem gasolinas com exclusividade de 4 distribuidoras diferentes (com bandeiras), denominados postos 1, 2, 3 e 4 e um sem bandeira, denominado posto 5 , os quais foram separados por regiões da cidade de Campina Grande - PB. 0 resultado pode ser observado na Tabela 2.

Tabela 2 - Relação e distribuição dos postos de combustíveis de bandeiras diferentes e sem bandeira em regiões na cidade de Campina Grande - PB.

\begin{tabular}{|l|c|c|c|c|c|}
\multicolumn{7}{c}{ POSTOS DE GASOLINA DA CIDADE DE CAMPINA GRANDE } \\
\multicolumn{1}{c|}{ Bandeira } & Zona Norte & Zona Sul & Zona Leste & Zona Oeste & TOTAL \\
\hline 1 & 7 & 13 & - & 7 & 27 \\
\hline 2 & 2 & 8 & 2 & 6 & 18 \\
\hline 3 & - & 4 & - & 1 & 5 \\
\hline 4 & 2 & - & - & 3 & 5 \\
\hline Sem bandeira & 2 & 2 & - & 3 & 13 \\
\hline TOTAL & 13 & 27 & 2 & 20 & 62 \\
\hline
\end{tabular}

Como pode ser observado na Tabela 2, entre os postos pesquisados, existe uma concentração maior de postos nas zonas Sul e Oeste na cidade de Campina Grande, onde o fluxo para pequenas cidades do interior é mais intenso, provavelmente este seja um fator determinante. Também, é possível observar que os postos de Bandeira 1 foram maioria na amostragem feita, com 27 postos, em segundo lugar estão os postos 2 com 18, em terceiro lugar os postos sem bandeira com 13 e em último os postos 3 e 4, empatados, ambos com 5 postos.

\subsection{ANÁLISES FÍSICO-QUÍMICAS}

Os resultados da determinação de densidade e teor de álcool, nas amostras de gasolina aditivada coletada nos postos avaliados estão apresentados na Tabela 3.

Tabela 3 - Resultados da determinação de densidade e teor de álcool, nas amostras de gasolina aditivada coletada nos postos avaliados.

\begin{tabular}{|c|c|c|c|}
\hline \multirow[t]{2}{*}{ Bandeira } & \multicolumn{3}{|c|}{ PROPRIEDADES FÍSICO-QUÍMICAS DA GASOLINA ADITIVADA (MÉDIA) } \\
\hline & Densidade $(\mathrm{g} / \mathrm{mL})$ & Teor de álcool (\%) & Aspecto visual/Cor \\
\hline 1 & 0,72234 & 28 & $\mathrm{AI}^{*} /$ Verde \\
\hline 2 & 0,7291375 & 24,5 & $\mathrm{AI}^{*} /$ Verde \\
\hline 3 & 0,7409725 & 26 & $\mathrm{AI}^{*} /$ Verde \\
\hline 4 & 0,7133225 & 28 & $\mathrm{AI}^{*} /$ Verde \\
\hline Sem bandeira & 0,72459 & 26 & $\mathrm{AI}^{*} /$ Verde \\
\hline Padrão & 0,72 a 0,76 & $25 \pm 1$ & $\mathrm{AI}^{*} /$ Verde \\
\hline
\end{tabular}

$\mathrm{AI}^{*} /$ Ausência de impureza

Por meio dos resultados das análises físico-químicas apresentados na Tabela 3 é possível observar que:

I - As densidades medidas estão em conformidade com os valores estabelecidos pela Ministério de Abastecimento, Pecuária e Agricultura (MAPA) e ANP para todas as gasolinas analisadas, com exceção da gasolina comercializada no posto 4 , cujo valor foi de $0,7133225 \mathrm{~g} / \mathrm{mL}$, abaixo do valor mínimo estabelecido de $0,72 \mathrm{~g} / \mathrm{mL}$;

II - Em relação aos teores de álcool foi observado que o percentual de álcool na gasolina aditivada variou entre $24,5 \%$ e $28 \%$ para os postos relacionados. Desde 16 de março de 2015, o percentual de etanol anidro combustível na gasolina aditivada é de $25 \% \pm 1 \%$, conforme Portaria №75, de 5 de março de 2015, do Ministério da Agricultura, Pecuária e Abastecimento (MAPA) e Resolução №1, de 4 de março de 2015, do Conselho Interministerial do Açúcar e do Álcool (CIMA). Desta forma, podemos observar que, para as gasolinas analisadas, os valores de teor de álcool encontram-se em conformidade com as normas, com exceção da gasolina aditivada dos postos 1 e 4 com valores de $28 \%$ para ambos, portanto com $2 \%$ acima do valor máximo especificado. 
III - A cor e o aspecto visual, das gasolinas analisadas, encontram-se dentro dos padrões especificados.

\section{CONCLUSÃO:}

Este trabalho apresentou resultados da caracterização físico-química da gasolina aditivada comercializada nos mais diversos postos na cidade de Campina Grande - PB. Os resultados mostraram que a densidade, o teor de álcool e o aspecto visual estavam conforme os padrões especificado pelos órgãos reguladores para a maioria dos postos avaliados, com exceção do teor de álcool para os postos 1 e 4 cujo valor foi de $28 \%$, $2 \%$ acima do valor máximo estipulado de $26 \%$ e da densidade da gasolina para o posto 4 que apresentou densidade de $0,7133225 \mathrm{~g} / \mathrm{mL}$, abaixo do valor mínimo tabelado de $0,72 \mathrm{~g} / \mathrm{mL}$.

\section{REFERÊNCIAS:}

[1] AMBroziN, A. R. P. ; Kuri, S. E. ; Monteiro, M. R.; Corrosão Metálica Associada ao Uso de Combustíveis Minerais e Biocombustíveis, Quim. Nova, Vol. 32, No. 7, 1910-1916, 2009.

[2] BOAMAR, P. F. de A. - Combustíveis Automotivos - Manual dos usuários e Revendedores, Ed. Nova Letra, 2005.

[3] BRASIL. C.I. do - Venda de combustíveis no mercado brasileiro caiu 1,9\% em 2015 - Disponível em: http://agenciabrasil.ebc.com.br/economia/noticia/2016-03/venda-de-combustiveis-no-mercado-brasileiro-caiu-19em-2015, acessado em 19 de agosto de 2016.

[4] MARTINS, G do S. V. - Caracterização e Comportamento Térmico de Gomas de Gasolina Depositadas em Veículos Automotivos, Dissertação de Mestrado, UFCG, 2006.

[5] MENDES, G. - Detecção de Adulterações em Gasolina e Previsão de Parâmetros Físico-Químicos a Partir de Curvas de Destilação Associadas à Ferramentas Quimiométricas. Tese de doutorado, UFMG, 2012.

[6] MinistÉRIO DA AGRICULTURA, PECUÁRIA E ABASTECIMENTO (MAPA). Portaria no 75, de 05/03/15. Publicada no Diário Oficial da União (DOU de 06/03/2015).

[7] MORISSON, R. T.; BOYD, R. N. Química Orgânica. Calouste Gulbenkian, 1996.

[8] OLANYK, L. Z.; SCHIRMER, W. N.; GUERI M. V. D.; GUEDES, C. L. B.; BORSATO, D.; RODRIGUES, P R. P.; QUESSADA, T. P.; OLIVEIRA, D. S. de - Avaliação das Emissões Gasosas, Parâmetros de Qualidade e Desempenho de Consumo de um Motor de Combustão Interna Operando com Misturas Gasolina/Adulterante em Diferentes Proporções, Revista CIATEC - UPF, vol.6 (2), p.15-30, 2014.

[9] PETROBRAS - Gasolina Automotiva. Informativo Técnico da PETROBRAS, REGAP 1996.

[10] PONTES, L. - O combustível automotivo no Brasil Qualidade e preço. Por que tanta confusão? Disponível em: http://www.comciencia.br/reportagens/petroleo/pet18.shtml acessado em 26 de agosto de 2016

[11] PORTARIA ANP no. 309, de 27/12/2001 Procedimentos para Testes de Qualidade de Combustíveis disponível em http://www.fepel.com.br/catalogos/manual_teste_combustivel.pdf. Acessado em 21 de agosto de 2016.

[12] RESOLUÇÃO ANP № 38, DE 9.12.2009 - DOU 10.12.2009.

[13] MAPA - Ministério da Agricultura, Pecuária e Abastecimento - Resolução no75, de 5 de março de 2015

[14] SILVA, F. L. do N; SANTOS Jr, J. R, dos; MOITA Neto, J. M.; SILVA, R. L. G. do N. P. da; FLUMIGNAN, D. L; OLIVEIRA, J. E. de - Determinação de benzeno, tolueno, etilbenzenos em gasolina comercializada nos postos do estado do Piauí, Química Nova, v.32, n.1, São Paulo, 2009.

[15] Tabela de Preço dos Postos de Combustíveis em Campina Grande - Paraíba, disponível em: http://www.precodoscombustiveis.com.br/postos/cidade/1290/pb/campina-grande. Acessado em 06 de março de 2016

[16] TAKESHITA, E. V. Adulteração de Gasolina por Adição de Solventes: Análise dos Parâmetros Físicos Químicos. Dissertação de Mestrado, UFSC, Florianópolis, 2006 


\section{Capítulo 15}

\section{Caracterização do querosene de aviação em mistura de pseudocomponentes e simulação do processo de hidrodessulfurização}

\section{Mateus Fernandes Monteiro}

Mario Hermes de Moura Neto

Diêgo Vinícius Fernandes Bezerra

Paula Fabiane Pinheiro do Nascimento

\section{Eduardo Lins de Barros Neto}

Osvaldo Chiavone Filho

Resumo: 0 querosene de aviação é produto da destilação fracionada do petróleo e sua temperatura de ebulição está entre 130 e $30{ }^{\circ} \mathrm{C}$. Quimicamente é composto por hidrocarbonetos com cadeias carbônicas contendo de 9 a 16 átomos. Existem também heteroátomos, dentre os quais se destaca o enxofre. Uma vez que a combustão dos compostos sulfurados gera produtos altamente poluentes, sua remoção é fundamental para minimizar o impacto ambiental atrelado à combustão do querosene. Nesse contexto, o processo de hidrotratamento desponta como alternativa para a remoção do enxofre de derivados de petróleo, sendo sua simulação em estado estacionário de suma importância para indústria petroquímica. Em razão de ser uma mistura complexa, há grande dificuldade em caracterizar o querosene por meio de métodos convencionais, analisando a quantidade de cada constituinte. Nesse cenário, métodos fundamentados na análise da destilação, se apresentam como alternativa adequada para representar a mistura. 0 ensaio ASTM D86 determina o intervalo de destilação do petróleo e de seus produtos por meio de uma destilação batelada simples. Convencionalmente são gerados pseudocomponentes, com o objetivo de representar o derivado de petróleo. Esses, são obtidos por métodos semi-empíricos e possuem propriedades individuais que não necessariamente correspondem a qualquer componente real. Assim, a obtenção das propriedades necessárias a utilização dos modelos termodinâmicos, é possível pela utilização de equações e correlações empíricas. Uma amostra de querosene de aviação (QAV) foi caracterizada em 10 pseudocomponentes com finalidade de simular uma unidade de hidrodessulfurização no software Aspen HYSYS. Como resultado, foi obtida uma corrente de combustível com teor de enxofre consideravelmente menor.

Palavras-chave: Destilação, ASTM D-86, Tiofeno, Hidrotratamento. 


\section{INTRODUÇÃO}

Os aviões modernos, dotados de motores à turbina utilizam o querosene de aviação (QAV) como combustível. Esse é obtido do fracionamento do petróleo em uma unidade de destilação atmosférica, na faixa de 130 a $300^{\circ} \mathrm{C}$.

O QAV é constituído por hidrocarbonetos com 9 a 16 átomos de carbono, sendo os principais compostos: parafinas, naftênicos, aromáticos e olefinas (CAMOLESI, 2009). Em menores quantidades estão presentes no QAV compostos de enxofre, nitrogênio e oxigênio, sendo a concentração desses relacionada com o petróleo de origem. As faixas típicas de participação dos hidrocarbonetos estão descritas na Tabela 1.

Tabela 1- Frações de hidrocarbonetos presentes no QAV

\begin{tabular}{|l|c|}
\hline Tipos de hidrocarbonetos & $33-61$ \\
\hline Parafinas (alcanos) & $33-45$ \\
\hline Naftênicos (cicloalcanos) & $12-25$ \\
\hline Aromáticos & $0,5-5$ \\
\hline Olefinas (alcenos) & \\
\hline
\end{tabular}

A caracterização em pseudocomponentes é um método discreto para representação de uma mistura. Esse método tem a finalidade de reduzir as dimensões do modelo das misturas complexas tipicamente presentes na indústria do petróleo, em razão do elevado número de constituintes (Castells e Miquel, 1993). Esse conceito foi desenvolvido sob o nome de Integral Method (Katz e Brown, 1933). Os pseudocomponentes estão associados a cortes em diferentes faixas de pontos de ebulição, sendo cada uma dessas faixas teóricas atreladas a pelo menos um componente, conforme observado na Figura 1.

Figura 1- Método de estimação dos pseudocomponentes a partir da curva de destilação ASTM D-86

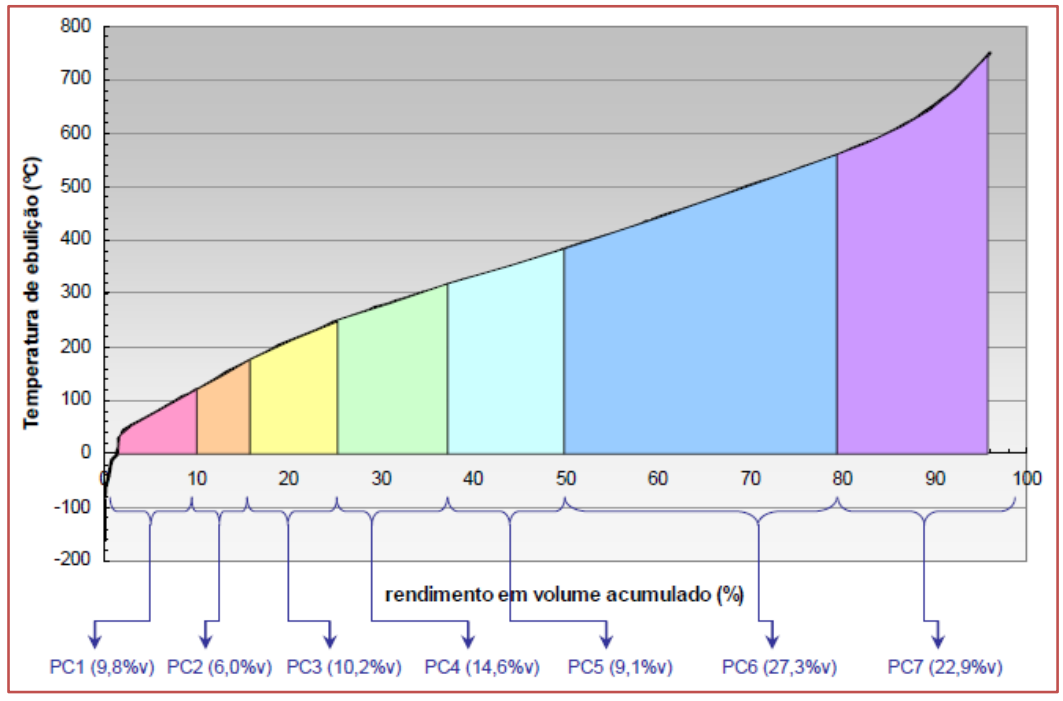

O método dos pseudocomponentes requer a obtenção de uma curva experimental de caracterização (ASTM), sendo a curva de Ponto de Ebulição Verdadeiro (PEV) a mais utilizada. Uma vez que o aparato experimental necessário para a aquisição desses dados é bastante robusto, frequentemente essa curva é substituída pela ASTM D-86. Existem correlações empíricas que se propõem a converter curvas ASTM D86 em curvas PEV (Daubert, 1994).

A utilização do processo de hidrotratamento é fundamental para a especificação de combustíveis, como o QAV. Esse processo tornou-se extremamente importante para atender à crescente demanda por combustíveis com baixo teor de impurezas. No hidrotratamento (HDR), a hidrodessulfurização (HDS) é um dos processos mais relevantes, uma vez que a queima dos compostos sulfurados gera produtos altamente danosos ao meio ambiente. Na amostra estudada, o enxofre apresenta-se sob a forma de compostos 
heterocíclicos condensados. 0 processo de remoção por método HDS utiliza catalisador comercial de $\mathrm{Ni}$ Mo/y-Al203 estudados em uma faixa de pressão de 35 a 100 atm e temperatura de 340 a $380^{\circ} \mathrm{C}$. As reações de organo-sulfurados são exotérmicas e irreversíveis dentro do processo de HDR.

Como forma de simplificar o processo de simulação, foi adotado o tiofeno como representante da classe de compostos sulfurados. Esse foi escolhido uma vez que o mecanismo reacional de HDS desse composto já foi elucidado previamente, bem como a cinética das reações catalíticas envolvidas. Foi adotado o modelo cinético de Langmuir-Hinshelwood (DOUKEH, 2018). As constantes desse modelo foram inseridas no simulador Aspen HYSYS. Foi proposto um reator PFR leito fixo com alimentação composta de hidrogênio e querosene para simular as condições operacionais do processo.

\section{METODOLOGIA}

Uma amostra de $250 \mathrm{~mL}$ de QAV foi destilada conforme norma ASTM D86, em aparato experimental semelhante ao observado na Figura 2.

Figura 2- Esquema do aparato experimental utilizado para destilação ASTM D86

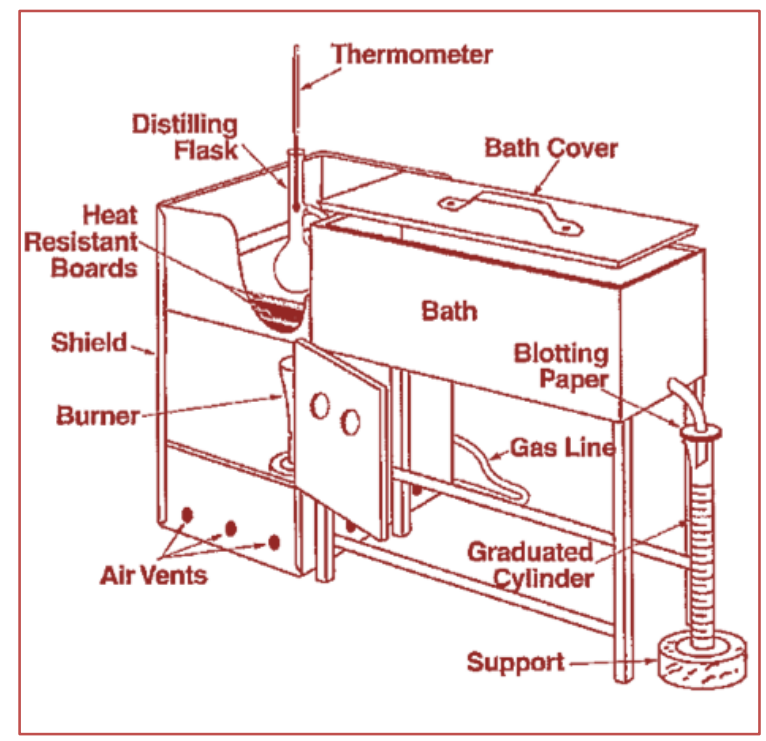

Para tornar a caracterização em pseudocomponentes mais consistente foi obtida uma curva de densidade da amostra de QAV para temperaturas entre 15 e $70{ }^{\circ} \mathrm{C}$ utilizando densímetro Anton Paar DMA 4500. 0 teor de enxofre presente na amostra do QAV foi quantificado por meio de fluorescência na região do ultravioleta, conforme norma ASTM D5453.

Com base nesses dados experimentais foi possível realizar a caracterização do QAV em pseudocomponentes. Essa caracterização permitiu a retratar as características físico-químicas desse combustível por meio da estimação das propriedades dos pseudocomponentes. Essa representação da mistura permitiu a simulação do processo de HDS.

Para a exeucusão dos calculos os a PVT utilizou-se a Equação de Estado Lee Kesler, uma vez que essa se adequa com alta precisão a misturas não polares como o caso do QAV (Lee e Kesler, 1975). Ademais, esse modelo termodinâmico não implica desvios acentuados em regiões de elevadas pressões, condição na qual ocorre as reações de HDS. Como regra de mistura foi adotado Plocker e Knaap (1978). As propriedades pseudocriticas foram estimadas a partir de correlações empíricas. 


\section{RESULTADOS E DISCUSSÃO}

A Figura 3 apresenta os dados obtidos da destilação do QAV, realizada conforme método ASTM D86. Observa-se que o ponto inicial de ebulição foi de $132{ }^{\circ} \mathrm{C}$ e ao final da curva, com $95 \%$ do volume destilado, foi de $251{ }^{\circ} \mathrm{C}$.

Figura 3 - Curva de destilação ASTM D86 do QAV: Input (experimental) versus Calc D86 (calculado considerando 10 pseudocomponentes).

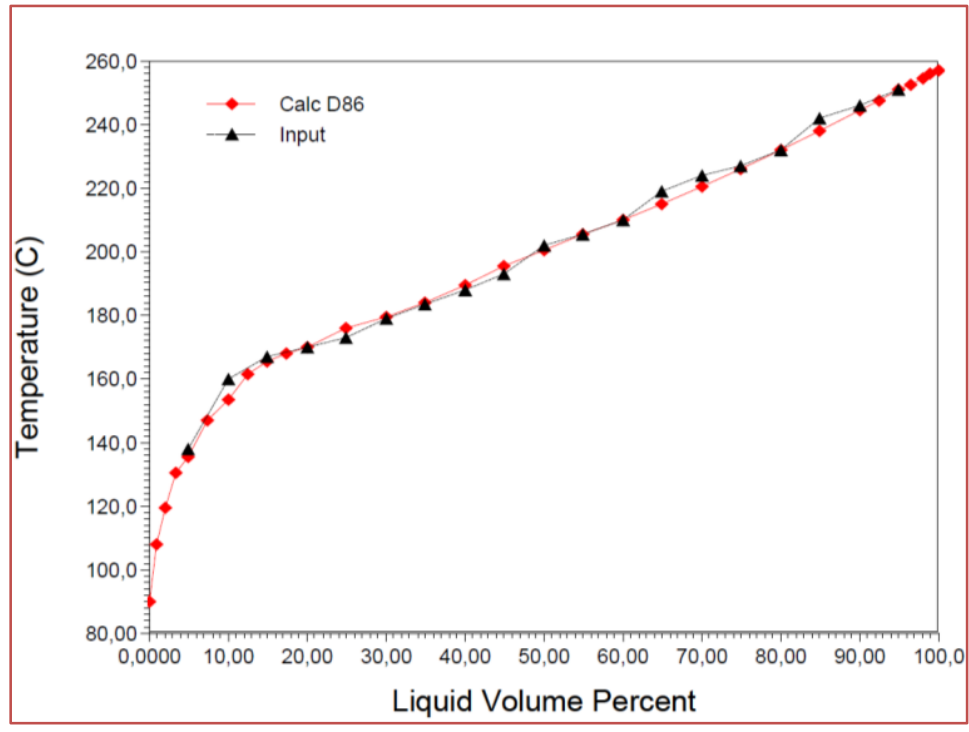

De forma complementar as informações sobre o QAV em estudo, seu teor de enxofre foi quantificado por meio da fluorescência na região do ultravioleta, sendo o valor obtido de 207,21 ppm. Ademais, a densidade da amostra foi medida para temperaturas entre 15 e $70{ }^{\circ} \mathrm{C}$, sendo os valores obtidos informados na Figura 4.

Figura 4 - Curva experimental de densidade do QAV

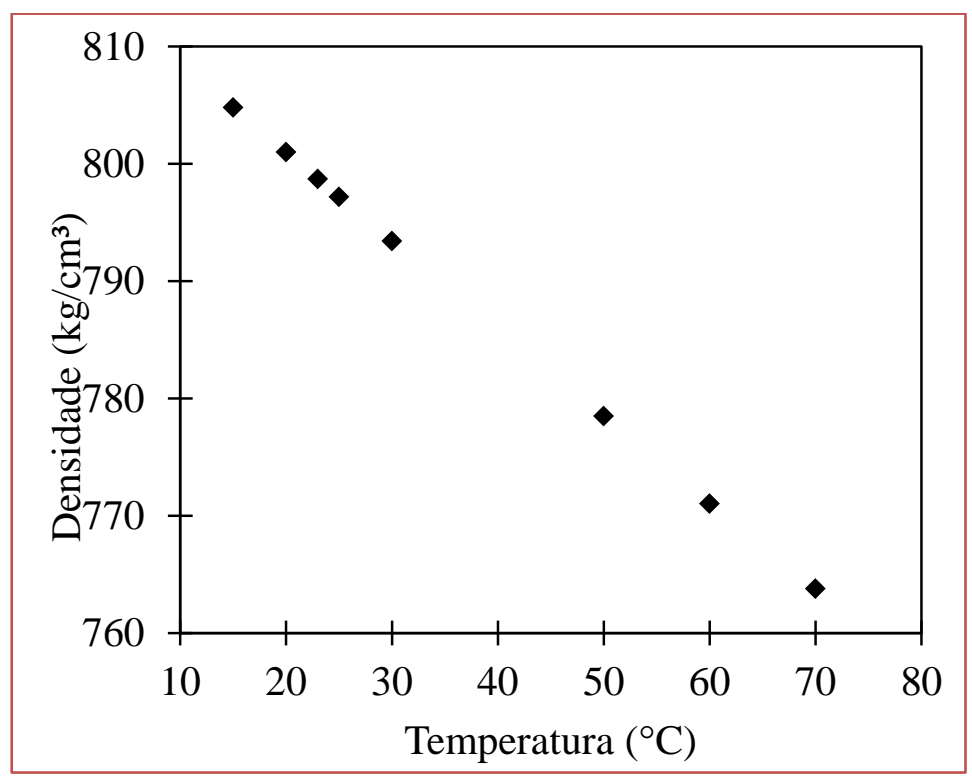


A partir da curva de destilação ASTM D86 a amostra de QAV foi caracterizada em 10 pseudocomponentes apresentados na Tabela 2. Para isso, foi utilizado o software ASPEN HYSYS. Dados de densidade, pressão e temperatura crítica, fator acêntrico e peso molecular, viscosidade e Fator de Caracterização de Watson também foram determinados para cada pseudocomponente. Além disso, pode-se observar o ponto normal de ebulição (NBP, ${ }^{\circ} \mathrm{C}$ ) na própria nomenclatura dos compostos, com $52{ }^{\circ} \mathrm{C}$ para o mais volátil (NBP52) e $264{ }^{\circ} \mathrm{C}$ para o menos volátil (NBP264). A representação do QAV por uma mistura de 10 pseudocomponentes permitiu estabelecer uma alimentação para o processo de HDS.

Tabela 2 - Propriedades dos pseudocomponentes

\begin{tabular}{|c|c|c|c|c|c|c|c|}
\hline Pseudo Comp. & $\begin{array}{l}\text { Densidade } \\
\mathrm{kg} \cdot \mathrm{m}-3\end{array}$ & $\begin{array}{l}\mathrm{Pc} \\
\mathrm{kPa}\end{array}$ & $\begin{array}{l}\mathrm{Tc} \\
{ }^{\circ} \mathrm{C}\end{array}$ & $\begin{array}{c}\text { Fator } \\
\text { acêntrico }\end{array}$ & $\begin{array}{c}\text { Peso } \\
\text { molecular } \\
\text { kg.kmol-1 }\end{array}$ & $\begin{array}{c}\text { Viscosidade } \\
\text { cP }\end{array}$ & $\begin{array}{c}\text { Fator } \\
\text { Watson }\end{array}$ \\
\hline NBP52 & 661,6 & 3137 & 218,5 & 0,243830 & 74,56 & 0,25705 & 12,640 \\
\hline NBP77 & 684,4 & 2990 & 247,2 & 0,292380 & 81,77 & 0,27055 & 12,528 \\
\hline NBP99 & 721,8 & 2950 & 277,8 & 0,299218 & 96,84 & 0,36209 & 12,119 \\
\hline NBP124 & 742,1 & 2739 & 305,9 & 0,335118 & 108,3 & 0,44381 & 12,048 \\
\hline NBP151 & 768,7 & 2580 & 337,3 & 0,367803 & 127,4 & 0,61340 & 11,888 \\
\hline NBP171 & 782,0 & 2427 & 359,2 & 0,400883 & 140,1 & 0,74211 & 11,873 \\
\hline NBP198 & 796,7 & 2243 & 385,8 & 0,445635 & 157,3 & 0,97798 & 11,878 \\
\hline NBP217 & 806,9 & 2114 & 405,3 & 0,480918 & 172,0 & 1,2316 & 11,887 \\
\hline NBP241 & 818,7 & 1970 & 428,2 & 0,525001 & 192,0 & 1,6590 & 11,901 \\
\hline NBP264 & 828,9 & 1836 & 449,8 & 0,570702 & 212,3 & 2,2143 & 11,928 \\
\hline
\end{tabular}

Para assegurar a presença de um componente sulfurado nessa corrente foi adicionado tiofeno, representante de todos os compostos que contêm enxofre. 0 processo de remoção desse contaminante do QAV foi simulado no software Aspen HYSYS. Os principais equipamentos utilizados nesse processo foram o reator de fluxo pistonado com leito fixo e separador bifásico líquido-gás. Como equipamentos secundários, para atingir as condições de operação do reator e separador, foram utilizados bomba, compressor, trocador de calor casco e tubos, aquecedor e resfriador elétrico, conforme visto na Figura 5.

Figura 5- Esquema do aparato utilizado para remoção de compostos sulfurados do QAV no ASPEN HYSYS

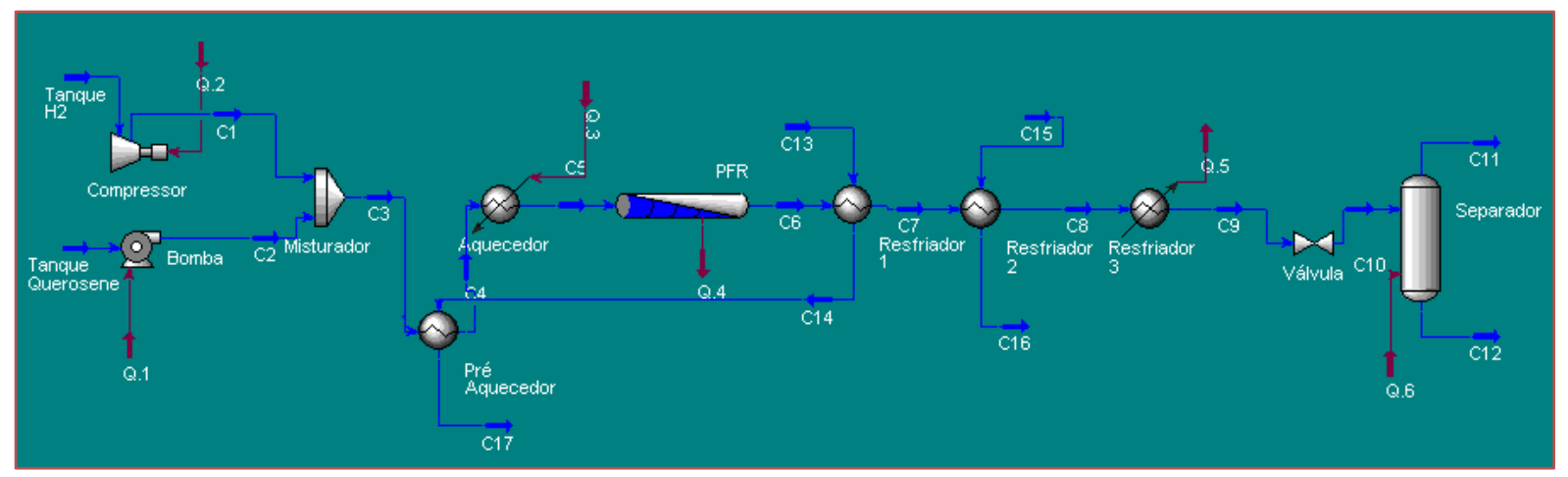

As condições ideais para a reação foram determinadas em 200 bar e $470^{\circ} \mathrm{C}$ e para o separador líquido-gás foram 10 bar e $20^{\circ} \mathrm{C}$. Nas condições descritas, o tiofeno reagiu em totalidade com o gás hidrogênio, conforme Reação 1, permanecendo constante a composição dos pseudocomponentes. 0 ácido sulfídrico formado permanece na fase gasosa, condição adequada para permitir a separação da fase líquida, composta somente por hidrocarbonetos, e da fase gás que além do H2S, contém hidrocarbonetos residuais em baixa concentração. 
Dessa forma, no processo de separação de fases já é possível extrair uma corrente líquida livre de enxofre. Essa é aditivada para adequar o querosene às normas da ANP para utilização comercial e industrial. Já a corrente gasosa segue para um outro processo de separação, visando recuperar o hidrogênio não reagido, para reciclo na planta e aproveitar o H2S como produto, aumentando a rentabilidade do processo de refino. A composição das correntes de saída do separador líquido-gás pode ser vista na Tabela 3.

Tabela 3 - Composição molar das correntes líquida e gasosa do separador bifásico

\begin{tabular}{|l|c|c|}
\multicolumn{1}{|c|}{ Componente } & $\begin{array}{c}\text { Fração molar Corrente } \\
\text { líquida }\end{array}$ & $\begin{array}{c}\text { Fração molar } \\
\text { Corrente gasosa }\end{array}$ \\
\hline NBP52 & 0,0057 & 0,0049 \\
\hline NBP77 & 0,0207 & 0,0038 \\
\hline NBP99 & 0,0442 & 0,0025 \\
\hline NBP124 & 0,0592 & 0,0008 \\
\hline NBP151 & 0,0750 & 0,0002 \\
\hline NBP171 & 0,0826 & 0,0001 \\
\hline NBP198 & 0,0907 & 0 \\
\hline NBP217 & 0,0963 & 0 \\
\hline NBP241 & 0,1027 & 0 \\
\hline NBP264 & 0,4229 & 0 \\
Tiofeno & 0 & 0,0001 \\
n-Butano & 0 & 0,0001 \\
H2S & 0 & 0,9873 \\
H2 & 0 & 0 \\
\hline
\end{tabular}

\section{CONCLUSÕES}

Por razões ambientais, remover os componentes sulfurados é de suma importância no processo de refino. Sendo assim, buscar vias que além de removê-los de forma eficiente aumentem a rentabilidade global do refino vem sendo estudadas com frequência. Nesse cenário a simulação do processo se apresenta como alternativa de baixo custo para determinar as condições ótimas de operação. Com a metodologia proposta foi possível remover todo o enxofre presente na corrente líquida, adequando o querosene as normas da ANP para QAV. 0 enxofre foi removido sob a forma de H2S, produto com valor agregado e de separação facilitada, por ser um gás nas condições de projeto. A unidade proposta é de alta rentabilidade, uma vez que o querosene isento de enxofre apresenta maior valor comercial. Ademais, o H2S removido também é um produto comercializado pela refinaria. 


\section{REFERÊNCIAS}

[1] CAMONLESI, V.J. Caracterização do Querosene através da espectroscopia de infravermelho próximo, 2009.

[2] DAUBERT, T. E. Petroleum fraction distillation interconversions. Hydrocarbon Processing, Houston, v. 73, n. 9, p. 75-78, 1994.

[3] DOUKEH, R.; BOMBOS, M. et al. Knetics of thiophene hydrodesulfurization over a supported Mo-Co-Ni catalyst. Comptes Rendus Chimie, 2018.

[4] KATZ, D. L.; BROWN, G. G. Vapor pressure and vaporization of the petroleum fractions. Industrial and Engineering Chemistry, Washington, v.25, n. 12, p. 1373-1384, 1993.

[5] LEE, B.L.; KESLER MG. Ageneralized thermodynamic correlation based on three-parameter corresponding states. AIChE Journal 1975, 21:510-527.

[6] MIQUEL, J.; CASTELL, F. Easy characterization of petroleum fractions. Hidrocarbon Processing, Houston, v. 72, n. 12, p. 101-105, 1993.

[7] PLOCKER U, KNAPP H, Calculation of High-Pressure Vapor-Liquid Equilibria from a Correspoding-States Correlation with Emphasis on Asymmetric Mixtures, Ind. Eng. Chem. Process Des. Dev 1978; 17:324-332. 


\section{Capítulo 16}

Simulação e Análise do Comportamento da Onda Eletromagnética de Dados GPR no Monitoramento de Postos de Gasolina

\section{Debora Abreu da Silva \\ Zoraida Roxana Tejada da Piedade \\ Anderson Almeida da Piedade}

Resumo: Uma variedade de problemas ambientais ocorre devido ao vazamento de hidrocarbonetos. Metodologias geofísicas aplicadas a estudos ambientais mostram ótimos resultados na investigação de contaminantes. 0 GPR é um método geofísico prático e rápido em tais investigações, porque o sinal eletromagnético auxilia na delimitação do contaminante, abordando técnicas diretas de investigação como furos e poços. Neste estudo, três situações ambientais foram modeladas em um posto de abastecimento, antes do vazamento do tanque subterrâneo, após o vazamento, e quando isso foi remediado, a simulação foi feita perpendicularmente à direção do fluxo do aqüífero utilizando duas antenas diferentes ( $100 \mathrm{MHz}$ e $250 \mathrm{MHz}$ ). Foi possível avaliar as zonas mais resistentes identificadas como zonas de sombreamento. Os resultados mostram que o sinal GPR após o vazamento é muito atenuado nas fases de contaminação, após a remediação o comportamento da onda EM tende a recuperar grande parte (existência de novos minerais) das propriedades originais do solo. Este fato pode ser resultado de uma atividade bacteriológica no resíduo ou aumento de sais dissolvidos no solo causada pelo $\mathrm{pH}$ ácido do poluente. 


\section{INTRODUÇÃO}

Segundo a ANM (Agência Nacional do Petróleo), até o começo de dezembro do ano de 2016, o número de postos de gasolina na cidade de Manaus era de 284. Atualmente, este valor possivelmente sofreu um acréscimo. E, segundo Lima (2010), a vida útil dos tanques de armazenamento de combustível dos postos da cidade está próxima do fim, aumentando dessa forma, a possibilidade de ocorrência de vazamento ou derramamento de gasolina. Ainda segundo o mesmo autor, riscos carcinogênicos pela exposição ao benzeno foram encontrados mais de $60 \%$ na cidade Manaus. Desta forma, é necessário que haja maior monitoramento tanto das regiões afetadas pela presença de benzeno quanto aquelas ainda livres da contaminação, visando a prevenção. Para isso, se faz necessário o incentivo ao estudo e pesquisas na área para que haja desenvolvimento e aperfeiçoamento de métodos que identifiquem zonas contaminadas e que impeçam novos derramamentos.

A contaminação do solo é preocupante porque pode atingir o lençol freático, e tornar a água imprópria para o consumo. Os vazamentos em postos de combustíveis provocam grandes problemas ao meio ambiente, (Prommer et al. (1999)) e os resíduos tóxicos podem penetrar no solo e atingir altas profundidades e tamanhos não estimáveis, considerado-se este como um passivo ambiental. A série de compostos denominados BTEX, compreende o benzeno, tolueno, etilbenzeno e xilenos. Estes efluentes apresentam um elevado potencial de poluição, representando um sério risco ao meio ambiente e ao ser humano (Mello (2007)). São vários os motivos pelo qual o vazamento pode existir: seja a pressão, material do tanque, armazenamento dos líquidos inflamáveis, manutenção dos equipamentos, instalações inadequadas e o monitoramento de entrada e saída do combustível, assim como o ambiente geológico e as forças tensionais aos quais os tanques estão submetidos. Entretanto, o fato mais frequente é que muitos tanques tem mais de 25 anos de uso e dessa forma,a possibilidade de ocorrerem vazamentos é extremamente grande, principalmente pelo surgimento de rachaduras ou corrosão (Tiburtius et al. (2004)).

Ante tal problemática, os métodos geofísicos, como o Ground Penetrating Radar (GPR) mostraram bons resultados na identificação de locais contaminados por "líquidos imiscíveis em fase não aquosa" - NAPL's (Dehaini (2001), Penner (2005) ; de Castro and Branco (2003)) e verificaram que a amplitude do sinal eletromagnético (EM) é menor na parte superior da pluma de hidrocarboneto, podendo ser provocada pela fase residual do mesmo. Autores como Moreira and Dourado (2007), identificam essas áreas como zonas de sombra. 0 objetivo principal deste trabalho foi de avaliar o comportamento da onda eletromagnética de um posto de combustível em diferentes ambientes (antes da contaminação, durante a contaminação e após a remediação) e assim avaliar a aplicabilidade do método ante situações de monitoramento.

Este estudo realiza uma análise comparativa entre radargramas obtidos antes de acontecer o vazamento do tanque subterrâneo, posterior ao vazamento e quando este foi remediado, bem como a simulação dos ambientes mencionados. Dessa forma será possível avaliar a influência dos compostos nas propriedades físicas do solo, alterando a condutividade elétrica nas diferentes fases de contaminação e assim, analisar a resposta nos seções proporcionadas pelo GPR. Por fim, o realce do refletor após a remediação segundo o estudo, mostra como o refletor é visivelmente perceptível à ausência de compostos.

\section{METODOLOGIA}

Dentro da estrutura de trabalho, o principal alvo na modelagem é analisar o comportamento da onda eletromagnética diante de possíveis vazamentos de hidrocarbonetos, em particular a gasolina, visto que é constituída por hidrocarbonetos mais leves e apresenta maior solubilidade, maior volatilidade, menor viscosidade, além de ter maior mobilidade no solo, tendendo a ser o hidrocarboneto com maior potencial de impacto ambiental.

Para isso, organizou-se o estudo da siguinte forma:

- Analisar o comportamento do hidrocarboneto na zona vadosa e zona saturada.

- Modelagem de três situações diferentes em GPR: Antes do meio ser contaminado, durante a contaminação e por último, quando este contaminante foi tratado ao longo dos anos.

- Simulação das três modelagens.

- Por fim, analisar o comportamento da onda dos dados sintético e compará-los aos dados reais de Dehaini (2001). 


\subsection{COMPORTAMENTO DO HIDROCARBONETO NA ZONA VADOSA E SATURADA}

0 processo inicial de contaminação de águas subterrâneas por constituintes de gasolina (benzeno, tolueno, etilbenzeno e xileno "BTEX") ocorre a partir da fase residual na zona vadosa (Fetter (1993)). No movimento descendente o LNAPL pode deslocar a água e o ar da zona vadosa e se acumular na zona capilar (Fase Livre). Esta zona pode desaparecer completamente migrando segundo o declive do nível de água, ficando o hidrocarboneto preso na zona saturada que é denominada fase dissolvida e consequentemente o aumento dos contaminantes e a adsorção dos mesmos pela matéria orgânica designa-se como fase adsorvida.

0 transporte na zona saturada basicamente depende da velocidade das águas subterrâneas, taxa de migração, dispersão, difusão, volatização e sorção. Enquanto a transformação dos contaminantes dissolvidos é afetada pelos processos químicos como a ionização, solubilidade e hidrólise, oxidação/redução, como também por processos biológicos de bioacumulação e biodegradação.

Moreira and Dourado (2007) explicam que a biodegradação contínua dos hidrocarbonetos aromáticos presentes no meio possivelmente resultou em elevadas concentrações de ácidos orgânicos, produzindo dissolução mineral, com aumento da porosidade e elevação nos teores de sólidos totais dissolvidos. Explicando assim que a existência de neoformação mineral nas diferentes fases de contaminação continua durante o tempo em que este permanecer no meio.

\subsection{MODELO DIRETO}

Para realizar a análise proposta e identificar as principais mudanças de comportamento de ondas eletromagnéticas diante as mudanças físicas provocadas pelos contaminantes, foi utilizado o software matGPR- Matlab. Para isso, elaboraram-se três modelos diretos:

Modelo 1 - Antes da contaminação: Tanque subterrâneo de armazenamento de combustível de um posto de abastecimento.

Modelo 2 - Contaminação do solo: Vazamento de combustível demarcando as fases decontaminação.

Modelo 3 - Remediação do solo: Neoformação de minerais durante a contaminação, alterando o material arenoso saturado.

Figura 1: Modelo sintético antes da contaminação do solo com tanque de aço carbono subterrâneo e interface das camadas geológicas de material argiloso e arenoso saturado.

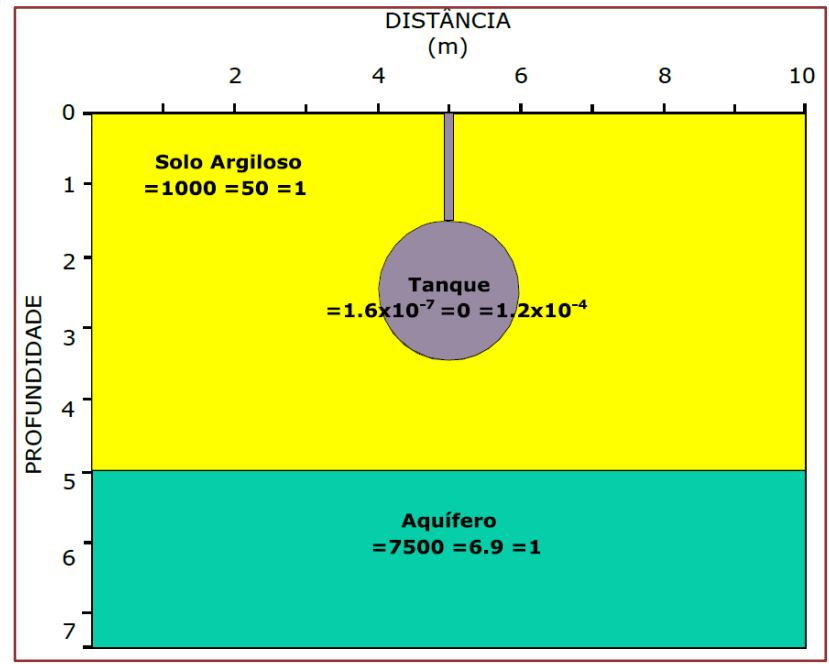

A geometria utilizada para a elaboração dos modelos foi de: $10 \mathrm{~m}$ de longitude e $7.5 \mathrm{~m}$ de profundidade, ver tabela 1. Esta foi dividida em duas camadas geológicas principais, a primeira contendo solo argiloso que vai de $0 \mathrm{~m}$ a $5 \mathrm{~m}$ (Zona Vadosa) e a segunda constituída de material arenoso saturado de $5 \mathrm{~m}$ a $7.5 \mathrm{~m}$ (Zona 
Saturada), o tanque de aço tem um diametro de $2 \mathrm{~m}$, enterrado a uma profundidade de 1.5m (ver figura 1). Também considera- se a existência das fases de contaminação, a residual de $3.1 \mathrm{~m}$ a $5 \mathrm{~m}$, a fase livre de $5 \mathrm{~m}$ a $7.5 \mathrm{~m}$ (ver figura 2) e após a remediação de solo, gerou-se a neoformação de minerais (alteração do material arenoso saturado) e considerou-se essa camada como "solo recuperado" com espessura de aproximadamente $1 \mathrm{~m}$ que va desde $5 \mathrm{~m}$ a $6 \mathrm{~m}$ como se constata na figura 3.

Figura 2: Modelo sintético com as fases de contaminação residual e livre.

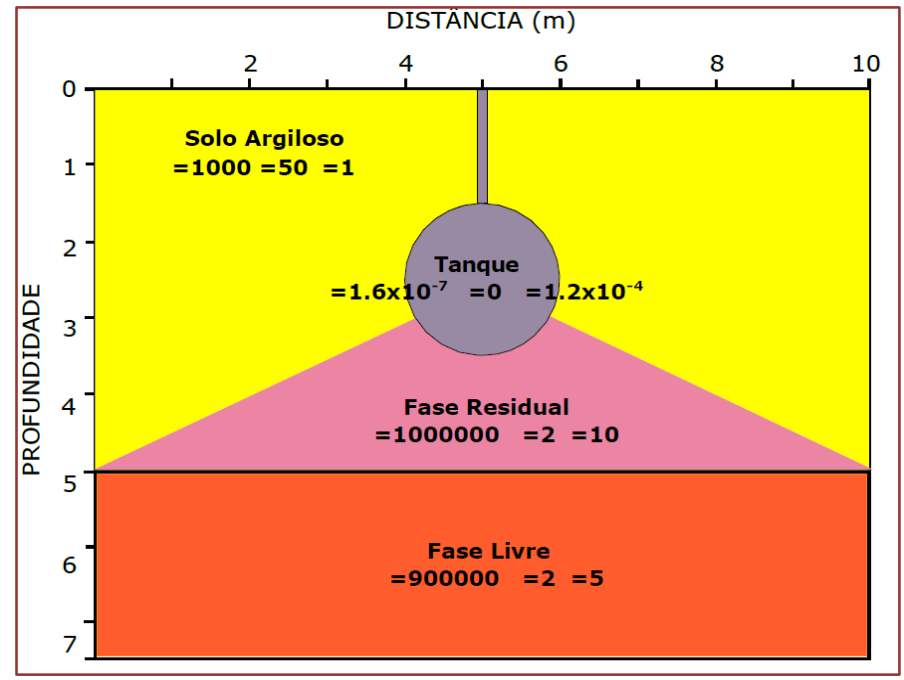

Figura 3: Modelo sintético de solo remediado e neoformação de minerais no material arenoso saturado.

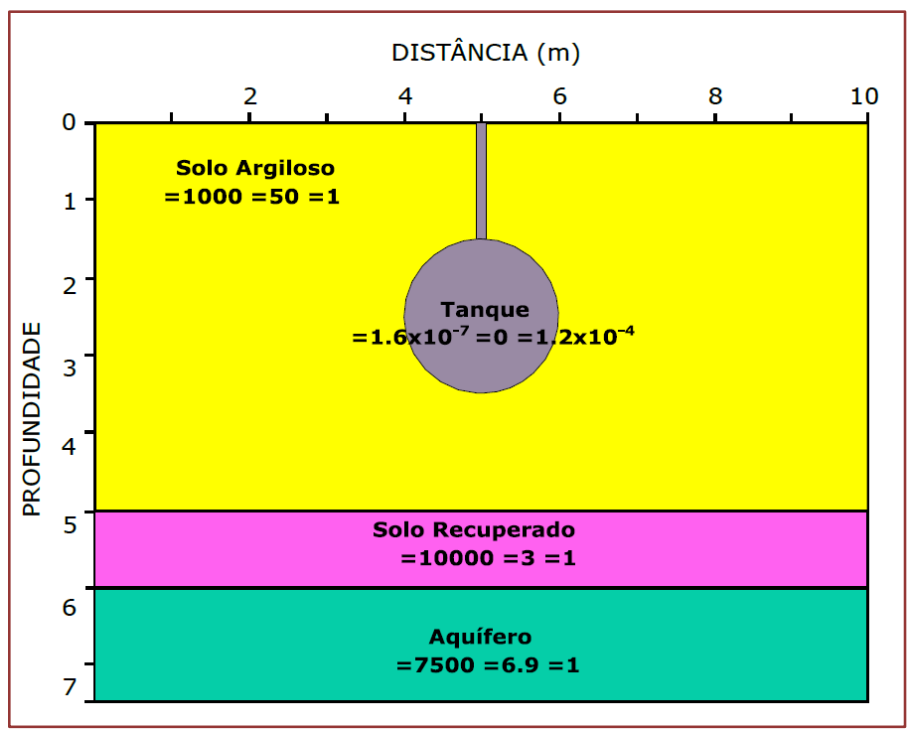

Tabela 1: Valores utilizados na modelagem para os diferentes materiais

\begin{tabular}{|ccc|}
\hline Material & Distância $(\mathrm{m})$ & Profundidade $(\mathrm{m})$ \\
\hline Solo Argiloso & 0 a 10 & 0 a 5 \\
Areia Saturada & 0 a 10 & 5 a 7.5 \\
Tanque & 4 a 6 & 1.5 a 3.5 \\
BTEX (Fase Residual) & 0 a 10 & 3.1 a 5 \\
BTEX (Fase Livre) & 0 a 10 & 5 a 7.5 \\
Recuperação do solo & 0 a 10 & 5 a 6 \\
\hline
\end{tabular}


Baseando-se em Dehaini (2001) os parâmetros elétricos como resistividade, constante dielétrica relativa e a permeabilidade magnética, utilizados na contrução dos modelos tem valores dispostos na tabela 2 . Desde um ponto de vista geofísico, as plumas de contaminação de hidrocarbonetos, possui caraterísticas elétricas resistivas (Atekwana et al. (2000)) o qual foi designado ao modelo 2.

\subsection{SIMULAÇÃO DO MODELO DIRETO}

Uma vez atribuidos os valores aos modelos diretos, obteve-se as seguintes radargramas:

Modelo 1: Antes do vazamento: Na figura 4 observam-se duas hipérboles, uma acentuada a um tempo de 70ns e a outra a 130ns, sendo estas o topo e base do tanque de aço carbono respectivamente. Assim mesmo, na delimitação entre o material argiloso e o material arenoso, tem-se demarcado um refletor a um tempo de $240 \mathrm{~ns}$.

Tabela 2: Valores de resistividade $[\rho(\mathrm{ohm} . \mathrm{m})]$, constante dielétrica $(\varepsilon)$ e permeabilidade magnética $[\mu$ (T.m/A)] de cada material.

\begin{tabular}{|cccc|}
\hline Material & $\rho$ & $\varepsilon$ & $\mu$ \\
\hline Solo Argiloso & 1000 & 50 & 1 \\
Areia Saturada (Aquífero) & 7500 & 19 & 1 \\
Aço Carbono (Tanque) & $1.6 \times 10^{-7}$ & 0 & $1.2 \times 10^{-4}$ \\
BTEX (Fase Residual) & 1000000 & 2 & 10 \\
BTEX (Fase Livre) & 900000 & 2 & 5 \\
Recuperação do solo & 10000 & 3 & 1 \\
\hline
\end{tabular}

Figura 4: Radargrama antes da contaminação com antena de $250 \mathrm{MHz}$

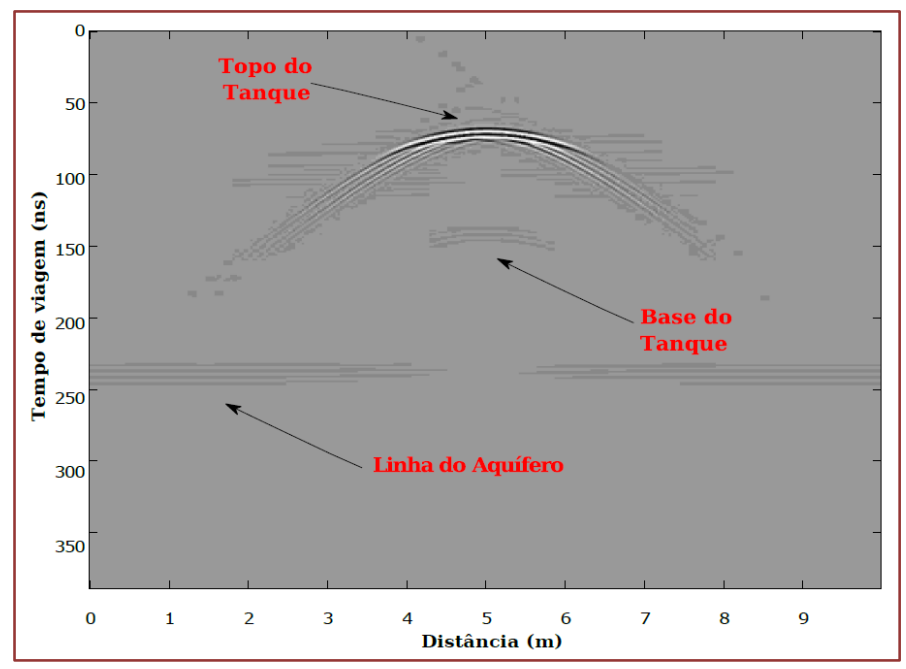

Modelo 2: Contaminação do solo - aquífero: Observou- se no radargrama a presença de uma zona sombra em lugar do refletor a 240ns, atenuando quase totalmente a interface entre o material argiloso e o aquífero. ver figura 5. 
Figura 5: Radargrama após a contaminação e identificação da zona de sombra.

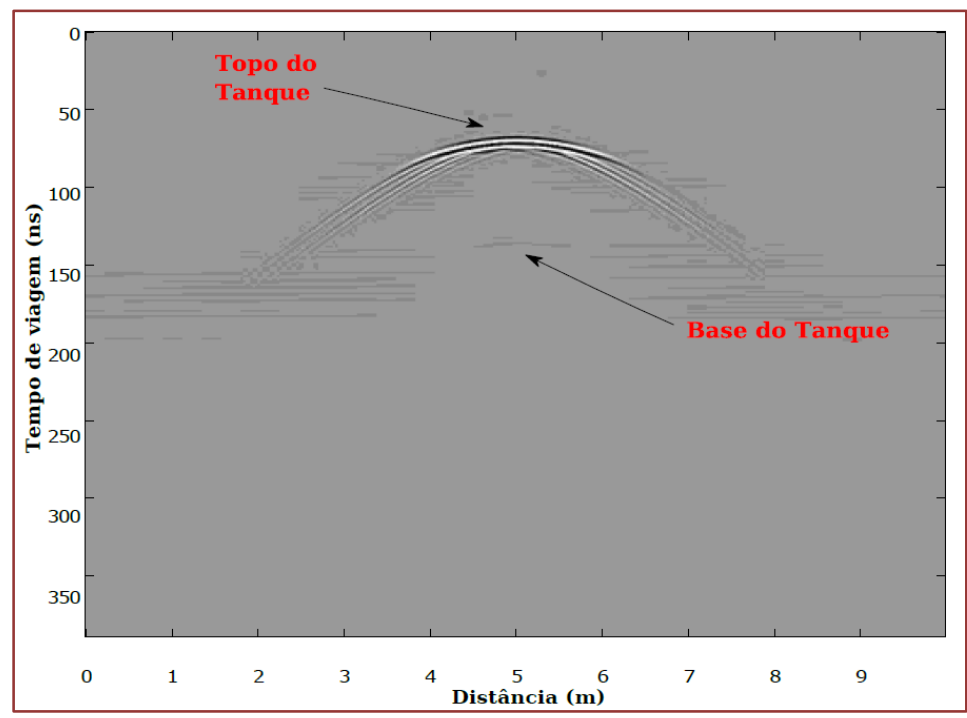

Modelo 3 - Remediação do solo: Neste radargrama observa-se o retorno do refletor entre um tempo de $240 \mathrm{~ns}$ e $250 \mathrm{~ns}$, correspondente a interface entre a argila e o aquífero recuperado com a neoformação dos minerais. Ver figura 6

Figura 6: Radargrama após a remediação do solo e interface do material arenoso saturado com neoformação dos minerais

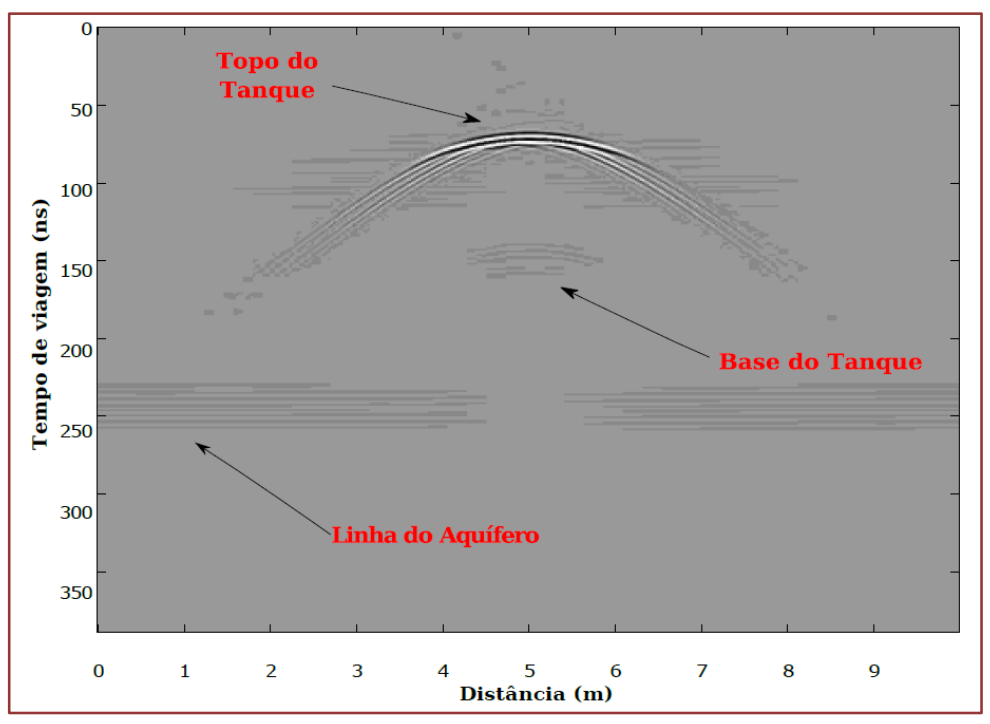

Segundo Chelmus (2016), a validação da interpretação dos radargramas usando a modelagem e simulação de propagação da onda eletromagnética de objetos enterrados e estratigrafias, pode ser utilizada na ausência de dados adquiridos in situ, a fim de entender melhor a propagação da onda em ambientes complexos. Neste trabalho, pretendeu-se verificar se após a remediação do solo, o ambiente geológico recupera as propriedades físicas como se este não tivesse sido contaminado antes.

Muitas vezes, a falta de monitoramente das propriedades físicas e análise do comportamento da onda EM do solo antes da implementação do posto, facilitaria de forma rápida o monitoramento após uma possível contaminação, tal como a delimitação, distribução, direção do fluxo dos contaminantes, dessa forma, evitaria-se a perfuração de excessivos poços de monitoramento. 


\section{RESULTADOS}

Foram realizados testes con antenas de $100 \mathrm{MHz}$ e $250 \mathrm{MHz}$ (figura 7) e quem proporcionou melhores resultados foi a de $250 \mathrm{MHz}$ provavelmente devido ao fato desta apresentar melhor resolução do que a de $100 \mathrm{MHz}$. Neste caso há a necessidade de avaliar a relação "resolução x profundidade", pois as seções produzidas pela antena de $100 \mathrm{MHz}$ apresentam zona de sombra de forma mais sutil que a antena de $250 \mathrm{MHz}$, ver figuras $8 \mathrm{a}$ e $8 \mathrm{~b}$.

Figura 7: Comparação do modelo antes da contaminação a) antena de $100 \mathrm{MHz}$ e b) antena de $250 \mathrm{MHZ}$

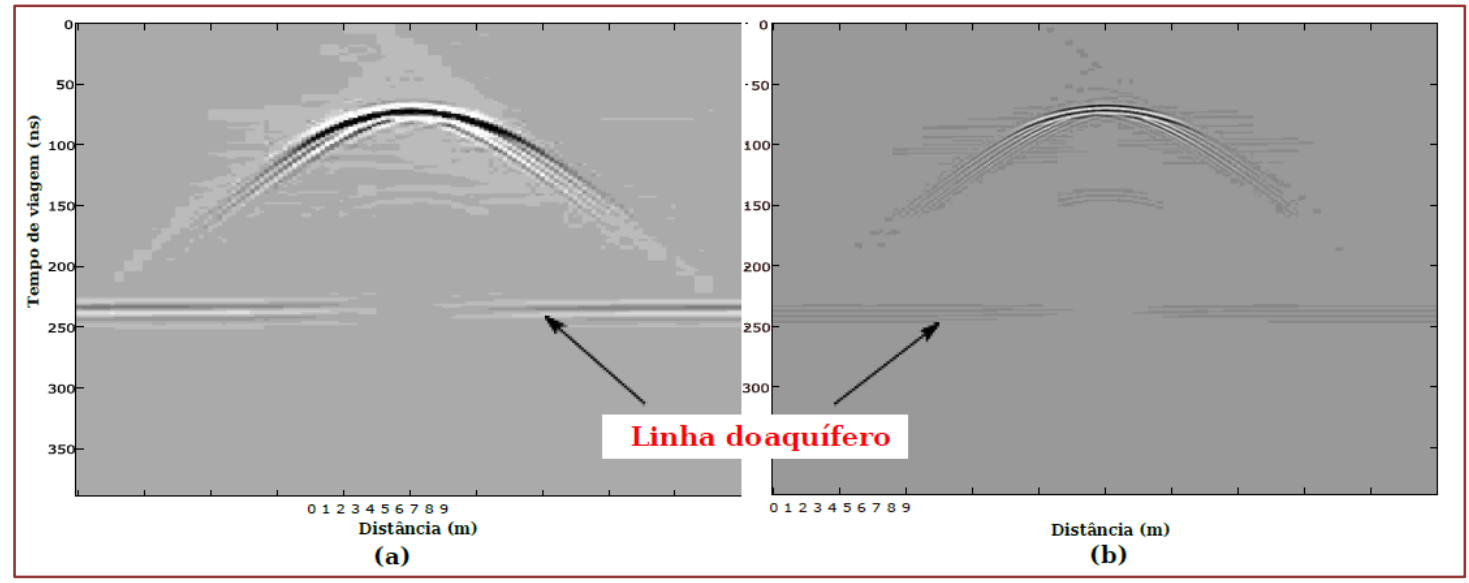

Notou-se também a ausência de reflexão logo abaixo do tanque de aço, denominada de zona de sombra ou shadow zone, e corresponde a atenuação da amplitude do sinal provocada pela alta condutividade do meio aparentemente devido aos produtos e subproductos da biodegradação de hidrocarbonetos. Esta zona de sombra atenuou-se quase por completo a uns 240ns, como mostra a figura 8, este fato é explicado por Moreira and Dourado (2007), Dehaini (2001) Rodrigues and Porsani (2006).

Pode-se entender a razão entre o aumento da condutividade elétrica e a evidência da zona de sombra, posto que, a medida que a remediação do solo se leve a cabo ao longo dos anos, a disperção dos contaminantes iônicos aumente e a degradação dos hidrocarbonetos por ação da bactérias incrementes nas diferentes fases de contaminação, isso reflete diretamente no parâmetro físico da condutividade, realçando ou atenuando o refletor (ver figura 9), permitindo assim um monitoramente ao longo da remediação.

Figura 8: Comparação do modelo com as fases de contaminação a) antena de $100 \mathrm{MHz}$ e b) antena de 250MHZ. Atenuação da onda EM devido à biodegradação do hidrocarboneto

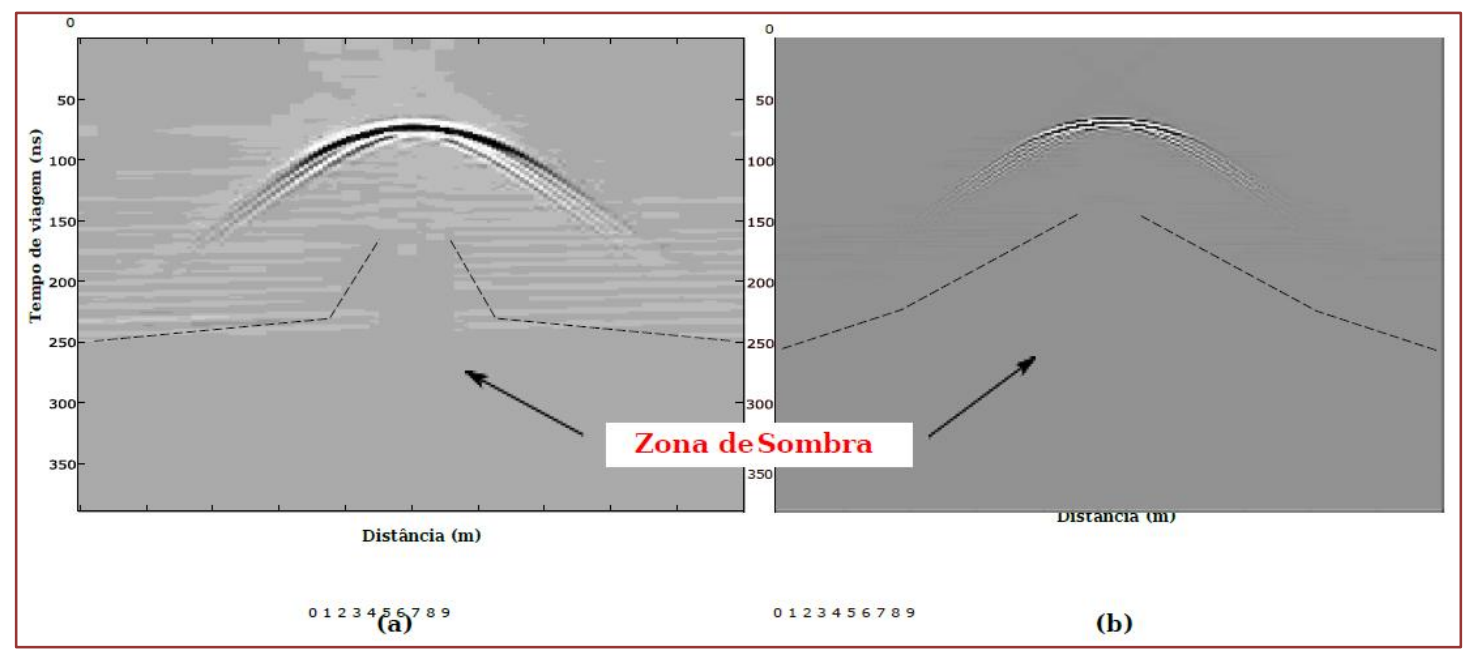


Figura 9: Comparação do modelo com solo remediado e realce do refletor a) antena de $100 \mathrm{MHz}$ e b) antena de $250 \mathrm{MHZ}$

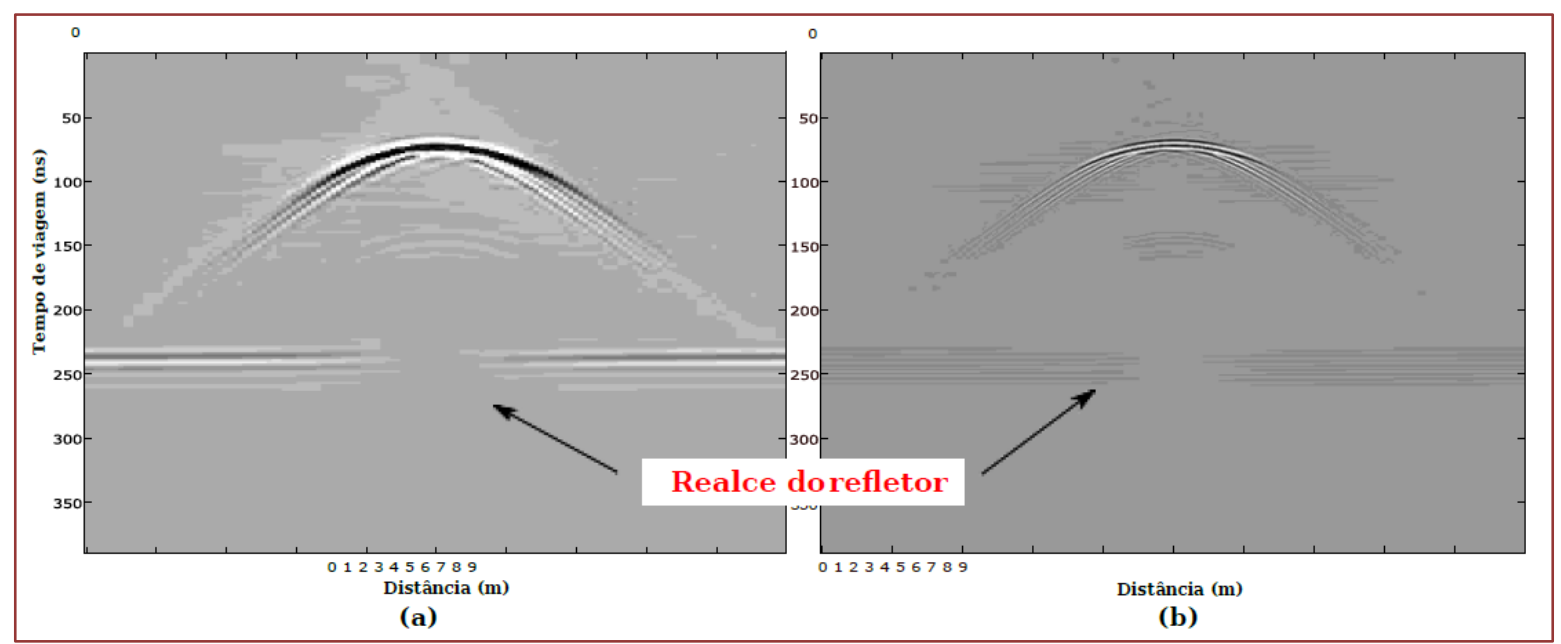

Neste trabalho teve-se como objetivo a análise de monitoramento antes de um possível vazamento, avaliando os diferentes ambientes geológicos sem a presença do hidrocarboneto. Este comportamento foi visualizado na figura 4. Para o segundo modelo, segundo Dehaini (2001), e Moreira and Dourado (2007), a zona de sombra no radargrama é causada pelos componentes do BTEX (figura 5) e após a remediação da pluma de contaminação, ao longo de 5 a 10 anos, a zona de sombra diminui ressaltando o material geológico original, pode-se dizer que zonas insentas de contaminação apresentam a formação do refletor. Isso foi constatado no modelo 3 na figura 6, visualizando o refletor entre o solo argiloso e o material arenoso saturado com neoformação de novos minerais, causado também pelos agente químicos, biológicos e físicos agindo no solo. 0 refletor mostrado a 240ns assemelha-se ao modelo original. Também, fez-se o experimento com 2 diferentes antenas (100 e $250 \mathrm{MHz}$ ) e a diferentes profundidades, obteve-se em ambos os modelos a zona de sombra, ver figura 5 e 8, sendo mais evidente na antena de $250 \mathrm{MHz}$ por conta da resolução/produndidade. Com isso, conseguiu- se avaliar a aplicabilidade do GPR ante situações de monitoramento conforme o exemplo de dado real de Dehaini (2001) e além disso avaliar o solo antes de este ser contaminado e constatar que além do controle pontual dos poços de monitoramento do posto, pode-se monitorar a extensão lateral e vertical de forma gradual e rápida, auxiliando assim no controle da qualidade da água. Tem-se também como preocupação a profundidade dos poços de monitoramento, que muitas vezes é inferior à profundidade das plumas dos contaminantes, dificultando assim a delimitação vertical do poluente. Desta forma, com o monitoramento por GPR, e a escolha da antena adequada, tornaria-se a melhor o controle do mesmo.

\section{REFERÊNCIAS}

[1] Atekwana, E. A., W. A. Sauck, and D. D. Werkema, 2000, Investigations of geoelectrical signatures at a hydrocarbon contaminated site: Journal of Applied Geophysics, 44, 167 - 180.

[2] Chelmus, A., 2016, Validation of ground penetrating radar data interpretation using an eletromagnetic wave propagation simulator: Romanian Reports in Physics, 68, 1584-1588.

[3] de Castro, D. L., and R. M. G. C. Branco, 2003, 4-d ground penetrating radar monitoring of a hydrocarbon leakage site in fortaleza (brazil) during its remediation process: a case history: Journal of Applied Geophysics, 54, 127 -144 .

[4] Dehaini, J., 2001, Detecção da pluma de contaminação de hidrocarbonetos em subsuperfície pelo método de radar de penetração: Dissertação de mestrado, Universidade de São Paulo.

[5] Fetter, C., 1993, Contaminant hydrogeology: Contaminant hydrogeology.

[6] Lima, R. M. S., 2010, Avaliação de risco à saúde humanadecorrentes dacontaminação da Água subterrânea por btex provenientes de postos de revenda de combustíveis em manaus: Dissertação de mestrado, Universidade Federal do Amazonas.

[7] Mello, J. M. M., 2007, Biodegradação dos compostos btex em um reator com biofilme: Dissertação de mestrado, Universidade Federal de Santa Catarina. 
[8] Moreira, C., and J. C. Dourado, 2007, Monitoramento da atenuação natural de pluma de contaminação élo método de radar de penetração no solo (GPR): Revista Brasileira de Geofísica, 25, 389 - 398.

[9] Penner, G. C., 2005, Estudo de caso da contaminação do solo e da água subterrânea por descarte de resíduos vinculados a óleos lubrificantes: Dissertação de mestrado, Universidade de São Paulo.

[10] Prommer, H., G. Davis, and D. Barry, 1999, Pht3d-a three-dimensional biogeochemical transport model for modelling natural and enhanced remediation. contaminated site remediation: Challenges posed by urban and industrial contaminants: 351-358.

[11] Rodrigues, S. I., and J. L. Porsani, 2006, Utilização do GPR para caracterizar tambores plásticos enterrados no sítio controlado de Geofísica rasa do IAG/USP: Revista Brasileira de GeofÃsica, 24, 157 - 168.

[12] Tiburtius, E. R. L., P. Peralta-Zamora, and E. S. Leal, 2004, Contaminação de águas por BTXs e processos utilizados na remediação de sítios contaminados: Química Nova, 27, 441 - 446. 


\title{
Capítulo 17
}

Royalties de petróleo e municípios paulistas confrontantes no contexto da sustentabilidade integral

\author{
Hirdan Katarina de Medeiros Costa \\ André Felipe Simões \\ Edmilson Moutinho dos Santos \\ Paulo Santos de Almeida \\ Homero Fonseca Filho \\ Ednílson Viana
}

Resumo: Em 2013, a Lei 12.858 tornou obrigatória a destinação da participação no resultado da compensação financeira pela exploração de petróleo e gás natural para as áreas de educação (75\%) e de saúde (25\%). No entanto, quais os programas e projetos nas áreas da educação, inclusive a básica, e de saúde, que atenderiam a população dos municípios beneficiários? Para responder a esta questão, o artigo desenvolve a ideia de unicidade e de completude da espécie humana, que corresponde à cumulatividade da experiência humana sobre a Terra. A efetivação de direitos fundamentais é o mecanismo de concretização dessa ideia. Assim, realizou-se estudo de caso pautado nos municípios paulistas confrontantes: Bertioga, Cananéia, Caraguatatuba, Cubatão, Guararema, Iguapé, Ilha Comprida, Ilha Bela, Peruíbe, Pindamonhangaba, Praia Grande, São Sebastião, São Vicente, Ubatuba. Considerando as características de cada comunidade, o estudo apresenta sugestões de mapeamento dos quadrantes para solucionar questionamentos sobre como direcionar as rendas de hidrocarbonetos em projetos nas áreas da educação (inclusive a básica), e de saúde, de modo a atender a integralidade humana. 


\section{INTRODUÇÃO}

O historicamente elevado patamar de consumo de petróleo e gás natural por parte da sociedade globalizada e a inevitável exaustão das reservas desses hidrocarbonetos (cotejando-se cenários de médio e longo prazo, em especial) circunscreve diversos dilemas de cunho estrutural. Nesse contexto e na perspectiva da esfera municipal, o fim de um fluxo específico de receitas e de riquezas pode ocasionar a estagnação da economia local. A sustentabilidade dessa riqueza ao longo do tempo é uma premissa fundamental colocada para a gestão local. Ademais, para determinados municípios, a oportunidade de perceber receitas pode significar, no presente, um alavanco na qualidade de vida e no incremento de direitos fundamentais.

Em 2013, o Congresso Nacional, por meio da Lei 12.858, tornou obrigatória a destinação da participação no resultado da compensação financeira pela exploração de petróleo e gás natural (rendas petrolíferas1) para as áreas de educação (75\%) e de saúde (25\%), bem como determinou configuração semelhante para $50 \%$ dos recursos do Fundo Social. Intui-se que, em princípio, essa Lei encerra grandes conquistas no sentido de aumento das possibilidades de a sociedade brasileira alcançar a efetivação de direito fundamentais e de incrementar as capacidades da sustentabilidade integral nas localidades beneficiadas. No entanto, quais os programas e projetos nas áreas da educação, inclusive a básica e de saúde, que de fato atenderiam aos preceitos da sustentabilidade integral ${ }^{2}$ ? Sem dúvida, a resposta para essa pergunta envolve considerações particulares a respeito de cada localidade beneficiada. Nesse contexto, o presente trabalho delineia argumentos para basear ou recomendar respostas, assim como direcionar a fiscalização necessária pelos órgãos públicos competentes e pela população local.

Além de ampla revisão da literatura e de análise da legislação específica, a metodologia utilizada para atingimento do objetivo do presente trabalho é constituída pela aplicação ao estudo de caso, da ferramenta qualitativa relativa aos quadrantes da estrutura da Teoria Integral para ser aplicada ao contexto da sustentabilidade (Brown, 2011).

Esses quadrantes representam lentes da realidade para o entendimento mais adequado de qualquer acontecimento; eles revelam as dinâmicas e as forças interiores e exteriores que compõe os indivíduos e a coletividade. Também, utilizou-se as ferramentas matriz de necessidade e de nível de vida e a espacialização do desenvolvimento (Souza, 2002).

Os municípios estudados3, à exceção de Pindamonhangaba, se enquadram como Estâncias Balneárias: Bertioga, Cananéia, Caraguatatuba, Iguapé, Ilha Comprida, Ilhabela, Peruíbe , Praia Grande, São Sebastião, São Vicente, Ubatuba. Construíram-se quadrantes para cada (e para dentro de cada) localidade considerando o respectivo nível de educação (infantil, básica, fundamental, técnica, especializada) e de prestação de atendimento hospitalar e médico (atendimentos de urgências ou rotinas, posto de saúde,

\footnotetext{
2 A sustentabilidade integral objetiva expandir o alicerce do debate sobre sustentabilidade. De modo geral, as visões sobre a sustentabilidade privilegiam sistemas objetivos e coletivos, tais como modelos de geração e de acumulação de renda, as trocas diversas entre os 4 grandes compartimentos ecossistêmicos (quais sejam: a água, o ar, o solo e a biota) e modelos de organização social e formas produtivas. Tais perspectivas carreiam, implícita ou explicitamente, a visão de que a sustentabilidade é apenas uma questão de adequação sistêmica: sistemas produtivos menos impactantes e um sistema econômico menos desigual. A importância destes aspectos jamais pode ser negada, mas não esgotam a questão. 0 pensador Ken Willber, criador da Psicologia Transpessoal, resumindo o conceito central de uma sustentabilidade integral, afirma que o principal problema socioambiental do planeta não é a expansão acintosa das desigualdades sociais, nem o avanço das mudanças climáticas globais (ou de seu mais proeminente fenômeno, ou seja, o aquecimento global), não é o modelo energo-intensivo de produção industrial, nem mesmo o declínio dos ecossistemas. Para Wilber, o principal problema socioambiental do planeta é que existem muito poucos seres humanos capazes de pensar sobre a complexidade desses problemas e de manter uma ética de vida com uma perspectiva de bem-estar global (WILBER, 2001).

3 Os municípios estudados se enquadram como beneficiários de participação governamental ou renda petrolífera nos termos do $\S 1$ ọ, do art. 20 da Constituição Federal de 1988: "É assegurada, nos termos da lei, aos Estados, ao Distrito Federal e aos Municípios, bem como a órgãos da administração direta da União, participação no resultado da exploração de petróleo ou gás natural, de recursos hídricos para fins de geração de energia elétrica e de outros recursos minerais no respectivo território, plataforma continental, mar territorial ou zona econômica exclusiva, ou compensação financeira por essa exploração." Posteriormente, a Lei 7.990/89 tratou de regular esse direito nos seguintes termos: "§ 4o É também devida a compensação financeira aos Estados, Distrito Federal e Municípios confrontantes, quando o óleo, o xisto betuminoso e o gás forem extraídos da plataforma continental nos mesmos $5 \%$ (cinco por cento) fixados no caput deste artigo, sendo 1,5\% (um e meio por cento) aos Estados e Distrito Federal e 0,5\% (meio por cento) aos Municípios onde se localizarem instalações marítimas ou terrestres de embarque ou desembarque; (...)."
} 
cirurgias). Os dados para compor esse mapeamento foram obtidos a partir da revisão de literatura sobre o tema e do Instituto Brasileiro de Geografia e Estatística (IBGE).

\section{METODOLOGIA: APLICABILIDADE DA SUSTENTABILIDADE INTEGRAL EM POLÍTICAS PÚBLICAS}

Esse trabalho parte da premissa de que o exame das características, das necessidades e das potencialidades territoriais deve ser um caminho para a realização da despesa e do investimento públicos. Nesse sentido, faz-se necessário elucidar os principais elementos da metodologia em relação à análise institucional do Poder Executivo Municipal, baseada na matriz de necessidade, na espacialização do desenvolvimento e na sustentabilidade integral.

A matriz de necessidades é uma metodologia utilizada por Souza $(2002,2009)$, direcionada ao estudo da desigualdade com base numa reflexão geográfica. Para a referida autora a desigualdade emerge a partir de uma dinâmica existente no mundo, e chega ao lugar através das modernizações.

Entende-se que as inovações tecnológicas para extração e beneficiamento do petróleo, graças à Petrobras, são modernizações presentes no território nacional que tem gerado receitas aos municípios produtores e/ou beneficiários. Entretanto, a não aplicação coerente das rendas para as reais demandas da população pode acirrar as desigualdades sociais nos municípios, bem como aumentar a dependência da econômica local a um recurso exaurível.

Neste sentido, Souza (2009) propõe o estudo da desigualdade pela Ciência Geográfica, a partir de uma visão do território, ou seja, compreender o funcionamento do território para fundamentar as prioridades de investimento, bem como pensar as políticas públicas integradas e voltadas a atender as necessidades crescentes das populações. Dentro desse viés proposto por Souza (2009), retoma-se também a noção de sustentabilidade integral (ALOE, 2010) e os seus quatro módulos ou dimensões de forma a propor a reflexão sobre se as políticas públicas devem abarcar essa complexidade das relações entre os indivíduos e do indivíduo entre o mundo.

A sustentabilidade integral incorpora quatro dimensões: (1) a social; (2) a ambiental; (3) a econômica; (4) e a mais integradora e holística, qual seja, a visão de mundo. Seu conceito central, seu cerne filosófico aponta que o ser humano precisa saber se socializar, cuidar do meio ambiente, da economia, do planeta, da água, da natureza e dos animais (ALOE, 2010, p. 01). Na dimensão visão de mundo, por exemplo, Aloe (2010, p. 01) afirma que a ideia é a reaproximação do ser humano com a comunidade, com o entorno natural e social.

Da simplicidade da abordagem de Aloe (2010), pode-se partir para os quadrantes da estrutura da Teoria Integral desenvolvida por Ken Wilber (2001), para ser aplicada ao contexto da sustentabilidade. Esses quadrantes representam lentes da realidade para o entendimento mais adequado de qualquer acontecimento; eles revelam as dinâmicas e as forças interiores e exteriores que compõe os indivíduos e a coletividade (BROWN, 2004, 2005 e 2011). Seriam as forças centrípetas e centrífugas que levam ao centro referenciadas por Egmond e Vries (2011). Juntos, os quadrantes oferecem a visualização de um mapa das perspectivas psicológicas, comportamentais, culturais e sistemáticas.

Brown (2004) desenvolve argumento no sentido de que os quadrantes oferecem três chaves para a prática de sustentabilidade: organizar a informação para o desenvolvimento da prática da sustentabilidade, diagnosticar os desafios a serem enfrentados, e prescrever a solução integrada dentro da maior quantidade de dinâmicas em jogo.

De acordo com Brown (2011, p. 04), os quadrantes servem como uma ferramenta para enxergar a dinâmica por trás de todo um cenário macro. Cada quadrante representa uma das quatro perspectivas universais, que não somente estão disponíveis para cada ser humano, mas também são comumente observadas e mais facilmente replicáveis (ver Tabela 1). 
Tabela 1: Quadrantes da sustentabilidade integral para preenchimento

\begin{tabular}{|c|c|c|}
\hline Influências psicológicas & & Influências Comportamentais \\
\hline Individual-Interior: Identificação da & & Individual-Exterior: cérebro e organismo; Ações \\
\hline personalidade e Consciência & & O objetivo, a realidade externa de um indivíduo \\
\hline O subjetivismo, a realidade interna c & um & Contexto: \\
\hline indivíduo & & Exemplos de áreas abordadas: \\
\hline Contexto: & & Ferramentas para a transformação: \\
\hline Exemplos de áreas abordadas: & & \\
\hline & Eu & Ele \\
\hline & Nós & Eles \\
\hline Influências culturais & & Sistemas de Influências \\
\hline Coletivo-Interior: culturas e visões d & mundo & Coletivo-Exterior: Sistemas Sociais e Ambientes \\
\hline $\begin{array}{l}\text { O intersubjetivismo, realidades } \\
\text { grupos }\end{array}$ & ternas dos & $\begin{array}{l}\text { O interobjetivismo, as realidades externas de } \\
\text { grupos }\end{array}$ \\
\hline Contexto; & & Contexto; \\
\hline Exemplos de áreas abordadas; & & Exemplos de áreas abordadas; \\
\hline Ferramentas para a transformação & & Ferramentas para a transformação \\
\hline
\end{tabular}

Fonte: Costa (2018) a partir de Brown (2011).

Para tornar mais palpável suas ideias, Brown (2011, p. 07) usa o exemplo de uma mulher que tem o objetivo de segregar resíduos recicláveis e passa a olhá-la pela ótica de cada quadrante, enunciado na Tabela 1. Assim, através de sua prática individual, subjetiva, a experiência da mulher pode ser direcionada aos sentimentos de orgulho e de senso de dever cumprido; na perspectiva da realidade exterior da mulher, de sua influência comportamental, pode-se enxergar seu ato físico de colocar garrafas de plásticos em containers específicos. Em termos de visão de mundo, aspecto cultural, a atitude da mulher manifesta os valores sociais que a encorajam a tomar a responsabilidade pelos resíduos que produz e a proteger os recursos naturais. No último quadrante, referente ao aspecto exterior da coletividade, ou seja, aos sistemas criados pela sociedade que a mulher vive. A atitude da mulher pode ser vista como uma forma de expansão para criação de sistemas econômicos e de transporte capazes de tornar a coleta seletiva uma opção financeira viável para a comunidade dela (COSTA, 2018).

Dessa forma, Brown (2011, p. 07) explica que cada quadrante da Tabela 1 oferece quatro distintas perspectivas do mesmo mundo. A primeira traz a dimensão psicológica; a segunda apresenta a dimensão cultural; a terceira mostra a dimensão comportamental e física; e a quarta perspectiva observa a dimensão de sistemas sociais e ambientais. A sustentabilidade integral teria , portanto, que enxergar cada dimensão da realidade, identificar e responder às dinâmicas que estão por detrás e que afetam determinada iniciativa (por exemplo, política pública, planejamento e gestão de atividades coletivas).

Na dimensão coletiva-exterior, encontra-se o território, que inclui pessoas, empresas, instituições e materialidade (natureza e objetos criados pelo homem). A partir desse quadrante, pode-se apontar a convergência com a matriz de necessidade e a espacialização do desenvolvimento, pois os diferentes usos que o homem faz do território, como moradia, trabalho, ação das empresas e do Estado, revela as desigualdades resultantes do próprio território. Dessa forma, é possível se correlacionar a matriz de necessidade, a espacialização do desenvolvimento e as quatro dimensões da sustentabilidade integral (COSTA, 2018).

Para entender melhor a propositura de uma matriz de necessidades, Souza (2009) adentra na representatividade do território, lugar em que o cidadão está inserido e que deverá englobar todas as demandas necessárias à sua existência, componentes das dimensões da sustentabilidade integral. Este é o diferencial da matriz de necessidades: pensar no cidadão que mora e vive naquele território. Essa matriz não se encerra em si, ela pode ser expandida, o que se aproxima cada vez mais da noção de sustentabilidade integral e do discurso dos direitos fundamentais; ressaltando-se que o princípio da justiça intra e intergeracional (PJI\&IG) abrange todos esses conceitos (COSTA, 2012).

A necessidade de asfalto (pavimentação), por exemplo, traz o sentido de fluidez de locomoção, que equivale também ao incremento de relações sociais, além de retomar a importância do saneamento básico, 
da drenagem de água e da conservação e da preservação do ambiente que circunda a localidade, cujo tema envolve a gestão no ambiente do território (COSTA, 2018).

0 enfoque da matriz de necessidade é verificar as particularidades de cada localidade, considerando que apesar do contexto global, o fator relevante para o desenvolvimento do cidadão se encontra fundamentalmente no território local. Por esse motivo, as necessidades não podem apenas ser listadas, "precisam ser mapeadas, cartografadas," com o objetivo de se ter uma visão socioespacial (SOUZA, 2002, p. 09). A autora, também, adota o cotejo da matriz dos elementos do nível de vida, em que os níveis básicos (biológicos, sanitários, domésticos, residenciais, etc.), níveis sociais (culturais, familiares, de sociabilidade, vida cívica, vida municipal, ético, espiritual), e as particularidades do urbano são examinados para se formar uma matriz de necessidade e de nível de vida (SOUZA, 2002, p. 09).

Dessa forma, é importante refletir sobre o papel a ser desempenhado pelo poder público enquanto gestor dos recursos financeiros necessários para a assunção de políticas públicas definidas em um plano que deve conter elementos, os quais: (i) efetivem direitos fundamentais; (ii) assegurem resposta às demandas básicas e ao nível de vida apresentadas pela comunidade; (iii) proponha o repensar e expansão do uso e da sustentabilidade econômica da localidade, que é o desenvolvimento das potencialidades do território, denominado por Souza (2002) de espacialização do desenvolvimento; (iv) somados à visualização da relevância de preservação e conservação do ambiente que o circunda.

Assume-se que a matriz de necessidade e de nível de vida e a espacialização do desenvolvimento possuem conteúdos correlatos à concretização de direitos fundamentais e da sustentabilidade integral, com respaldo em enxergar as demandas de determinadas populações, dentro da particularidade de respeitar as diversidades existentes no mundo, o que inclui o relacionamento homem-natureza. Assim, entende-se que mapear o perfil socioespacial, através da matriz de necessidade e de nível de vida, e o socioeconômico, por meio da espacialização do desenvolvimento, é um caminho para oferecer ferramentas para a realização de políticas públicas ou programas direcionados para a efetivação de direitos fundamentais (COSTA, 2018).

\section{RESULTADOS E DISCUSSÃO: O CASO DOS MUNICÍPIOS SELECIONADOS DA BACIA DE SANTOS}

A proposta desse estudo, a partir do referencial teórico da sustentabilidade integral, portanto, passa por transformar a realidade a partir do indivíduo, que expande sua consciência e se aprimora para enxergar como sua atuação diária impacta na localidade. Propõem-se como força-motriz embrionária o delineamento e a promoção de uma educação que alcance os aspectos psicológicos, comportamentais, culturais e sistemáticos da sociedade. Saindo do Eu para o Nós, assim como migrando do Ele para os Eles (COSTA, 2018).

O indivíduo ressoa através de sua essência (personalidade) para entender como se socializar consigo, com os outros, e com a natureza. Ao entender que faz parte da natureza, o indivíduo se vê como agente da mudança com capacidade de escolher diariamente o que consumir e como consumir, de modo a respeitar o planeta, a si mesmo e aos outros. Um indivíduo que entende que cada uma de suas atitudes reflete no todo, que faz parte de uma coletividade, e que é consciente da alteração que pode provocar na comunidade.

As políticas públicas, em regra, alcançam a perspectiva exterior, pretendem abranger as realidades externas dos diversos grupos que compõem determinada comunidade, traçando diretrizes para fundamentar as prioridades de investimento. $\mathrm{Na}$ área de educação e de saúde, boa parte das políticas se refere ao acesso dos indivíduos ao sistema, sem se preocupar com os quadrantes das influências psicológicas, comportamentais, e das visões de mundo.

Hodiernamente, pensar as políticas públicas integradas e voltadas a atender outros tipos de necessidades crescentes de cada indivíduo passa a ser fundamental quando se começa a observar cada vez mais a relevância e eficácia de determinados métodos de cura, delineados dentro de outras visões de mundo diferentes da institucionalizada em hospitais e postos de saúde.

Assim, após essas ponderações, o presente trabalho traça alguns exemplos dessas ideias a partir das cidades escolhidas no estudo de caso. Primeiramente, julgou-se oportuno mapear as informações socioeconômicas e geográficas dos municípios em questão.

Como já salientado, boa parte dos municípios fazem parte da zona litorânea, com economias pautadas substancialmente no turismo (setor de serviços), e no extrativismo (pesca). Exceções como Cubatão e Pindamonhangaba, por sua feita, encerram pujante base industrial (ver Figura 1, a seguir). 
Figura 1: Litoral Paulista e subdivisões: Litoral Sul, Baixada Santista e Litoral Norte

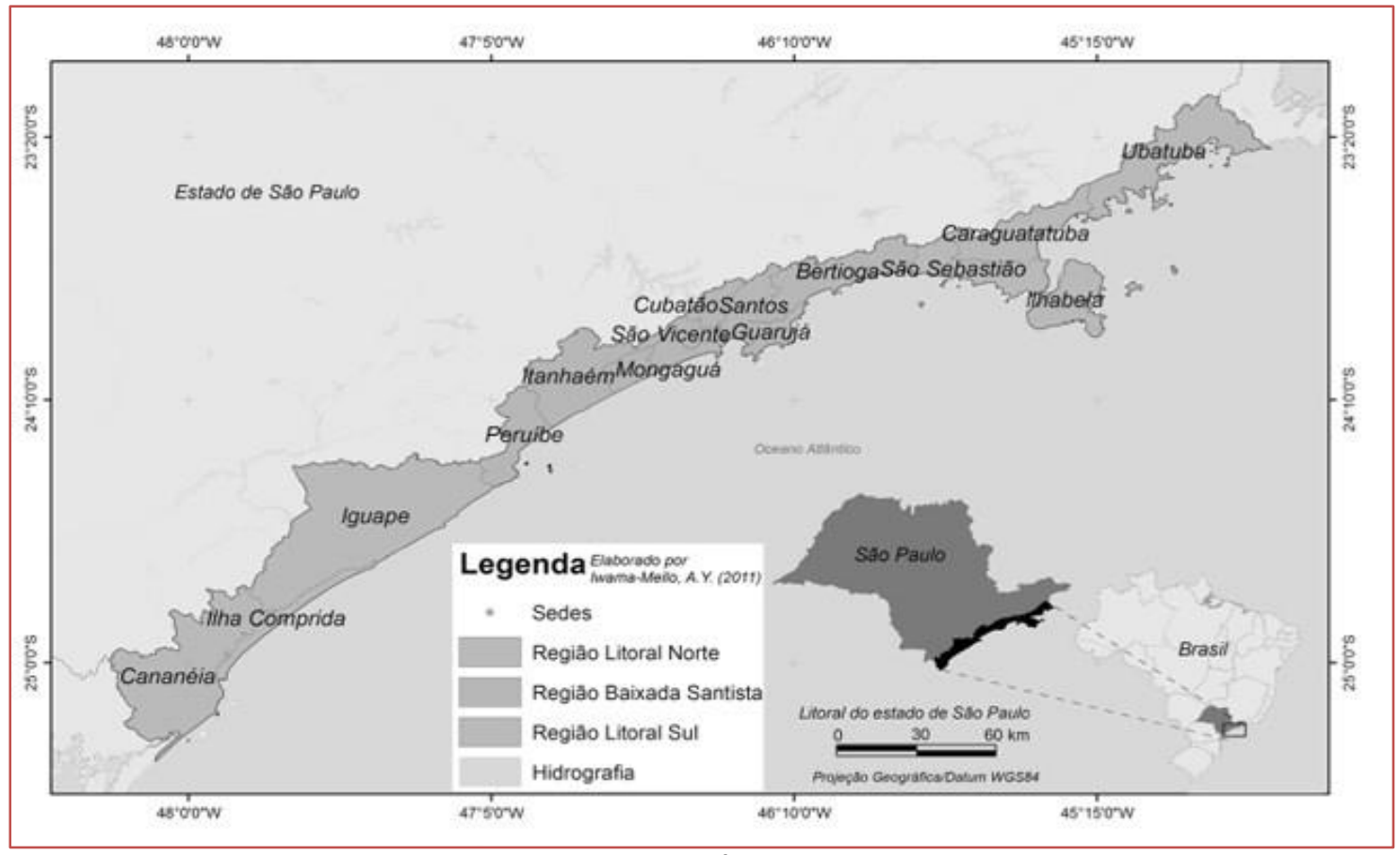

Fonte: IWAMA-MELLO, A. Y., TOMÁS, L. R. e D'ANTONA, A (2001)

Ademais, os municípios selecionados apresentam IDH-M elevado, principalmente, comparativamente, a outras regiões do próprio Estado de São Paulo. Em termos ambientais, a maioria, por estar no bioma Mata Atlântica, apresenta grande biodiversidade. Culturalmente, são localidades de grande tradição caiçara.

A maior parte dos municípios estudados se enquadram como Estâncias Balneárias: Bertioga, Cananéia, Caraguatatuba, Iguapé, Ilha Comprida, Ilhabela, Peruíbe, Pindamonhangaba (exceção à regra), Praia Grande, São Sebastião, São Vicente, Ubatuba.

Considerando-se as características de cada comunidade, o presente estudo apresenta sugestões de mapeamento dos quadrantes para equacionar o direcionamento das rendas de hidrocarbonetos em projetos nas áreas da educação, inclusive a básica, e de saúde dentro dos argumentos expostos no item 2 a partir do caso de Bertioga (Tabela 2).

A Tabela 2 mostra de forma genérica um programa para atuação na área de educação ambiental no nível básico no município de Bertioga. Salienta-se que, o presente estudo, acredita no potencial de discussão, de diálogo e de participação popular na construção e contínua expansão do desenvolvimento das questões que envolvem cada um desses quadrantes (COSTA, 2018).

Como se nota na Tabela 2, os pontos são gerais e podem ser expandidos com a participação popular, o que pode tornar um programa educacional um grande suporte para a transformação ampla, do indivíduo ao coletivo (COSTA, 2018).

Muitos dos aspectos citados na Tabela 2 precisam ser tratados de forma integral. Assim, o que essa ferramenta dos quadrantes propõe é olhar o grande cenário por detrás de questões simples, como calçadas sujas, garrafas pet jogadas em todos os locais, sobretudo em áreas em que a preservação e a conservação ambiental são partes integrantes da economia local (COSTA, 2018).

Dessa forma, cabe ressaltar a importância do envolvimento dos atores multilateralmente nas ações de regulamentação ambiental, ultrapassando os desafios pertinente ao equilíbrio entre o poder expresso pelos governos (local ou regional) e a participação construtiva representativa desses interesses sustentáveis (SOUSA CAMILO \& ALMEIDA, 2019, p 400). 
Tabela 2: Aplicação dos quadrantes da sustentabilidade integral-BertiogaInfluências psicológicas (Eu)

\begin{tabular}{|c|c|}
\hline Influências psicológicas (Eu) & Influências Comportamentais (Ele) \\
\hline $\begin{array}{l}\text { Motivação individual para o aprendizado } \\
\text { Contexto: expansão da consciência, auto- } \\
\text { reconhecimento, como o indíviduo cuida de } \\
\text { si mesmo, compreensão de sua posição em } \\
\text { relação ao mundo exterior que o sustenta, } \\
\text { expansão do auto cuidado para o cuidado } \\
\text { com o entorno. } \\
\text { Exemplos de áreas abordadas: } \\
\text { compreensão do próprio papel na } \\
\text { comunidade e do próprio impacto sobre o } \\
\text { meio ambiente. } \\
\text { Ferramentas para a transformação: } \\
\text { interação com o meio ambiente, natação, } \\
\text { caminhadas, lazer, acampamentos; meditação } \\
\text { para interiorização. Como posso usar o meio } \\
\text { ambiente para cura? Como posso usar o meio } \\
\text { ambiente para sustento individual e familiar, } \\
\text { e ao mesmo tempo, respeitando e } \\
\text { preservando-o? }\end{array}$ & $\begin{array}{l}\text { Contexto: comportamentos e ações no } \\
\text { sentido de preservar a natureza. } \\
\text { Exemplos de áreas abordadas: poluição } \\
\text { nos manaciais de água doce local; produção } \\
\text { de lixo; consumo excessivo; desperdício; } \\
\text { desleixo. } \\
\text { Ferramentas para a transformação: } \\
\text { exercícios de divulgação da importância de } \\
\text { preservação dos manaciais através do } \\
\text { consumo consciente, com produção de menor } \\
\text { quantidade de lixo; participação em ações em } \\
\text { grupos de ciências e de defesa da natureza; } \\
\text { grupos de apoio à consciência ambiental. }\end{array}$ \\
\hline $\begin{array}{l}\text { Influências culturais } \\
\text { Contexto: as normas e valores da } \\
\text { comunidade incentivam a preservação do } \\
\text { ambiente. } \\
\text { Exemplos de áreas abordadas: outras } \\
\text { pessoas fazem a mesma atuação de } \\
\text { preservação ambiental, existe uma cultura } \\
\text { local de conservação e valorização dos } \\
\text { recursos naturais. } \\
\text { Ferramentas para a transformação: } \\
\text { diálogo, inclusão da comunidade no } \\
\text { planejamento do uso dos recursos naturais } \\
\text { por meio de fóruns e eventos dedicados ao } \\
\text { tema, campanhas de conscientização ou } \\
\text { sensibilização ambiental. }\end{array}$ & $\begin{array}{l}\text { Sistemas de Influências } \\
\text { Contexto: poluição local; degradação de } \\
\text { recursos naturais; produção de lixo } \\
\text { exagerada. } \\
\text { Exemplos de áreas abordadas: educação; } \\
\text { criação de emprego e comércio; proteção e } \\
\text { uso sustentável dos recursos naturais. } \\
\text { Ferramentas para a transformação: } \\
\text { impostos sobre a poluição; restauração e } \\
\text { gestão dos recursos naturais; reciclagem e } \\
\text { reutilização; campanha do controle de } \\
\text { resíduos domésticos; compostagem; } \\
\text { produção de adubo natural. }\end{array}$ \\
\hline
\end{tabular}

Fonte: Costa (2018) a partir de Brown (2011).

\section{CONCLUSÕES}

Os percentuais de aplicabilidade da participação na exploração e produção de petróleo e gás já estão norteados pela Lei 12.858/2013, o que diminui a influência da matriz de necessidade e da espacialização do desenvolvimento como políticas públicas de atuação da destinação das rendas de petróleo e gás.

Não obstante tal assertiva, as áreas de educação e saúde fazem parte da matriz de necessidades e da espacialização do desenvolvimento, sendo fundamental observar como propiciar maior abrangência e ressonância a tais áreas para que os efeitos positivos gerados sejam espalhados por outros setores e áreas da coletividade. Ainda, a tarefa continua, pois resta definir como destinar os valores dentro de políticas públicas das áreas de educação e saúde.

A indústria do petróleo e gás natural representa riqueza financeira para suportar economicamente programas e políticas de educação e saúde no Brasil que a sociedade e que cada indivíduo deseja. É nessa diversidade que o uso dessa riqueza deve ser inserido. Cada cidade beneficiária deve olhar para dentro, chamar seus cidadãos para conduzir as questões educacionais e de saúde importantes para aquela localidade.

Relembrar os valores de cada cultura, realizar interligações entre grupos sociais de uma mesma comunidade e de diferentes faixas etárias, redescobrir o potencial da natureza e do entorno, buscar a cura 
diária, sentir as necessidades do corpo e da alma serão, sem dúvidas, grandes desafios para a educação e para a saúde delineadas pelo princípio da justiça intra e intergeracional e abraçadas pelas ferramentas da sustentabilidade integral.

\section{AGRADECIMENTOS}

Os autores agradecem o suporte da BG E\&P Brasil e FAPESP através do Centro de Pesquisa e Inovação do Gás (FAPESP Proc. 2014/50279-4), assim como da Universidade de São Paulo e a importância estratégica do suporte dado pela ANP (Agência Nacional de Petróleo, Gás Natural e Biocombustíveis) através da cláusula de P\&D.

\section{REFERÊNCIAS}

[1] ALOE, G. O que é sustentabilidade? Entrevista realizada em 23 de outubro de 2010, Centro de Sustentabilidade, Fundação Alphaville, Santana do Paranaíba, São Paulo, 2010.

[2] BROWN, B.C. (2011). The Four Worlds of Sustainability. Drawing upon four universal perspectives to support sustainability initiatives. Disponível em: http://nextstepintegral.org/wpcontent/uploads/2011/04/Four-Worlds-ofSustainability-Barrett-C-Brown.pdf. Acesso em: fev. 2019.

[3] _. (2004). Integral Sustainability $101 . \quad$ Disponível em: http://terrypatten.typepad.com/iran/files/quadrants_undp.pdf. Acesso em: fev. 2019.

[4] _ (2005). Theory and practice of integral sustainable development: Part 1 - Quadrants and the practitioner. AQAL: Journal of Integral Theory and Practice, 1 (2), 351-386.

[5] _ _ (2005). Theory and practice of integral sustainable development: Part 2 - Values, developmental levels, and natural design. AQAL: Journal of Integral Theory and Practice, 1 (2), 386-448.

[6] COSTA, H. K. M. O princípio da justiça intra e intergeracional como elemento na destinação das rendas de hidrocarbonetos: temática energética crítica na análise institucional brasileira. Tese (Doutorado em Ciências) Programa de Pós-Graduação em Energia. Instituto de Eletrotécnica e Energia (IEE), USP, São Paulo, 2012.

[7] COSTA, Hirdan Katarina de Medeiros. Royalties de petróleo: Justiça e Sustentabilidade. Rio de Janeiro: Synergia, 2018.

[8] EGMOND, N. D.; VRIES, H.J.M. Sustainability: The search for the integral worldview. Futures 43 (2011) 853867.

[9] IWAMA-MELLO, A. Y., TOMÁS, L. R. e D'ANTONA, A. O. Análise de vulnerabilidades às mudanças climáticas: proposta de abordagens por setores censitários e áreas de ponderação em Caraguatatuba e Santos - São Paulo. In: Simpósio Brasileiro de Sensoriamento Remoto, 2011, Curitiba-PR. XV SBSR, 2011.

[10] SOUSA CAMILO, A. S; ALMEIDA, P. S. Proteção da biodiversidade ambiental e cultural latino-americana: o caso da participação social na avaliação de impacto ambiental nos países do Mercosul. In Democracia, Liderança e Cidadania na América Latina, Laura Chinchilla (coordenação); Wagner Pinheiro Pereira e Carlos Lugo (organização). São Paulo: Editora da Universidade de São Paulo, 2019, pp. 393-411.

[11] SOUZA, M. A. A. de. Meio Ambiente e Desenvolvimento Sustentável. As metáforas do capitalismo. Professora Titular de Geografia Humana (Disciplina Planejamento) da USP e Presidente do TERRITORIAL Instituto de Pesquisa, Informação e Planejamento, Palestra proferida em 2002.

[12] ___ Planejamento Urbano e Regional. Notas de aula. Universidade Federal do Rio Grande do Norte, 26 de fevereiro de 2009.

[13] WILBER, K., Sex, Ecology, Spirituality: The Spirit of Evolution, Second Edition Paperback, 2001. 


\section{Capítulo 18}

Propriedades do biodiesel de sebo bovino e suas misturas bx a baixas temperaturas

\section{Maria Gabriela da Silva Cavalcanti}

\section{Luiz Antônio Pimentel Cavalcanti}

Resumo: A tendência de um combustível solidificar a baixas temperaturas é verificada através das Propriedades de Escoamento a Frio (PEF). Tais propriedades no biodiesel de sebo bovino (B100-Sb) podem afetar a viabilidade comercial desse combustível, devido à composição em termos de ésteres metílicos de ácidos graxos (EMAG) ser predominantemente composta por saturados. Estudou-se o efeito de adição de triacetina sobre o melhoramento das PEF do B100-Sb e das misturas BX (B5a B50) nas frações volumétricas de $0,5,1,5,10$ e $20 \%$ (v/v) de triacetina dissolvida no B100-Sb, bem como o comportamento reológico desses combustíveis foram obtidos usando-se um reômetro do tipo Searle. As propriedades de escoamento a frio de tais combustíveis foram obtidas através dos Mini Pour Point/Cloud Point e CFPP testers. A adição da triacetina teve uma ação discreta quanto à diminuição do ponto de névoa, porém, atuou de forma mais efetiva sobre o ponto de fluidez desses combustíveis. Foi constatado que nas misturas BX quanto maior a proporção de B100-Sb presente na mistura, maior a redução do PF do combustível. Com relação ao B100-Sb, os melhores resultados foram obtidos com o percentual de 1,0 \% de triacetina no combustível, aumentando-se tal valor percentual não houve alteração com relação aos PEF. Os B100-Sb, óleo diesel e misturas BX e misturas BX-Triacetina comportaram-se como Fluidos Newtonianos e Fluidos pseudoplásticos a $20 \leq \mathrm{T} \leq 90^{\circ} \mathrm{C}$ e $14 \leq \mathrm{T} \leq 18^{\circ} \mathrm{C}$, respectivamente. As curvas de viscosidade evidenciaram que presença da triacetina atua inibindo o crescimento e aglomeração dos cristais de EMAG.

Palavras-chave: Biodiesel, Triacetina, Propriedades de Escoamento a Frio, Comportamento Reológico. 


\section{INTRODUÇÃO}

A crescente demanda energética mundial, associado a perspectiva de desabastecimento de combustíveis de origem fóssil e a necessidade de uma maior atenção com questões ambientais provocaram o rápido avanço em pesquisas que visam o desenvolvimento de tecnologias limpas, assim como, a busca por combustíveis alternativos provindos de fontes renováveis como o biodiesel [SHARMA et al., 2008].

A produção mundial de carne bovina deverá aumentar sua produção em 56,8 milhões de toneladas, o mercado internacional terá uma expansão de $24 \%$, sendo o Brasil e a Índia os maiores responsáveis por esse aumento [BEEFPOINT, 2014]. A atual posição do Brasil no cenário mundial favorece a disponibilidade de uma quantidade elevada de gorduras residuais. Esse subproduto normalmente não é reutilizado por indústrias ou comerciantes e aumentam os problemas de resíduos sólidos e poluição ambiental [RAMALHO et al, 2012].

Dentre as inúmeras vantagens apresentadas pelas gorduras animais para a produção de biodiesel, destacam-se o fato do custo relativamente baixo, o alto poder calorífico e número de cetano. Um problema inerente ao biodiesel produzido a partir de gorduras animais é a sua propensão para solidificar a temperaturas frias. Este risco de solidificação na maioria das vezes limita o uso generalizado do biodiesel [RAO e RAO, 2011].

As propriedades de escoamento a frio (PEF) são parâmetros de extrema importância como indicadores de desempenho para combustíveis diesel, e é altamente relevante, tanto para a manutenção, para o armazenamento e transporte de diesel, a baixas temperaturas. Uma vez que a alta viscosidade e as baixas PEF do biodiesel podem facilmente resultar no entupimento das tubulações e filtros de combustível durante o uso normal [MOSER, 2014].

A comunidade científica tem se dedicado a avaliar diversos métodos visando a melhoria dos PEF do biodiesel, dentre eles destacam-se: a) winterização; b) ozonização; c) aplicação de aditivos químicos como melhoradores de fluxos e; d) modificação na composição dos ésteres de ácidos graxos. Dentre tais métodos, o uso de aditivos como melhoradores de fluxo a frio proporciona uma forma econômica e prática de solução de problemas relacionados ao congelamento e tem sido investigada em diversos estudos [KNOTHE, 2009; CHEN et al., 2010; PEREZ et al., 2010; SMITH et al., 2010].

A triacetina (triacetato de glicerol) é um importante derivado da glicerina, sendo um composto químico artificial que apresenta diversas aplicações industriais, possuindo maior valor agregado comparado a glicerina, podendo ser utilizado como aditivo antidetonante para combustíveis e para melhorar as propriedades de escoamento à frio do biodiesel em baixas temperaturas [MUFRODI et al., 2013].

Saka et al. [2009], estudaram o efeito da adição da triacetina sobre propriedades como número de cetano, massa específica, viscosidade cinemática e propriedades de escoamento a frio em biodiesel de canola produzido sob condições supercríticas. Relataram que a adição de triacetina diminuiu o número de cetano, causou um aumento da densidade e da viscosidade e pouco melhorou as propriedades de escoamento a frio e estabilidade à oxidação do biodiesel de canola.

Casas et al. [2010], avaliaram propriedades, tais como a densidade, viscosidade cinemática e dinâmica, ponto de névoa (PN), ponto de fluidez (PF), ponto de entupimento de filtro a frio (CFPP), índice de cetano, curva de destilação e ponto de fulgor, para misturas de biodiesel (palma, soja, girassol, alto teor de ácido oléico e colza).e triacetina em diferentes proporções de até $20 \%$ em peso de triacetina. Constataram uma redução de $4^{\circ} \mathrm{C}$ para os B100 de palma e canola para o teor de $20 \%$ em peso de triacetina nos respectivos biodiesel. Para o PF, obtiveram reduções de $9^{\circ} \mathrm{C}$ para o B100 de canola e de $3^{\circ} \mathrm{C}$ para o de palma.

A maioria dos fluidos, como diesel mineral (B0), B100 e Misturas BX, torna-se mais viscoso com o decréscimo da temperatura [KNOTHE et al., 2006]. Esses fluidos apresentam comportamento reológico de um fluido Newtoniano para temperaturas acima de seu ponto de névoa [MACHADO, 2002].

O objetivo do presente trabalho foi avaliar os efeitos da adição de triacetina no B100 de sebo bovino (B100-Sb) e suas misturas BX com diesel comercial isento de corantes e aditivos sobre as propriedades de esocamento a frio como o PN, PF e CFPP. Além de avaliar os efeitos da adição da triacetina sobre o comportamento reológico e massa específica para o B100-Sb e Misturas BX em temperaturas acima e abaixo do ponto de névoa. 


\section{METODOLOGIA}

\subsection{PRODUÇÃO DO BIODIESEL}

O B100-Sb, 2L, foi produzido através das reações de esterificação para pré-tratamento dos ácidos graxos livres presentes no óleo de sebo bovino, seguida de transesterificação alcalina homogênea (catalisador: $\mathrm{KOH}, 1 \%$ w/w, com relação a massa de óleo). O reator químico foi de marca Marconi, modelo MA502/5/C (volume útil máximo: 3L) com controle de temperatura e agitação mecânica (impelidor do tipo pás). As condições operacionais dessas etapas foram: 60ํㅡ, 1 atm, $300 \mathrm{rpm}$, razão molar álcool 6:1, tempo reacional de $1 \mathrm{~h}$. Em seguida, procedeu-se a separação da glicerina da mistura reacional (método da decantação). A fase mais leve da mistura, contendo B100-Sb, catalisador, excesso de metanol, passou pela etapa de purificação que constou de lavagem ácida com solução de ácido clorídrico 0,5M e as demais lavagens foram realizadas com água destilada, visando o ajuste do $\mathrm{pH}$ e retirada do residual de $\mathrm{KCl}$ formado. A secagem do biodiesel foi realizada em evaporador rotativo com vidraria vertical Marca IKA, Modelo RV10. Após a secagem houve a adição de sulfato de sódio anidro na proporção de 10\% (w/w) para remoção de algumas moléculas de água ainda dispersas, seguida de filtração para remoção deste sal.

\subsection{COMPOSIÇÃO QUÍMICA}

A composição química do B100-Sb foi analisada por cromatografia gasosa, com cromatógrafo de Marca Ciola Gregory, modelo CG Máster, coluna Carbowax (Dimensão: 30,0m de comprimento, 5,3 x 10-4 m de diâmetro interno e espessura da fase estacionária de $1,0 \times 10^{-9} \mathrm{~m}$ ). Usou-se o hidrogênio (White Martins, $\geq$ 99,99\%) como eluente. Os padrões do EMAG foram adquiridos a Sigma-Aldrich.

\subsection{MISTURAS BX PURAS E ADITIVADAS}

As Misturas BX, frações volumétricas de biodiesel de 5\%, 10\%, 20\%, 30\%, 40\% e 50\% (v/v), foram preparadas em base gravimétrica para minimizar erros sistemáticos devido a variações causadas pela influência da temperatura. Usou-se para tal a balança semi-analítica, Marca Metler-Toledo, modelo PB3002-S de incerteza \pm 0,0001 g. 0 B100 foi aditivado com triacetina cuja fração volumétrica na mistura final foi de $0,5,1,0,5,0,10,0$ e 20,0\% (v/v). A mistura resultante foi utilizada para formular as Misturas BX-T, de forma similar a preparação das Misturas BX.

\subsection{PROPRIEDADES DE ESCOAMENTO A FRIO (PEF)}

As propriedades de escoamento a frio dos combustíveis B0, B100-Sb, Misturas BX e Misturas BX-T. investigadas foram os PF, PN e CFPP. Os PF e PN dos combustíveis foram obtidos com o auxílio de um Mini Pour Point (PP) \& Cloud Point (CP) tester de Marca Koehler, modelo K46300, utilizando um termômetro ASTM 6C-86 76mm 1mm, Marca INCOTERM, modelo 87830/05. Os CFPP dos combustíveis foram mensurados usando o CFPP tester, Marca TANAKA, modelo AFP-102. As PEF seguiram as Normas ASTM D6371 (CFPP), ASTM D97 (PN) e ASTM D2500 (PF).

\subsection{CARACTERIZAÇÃO REOLÓGICA}

O comportamento reológico (CR) dos combustíveis em estudo foi obtido associando-se dados oriundos da reometria (SCHRAMM, 2006) e ajuste de modelos clássicos encontrados na literatura (BIRD et al., 1960). Utilizou-se reômetro do tipo Searle, Marca Brookfield, modelo R/S - SST2000, com temperatura controlada por um banho ultra-termostatizado, Marca Lauda, modelo RE206, acoplado em série ao reômetro. Tal reômetro pode ser operado com controle de tensão ou taxa de cisalhamento. 0 fluido térmico utilizado foi uma solução aquosa de etileno glicol a $30 \%$ (v/v). 
O CR dos B0, B100-Sb e suas Misturas BX foi investigado de formas distintas: a) Combustíveis sem aditivos na temperatura de $20-90^{\circ} \mathrm{C}$ com controle da taxa de cisalhamento $3,0 \times 10^{2}-2,2 \times 10^{3} \mathrm{~s}^{-1}$; b) combustíveis isentos de aditivos e aditivados com triacetina em temperaturas de: 1) $14-18^{\circ} \mathrm{C}$ (B100-Sb); 2) $-2-11^{\circ} \mathrm{C}$ (B0,Misturas BX e BX-T) correspondendo os limites inferiores dessas faixas ao PN desses combustíveis. Em geral, a temperatura foi incrementada em $2^{\circ} \mathrm{C}$ em cada ensaio. Neste caso a reometria dos combustíveis foi realizada com controle de tensão, CSS, tendo a tensão variado na faixa de $0,6-5,0 \mathrm{~Pa}$, gerando taxa de cisalhamento na faixa de $0,0 \mathrm{~s}-1<\dot{\gamma} \leq 200,0 \mathrm{~s}^{-1}$.

\section{RESULTADOS E DISCUSSÃO}

\subsection{COMPOSIÇÃO QUÍMICA}

A Tabela 1 mostra composição do B100-Sb em função do teor dos ésteres metílicos de ácidos graxos (EMAG), como pode ser observado $55,0 \%$ dos ésteres presentes são saturados, enquanto 45,0\% são insaturados, caracterizando que o ponto de cristalização dos EMAG é alto, pois a composição do B100 é majoritariamente formada por EMAG saturados. Segundo Knothe (2006) a presença de EMAG como os C16:0 e C18:0 principalmente leva estes compostos nuclearem-se formando cristais que ficam suspensos na fase líquida podendo causar entupimento dos filtros e bicos injetores, bem como restrição no fluxo de combustível em motores a diesel.

Tabela 1 - Composição em teor de massa (TM) do B100-Sb
\begin{tabular}{|c|c|c|c|c|c|} 
EMAG & C14:0 & C16:0 & C17:0 & C18:0 & $\begin{array}{c}\text { T S.* } \\
(\%)\end{array}$ \\
\begin{tabular}{|c|c|c|c|c|c|} 
Teor \\
$(\%)$
\end{tabular} & 3,3 & 24,9 & 1,3 & 25,5 & 55,0 \\
\hline EMAG & C14:1 & C16:1 & C18:1 & C18:2 & $\begin{array}{c}\text { T.I.** } \\
(\%)\end{array}$ \\
\hline $\begin{array}{c}\text { Teor } \\
(\%)\end{array}$ & 0,3 & 2,1 & 38,1 & 4,5 & 45,0 \\
\hline
\end{tabular}
* Percentual total de EMAG Saturados
* Percentual total de EMAG Insaturados

\subsection{PROPRIEDADES DE ESCOAMENTO A FRIO}

Os valores obtidos para os ponto de névoa (PN), ponto de entupimento de filtro a frio (CFPP) e ponto de fluidez (PF) dos B0, B100-Sb e Misturas BX-T(fração volumétrica de triacetina: 0,0\%, 0,5\%, 1,0\% e 5,0\%), são mostrados nas Tabelas 2, 3 e 4, respectivamente.

Tabela 2 - PN para os B0, B100-Sb e Misturas BX-T

\begin{tabular}{cc|c|c|c|}
\multirow{2}{*}{ Combustível } & \multicolumn{5}{c|}{ Teor de triacetina (\%) } \\
\cline { 2 - 5 } & 0,0 & 0,5 & 1,0 & 5,0 \\
\hline Diesel & 11,0 & 11,0 & 11,0 & 11,0 \\
\hline B5 & 11,0 & 11,0 & 11,0 & 11,0 \\
\hline B10 & 11,0 & 11,0 & 11,0 & 11,0 \\
\hline B20 & 11,0 & 11,0 & 11,0 & 11,0 \\
\hline B30 & 11,0 & 11,0 & 11,0 & 11,0 \\
\hline B40 & 12,0 & 11,0 & 11,0 & 11,0 \\
\hline B50 & 12,0 & 11,0 & 11,0 & 11,0 \\
\hline B100 & 17,0 & 17,0 & 15,0 & 15,0 \\
\hline
\end{tabular}


Tabela 3 - CFPP para os B0, B100-Sb e Misturas BX-T

\begin{tabular}{cc|c|c|c|}
\multirow{2}{*}{ Combustível } & \multicolumn{5}{c|}{ Teor de triacetina $(\%)$} \\
\cline { 2 - 5 } & 0,0 & 0,5 & 1,0 & 5,0 \\
\hline Diesel & 9,0 & 9,0 & 9,0 & 9,0 \\
\hline B5 & 9,0 & 9,0 & 9,0 & 9,0 \\
\hline B10 & 9,0 & 9,0 & 9,0 & 9,0 \\
\hline B20 & 9,0 & 9,0 & 9,0 & 9,0 \\
\hline B30 & 9,0 & 8,0 & 8,0 & 8,0 \\
\hline B40 & 9,0 & 8,0 & 8,0 & 8,0 \\
\hline B50 & 9,0 & 9,0 & 9,0 & 8,0 \\
\hline B100 & 14,0 & 14,0 & 13,0 & 13,0 \\
\hline
\end{tabular}

Para o B100-Sb os resultados dos PN, CFPP e PF foram superiores àqueles referentes ao B0. Este fato era esperado, pois o B100-Sb possui alto teor de EMAG saturados (Tabela 1).

Tabela 4 - PF para os B0, B100-Sb e Misturas BX-T

\begin{tabular}{|c|c|c|c|c|}
\multirow{2}{*}{ Combustível } & \multicolumn{5}{c}{$\mathrm{PF}\left({ }^{\circ} \mathrm{C}\right)$} \\
& 0,0 & 0,5 & 1,0 & 5,0 \\
\hline Diesel & 0,0 & $-2,0$ & $-2,0$ & $-2,0$ \\
\hline B5 & 0,0 & $-2,0$ & $-2,0$ & $-2,0$ \\
\hline B10 & 1,0 & $-3,0$ & $-3,0$ & $-3,0$ \\
\hline B20 & 2,0 & $-1,0$ & $-1,0$ & $-1,0$ \\
\hline B30 & 2,0 & $-1,0$ & $-1,0$ & $-1,0$ \\
\hline B40 & 3,0 & 1,0 & 1,0 & 1,0 \\
\hline B50 & 5,0 & 4,0 & 4,0 & 4,0 \\
\hline B100 & 13,0 & 13,0 & 11,0 & 11,0 \\
\hline
\end{tabular}

A formulação das Misturas BX gerou combustíveis cujas propriedades de escoamento a frio possuem as seguintes características: a) PN: similar ao do diesel para as Misturas BX com até 30\% de B100-Sb, havendo acréscimo em 1으 $\mathrm{C}$ para aquelas com 40 a 50\%; b) CFPP: similar ao diesel para Misturas com até 40\% de B100-Sb; c) PF: afasta-se daquele observado para o diesel a medida que a fração volumétrica do B100-Sb aumenta.

Os B100-Sb-T, diesel-T e Misturas BX-T preparados com 0,5 a 5,0\% (v/v) de triacetina tiveram as seguintes características: a) PN: o B100-T teve seu PN reduzido em 4ํ $\mathrm{C}$ para teor de triacetina superior a 0,5\% v/v, o PN diesel-T manteve-se inalterado e o PN das Misturas BX comportou-se como o do diesel; b) CFPP: Apenas as Misturas B30 a B50 tiveram seu CFPP reduzido em 1ํ C; c) PF: Os PF de todos os combustíveis foram afetados pela adição de triacetina ao seu volume. Tais resultados nos levam a conclusão que a triacetina atua sobre os ésteres de ácidos graxos saturados, modificando a dinâmica de crescimento e aglomeração dos cristais de EMAG.

Segundo Lopes [2010], a interação dos aditivos com o sistema pela introdução de ramificações e/ou interações moleculares, causa um rearranjo do cristal, neste caso, diminui o tamanho e a forma deste.

\subsection{CARACTERIZAÇÃo REOLÓGICA}

As curvas de viscosidade traçadas para os B0, B100-Sb e Misturas BX, com taxa de cisalhamento variando na faixa de $300,0-2200,0 \mathrm{~s}^{-1}$ e faixa de temperatura de 10 a $90^{\circ} \mathrm{C}$ podem ser observadas nas Figuras $1 \mathrm{a}$ a $1 \mathrm{~d}$. Foram omitidas as curvas referentes as Misturas B10 a B40, porém estas apresentam comportamento similar as exibidas na Figura 1. 
Figura 1 - Curvas de viscosidade: (a) B0; (b) B100-Sb; (c) Mistura B5-Sb e; (d) Mistura B50-Sb (a)

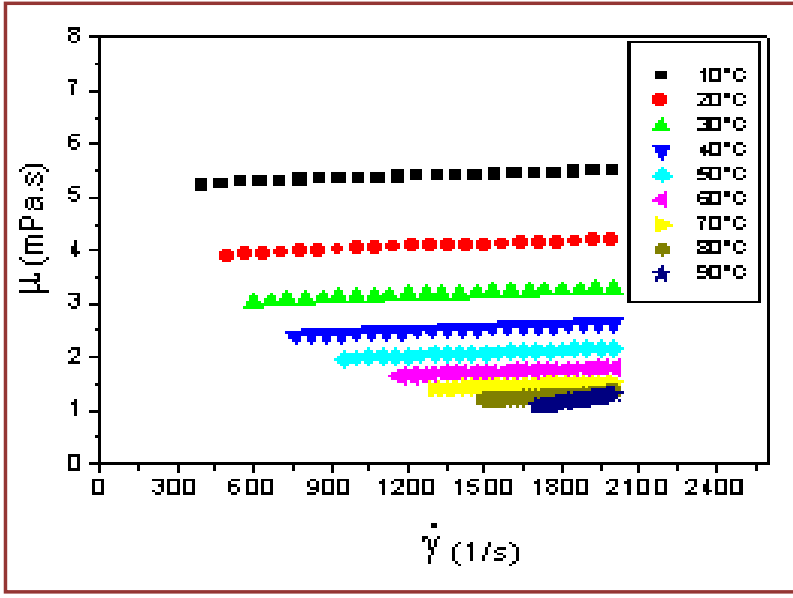

(b)

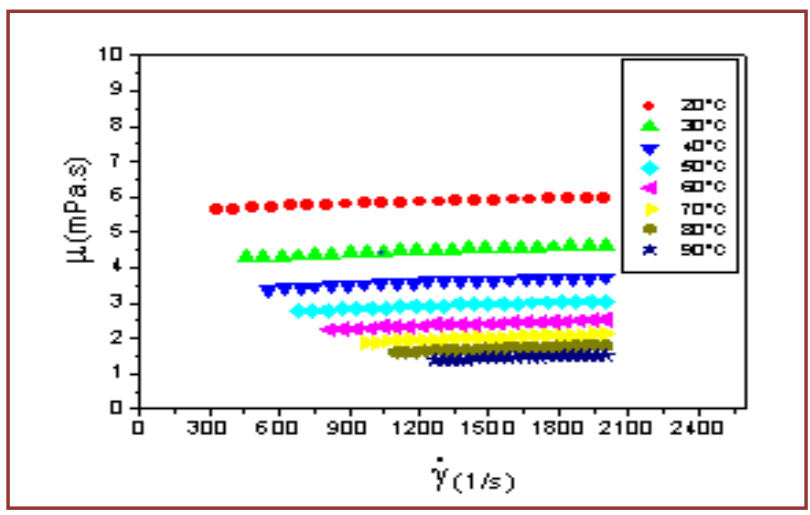

(c)

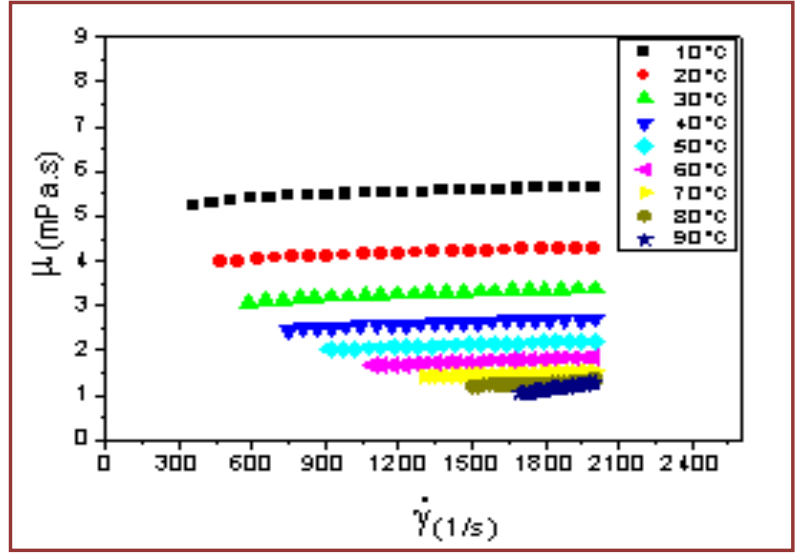


(d)

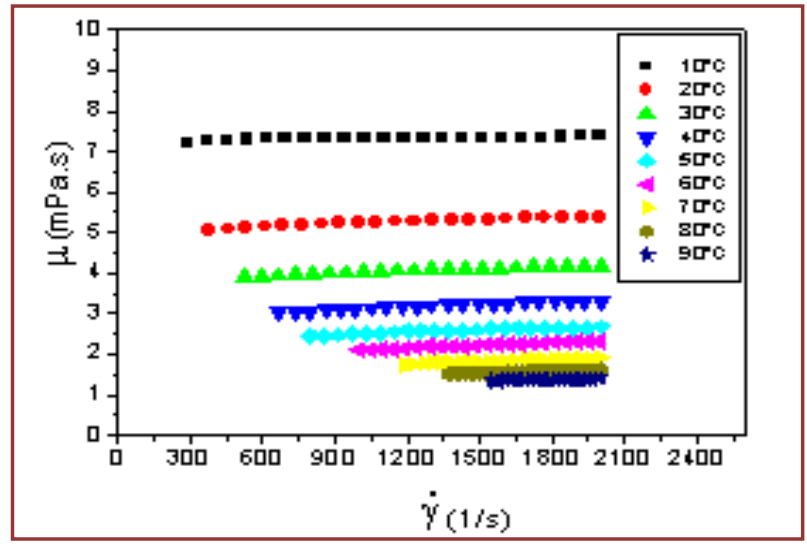

Ao avaliar a Figura 1, em todos os casos, verificou-se que essas eram compostas por retas paralelas a abscissas cujos coeficientes lineares também são função temperatura e da composição, caracterizando em todos os casos o comportamento de fluido Newtoniano para a faixa de temperatura e taxa de cisalhamento estudadas. De forma similar as curvas de viscosidade a medida que a temperatura aumenta a distância entre duas retas sucessivas diminui mostrando que relação entre a temperatura e a viscosidade não é linear.

\subsection{REOMETRIA A TEMPERATURAS PRÓXIMAS AO PN DO COMBUSTÍVEL}

As curvas de viscosidade traçadas para os B100-Sb e suas respectivas misturas com a triacetina (B100-Sb$\mathrm{T}$ ), nas condições em que a taxa de cisalhamento variou na faixa de 0,0 a $550 \mathrm{~s}^{-1}, \mathrm{~T} \leq \mathrm{PN}$ dos combustíveis, podem ser observadas nas Figuras 2.

Figura 2 - Curvas de viscosidade (B100-Sb/T): (a): 0,0\%; (b) 5,0\%

(a)

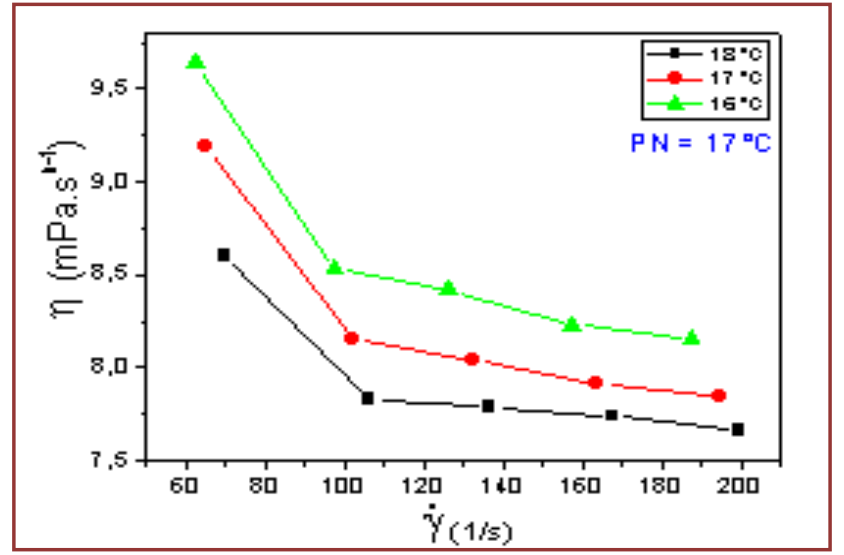


(b)

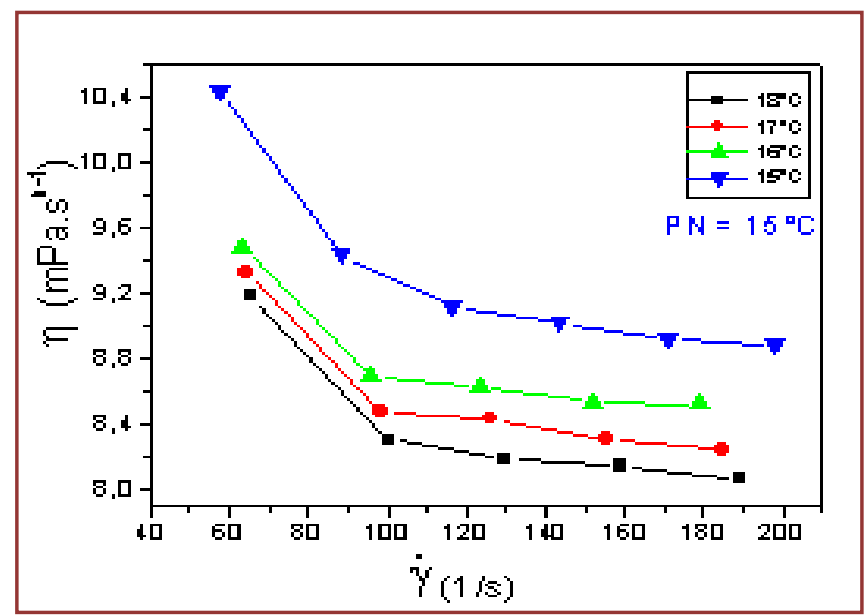

O B100-Sb (Figura 2) apresentou comportamento inalterado para aditivação 1\% (v/v) de triacetina. Sua influência só foi evidenciada a partir de $5 \%(\mathrm{v} / \mathrm{v})$ de aditivação, pois a temperatura de $14^{\circ} \mathrm{C}$ até então não havia sido avaliada devido ao congelamento total do B100-Sb e com este percentual de aditivação conseguiu ser realizado o teste. 0 congelamento total do combustível avaliado só ocorreu na temperatura de $13^{\circ} \mathrm{C}$

As Figuras 3 apresentam o efeito da ação da triacetina sobre as Misturas BX formuladas a partir do B100$\mathrm{Sb}$.

Figura 3 - Curvas de viscosidade B5-Sb/T - (a) 0,0 \% e; (b) 5,0 \%

(a)

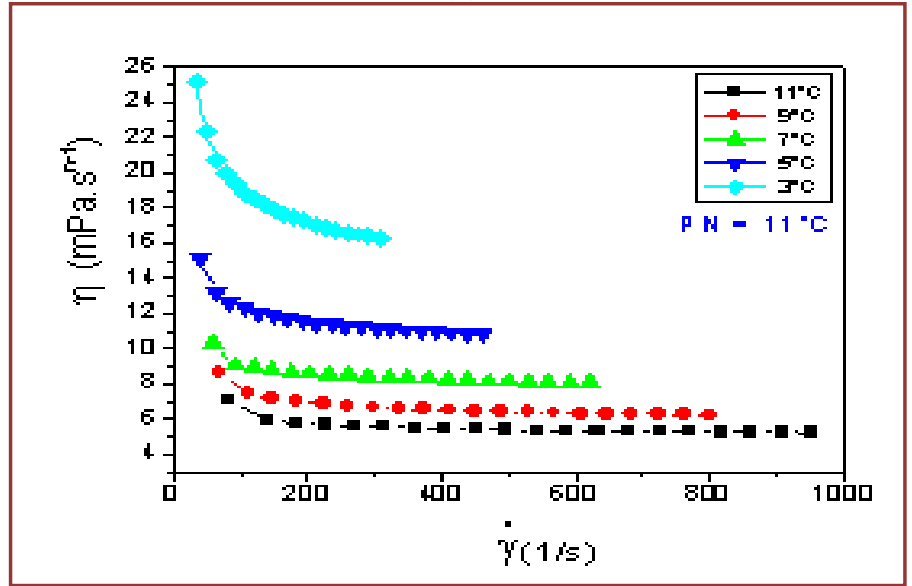


(b)

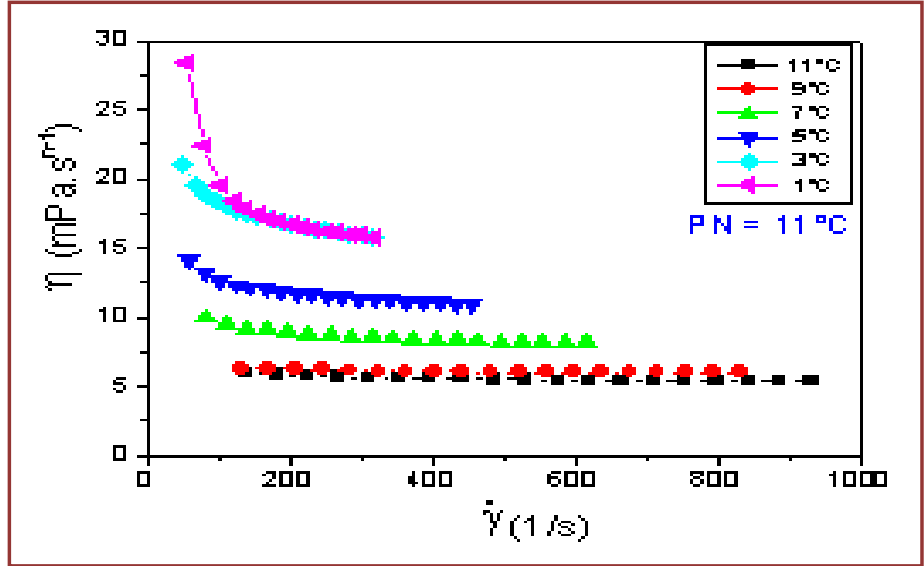

As Figuras 3 mostram as curvas de viscosidade Misturas BX formuladas adicionando B100-Sb com teores triacetina de 0,0 e $5,0 \%(\mathrm{v} / \mathrm{v})$ nas seguintes faixas de temperatura: 1 a $11^{\circ} \mathrm{C}$ em todos os casos avaliados. Com o decréscimo da temperatura na mesma faixa de taxa de cisalhamento na Figura 3, nota-se que há a transição do CR dos fluidos, a medida que a taxa de cisalhamento aumenta, os cristais de EMAG são dissolvidos, marcando a transição do comportamento de FNNIT-P para um newtoniano.

Nota-se principalmente na temperatura de $1^{\circ} \mathrm{C}$ que a curva é mais acentuada uma vez que nas proporções de $0,0,5$ e 1,0\% de adição de triacetina essa temperatura não conseguia ser lida. A adição da triacetina mostrou-se mais efetiva nas Misturas BX formuladas com maior concentração do B100-Sb, como pode ser observado, uma intensa atenuação da curva de viscosidade para a Mistura B50-Sb do percentual de aditivação de 0\% (v/v) de triacetina (Figura 4a) para o teor de 5\% (v/v) (Figura 4b).

Figura 4 - Curvas de viscosidade B50-Sb/T - (a) 0,0 \% e; (b) 5,0 \%

(a)

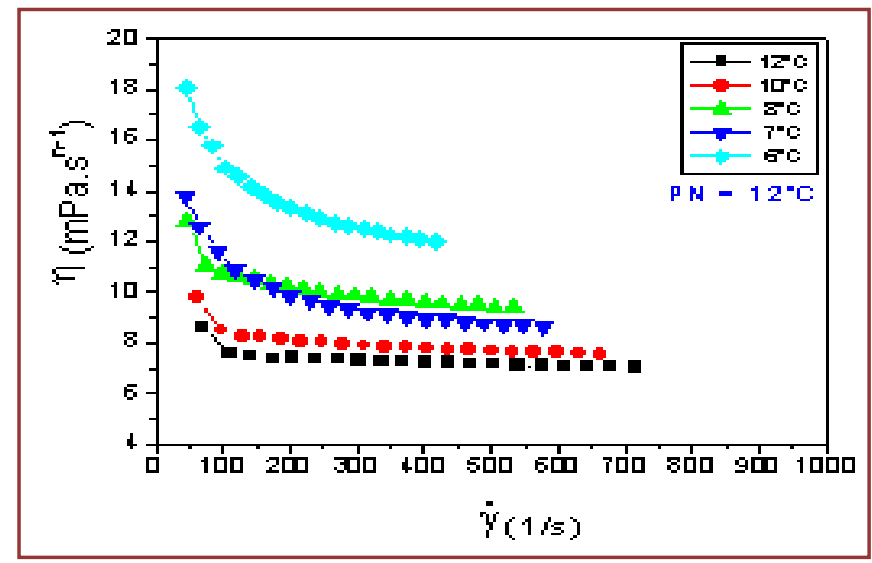


(b)

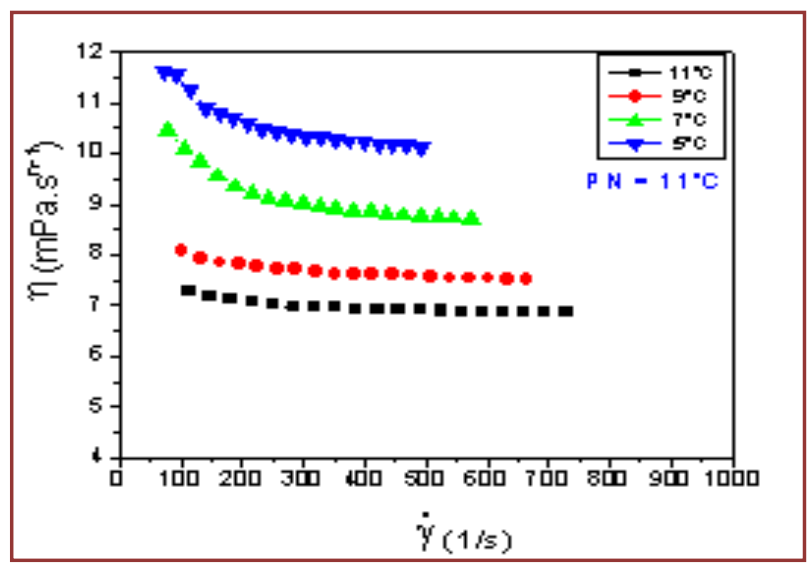

\section{CONCLUSÕES}

O B100-Sb produzido é composto por EMAG saturados e instaurados, predominando os primeiros na proporção de 55,0\%, tal fato ocasionou um aumento nas PEF das Misturas BX formuladas com o B100-Sb, uma vez que os EMAG saturados apresentam maior tendência à formação de cristais em baixas temperaturas.

Dentre as PEF o ponto de fluidez foi o que mais sofreu influência da adição de triacetina tanto para o B100 quanto para Misturas BX; As temperaturas próximas do ponto de névoa dos B100-Sb, B0 e Misturas BX é evidenciado o estado de transição de comportamento reológico de fluido newtoniano para fluido pseudoplásticos desses combustíveis;

\section{AGRADECIMENTOS}

Os autores agradecem ao Laboratório de Combustíveis (LAC) e ao Laboratório de Cromatografia da UFPE pelo apoio na realização deste trabalho

\section{REFERÊNCIAS}

[1] Beefpoint, Confira a projeção mundial do mercado de carnes para 2014 (Relatório USDA), disponível em: < http://www.beefpoint.com.br/cadeia-produtiva/especiais/confira-a-projecao-mundial-do-mercado-de-carnes-para2014-relatorio-usda/>. Acesso em: 30 mar. 2014.

[2] Bird, r. B. Steward, w. E.; lightfoot, e. N.; Transport Phenomena, Wiley: Singapore, 1960.

[3] Casas, a., ruiz, j. R., ramos, m. J., perez, a.. Effects of Triacetin on Biodiesel Quality. Energy Fuels 2010, 24, 4481-4489.

[4] Chen, B.S., sun, Y.q., FANG, J.h., WANG, J., WU, J., Effect of cold flow improvers on flow properties of soybean biodiesel. Biomass and Bioenergy 34 (2010) 1309-1313.

[5] Knothe, G., gerpen, J. V., krani, J., ramos, L. P.. Manual do Biodiesel. São Paulo. Editora Edgard Blücher, 2006.

[6] knothe, G., Improving biodiesel fuel properties bymodifying fatty ester composition, Energy \& Environmental Science 2 (2009) 759-766.

[7] Lopes, M. S.; Caracterizações Especiais de Combustíveis Fóssil e Renovável. Dissertação de Mestrado Universidade Estadual de Campinas, Faculdade de Engenharia Química, Campinas, São Paulo, 2010.

[8] Machado, J. C. V.; Reologia e Escoamaneto de Fluidos - Ênfase na Indústria de Petróleo, Rio de Janeiro: Editora Interciência, 2002.

[9] Moser, B. R. Impact of fatty ester composition on low temperature properties of biodiesel-petroleum diesel blends. Fuel 115 (2014) 500 - 506.

[10] Mufrodi, Z., Rochmadi, Sutijan, Budiman, A.; Continuous Process of Reactive Distillation to Produce Bioadditive Triacetin From Glycerol. Modern Applied Science; Vol. 7, No. 10; 2013 
[11] Pérez, J., Casas, A., Fernández, C.M., Ramos, M.J., Rodríguez, L., Winterization of peanut biodiesel to improve the cold flow properties, Bioresource Technology 101 (2010) 7375-7381.

[12] Ramalho, E. F. S. M., Carvalho Filho, J. R., Albuquerque, A. R., Oliveira, S. F., Cavalcanti, E. H. S., Stragevitch, L., Santos, I. M. G., Souza, A. G.; Low temperature behavior of poultry fat biodiesel:diesel blends. Fuel, v. 93 (2012) 601605.

[13] Rao, P. V., RAO, B. V. A., Effect of adding Triacetin additive with Coconut oil methyl ester (COME) in performance and emission characteristics of DI diesel engine. International Journal of Thermal Technologies, vol 1, $\mathrm{n}^{\circ} 1,2011$.

[14] SAKA, S.; ISAYAMA, Y. A NEW PROCESS FOR CATALYST-FREE PRODUCTION OF BIODIESEL USING SUPERCRITICAL METHYL ACETATE, FUEL, 2009, 88, 1307-1313.

[15] Schramm, G.; Reologia e Reometria, Fundamentos Teóricos e Práticos, Artliber do Brasil LTDA: São Paulo, 2006.

[16] Sharma, Y. C., SINGH, B., UPADHYAY, S. N., Advancements in development and characterization of biodiesel: A review. FUEL, v.87, p.2355-2373, 2008.

[17] Smith, P. C., Ngothai, Y., Nguyen, Q. D., Neill, B. K. O., Improving the low-temperature properties of biodiesel: methods and consequences, Renewable Energy 35 (2010) 1145-1151. 


\title{
Capítulo 19
}

Estudos comparativos no processo industrial de produção de bioetanol a partir do melaço e caldo de cana-de-açúcar

\author{
Scarllet O'hara de Oliveira Moraes \\ Wellington da Silva Rodrigues \\ Kelson Carvalho Lopes \\ Fábio de Melo Resende
}

Resumo: 0 objetivo deste estudo foi avaliar o processo fermentativo na produção de etanol de $1^{\circ}$ geração (bioetanol) de uma usina de álcool e açúcar. Os parâmetros observados foram: o brix, o art e a pureza, e como eles podem influenciar na produtividade do teor álcool no processo fermentativo. Os dados foram coletados dos boletins de análises extração e análise fermentação. Para análise dos dados foi adotado o mês de setembro de 2014 como referência, (por ser um mês em que a oferta de matéria é mais disponível e o processo industrial na destilaria sobre poucas flutuações). A Usina em estudo foi da macrorregião paraibana produtora de álcool de $1^{\circ}$ geração, e o melaço foi proveniente da unidade produtora de açúcar, ambas do mesmo grupo. Diante dos dados avaliados, podemos concluir que para três dos quatro parâmetros avaliados, houve médias significativamente maiores para o melaço, sendo seus resultados 15,75 , 11,84 e 7,72, enquanto que o caldo obteve as médias de 12,16, 10,6 e 6,57 para brix, art e teor alcoólico respectivamente. Porém a pureza mais elevada é a do caldo de cana, com uma média de 85,2, enquanto que a pureza do melaço ficou com uma média de 53,43. Isto se dá porque o melaço é o mel final esgotado da produção de açúcar, são os açúcares que não foram cristalizados, de forma que ${ }^{\circ}$ brix e art serão bem maiores. Mas os compostos do brix não são apenas sacarose, glicose e frutose, assim sua pureza será bem menor. 0 teor alcoólico elevado do melaço pode ser explicado pela quantidade de art, pois a produção por via fermentativa é feita pela conversão de açúcares em álcool e CO2.

Palavras-chave: Etanol, melaço, art, pureza, brix. 


\section{INTRODUÇÃO}

A produção de álcool de primeira geração (bioetanol) a partir da cana-de-açúcar dar-se-á através de processos de fermentação microbiológica, onde os açúcares são convertidos em álcool e CO2. Ainda de acordo com RAMBLA (Ano) o álcool pode ser obtido de diversas formas, não somente por síntese química dos recursos fósseis mais também pela via fermentativa do açúcar (caldo ou melaços), milho, outros grãos ou resíduos agrícolas.

O presente artigo busca avaliar dados do processo fermentativo de usina de álcool de primeira geração que utiliza caldo e melaço vindo para produção de bioetanol.

\subsection{ETAPAS DE PRODUÇÃO DO BIOETANOL.}

A cana-de-açúcar colhida no campo é transportada para a usina através de caminhões, na recepção a cana é pesada para que haja um controle do peso em toneladas, logo após é retirada uma amostra para as análises de POL, PUREZA, PCC, FIBRA e AR.

Apos a etapa de recepção a cana deverá é conduzida para a mesa alimentadora, onde é lavada para retirada de compostos inorgânicos, principalmente areia, como mostrado na figura 01, então a cana é levada em uma esteira transportadora e vai para os picadores, depois passa por um desfibrador, e através de uma esteira de borracha chega às moendas.

Figura 01 - Lavagem de Cana

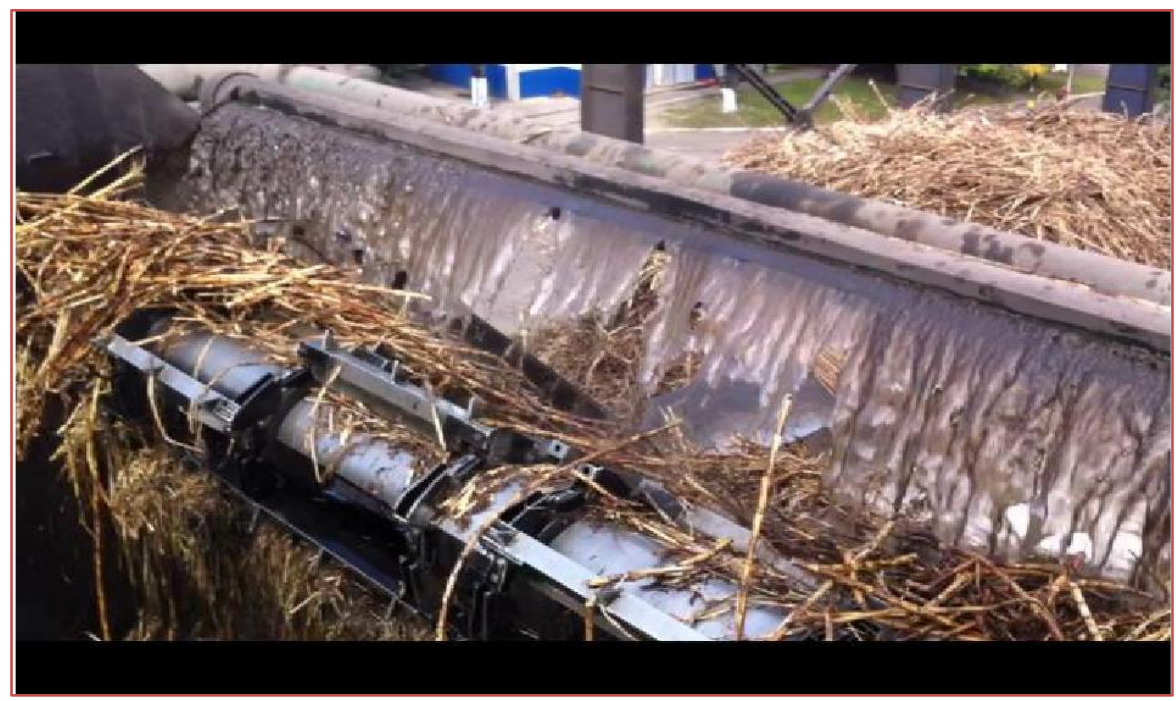

Fonte: AUTOR

Nos ternos de moendas a cana é esmagada para que haja a separação do caldo com o bagaço, logo após é embebida com água para que haja uma melhor extração dos açúcares redutores totais, este processo de embebição se repete três vezes. A figura 02 mostra um terno de moenda. 0 caldo final é denominado de caldo misto, este é enviado para as dornas de fermentação, onde adciona-se o fermento (leite tratado) pelo processo Mellé-Boinot (levedura Saccharomyces cerevisiae), passando a ser chamado de mosto fermentado. 
Figura 02 - Terno de Moenda

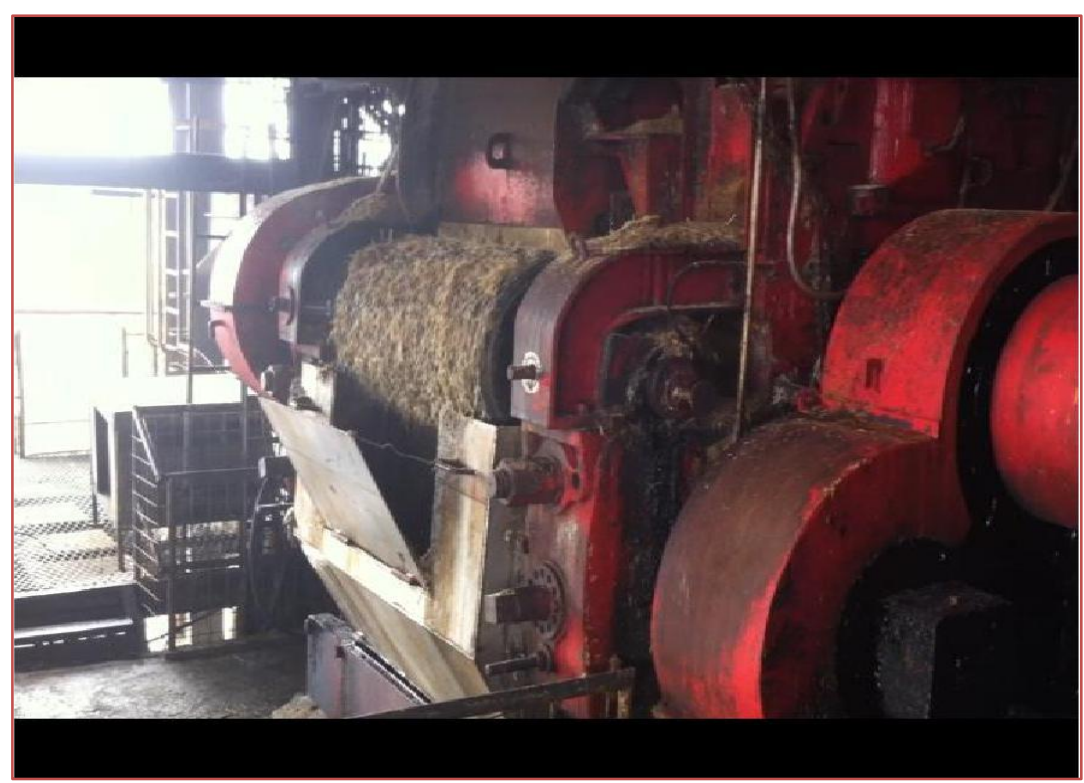

Fonte: AUTOR

\subsubsection{MELAÇO}

No processo de fabricação de açúcar, logo após as moendas o caldo passará por alguns processos de clarificação do caldo.

"Para se obter um açúcar de qualidade é necessário clarificar com produtos alcalinos, oxidantes e de agentes floculantes, para minimizar os efeitos destas substâncias no produto final" (ALBUQUERQUE, 2009).

Depois da clarificação o caldo é encaminhado para filtração e em seguida para a evaporação, que tem como principal objetivo retirar a água do caldo para geração de vapor. Seguindo para cristalização, é nesta etapa que o açúcar é realmente produzido. Ao final desta etapa temos o açúcar que ainda seguirá para secagem. E o melaço, que é o mel final que contém os açúcares redutores totais que não foram cristalizados é enviado para dornas de fermentação.

"A quantidade de melaço produzida está normalmente na faixa de 3 a 4,5 ton /100 ton de cana, sendo fortemente dependente da quantidade de não sacarose contida no caldo bruto. (REIN, 2013).

\subsubsection{FERMENTAÇÃO}

O processo de fermentação alcoólica ocorre nas dornas de fermentação. Nelas o caldo misto é misturado ao leite tratado (inóculo de Saccharomyces cerevisiae) no percentual de 20 á 30\% que são responsáveis pela produção das enzimas capazes de hidrolisar, ou seja, promover a inversão dos açucares não redutores (sacarose) em açúcares redutores (glicose e frutose) onde são convertidos em etanol e CO2, as principais enzimas que dominam o processo são a invertase e zimase. Na figura 03 observa-se as dornas de fermentação da Usina em estudo.

Existem duas formas de condução de processos de fermentação alcoólica, classificadas em descontínuos (batelada) e contínuos, assim como os que reutilizam e os que não reutilizam o inóculo. 
Figura 03 - Dornas de Fermentação

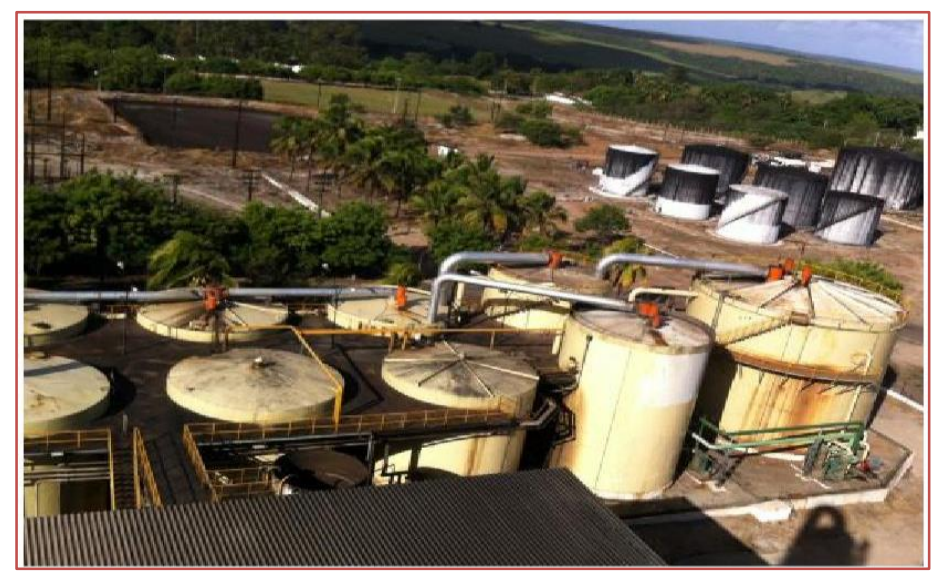

Fonte: AUTOR

A Usina em estudo utiliza ambos os processos. 0 processo descontínuo (batelada) pode ser conduzido de diferentes modos. As operações de carga, fermentação, descarga do meio fermentado e limpeza são realizadas de modo intermitente. Já no processo contínuo a forma de condução é a alimentação do mosto (adição do substrato) e a retirada do meio fermentado se processa de modo contínuo e na mesma vazão.

\subsubsection{DESTILAÇÃO.}

Depois do processo de fermentação vem a destilação que é uma operação unitária que visa a separação de componentes do vinho (mosto fermentado), de acordo com a volatilidade relativa dos mesmos, o mais volátil desloca-se para a fase leve, enquanto que o menos volátil permanece preferencialmente na fase pesada (vinhaça ou restilo).

"A destilação é a operação de transferência de massa mais empregada na indústria química. A diferença de volatilidade (ponto de ebulição) existente entre os componentes presentes no vinho é a força motriz efetiva da separação neste processo. 0 agente que promove essa separação é o calor, aliado aos pratos internos da coluna de destilação de separação." (CALDAS, et al. 2007)

0 vinho é introduzido na parte superior da torre de destilação, enquanto que o vapor e introduzido na parte inferior, eles entram na torre já no ponto bolha e ponto orvalho, é o ponto em que o líquido está prestes a virar vapor e o vapor está prestes a virar líquido. A medida que o vapor sobe o vinho vai sendo esgotado, enriquecendo cada vez mais o vapor de álcool. A figura 04 ilustra as colunas de destilações da usina em estudo.

Figura 04 - Torres de Destilação

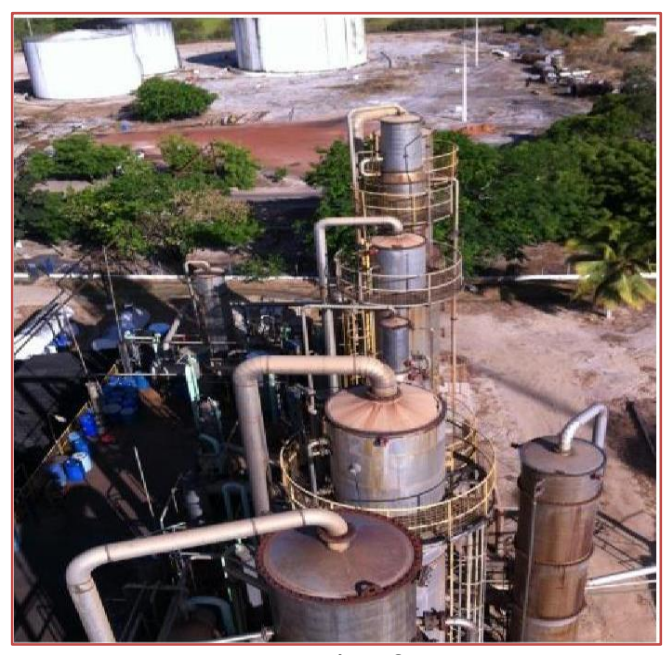

Fonte: AUTOR 
Industrialmente, a destilação é feita em equipamentos chamados de colunas ou torres de destilação, que podem ser de estágios (pratos ou bandejas) ou de contato (recheio).

Após a etapa de destilação o etanol é encaminhado ao armazenamento, ilustrado na figura 05 , onde são realizadas análises de acordo com a ANP.

Figura 05 - Estoque de Álcool

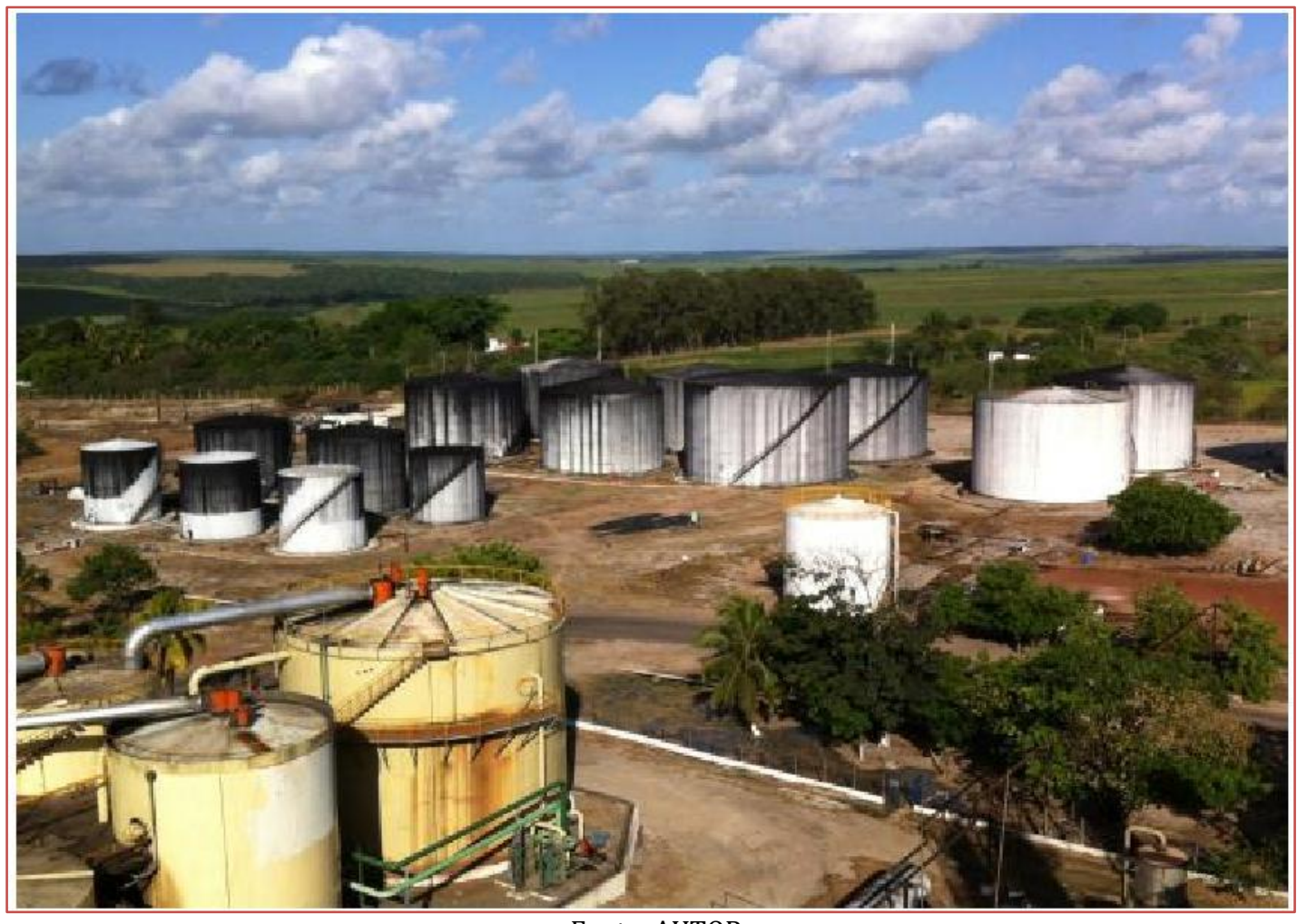

Fonte: AUTOR

\section{METODOLOGIA}

No presente estudo foram avaliados dados dos boletins de análise do acompanhamento na destilaria da Usina em estudo, que produz etanol $1 \mathrm{G}$, e da unidade produtora de açúcar. Foi escolhido o mês de setembro de 2014, (por ser um mês em que a oferta de matéria é mais disponível e o processo industrial na destilaria) não sofre flutuações para a coleta de dados e análises feitas em laboratório industrial da referida usina.

Nos boletins de análises foram acompanhados os seguintes parâmetros: Brix, Art e pureza do caldo misto e do melaço diluído. Já nos boletins de análise fermentação da destilaria foi observado o seguinte parâmetro: teor alcoólico do vinho expresso em Graduação alcoólica (oGL) produzido a partir do processo de fermentação do caldo misto e do melaço diluído. 0 teor de álcool final nas dornas de fermentação é quantificado por ebuliometria.

\section{RESULTADOS E DISCUSSÃO}

0 melaço proveniente da fabricação de açúcar chega com uma concentração de $78^{\circ}$ Brix e Art de $60 \mathrm{mg} / \mathrm{L}$ porém o mesmo é diluído em $20 \%$ com água.

Nas tabelas 01, 02 e 03 estão expostos os valores para os parâmetros brix, art e pureza respectivamente para o melaço diluído e o caldo misto, retirados dos boletins de análises no mês de setembro de 2014. 
Tabela 01: Brix do melaço diluído e do caldo misto da cana-de-açúcar.

\begin{tabular}{|c|c|c|}
\hline \multirow[t]{2}{*}{ Data } & \multicolumn{2}{|c|}{ Brix } \\
\hline & Melaço & Caldo \\
\hline $01 / 09 / 2014$ & 15,64 & 11,40 \\
\hline $02 / 09 / 2014$ & 16,04 & 11,36 \\
\hline $03 / 09 / 2014$ & 15,84 & 12,70 \\
\hline $04 / 09 / 2014$ & 16,12 & 12,52 \\
\hline $05 / 09 / 2014$ & 16,04 & 13,57 \\
\hline $06 / 09 / 2014$ & 16,08 & 11,82 \\
\hline $07 / 09 / 2014$ & 15,92 & 12,38 \\
\hline $08 / 09 / 2014$ & 15,96 & 12,25 \\
\hline $09 / 09 / 2014$ & 16,00 & 11,78 \\
\hline $10 / 09 / 2014$ & 16,00 & 11,73 \\
\hline $11 / 09 / 2014$ & 14,96 & 11,78 \\
\hline $12 / 09 / 2014$ & 15,00 & 12,21 \\
\hline $13 / 09 / 2014$ & 15,40 & 12,00 \\
\hline $14 / 09 / 2014$ & 15,60 & 11,56 \\
\hline $15 / 09 / 2014$ & 15,68 & 11,13 \\
\hline $16 / 09 / 2014$ & 15,76 & 11,87 \\
\hline $17 / 09 / 2014$ & 15,60 & 12,55 \\
\hline $18 / 09 / 2014$ & 15,96 & 12,45 \\
\hline $19 / 09 / 2014$ & 15,36 & 12,47 \\
\hline $20 / 09 / 2014$ & 15,68 & 12,72 \\
\hline $21 / 09 / 2014$ & 15,96 & 12,56 \\
\hline $22 / 09 / 2014$ & 15,6 & 13,18 \\
\hline $23 / 09 / 2014$ & 15,44 & 12,53 \\
\hline $24 / 09 / 2014$ & 15,68 & 11,80 \\
\hline $25 / 09 / 2014$ & 16,04 & 11,41 \\
\hline $26 / 09 / 2014$ & 16,16 & 12,02 \\
\hline $27 / 09 / 2014$ & 15,52 & 12,68 \\
\hline $28 / 09 / 2014$ & 16,32 & 11,82 \\
\hline $29 / 09 / 2014$ & 15,66 & 11,82 \\
\hline $30 / 09 / 2014$ & 15,6 & 12,85 \\
\hline MÉDIA & 15,75 & 12,16 \\
\hline
\end{tabular}

A tabela 01 mostra que existe uma diferença entre a média do brix do melaço diluído e o brix do caldo misto.

A figura 06 a seguir ilustra o range de diferença existente entre o processo fermentativo levado a cabo com melaço e caldo misto. Observa-se que o ajuste do brix torna-se maior quando a dorna é preparada com melaço.

Figura 6. Gráfico do brix nas dornas

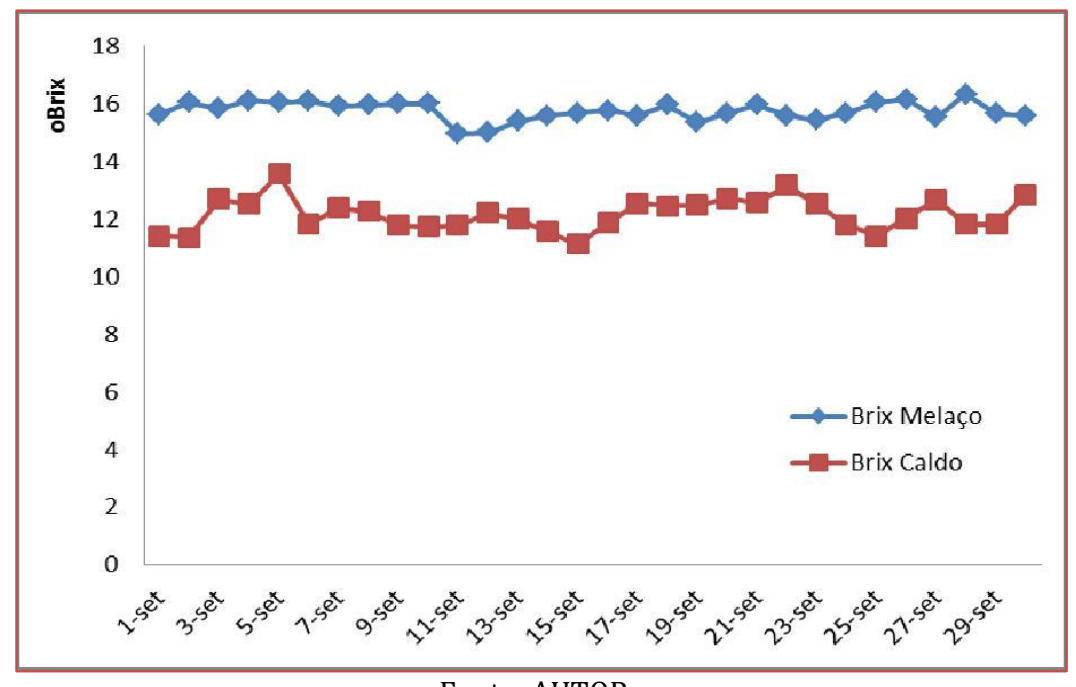


A tabela 02 também mostra uma média maior para o art do melaço diluído.

Tabela 02: ART do melaço diluído e do caldo misto da cana-de-açúcar .

\begin{tabular}{|c|c|c|}
\hline \multirow[t]{2}{*}{ Data } & \multicolumn{2}{|c|}{ ART } \\
\hline & Melaço & Caldo \\
\hline $01 / 09 / 2014$ & 12,16 & 10,85 \\
\hline $02 / 09 / 2014$ & 12,04 & 09,89 \\
\hline $03 / 09 / 2014$ & 12,10 & 11,06 \\
\hline $04 / 09 / 2014$ & 12,15 & 09,72 \\
\hline $05 / 09 / 2014$ & 12,10 & 09,17 \\
\hline $06 / 09 / 2014$ & 12,16 & 10,88 \\
\hline $07 / 09 / 2014$ & 12,10 & 11,22 \\
\hline $08 / 09 / 2014$ & 12,21 & 11,25 \\
\hline $09 / 09 / 2014$ & 11,98 & 10,33 \\
\hline $10 / 09 / 2014$ & 11,98 & 09,69 \\
\hline $11 / 09 / 2014$ & 11,76 & 10,43 \\
\hline $12 / 09 / 2014$ & 11,65 & 09,93 \\
\hline $13 / 09 / 2014$ & 10,89 & 10,02 \\
\hline $14 / 09 / 2014$ & 11,76 & 09,49 \\
\hline $16 / 09 / 2014$ & 11,70 & 09,88 \\
\hline $17 / 09 / 2014$ & 11,76 & 10,91 \\
\hline $18 / 09 / 2014$ & 11,70 & 11,41 \\
\hline $19 / 09 / 2014$ & 11,43 & 10,71 \\
\hline $20 / 09 / 2014$ & 11,54 & 10,79 \\
\hline $21 / 09 / 2014$ & 11,54 & 11,13 \\
\hline $22 / 09 / 2014$ & 11,76 & 11,76 \\
\hline $23 / 09 / 2014$ & 11,76 & 11,36 \\
\hline $24 / 09 / 2014$ & 11,76 & 10,40 \\
\hline $25 / 09 / 2014$ & 11,98 & 10,28 \\
\hline $26 / 09 / 2014$ & 11,82 & 10,38 \\
\hline $27 / 09 / 2014$ & 11,92 & 11,67 \\
\hline $28 / 09 / 2014$ & 12,04 & 10,42 \\
\hline $29 / 09 / 2014$ & 11,92 & 10,71 \\
\hline $30 / 09 / 2014$ & 11,65 & 12,10 \\
\hline MÉDIA & 11,84 & 10,60 \\
\hline
\end{tabular}

A tabela 03 mostra que existe uma média de pureza significativamente maior para o caldo misto.

O teor alcoólico do vinho é de extrema importância no processo de fabricação do álcool, pois é ele que será esgotado nas colunas ou torres de destilação, porém o mesmo não pode ser alto demais para não prejudicar as leveduras. A tabela 04 mostra os dados dos teores alcoólicos do vinho, provenientes da fermentação com melaço diluído e com caldo misto, retirados dos boletins de Análise Fermentação do mês se setembro de 2014. 
Tabela 03: Pureza do melaço diluído e do caldo misto da cana-de-açúcar.

\begin{tabular}{|c|c|c|}
\hline \multirow[t]{2}{*}{ Data } & \multicolumn{2}{|c|}{ Pureza } \\
\hline & Melaço & Caldo \\
\hline 01/09/2014 & 53,50 & 80,17 \\
\hline $02 / 09 / 2014$ & 52,74 & 78,52 \\
\hline $03 / 09 / 2014$ & 52,19 & 81,18 \\
\hline $04 / 09 / 2014$ & 52,41 & 75,48 \\
\hline $05 / 09 / 2014$ & 53,76 & 80,98 \\
\hline $06 / 09 / 2014$ & 54,72 & 79,53 \\
\hline $07 / 09 / 2014$ & 51,96 & 80,69 \\
\hline $08 / 09 / 2014$ & 52,87 & 81,06 \\
\hline $09 / 09 / 2014$ & 52,94 & 79,79 \\
\hline $10 / 09 / 2014$ & 52,94 & 78,18 \\
\hline $11 / 09 / 2014$ & 56,61 & 79,20 \\
\hline $12 / 09 / 2014$ & 55,33 & 75,84 \\
\hline $13 / 09 / 2014$ & 55,97 & 80,16 \\
\hline $14 / 09 / 2014$ & 55,44 & 80,96 \\
\hline $15 / 09 / 2014$ & 53,34 & 80,41 \\
\hline $16 / 09 / 2014$ & 52,16 & 80,79 \\
\hline $17 / 09 / 2014$ & 52,97 & 80,31 \\
\hline $18 / 09 / 2014$ & 53,36 & 82,57 \\
\hline $19 / 09 / 2014$ & 54,84 & 80,75 \\
\hline $20 / 09 / 2014$ & 53,29 & 52,55 \\
\hline $21 / 09 / 2014$ & 52,79 & 79,85 \\
\hline $22 / 09 / 2014$ & 53,29 & 81,64 \\
\hline $23 / 09 / 2014$ & 53,44 & 79,41 \\
\hline $24 / 09 / 2014$ & 54,84 & 79,07 \\
\hline $25 / 09 / 2014$ & 52,30 & 78,88 \\
\hline $26 / 09 / 2014$ & 52,41 & 79,95 \\
\hline $27 / 09 / 2014$ & 52,64 & 80,83 \\
\hline $28 / 09 / 2014$ & 52,00 & 77,07 \\
\hline $29 / 09 / 2014$ & 52,74 & 82,31 \\
\hline $30 / 09 / 2014$ & 52,82 & 81,79 \\
\hline MÉDIA & 53,42 & 79,00 \\
\hline
\end{tabular}

Tabela 04: Teor alcoólico do vinho $\left({ }^{\circ} \mathrm{GL}\right)$

\begin{tabular}{|c|c|c|}
\hline \multirow[t]{2}{*}{ Data } & \multicolumn{2}{|c|}{ Teor Alcoólico } \\
\hline & $\left({ }^{\circ} \mathrm{GL}\right)$ Melaço & $\left({ }^{\circ} \mathrm{GL}\right)$ Caldo \\
\hline $01 / 09 / 2014$ & 7,20 & 6,00 \\
\hline $02 / 09 / 2014$ & 8,40 & 6,08 \\
\hline $03 / 09 / 2014$ & 8,30 & 6,25 \\
\hline $04 / 09 / 2014$ & 8,93 & 6,90 \\
\hline $05 / 09 / 2014$ & 7,85 & 7,11 \\
\hline $06 / 09 / 2014$ & 8,10 & 6,79 \\
\hline $07 / 09 / 2014$ & 7,46 & 6,70 \\
\hline $08 / 09 / 2014$ & 7,90 & 6,22 \\
\hline $09 / 09 / 2014$ & 6,90 & 6,20 \\
\hline $10 / 09 / 2014$ & 7,30 & 6,23 \\
\hline $11 / 09 / 2014$ & 8,30 & 6,25 \\
\hline $12 / 09 / 2014$ & 8,00 & 6,39 \\
\hline $13 / 09 / 2014$ & 7,90 & 6,22 \\
\hline $14 / 09 / 2014$ & 7,46 & 6,60 \\
\hline $15 / 09 / 2014$ & 7,68 & 6,38 \\
\hline $16 / 09 / 2014$ & 7,30 & 6,33 \\
\hline $17 / 09 / 2014$ & 7,70 & 6,50 \\
\hline $18 / 09 / 2014$ & 7,80 & 6,57 \\
\hline $19 / 09 / 2014$ & 7,95 & 6,95 \\
\hline $20 / 09 / 2014$ & 9,35 & 6,79 \\
\hline $21 / 09 / 2014$ & 7,55 & 6,95 \\
\hline $22 / 09 / 2014$ & 8,10 & 6,88 \\
\hline $23 / 09 / 2014$ & 7,35 & 6,96 \\
\hline $24 / 09 / 2014$ & 7,50 & 6,69 \\
\hline $25 / 09 / 2014$ & 7,70 & 6,80 \\
\hline $26 / 09 / 2014$ & 6,95 & 6,55 \\
\hline $27 / 09 / 2014$ & 7,00 & 6,85 \\
\hline $28 / 09 / 2014$ & 7,30 & 6,41 \\
\hline $29 / 09 / 2014$ & 7,05 & 6,85 \\
\hline $30 / 09 / 2014$ & 7,40 & 6,72 \\
\hline MÉDIA & 7,72 & 6,57 \\
\hline
\end{tabular}


Na tabela 04 é possível observar que a média para o teor alcoólico do vinho proveniente da fermentação do melaço diluído é maior que o teor alcoólico proveniente da fermentação do caldo misto.

Na figura 7 a seguir observa-se que o maior rendimento no processo de fermentação nas dornas, acontece quando a matéria-prima de produção é o melaço. Isso acontece em virtude de se ter um controle maior sobre o brix de alimentação das dornas. Como o melaço tem um brix de $78^{\circ}$ o mesmo pode ser corrigido para um valor que permita um maior rendimento de etanol no vinho final.

Isso mostra que o processo fermentativo de produção do etanol de primeira geração a partir do melaço, traz um ganho significativo para a Usina em estudo.

Figura 7. Gráfico do teor de álcool nas dornas

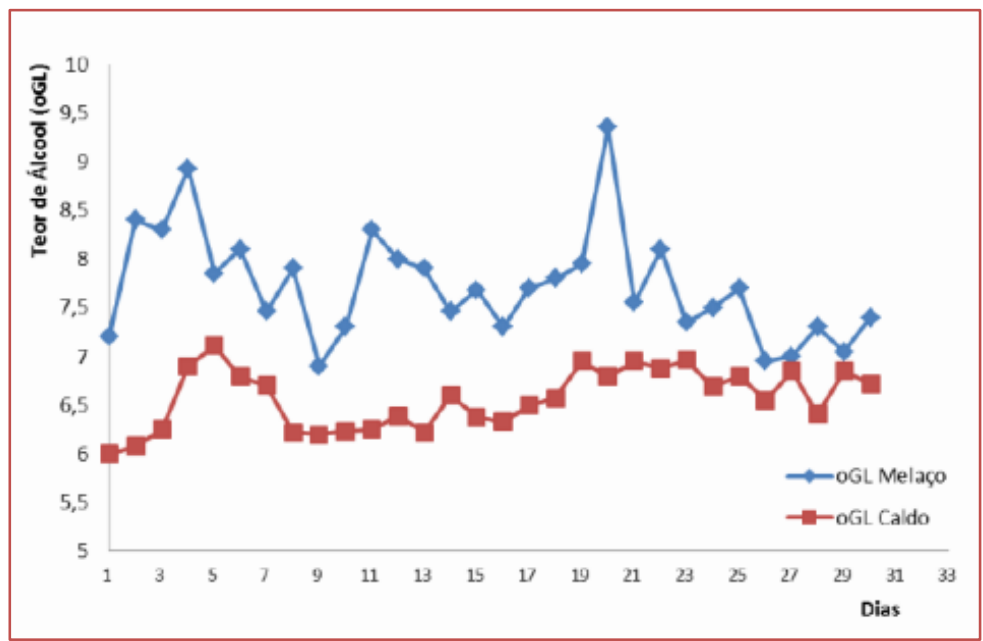

Fonte: AUTOR

\section{CONCLUSÕES}

No mês em questão houve um total de cana moída de 134.471,94 toneladas e uma produção de álcool de 11.445.362 litros, que dá um total de aproximadamente 85 litros de álcool para cada tonelada de cana moída.

Os valores mais elevados de Brix e Art para o melaço podem ser explicados pelo fato do melaço conter os açúcares que não foram cristalizados. De forma que o caldo de cana terá sempre valores mais baixos para os parâmetros em questão.

A pureza do caldo é maior que a do melaço graças ao teor de Brix, pois o mesmo não possui apenas sacarose, glicose e frutose.

Segundo Celso Caldas (2005) a definição de brix em fábricas sucroalcooleiras pode ser aperfeiçoada para porcentagem aparente de sólidos dissolvidos em solução. Pois a mesma não mostra apenas a quantidade de açúcares, mas também de impurezas contidas na solução.

Portanto quanto maior o Art e brix no início da fermentação, maior será o teor alcoólico no vinho.

Nos dados apresentados é possível observar que é mais vantajoso a produção de álcool a partir do melaço.

Utilizado o melaço em usinas que produzem álcool e tem um anexo que produz açúcar ou que sejam do mesmo grupo ou que tenham parcerias, pois no melaço existe um alto índice de açúcares que não foram cristalizados.

As usinas que são produtoras apenas de álcool compram o melaço tendo como vantagem o baixo preço deste subproduto da produção de açúcar. 


\section{AGRADECIMENTOS}

A Destilaria Japungu e Destilaria Agroval.

\section{REFERÊNCIAS}

[1] ALBUQUERQUE, Fernando Medeiros de. Processo de Fabricação do Açúcar. Editora Universitária UFPE, 2009.

[2] açúcares não sejam perdidos são reutilizados nas usinas de álcool, para que sejam fermentados e convertidos.

[3] ANVISA. Melaço, Melado, Rapadura. Disponível em:<www.anvisa.gov.br>.16 de janeiro de 2015.

[4] CALDAS, Celso. Teoria Básica das Análises Sucroalcooleiras. Central Analítica, 2005.

[5] CALDAS, Jorge Navaes. et al. Internos de Torres. Interciéncia, 2007.

[6] HUGOT, Emile. Manual de Engenharia Açucareira. Mestre Jou, 1977.

[7] REIN, Peter. Engenharia do Açúcar de Cana. Bartens, 2013. 


\section{Capítulo 20}

Síntese de catalisadores a base de cério e zircônio por decomposição térmica de nitratos

\section{Cristiane Leal}

Thaís Mendonça de Carvalho

Rogério Navarro Correia de Siqueira

Resumo: 0 presente trabalho tem como objetivo sintetizar nanocatalisadores de óxido de cério dopado com óxido de cálcio e óxido de zircônio dopado, também, com óxido de cálcio, a partir de seus respectivos nitratos por decomposição térmica, seguido do processo de calcinação, para futura utilização dos mesmos na produção de bioóleo a partir de biomassa lignocelulósica através da pirólise rápida. A síntese foi feita utilizando uma solução de cada nitrato, do dopante e do dopado. Os materiais foram submetidos à Microscopia Eletrônica de Varredura (MEV), Espectroscopia de Energia Dispersiva (EDS) e Difração de Raio-X (DRX), que confirmaram a síntese de materiais de natureza nanoestruturadas e com composição elementar condizente com as expectativas.

Palavras-chave: nanocatalisadores, óxidos, decomposição térmica, biodiesel. 


\section{INTRODUÇÃO}

0 uso de catalisadores é essencial na área tecnológica pois faz com que a velocidade de uma reação química aumente de maneira significativa, isso ocorre devido a diminuição da energia de ativação, que é a energia mínima necessária para que o reagente comece a se transformar em produto (CHAGAS, 2013).

Materiais nanoestruturados vêm sendo bastante explorados no meio científico e têm se tornado fundamentais em diversas áreas tecnológicas como eletrônica, catálise, sensores, entre outras. Materiais nano tem muitas vezes propriedades físicas e químicas superiores aos materiais mássicos de mesma composição química (MAYRINCK et al., 2014). Na catálise, a busca por um catalisador adequado é um dos maiores desafios para os pesquisadores, a razão entre sua área e volume deve ser a maior possível, afim de maximizar sua exposição quando em contato com o reagente (BACANI, 2014). Catalisadores precisam ser seletivos, ativos e estáveis, sendo assim, um caminho para otimizar tais propriedades, o controle da adição de cátions metálicos dopantes.

Os óxidos metálicos vêm sendo cada vez mais explorados na confecção de catalisadores eficientes voltados à aceleração de reações orgânicas, apresentam ótimas propriedades catalíticas, atingindo tamanho nano de partículas, e com isso, superfície de contato considerável. 0 óxido contendo céria (CeO2) é amplamente usada neste contexto, sendo muito utilizada na catálise automotiva de três vias, que tem como finalidade eliminar gases poluentes, oxidando $\mathrm{CO}$ em $\mathrm{CO} 2$ e reduzindo NOX em N2, devido a algumas de suas propriedades, tais como: mobilidade de oxigênio na rede cristalina, afinidade por compostos contendo oxigênio, nitrogênio e enxofre e ausência de oxirredução (MARTINS; HEWER; FREIRE, 2007). 0 óxido de cério é utilizado como suporte nos catalisadores metálicos por apresentarem estabilidade térmica na sua estrutura do tipo fluorita promovendo uma forte interação entre os metais, concedendo seletividade aos catalisadores (SILVA, 2011).

Já zircônia (ZrO2) tem se destacado em diversos setores tecnológicos e científicos devido sua alta estabilidade mecânica e térmica. Este óxido é um material polimorfo que dependendo da temperatura em que é colocado pode sofrer alterações na sua rede cristalina. As estruturas cristalinas mais comuns são: monoclínica, tetragonal e cúbica. Na catálise, quando estabilizada em sua estrutura cúbica, tem aplicação em sensores de oxigênio e células de combustível, já que existe uma alta mobilidade dos íons oxigênio em seu arranjo (MINEIRO; MARQUES, 2016).

De acordo com (BORGES; DÍAZ, 2012), óxido de cálcio, contem características básicas, e apresenta muitas vantagens como aumento de vida útil do catalisador e alta atividade catalítica. Também pode-se dizer que há um baixo impacto ambiental devido à sua baixa solubilidade em metanol e fontes naturais ou de resíduos baratos, a partir das quais pode ser obtido (MARINKOVIĆ et al., 2016). MARINKOVIĆ e colaboradores também verificaram que os catalisadores, contendo este óxido como base, têm potencial para serem utilizados como heterogêneos na produção de biodiesel, devido sua alta eficiência na reação de transesterificação, formando uma menor quantidade de rejeitos.

Neste trabalho, foi sintetizado óxido de zircônio e óxido de cério, ambos dopados com óxido de cálcio, a fim de produzir soluções sólidas nanoestruturadas para futura produção de biodiesel a partir de biomassa. Análises de MEV/EDS foram feitas afim de avaliar a composição elementar dos materiais sintetizados e a possibilidade de impurezas. Já as difrações de raio X para verificar se houve a produção de uma estrutura monofásica.

\section{METODOLOGIA}

0 procedimento de síntese começa com a preparação de duas amostras, onde, primeiramente, produz uma solução 0,05 mol. L-1 de nitrato cálcio. Essa solução é misturada, separadamente, à solução do nitrato de cério ou de zircônio, contendo a concentração de 0,1624 mol. L-1 (SILVA-CALPA et al., 2016). Foram adicionadas em um béquer e permaneceram em uma manta com uma taxa de aquecimento de $10 \stackrel{\circ}{\circ} \mathrm{C}$ por minuto até, em média, a temperatura de $350{ }^{\circ} \mathrm{C}$, permanecendo até completar 120 minutos, em seguida, foram trituradas e levadas para mufla à $600^{\circ} \mathrm{C}$ por 3 horas.

As imagens obtidas para os óxidos sintetizados foram feitas com o Microscópio Eletrônico de Varredura/Espectroscopia de Raio X por Dispersão em Energia (MEV/EDS) da Hitachimodelo TM-3000 com a intenção de analisar a morfologia superficial e a composição química elementar das substâncias.

O equipamento utilizado para a análise referente a DRX foi o Difratômetro de Raios X da Bruker modelo D8 Discover. A comprovação da dopagem, contendo $\mathrm{Zr}$ e Ce, e a formação do material de interesse, mediante a determinação das frações em massa de todas as fases cristalinas presentes, foi utilizado a 
análise de Rietveld, onde, utilizando o software topas 4.2, implementou-se um ajuste via parâmetros fundamentais com a base de dados do Inorganic Crystal Structure Database (ICSD).

\section{RESULTADOS E DISCUSSÃO}

A Figura 1 apresenta a micrografia obtida via MEV e resultados do EDS referentes a amostra de 0,1624 mol. L-1 de Ce(NO3)3 dopado com 0,05 mol. L-1 de $\mathrm{Ca}(\mathrm{NO}) 2.4 \mathrm{H} 2 \mathrm{O}$, nomeada como amostra A e as porcentagens em massa e atômica também foram exibidas. Os picos sugerem a presença de oxigênio, cálcio e cério, conforme o previsto, além do pico que não foi nomeado, que está relacionado ao alumínio, o elemento presente no material do porta-amostra.

Figura 1- Resultados da MEV e EDS referentes à amostra A com ampliação de 2.000X.

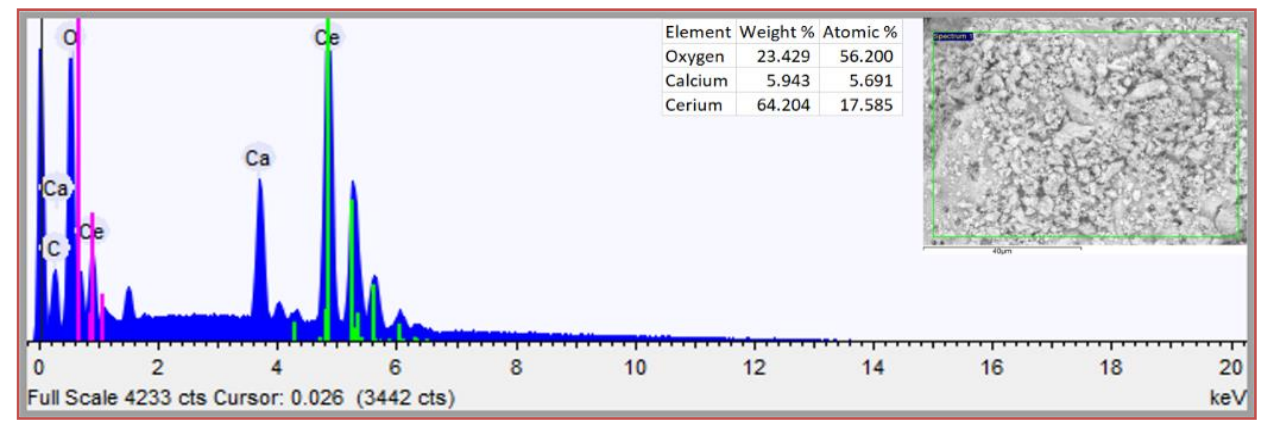

Fonte: própria

A base ICSD do difratograma, para análise Rietveld, referente ao CaO_CeO2 foi realizado através do CHANDRA et al. (2006) e comparado com a amostra A.

Figura 2- Difratograma dos dados de DRX da amostra A sintetizada por decomposição térmica.

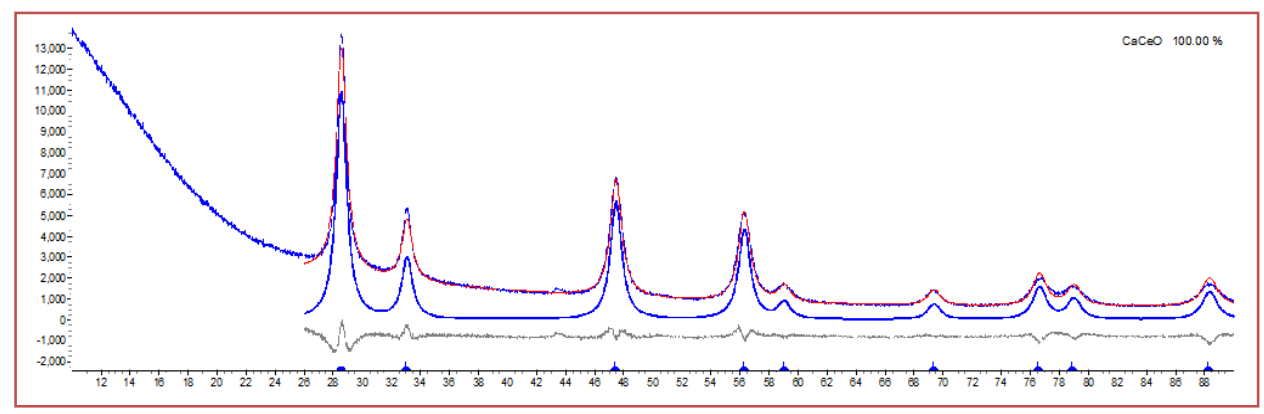

Fonte: própria

O difratograma apresenta picos alargados, característico de um material nanoestruturado. Após a análise de Rietveld foi confirmada a síntese de um material monofásico, que apresenta $95 \% \mathrm{Ce}+4$ e $5 \%$ de $\mathrm{Ca}+2$.

A Figura 3 mostra a micrografia obtida via MEV da amostra de 0,1624 mol L-1 de nitrato de zircônio dopada com 0,05 mol. L-1 de Ca(NO3)2.4H2O, nomeada como amostra B. 0 espectro obtido por EDS, também é apresentado incluindo porcentagens em massa e atômica. 0 espectro apresenta picos referentes aos elementos presentes na amostra, como esperado, sendo um correspondente ao alumínio, material do porta-amostras. 
Figura 3- Resultados da MEV e EDS referentes à amostra B com ampliação de 300X.

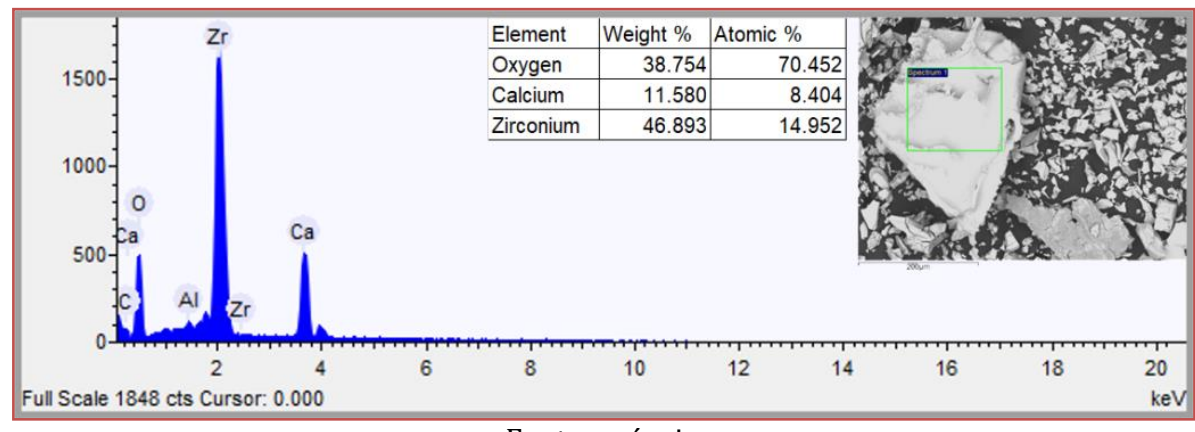

Fonte: própria

Para as amostras contendo CaO_ZrO2, foi utilizado a base de dados de FÁBREGAS et al. (2008) e SHEN et al. (2011) comparado com obtido a amostra B sintetizada.

Figura 4- Difratograma dos dados de DRX da amostra B sintetizada por decomposição térmica.

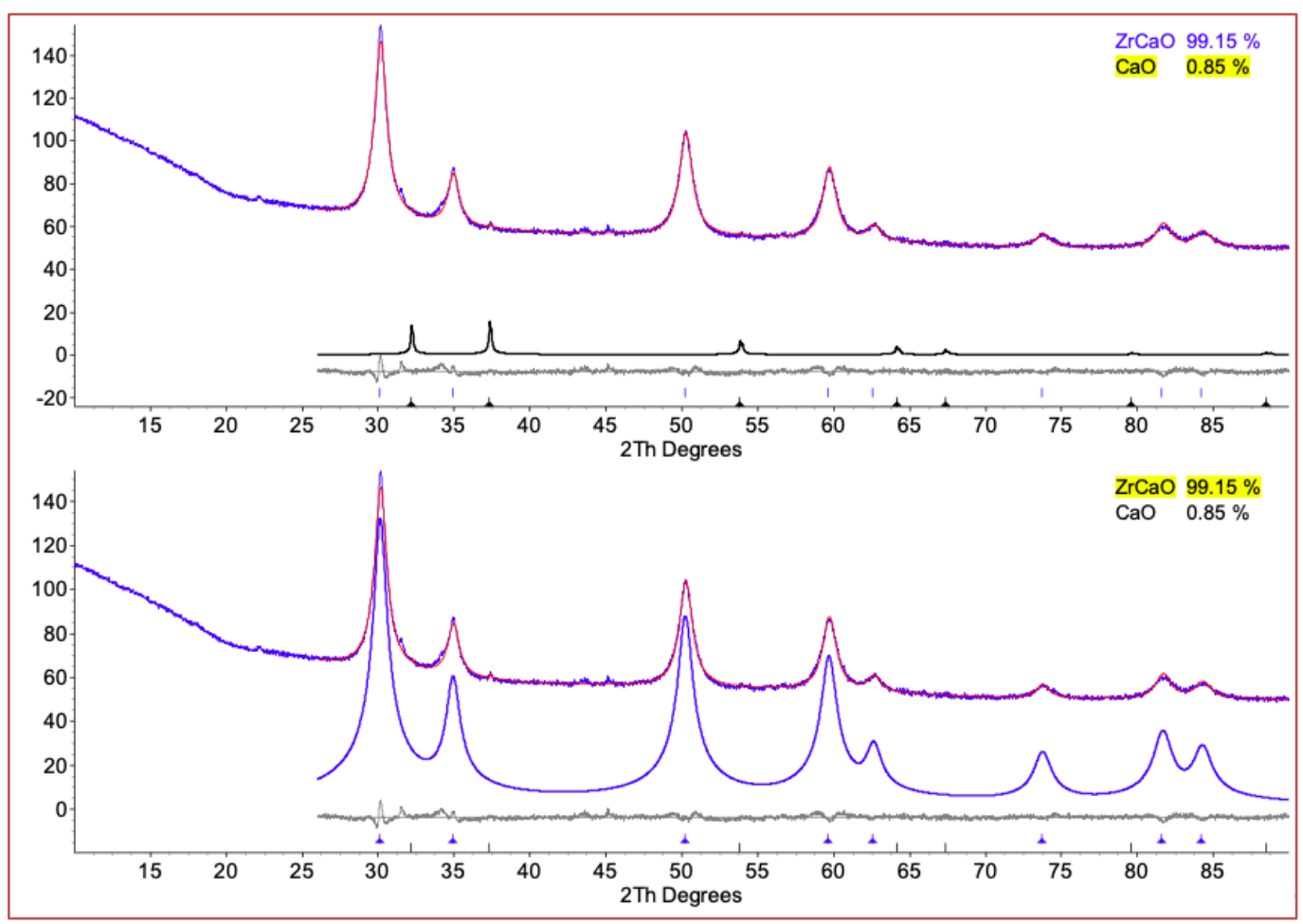

Fonte: própria

O material sintetizado possui em sua composição uma porcentagem em que a maior parte do cálcio está na forma de uma solução sólida, dopada com a zircônia e uma pequena proporção referente ao óxido de cálcio. Uma possível explicação, seria a falta de tratamento térmico eficiente e/ou o excesso do cálcio no processo. A grande maioria dos picos são provenientes da formação do $\mathrm{CaO}_{\mathrm{Z}} \mathrm{ZrO}$ 2. O material foi sintetizado na faixa nanométrica pelo os picos alargados e tamanho médio de cristalino pequeno.

A Tabela 1 mostra o tamanho médio de cristalito referente à cada material sintetizado. 0 fato dos valores médios sugerirem a presença de material nanoestruturado, conforme já observado pelo expressivo alargamento do pico. No caso do material contendo $\mathrm{Zr}$, devemos observar que se trata da solução sólida. Também vale a pena ressaltar o fato de os valores serem bastante similares. Isso naturalmente decorre das condições de tratamento térmico. 
Tabela 1- Tamanho médio de cristalito de cada material.

\begin{tabular}{|c|c|}
\hline Amostra & Tamanho médio de cristalito (nm) \\
\hline A & 10,8 \\
\hline B & 11,4 \\
\hline
\end{tabular}

Fonte: própria

\section{CONCLUSÃO}

Os nanocatalisadores à base de céria e zircônia foram sintetizados por decomposição térmica seguido do processo de calcinação, obtendo o material nano de interesse, presença de soluções sólidas cristalinas, comprovando que a dopagem com cálcio foi bem-sucedida e composição química esperada. 0 catalisador contendo zircônia demonstra uma pequena porcentagem $(0,85 \%)$ de óxido de cálcio, isso porque o cálcio pode não ter sido incorporado completamente, devido ao tratamento térmico não ter sido eficiente ou o fato do limite de solubilidade (melhor do que excesso) ser ultrapassado.

\section{REFERÊNCIAS}

[1] BACANI, R. Síntese e caracterização de nanocatalisadores de ZrO2-Ce02/Ni para aplicação em ânodos de células a combustível de óxido sólido. [s.l: s.n.].

[2] BORGES, M. E.; DÍAZ, L. Recent developments on heterogeneous catalysts for biodiesel production by oil esterification and transesterification reactions: A review. Renewable and Sustainable Energy Reviews, v. 16, n. 5, p. 2839-2849, 2012.

[3] CHAGAS, L. H. Produção , caracterização e determinação de propriedades físico- químicas de catalisadores e suportes utilizados em processos de hidrotratamento. p. 201, 2013.

[4] MARINKOVIĆ, D. M. et al. Calcium oxide as a promising heterogeneous catalyst for biodiesel production: Current state and perspectives. Renewable and Sustainable Energy Reviews, v. 56, p. 1387-1408, 2016.

[5] MARTINS, T. S.; HEWER, T. L. R.; FREIRE, R. S. Cério: Propriedades catalíticas, aplicações tecnológicas e ambientais. Quimica Nova, v. 30, n. 8, p. 2001-2006, 2007.

[6] MAYRINCK, C. et al. Síntese, propriedades e aplicações de óxido de zinco nanoestruturado. Revista Virtual de Quimica, v. 6, n. 5, p. 1185-1204, 2014.

[7] MINEIRO, S. L.; MARQUES, R. B. SÍNTESE DE PÓS CERÂMICOS DE ÓXIDO DE ZIRCÔNIO PELO MÉTODO DE PRECIPITAÇÃO VIA ULTRASSONIFICAÇÃO. 60o Congresso Brasileiro de Cerâmica. Anais...2016

[8] SAVAGIN, B. SÍNTESE , CARACTERIZAÇÃO E APLICAÇÃO DE ÓXIDOS METÁLICOS SUPORTADOS EM ZIRCÔNIA COMO CATALISADORES NA PRODUÇÃO DE BIODIESEL, 2016. Disponível em: <http://repositorio.roca.utfpr.edu.br/jspui/bitstream/1/7457/1/PG_COENQ_2016_2_04.pdf>

[9] SCHMAL, M. Catálise Heterogênea. Synergia ed. Rio de Janeiro: [s.n.].

[10] SILVA-CALPA, L. DEL R. et al. The ZnxZr1-xO2-ysolid solution on m-ZrO2: Creating 0 vacancies and improving the m-ZrO2redox properties. Journal of Molecular Catalysis A: Chemical, v. 425, p. 166-173, 2016.

[11] SILVA, M. F. P. DA. Óxidos De Lantanídeos a Partir Da Calcinação De Citratos: Síntese, Morfologia E Teste Catalítico. 2011. 


\section{Capítulo 21}

Avaliação da eficiência do extrato de alecrim na estabilidade oxidativa do biodiesel soja/sebo 80/20\% $(\mathrm{m} / \mathrm{m})$.

\section{Ingrid Rocha Teixeira}

Daniel Freire Almeida

Selmo Queiroz. Almeida

Iran Talis Viana Santos

Leila Maria Aguilera Campos

Resumo: Biodiesel é suscetível a processos oxidativos devido a vários fatores, como, por exemplo, a presença de oxigênio, calor, luz e metais. Estas reações oxidativas acarretam em alterações nos parâmetros de qualidade deste biocombustível, como o aumento da acidez e viscosidade. Com a finalidade de retardar ou inibir essas respectivas reações, o uso de antioxidantes naturais é favorável, devido ao seu baixo custo quando comparado aos antioxidantes sintéticos. Sendo assim, o presente trabalho visa à utilização do extrato de alecrim como inibidor das reações oxidativas no biodiesel Soja/Sebo 80/20\% $(\mathrm{m} / \mathrm{m})$. Foram realizados ensaios avaliativos de estabilidade oxidativa no equipamento Rancimat e análises de cromatografia a gás para verificar a degradação dos ésteres metílicos. Os resultados demonstraram que a adição de $1 \%(\mathrm{~m} / \mathrm{m})$ do extrato de alecrim elevou em aproximadamente $284 \%$ o parâmetro de estabilidade oxidativa. Ademais, foi verificado, através dos ensaios cromatográficos, que o extrato inibiu em 5 horas a degradação dos principais ésteres oxidados. Portanto, é possível demonstrar, portanto, que o extrato de alecrim apresentou viabilidade como estabilizador do biodiesel comercial.

Palavras-chave: Antioxidante, Biodiesel, Estabilidade Oxidativa, Alecrim. 


\section{INTRODUÇÃO}

A finitude dos recursos fósseis, bem como, o seu impacto negativo ao meio ambiente, como, por exemplo, a destruição da camada de ozônio e o aquecimento global, têm contribuído para a diversificação da matriz energética mundial e para o desenvolvimento dos combustíveis alternativos [1]. Neste contexto, o uso do biodiesel como biocombustível tem crescido no mundo inteiro, por apresentar características e potencialidades para ser um substituto parcial ou total do diesel derivado do petróleo.

O biodiesel apresenta inúmeras vantagens em relação ao diesel. Apresenta lubricidade superior, é praticamente isento de enxofre, possui origem renovável e sustentável [2]. No entanto, o biodiesel se oxida com grande facilidade, especialmente quando armazenado por muito tempo. A oxidação é proveniente de sucessivas reações radicalares que ocorrem, preferencialmente, nas insaturações dos ésteres de ácidos graxos em contato com o oxigênio atmosférico, a qual acelerada pela presença de íons metálicos, contaminantes, luz e temperaturas elevadas [3].

A intensidade da oxidação está relacionada ao grau de insaturação dos ésteres. Logo, os ácidos graxos insaturados, particularmente os ácidos oléico (C18:1), linoléico (C18:2) e linolênico (C18:3), apresentam alta propensão a auto-oxidação [4]. Ao se degradar, o biodiesel perde as qualidades de um biocombustível, o que pode acarretar danos ao motor, por isso é necessário um controle de qualidade rigoroso na estabilidade oxidativa para evitar efeitos negativos em seu uso.

Alternativas para melhorar a resistência do biodiesel à oxidação têm sido pesquisadas através da adição de antioxidante sintéticos e naturais. Devido ao alto custo dos antioxidantes sintéticos, bem como ao potencial de toxicidade relacionada ao seu uso, os estudos voltaram-se aos naturais. Dentre os antioxidantes naturais, destacam-se os compostos fenólicos, como os ácidos fenólicos, flavonoides e os tocoferóis. Os compostos fenólicos permitem a doação do hidrogênio fenólico a um radical livre, regenerando o radical a uma espécie mais estável e, assim, interrompe o mecanismo de oxidação. Desta maneira, os compostos fenólicos transformam-se em radicais livres e, posteriormente, são estabilizados por ressonância [5].

Entre as fontes vegetais, o Rosimarinus officinalis L., alecrim, tem se destacado por apresentar grande número de compostos que são potenciais fontes de antioxidantes, como os ácidos fenólicos, flavonóides, diterpenóides e triterpenos fenólicos, ricos em ácido carnósico, rosmanol e rosmarínico [6,7]. Estudos realizados evidenciaram, através do tempo de indução pelo método de Rancimat em função dos dias de estocagem, que o extrato etanoico de alecrim foi eficiente durante 60 dias de armazenamento do biodiesel do óleo de algodão, atendendo às exigências da ANP [8]. Além disso, o extrato de alecrim se mostrou mais eficiente que o BHT, um antioxidante sintético, frente ao processo oxidativo do biodiesel do óleo de algodão.

Vários estudos têm demonstrado que o extrato do alecrim possui um elevado poder antioxidante, todavia não se encontraram na literatura avaliações do extrato em um blend de biodiesel de composição próxima ao comercializado no Brasil, que segundo a Agência Nacional do Petróleo, Gás Natural e Biocombustíveis, ANP, tem como principais matérias primas o óleo de soja e o sebo animal [9]. 0 objetivo do presente trabalho, portanto, foi verificar a atividade antioxidante do extrato etanoico do alecrim no biodiesel sintetizado a partir de $80 / 20 \%(\mathrm{~m} / \mathrm{m})$ Soja/Sebo, através de técnicas de oxidação forçada no equipamento Rancimat e de cromatografia gasosa para verificar a degradação dos ésteres.

\section{METODOLOGIA}

O biodiesel de estudo foi sintetizado através da mistura 80/20\% (m/m) Soja/Sebo utilizando como catalisador o $\mathrm{KOH}, 2 \% \mathrm{~m} / \mathrm{m}$, com razão molar óleo/álcool 1:6, na temperatura de 50 으 e com tempo reacional de 30 minutos sob agitação de 350 rpm. Após reação, a glicerina foi separada por decantação e o biodiesel foi lavado até que o $\mathrm{pH}$ aproximou-se de 7,0 por uma solução de cloreto de amônio (NH4Cl) $5 \%$ $(\mathrm{m} / \mathrm{v})$. Posteriormente, o biodiesel foi encaminhado para a etapa de secagem, na qual se objetiva retirar o excesso de água proveniente da solução utilizada na etapa de lavagem.

0 aditivo proposto foi obtido através do extrator Soxhlet por via alcoólica, e o processo de secagem das amostras foi realizado em rotaevaporador, sob pressão reduzida e a uma temperatura próxima ao ponto de ebulição do solvente (etanol). Para aditivar o biodiesel, utilizou-se 1\% em massa do extrato de alecrim. Na sequência, as amostras seguiram para análises.

A caracterização das amostras em estudo foi feita através da cromatografia a gás. Para tanto, foi utilizado um cromatógrafo Agilent, modelo 7890 A, com injetor automático, detector de ionização de chama (DIC), 
sistema de injeção split/splitless, tendo como base a norma BS EN 14103:2003 [10]. O estudo de estabilidade oxidativa foi realizado no equipamento Rancimat, do fabricante Metrohm, modelo 743, segundo a metodologia europeia EN 14112:2003 [11]. No método empregado, 3 gramas da amostra foram analisadas a $110^{\circ} \mathrm{C}$, com um fluxo de ar de $10 \mathrm{~L} \mathrm{~h}-1$ e os ensaios foram realizados em triplicata.

\section{RESULTADOS E DISCUSSÃO}

Os resultados obtidos dos testes de oxidação forçada no Rancimat estão presentes na Tabela 1. Estes ensaios revelam que a adição do extrato de alecrim no biodiesel elevou em 284,33\% o parâmetro de estabilidade oxidativa, alcançando um valor de aproximadamente 16 horas. 0 biodiesel puro de estudo composto por $80 / 20 \%$ (m/m) Soja/Sebo tem uma estabilidade maior que o biodiesel de Soja estudado por Oliveira e colaboradores [12]. Tal aumento pode ser atribuído à maior parte dos ésteres constituintes do biodiesel de sebo serem saturados, uma vez que a quebra oxidativa de ácidos graxos saturados é energeticamente desfavorável [13].

Tabela 1. Estabilidade oxidativa do biodiesel

\begin{tabular}{|c|c|c|}
\hline Amostras & Concentração do aditivo $(\mathrm{m} / \mathrm{m})$ & Período de Indução (h) \\
\hline BP & - & 4,18 \\
\hline BA & 1,00 & 16,07 \\
\hline BP Oliveira e colab. & - & 2,56 \\
\hline BA Oliveira e colab. & 0,50 & 2,25 \\
\hline
\end{tabular}

$\mathrm{BP}=$ Biodiesel Puro; $\mathrm{BA}=$ Biodiesel+alecrim.

Fonte: Própria, 2017.

No Brasil, a ANP, através da norma EN 14112 [11], estabelece um período mínimo de indução de 6 horas para que o biodiesel possa ser comercializado no país, e de 8 horas para a venda no mercado exterior. Também é observado que o parâmetro de estabilidade oxidativa do blend de estudo ainda está abaixo do estabelecido pela norma brasileira, fato que evidencia a importância da adição do extrato de alecrim como estabilizador do biodiesel comercial. Todavia, a Tabela 1 mostra que o extrato não foi eficiente em estabilizar o biodiesel de Soja de Oliveira e colaboradores [12]. Tal fator pode ser associado à menor concentração de aditivo, bem como, ao método de extração utilizado.

Para verificar o comportamento dos ésteres de ácido graxo em ambiente oxidativo, foram realizadas análises cromatográficas de alíquotas retiradas durante 10 horas de degradação oxidativa no equipamento Rancimat. Estes ensaios demonstraram que os ésteres C18:2 e C18:3 foram os que apresentaram, em relação à sua massa inicial, uma maior quebra oxidativa, diminuindo a sua massa no sistema. No intervalo de 10 horas de degradação oxidativa, o éster C18:3 e C18:2 apresentaram, respectivamente, uma redução da concentração de $83 \%$ e 66\%. Com a adição do extrato de alecrim, observou-se que o aditivo retarda os processos oxidativos, levando o éster C18:3 a uma redução de 63\%, e o éster C18:2 a 33\% (FIGURA 1).

No entanto, avaliando-se as concentrações destes ésteres em tempos menores que 7 horas, a porcentagem de redução com o a adição do alecrim para o C18:3 é menor que 1\%, para o C18:2 é de 5\%, e as concentrações dos ésteres C14, C16, C18:0 e C18:1 permanecem constantes, demostrando que a adição do alecrim retarda o processo oxidativo por um tempo de sete horas. Entretanto, comparando o gráfico (a) e (b) é possível concluir que a adição do extrato inibiu as reações oxidativas por um tempo máximo de 5 horas, uma vez que, nas duas primeiras horas, ambos os gráficos possuem a mesma tendência (FIGURA 1). 
FIGURA 1- Avaliação da concentração dos ésteres metílicos (ME) de biodiesel puro (b) e do biodiesel aditivado (a) ao longo do tempo de indução.

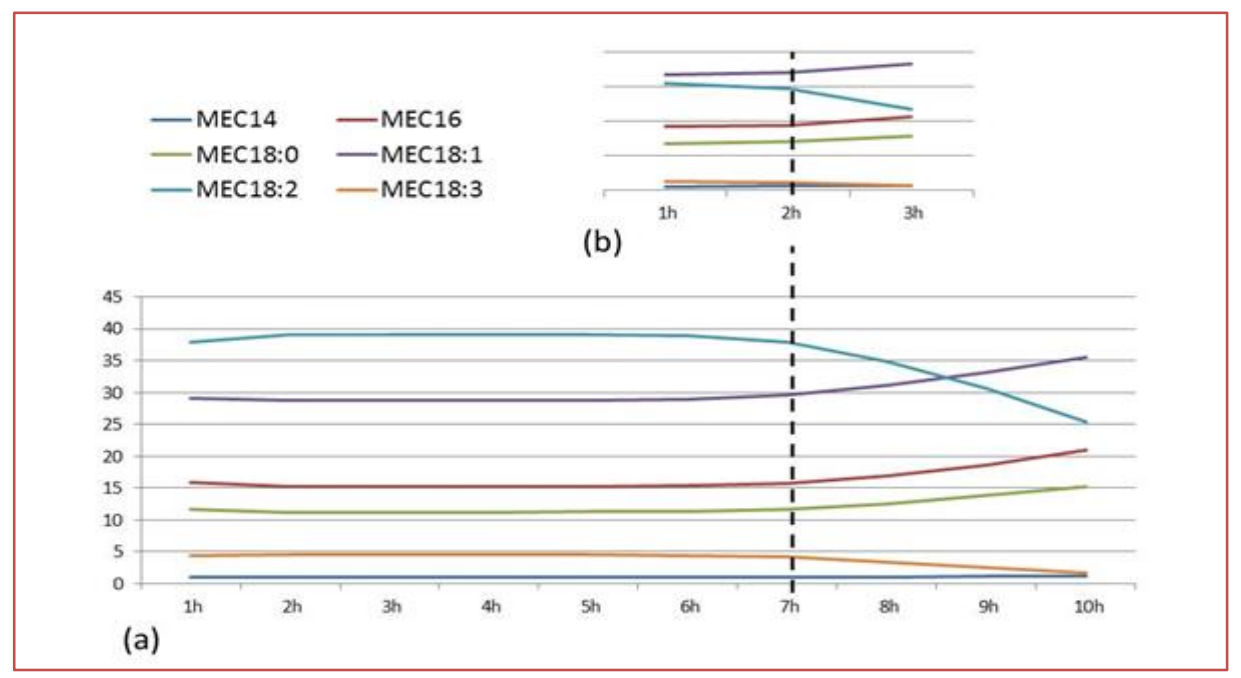

Fonte: Própria, 2017.

\section{CONCLUSÕES}

Diante dos respectivos resultados, é possível concluir que o extrato de alecrim apresentou um elevado potencial antioxidante em estabilizar o biodiesel Soja/Sebo $80 / 20 \%(\mathrm{~m} / \mathrm{m})$. Os resultados dos ensaios oxidativos indicam que a adição do extrato de alecrim no biodiesel elevou em $284,3 \%$ o parâmetro de estabilidade oxidativa em relação ao biodiesel puro. Os ensaios cromatográficos evidenciaram que esse aumento do tempo de indução deve-se à menor degradação dos ésteres metílicos quantificados nas amostras. Entretanto, novos estudos são necessários para avaliar como esse extrato influencia em outros parâmetros importantes para a comercialização deste biocombustível.

\section{AGRADECIMENTOS}

A FAPESB pelo auxílio financeiro; a UNIFACS e a UFBA pelo uso dos laboratórios; e ao IBTR por disponibilizar os equipamentos.

\section{REFERÊNCIAS}

[1] VICHI, F. M., \& MANSOR, M. T. C. Energia, meio ambiente e economia: o Brasil no contexto mundial. Química Nova, v. 32, n. 3, p. 757-767, 2009.

[2] FERRARI, R. A., OLIVEIRA, V. D. S., \& SCABIO, A. Biodiesel de soja-taxa de conversão em ésteres etílicos, caracterização físico-química e consumo em gerador de energia. Química Nova, v. 28, n. 1, p. 19-23, 2005.

[3] KNOTHE, G. Some aspects of biodiesel oxidative stability. Fuel Processing Technology, v. 88, n. 7, p. 669-677, 2007.

[4] FRANKEL, N.F., Lipid Oxidation, The Oily Press, Bridgwater, p.209-2012. 2005.

[5] RAMALHO, V. C.; JORGE, N. Antioxidantes utilizados em óleos, gorduras e alimentos gordurosos. Química Nova, p. 755-760, 2006.

[6] ALMELA, L., SÁNCHEZ-MUNOZ, B., FERNÁNDEZ-LÓPEZ, J. A., ROCA, M. J., RABE, V. Liquid chromatograpicmass spectrometric analysis of phenolics and free radical scavenging activity of rosemary extract from different raw material. Journal of Chromatography A, v. 1120, n. 1-2, p. 221-229, 2006.

[7] MAHMOUD, A.A., AL-SHIHRY, S.S., SON, B.W. Diterpernoidquinones from (Rosimarinus officinalis L). Phytochemistry, v. 66, p. 1685-90, 2005

[8] MEDEIROS, L. M. Extrato de alecrim (Rosmarinus officinalis L.): um antioxidante eficiente para uso no biodiesel. 2013. 74f. Dissertação (Mestrado). Universidade Federal da Paraíba - UFPB, João Pessoa, 2013.

[9] AGÊNCIA NACIONAL DO PETRÓLEO, GÁS NATURAL E BIOCOMBUSTÍVEIS. Anuário estatístico brasileiro do petróleo, gás natural e biocombustíveis: 2017. Rio de Janeiro, 2017. 263.p. 
[10] EUROPEAN COMMITTEE FOR STANDARDIZATION. EN 14103:2003: Fat and oil derivatives. Fatty Acid Methyl Esters (FAME). Determination of ester and linolenic acid methyl esters contents. Brussels, 2003. 14.p.

[11] EUROPEAN COMMITTEE FOR STANDARDIZATION. EN 14112:2003: Fat and Oil Derivatives - Fatty Acid Methyl Esters (FAME) - Determination of Oxidation Stability (Accelerated Oxidation Test). Dublin, 2003. 6.p.

[12] OLIVEIRA, R.S., SILVA, E.A., RODRIGUES, P.R.P., SOUZA, S.N.M. Avaliação da ação antioxidante de produtos naturais no biodiesel B100. Engevista, v. 16, n. 3, p.410-419, Setembro 2014.

[13] FREITAS, O. N. Estudo de diversas misturas de biodiesel de óleo de soja e de sebo bovino. 2015. $111 \mathrm{f}$. Dissertação (Mestrado). Universidade Federal de Mato Grosso do Sul - UFMS - Campo Grande, 2015. 


\section{Capítulo 22}

\section{Análise de rendimento do catalisador heterogêneo óxido de alumínio (al2o3) na produção de biodiesel de soja (Glycine Max)}

\section{Rayanne Samara de Sousa Reinaldo}

\section{Leonardo Alcântara Alves}

Maria Rosimar de Sousa

Klismeryane Costa de Melo

Resumo: Os biocombustíveis surgiram com o objetivo de diminuir a forte dependência existente sobre o petróleo pelo fato de serem menos poluentes ao meio ambiente, renováveis e terem um grande leque de matérias primas para sua produção, dentre elas a soja. 0 biodiesel de soja é o mais produzido no Brasil, logo, é adicionado ao diesel comum com uma porcentagem de cerca de 10\%, o chamado B10. Pode ser obtido por vários procedimentos, no presente trabalho o biodiesel de óleo de soja foi obtido através de um processo de saponificação (formação de sabão), seguido da esterificação dos ácidos graxos, utilizando como catalisador o óxido de alumínio (Al203). Foram realizadas analises com o fim de verificar o rendimento do catalisador, em três momentos, onde o rendimento variou de $46,7 \%$ à $63,3 \%$. Diante desses resultados foi possível verificar o melhoramento no rendimento dos ácidos graxos a medida que o tempo de reação aumenta, além de verificar a viabilidade deste processo.

Palavras-chave: Óleo, Soja, Biodiesel, Catalisador, Heterogêneo. 


\section{INTRODUÇÃO}

Desde a descoberta do petróleo o mundo passou a depender fortemente do mesmo e de seus derivados. Contudo, depois da primeira grande crise desse recurso, pesquisadores na área perceberam a carência de outras formas de combustíveis, assim, novas pesquisas foram iniciadas visando obter fontes alternativas de combustíveis, foi diante desse contexto que surgiu os biocombustíveis. Apesar das inúmeras dificuldades enfrentadas para produção dos biocombustíveis até hoje, as vantagens destes combustíveis são muitas, sobretudo do biodiesel, a começar por serem menos poluentes ao meio ambiente, renováveis, além de terem uma grande diversidade de matérias primas, como soja, algodão, gergelim, mamona, entre outros. (SILVA, 2010)

Dentre esses combustíveis, o biodiesel é o mais visado, pois como citado anteriormente possui mais opções. Este é obtido, na maioria das vezes, a partir do processo de transesterificação, onde se gera ésteres e glicerina. No Brasil, a matéria prima mais utilizada entre as várias opções é a soja, produzida em larga escala, visto que o país domina grande parte das mais avançadas tecnologias para produção desta oleaginosa.(POMPELLI et al., 2011).

Esse biodiesel é obtido, na maioria das vezes a partir do processo de transesterificação e a esterificação de triglicerídeos, que juntamente com o metanol ou o etanol e catalisadores homogêneos ou heterogêneos para acelerar as reações, geram o biodiesel e a glicerina. Os catalisadores heterogêneos surgiram como uma alternativa desejável para aperfeiçoar a síntese de biodiesel realizada pelo catalisador homogêneo. (CORDEIRO, SILVA; WYPYCH; RAMOS, 2011).

Neste contexto, este trabalho tem como objetivo principal o estudo do desempenho de um catalisador heterogêneo, o óxido de alumínio (Al203), na produção do biodiesel do óleo comercial de soja. 0 estudo se estende também a avaliar a relação do tempo de reação de transesterificação do óleo de soja com o referido catalisador heterogêneo. (CORDEIRO, SILVA; WYPYCH; RAMOS, 2011)

\section{PROCEDIMENTO EXPERIMENTAL}

A metodologia empregada para o desenvolvimento desse trabalho foi a de Pousa (2007). Dividida nas seguinte etapas:

\section{Preparação do Metóxido de Potássio}

Em um béquer adicionou-se $30 \mathrm{~g}$ de hidróxido de potássio $(\mathrm{KOH})$ em $40 \mathrm{~mL}$ de metanol. Em seguida, adicionou-se $\mathrm{KOH}$ sob agitação constante, até a total dissolução do mesmo.

\section{Reação de Saponificação}

Em um balão pesou-se aproximadamente $30 \mathrm{~g}$ de óleo de soja e adicionou a solução de metóxido de potássio previamente preparada, a fim de que saponificasse o mesmo. Em seguida, colocou-se o material em manta aquecedora sob refluxo por um período de $1 \mathrm{~h} 30 \mathrm{~min}$.

Feito isso, foi transferido o conteúdo para um béquer, no qual foi deixado em banho-maria com a finalidade de evaporar o metanol ali contido. Posteriormente, adicionou-se a mistura com $40 \mathrm{~mL}$ de água destilada, e lavou-se com hexano três vezes para retirada do material não saponificado. Em seguida, dentro da capela adicionou aos sais de ácido graxo $5 \mathrm{~mL}$ de ácido sulfúrico (H2SO4), com a finalidade de que o $\mathrm{pH}$ atingisse valor próximo à 3 (ácido). Por fim, lavou-o 3 vezes com um acetato de etila. 0 material foi colocado em um rota evaporador para evaporar o acetato e pesou-o para saber o rendimento de ácido graxos. 
Figura 4: Reação de saponificação

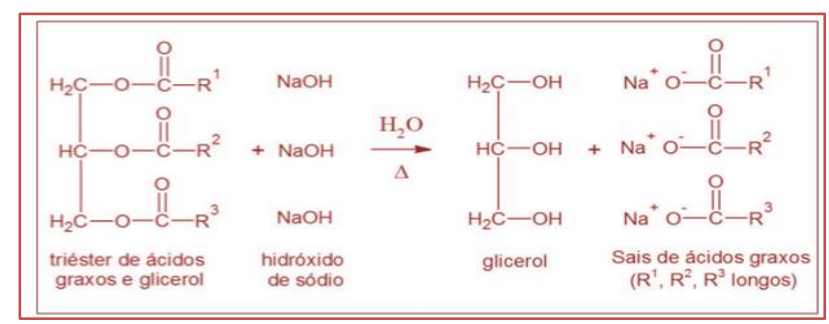

Fonte: < https://www.slideshare.net/LucasCampos13/a-qumica-do-sabo >

\section{- Produção do biodiesel}

Em um balão, adicionou $10 \mathrm{~g}$ dos ácidos graxos previamente preparado, juntamente com $10 \mathrm{~g}$ de metanol e 0,5 g de óxido de alumínio (Al203), onde o último foi empregado como catalisador. Colocou-se a solução num sistema de refluxo, por volta de 4 horas. Durante esse período foram retiradas alíquotas, uma com 1 hora, outra com 2 horas e uma última com 4 horas, para desse modo determinar o rendimento de cada uma.

\section{- Determinação do índice de acidez}

Este procedimento foi realizado por meio da titulação de $0,1 \mathrm{~g}$ da amostra com $\mathrm{NaOH} 0,01 \mathrm{~mol} / \mathrm{l}$, usando 3 gotas de fenolftaleína como indicador até o surgimento de uma coloração levemente rosa na mistura. 0 volume do hidróxido de sódio $(\mathrm{NaOH})$ utilizado na titulação será empregado como base para determinação de acidez na amostra de acordo com a Equação (1):

Equação 1: índice de acidez:

$$
I a=\frac{V x c x 5,61}{P}
$$

Onde:

$$
\begin{aligned}
& \text { IA = Índice de acidez; } \\
& \text { V =Volume de solução de NaOH gasto na titulação da amostra }(\mathrm{mL}) ; \\
& \mathrm{c}=\text { Concentração do titulante }(\mathrm{mol} / \mathrm{L}) ; \\
& \mathrm{P}=\text { Massa da amostra titulada }(\mathrm{g}) .
\end{aligned}
$$

Rendimento da reação pelo índice de acidez da solução A avaliação do índice de acidez foi realizada em triplicata, retirando-se três amostras, a primeira com 1 hora, a segunda com 2 horas e a última com 4 horas, para que no final fossem comparados os rendimentos de cada uma. Em cada avaliação, a esterificação foi realizada com adição de $10 \mathrm{~g}$ de ácidos graxo previamente do preparado, $10 \mathrm{~g}$ de metanol e 0,5 g do catalisador, no caso o óxido de alumínio (Al203) em um balão de $250 \mathrm{ml}$. 0 material foi deixado sob refluxo durante 4 horas. 0 rendimento de cada amostra foi avaliado de acordo com a equação 2 , com auxílio dos dados encontrados na Equação (2):

Equação 2: Rendimento da reação pela variação de acidez da solução:

$$
R(\%)=\left(1-\frac{\text { indicedeacidezfinal }}{\text { indicedeacidezinicial }}\right) * 100
$$




\section{RESULTADOS E DISCUSSÕES}

Durante o a etapa de reação de saponificação foi analisada à instabilidade do óleo de soja, quando exposto as altas temperaturas. (Figura 1).

Figura 5: Produção de sabão, na manta aquecedora

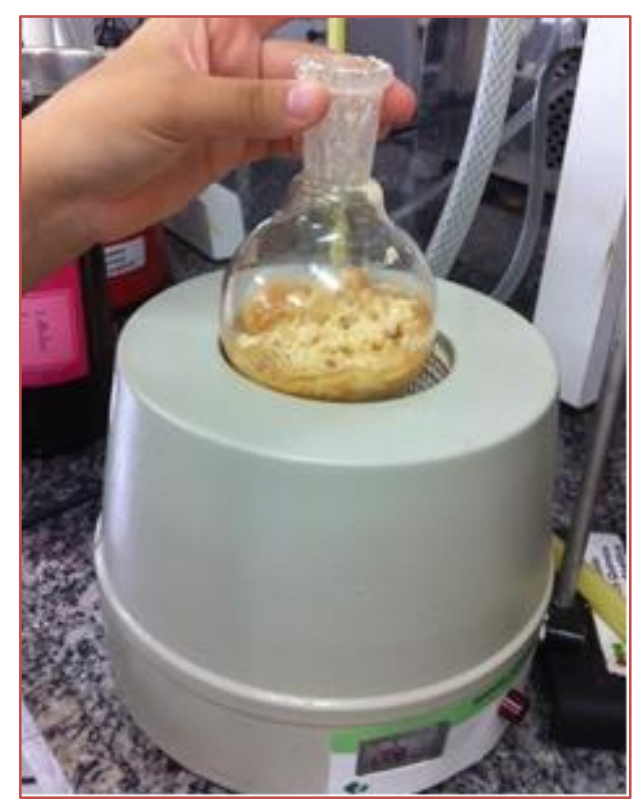

Fonte: Fotografia produzida pelos autores.

Finalizada a reação de saponificação, foram realizadas algumas lavagens, cada uma com o seu objetivo especifico. A primeira delas foi feita utilizando $40 \mathrm{~mL}$ de água, a fim de que a mesma se unisse com os saponificados. Na segunda etapa de lavagem foi executado uma triplicada empregando hexano, na qual cada uma contendo $40 \mathrm{~mL}$, para que interagisse com os insaponificáveis. Foi adicionado também $5 \mathrm{~mL}$ de ácido sulfúrico (H2SO4) aos sais de ácidos graxos, com o objetivo de virar o pH de básico à ácido. Por fim, lavou-se 3 vezes com o solvente, acetato de etila, no qual foi levado até o rotaevaporador para que todo o solvente fosse evaporado, obtendo-se assim os ésteres de ácidos graxos. Em seguida pesou-se o material, obtendo-se 11,698 g de ácidos graxos livres (Figura 6).

Figura 6: Ácido graxo produzido

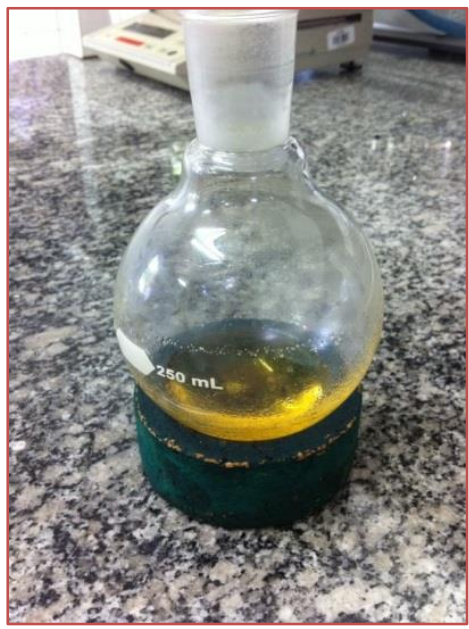

Fonte: Fotografia produzida pelos autores. 
Após esse procedimento, foi feita a avaliação do índice de acidez dos ésteres obtidos. Nesse procedimento foram utilizados: um volume de $15 \mathrm{~mL}$ de $\mathrm{NaOH}$; Um fator de concentração equivalente a 0,01 mol/L, para titular uma amostra de $1 \mathrm{~g}$. Desta forma, o índice de acidez do éster de ácido graxo, foi:

$$
I A=\frac{V x F x 5,61}{P}=\frac{15 \times 0,01 \times 5,61}{0,1}=\frac{8,415 g}{g d e K O H}
$$

Figura7: Determinação do índice de acidez do ácido graxo produzido

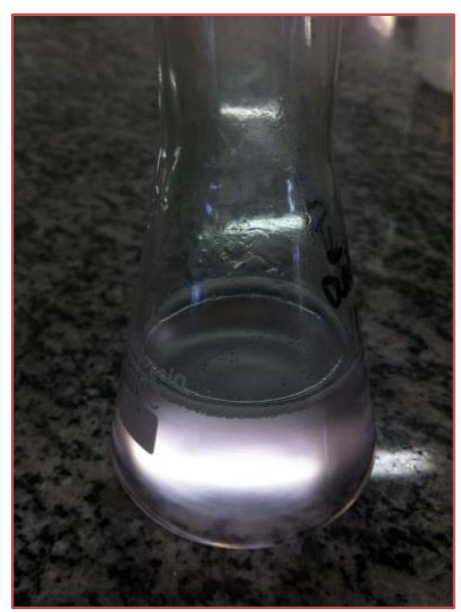

Fonte: Fotografia produzida pelos autores.

Depois disso, por meio da reação de esterificação de uma amostra de $10 \mathrm{~g}$ de ácido graxo, fez-se a determinação do índice de acidez em 3 momentos (1h, $2 \mathrm{~h}$ e $4 \mathrm{~h}$ ), com o objetivo de calcular o rendimento de cada amostra. Os resultados desse rendimento estão dispostos na Tabela 1.

Tabela 1: Rendimento da amostra ácido graxo de acordo com o tempo gasto

\begin{tabular}{|c|c|}
\hline Amostra & Rendimento (\%) \\
\hline Amostra de $1 \mathrm{~h}$ & 46,7 \\
\hline Amostra de $2 \mathrm{~h}$ & 56,7 \\
\hline Amostra de $4 \mathrm{~h}$ & 63,3 \\
\hline
\end{tabular}

Por fim, comparando com a literatura empregada como base para o trabalho, POUSA, 2007, expostos na Tabela 2, os rendimentos encontrados foram inferiores aos esperados. Isso pode ter acontecido em virtude de diferenças entre as condições reacionais.

Tabela 2: Rendimento da amostra ácido graxo de acordo com o tempo gasto, segundo Pousa, 2007

\begin{tabular}{|c|c|}
\hline Amostra & Rendimento (\%) \\
\hline Amostra de $30 \mathrm{~min}$ & 60 \\
\hline Amostra $1 \mathrm{~h}$ & 74 \\
\hline Amostra $2 \mathrm{~h}$ & 87 \\
\hline Amostra 3h & 89 \\
\hline
\end{tabular}




\section{CONCLUSÃO}

Diante dos resultados obtidos e das experiências tidas durante a realização do trabalho é possível tomar algumas conclusões:

O emprego de catalisadores heterogêneos, pelo menos no que diz respeito ao óxido de alumínio (Al203) é um bom catalisador para obtenção de biodiesel.

0 rendimento dos ácidos graxos em biodiesel aumenta à medida que o tempo de reação aumenta. Variando de $46,7 \%$ para $63,3 \%$.

Óleo de soja tem comportamento instável, quando submetido a altas temperaturas, como aconteceu no período que esteve na manta.

\section{REFERÊNCIAS}

[1] CORDEIRO, C. S.; SILVA F. R.; WYPYCH, F.; RAMOS, L. P.. Catalisadores Heterogêneos Para A Produção De Monoésteres Graxos (Biodiesel). Química Nova, v.34, n.3, p. 477-486, 2011.

[2] POUSA, G. P. A.; Avaliação do desempenho óxidos metálicos em reações de esterificação de ácidos graxos obtidos a partir do óleo de soja para produção de biodiesel. 2007. 55f. Dissertação (Mestrado em Química) Universidade de Brasília, Brasília, 2007.

[3] POMPELlI, M. F.; JARMA, A. J.; OLIVEIRA, M. T.; RODRIGUES, B. R. M.; BARBOSA, M. O.; SANTOS, M. G.; OLIVEIRA, A. F. M.; ALMEIDA-CORTEZ, J. S. Crise energética mundial e o papel do Brasil na problemática de biocombustíveis. Agronomia colombiana, v. 29, p. 231-240, 2011.

[4] PEREIRA, F. C. K.; VALENTIM, G. L.; LESSA, A. R. Biocombustíveis: solução e problema, Revista de Divulgação do Projeto Universidade Petrobrás e IF Fluminense, v. 1, p. 343-347, 2010.

[5] SILVA, R. C. P. Biocombustíveis, Revista de Divulgação do Projeto Universidade Petrobrás e IF Fluminense, v. 1, p. 365-370, 2010.

[6] TAVARES, A. H. M.; Obtenção de catalisadores heterogêneos para reação de transesterificação. 2010. 83f. Dissertação de Mestrado (Centro de Ciências Exatas e Tecnologias). Universidade do Maranhão, São Luís, 2010. 


\section{Capítulo 23}

Escala piloto de produção da Nanoferrita Nio, Zno,5 $\mathrm{Fe}_{2} \mathrm{O}_{4}:$ Avaliação da reprodutibilidade para aplicação como catalisador nanomagnético na obtenção de biodiesel

Joelda Dantas

Ana Cristina Figueiredo de Melo Costa

Resumo: Este trabalho descreve as vantagens dos catalisadores nanomagnéticos quanto a sua eficiência na conversão e na sua recuperação para posterior reuso na produção de biodiesel, frente aos tradicionais catalisadores heterogêneos. Foi utilizado como referência a nanoferrita Ni0,5Zn0,5Fe204, a qual foi sintetizada com o diferencial inovador de sua produção em escala piloto de até $200 \mathrm{~g} /$ batelada, por reação de combustão. Como também foi intensivamente avaliada a sua reprodutibilidade por meio de diversas técnicas de caracterização de materiais, visando possível produção industrial para catálise heterogênea na obtenção de biodiesel a partir de fontes de biomassa como óleos vegetais comestíveis e não comestíveis, óleos residuais e/ou gordura animal. Para tanto, as amostras foram sintetizadas usando três recipientes com capacidade de produção de 10, 100 e 200 g/produto por batelada. Durante as sínteses foi aferido a temperatura e o tempo de chama de combustão das reações. Os produtos foram nomeados PM, MM e GM, respectivamente, e caracterizados por difração de raios $\mathrm{X}$, densidade por picnometria a hélio, espectroscopia na região do infravermelho, espectroscopia de fluorescência de raios $X$, análise textural por adsorção de nitrogênio, distribuição granulométrica, microscopia eletrônica de varredura e medidas magnéticas. Todas as amostras apresentaram a formação da fase majoritária Ni0,5Zn0,5Fe204 e traços de fases segregadas de Fe203 e ZnO, com morfologia constituída por aglomerados na forma de blocos irregulares. Os valores de área superficial foram 65,3; 50,9 e 64,2 m2g-1, com classificação dos poros na faixa mesoporosa e com característica típica de material magnético mole, cujos valores de magnetização de saturação e campo coercitivo foram 36,6; 21,0 e 20,0 emu/g, e 0,0896; 0,0965 e 0,0928 K0e, respectivamente. Assim, a síntese se evidenciou adequada para produção de nanoferritas $\mathrm{Ni0}, 5 \mathrm{Zn} 0,5 \mathrm{Fe} 2 \mathrm{O} 4$ em escala piloto, com excelente reprodutibilidade e características adequadas para o uso em diferentes aplicações tecnológicas, como na catálise heterogênea.

Palavras-chave: Reação de combustão, nanoferritas Ni0,5Zn0,5Fe204, escala piloto, reprodutibilidade, catálise. 


\section{INTRODUÇÃO}

A intensificação das ações humanas que está associada ao desenvolvimento econômico, tem sido a causa do desenfreado aumento da geração de resíduos, da poluição atmosférica e dos corpos hídricos. Nas refinarias, por exemplo, são gerados muitos poluentes, como os hidrocarbonetos, cinzas voláteis, gases de combustão, lodos, óleos, graxas e águas residuárias. Estes são altamente reativos e compostos por metais pesados como o mercúrio, prejudicial ao meio ambiente devido ao alto potencial carcinogênico e mutagênico [1,2]. Tais poluentes são muito comuns nos processos industriais e são os mais mortais do planeta, porque quando descartados sem tratamento adequado, podem contaminar a atmosfera e os ecossistemas aquáticos, promovendo alterações significativas no ciclo de vida, porque são efluentes altamente tóxicos e cancerígenos, provocando problemas de saúde pública e que podem levar a morte de peixes e plantas aquáticas [3,4].

Na proposta de mitigar danos ambientais, as instalações de biorrefinarias têm apresentado expressivos resultados de sustentabilidade, uma vez que produzem energias renováveis, contudo, nos processos para produzir biocombustíveis, ainda ocorre a liberação de $\mathrm{CO} 2$, embora em menor proporção daqueles para combustíveis fósseis, porque durante o crescimento de biomassa vegetal acontece a captura das emissões de $\mathrm{CO} 2$ [5]. Ademais, especialmente na produção de biodiesel, são geradas uma grande quantidade de águas residuais, devido as lavagens úmidas para purificação de ésteres [6], o que é tido como um problema não resolvido se descartada sem tratamento prévio, e que demanda ainda muitos esforços no sentido de desenvolvimento e otimização das vias e dos processos gerais de produção.

O biodiesel vem ganhando cada vez mais espaço dentro do cenário da matriz energética mundial, sendo o Brasil um potencial promotor de expansão desse biocombustível devido a diversidade de matéria-prima disponível. Tanto é, que assumiu no acordo de Paris, durante a 21 â Conferência das Partes (COP 21), onde 195 países se comprometeram a limitar o aquecimento da Terra a até $2^{\circ} \mathrm{C}$ até o fim do século, o compromisso de reduzir, em 2025, as emissões de GEE em 37\% e em 2030, fez a indicação de reduzir em $43 \%$, tendo o ano de 2005 como referência. Tais medidas englobam os setores de energia, agricultura, floresta, resíduos e processos industriais. Conforme o RenovaBio lançado em 2017, em relação às atividades de produção e uso da energia, dentre os compromissos assumidos consta a expansão do consumo de biocombustíveis e o aumento do teor de biodiesel na mistura do diesel [7].

Com base nesse contexto, se tem despertado na indústria e na academia uma real motivação em busca de otimizar as variáveis envolvidas na produção de biodiesel, como também a busca por novas matériasprimas e processos que agreguem maior valor à sua produção. As matérias-primas oriundas da biomassa utilizadas na produção de biodiesel podem ser de origem vegetal e animal [8]. As que se destacam como mais potenciais podem ser classificadas em três categorias, óleos usados, óleos de planta não comestível e óleos microbianos. 0 uso destas matérias-primas é uma alternativa para reduzir as onerações de produção de biodiesel.

Especialmente em relação aos óleos residuais de fritura, estes são amplamente disponíveis, têm um custo de duas a três vezes menor do que os óleos vegetais refinados típicos, não compete com a indústria de alimentos e fornece uma solução para a eliminação de resíduos [9-11]. A nível mundial, a geração de resíduos oleosos é uma grande problemática nas plantas de processamento industrial, bem como nas empresas de fast food. Em alguns casos, esses óleos são misturados na alimentação animal e fertilizantes. No entanto, a grande maioria dos óleos usados é despejada nas redes de esgotos [12], assim, a destinação dos óleos que já passaram por processos de fritura, para utilização como fonte promissora de substrato na produção de biodiesel, vem ser de especial relevância diante do consumismo contemporâneo associado.

Outro essencial fator a se considerar além da matéria-prima na cadeia de produção do biodiesel, são os catalisadores envolvidos nas reações de obtenção. Nas últimas décadas, os pesquisadores que tem estudado alternativas aos inconvenientes da catálise homogênea, concluíram que a utilização da catálise heterogênea apresenta eficiência elevada devido minorar etapas de purificação, como a lavagem e, também, devido o catalisador não ser consumido no meio reacional, possibilitar a fácil recuperação e reuso $[13,14]$. A tecnologia verde incluiu os catalisadores heterogêneos devido às características de reciclabilidade dos catalisadores, produção de menor quantidade de águas residuais, separação mais fácil do biodiesel do glicerol [15]. Estas vantagens são ambientalmente favoráveis. A principal desvantagem dos catalisadores heterogêneos básicos ou ácidos está associada à lixiviação dos sítios ativos após reações, reduzindo dessa forma sua atividade catalítica $[16,17]$.

Ou seja, no processamento industrial de produtos, como por exemplo o biodiesel, faz-se necessário o uso de catalisadores homogêneos, entretanto, a remoção deste tipo de catalisador após reação é tecnicamente difícil e grande quantidade de água de rejeito é produzida. Daí o interesse em substituir os catalisadores 
homogêneos por heterogêneos, visto que estes últimos são de procedimentos operacionais mais fáceis e reduzem a poluição ambiental.

Os materiais cerâmicos representam importantes produtos comerciais para indústrias, sendo utilizados nas mais diversas áreas tecnológicas, e quando sintetizados com características nanoestruturais se revelam atrativos para aplicações como catalisadores heterogêneos em diversos processos químicos.

Dentre as diferentes classes de materiais cerâmicos, os óxidos metálicos ferrimagnéticos conhecidos como ferritas, são uma importante classe de compostos que se destacam em estudos voltados à catálise heterogênea, isto devido as suas excelentes propriedades, tais como elevada estabilidade termodinâmica e térmica, eletromagnética, atividade catalítica e resistência à corrosão. Pesquisas [18, 19] reportam que as ferritas do tipo espinélio são largamente estudadas, pois têm sido consideradas como materiais proeminentes para várias aplicações tecnológicas e que os avanços em tecnologias de fabricação nos últimos 10 anos têm sido impressionantes. 0 interesse nas ferritas tipo espinélio em escala nanométrica aumentou nos últimos anos devido à importância da compreensão do nanomagnetismo. Os materiais nanométricos exibem propriedades magnéticas substancialmente diferentes quando comparados com moléculas e estruturas em nível atômico, devido à sua elevada superfície em relação ao volume respectivo [20-23].

A produção de ferritas em nanoescala abre um leque de novas propriedades, como o confinamento quântico, efeito de superparamagnetismo, estrutura de monodomínio e comportamento spin-vítreo [24]. A compreensão das propriedades das nanoferritas certamente potencializa o uso destes materiais em várias aplicações tecnológicas. Várias aplicações são citadas envolvendo as nanoferritas devido as suas propriedades magnéticas, tais como transportadores de oxigênio, tecnologia de sensores, refrigeração magnetocalórico, spintrônica, catálise heterogênea, entrega de drogas magneticamente guiada, ressonância magnética, sistemas de alta frequência, circuitos eletrônicos, supressão de interferência eletromagnética e em biotecnologia [25-28].

Além disso, as ferritas espinélios têm desempenhado importantes papéis na vida diária, devido ao uso no campo do armazenamento de dados de alta densidade, em separação magnética, tecnologia de ferrofluidos, catalisadores, seleção de medicamentos, imagem por ressonância magnética, dispositivos para sensor de gás e armazenamento de energia. Os espinélios magnéticos são uma importante classe de materiais por causa de sua alta permeabilidade na região de frequência de rádio, alta resistividade elétrica, resistência mecânica e estabilidade química [29-35].

Além de todas as características mencionadas que impulsionam a aplicação das nanoferritas, pode-se acrescentar que a sua utilização como catalisador heterogêneo possibilita a fácil separação do produto reacional, por atração magnética, mediante a aplicação de um campo magnético externo (ímã), possibilitando que o catalisador seja recuperado e reutilizado várias vezes em processos químicos, como exemplo, reações de transesterificação e esterificação. A remoção do catalisador em suspenção do meio em que está envolvido, por separação magnética, é relativamente rápida e de fácil operação, requerendo equipamentos simples. Associado a tais vantagens, as nanoferritas também são facilmente obtidas por métodos de processamento economicamente viáveis e com características nanoestruturais, favorecendo a formação de partículas com elevada área superficial, o que é extremamente viável para inúmeras aplicações, como em catálise.

Em relação a tecnologia da síntese de nanoferritas Ni0,5Zn0,5Fe204 em escala de laboratório, os principais desafios já foram superados, que seriam o desenvolvimento de métodos de processamento que gerassem produtos com partículas em escala nanométrica e consequentemente com elevada área de superfície. No entanto, quando se necessita destes materiais com características nanométricas para reprodução em escala piloto, e com características adequadas para diferentes aplicações tecnológicas, surge o maior desafio observado atualmente na tecnologia das nanocerâmicas, o qual precisa ser superado a fim de garantir o desenvolvimento deste setor tecnológico. Isto não é fácil de ser obtido e vem exigindo muito esforço e dedicação dos pesquisadores para o desenvolvimento de tecnologias que superem este obstáculo, e também que atendam a obtenção de produtos com reprodutibilidade e características adequadas para a aplicação tecnológica desejada.

O método de preparação é muito significativo na adaptação das propriedades das nanoferritas, dentre eles são conhecidos muitos processos de sínteses, como moagem de alta energia, coprecipitação, citrato precursor, rota de reação de estado sólido, pirólise por pulverização, no entanto, para a produção destes materiais em larga escala a maioria destes métodos é economicamente inviável [36]. 
Assim, a possibilidade da reprodutibilidade de nanoferritas em escala piloto por reação de combustão vislumbra inúmeras aplicações tecnológicas, e entre as várias, destaca-se o uso da nanoferrita Ni0,5Zn0,5Fe204 como catalisador heterogêneo magnético, nas reações químicas para produção de biodiesel. Isto é mais um ponto atrativo para a utilização e consolidação deste produto na catálise heterogênea voltada para produção de biocombustível.

As pesquisas pioneiras no campo especial da catálise para biodiesel utilizando materiais nanomagnéticos foram publicadas. Como resultados foram relatados desempenhos favoráveis e promissores de nanoferritas magnéticas como (NiCuZn)Fe204, (CuZn)Fe204, (NiZn)Fe204, CoFe204, MnFe204, NiFe204, $\mathrm{CuFe} 204$ e FeFe204, obtidas via síntese por reação de combustão, em escala de até $10 \mathrm{~g}$ do produto por batelada, com expressiva aplicação na preparação de biodiesel por transesterificação e esterificação, atrelado a fácil recuperação e visando futura reutilização [37-41]. Dentre os testes, as composições indicadas mais promissoras foram as nanoferritas mistas Ni0,5Zn0,5Fe2O4 e Ni0,2Cu0,3Zn0,5Fe2O4 [42, 43]. Outros estudos vêm sendo reportados sobre a utilização vantajosa das ferritas devido ao seu magnetismo [44-47], comprovando que embora a investigação sobre o uso de catalisadores heterogêneos para obtenção de biodiesel ainda esteja em seus estágios iniciais, tem-se obtido resultados interessantes.

$\mathrm{Na}$ busca por novos catalisadores heterogêneos, se faz necessário o desenvolvimento de materiais eficientes, baratos, de fácil preparação, produção em larga escala e que sejam ambientalmente benignos [48]. Por causa disto, nesta última década foi dada muita atenção à concepção de alguns catalisadores heterogêneos de ciclos longos e multifuncionais [49]. Esses catalisadores foram essenciais para minimizar o consumo de energia em todos os processos de separação, ademais, um catalisador multifuncional seria mais competitivo na indústria, indicando que estes tipos de catalisadores teriam uma perspectiva promissora num futuro próximo, por exemplo, na área da transesterificação [50].

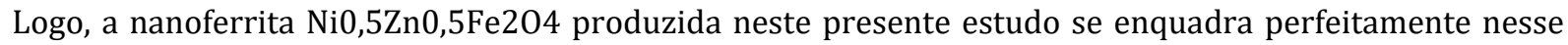
cenário, porque o princípio do trabalho realizado estabeleceu justamente ultrapassar as desvantagens do uso de catalisador homogêneo e assim possibilitar a redução de custos ambientais e financeiros da produção de biodiesel, e principalmente possibilitar a produção em larga escala de nanocatalisadores que possam ser facilmente recuperados e reutilizados, mantendo suas propriedades.

Além disso, o desenvolvimento de tecnologias que venham contribuir para acelerar o uso de nanomateriais facilmente recuperáveis e reutilizáveis convergem para expressivos benefícios. A produção e o uso destes nanomateriais chega a ser nos dias atuais uma questão de sobrevivência, devido não colaborar com a poluição ambiental e ecológica, que despertam a preocupação mundial em decorrência da poluição nas grandes cidades. Os materiais nanoestruturados são amplamente adequados para enfrentar os desafios prementes associados à conversão de energia, isto porque atuam eficazmente nos principais domínios da investigação de conversão de energia, como a química, térmica, eletroquímica e solar.

Dentro deste contexto, considerando-se fatores como o custo de produção destes materiais, maior segurança ambiental oferecida devido a característica intrínseca do magnetismo, o que resulta num incremento exponencial de sua recuperação, e com isto diminuição das perdas de catalisador, como também a sua atividade catalítica estável, estes superam e evidenciam substanciais vantagens em comparação a outras classes de catalisadores heterogêneos. Então, no intuito de contribuir com as pesquisas neste âmbito, e com o diferencial de concretização da produção de materiais nanomagnéticos em larga escala, este trabalho se propôs a sintetizar nanoferritas de Ni0,5Zn0,5Fe204, por reação de combustão, em escalas de produção de 10, 100 e $200 \mathrm{~g}$ do produto por batelada, e avaliar a sua reprodutibilidade. Para tanto, as características estruturais, morfológicas, químicas, térmicas, magnéticas e físicas desses materiais foram investigadas afim de validar a produção em maior escala.

\section{EXPERIMENTAL}

A metodologia consistiu na realização das sínteses das amostras de Ni0,5Zn0,5Fe204 em três recipientes de aço inox e na caracterização dos produtos sintetizados quanto a estrutura, morfologia, propriedades térmicas, magnéticas e físicas. As sínteses envolveram a mistura de sais de íons metálicos como reagentes oxidantes (nitratos de níquel - Ni(NO3)2.6H2O e zinco hexahidratado - Zn(NO3)2.6H2O, nitrato de ferro nonohidratado - Fe(NO3)3.9H2O e ureia - (NH2)2CO como agente redutor, de modo a formar uma solução redox.

A composição inicial da solução foi calculada com base na valência total dos reagentes oxidantes e redutores, utilizando conceitos da química dos propelentes e explosivos [51], de forma a estabelecer a estequiometria da fase de interesse. A mistura redox entre os nitratos metálicos e o combustível foi 
submetida à aquecimento direto em reatores cônicos desenvolvidos para síntese de combustão, que possibilitam a produção em bateladas distintas de 10, 100 e 200 gramas do produto [52]. As reações de combustão foram reproduzidas alternando-se dias e horários. As amostras de Ni0,5Zn0,5Fe204 foram designadas pelas nomenclaturas PM, MM e GM, respectivamente.

Na Tabela I estão descritas a capacidade volumétrica dos recipientes (Cv), capacidade de produção dos recipientes (Cp), quantidade total de reagentes $(\mathrm{Tr})$ e a porcentagem de reagentes utilizada para a síntese em cada recipiente ( $\mathrm{Pr}$ ), onde foi levado em considerado o recipiente R12, o qual possui maior capacidade $(100 \%)$.

Tabela I - Capacidade dos recipientes, quantidade total de reagentes e porcentagem utilizada para as sínteses por reação de combustão das amostras PM, MM e GM.

\begin{tabular}{|c|c|c|c|c|}
\hline Recipientes/Amostras & $\mathrm{Cv}(\mathrm{L})$ & $\mathrm{Cp}(\mathrm{g})$ & $\operatorname{Tr}(\mathrm{g})$ & $\operatorname{Pr}(\%)$ \\
\hline P01/PM & 1,8 & 10 & 100 & 6,67 \\
\hline R01/MM & 15 & 100 & 1.000 & 66,7 \\
\hline R12/GM & 35 & 200 & 1.500 & 100 \\
\hline
\end{tabular}

Os reagentes foram pesados em balança semi-analítica e a quantidade total foi colocada em seus respectivos recipientes e submetidos à aquecimento direto até ocorrer a combustão, onde obteve-se as amostras na forma de flocos porosos, as quais foram desaglomeradas com almofariz e pistilo e passadas em peneira ABNT malha 325 (abertura $45 \mu \mathrm{m}$ ). Posteriormente foram submetidas as devidas caracterizações estruturais, morfológicas e magnéticas.

Para garantir a reprodutibilidade das amostras nos três recipientes distintos, foram realizadas 31 sínteses para obter $500 \mathrm{~g}$ da amostra PM; 7 sínteses para produzir 850 g de MM e 7 sínteses para obter 1 kg de GM.

A temperatura da reação de combustão foi medida de forma on-line num intervalo de 5 em 5 segundos entre cada medição, de acordo com a calibração do aparelho e seu software de registro, o qual possui precisão para medir temperaturas no intervalo de $250 \mathrm{oC}$ a $1700 \mathrm{oC}$, registrando automaticamente a máxima temperatura alcançada durante a combustão. 0 início da medição da temperatura de reação foi efetuado após a dissolução total dos reagentes e o final da medição da temperatura de reação foi medida 5 segundos após atingir a temperatura máxima da chama de combustão. 0 tempo da síntese de combustão foi medido por um cronômetro digital.

A partir dos dados coletados foram plotados gráficos $(\mathrm{T} \times \mathrm{t}$ ), e determinados o tempo total da síntese, tempo de chama e a temperatura máxima da reação.

As amostras como sintetizadas foram submetidas às caracterizações de Difração de Raios X (DRX), Densidade Experimental (DE), Espectrometria de Infravermelho com Transformada de Fourier (FTIR), Fluorescência de Raios X por Energia Dispersiva (EDX), Distribuição Granulométrica (DG), Microscopia Eletrônica de Varredura (MEV), Análise Textural (BET) e Medidas Magnéticas (AGM). As caracterizações foram realizadas em triplicatas.

A determinação das fases presentes, cristalinidade e o tamanho de cristalito das amostras foram determinados a partir dos dados de difração, utilizando um difratômetro de raios $\mathrm{X}$, radiação $\mathrm{Cu}-\mathrm{K} \alpha$, operando com tubo de alvo de cobre a uma tensão de 30,0 kV e 10,0 mA de corrente, com detector de 55D160. A cristalinidade foi determinada a partir da razão entre a área integrada do pico referente à fase cristalina e a área referente à fração amorfa, utilizando o software DIFRACT.EVA. 0 tamanho médio de cristalito foi calculado a partir da linha de alargamento de raios X (d311) através da deconvolução da linha de difração secundária do padrão de césio policristalino, utilizando-se a equação de Scherrer [53], utilizando o software.

De posse dos dados de difração de raios X foi realizado o refinamento dos parâmetros estruturais pelo método Rietveld [54], usando o programa DIFFRAC.TOPAS, sendo possível assim determinar a quantidade de cada fase presente nas amostras PM, MM e GM. 0 refinamento de estrutura foi baseado na minimização da soma dos quadrados da diferença entre a intensidade calculada e observada para cada ponto do padrão de difração. Para tanto, o método necessitou previamente da estrutura cristalina de todas as fases envolvidas na mistura. 0 erro residual foi minimizado pela Equação: Sy = $\sum$ wi (IObs - Icalc)2.

As análises das densidades das amostras foram realizadas em um equipamento de picnometria, operando com gás hélio (He). Os espectros foram obtidos num equipamento que opera entre 4000 e $650 \mathrm{~cm}-1$, com 
resolução de 4 cm-1 e 20 varreduras. Esta técnica foi utilizada para observar as bandas características dos materiais avaliados. Os espectros foram obtidos na região de 4000 a $200 \mathrm{~cm}-1$, porém consta nos resultados a ampliação de 900 a $200 \mathrm{~cm}-1$.

A análise semi-quantitativa dos óxidos e elementos presentes nas amostras PM, MM e GM, foi determinado por espectroscopia de fluorescência de raios X por energia dispersiva. As análises granulométricas foram realizadas na faixa de $0,3 \mathrm{~nm}$ a $8 \mu \mathrm{m}$ em um analisador de nanopartículas, operando na faixa de 10 a $10.000 \mathrm{~nm}$. Os aspectos morfológicos foram obtidos em um microscópio eletrônico de varredura (MEV).

A medida de área superficial foi realizada pelo método de adsorção de nitrogênio/hélio desenvolvido por Brunauer, Emmett e Teller (BET) visando determinar a área superficial específica. Esta técnica também foi usada para determinar o tamanho médio de aglomerados de partículas (diâmetro esférico equivalente) por meio da equação de Reed [55]. A densidade teórica $(\rho)$ utilizada foi de 5,361 g/cm3 para nanoferrita Ni-Zn, obtida de acordo com a ficha cristalográfica JCPDF 08-0278. 0 volume de poro e o diâmetro de poro foram determinados pela teoria desenvolvida por Brunauer, Joyner e Halenda (BJH).

As análises termogravimétricas (TG/DTA) foram realizadas utilizando $5 \pm 0,5 \mathrm{mg}$ das amostras, sendo acondicionadas em um suporte de alumina com razão de aquecimento de $12,5^{\circ} \mathrm{C}$.min-1, numa faixa variando da temperatura ambiente a $1000^{\circ} \mathrm{C}$, sob uma atmosfera dinâmica de nitrogênio, com vazão de 50 mL.min-1, buscando identificar a temperatura de eliminação da parte orgânica da nanoferrita, dos formadores de poros e as possíveis transformações de fase a elevadas temperaturas

Os ciclos de histerese magnética ( $\mathrm{M} \mathrm{x} \mathrm{H}$ ) foram obtidos por um magnetômetro de gradiente alternado (AGM). Por meio das curvas $\mathrm{M} \mathrm{x} \mathrm{H}$, foi possível determinar os valores de alguns parâmetros magnéticos, tais como: campo coercitivo (Hc), magnetização remanescente (Mr), magnetização de saturação (Ms). A magnetização de saturação foi determinada fazendo um fitting dos dados do campo aplicado para a função $M=M s(1-\alpha / H)$, onde $M$ é a magnetização, Ms é a magnetização de saturação, $\alpha$ é o parâmetro do fitting e H é o campo aplicado. Assim, as características magnéticas foram obtidas a partir do gráfico das histereses, observando-se o comportamento das curvas nas proximidades da origem do plano cartesiano.

\section{RESULTADOS E DISCUSSÃO}

Na Figura 1 encontra-se a variação da temperatura em função do tempo de reação das amostras PM, MM e GM.

Figura 1 - Variação da temperatura em função do tempo de reação (T x t) para as amostras PM, MM e GM.
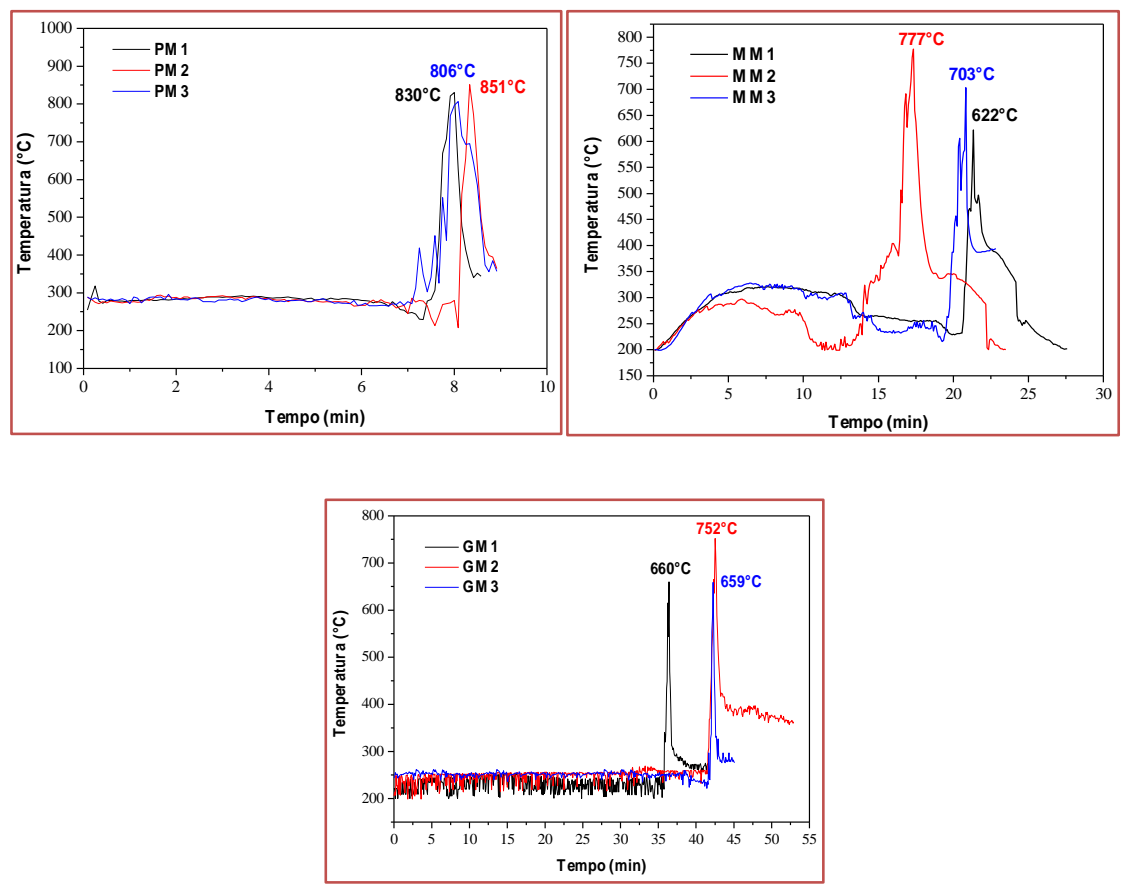
De maneira geral, observa-se que as variações da temperatura em função do tempo das reações de combustão para as amostras variaram em função dos recipientes utilizados. Entretanto, pode-se também observar que o perfil das curvas das reações foi semelhante para cada recipiente individualmente. Para os três recipientes utilizados, foi observado que as sínteses exibiram um comportamento típico das reações de combustão, de inicialmente apresentarem oscilações nas suas respectivas temperaturas, até atingirem suas temperaturas de ignição, a partir das quais se observa um evento brusco de elevação de temperatura até os seus respectivos alcances máximos de combustão.

Mais detalhadamente, observa-se que as reações executadas no recipiente com capacidade de produção de 10 g (P01) desenvolveram temperaturas máximas de 830, 851 e 806 oC, com média de 829,0 $\pm 22,52$ oC, para o recipiente com capacidade de $100 \mathrm{~g}$ (R01) temperaturas máximas de 777, 703 e 622 oC, com média de 700,1 $\pm 77,53$ oC, e para o recipiente com capacidade de $200 \mathrm{~g}$ (R12), temperaturas máximas de 659, 660 e 752 oC, com média de 690,3 \pm 53,41 oC. Logo, observa-se que as reações no recipiente P01, referentes a amostra PM atingiu valores de temperaturas máximas superiores em 15,5\% e 16,7\%, em relação as reações nos recipientes R01 e R12, referentes as amostras MM e GM, respectivamente. Isto evidencia que apesar dos recipientes possuírem capacidade de produção diferenciada, e em vista disto ser necessário uma quantidade total de reagentes diferentes, as temperaturas alcançadas durante as sínteses foram próximas, indicando a eficácia da reprodutibilidade das reações por combustão em bateladas de produto, desde pequena a grande escala, das amostras de Ni0,5Zn0,5Fe204.

Além do mais, como as temperaturas máximas alcançadas durante as sínteses foram relativamente baixas (< 1000 oC), isto favorece a obtenção de produtos com elevada área de superfície, o que torna o material produzido adequado para o uso como catalisadores, por exemplo, porque a temperatura impõe alterações diretas na superfície do material. Em temperaturas superiores a $1000^{\circ} \mathrm{C}$, as alterações de superfície são mais pronunciadas, e em alguns casos, estas modificações reduzem consideravelmente a área de superfície e os sítios ativos dos catalisadores [56].

Os parâmetros tempo de chama, tempo de reação, temperatura máxima e cor de chama, foram também avaliados e se encontram reportados na Tabela II.

Tabela II - Parâmetros determinados durante as sínteses por reação de combustão para as amostras PM, MM e GM.

\begin{tabular}{|l|c|c|c|}
\multicolumn{1}{c}{ Amostras } & PM & MM & GM \\
\hline Cor da chama & Amarela & Amarela & Amarela \\
\hline Tempo de chama $(\mathrm{s})$ & $24,67 \pm 1,53$ & $41,33 \pm 11,37$ & $44,33 \pm 7,50$ \\
\hline Temperatura de chama máxima $\left({ }^{\circ} \mathrm{C}\right)$ & $829,0 \pm 22,52$ & $700,1 \pm 77,53$ & $690,3 \pm 53,41$ \\
\hline Tempo total de reação $(\mathrm{min})$ & $10,00 \pm 1,00$ & $20,00 \pm 1,00$ & $43,00 \pm 6,56$ \\
\hline Produto final $(\mathrm{g})$ & $14,77 \pm 1,53$ & $141,37 \pm 5,31$ & $175,06 \pm 6,75$ \\
\hline
\end{tabular}

Com relação ao tempo total das sínteses, já se esperava um maior intervalo de tempo nas reações quando se utilizou os recipientes maiores, para produzir as amostras MM e GM. Isto porque, além da maior quantidade de reagentes requeridos para estas sínteses, às superfícies de contato da mistura dos regentes com as paredes desses recipientes foram menores por causa dos seus diâmetros. Deste modo, o calor recebido na reação, que foi transportado nas paredes do recipiente, levou mais tempo para se propagar de forma uniforme, para o centro. Para o recipiente menor, utilizado na produção da amostra PM, a mistura dos reagentes teve um maior contato com as paredes do recipiente e a propagação do calor foi mais rápida para a mistura, levando a ignição da combustão mais rapidamente.

A cor da chama de combustão emitida durante as reações foi amarela, independentemente da quantidade de reagentes e do recipiente utilizado. Isso porque a cor da chama é mais dependente da característica química dos elementos utilizados, os quais neste caso foram os mesmos, pois a composição química foi a mesma para todas as amostras, em que se variou apenas a quantidade de reagentes, conforme foi a capacidade individual de cada recipiente utilizado.

Tais considerações abordadas encontram respaldo na literatura, uma vez que a coloração da chama é característica dos elementos químicos presentes que estejam em maior abundância no sistema em queima [57]. Outros autores também relataram comportamento semelhante quando produziram nanomateriais por reação de combustão [58]. 
Nas Figuras 2 ( $a$, b e c) estão os difratogramas de raios X das amostras PM, MM e GM obtidas por reação de combustão, nos diferentes recipientes com capacidades de 10, 100 e 200 g de produção. As curvas de difração de raios $\mathrm{X}$ exibiram a presença dos picos principais característicos da estrutura do espinélio inverso, evidenciada pelo aparecimento do pico principal $2 \theta=35,5^{\circ}$, conforme ficha cristalográfica JCPDF 52-0278, independentemente do recipiente utilizado. Todos os difratogramas evidenciaram picos bem definidos e elevada largura basal para todas as reflexões, revelando que os materiais sintetizados são cristalinos e com características nanoestruturais.

Observa-se que todas as amostras obtidas apresentaram a fase majoritária do espinélio inverso da ferrita $\mathrm{Ni}-\mathrm{Zn}$, com a presença de picos característicos de fases segregadas de hematita (Fe203) e óxido de zinco (ZnO). A fase Fe203 foi identificada mediante a ficha padrão JCPDS 40-1139, e a fase ZnO foi identificada mediante a ficha padrão JCPDS 36-1451.

Figura 2 - Difratogramas de raios X das amostras: (a) PM, (b) MM e (c) GM.
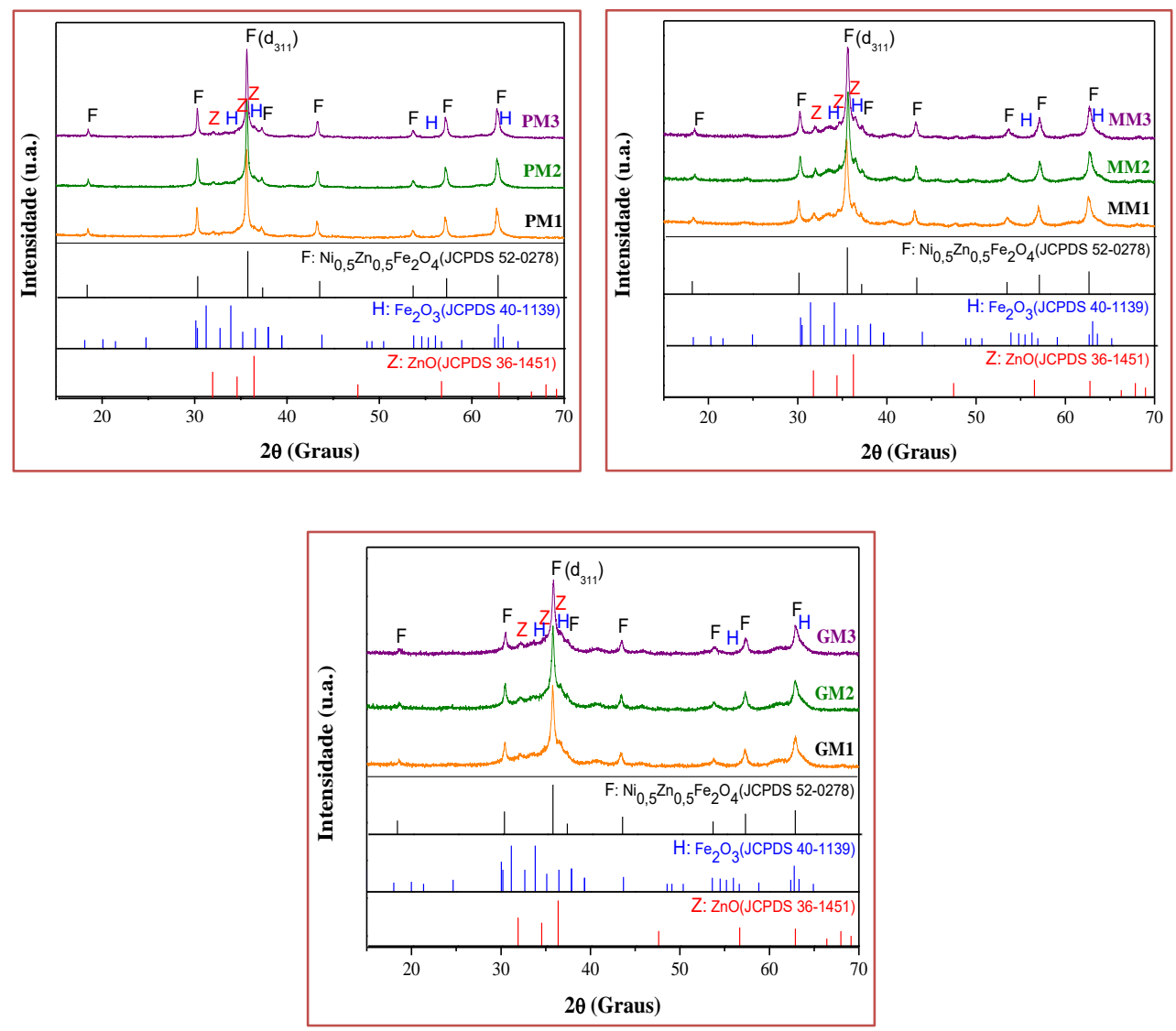

Numa análise mais detalhada, o refinamento por Rietveld foi ilustrado na Figura 3, o qual foi realizado com a mistura de três amostragens de cada amostra em estudo. Os pontos experimentais (azuis e pretos) foram ajustados à intensidade (linha vermelha) pelo programa TOPAS, de acordo com as respectivas fichas padrão ICDD (international Center for Diffraction Data), ICDD 184163 para a ferrita Ni-Zn, ICDD 15840 para a Fe203 e ICSD 26170 para ZnO.

Por meio do refinamento foi possível observar que as amostras apresentaram picos característicos da fase majoritária do espinélio (nanoferrita Ni-Zn), e picos característicos das fases segregadas de Fe203 e ZnO, comprovando os resultados reportados na análise de DRX. 
Figura 3 - Difratograma de raios X das amostras de Ni0,5Zn0,5Fe204: (a) PM, (b) MM e (c) GM, obtidos por refinamento Rietveld.

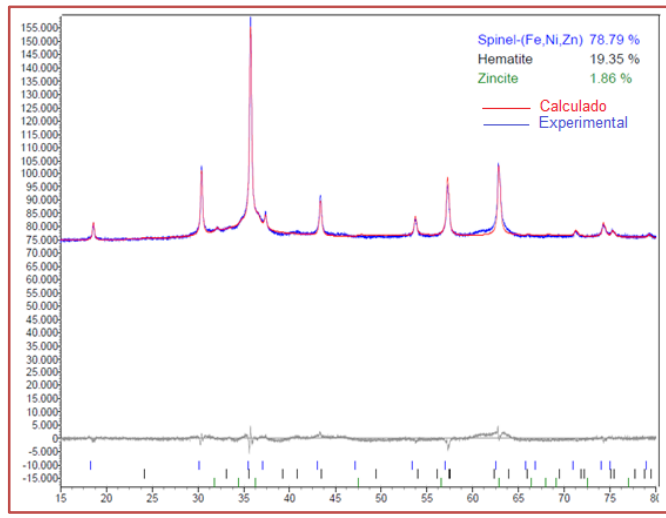

(a)

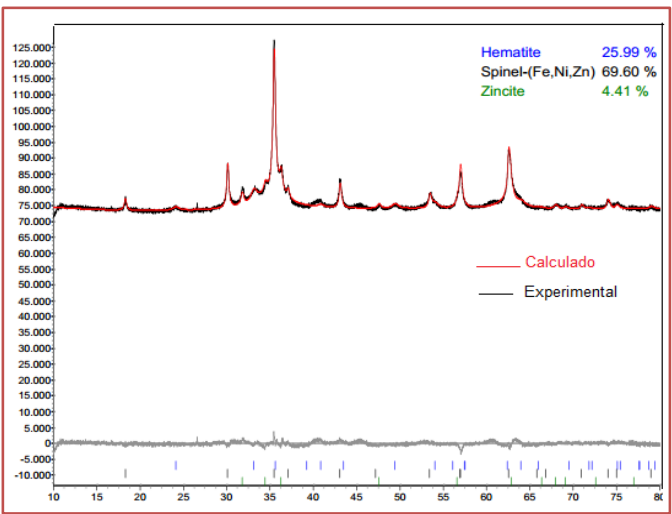

(b)

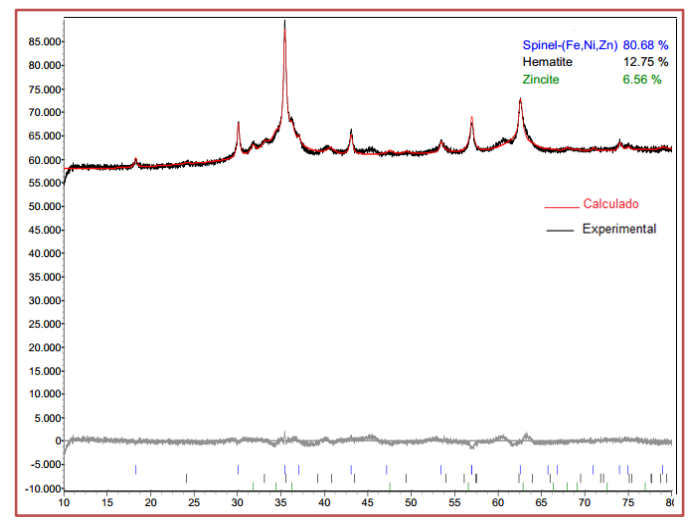

(c)

Na Tabela III estão apresentados os parâmetros de rede e as quantificações das fases presentes de cada fase reportada para as amostras, após refinamento por Rietveld.

Tabela III - Quantificação de fases presentes nas amostras PM, MM e GM, proveniente do Refinamento Rietveld.

\begin{tabular}{|c|c|c|c|c|c|}
\hline Amostras & Parâmetro de Rede & Quantificação (\%) & Rwp & $\operatorname{Rexp}$ & GOF \\
\hline PM & $\begin{array}{c}a=b=c=8,3940 \\
a=5,2368 \text { e } c=11,0150 \\
a=3,2201 \text { e } c=5,1882\end{array}$ & $\begin{array}{c}\mathrm{Ni}-\mathrm{Zn}=78,79 \\
\mathrm{Fe} 2 \mathrm{O} 3=19,35 \\
\mathrm{ZnO}=1,86\end{array}$ & 8,26 & 4,35 & 1,89 \\
\hline MM & $\begin{array}{c}a=b=c=8,397 \\
a=5,0602 \text { e } c=13,6399 \\
a=3,2546 \text { e } c=5,1795\end{array}$ & $\begin{array}{c}\mathrm{Ni}-\mathrm{Zn}=69,60 \\
\mathrm{Fe} 2 \mathrm{O} 3=25,99 \\
\mathrm{ZnO}=4,41\end{array}$ & 9,62 & 5,36 & 1,79 \\
\hline GM & $\begin{array}{c}a=b=c=8,3966 \\
a=5,0380 \text { e } c=13,7720 \\
a=3,2304 \text { e } c=5,1683\end{array}$ & $\begin{array}{c}\mathrm{Ni}-\mathrm{Zn}=80,68 \\
\mathrm{Fe} 2 \mathrm{O} 3=12,75 \\
\mathrm{ZnO}=6,56\end{array}$ & 9,67 & 5,86 & 1,65 \\
\hline
\end{tabular}

De forma geral, observa-se que os parâmetros de rede calculados para a fase principal das amostras foram bem próximos do valor teórico padrão $(8,3827)$ da ferrita Ni-Zn. Comparado os sistemas entre si, os valores dos parâmetros de rede apresentaram uma leve variação na terceira e quarta casa decimal, porém, mantendo a célula unitária ainda com simetria cúbica.

Em relação a quantificação de fases, observa-se a presença da fase principal da nanoferrita Ni-Zn em maior quantidade para as três amostras, variando entre $69,60-80,68 \%$, bem como das fases segregadas de Fe2O3 (variando entre 12,75 - 25,99\%) e ZnO (variando entre 1,86 - 6,56\%). A amostra GM apresentou um maior percentual da fase principal $\mathrm{Ni}-\mathrm{Zn}$, em que esse comportamento pode ser justificado pelo maior tempo de chama e maior tempo total de reação alcançados durante as sínteses, quando em comparação as demais amostras. 
Além disso, as variações nas quantidades de fases indicam a influência conjunta da forma geométrica, da capacidade volumétrica dos recipientes e da quantidade de reagentes usadas para as sínteses de PM, MM e GM. Isto corrobora ao relato de alguns autores [59] de que na síntese por reação de combustão, vários parâmetros influenciam as características do produto final, como por exemplo, o tipo de recipiente utilizado, o agente redutor (combustível), o material e a geometria do recipiente, tipo do precursor, bem como a forma de aquecimento utilizada.

Todos os recipientes possuem formato cônico, variando a razão entre o diâmetro superior e o diâmetro inferior (Dsup/Dinf) e com alturas diferentes, o que leva a distintas capacidades volumétricas [52] e consequentemente permitem quantidades de reagentes diferentes. Porém, de modo geral, apesar de uma leve diferença na quantidade das fases segregadas, pode-se afirmar que em todas as condições de reação, as sínteses foram reprodutíveis, indicando que as amostras apresentaram a fase majoritária de interesse, podendo ser processadas por reação de combustão em bateladas de escala piloto.

Com relação aos indicadores numéricos que serviram de parâmetros de qualidade, tem-se o índice ponderado (Rwp), que deve ser analisado quando se deseja verificar se o refinamento está convergindo. Se ao longo dos ciclos de refinamento, o valor RWP estiver diminuindo, significa que o refinamento está sendo bem-sucedido. Outro indicador adotado é o índice esperado (Rexp), que mede a qualidade das intensidades coletadas. Valores de Rwp e Rexp próximos, significa que eles apresentam uma mesma tendência, sendo assim, é possível considerar o refinamento como satisfatório. Por fim, é considerado satisfatório o refinamento cujo goodness-of-it (GOF) (valor equivalente da relação entre o Rwp e Rexp) for menor que 1,7. Portanto, com base nos resultados obtidos do refinamento, pode-se considerar que foram obtidos resultados satisfatórios.

Caso seja primordial a obtenção de um material monofásico, pode-se estudar mudanças simples na quantidade de combustível ou mesmo no tratamento térmico das amostras sintetizadas. Para respaldar esta afirmação, foi escolhida a amostra GM, a qual foi obtida no recipiente de maior capacidade de produção e submetida a processo de calcinação e posterior caracterização por DRX, como ilustra a Figura 4. Pode-se observar que após o tratamento térmico a $1200{ }^{\circ} \mathrm{C}$, as fases segregadas reagiram transformando-se totalmente na fase espinélio inverso, obtendo-se um produto totalmente monofásico.

Figura 4 - Difratograma de raios X da amostra GM calcinada.

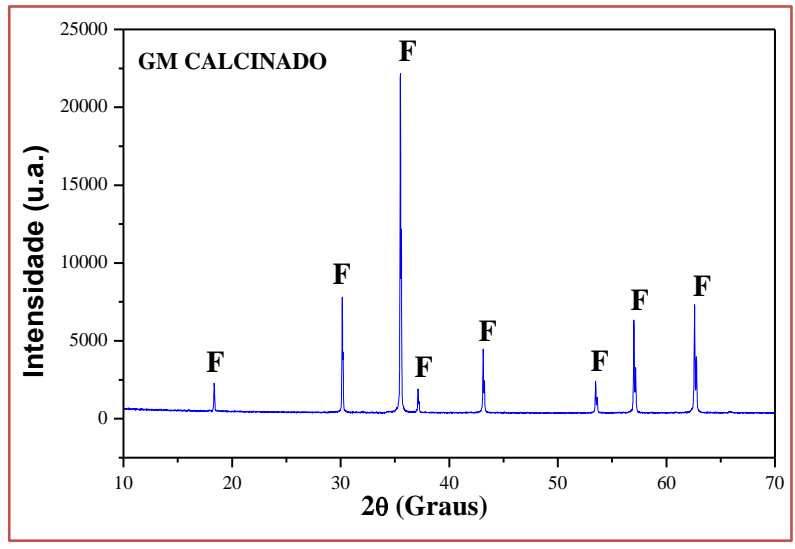

Com base no resultado após calcinação, verifica-se que a presença das fases segregadas nos produtos sintetizados utilizando os três recipientes, foram geradas possivelmente pela rapidez das sínteses, que não possibilitou a completa formação e cristalização da fase do espinélio em estudo. Possivelmente também devido as baixas temperaturas alcançadas em todas as reações, as quais foram muito próximas e não excederam os $830 \mathrm{oC}$, de forma que não cristalizou todo material, segregando outras fases. Porém, isso não comprometeu a eficiência das sínteses, mas sim, indicou que se pode alterar as suas condições e propiciar a formação de um produto monofásico, caso seja essencialmente necessário, como é o caso por exemplo da catálise, em que as fases segregadas na maioria das vezes atuam como promotores das reações catalíticas favorecendo à melhores conversões.

Alguns estudos semelhantes foram reportados. Por exemplo, a ferrita $\mathrm{ZnFe} 204$ quando sintetizada pelo método hidrotermal utilizando diferentes combustíveis apresentou o $\mathrm{ZnO}$ como fase segregada, e isto foi também atribuído a temperatura [60]. A ferrita Ni0.4Zn0.6Fe204 sintetizada pelo método de combustão, 
quando investigado as fases obtidas, semelhantemente apresentou majoritariamente picos de difração típicos da estrutura espinélio da ferrita Ni-Zn, além da presença de traços de segunda fase, que neste caso foram a Fe2O3 e FexO. Posteriormente com a calcinação do produto foi observado a presença apenas de picos característicos da fase majoritária, sem traços de segunda fase, e isso também foi atribuído a transformação das fases de Fe2O3 e FexO em ferrita de Ni-Zn e a formação da estrutura do espinélio cúbico de cristais de ferrita depois do recozimento [61].

Tomando como base os resultados obtidos neste trabalho e comparando com os resultados obtidos em outros estudos disponíveis, pode-se inferir a viabilidade e a eficácia do método de combustão em produzir nanomateriais em escala piloto de até $200 \mathrm{~g} /$ produto, visto que, exceto para método convencional de misturas de óxidos, todos os outros métodos até o presente oferecem ainda uma baixa escala de produção. Assim, mediante as curvas de difração reproduzidas das amostras PM, MM e GM, demonstra-se a reprodutibilidade da síntese e a vantagem do método de combustão.

Na Tabela IV estão apresentados os dados estruturais obtidos a partir dos resultados de DRX para as amostras estudadas. A princípio observa-se que apesar do tamanho de cristalito das três amostras serem próximos, o valor do tamanho de cristalito determinado para amostra PM foi maior 23\% em relação ao valor referente a amostra MM, e aproximadamente $11 \%$ do valor da amostra GM. Isto está relacionado com as temperaturas de combustão alcançadas durante as sínteses, pois com relação a PM as temperaturas máximas foram superiores às alcançadas pelas amostras MM e GM, como reportado na Tabela II. Para PM, devido as maiores temperaturas houve maior energia disponível para que os cristais crescessem. Também pode ser atribuído à variação da quantidade das fases segregadas reportadas para as amostras.

Tabela IV - Cristalinidade e tamanho de cristalito, para família de planos $\{311\}$, calculada a partir dos difratogramas de raios $\mathrm{X}$.

\begin{tabular}{|c|c|c|c|c|}
\hline Amostras & $\begin{array}{c}\text { Cristalinidade } \\
(\%)\end{array}$ & $\begin{array}{c}\text { Tamanho de } \\
\text { Cristalito (nm) }\end{array}$ & $\begin{array}{c}\text { Cristalinidade } \\
\text { Média (\%) }\end{array}$ & $\begin{array}{c}\text { Tamanho Médio de Cristalito } \\
\text { (nm) }\end{array}$ \\
\hline PM1 & 62,2 & 42,1 & & $42,13 \pm 0,4509$ \\
PM2 & 63,9 & 42,6 & $63,40 \pm 1,044$ & \\
PM3 & 64,1 & 41,7 & & $32,07 \pm 0,6351$ \\
\hline MM1 & 66,1 & 31,7 & & \\
MM2 & 69,1 & 32,8 & $67,27 \pm 1,6072$ & $36,93 \pm 1,3576$ \\
MM3 & 66,6 & 31,1 & & \\
\hline GM1 & 58,7 & 38,2 & & \\
GM2 & 56,1 & 37,1 & $56,80 \pm 1,6643$ & \\
GM3 & 55,6 & 35,5 & & \\
\hline
\end{tabular}

Estas atribuições estão consistentes com outros estudos sobre a ferrita Ni-Zn, por exemplo, quando concluíram que a temperatura, modo de tratamento de calor, formação de fases secundárias, método de preparação, natureza de aditivos, entre outros fatores, influenciam nos tamanhos dos cristalitos [62]. Num estudo de filmes finos de Ni-Zn foi reportado um aumento no tamanho de cristalito e, em seguida, uma diminuição com o aumento da concentração de íons de Ni2+. Esta variação foi atribuída à formação da fase secundária de $\alpha$-Fe203 em concentrações mais elevadas de Ni2+ [63].

De maneira geral, por meio da Tabela IV, pode-se observar uma baixa variação no tamanho de cristalito, indicando que as reflexões basais identificadas difratam com boa uniformidade, sugerindo que as nanopartículas de $\mathrm{Ni0}, 5 \mathrm{Zn} 0,5 \mathrm{Fe} 2 \mathrm{O} 4$ apresentaram característica de baixa anisotropia na difração. Desta maneira, a obtenção de cristalitos em escala nanométrica confirma a eficiência do método de reação de combustão para síntese de nanomateriais.

Ainda com relação ao tamanho de cristalito, observa-se que em média os valores obtidos variaram de $32,07 \mathrm{~nm}$ a $42,13 \mathrm{~nm}$. Estes resultados foram semelhantes aos relatados em outros estudos, quando a ferrita $\mathrm{Ni} 0,5 \mathrm{Zn} 0,5 \mathrm{Fe} 204$ foi sintetizada por coprecipitação e sinterizada de 800 a $900{ }^{\circ} \mathrm{C}$ [64], e quando sintetizaram ferritas do sistema Ni1-xZnxFe204 pelo método de combustão e calcinaram a $1000{ }^{\circ} \mathrm{C}$ [65]. 
Isto evidencia que neste presente trabalho foi possível a obtenção de resultados com valores próximos aos apresentados por estes autores, com o diferencial de não ser necessário etapa de calcinação e de ser em escala piloto.

Com relação a cristalinidade das amostras resultantes da combustão, observa-se que também apresentaram valores próximos, e variaram em média de 56,80\% a 67,27\%. A amostra MM foi a que apresentou uma maior cristalinidade (67,3\%) em comparação as amostras PM e GM (63,4 e 56,8\%, respectivamente). Vale ressaltar que embora o tamanho de cristalito para a amostra MM tenha sido menor em relação a PM, pode-se dizer que amostra MM possivelmente apresentou uma melhor organização estrutural e/ou até mesmo a presença de mais cristais por partícula, porém com maior periodicidade dentro da rede, o que levou a uma maior cristalinidade.

Em todo caso, neste estudo, o processo de reação de combustão se evidenciou uma excelente técnica para obtenção de materiais magnéticos cristalinos em escala nanométrica e em grandes bateladas.

Na Tabela V encontram-se os valores das densidades teórica (identificada a partir da ficha padrão JCPDF), da experimental (identificada a partir do ensaio de picnometria de hélio) e relativa (entre a densidade teórica e experimental) referentes as amostras estudadas.

Tabela V - Densidades teórica, experimental e relativa das amostras PM, MM e GM.

\begin{tabular}{|c|c|c|c|c|}
\hline Amostras & PM1 & PM2 & PM3 & Média \\
\hline Densidade Teórica [g/cm3] & 5,361 & 5,361 & 5,361 & 5,361 \\
\hline Densidade Experimental [g/cm3] & 5,2025 & 5,0623 & 5,0249 & $5,096 \pm 0,094$ \\
\hline Densidade Relativa [\%] & 97,04 & 94,43 & 93,73 & $95,06 \pm 1,744$ \\
\hline Amostras & MM1 & MM2 & MM3 & Média \\
\hline Densidade Teórica [g/cm3] & 5,361 & 5,361 & 5,361 & 5,361 \\
\hline Densidade Experimental [g/cm3] & 5,1255 & 5,0928 & 5,0575 & $5,092 \pm 0,034$ \\
\hline Densidade Relativa [\%] & 95,61 & 95,00 & 94,34 & $94,98 \pm 0,635$ \\
\hline Amostras & GM1 & GM2 & GM3 & Média \\
\hline Densidade Teórica [g/cm3] & 5,361 & 5,361 & 5,361 & 5,361 \\
\hline Densidade Experimental [g/cm3] & 5,2485 & 5,0404 & 5,0121 & $5,100 \pm 0,129$ \\
\hline Densidade Relativa [\%] & 97,90 & 94,02 & 93,49 & $95,13 \pm 2,407$ \\
\hline
\end{tabular}

Observa-se que as densidades experimentais foram de 5,096; 5,092 e 5,100 g/cm3 para PM, MM e GM, respectivamente. Ou seja, valores muito próximos da densidade teórica de $5,361 \mathrm{~g} / \mathrm{cm} 3$, correspondendo a densidades relativas de 95,07; 94,98 e 95,14\%. Estes valores reais das densidades confirmam também a eficácia do método de síntese por reação de combustão na produção das amostras com reprodutibilidade.

Ademais, pode-se observar que os valores de densidade experimental foram equivalentes ao valor teórico conforme a ficha padrão, com densidade relativa máxima de $95,14 \%$, e apenas $4,87 \%$ de diferença entre a densidade teórica e a experimental. Analisando-se a amostra produzida no recipiente com capacidade de 200 g do produto, é possível comprovar a formação da fase na estequiometria pré-estabelecida, confirmando os dados reportados nos difratogramas de raios $\mathrm{X}$.

$\mathrm{Na}$ área de catálise, o conhecimento dos poros, sua forma e como eles se distribuem, são requisitos importantes, desta forma, se faz necessário lançar mão de conceitos como os de densidade, ademais, tais esclarecimentos são importantes, pois as medidas de densidade definem de certa forma, a massa de sólido catalítico que será utilizada num reator industrial.

A densidade então é definida como sendo a razão entre a massa e o volume de uma determinada substância. Tem-se que para materiais homogêneos ela é constante, no entanto, para materiais heterogêneos ou porosos a determinação desta propriedade é mais complexa, envolvendo os conceitos de densidade real e densidade aparente. Quando se analisa um material poroso, deve-se atentar que ele é constituído do sólido propriamente dito (volume real) e de poros (volume de poros que são os vazios 
entre os aglomerados de partículas, sejam elas primárias, secundárias ou terciárias), que formam a sua estrutura. Estes vazios ocupam parte do volume total do sólido poroso.

Assumindo uma abordagem simples, pode-se considerar que existem dois tipos diferentes de formação porosa, o primeiro é constituído por espaços existentes entre as partículas primárias de um sólido, e quando elas estão ligadas pela ação de forças de superfície, formando aglomerados, são denominadas partículas secundárias. 0 segundo tipo de porosidade é formado quando uma parte do sólido é removida, seja por um processo de solubilização parcial do sólido, reações com formação e permeação de gases ou, pela separação de fases durante o processo de síntese. A diferença entre a densidade real e a aparente, é que a densidade aparente é uma característica do leito de sólidos, ou seja, do leito catalítico, e é obtida pela razão entre a massa do sólido e o volume total ocupado pelo sólido. Na densidade real, não se considera o volume relacionado aos espaços vazios inter e intrapartículas [66, 67].

Assim, para medir a densidade real no caso de um material poroso, utiliza-se a picnometria a hélio, uma vez que este gás, durante a análise ocupa todos os poros existentes no material, exceto aqueles que se encontram fechados ou bloqueados. A análise granulométrica determina a distribuição relativa do tamanho das partículas dos materiais que se apresentem na forma de pó ou grãos. Na indústria, por exemplo, quando se utiliza reator de leito catalítico, a granulometria do catalisador é de fundamental importância, pois o tamanho da partícula tem implicações diretas nas condições operacionais. Além disso, conforme a literatura[66], a determinação granulométrica de pós é muito importante para a produção de pastilhas ou extrudados de catalisadores, pois, dependendo do resultado, tem-se ou não uma resistência mecânica satisfatória, que por sua vez é outro requisito importante, uma vez que se reproduz o mecanismo de quebra das partículas do sólido, seja ela causada por colisão entre as partículas, ou por impacto e abrasão delas sobre as paredes do reator. É em função dos resultados obtidos da resistência mecânica que se decide se um catalisador pode ou não ser utilizado industrialmente.

Na Figura 5 ( $a, b$ e c) estão ilustrados os espectros vibracionais na região do infravermelho, na faixa de 900-200 cm-1, para as amostras de Ni0,5Zn0,5Fe204, PM, MM e GM, obtidas por reação de combustão. Foi observado em todas a presença de bandas abaixo de $1000 \mathrm{~cm}-1$, que por sua vez são características das ferritas com estrutura cristalina do tipo espinélio.

Figura 5 - Espectro na região do infravermelho para as amostras de Ni0,5Zn0,5Fe204: (a) PM, (b) MM e (c) GM.
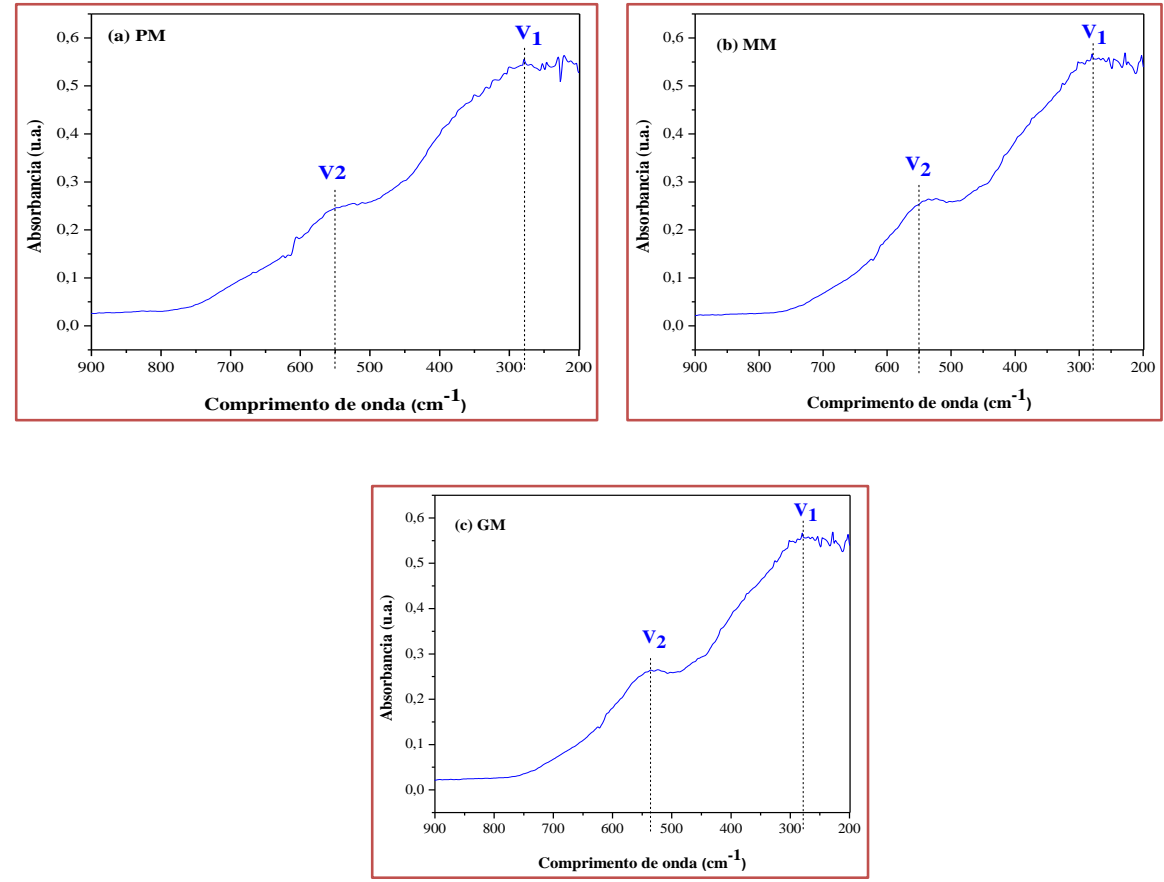

Nos espectros de infravermelho para cada amostra, observou-se a presença de duas bandas de absorção numa frequência de 200-750 cm-1, as quais são características do espinélio AB204. Tais bandas são caracterizadas por vibrações dos íons bivalentes e trivalentes na rede do cristal. A banda de absorção u2, 
localizada na faixa de aproximadamente $550 \mathrm{~cm}$-1 é atribuída às vibrações dos sítios tetraédricos e a banda v1, localizada na faixa de aproximadamente $300 \mathrm{~cm}-1$ corresponde às vibrações dos sítios octaédricos.

Estes resultados estão em concordância com a literatura, que reportam estas bandas como sendo atribuídas as vibrações na posição tetraédrica e octaédricas da estrutura do espinélio inverso. A banda v1 como sendo vibrações intrínsecas dos sítios tetraédricos e a banda $v 2$ a vibrações dos sítios octaédricos $[68,69]$. Em outras pesquisas [70], em que foi objetivado estudar e avaliar as propriedades estruturais e magnéticas de ferritas $\mathrm{Ni}-\mathrm{Zn}$ (dopadas com cátions trivalentes Al3+ e Cr3+) observaram também as bandas de absorção $v 1$ e v2, e atribuíram como sendo características do espinélio inverso abaixo de 1000 cm-1. Quando estudaram as ferritas magnéticas de $\mathrm{Co}(\mathrm{Fe} 204), \mathrm{Ni}(\mathrm{Fe} 204), \mathrm{Cu}(\mathrm{Fe} 2 \mathrm{O} 4)$ e $\mathrm{Zn}(\mathrm{Fe} 204)$ [71], semelhantemente observaram bandas na faixa de 590 a $600 \mathrm{~cm}-1$ para ambas ferritas e atribuíram como sendo do espinélio inverso. Outros autores [72], também observaram as bandas de vibração de espinélio, e propuseram que os íons bivalentes tetraédricos foram frequentemente observados nas frequências de 417 e $550 \mathrm{~cm}-1$, e espécies octaédricas perto da região de $400 \mathrm{~cm}-1$.

A espectroscopia na região do infravermelho é uma importante ferramenta para a investigação da formação de fase das nanopartículas de ferritas tipo espinélios, isto porque ela fornece informações não só sobre as posições de íons dos metais bivalentes e trivalentes na estrutura espinélio, como também fornece informações sobre o seu modo de vibração. Para as ferritas, então, as bandas de absorção do espectro são produzidas devido às vibrações dos íons de oxigênio com os cátions presentes nos sítios tetraédricos e octaédricos na célula unitária.

A análise dos dados de EDX lançou mão do prévio conhecimento dos valores teóricos em porcentagem, referentes aos óxidos individuais que constituem a composição estequiométrica em mol das amostras PM, MM e GM. Na Tabela VI estão descritos esses valores, bem como os valores experimentais da análise semiquantitativa dos óxidos presentes nas amostras, determinados por EDX, realizado em triplicatas.

Tabela VI - Percentuais de óxidos presentes teóricos e determinados por fluorescência de raios X (EDX) para $\mathrm{NiO}, \mathrm{ZnO}$ e $\mathrm{Fe}_{2} \mathrm{O}_{3}$.

\begin{tabular}{|c|c|c|c|}
\hline \multirow{2}{*}{ Óxidos } & PM & MM & GM \\
\hline \multirow{2}{*}{$\mathrm{NiO}$} & $* \mathrm{E}-16,337 \pm 0,323$ & $\mathrm{E}-15,721 \pm 0,144$ & $\mathrm{E}-16,574 \pm 0,126$ \\
& $* \mathrm{~T}-15,712$ & $\mathrm{~T}-15,712$ & $\mathrm{~T}-15,712$ \\
& $* \mathrm{D}-0,625$ & $\mathrm{D}-0,009$ & $\mathrm{D}-0,862$ \\
\hline \multirow{2}{*}{$\mathrm{ZnO}$} & $\mathrm{E}-13,019 \pm 0,210$ & $\mathrm{E}-16,054 \pm 0,200$ & $\mathrm{E}-15,280 \pm 0,158$ \\
& $\mathrm{~T}-17,113$ & $\mathrm{~T}-17,113$ & $\mathrm{~T}-17,113$ \\
& $\mathrm{D}--4,094$ & $\mathrm{D}--1,059$ & $\mathrm{D}--1,833$ \\
\hline \multirow{2}{*}{$\mathrm{Fe}_{2} \mathrm{O}_{3}$} & $\mathrm{E}-70,644 \pm 0,225$ & $\mathrm{E}-68,225 \pm 0,121$ & $\mathrm{E}-68,011 \pm 0,379$ \\
& $\mathrm{~T}-67,175$ & $\mathrm{~T}-67,175$ & $\mathrm{~T}-67,175$ \\
& $\mathrm{D}-3,469$ & $\mathrm{D}-1,050$ & $\mathrm{D}-0,836$ \\
\hline
\end{tabular}

*T - teórico, *E - experimental e *D - diferença do valor experimental em relação ao valor teórico.

Todos os reagentes utilizados para a síntese das amostras possuem grau de pureza 98\%, isto significa que $2 \%$ são de impurezas, relatadas pelo fabricante como resíduos de cloreto, sulfato, ferro, cálcio, magnésio, potássio, sódio, níquel, chumbo, zinco e cobalto. As impurezas concernentes aos valores experimentais são atribuídas aos resíduos após ignição e SO3.

De maneira geral, frente aos resultados detectados, expressos na Tabela VI, verifica-se que os valores foram próximos aos valores teóricos calculados, considerando o fato dos reagentes utilizados conterem $2 \%$ de impurezas. Entretanto, observa-se que as concentrações do $\mathrm{ZnO}$ e Fe2O3 para as amostras apresentaram pequenas variações em detrimento das concentrações do $\mathrm{NiO}$, que por sua vez se mantiveram muito próximas.

Com base numa análise mais detalhada das variações dos valores dos óxidos de $\mathrm{ZnO}$ e $\mathrm{Fe} 2 \mathrm{O3}$, possivelmente isto justifica a formação dos traços de segunda fase apresentadas nos difratogramas, que 
foram atribuídos também a insuficiência das temperaturas de combustão alcançadas. Estas variações são devidas principalmente ao balanço de massa estequiométrico feito entre os teores de óxidos presentes nas amostras, ou seja, se os teores de ZnO reduziram em média 40,82\% do seu valor teórico, em detrimento da elevação dos teores de Fe203, que em média foi 7,97\% do valor teórico, isto como consequência do comportamento dos gases gerados durante as sínteses de combustão, então as quantidades como um todo são balanceadas para atingir um total de $100 \%$.

0 efeito comportamental de gases durante as reações, como por exemplo, efeito de volatização, foram reportados por outros autores [73] quando sintetizaram pelo método convencional hidrotermal a ferrita $\mathrm{Ni} 0,6 \mathrm{Zn} 0,4 \mathrm{Fe} 204$, e estudaram a diferença das técnicas de sinterização convencional e em micro-ondas nas propriedades estruturais, morfológicas e magnéticas. Semelhantemente reportaram [74] a elevação do óxido de Fe203, quando estudaram o efeito das propriedades microestruturais e magnéticas de ferritas Mn-Zn sintetizadas por método de combustão.

As isotermas de adsorção/dessorção de N2 para as três amostras estudadas estão ilustradas na Figura 6. A linha tracejada na cor preta representa a adsorção (condensação de líquido nos poros) e a linha tracejada na cor vermelha representa dessorção (evaporação de líquidos nos poros). Este estudo do fenômeno de adsorção foi feito visando a obtenção de informações concernente a área específica e a estrutura porosa das amostras, visto que a construção da curva isoterma de adsorção é de fundamental importância, pois seu formato revela detalhes sobre a característica morfológica, ou seja, a forma da curva é função do tipo de porosidade do material. A princípio as isotermas foram plotadas em um único gráfico objetivando uma melhor comparação de suas respectivas formas.

Figura 6 - Isotermas de adsorção/dessorção de nitrogênio das amostras PM, MM e GM.

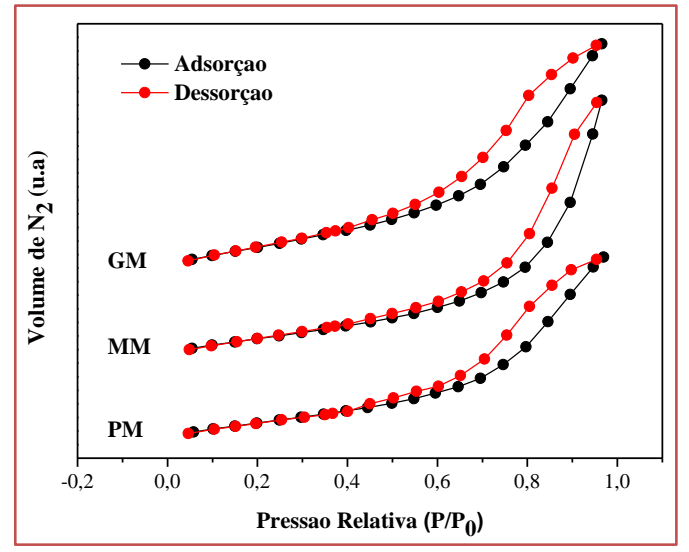

As três amostras apresentaram característica de materiais mesoporos, entretanto, as características de PM e GM foram mais semelhantes entre si em alguns parâmetros, quando comparados com a amostra MM.

Assim, PM e GM apresentaram estruturas de superfícies com perfil da curva isoterma de adsorção, que de acordo com a classificação da International Union of Pure and Applied Chemistry - IUPAC [75], se enquadram no tipo $\mathrm{V}$, sugerindo uma característica mesoporosa do material (poros com raios variando de 10 a $250 \AA$ Å). Analisando também a forma de histerese que corresponde a diferentes geometrias de poros, pode-se observar que as nanopartículas das referidas amostras são representadas por loop de histerese tipo H3 (que constitue a formação de poros com formato de cunha, cones ou placas paralelas). Também estão associadas a histerese tipo $\mathrm{H} 2$ (poros cilíndricos abertos e fechados com estrangulações, morfologia tipo garrafa). Isso indica que as amostras apresentaram poros de diversos formatos e tamanhos.

A amostra MM apresentou estrutura de superfície com perfil da curva isoterma de adsorção enquadrada no tipo V (sólidos com mesoporos) e conjuntamente ao tipo III (sólidos não porosos associados a mesoporos). A forma de histerese foi representada por loop de histerese tipo H3, cujos poros possuem formato de cunha, cones ou placas paralelas. Logo, isto sugere poros mais regulares quando comparados aos poros apresentados pelas amostras PM e GM. Desta forma, isto pode ter correlação com a sua estrutura, uma vez que a amostra MM se apresentou mais cristalina em relação as demais amostras estudadas. Ressalta-se que quanto maior a organização estrutural, maior a possibilidade de partículas com formatos mais uniformes, gerando poros igualmente uniformes. 
Pode-se existir materiais que apresentam isotermas que não se enquadram claramente em um único tipo de isoterma padrão, apresentado características de mais de um tipo delas. A exemplo, adsorvatos com microporos e mesoporos exibem uma mistura de isoterma do tipo I com o tipo IV [76, 77].

0 fenômeno de histerese resulta da diferença entre o mecanismo de condensação e evaporação do gás adsorvido, este fenômeno está associado a condensação capilar em estruturas mesoporosas. Conforme estudos [78], a histerese do tipo $\mathrm{H} 3$, está normalmente associada a agregados não rígidos de partículas em forma de placa, originando poros em fenda e, que é caracterizada por apresentar diferentes caminhos de evaporação e condensação entre os processos de adsorção e dessorção sofridos pelos materiais adsorventes. A curva deste sistema apresenta um patamar para valores de P/P0 entre 0 e 0,4 e depois um ramo de histerese na região de elevada pressão relativa com declividade bastante acentuada, demonstrando assim a formação de multicamadas e a presença de mesoporos interpartículas, ou seja, poros que se originaram em virtude da aglomeração de pequenos cristais [79].

Na Tabela VII encontram-se os valores de área superficial específica (SBET), tamanho de partícula (DBET), volume do poro (Vp), raio do poro (Rp), relação entre o tamanho de partícula e o tamanho de cristalito (Tc) e o volume adsorvido de N2, referente as amostras PM, MM e GM.

Tabela VII - Valores de área superficial específica, tamanho de partícula, volume e diâmetro de poro das amostras PM, MM e GM.

\begin{tabular}{|c|c|c|c|c|c|}
\hline Amostras & $\begin{array}{l}\text { Área superficial } \\
\text { (SBET) }(\mathrm{m} 2 \mathrm{~g}-1)\end{array}$ & $\begin{array}{c}\text { Tamanho de } \\
\text { partícula (DBET) } \\
(\mathrm{nm})\end{array}$ & $\begin{array}{l}\text { Volume do poro } \\
\text { (Vp) (cm3/g) }\end{array}$ & $\begin{array}{l}\text { Raio do poro } \\
\text { (Rp) }(\AA)\end{array}$ & DBET/Tc* \\
\hline PM & $65,289 \pm 0,324$ & $17,14 \pm 0,085$ & $0,167 \pm 0,015$ & $42,754 \pm 4,739$ & 0,41 \\
\hline MM & $50,942 \pm 0,076$ & $21,97 \pm 0,036$ & $0,171 \pm 0,011$ & $48,042 \pm 10,228$ & 0,69 \\
\hline GM & $64,171 \pm 1,074$ & $17,44 \pm 0,293$ & $0,152 \pm 0,007$ & $32,630 \pm 5,1215$ & 0,47 \\
\hline
\end{tabular}

${ }^{*} \mathrm{TC}=$ Tamanho de cristalito.

0 maior valor médio de área superficial específica, de 65,29 m2g-1, foi apresentado por PM, e o menor valor de área superficial foi de 50,94 m2g1, apresentado por MM. Consequentemente, ambas apresentaram respectivamente, o menor $(17,14 \mathrm{~nm})$ e o maior $(21,97 \mathrm{~nm})$ valor de tamanho de partículas. Entretanto, as áreas superficiais de PM e GM foram muito próximas, visto que para GM o valor médio de área superficial obtido foi de 64,17 m2g-1, com tamanho médio de partícula de 17,44 nm, ou seja, apenas 1,7\% de diferença entre as suas respectivas áreas de superfície.

Comparando os resultados de tamanho de partículas alcançados pelas amostras obtidas por reação de combustão em diferentes bateladas de produção, com o tamanho de partícula reportado por outros autores [80] ao sintetizarem o mesmo sistema pelo método sol-gel, cujos valores foram entre 1-4 $\mu \mathrm{m}$ (1000-4000 nm), verifica-se mais uma vez a eficiência da técnica por reação de combustão na produção de nanomateriais em escala piloto.

Então, com relação ao tamanho de partícula obtido pela área superficial, um gás (N2) é que passa entre as partículas, quanto mais finas elas forem e mais porosidade interpartícula existir, a leitura feita na passagem do gás indicará uma maior área superficial, que é a área de contato. Diante do contexto que remete a importância exercida pela característica porosa das amostras estudadas, foram plotadas curvas de isoterma para cada amostra individualmente, obtidas em triplicatas por BET (Figura 7), visando uma melhor visualização e entendimento da porosidade apresentada, além de comprovação da reprodutibilidade. 
Figura 7 - Isotermas de adsorção/dessorção de N2 em triplicatas das amostras PM, MM e GM.
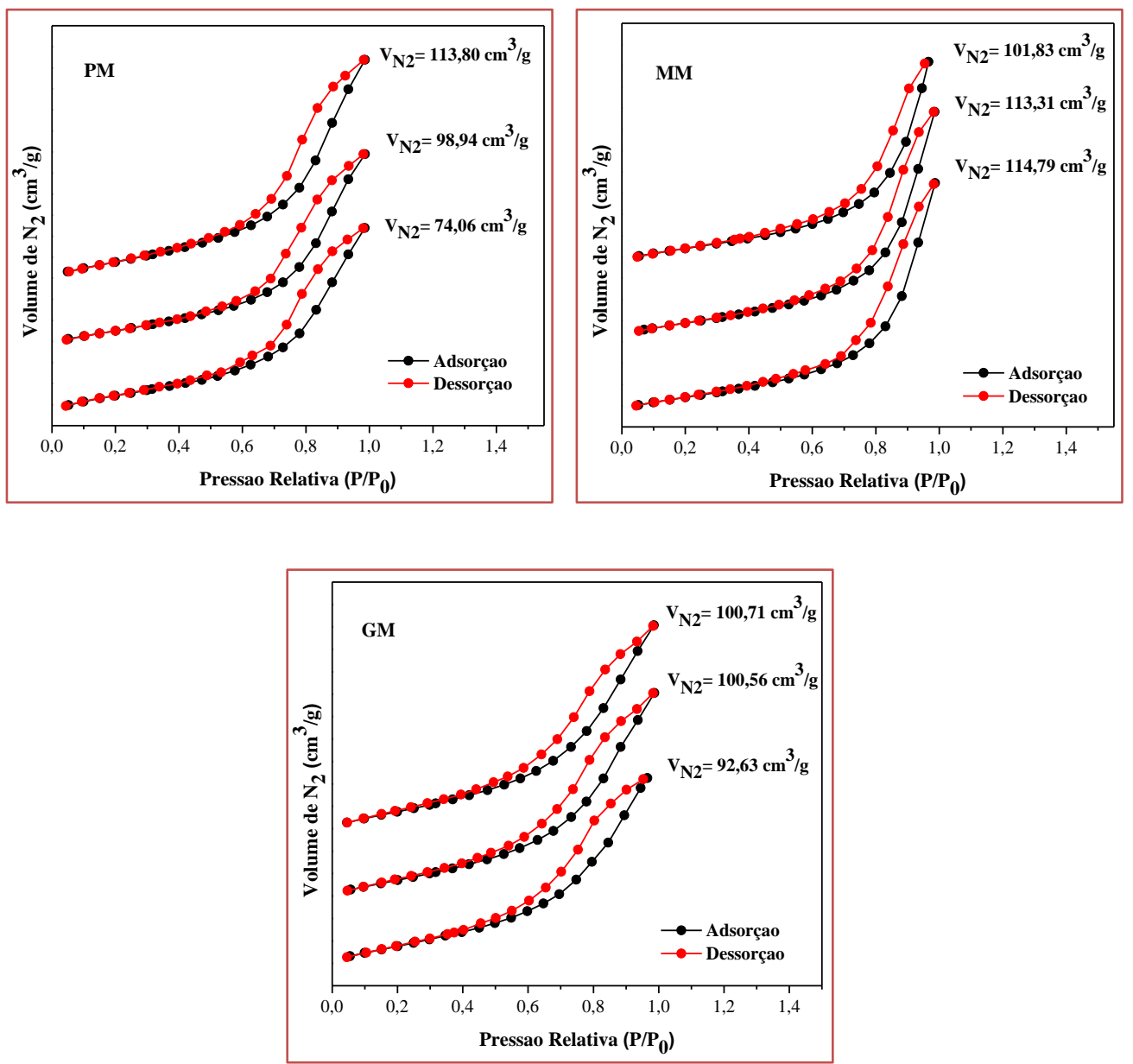

Desta maneira, procurou-se correlacionar o volume de poros (que são os vazios entre os aglomerados das nanopartículas, que formam a sua estrutura) com os seus respectivos volumes adsorvidos de N2. Percebese então que MM foi a amostra que apresentou o maior volume de N2 adsorvido, com valor de 109,98 cm3/g, seguido de GM e PM, com valores de 97,97 e 95,60 cm3/g, respectivamente. Isto provavelmente está relacionado com a porosidade de cada uma delas, ou seja, quanto maior a porosidade maior é o volume de $\mathrm{N} 2$ adsorvido, confirmando assim os valores de volumes de poros obtidos, que foram em média respectivamente de 0,$171 ; 0,152$ e $0,162 \mathrm{~cm} 3 / \mathrm{g}$.

Consequentemente, nesta mesma ordem, têm-se os valores dos raios dos poros, que foram de 48,042; 32,630 e 42,754 $\AA$, ou seja, quanto maior foram, maior o volume respectivo associado. Logo, isto corrobora aos formatos dos poros obtidos por PM e GM, que em conformidade com as suas histereses, apresentaram geometrias mais variadas, e inclusive a de poros fechados, o que dificulta o processo de adsorção/dessorção, levando possivelmente a uma menor porosidade, quando comparadas a amostra MM.

Ainda se observou na Tabela 7, mediante os valores da relação tamanho de partícula/tamanho de cristalito (DBET/TC), que para as três amostras esta relação foi menor que 1, ou seja, são constituídos por partículas muito pequenas (nanométricas e monocristalinas). Sabe-se que quanto mais próximo de 1 for esta relação, mais sugere que o tamanho de partícula é próximo do tamanho do cristal, indicando desta maneira que a partícula tende a ser monocristalina, confirmando a maior cristalinidade obtida para a amostra MM e que as suas partículas teriam formatos mais uniformes. A relação DBET/TC foi maior para as amostras PM e GM. Isto também indica que o estado de aglomeração se tornou maior, podendo possivelmente justificar a presença de poros fechados em virtude da aglomeração do material.

Portanto, os resultados obtidos são bastante atrativos, visto que em conformidade com alguns autores [81], o desenvolvimento de materiais com uma maior quantidade de sítios químicos ativos mediante a expansão de sua área superficial, tornou-se o expressivo desafio da comunidade científica e empresarial. Assim, a redução do tamanho da partícula destes materiais, até uma escala nanométrica, vem sendo alvo de diversos estudos. Como exemplo cita-se que os catalisadores em escala nanométrica proporcionam um 
aumento da razão área superficial/volume, levando a elevadas atividades catalíticas, quando comparados aos tradicionais catalisadores com largos cristais, resultando em alta reatividade química [82].

As análises granulométricas em triplicatas estão ilustradas graficamente na Figura 8 (a, b e c), que expressam os valores de distribuição dos diâmetros esféricos das partículas equivalentes em função do volume cumulativo das amostras PM, MM e GM.

Os poros de um catalisador são interstícios contínuos e interconectados, estatisticamente homogêneos, entre os aglomerados irregulares compostos por partículas, dando origem a estrutura do sólido. Estes interstícios ocupam parte do volume do catalisador, chegando até cerca de $80 \%$. Os poros são classificados de acordo com seus tamanhos, desta forma, são considerados microporos (menores que $2 \mathrm{~nm}$ ), mesoporos (classificados entre 2 e $50 \mathrm{~nm}$ ) e macroporos (maiores que $50 \mathrm{~nm}$ ). A distribuição de tamanhos de poro e de partículas também é um parâmetro muito importante para o estudo da estrutura porosa de um catalisador, pois está relacionado à sua área total [83].

Figura 8 - Distribuição granulométrica das amostras de Ni0,5Zn0,5Fe204 (PM, MM e GM).
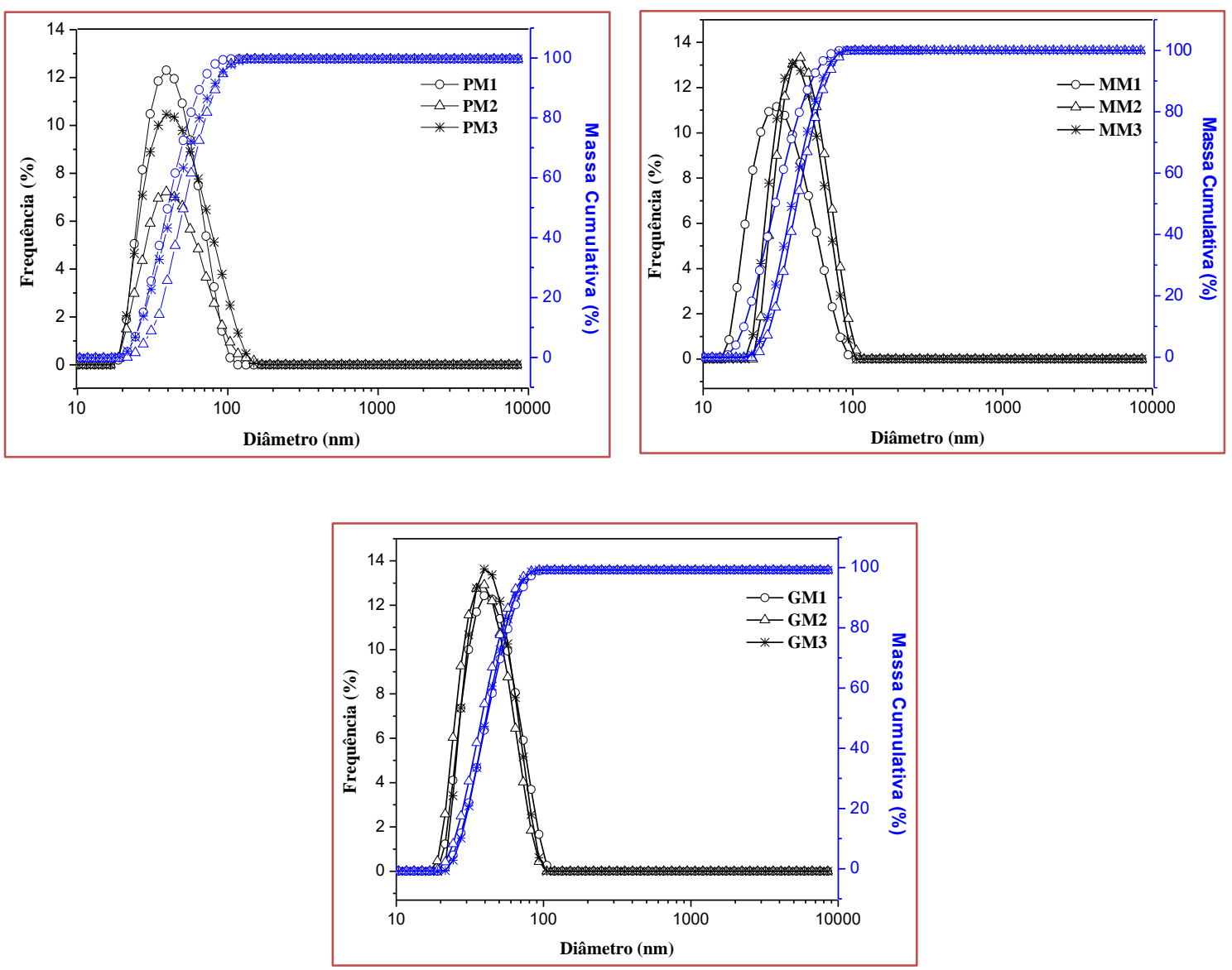

De forma geral, na Figura 8 observa-se uma distribuição relativamente larga, exibindo um comportamento simétrico e monomodal, cujos diâmetros medianos (50\%) são de 39,87; 43,58 e 40,55 nm. Assim, as amostras apresentaram curvas com praticamente a mesma largura, sem grandes variações na distribuição e nos diâmetros médios de partículas.

Na Tabela VIII estão apresentados o tamanho do diâmetro das partículas das três amostras estudadas, em conformidade com os índices de distribuição de tamanho de partícula D10, D50 e D90. Os parâmetros D10 e D90 estão correlacionados aos diâmetros de corte da curva de distribuição acumulada em $10 \%$ e 90\%, respectivamente. Enquanto que o parâmetro D50 está correlacionado à mediana da distribuição e corresponde ao diâmetro médio de partícula (Dm). 
Tabela VIII - Diâmetros das partículas das amostras PM, MM e GM, de acordo com os índices de distribuição.

\begin{tabular}{|c|c|c|c|}
\hline \multicolumn{2}{|c|}{$\begin{array}{c}\mathrm{D}(10 \%) \\
(\mathrm{nm})\end{array}$} & $\begin{array}{c}\mathrm{D}(50 \%) \\
(\mathrm{nm})\end{array}$ & $\begin{array}{c}\mathrm{D}(90 \%) \\
(\mathrm{nm})\end{array}$ \\
\hline PM & 26,30 & $39,87 \pm 0,344$ & 64,82 \\
\hline MM & 29,30 & $43,58 \pm 0,429$ & 68,48 \\
\hline GM & 27,27 & $40,55 \pm 0,220$ & 62,53 \\
\hline
\end{tabular}

De acordo com os resultados, observa-se que o tamanho dos diâmetros das partículas alcança uma variação crescente, do início em $\mathrm{D}(10 \%)$ até $\mathrm{D}(90 \%)$ para as amostras. Fixando o diâmetro mediano $\mathrm{D}(50 \%)$, as três amostras apresentaram tamanhos de partículas próximos, com valores de 39,87; 43,58 e $40,55 \mathrm{~nm}$, de forma que se obteve curvas de distribuição praticamente da mesma largura. Isto indica boa semelhança na distância média de separação entre as partículas. Estes resultados delineiam o mesmo comportamento observado para o tamanho de cristalito calculado para a reflexão de primeira ordem (intensidade 100) correspondendo à família de planos $\{113\}$ do espinélio inverso $\mathrm{Ni} 0,5 \mathrm{Zn} 0,5 \mathrm{Fe} 2 \mathrm{O} 4$ (que foram em média de 42,10; 32,06 e 36,93 nm, para as amostras PM, MM e GM, respectivamente).

Desta maneira, em relação a produção das amostras em diferentes bateladas, pode-se inferir que não houve uma grande variação no crescimento das partículas, tendo assim comportamentos muito próximos. Logo, fica comprovada a eficiência da reprodutibilidade da síntese. Além disto, fixando o tamanho mediano de partícula, observa-se que embora os valores obtidos sejam próximos, as amostras PM e GM apresentaram menores tamanhos em relação a amostra MM, coincidindo desta maneira com os resultados reportados para os tamanhos de partículas na análise textural.

Concernente a morfologia dos materiais, o processo de aglomeração das partículas refere-se à adesão destas entre si, por forças de atração fracas como as de Van der Waals, que por sua vez são consideravelmente mais intensas em partículas na escala nanométrica. Portanto, os materiais aglomerados formados por ligações fracas interpartícula são facilmente desaglomerados em meio líquido ou fisicamente. Por outro lado, a agregação refere-se a partículas que sinterizam incipientemente, tornando difícil a quebra do aglomerado de partículas [84]. Tais características favorece às nanopartículas elevada área de superfície e elevada tensão superficial (área de contato), o que as tornam mais reativas, favorecendo a formação de aglomerados conhecidos por "soft" ou comumente moles ou não densos.

Nas Figuras 9, 10 e 11 encontram-se ilustradas a morfologia das amostras PM, MM e GM. De maneira geral, na Figura 9(a), 10(a) e 11(a) verificou-se a formação de aglomerados não densos na forma de blocos irregulares, de aspecto frágil, e com presença de poros, os quais são provenientes dos gases de combustão expelidos durante a síntese. A característica da porosidade presente, pode ser atribuída ao comportamento do combustível na reação, uma vez que a natureza da aglomeração é regida por entalpia e pela temperatura da chama gerada durante a combustão, que por sua vez é dependente da natureza do combustível e da relação agente oxidante/agente redutor.

Mediante as Figuras 9(b), 10(b) e 11(b), verificou-se que estes aglomerados são formados por partículas pequenas ligadas por forças fracas (ou seja, as partículas estão apenas em contato umas com as outras, sem observar pré-sinterização), sendo, portanto, facilmente desaglomerados. Experimentalmente, durante o processo de peneiramento, foram verificados aglomerados friáveis, ou seja, a desaglomeração dos materiais foi de fácil procedimento.

Por outro lado, todas as amostras apresentaram aglomerados de formato irregular e com uma estreita distribuição de tamanho. Para a amostra PM os tamanhos dos aglomerados variaram entre 1,92 e 28,44 $\mu \mathrm{m}$, cujo tamanho médio foi de 8,34 $\mu \mathrm{m}$. Para MM os tamanhos variaram entre 2,17 e 26,73 $\mu \mathrm{m}$, com tamanho médio de 9,12 $\mu \mathrm{m}$. Para GM os tamanhos variaram entre 1,76 e 28,65 $\mu \mathrm{m}$, com tamanho médio de $8,79 \mu \mathrm{m}$. Os tamanhos dos aglomerados foram calculados a partir da contagem de 15 aglomerados para cada amostra. A contagem foi feita em regiões distintas das micrografias. 
Figura 9 - Morfologias obtidas por MEV para a amostra PM: (a) $20 \mu \mathrm{m}$ aumento de 500x e (b) $10 \mu \mathrm{m}$, aumento de $2000 x$.
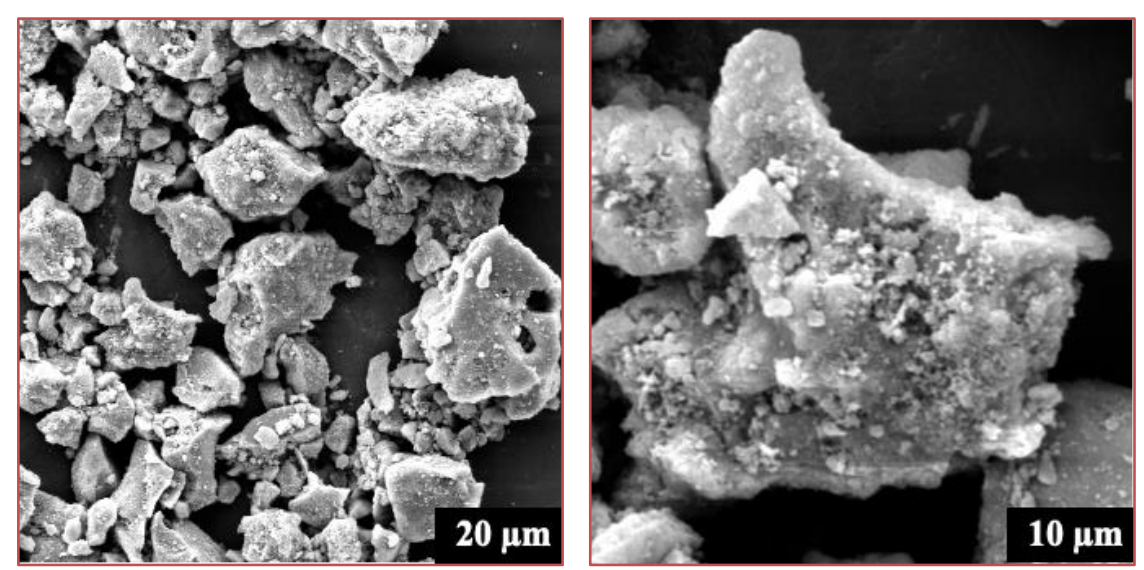

(a) (b)

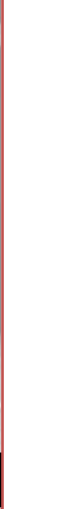

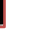

Figura 10 - Morfologias obtidas por MEV para a amostra MM: (a) $20 \mu \mathrm{m}$ e (b) $10 \mu \mathrm{m}$.
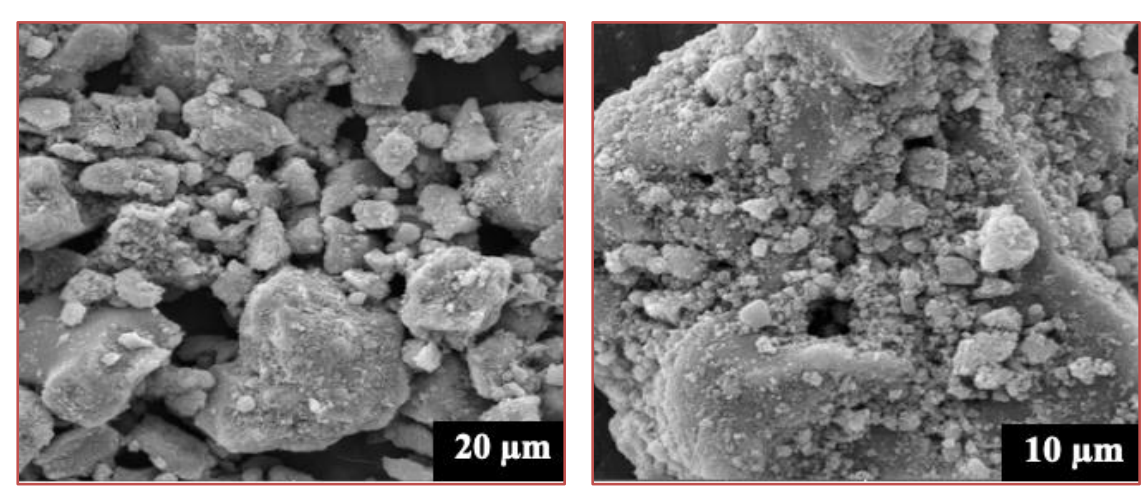

(b)

(a)

Figura 11 - Morfologias obtidas por MEV para a amostra GM: (a) $20 \mu \mathrm{m}$, e (b) $10 \mu \mathrm{m}$.
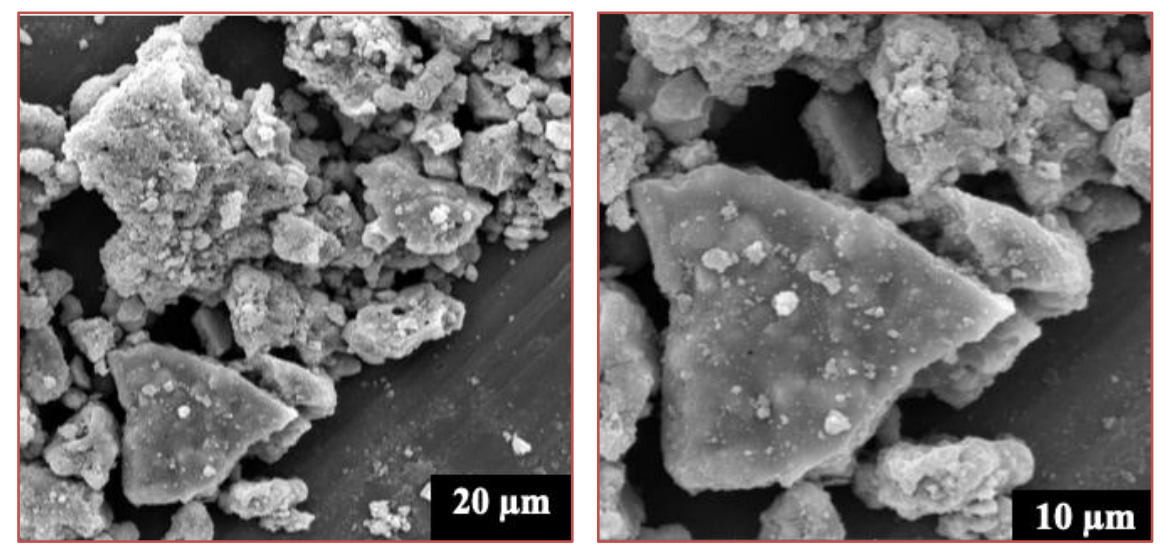

(b)

(a)

Então, os aglomerados porosos na forma de blocos irregulares constituídos por partículas finas, confirmam a análise dos resultados discutidos anteriormente para o tamanho de partícula obtido por intermédio da área superficial, visto ser conhecido que quanto menor o tamanho de partículas, maior a sua área superficial, o que gera força motriz para favorecer o aumento do estado de aglomeração e/ou agregação. Alguns autores [85] quando sintetizaram nanoferritas $\mathrm{Ni0}, 5 \mathrm{Zn} 0,5 \mathrm{Fe} 2 \mathrm{O} 4$ por reação de combustão e avaliaram sua morfologia por meio da microscopia eletrônica de varredura, também observaram um material com aglomerados de característica esponjosa e frágil. Outros pesquisadores [86], 
também estudando ferritas Ni-Zn como sintetizadas e silanizadas, observaram semelhantemente, a presença de aglomerados porosos na forma de blocos irregulares de aspecto frágil.

Os materiais cerâmicos porosos reúnem características tais como alta resistência química, térmica e mecânica, alta permeabilidade, valores de densidade intermediária e tempo de vida longo. Para catálise, estas características são requisitos importantes para constituir um catalisador. Particularmente, a resistência térmica é fundamental para que se tenha um bom catalisador, e pode ser aferida mediante uma análise termogravimétrica (TGA e DTG) onde a massa do catalisador numa atmosfera controlada é registrada continuamente como uma função do tempo, à medida que a temperatura da amostra aumenta (em geral linearmente com o tempo).

Na área catalítica, a TG é usada para se estudar em detalhes o caminho das alterações que o aquecimento pode provocar nas substâncias, visando estabelecer a faixa de temperatura nas quais o material adquire composição química definida, ou a temperatura onde se iniciam os processos como os de decomposição, sinterização e mudança cristalina. Deste modo, a literatura [87] aborda que as curvas de variação de massa em função da temperatura obtida a partir de uma termobalança, permitem obter algumas conclusões sobre a composição e estabilidade dos compostos intermediários e sobre a composição do composto formado após aquecimento.

Os eventos observados a partir das curvas sobrepostas de TG/DTG para as amostras de Ni0,5Zn0,5Fe204 estão ilustrados na Figura 12. Por meio desses eventos foi possível determinar as temperaturas $\left({ }^{\circ} \mathrm{C}\right)$ de decomposição e as perdas de massa (\%). De maneira geral, foram observados o mesmo perfil das curvas sobrepostas de TG/DTG e também três eventos térmicos, embora muito sutis, o que demonstra a alta estabilidade das amostras frente às temperaturas impostas. As análises apresentaram perdas de massas numa faixa de aproximadamente 20 a $630^{\circ} \mathrm{C}$ e, acima deste intervalo, não se observa nenhum evento característico de formação de fase, ou seja, observa-se apenas valores de massa praticamente constante até o final das análises em $1000{ }^{\circ} \mathrm{C}$, constatando desta forma a eliminação total da matéria orgânica presente inicialmente nas amostras em estudo. Levando em consideração as faixas de temperatura onde ocorreram os eventos de perda de massa, pode-se atribuir que estas perdas são possivelmente referentes a evaporação de água residual, ao ar, oxigênio, nitrogênio, nitratos residuais e compostos orgânicos presentes na superfície e nos poros das ferritas Ni0,5Zn0,5Fe204, como também a cristalização da fase do espinélio.

Figura 12 - Curvas sobrepostas de TG/DTG das amostras PM, MM e GM.
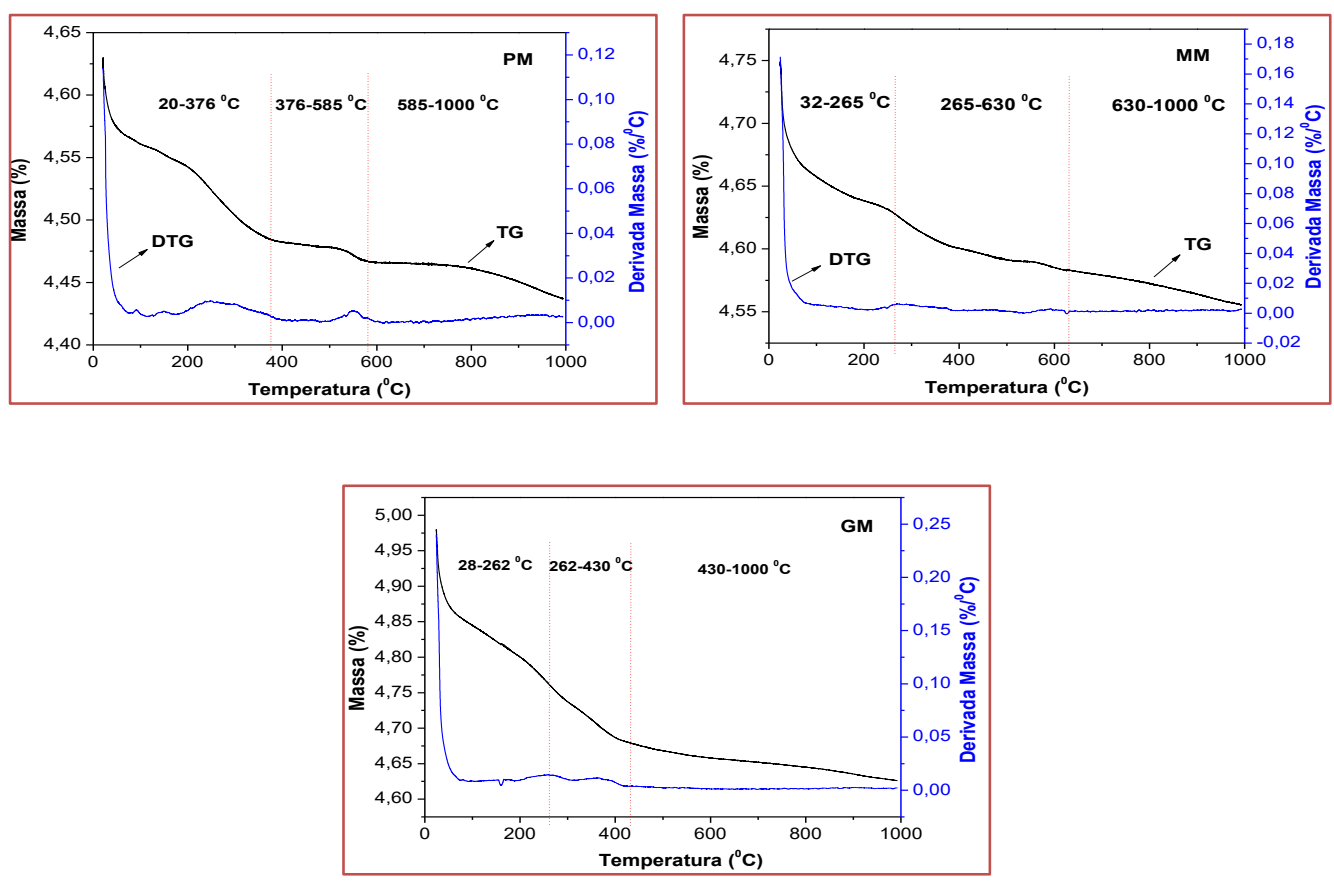

Mais detalhadamente, para a amostra PM, a análise apresenta uma primeira perda de massa de 0,15\%, no intervalo entre 20 e $376^{\circ} \mathrm{C}$, a qual é associada ao desprendimento de gases e água adsorvida, posteriormente, uma segunda perda de massa de $0,02 \%$, no intervalo de 376 a $585 \stackrel{\circ}{-}$, a qual é equivalente 
a nitratos residuais e outros possíveis compostos orgânicos presentes, como também a cristalização da fase espinélio. A partir deste intervalo de temperatura, observa-se uma massa constante até $1000{ }^{\circ} \mathrm{C}$.

Para a amostra MM, a primeira perda de massa de $0,07 \%$ foi observada no intervalo de 32 e 265 o $\mathrm{C}$, atribuída semelhantemente a evaporação de gases e água adsorvida, seguidamente, a segunda perda de massa no valor de $0,05 \%$, ocorreu entre 265 e $630 \stackrel{\circ}{\circ}$, correspondente aos nitratos e matérias orgânicas residuais e, a cristalização do espinélio. Posteriormente, observa-se uma massa constante até $1000{ }^{\circ} \mathrm{C}$.

Para a amostra GM, o primeiro evento de perda de massa, que foi no valor de $0,18 \%$, se deu no intervalo de 28 a $262{ }^{\circ} \mathrm{C}$ e o segundo evento ocorreu com perda de massa de $0,07 \%$, entre 262 e $430{ }^{\circ} \mathrm{C}$, referentes ao desprendimento de gases e água adsorvida e a outros eventuais compostos orgânicos presentes, respectivamente. 0 terceiro evento ocorreu posteriormente, onde observa-se uma massa constante até $1000 \stackrel{\circ}{\circ}$.

Com a finalidade de uma melhor visualização concernente as perdas de massa apresentadas pelas três amostras analisadas, uma vez que o comportamento térmico destas, quando submetidas a uma rampa de aquecimento, foi muito estável, que quase não houve perdas evidentes, como demonstram as curvas de TG e DTG sobrepostas apresentadas, procurou-se compilar na Tabela IX estes pequenos valores de perda e o intervalo em que ocorreram, além da perda total obtida.

Tabela IX - Comportamento térmico das amostras PM, MM e GM sintetizados por reação de combustão.

\begin{tabular}{|c|c|c|c|}
\hline Amostras & PM & MM & GM \\
\hline Evento $\left.1{ }^{\circ} \mathrm{C}\right)$ & $20-376$ & $32-265$ & $28-262$ \\
\hline Evento $\left.2{ }^{\circ} \mathrm{o}\right)$ & $376-585$ & $265-630$ & $262-430$ \\
\hline Evento 3 $\left.{ }^{\circ} \mathrm{C}\right)$ & $585-1000$ & $630-1000$ & $430-1000$ \\
\hline Perda Massa Total $(\%)$ & 0,18 & 0,15 & 0,31 \\
\hline
\end{tabular}

Assim, conforme as análises das curvas TG/DTG tabeladas, observa-se que PM, MM e GM, apresentaram excelente estabilidade térmica, visto que não foi verificado elevados valores de perda de massa. A maior perda de massa ocorreu para GM, sendo apenas de 0,31\%. Assim, as amostras avaliadas como material catalítico caracterizam-se como muito estáveis, ou seja, não apresentaram variação significativa em suas respectivas massas em função do tempo e temperatura programados. Além disto, pode-se sugerir que, dos resultados alcançados, a temperatura adequada para formação da fase única da nanoferrita sob investigação, é cerca de no máximo $1000^{\circ} \mathrm{C}$.

Esta afirmação encontra respaldo no estudo [88], onde foi relatado que a temperatura mínima para o processo de decomposição completa, o que pode ser considerado como a temperatura mínima para o processo de calcinação, pode ser estimada a partir das medições do comportamento térmico de precursores como sintetizados. Outros estudos [89], quando abordaram as propriedades estruturais, elétricas e magnéticas de ferritas de (Ni-Zn)Fe204, com incremento de $\mathrm{Cr} 3+$, sintetizadas pela decomposição do oxalato, sugeriram que a temperatura de calcinação adequada para a formação da ferrita composta pelos precursores sob investigação era de cerca de $1000^{\circ} \mathrm{C}$.

Outras pesquisas sobre materiais mistos da família das ferritas espinélios, reportaram eventos térmicos semelhantes aos apresentados neste trabalho. Por exemplo, pode-se citar o estudo da ferrita de (CoZn)Fe204, sintetizadas pelo método sol gel, atribuíram mediante as análises termogravimétricas (TG/DTA), que a segunda perda de massa observada nas curvas são também referentes a cristalização da fase do espinélio [90]. No estudo dos efeitos do tempo de moagem, tratamento térmico e o mecanismo de reação da ferrita (Mn-Zn)Fe204, sintetizada pelo método mecanoquímico, também associaram a primeira e a segunda perda de massa nas curvas termogravimétricas, como estando associadas, respectivamente, a remoção de água absorvida e a causas das decomposições dos materiais iniciais [91]. No estudo das propriedades estruturais e magnéticas da ferrita de ( $\mathrm{Ni}-\mathrm{Zn}-\mathrm{Co}$ )Fe204, pelo incremento de $\mathrm{Cr} 3+$, observaram eventos semelhantes, praticamente nas mesmas faixas de temperatura deste presente trabalho, e atribuíram também à evaporação da água residual com a desidratação dos precursores, bem como a decomposição oxidativa dos nitratos residuais e matéria orgânica, posteriormente, conforme a curva TG/DTA, a massa manteve-se constante até o final da análise [92].

Na Figura 13 encontra-se apresentado a dependência da magnetização M em função do campo magnético aplicado $\mathrm{H}$ para as amostras estudadas. As propriedades magnéticas de ferritas são sensivelmente dependentes da estrutura, da composição, dos defeitos, do tamanho dos cristalitos, da tensão interna e da distribuição de cátions. Observou-se que as três amostras possuem curvas de histerese de comportamento 
ferrimagnético, que são características de materiais magnéticos moles, os quais magnetizam e desmagnetizam com baixos valores de campo devido aos seus pequenos valores de magnetização remanente e coercividade, porém diferentes de zero.

Figura 13 - Curvas de histerese M x H das amostras PM, MM e GM.

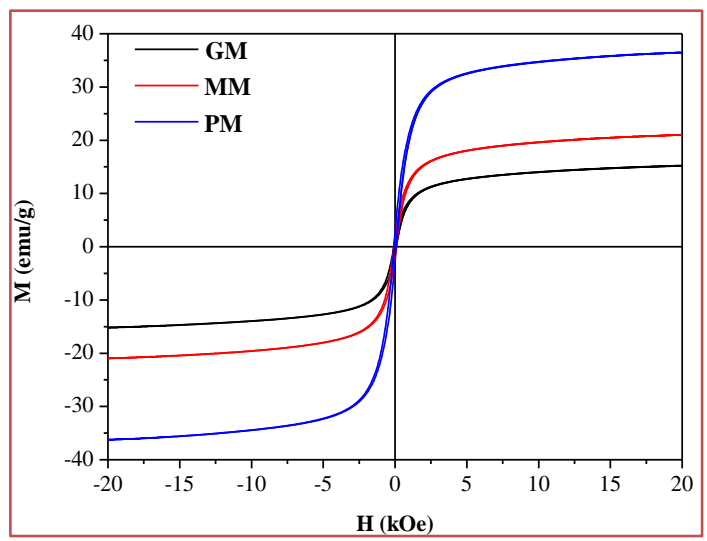

Para um melhor entendimento, as curvas de histerese de cada amostra foram plotadas individualmente (14a) com as suas respectivas ampliações (14b) para visualização da determinação da magnetização remanente (Mr) e do campo coercitivo (Hc), conforme apresentado na Figura 14.

Figura 14 - Curvas de histerese M x H das amostras PM, MM, GM - (a) e suas respectivas ampliações para determinação da Mr e do Hc - (b).
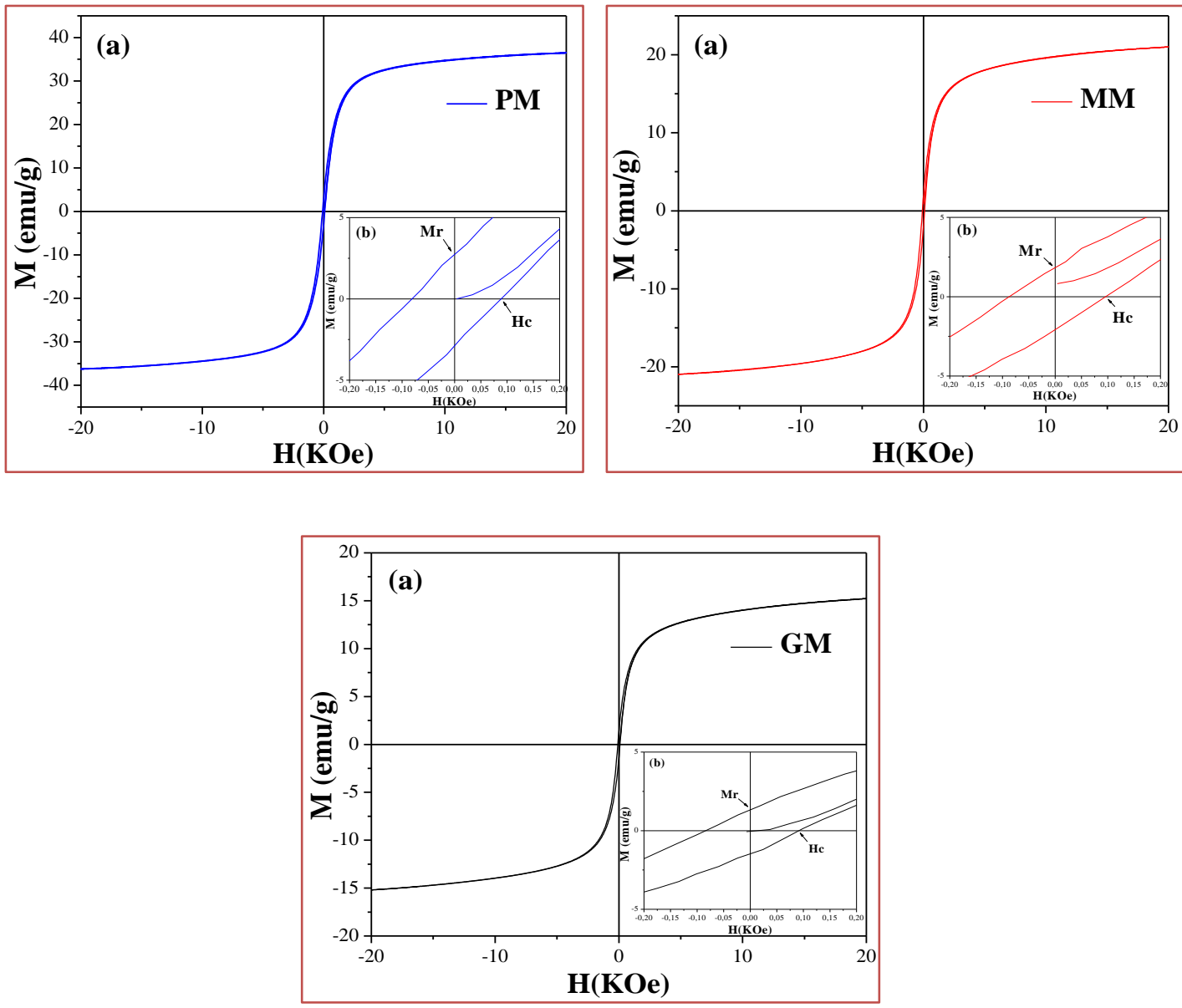
Na Tabela X foram apresentados os parâmetros magnéticos (magnetização de saturação (Ms), magnetização remanescente (Mr) e campo coercivo $(\mathrm{Hc})$ ) calculados a partir das curvas de histerese das amostras estudadas. Observa-se que o maior valor de magnetização de saturação foi apresentado pela amostra PM, a qual foi sintetizada na menor escala de produção (10 g/batelada), e o menor valor de magnetização foi apresentado pela amostra GM, sintetizada na maior escala (200 g/batelada).

Tabela X - Parâmetros de histerese para as amostras PM, MM e GM obtidas por reação de combustão.

\begin{tabular}{|c|c|c|c|}
\hline \multicolumn{2}{|c|}{ Amostra } & MS (emu/g) & Hr (emu/g) \\
\hline PM & 36,5702 & 2,7717 & 0,08965 \\
\hline MM & 20,9721 & 1,7996 & 0,0965 \\
\hline GM & 19,8312 & 1,3244 & 0,0928 \\
\hline
\end{tabular}

O valor da magnetização de saturação máxima para as amostras PM, MM e GM foram de 36,5702; 20,9721 e 19,8312 emu/g, respectivamente. A magnetização máxima apresentada por PM foi 74,37 e 84,41\% superior as apresentadas por MM e GM, respectivamente. Estes valores de magnetização para PM, MM e GM foram 54,29; 73,78 e 75,21\% inferiores ao valor de 80,0 emu/g reportado por outros autores [93], quando sintetizaram pelo método sol gel a ferrita $\mathrm{Ni}-\mathrm{Zn}$.

Esta discrepância se deve principalmente ao tipo do método empregado para as sínteses, onde a reação de combustão foi consideravelmente mais eficiente para produção em nanoescala, cujos tamanhos de partículas $(17,14 ; 21,97 ; 17,44 \mathrm{~nm})$ foram bem inferiores ao valor reportado para o método sol gel (350 $\mathrm{nm}$ ). Esta afirmação pode ser respaldada no relato [94] de que as ferritas Ni-Zn são excelentes materiais magnéticos moles e que é bem conhecido que as propriedades das ferritas são altamente sensíveis ao método de preparação, as condições de sinterização e modificações químicas.

As propriedades magnéticas dependem de vários fatores, tais como o tamanho, o formato e a distribuição de cátions [95]. Estes autores obtiveram tamanhos de partículas de 40 a $110 \mathrm{~nm}$ para a ferrita Ni0.5Zn0.5Fe204 sintetizada pelo método da autocombustão, cuja magnetização foi de 73,13 emu/g. Valor este que é mais elevado que a magnetização de $59,0 \mathrm{emu} / \mathrm{g}$ relatado em outra pesquisa [96], para as partículas de $\mathrm{Ni} 0.5 \mathrm{Zn} 0.5 \mathrm{Fe} 2 \mathrm{O} 4$ produzidas pelo método do estado sólido, onde foi mencionado que o aumento da magnetização pode ser explicado com base em mudanças nas interações de troca entre as sub-redes tetraédricas e octaédricas devido a cristalinidade, forma das partículas e direção da magnetização.

Logo, os valores de magnetização deste presente trabalho em função do tamanho de partículas obtidos, está consistente ao tamanho de partículas e magnetização reportada por outros autores, pois a magnetização é influenciada pelo tamanho de partículas. Isto se deve ao fato de que para os diferentes métodos de síntese, a magnetização se dá conforme seja a distribuição dos cátions nos interstícios disponíveis, o que afeta as interações de troca e, portanto, o momento magnético total da ferrita.

Isto pode ser respaldado devido ao momento magnético de Bohr, que está relacionado a maior ou menor ocupação de íons nos sítios octaedrais (spin down ou spin up, respectivamente), ocasionando aumento ou redução do momento magnético total da rede. No entanto, por outro lado, foi reportado [97] que as características extrínsecas como tamanho de grão e/ou partícula influenciam a área de domínio magnético e podem contribuir para o aumento da magnetização, pois quanto maior o tamanho da partícula e/ou dos grãos, menor o número de barreiras, favorecendo uma maior magnetização.

Assim, fica evidenciado que as amostras sintetizadas por reação de combustão em diferentes bateladas são extremamente nanométricas, apresentam boa magnetização de saturação e são muito reativas, o que é perfeitamente adequado para muitas aplicações, como a catálise.

$\mathrm{Na}$ finalidade de ilustrar a excelente resposta magnética da nanoferrita $\mathrm{Ni} 0,5 \mathrm{Zn} 0,5 \mathrm{Fe} 2 \mathrm{O}$, foi selecionada a amostra GM, sintetizada na maior escala, a qual apresentou a menor magnetização de saturação quando comparada as demais, e submetida a um teste experimental (Figura 13), onde as suas nanopartículas envolvidas também num meio reacional oleoso, responde prontamente aos estímulos de um campo magnético externo (ímã), facilitando desta forma a sua recuperação por intermédio de um método simples, rápido e eficiente. 
Figura 13 - Resposta magnética das nanopartículas da amostra GM frente ao estímulo de um ímã.

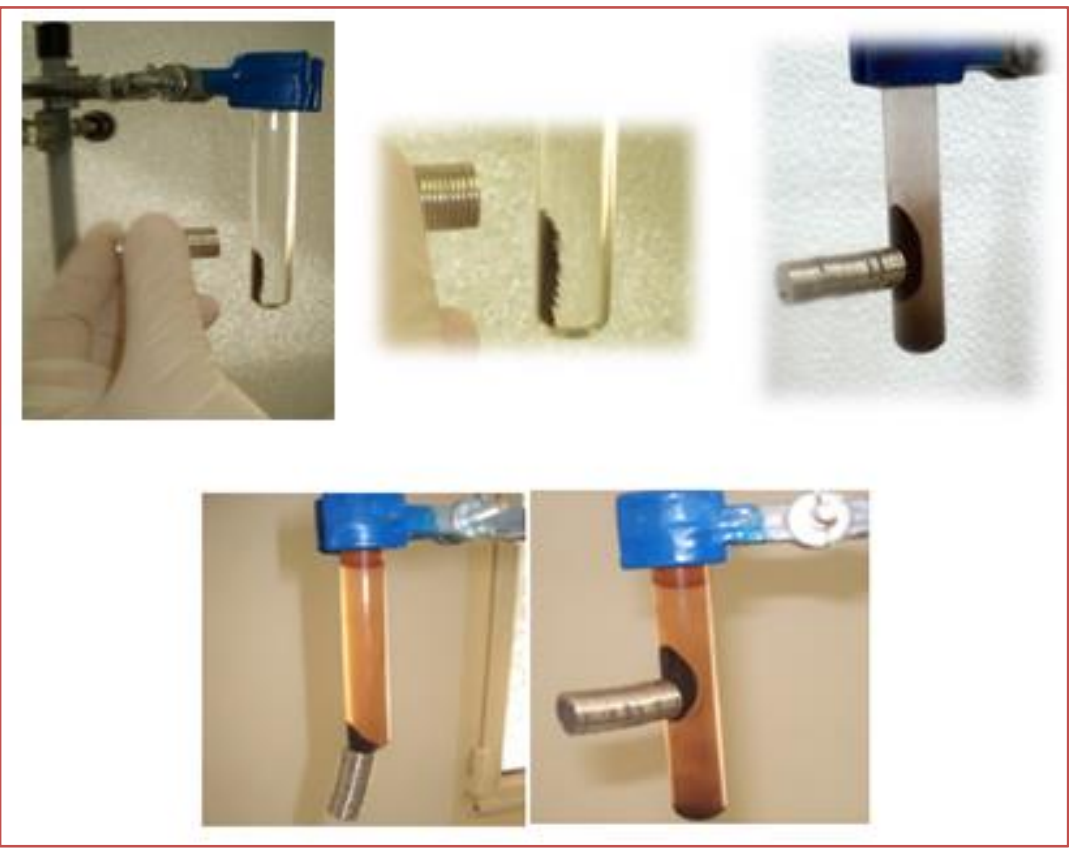

Portanto, esta propriedade magnética contribui efetivamente para evitar a perda das nanopartículas e aumentar a sua taxa de recuperação durante o processo de separação, pois normalmente estes materiais são separados do meio reacional mediante intensas etapas de filtração e/ou centrifugação. Assim, muita investigação tem sido dedicada ao desenvolvimento de nanopartículas magnéticas que são facilmente separáveis, e este trabalho não só efetiva esta investigação, como também a faz com o diferencial da obtenção destas nanopartículas com características altamente nanométricas e em escala piloto.

Desta maneira, diante de todos os resultados apresentados fica evidenciado a possível reprodutibilidade da nanoferrita Ni-Zn numa maior escala de produção, bem como a sua potencial aplicabilidade onde as nanopartículas magnéticas são requisitadas como um diferencial devido a sua fácil recuperação para uma posterior reutilização, como por exemplo, pode-se citar a catálise heterogênea na produção de biodiesel.

\section{CONCLUSÃO}

A síntese por reação de combustão foi altamente eficaz para obtenção da nanoferrita Ni0,5Zn0,5Fe204 com o diferencial de produção em escala de até $200 \mathrm{~g} /$ batelada do produto final e com excelente reprodutibilidade. 0 tempo reacional máximo de síntese entre as bateladas foi de menos de 1 hora, e as temperaturas máximas alcançadas durante as sínteses foram relativamente baixas (< 1000 oC), isto favoreceu a obtenção de produtos com elevada área de superfície, o que torna o material produzido adequado para várias aplicações tecnológicas, como por exemplo, catalisadores.

As amostras apresentaram partículas muito finas e nanométricas $(17,14-21,97 \mathrm{~nm})$, com fase majoritária do espinélio inverso e cristalinas. As densidades experimentais (5,096; 5,092 e 5,100 g/cm3) foram muito próximas da teórica (5,361 g/cm3), e apresetaram as bandas abaixo de $1000 \mathrm{~cm}-1$, que por sua vez são características das ferritas com estrutura cristalina do tipo espinélio. Na análise química verificou-se que os valores experimentais foram próximos aos valores teóricos calculados. Os diâmetros das partículas também muito próximos, aglomerados de formato irregular e com uma estreita distribuição de tamanho e com magnetização de saturação entre 19,8 e 36,6 emu/g. Além disso, as nanopartículas magnéticas exibiram uma excelente estabilidade térmica.

Portanto, mediante o presente estudo, foi possível a obtenção de um produto final com amplas possibilidades de aplicação, disponibilizando assim, mais dados e informações na soma das pesquisas sobre as cerâmicas magnéticas, que por sua vez gira em torno de apresentar um material novo ou para novas aplicações, com custo relativamente baixo, e principalmente com a eventual possibilidade de se ter um produto tecnológico ambientalmente correto e direcionado para benefício da sociedade, no que diz respeito à preservação da vida e do meio ambiente, além de servir como parâmetro para os demais 
sistemas de ferritas com foco na aplicação como catalisadores nanomagnéticos na produção de biodiesel, de forma que se cumpre o verdadeiro papel da ciência, que deve ser o de promover o bem comum da sociedade em geral.

\section{REFERÊNCIAS}

[1] D.B. Walker, D.J. Baumgartner, C.P. Gerba, K. Fitzsimmons. Environmental and Pollution Science (Third Edition), Chapter 16 - Surface Water Pollution, (2019), p. 261-292.

[2] P.S. Chauhan, R. Kant, A. Rai, A. Gupta, S. Bhattacharya. Facile synthesis of ZnO/GO nanoflowers over Si substrate for improved photocatalytic decolorization of MB dye and industrial wastewater under solar irradiation. Materials Science in Semiconductor Processing, 89 (2019), 6-17.

[3] A.H.M. Mojammal, Seung-Ki Backa. Yong-ChilSeo, Jeong-Hun Kim. Mass balance and behavior of mercury in oil refinery facilities. Atmospheric Pollution Research. v. 10, n. 1, (2019), p. 145-151.

[4] M.Y. Nassar, I.S. Ahmed, T.Y. Mohamed, M. Khatab. A controlled, template-free, and hydrothermal synthesis route to sphere-like $\alpha$-Fe203 nanostructures for textile dye removal. RSC Adv, 6 (2016), 20001-20013. A.F. Sánchez Bautista, J.E. Santibañez-Aguilara, F. Youb, J.M. Ponce-Ortega. Optimal Planning of Distributed Systems of Refineries and Biorefineries Considering Pollution Trading with Forest Plantations. Computer Aided Chemical Engineering, v. 38, (2016), p.1099-1104.

[5] Z.J. Predojević. The production of biodiesel from waste frying oils: A comparison of different purification steps. Fuel, 87 (2008), p. 3522-3528.

[6] RenovaBio. Ministério de Minas e Energia (MME). http://www.mme.gov.br/documents/10584/7948692/EPE_NT1_PAPEL+DOS+BIOCOMBUST\%C3\%8DVEIS.pdf/779d 7ffd-4169-4e10-a1a1 9a93184f6209;jsessionid=BC69E6F175F98A700035966D239A65BA.srv154. (Acessado em 21 de março, 2019).

[7] Sander, M. Antonije Košćak, D. Kosir, N. Milosavljević, J. Parlov Vuković, L. MagićThe influence of animal fat type and purification conditions on biodiesel quality. Renew Energy, 118 (2018), p. 752-760.

[8] J.M. Fonseca, J.G. Teleken, V.C. Almeida, C. Silva. Biodiesel from waste frying oils: Methods of production and purification. Energy Conversion and Management, v. 184, n. 15 (2019), p. 205-218.

[9] N. Mansir, S.H. Teo, U. Rashid, M.I. Saiman, Y.P. Tan, G.A. Alsultan, et al.Modified waste egg shell derived bifunctional catalyst for biodiesel production from high FFA waste cooking oil. A review. Renew Sustain Energy Rev, 82 (2018), p. 3645-3655.

[10] M. Farooq, A. Ramli, A. NaeemBiodiesel production from low FFA waste cooking oil using heterogeneous catalyst derived from chicken bonés. Renew Energy, 76 (2015), p. 362-368.

[11] M. Bril'kov, A.B. Falck-Ytter, K.O. Strætkvern. Evaluation of methods for reducing the ash content of waste frying oil processed to biofuel oil. Fuel Process Technol, 134 (2015), p. 487-493.

[12] J. Dantas, E. Leal, D.R. Cornejo, R.H.G.A. Kiminami, A.C.F.M. Costa. Biodiesel production evaluating the use and reuse of magnetic nanocatalysts Ni0.5Zn0.5Fe204 synthesized in pilot-scale. In Press. Arabian Journal of Chemistry (2019). https://doi.org/10.1016/j.arabjc.2018.08.012.

[13] X.X. Yang, Y.T. Wang, Y.T. Yang, E.Z. Feng, J. Luo, F. Zhang, et al.Catalytic transesterification to biodiesel at room temperature over several solid bases. Energy Convers Manag, 164 (2018), p. 112-121.

[14] S. Sharma, V. Saxena, A. Baranwal, P. Chandra, L.M. Pandey. Engineered na-noporous materials mediated heterogeneous catalysts and their implications in biodiesel production. Mater. Sci. Energy Technol, v. 1, n. 11, 2018.

[15] A.F. Lee, K. Wilson. Recent developments in heterogeneous catalysis for the sustainable production of biodiesel. Catal Today, 242 (2015), p. 3-18.

[16] F.E. Kiss, M. Jovanović, G.C. Bošković. Economic and ecological aspects of biodiesel production over homogeneous and heterogeneous catalysts. Fuel Process Technol, 91 (2010), p. 1316-1320.

[17] S.S. Ata-Allah, A.M. Balagurov, A. Hashhash, I.A. Bobrikov, Sh. Hamdy. Refinement of atomic and magnetic structures using neutron diffraction for synthesized bulk and nano-nickel zinc gallate ferrite. Physica, B, Condens. Matter, 481 (2016), p. 118-123.

[18] Ch. Srinivas, B.V. Tirupanyam, S.S. Meena, S.M. Yusuf, Ch. Seshu Babu, K.S. Ramakrishna, D.M. Potukuchi, D.L. Sastry. Structural and magnetic characterization of co-precipitated NixZn1-xFe2O4 ferrite nanoparticles. J. Magn. Magn. Mater, 407 (2016), p. 135-141.

[19] K.W. Zhou, L.Q. Qin, X.H. Wu, W.W. Wu, Y.X. Shen, Y.L. Tian, J.Y. Lu, Structure and magnetic properties of manganese-nickel ferrite with lithium substitution. Ceram. Int, 41 (2015), p. 1235-1241. 
[20] A.G. Kolhatkar, A.C. Jamison, D. Litvinov, R.C. Willson, T.R. Lee, Tuning the Magnetic Properties of Nanoparticles. Int. J. Mol. Sci, 14 (8) (2013), p. 15977-16009.

[21] Kumar, P.S. Rana, M.S. Yadav, R.P. Pant. Effect of Gd3+ ion distribution on structural and magnetic properties in nano-sized Mn-Zn ferrite particles. Ceramics International, 41 (1), Part B, (2015), pp. 1297-1302.

[22] Km Rachna, Anupam Agarwal, N.B Singh. Preparation and characterization of zinc ferrite-Polyaniline nanocomposite for removal of rhodamine B dye from aqueous solution. Environmental Nanotechnology, Monitoring \& Management, 9 (2018), p. 154-163.

[23] A.T. Raghavender, H.H. Nguyen. Dependence of Néel temperature on the particle size of MnFe204. J. Magn. Magn. Mater, 323 (2011), p. 2145-2147.

[24] X. Wang, Z. Chen, M. Hu, Y. Tian, X. Jin, S. Ma, T. Xu, Z. Hu, S. Liu, D. Guo, B. Xiao. Chemical looping combustion of biomass using metal ferrites as oxygen carriers. Chem. Eng. J, 312, 15 (2017), pp. 252-262.

[25] H.E. Moussaoui, T. Mahfoud, S. Habouti, K.E. Maalam, M.B. Ali, M. Hamedoun, O. Mounkachi, R. Masrour, E.K. Hlil, A. Benyoussef. Synthesis and magnetic properties of tin spinel ferrites doped manganese. J. Magn. Magn. Mater, 405 (2016), p. 181-186.

[26] E. Uyanga, D. Sangaa, H. Hirazawa, N. Tsogbadrakh, A.M. Balagurov. Structural investigation of chemically synthesized ferrite magnetic nanomaterials. Journal of Molecular Structure, 1160 (2018), pp. 447-454.

[27] E. Leal, J. Dantas, P.T.A. Santos, S.M.C.M. Bicalho, R.H.G.A. Kiminami, M.R. Silva, A.C.F.M. Costa. Effect of the surface treatment on the structural, morphological, magnetic and biological properties of MFe204 iron spinels ( $\mathrm{M}=$ $\mathrm{Cu}, \mathrm{Ni}, \mathrm{Co}, \mathrm{Mn}$ and Fe). Applied Surface Science, 455C, (2018), p. 635-645.

[28] W. Chen, Y. Zhou, J. Lu, X. Huang, W. Wu, C. Lin, Q. Wang. Effects of Li+ substitution on the structural and magnetic properties of Co0.5Mn0.5Fe204 particles. Ceramics International, 42 (1), Part B, (2016), p. 1114-1121.

[29] Jitu Das, Vijayanand S. Moholkar, Sankar Chakma. Structural, magnetic and optical properties of sonochemically synthesized Zr-ferrite nanoparticles. Powder Technology, 328 (2018), p. 1-6.

[30] K.W. Zhou, L.Q. Qin, X.H. Wu, W.W. Wu, Y.X. Shen, Y.L. Tian, J.Y. Lu. Structure and magnetic properties of manganese-nickel ferrite with lithium substitution. Ceramics International, 41 (2015), p. 1235-1241.

[31] J. Singh, B.S. Randhawa, H. Kaur, H.S. Dosanjh. Direct and facile synthesis of Li-Sr-Zn ferrites via low temperature solution combustion route. Ceram. Int, 41 (2015), p. 9931-9938.

[32] F. Saffari, P. Kameli, M. Rahimi, H. Ahmadvand, H. Salamati. Effects of Co-substitution on the structural and magnetic properties of NiCoxFe2-xO4 ferrite nanoparticles. Ceramics International, 41 (2015), p. 7352-7358.

[33] O.N. Kondrat'eva, G.E. Nikiforova, A.V. Tyurin, E.V. Shevchenko, K.S. Gavrichev. Thermodynamic and magnetic properties of magnesium-gallium ferrite ceramics. Ceramics International, 44, Issue 4 (2018), p. 4367-4374.

[34] X.H. Wu, W.W. Wu, L.Q. Qin, K.T. Wang, S.Q. Ou, K.W. Zhou, Y.J. Fan. Structure and magnetic properties evolution of nickel-zinc ferrite with lanthanum substitution. J. Magn. Magn. Mater, 379 (2015), p. 232-238.

[35] M.K. Anupama, B. Rudraswamy, N. Dhananjaya. Investigation on impedance response and dielectric relaxation of Ni-Zn ferrites prepared by self-combustion technique. J. Alloys Compd, 706 (2017), p. 554-561.

[36] J. Dantas, A.S. Silva, P.T.A. Santos, J.R.D. Santos, D.C. Barbosa, S.M.P. Meneghetti, A.C.F.M. Costa. Evaluation of catalyst $\mathrm{Ni} 0.4 \mathrm{Cu} 0.1 \mathrm{Zn} 0.5 \mathrm{Fe} 2 \mathrm{O} 4$ on methyl esterification of free fatty acid present in cottonseed oil. Mater. Sci. Forum, 727-728 (2012a), p. 1302-1307.

[37] J. Dantas, A.S. Silva, A.C.F.M. Costa, N.L. Freitas. Síntese, caracterização dos espinélios NiFe204 e CoFe204 e avaliação do desempenho na transesterificação e esterificação do óleo de algodão, Revista Eletrônica de Materiais e Processos, 7.3 (2012b), p. 174-179.

[38] J. Dantas, J.R.D. Santos, R.B.L. Cunha, R.H.G.A. Kiminami, A.C.F.M. Costa. Use of Ni-Zn ferrites doped with Cu as catalyst in the transesterification of soybean oil to methyl esters. Mater. Res, 16 (3) (2013), p. 625-627.

[39] J. Dantas, J.R.D. Santos, F.N. Silva, A.S. Silva, A.C.F.M. Costa. Study of nanoferrites Ni0.5Zn0.5Fe204 and Ni0.1Cu0.4Zn0.5Fe204. Mater. Sci. Forum, 775-776 (2014), p. 705-711.

[40] J. Dantas, F.N. Silva, K.R.O. Pereira, A.S. Silva, A.C.F.M. Costa. Evaluation of the Processing Conditions in the Transesterification for Biodiesel Production Using the Nanomagnetic Catalyst Ni0.5Zn0.5Fe204. Mater. Sci. Forum, 820 (2015), p. 113-118.

[41] J. Dantas, E. Leal, A.B. Mapossa, A.S. Silva, A.C.F.M. Costa. Síntese, caracterização e performance catalítica de nanoferritas mistas submetidas a reação de transesterificação e esterificação via rota metílica e etílica para biodiesel. Revista Matéria. ISSN 1517-7076. 21 (4) (2016), p. 1080-1093. 
[42] J. Dantas, E. Leal, A.B. Mapossa, D.R. Cornejo, A.C.F.M. Costa. Magnetic nanocatalysts of Ni0.5Zn0.5Fe204 doped with $\mathrm{Cu}$ and performance evaluation in transesterification reaction for biodiesel production. Fuel, 191(2017), p. 463-471.

[43] Shervin Alaei, Mohammad Haghighi, Javad Toghiani, Behgam Rahmani Vahid. Magnetic and reusable $\mathrm{MgO} / \mathrm{MgFe} 204$ nanocatalyst for biodiesel production from sunflower oil: Influence of fuel ratio in combustion synthesis on catalytic properties and performance. Industrial Crops and Products, 117 (2018), p. 322-332.

[44] István Pálinkó. Chapter 3.12: Heterogeneous Catalysis: A Fundamental Pillar of Sustainable Synthesis. Green Chemistry, 2018, p. 415-447.

[45] N. Sano, K. Yamada, S. Tsunauchi, H. Tamon. A novel solid base catalyst for transesterification of triglycerides toward biodiesel production: Carbon nanohorn dispersed with calcium ferrite. Chem. Eng. J, 307 (2017), pp. 135-142.

[46] Y. Liu, P. Zhang, M. Fan, P. Jiang. Biodiesel production from soybean oil catalyzed by magnetic nanoparticle MgFe204@CaO. Fuel, 164 (2016), p. 314-321.

[47] J.P.C. Evangelista, A.D. Gondim, L.D. Souza, A.S. Araújo. Alumina-supported potassium compounds as heterogeneous catalysts for biodiesel production: A review. Renew. Sust. Energ. Rev, 59 (2016), p. 887-894.

[48] F. Zhang, X.H. Wu, M. Yao, Z. Fang, Y.T. Wang. Production of biodiesel and hydrogen from plant oil catalyzed by magnetic carbon-supported nickel and sodium silicate. Green. Chem, 18 (2016), p. 3302-3314.

[49] M. Shi, P. Zhang, M. Fan, P. Jiang, Y. Dong. Influence of crystal of Fe203 in magnetism and activity of nanoparticle CaO@Fe2O3 for biodiesel production. Fuel, 197 (2017), p. 343-347.

[50] S.R. Jain, K.C. Adiga, V.R. Pai Verneker. A new approach to thermochemical calculations of condensed fueloxidizer mixtures. Combust. Flame, 40 (1981), p. 71-79.

[51] A.C.F.M. Costa, R.H.G.A. Kiminami. Dispositivo para produção de nanomateriais cerâmicos em larga escala por reação de combustão e processo contínuo de produção dos nanomateriais. Brasil. Revista de Propriedade Industrial RPI, BR 102012 002181-3, 2012.

[52] M.M.A. Sekar, A. Halliyal. Low-temperature synthesis, characterization, and properties of lead-based ferroelectric niobates. J. Am. Ceram. Soc, 88 (1998), p. 380-388.

[53] H.M. Rietveld. Line profile of neutron powderdiffraction peaks for structure refinement. Acta Crystallogr, 22 (1967), p. 151-152.

[54] J.S. Reed. Principles of ceramics processing. New York, EUA: John Wiley \& Sons, 1996.

[55] S. Tang, L. Wang, Y. Zhang, S. Li, S. Tian, B. Wang. Study on preparation of Ca/Al/Fe304 magnetic composite solid catalyst and its application in biodiesel transesterification. Fuel Process. Technol, 95 (2012), p. 84-89.

[56] J.A. Vanim. Alquimistas e químicos: o passado, o presente e o futuro. São Paulo, Ed. Moderna, 12. ed., 1999.

[57] E. Leal, N.L. Freita, R.H.G.A. Kiminami, A.C.F.M. Costa, H.L. Lucena, L. Gama. NiAl204 catalysts prepared by combustion reaction using glycine as fuel. Materials Research Bulletin, v. 46, p. 1409-1413, 2011.

[58] M.C. Silva, J.P. Coutinho, A.N. Simões, A.C.F.M. Costa, H.L. Lira, N.L. Freitas. Síntese por reação de combustão do espinélio inverso avaliação da forma de aquecimento. Cerâmica, 3 (2011), p. 151-157.

[59] M.M.A. Sinthiya, K. Ramamurthi, S. Mathuri, T. Manimozhi, N. Kumaresan, M.M. Margoni, P.C. Karthika. Synthesis of zinc ferrite (ZnFe204) nanoparticles with different capping agents. Int. J. Chem. Tech. Res, 7 (5) (2015), p. 2144-2149.

[60] P. La, W. Lei, X. Wang, Y. Wei, Y. Ma. Effects of excess NaClO4 on phases, size and magnetic properties of NiZn ferrite powders prepared by combustion synthesis. Ceramics International, 41 (8) (2015), p. 9843-9848.

[61] Ch. Srinivas, B.V. Tirupanyam, S.S. Meena, S.M. Yusuf, Ch. Seshu Babu, K.S. Ramakrishna, D.M. Potukuchi, D.L. Sastry. Structural and magnetic characterization of co-precipitated NixZn1-xFe204 ferrite nanoparticles. J. Magn. Magn. Mater, 407 (2016), p. 135-141.

[62] A.E. Saba, E.M. Elsayed, M.M. Moharam, M.M. Rashad, R.M. Abou-Shahba. Structure and magnetic properties of NixZn1-xFe204 thin films prepared through electro deposition method. J. Mater. Sci, 46 (2011), p. 3574-3582.

[63] Thakur, P. Kumar, P. Thakur, K. Rana, A. Chevalier, J.-L. Mattei, P. Queffélec Enhancement of magnetic properties of Ni0.5Zn0.5Fe204 nanoparticles prepared by the co-precipitation method. Ceramics International, 42(9) (2016), p. 10664-10670.

[64] A.S. Džunuzović, N.I. Ilić, M.M.V. Petrović, J.D. Bobić, B. Stojadinović, Z. Dohčević-Mitrović, B.D. Stojanović. Structure and properties of Ni-Zn ferrite obtained by auto-combustion method. J. Magn. Magn. Mater, 374 (2015), p. $245-251$.

[65] N.J. Barrichello, A.C.J. Faro. Caracterização de catalisadores. Rio de Janeiro: Instituto Brasileiro de Petróleo, p. $111,1995$. 
[66] V.G. Teixeira, F.M.B. Coutinho, A.S. Gomes. The most important methods for the characterization of porosity of styrene-divinylbenzene based resins. Química Nova, v. 24, n. 6, p. 808, 2001.

[67] M. Srivastava, A.K. Ojha, S. Chaubey, P.K. Sharma, A.C. Pandey. Structural study of glasses in the binary system NaP03-MoO3 by X-ray absorption spectroscopy at the MoK and L3 edges. Materials Chemistry and Physics, v. 120, p. $493,2010$.

[68] D. Varshney, A. Yogi. Structural and transport properties of stoichiometric Mn2+-doped magnetite: Fe3xMnx04. Materials Chemistry and Physics, v. 128, n. 3, p. 489-494, 2011.

[69] Ghasemi, M. Mousavinia. Structural and magnetic evaluation of substituted NiZnFe204 particles synthesized by conventional sol-gel method. Ceramics International, v. 40, n. 2, p. 2825-2834, 2014.

[70] R.S. Melo, F.C. Silva, K.R.M. Moura, S. Menezes, F.S.M. Sinfrônio. Magnetic ferrites synthesised using the microwave-hydrothermal method. Journal of Magnetism and Magnetic Materials, v. 381, n. MAY, p. 109-115, 2015.

[71] Tadjarodi, M. Salehi, M. Imani. Innovative one pot synthesis method of the magnetic zinc ferrite nanoparticles with a superior adsorption performance. Materials Letters, v. 152, p. 57-59, 2015.

[72] Z. Wang, Y. Xie, P. Wang, Y. Ma, , S. Jin, X. Liu. Microwave anneal effect on magnetic properties of $\mathrm{Ni0.6Zn0.4Fe204} \mathrm{nano-particles} \mathrm{prepared} \mathrm{by} \mathrm{conventional} \mathrm{hydrothermal} \mathrm{method.} \mathrm{Journal} \mathrm{of} \mathrm{Magnetism} \mathrm{and} \mathrm{Magnetic}$ Materials, v. 323, n. 23, p. 3121-3125, 2011.

[73] K.E. Ranjith. R. Jayaprakash, M.S. Seehra, T. Prakash, S. Kumar. Effect of $\alpha$-Fe203 phase on structural, magnetic and dielectric properties of Mn-Zn ferrite nanoparticles. Journal of Physics and Chemistry of Solids, v. 74, n. 7, p. 943-949, 2013.

[74] K. Sing, D. Everett, R. Haul, L. Moscou, R. Pierotti, J. Rou-Querol, T. Siemieniewska. Reporting physisorption data for gas/solid systems - with special reference to the determination of surface area and porosity. Pure Appl. Chem, (IUPAC), 57 (1985), p. 603-619.

[75] R. Setton, P. Bernier, S. Lefrant. Carbon Molecules and Materials. 1a ed., ISBN 0-415-28442-2, New York, USA: Taylor \& Francis Inc., p. 10-12, 2002.

[76] J.L. Figueiredo, J.A. Moulijn, Carbon and Coal Gasification: Science and Technology, ISBN 90-247-3286-7, Hingham, USA: Kluwer Academic Publishers, 105, p. 142-146, 1985.

[77] J.B. Silva, J.A.J. Rodrigues, M.C.A. Nono. Caracterização de materiais catalíticos. Instituto Nacional de Pesquisas Espaciais (INPE), 15252-PUD/198, 2008.

[78] S. Korichi, A. Elias, A. Mefti, A. Bensmaili. The effect of microwave irradiation and conventional acid activation on the textural properties of smectite: Comparative study. Appl. Clay Sci, 59-60 (2012), p. 76-83.

[79] Ghasemi, M. Mousavinia. Structural and magnetic evaluation of substituted NiZnFe204 particles synthesized by conventional sol-gel method. Ceramics International, 40 (2) (2014), p. 2825-2834.

[80] S. Chaturvedi, P.N. Dave, N.K. Shah. Applications of nano-catalyst in new era. J. Saudi Chem. Soc, 16 (3) (2012), p. 307-325.

[81] A.Z. Moshfegh. Nanoparticle catalysts. J. Phys. D: Appl. Phys, 42 (23) (2009), p. 233001.

[82] H.W. Lohse. Catalytic chemistry. New York, EUA: Chemical Publishing, p. 175, 1945.

[83] J.S. Reed. Principles of ceramics processing. New York, EUA: John Wiley \& Sons, 1996.

[84] N.M. Deraz, 0.H. Abd-Elkader. Production and characterization of nano-magnetic Ni0.5Zn0.5Fe204 spinel solid solution. J. Anal. Appl. Pyrolysis, 106 (2014), p. 171-176.

[85] P.T.A. Santos, J. Dantas, P.M.A.G. Araújo, P.T.A. Santos, A.C.F.M. Costa. Nanoferrites Ni-Zn silanized with 3aminopropyltrimethoxysilane using the reflux method. Mater. Sci. Forum, 805 (2015), p. 94-99.

[86] M.E. Brown. Introduction to Thermal Analysis - Techniques and Applications. New York: Chapman and Hall, p. 211, 1988.

[87] W.A. Bayoumy, M.A. Gabal. Synthesis characterization and magnetic properties of Cr-substituted NiCuZn nanocrystalline ferrite. Journal of Alloys and Compounds, v. 506, n. 1, p. 205-209, 2010.

[88] M.A. Gabal, Y.M. Al-Angari, F.A Al-Agel. Cr-substituted Ni-Zn ferrites via oxalate decomposition. Structural, electrical and magnetic properties. Journal of Magnetism and Magnetic Materials, v. 391, p. 108-115, 2015.

[89] M. Ben Ali, K. El Maalam, H. El Moussaoui, O. Mounkachi, M. Hamedoun, R. Masrour, E.K. Hlil, A. Benyoussef. Effect of zinc concentration on the structural and magnetic properties of mixed Co-Zn ferrites nanoparticles synthesized by sol/gel method. Journal of Magnetism and Magnetic Materials, v. 398, p. 20-25, 2016. 
[90] Hajalilou, M. Hashim, M.T. Masoudi. A comparative study of in-situ mechanochemically synthesized $\mathrm{Mn0.5Zn0.5Fe204}$ ferrite nanoparticles in the $\mathrm{MnO} / \mathrm{ZnO} / \mathrm{Fe} 2 \mathrm{O} 3$ and $\mathrm{MnO} 2 / \mathrm{Zn} / \mathrm{Fe} 2 \mathrm{O} 3$ systems. Ceramics International, v. 41, n. 6, p. 8070-8079, 2015.

[91] L.-Z. Li, X.-Q. Tu, R. Wang, L. Peng. Structural and magnetic properties of Cr-substituted NiZnCo ferrite nanopowders. Journal of Magnetism and Magnetic Materials, v. 381, p. 328-331, 2015.

[92] S.E. Jacobo, P.G. Bercoff. Structural and electromagnetic properties of yttrium-substituted Ni-Zn ferrites. Ceramics International, 42 (6) (2016), p. 7664-7668.

[93] S. Ramesh, B. Dhanalakshmi, B.C. Sekhar, P.S.V.S. Rao, B.P. Rao. Effect of Mn/Co substitutions on the resistivity and dielectric properties of nickel-zinc ferrites. Ceramics International, 42 (8) (2016), p. 9591-9598. 


\title{
Capítulo 24
}

\section{Avaliação Catalítica de Cerâmicas Magnéticas $\mathrm{NiFe}_{2} \mathrm{O}_{4}$ e Dopadas com $\mathrm{Zn}^{2+}$, $\mathrm{Co}^{2+}$ e $\mathrm{Cu}^{2+}$ para obtenção de Biodiesel}

\author{
Daniela da Costa Barbosa \\ Adriano Lima da Silva \\ Ana Flávia Felix Farias \\ Joelda Dantas
}

Ana Cristina Figueiredo de Melo Costa

Simoni Margareti Plentz Meneghetti

Resumo: 0 biodiesel constitui uma fonte renovável de combustível em expansão crescente no Brasil e o mesmo pode ser produzido por transesterificação ou esterificação. Assim, um parâmetro importante é o tipo de catalisador empregado em sua produção, e sua escolha envolve tanto aspectos cinéticos quanto econômicos. 0 objetivo desse estudo é a aplicação de cerâmicas magnéticas com potencial catalítico para produção de biodiesel. As cerâmicas magnéticas testadas foram $\mathrm{NiFe}_{2} \mathrm{O}_{4}$ e Dopadas com $\mathrm{Zn}^{2+}, \mathrm{Co}^{2+}$ e $\mathrm{Cu}^{2+}$ as quais foram caracterizadas quanto a suas características estruturais, morfológicas, e texturais. Os resultados evidenciaram que as cerâmicas apresentaram a fase característica de espinélio inverso e fases segregadas de hematita, com tamanho de cristalito entre 20 a $93 \mathrm{~nm}$. Observou-se que a dopagem com $\mathrm{Zn}^{2+}$ e $\mathrm{Cu}^{2+}$ na amostra $\mathrm{NiFe}_{2} \mathrm{O}_{4}$ não alterou a morfologia, que é baseada em aglomerados grandes, na forma de blocos irregulares, não porosos e de aspecto frágil. Já a amostra dopada com $\mathrm{Co}^{2+}$ foi possível observar blocos densos irregulares com formação de partículas pré-sinterizadas. As amostras apresentaram valores de área superficial entre 33 e 84 m2.g-1. Os testes catalíticos indicaram que os sistemas mostraram-se promissores na esterificação, com destaque para a reação em que 10\% de FeNiZn foi empregado, na razão molar metanol:ácido oleico de 10:1, a 160․ Nessa condição, em 15 min e 30 min de reação, 89\% e 95\% de conversão foram obtidas respectivamente.

Palavras-chave: biodiesel, esterificação, catálise, ferritas magnéticas. 


\section{INTRODUÇÃO}

Desde a revolução industrial a matriz energética mundial tem como base os combustíveis fósseis oriundos do petróleo, carvão e gás. Contudo, a preocupação ambiental em deter o atual processo de mudança climática causada pela elevada emissão de gases poluentes busca novas tecnologias e metas globais de transição para uma economia sustentável, embasada em recursos renováveis (GALEMBECK, 2009). Entretanto, uma das principais limitações e gargalos do desenvolvimento industrial e social é a inserção de novas fontes de energia, que sejam renováveis e ambientalmente amigáveis.

O biodiesel constitui uma fonte energética de alta viabilidade econômica social, pois possibilita gerar empregos em áreas geográficas menos propícias, promovendo inclusão social e econômica, considerado uma das fontes renováveis em expansão no Brasil (BARBOSA, 2012). No que diz respeito a sua produção, um parâmetro importante é o tipo de catalisador empregado em sua produção, seja por transesterificação ou esterificação, e sua escolha envolve tanto aspectos cinéticos quanto econômicos. Assim, essa seção enfatiza o biodiesel dentre os outros biocombustíveis, apresentando aspectos históricos, o potencial brasileiro para produção de biodiesel e desafios tecnológicos, além de apresentar e discutir as rotas tecnológicas mais propícias, mecanismos mais aceitos para as rotas de transesterificação e esterificação para produção de biodiesel e conceito de cerâmicas magnéticas (ferritas), utilizadas para catalisar a síntese de biodiesel.

Na década de 1950, as ferritas referiam-se a cristais com estrutura espinélio, entretanto, recentemente o termo se tornou amplo referindo-se a toda família das cerâmicas ternárias contendo em torno de $70 \%$ de óxidos de ferro, incluindo espinélios, granadas, hexaferritas e ortoferritas (RANE, et al, 1994).

As propriedades das ferritas em geral são substancialmente dependentes da distribuição dos cátions sobre os sítios cristalográficos (posições intersticiais) da estrutura cristalina. As ferritas do tipo $\mathrm{MFe}_{2} \mathrm{O}_{4}$ (onde $\mathrm{M}$ = Co, Ni, Mn, Mg, Zn, etc), apresentam diversas aplicações promissoras em ferrofluidos, gravação de disco e dispositivos de armazenamento magnéticos, materiais fotomagnéticos e sistemas de refrigeração magnéticos, entrega de drogas magnéticas e armazenamento de informações de alta densidade magnética (SIVAKUMAR, et al, 2012a). São utilizados como catalisadores de hidrogenação oxidativa de hidrocarbonetos, decomposição de alcoóis, oxidação seletiva de monóxido de carbono carbono, decomposição de peróxido de hidrogênio, e hidrodesulfurização do petróleo cru (JACOB, 1994; LI, et al, 2012).

O objetivo desse estudo foi a caracterização físico-química, morfológica, e textural das cerâmicas magnéticas $\mathrm{NiFe}_{2} \mathrm{O}_{4}, \mathrm{Ni}_{0,5} \mathrm{Zn}_{0,5} \mathrm{Fe}_{2} \mathrm{O}_{4}, \mathrm{Ni}_{0,5} \mathrm{Cu}_{0,5} \mathrm{Fe}_{2} \mathrm{O}_{4} \mathrm{e} \mathrm{Ni}_{0,5} \mathrm{Co}_{0,5} \mathrm{Fe}_{2} \mathrm{O}_{4}$, assim como a avaliação do potencial catalítico dessas na para produção de biodiesel.

\section{MATERIAIS E MÉTODOS}

\subsection{MATERIAIS}

As cerâmicas magnéticas foram sintetizadas por reação de combustão em escala semi-piloto em bateladas de 10g por reação, no Laboratório de Síntese de Materiais Cerâmicos (LabSMaC) da UFCG. As sínteses foram realizadas utilizando reagentes e metodologia proposta por Dantas 2012b. A classificação simbólica (Códigos) das cerâmicas magnéticas obtidas e suas respectivas composições químicas foram: NiFe204 (FNi), $\mathrm{Ni}_{0,5} \mathrm{Zn}_{0,5} \mathrm{Fe}_{2} \mathrm{O}_{4}$ (FNiZn), $\mathrm{Ni}_{0,5} \mathrm{Cu}_{0,5} \mathrm{Fe}_{2} \mathrm{O}_{4}$ (FNiCu) e $\mathrm{Ni}_{0,5} \mathrm{Co}_{0,5} \mathrm{Fe}_{2} \mathrm{O}_{4}$ (FNiCo). Os reagentes utilizados nos testes catalíticos com os respectivos graus de pureza foram: Metanol (> 99,5 \%), Ácido oleico (refinado), e Sulfato de magnésio anidro (98\%).

\subsection{CARACTERIZAÇÕES}

\subsubsection{DIFRAÇÃO DE RAIOS-X (DRX)}

As análises de DRX, determinações das fases cristalinas, grau de cristalinidade e o tamanho de cristalito das amostras foram realizadas no Laboratório de Engenharia de Materiais da UFCG, utilizando um difratômetro de raios-X SHIMADZU (modelo XRD 6000, radiação Cu K),. A cristalinidade das cerâmicas magnéticas foi determinada por meio da razão entre a área integrada dos picos de difração da porção cristalina e a área integrada da fração amorfa, usando o software Crystallinity fornecido pelo fabricante do difratômetro. E o tamanho de cristalito Dhkl para cada conjunto da família de planos \{hkl\} foi realizada pelo uso da equação de Scherrer (1) (KUNGLE et al., 1962) 


$$
D_{h k l}=\frac{k \lambda}{\beta \cos \theta}(1)
$$

Em que: D - diâmetro médio das partículas; $\mathrm{K}$ - constante que depende da forma das partículas (esfera = 0,94); $\lambda$ - comprimento de onda da radiação eletromagnética (Cu K = 1,5406); $(\theta)$ - ângulo de difração; $\beta(2 \theta)$ - largura na metade da altura do pico de difração.

\subsubsection{ESPECTROSCOPIA RAMAN}

Os espectros Raman foram obtidos no equipamento Renishaw Sistem In Via Raman utilizando laser RL 633 Renishaw Class 3B HeNe, Graffting de 1800 l/mm, modo Extendido, com potência do lazer de 5\%, tempo de exposição de 10 segundos e 6 acumulações, registrado na região entre 200 e $800 \mathrm{~cm}-1$ à temperatura ambiente. Este ensaio foi realizado no Laboratório do GCaR da UFAL.

\subsubsection{ESPECTROSCOPIA NA REGIÃO DO INFRAVERMELHO COM TRANSFORMADA DE FOURIER (FTIR)}

Os espectros na região do infravermelho médio foram obtidos num espectrofotômetro por tranformada de Fourier (FTIR), modelo 660-IR da marca VARIAN, usando o método de transmissão com porta amostra da Pike e KBr como agente dispersante. Este ensaio foi realizado no Laboratório do GCaR da UFAL.

\subsubsection{ANÁLISE DE FISISSORÇÃO}

As curvas de adsorção e dessorção de nitrogênio foram obtidas através do instrumento da marca Nova 2200 e onde as amostras foram previamente ativadas à $200^{\circ} \mathrm{C}$ sob vácuo durante 3 horas, em seguida foram submetidos às análises de adsorção/desorção física de $\mathrm{N}_{2}$ à $-196^{\circ} \mathrm{C}$. Este ensaio foi realizado no Laboratório do GCaR da UFAL. A partir dos dados da isoterma de adsorção na faixa de pressão relativa $(\mathrm{P} / \mathrm{P} 0)$ de 0,05 a 0,30 foi determinada a área superficial específica pelo método de BET e pelo método de BJH foram mensurados o diâmetro, a distribuição e o volume poroso pela quantidade de nitrogênio adsorvido a P/P0 igual a 0,95. Pela técnica de fisissorção também foi calculado o tamanho médio da partícula por meio da equação proposta por Reed (1938), que considera a partícula esférica e sem rugosidade (Equação 2),

$$
D_{B E T}=\frac{6}{M \cdot S_{B E T}}(2)
$$

em que,

$$
\begin{aligned}
& D_{B E T}=\text { diâmetro esférico equivalente }(\mathrm{nm}) ; \\
& \mathrm{D}=\text { Massa específica }\left(\frac{\mathrm{g}}{\mathrm{cm} 3}\right) ; \\
& S_{B E T}=\text { área superficial }(\mathrm{m} 2 / \mathrm{g}) .
\end{aligned}
$$

A massa específica utilizada como referência para os cálculos do tamanho de partícula foi de 5,373 g/cm3 da amostra FNi obtida na ficha cristalografica JCPDF 86-2267. A massa específica usada para as demais amostras (FNiZn, FNICu e FNiCo) foi 5,361 g/cm3 obtida também da ficha cristalográfica JCPDF 08-0278. 


\subsubsection{MICROSCOPIA ELETRÔNICA DE VARREDURA (MEV)}

As amostras na forma de pó foram dispersas em acetona e posteriormente depositada na superfície de porta-amostras polido e em seguida foram recobertas com uma película de ouro. Para a análise das amostras foi feito polimento, seguido de ataque térmico na temperatura $1000 \mathrm{oC}$ abaixo da temperatura de sinterização, para revelar os contornos dos grãos. Por fim as amostras foram analisadas em um microscópio eletrônico de varredura (MEV), Philips, modelo XL30 FEG, realizado por alunos do Laboratório de Caracterização de Materiais da UFCG.

\subsubsection{TESTES CATALÍTICOS - REAÇÃO DE ESTERIFICAÇÃO}

As reações de esterificação foram efetuadas em dois tipos de reatores: Reator com agitação magnética e Reator com agitação mecânica (Figura 1). Os testes preliminares em batelada foram realizados com agitação magnética em reator de aço inox de $200 \mathrm{~mL}$, acoplado a um manômetro e composto de um duto para entrada do termopar, conforme Figura 1(a). Já a cinética da reação foi investigada fazendo uso do reator Parr 4848, com capacidade de $100 \mathrm{~mL}$, conforme ilustrado na Figura 1(b). Ambas as reações foram realizadas pela rota alcoólica metílica, em temperatura de $160^{\circ} \mathrm{C}$.

Figura 1- Reator de aço inox acoplado a chapa aquecedora, um manômetro e termopar (a) e Reator Parr 4848 (b)

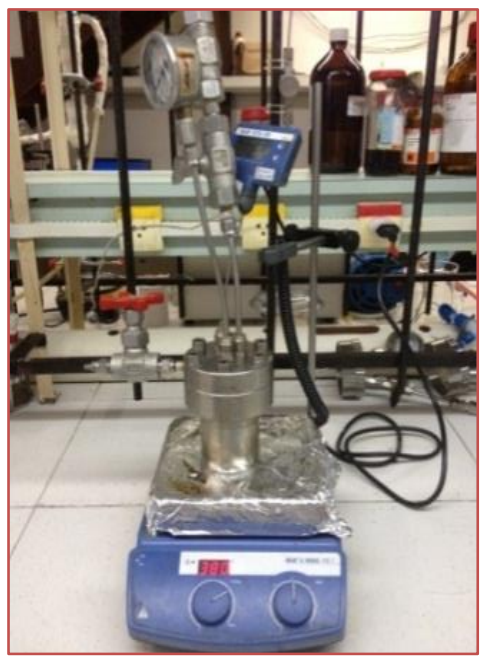

(a)

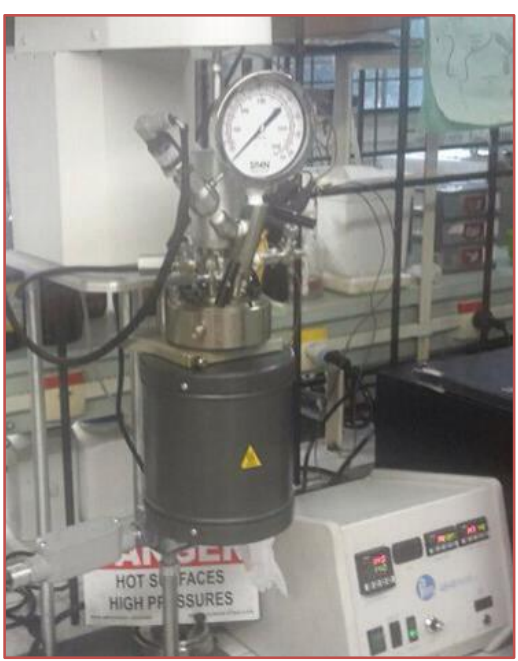

(b)

Os testes catalíticos envolvendo os sistemas FNi, FNiZn, FNiCu e FNiCo foram realizadas em reator com agitação magnética, utilizando razão molar de metanol:ácido oleico de 4:1 e conduzidas em tempos reacionais de 1, 2 e 4 h e utilizando $1 \%$ em massa de catalisador em relação à massa do substrato graxo. Para todos os testes catalíticos foram também realizados testes sem a presença dos catalisadores reproduzindo as mesmas condições reacionais, utilizando apenas as proporções de substrato graxo e o metanol para avaliar o comportamento autocatalítico da esterificação na reação.

Após os testes para a otimização do catalisador de melhor atividade catalítica na produção de biodiesel, ou seja, o catalisador que foi o mais promissor na conversão em ésteres de ácidos graxos, este foi utilizado na reação de esterificação em reator com agitação mecânica (mais vigorosa) seguindo a mesma razão estequiométrica dos testes realizados em reator com agitação magnética. Contudo, todos os reagentes (óleo/ ácido oleico, metanol e catalisador) nessa etapa do trabalho, foram misturados no copo de aço inoxidável do reator e foi realizado um estudo cinético durante 8 horas de reação. 0 potencial catalítico desse material também foi explorado em condições mais severas na esterificação metílica, com a variação da massa do catalisador (1, 5 e 10\%) e aumento do teor de álcool presente no meio reacional (10:1 de metanol: ácido oleico) e em temperatura de $160^{\circ} \mathrm{C}$. 0 estudo cinético também foi monitorado a partir de 15 minutos até 8 horas de síntese. Os produtos dos testes catalíticos obtidos foram purificados por lavagem seguida de centrifugação e por fim secos utilizando sulfato de magnésio anidro como agente 
dessecante e centrifugados por mais uma vez, para então caracterizados para a quantificação em ésteres utilizando o método de titulação ácido-base.

\subsubsection{TITULAÇÃO ÁCIDO-BASE}

A conversão das reações de esterificação foi medida pela diminuição do índice de acidez dos produtos em relação ao índice de acidez da mistura inicial de ácidos graxos de acordo com a especificação AOCS Cd3d63. Os resultados de conversão foram calculados conforme a equação (3):

$$
\text { Conversão(\%) }=\frac{\text { Valor da Acidez Inicial-Valor da Acidez Final }}{\text { Valor da Acidez Inicial }} \times 100 \%(3)
$$

\section{RESULTADOS E DISCUSSÃO}

\subsection{DIFRAÇÃO DE RAIOS-X}

A análise por difração de raios X para as amostras de cerâmicas magnéticas FNi, FNiZn, FNiCu e FNiCo está esquematizada na Figura 2 (a), (b), (c), e (d) respectivamente.

Figura 2- Difratograma de raios-X: (a) FNi (b) FNiZn, (c) FNiCu e (d) FNiCo

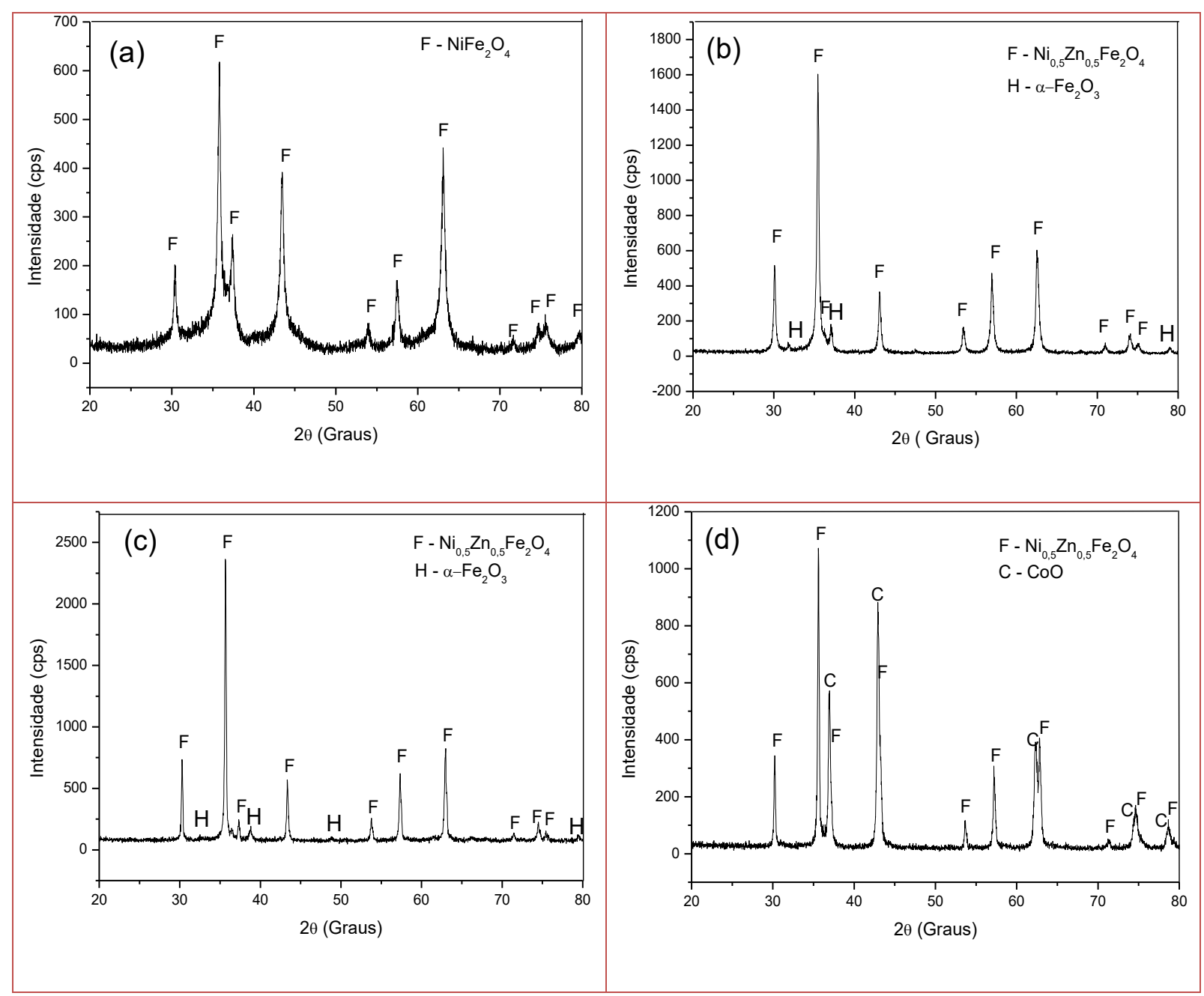


O digratograma, apresentado na Figura 2a, revela presença da fase cristalina única da ferrita NiFe204 característica de espinélio inverso identificada pela ficha cristalográfica padrão JCPDF 86-2267. Observase que o mesmo apresenta uma considerável largura basal nos picos de difração, indicando a característica nanométrica deste material. Estas mesmas observações foram reportadas por Dantas et al, 2012a e Santos et al, 2009 quando estudaram a síntese desta ferrita pelos métodos de reação de combustão, visando o uso como catalisador na transesterificação e esterificação do óleo de algodão e na reação de oxidação seletiva do monóxido de carbono, respectivamente.

Na Figura 2b temos a identificação da formação da fase da ferrita Ni0,5Zn0,5Fe204, de acordo com a ficha padrão JCPDF 52-0278 com traços da segunda fase $\alpha$-Fe203 (hematita) conforme ficha cristalográfica JCPDS 89-8104. Esta mesma característica também foi relatada por Vieira et al, 2009, quando avaliou a produção desta ferrita por reação de combustão em diversas escalas de bateladas para uso como dispositivos magnéticos moles e por Dantas et al 2014, quando estudou a síntese desta ferrita também por reação de combustão e avaliou o desempenho em reações de transesterificação metílica do óleo de soja.

Já os difratogramas das Figuras 2c e 2d também foram identificadas utilizando a ficha padrão JCPDF 520278 da ferrita Ni0,5Zn0,5Fe204, visto que o banco de dados não dispôs de ficha padrão para espinélio com esta estequiometria. Esses difratogramas possuem indicativo de formação das ferritas $\mathrm{Ni0}, 5 \mathrm{Cu} 0,5 \mathrm{Fe} 2 \mathrm{O} 4$ e $\mathrm{Ni}_{0,5} \mathrm{Co}_{0,5} \mathrm{Fe}_{2} \mathrm{O}_{4}$, respectivamente porém, com traços da segunda fase $\alpha-\mathrm{Fe}_{2} \mathrm{O}_{3}$ (hematita) que foi identificada pela ficha cristalográfica JCPDS 89-8104 como fase secundária do sistema $\mathrm{Ni}_{0,5} \mathrm{Cu}_{0,5} \mathrm{Fe}_{2} \mathrm{O}_{4}$ (Figuras 2c) e a cerâmica $\mathrm{Ni}_{0,5} \mathrm{Co}_{0,5} \mathrm{Fe}_{2} \mathrm{O}_{4}$ (Figura 2d) foi identificada uma segunda fase do CoO pela ficha padrão JCPDF 75-0418. Estes resultados estão em concordância com os dados reportados por Zaki 2012, quando estudou a síntese pelo método de combustão de nanocristais de cerâmicas do tipo $\mathrm{Ni}-\mathrm{Cu}$, de fórmula geral $\mathrm{Ni1}-\mathrm{xCuxFe}_{2} \mathrm{O}_{4}$ (onde x variou de $0,0,0,2,0,4$ e 0,6). Os autores confirmaram a presença do espinélio em todas as composições e na dopagem com razão estequiométrica de $\mathrm{x}=0,4 \mathrm{~mol}$ foi observada a presença da segunda fase hematita $\left(\alpha-\mathrm{Fe}_{2} \mathrm{O}_{3}\right)$.

A Tabela 1 mostra os resultados do percentual de cristalinidade e tamanho de cristalito para o pico principal referente ao plano (311), calculado a partir dos dados de difração de raios-X para as amostras em estudo.

Tabela 1 - Cristalinidade e tamanho de cristalito das amostras de ferritas.

\begin{tabular}{|c|c|c|}
\hline \multirow{2}{*}{$\begin{array}{c}\text { Composição } \\
\text { Cristalinidade (\%) }\end{array}$} & Tamanho de Cristalito (311) (nm) \\
\hline FNi & 46 & 20 \\
\hline FNiZn & 60 & 26 \\
\hline FNiCu & 82 & 71 \\
\hline FNiCo & 72 & 93 \\
\hline
\end{tabular}

Observa-se que a ferrita NiFe204 apresenta característica do tamanho de cristalito em escala nanométrica inferior as demais ferritas dopadas com os ions $\mathrm{Zn}^{2+}, \mathrm{Cu}^{2+} \mathrm{e} \mathrm{Co}^{2+}$. Foi possível verificar que a dopagem do sistema cerâmico promoveu considerável aumento de cristalinidade nas amostras, o qual chegou a um aumento máximo de 36\% para a ferrita dopada com Cu e 26\% quando a dopagem ocorreu com Co. De uma forma geral os valores de tamanho de cristalito obtidos para as ferritas estudadas estão em concordância com os valores determinados por outros pesquisadores (13 à $51 \mathrm{~nm}$ para o sistema NiFe204; $57-64 \mathrm{~nm}$ para o sistema Ni1-xCuxFe204 onde x variou de 0,0,0,2, 0,4 e 0,6) quando estudaram estes sistemas em estequiometria idêntica ou similar (Jacob e Khadar 2010; Zaki 2012 e Shobana et al, 2007).

\subsection{ESPECTROSCOPIA RAMAN}

A investigação relacionada às vibrações dos cristais nos espectros Raman é de interesse significativo, do ponto de vista da desordem dos cátions ou interações entre íons em diferentes locais. Segundo Sathe et al. 2011, a classe das cerâmicas magnéticas pertencentes ao grupo espacial $07 \mathrm{~h}(\mathrm{Fd}-3 \mathrm{~m})$, com características de sistemas cúbicos, possui quatro modos ativos no infravermelho e cinco modos ativos no Raman, estes são nomeadamente A1g + Eg + 3T2g. Na Figura 3 são apresentados os espectros Raman para as cerâmicas magnéticas envolvidas nesse estudo. Pode-se observar que todas as bandas no espectro confirmam a 
presença do espinélio inverso, e essas informações estão em consonância com os dados demostrados pela análise de DRX (Figura 2).

Figura 3 - Espectro Raman: (a) FNi, (b) FNiZn, (c) FNiCu e (d) FNiCo

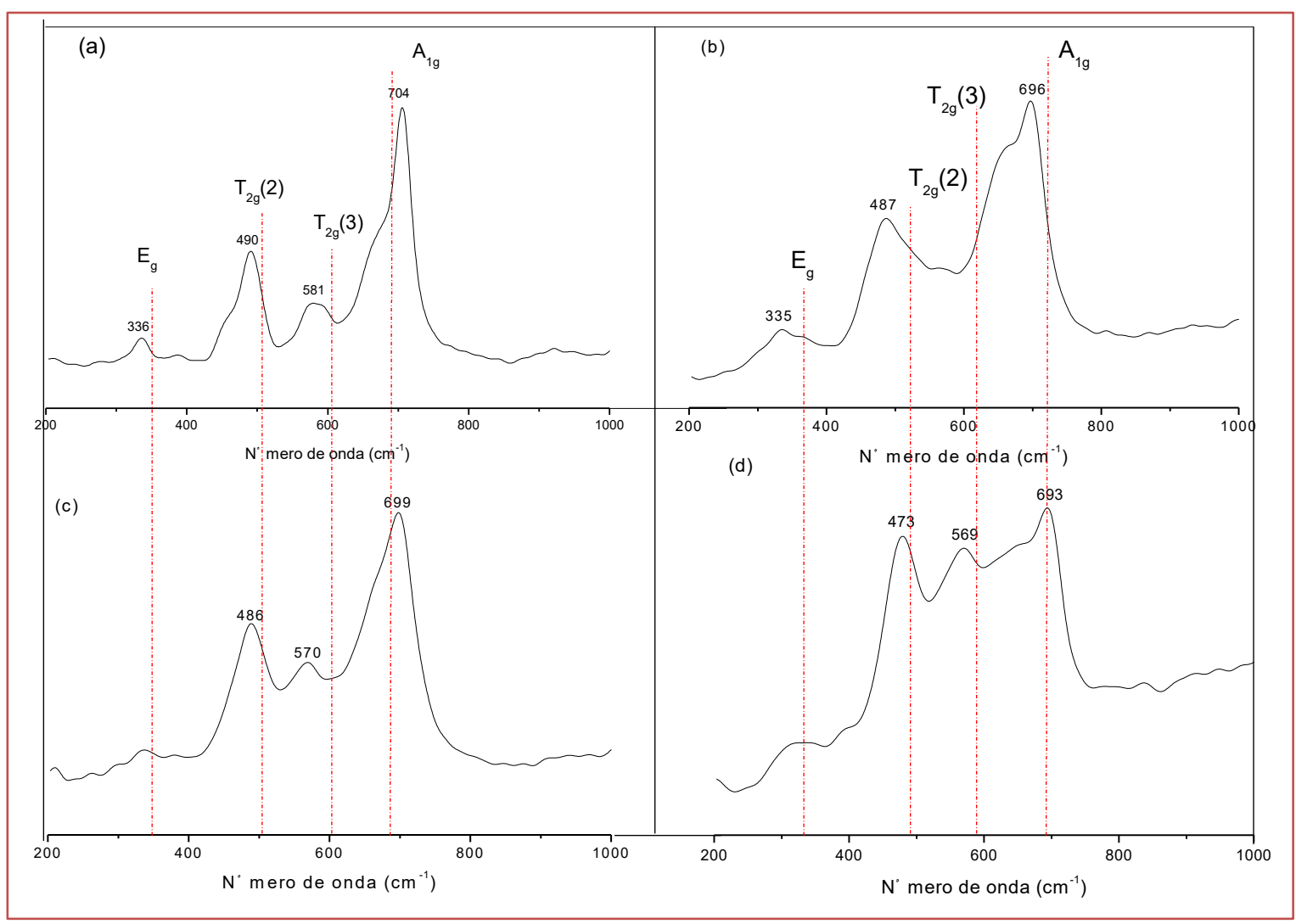

A análise do espectro Raman da amostra FNi da Figura 3(a) revela os picos em $336 \mathrm{~cm}-1$ e $490 \mathrm{~cm}-1$ que são atribuídos às vibrações em sítios octaédricos enquanto os picos em $581 \mathrm{~cm}-1$ e $704 \mathrm{~cm}-1$ correspondem às vibrações nos sítios tetraédricos, o que está em consonância com estudos de Sivakumar, et al, 2012a. 0 pico intenso em $704 \mathrm{~cm}-1$, relatado como o pico característico de $\mathrm{NiFe}_{2} \mathrm{O}_{4}$ também foi observado por Belo et al., 1988.

Na Figura 3(b) tem-se o espectro de Raman da ferrita Ni-Zn, no qual observam-se os picos em $335 \mathrm{~cm}-1$, 487 cm-1 que correspondem a vibrações em sítios octaédricos e $696 \mathrm{~cm}-1$ a vibrações nos sítios tetraédricos. Estes mesmos picos entre 490 e 705 cm-1 foram observados por Akhtar et al., 2011 quando sintetizaram cerâmicas do tipo Ni-Zn via método sol-gel. Segundo Tang et al., 2011 o aumento da altura dos picos Raman, geralmente indica o crescimento de cristal.

Para o espectro da Figura 3(c) observa-se em $486 \mathrm{~cm}-1$ e $570 \mathrm{~cm}-1$ vibrações referentes aos sítios tetraédricos das vibrações Fe-O e o pico em 699 cm-1 aos sítios octaédricos das vibrações Ni-O, Cu-O e FeO. Srivastava et al., 2010, quando sintetizaram nanocompósitos de $\mathrm{Cu}$-Ni-Fe observaram vibrações devido principalmente aos grupos octaédricos, entre 500 e $700 \mathrm{~cm}-1$, resultados estes que estão em consonância com os reportados para a amostra $\mathrm{FNiCu}$.

0 espectro da Figura 3(d), para amostra FNiCo, revela picos em $478 \mathrm{~cm}-1,569 \mathrm{~cm}-1$ que são referentes aos modos de vibração tetraédricos e o pico em $693 \mathrm{~cm}-1$ refere-se às vibrações de sítios octaédricos. As bandas observadas em 455 e 674 cm-1 são atribuídas à formação do monóxido de cobalto. Li et al, 2012; Gwag, Sohn, 2012 reportaram essas mesmas bandas quando avaliaram nanocompósitos Co1xNixFe204/grafeno, sintetizados pelo método solvotérmico. Xiong et al, 2012 também reportaram picos em cerca de $480 \mathrm{~cm}-1$ correspondentes às vibrações de íons como Fe-0 em sítios octaédricos e as bandas em 640 e 680 cm-1 representam as vibrações de alongamento de íons Fe-0 no sítio tetraédrico. 


\subsection{ESPECTROSCOPIA NA REGIÃO DO INFRAVERMELHO}

Esta técnica foi utilizada para observar as bandas características das ferritas em estudo. Assim, a presença de bandas vibracionais, localizadas numa determinada região de número de onda, indica o tipo de grupos funcionais e/ou vibrações entre os átomos presentes na estrutura da molécula. A Figura 4 apresenta os espectros de infravermelho para as cerâmicas magnéticas estudadas.

Figura 4- Espectroscopia na região do infravermelho para as composições (a) FNi, (b) FNiZn, (c)FNiCu e (d) FNiCo
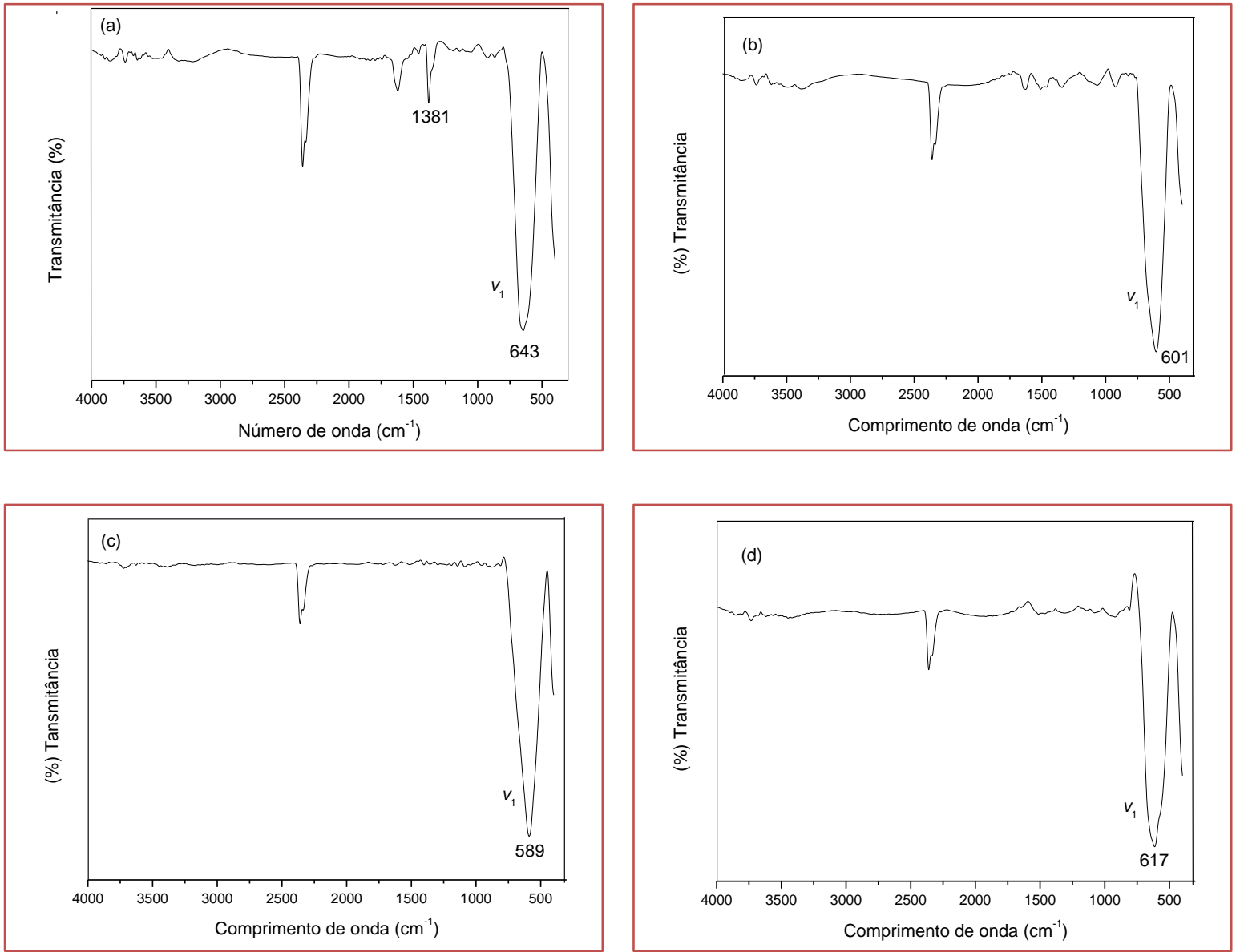

As bandas observadas no infravermelho dos sólidos são geralmente caracterizadas por vibrações de íons na rede do cristal. A formação da estrutura espinélio das amostras (cerâmicas) foram confirmadas na região do infravermelho, na faixa de 4000 a $400 \mathrm{~cm}$-1. Por meio da análise da Figura 4(a), (b), (c) e (d) observam-se absorções pouco intensas em aproximadamente $3392 \mathrm{~cm}-1$ atribuídas ao modo de vibração de grupos hidroxila, provenientes de adsorção superficial de moléculas de água, e este mesmo comportamento foi relatado por Srivastava, et al, 2010. Contudo, as principais bandas estão por volta de 600 e $400 \mathrm{~cm}-1$ correspondente aos estiramentos $v 1$ e $v 2$ dos sítios tetraédricos e octaédricos respectivamente, da estrutura cristalina do espinélio inverso (Santos, 2011).

No espectro da Figura 4(a) nota-se uma banda bastante intensa em torno de $643 \mathrm{~cm}-1$ atribuída ao estiramento metal-oxigênio em sítios tetraédricos. A banda de absorção observada em volta de $1381 \mathrm{~cm}-1$ é atribuída à vibração da ligação N-O decorrente do nitrato, grupo este presente no produto da reação de combustão. Segundo, Sivakumar et al., 2012b, observou alta freqüência de banda v1 e frequência v2 na faixa de 601-549 cm-1 e 450-385 cm-1 respectivamente, que correspondem às vibrações de alongamento intrínsecas do metal-oxigênio (Fe-O) nos sítios tetraédricos e Ni-O, Fe-O nos sítios octaédricos respectivamente na ferrita $\mathrm{NiFe}_{2} \mathrm{O}_{4}$. Segundo Khadar e Jacob 2010, esse aspecto pode ser atribuído à variação do tamanho do cristalito, ou seja, a diferença entre as intensidades relativas das bandas v1 e v2. Esta alteração na intensidade relativa das bandas pode ainda ser justificado pelas alterações estruturais associados às nanopartículas de $\mathrm{NiFe}_{2} \mathrm{O}_{4}$, pois há parte de íons $\mathrm{Fe}^{3+}$ coordenados em sítios tetraédricos e 
octaédricos aumentando a coordenação de íons ferro, causando uma alteração na intensidade relativa das bandas em $\mathrm{v} 1 \mathrm{e} \mathrm{u} 2$.

As vibrações de íons na rede cristalina também foram observadas pela análise do espectro da Figura 4(b) para a amostra FNiZn. Uma banda principal em $600 \mathrm{~cm}-1$ (v1) foi atribuída a vibrações Fe-O e Zn-O em sítios tetraédricos. Köseoglu et al., 2009 estudaram a influência do aumento de teor de íons $\mathrm{Zn}^{2+}$, com o deslocamento para comprimento de onda menor. Dessa forma, foi observado deslocamento com variação cerca de $10 \mathrm{~cm}-1$ para a ferrita com maior teor de zinco $\left(\mathrm{Zn}_{0,7} \mathrm{Ni}_{0,3} \mathrm{Fe}_{2} \mathrm{O}_{4}\right)$. Como a dopagem realizada com zinco foi apenas 0,5 ; essa tendência não foi observada em nosso estudo.

Nota-se através do espectro da Figura 4 (c) para a amostra FNiCu bandas em $589 \mathrm{~cm}-1$ (u1) que foram atribuídas as vibrações Fe-0 em sítios tetraédricos. A banda em torno de $400 \mathrm{~cm}-1$ (v2) estão relacionadas as vibrações $\mathrm{Fe}-\mathrm{O}$, $\mathrm{Ni}-\mathrm{O}$ e $\mathrm{Cu}-\mathrm{O}$ em sítios octaédricos respectivamente. Segundo Moustafa, Salah, Farag, 2012 quando sintetizaram ferritas do tipo $\mathrm{CuMnFe} 2 \mathrm{O} 4$ variando o teor de íons $\mathrm{Cu}^{2+}$ mostram a presença de três bandas fundamentais como v1 (547-555 cm-1), v2 (373-380 cm-1) e v3 (222-223 cm-1) na faixa espectral esperada para esse tipo de cerâmica magnética. Foi ressaltado ainda, que as banda em v1 e v2 aumentam sutilmente a faixa espectral $( \pm 8 \mathrm{~cm}-1)$ com aumento da concentração de íons $\mathrm{Cu}^{2+}$. 0 ligeiro aumento em $\mathrm{v} 1$ relacionado com o aumento do $\mathrm{Cu}^{2+}$ pode ser não apenas devido à diferença no raio iônico entre $\mathrm{Cu}^{2+} \mathrm{Mn}^{2+}$, mas também devido à diferença de suas massas atômicas.

0 espectro da Figura 4(d) para amostra FNiCo mostra duas bandas de absorção principais em $617 \mathrm{~cm}-1$ (u1) que foram atribuídas as vibrações Fe-O em sítios tetraédricos. A banda (u2) refere-se as vibrações entre os átomos Fe-O, Ni-O e Cu-O em sítios octaédricos respectivamente. Rajendran et al, 2007; Sindhu, et. al., 2011 obtiveram espectro de FTIR com picos característicos do óxido em questão em 582 (v1),394 (v2) e $361 \mathrm{~cm}$-1indicando a presença da cerâmica. A formação da ferrita reportado na literatura de Sindhu et al., 2011 apoia a observação feita no presente estudo. As investigações acerca de espectros Raman para as amostras estão em consonância com as conclusões realizadas pelos espectros de FTIR, confirmando formação do espinélio inverso para todas as ferritas analisadas, e a presença da fase $\mathrm{CoO}$ especificamente para a amostra FNiCo.

\subsection{ANÁLISE TEXTURAL}

Para catálise heterogênea, o conhecimento das propriedades texturais é considerado importante para interpretação do potencial catalítico, pois o fenômeno de superfície pode variar em materiais nonométricos. Já a distribuição de tamanho de poros é um importante parâmetro para o estudo da estrutura porosa, estando relacionada à área total do sólido e as cerâmicas magnéticas sintetizadas via reação de combustão podem apresentar variações significativas quanto à porosidade do material, considerando fatores como o tipo de combustível usado, razão estequiométrica combustível/reagentes, temperatura da chama, forma de aquecimento, tipo e volume do recipiente usado para síntese. Com a análise dos resultados de fisissorção das ferritas estudadas, exibidos na Figura 5 e na Tabela 5, foi possível obter as isotermas de adsorção/dessorção, a área superficial específica, além do volume total, o diâmetro e a distribuição de poros das amostras. 
Figura 5 - Análise de Fisissorção para as composições (a) FNi, (b) FNiZn, (c)FNiCu e (d) FNiCo
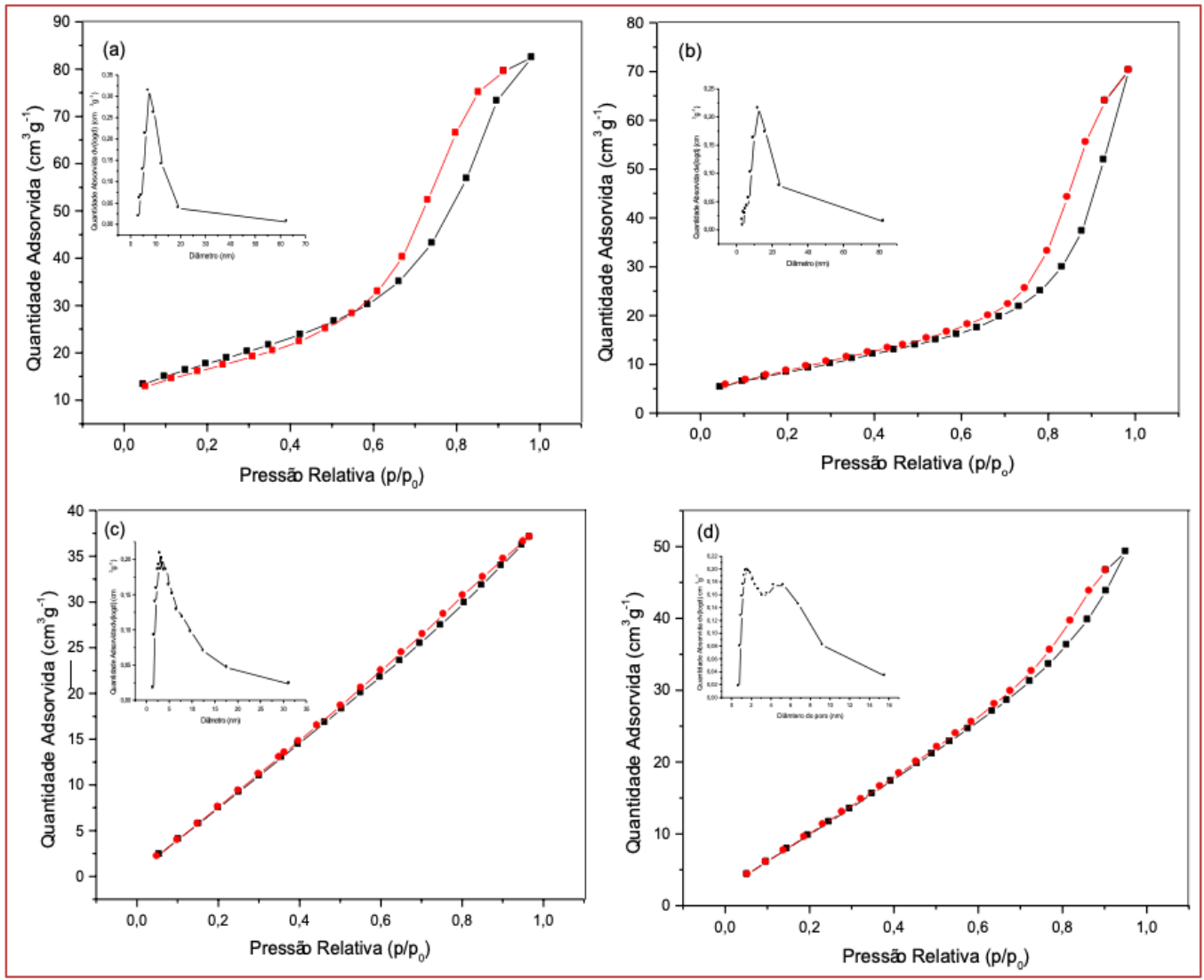

Mediante o perfil das isotermas para todas as composições de ferritas, pode-se observar presença de mesoporosos caracterizada por isoterma do tipo II e H3 de acordo com a classificação BDDT/IUPAC, típicos de sólidos com diâmetro de poro entre $2-50 \mathrm{~nm}$ formados pela agregação de partículas originando poros em forma de fendas. Apesar da ferrita FNiCu apresentar histerese discreta, a mesma também foi atribuída ao tipo $\mathrm{H} 3$.

Foi notável que a distribuição de tamanho de poro BJH, calculada usando o ramo de dessorção, indica claramente a presença de mesoporos centradas principalmente entre 2 e19 $\mathrm{nm}$ para as ferritas em questão (Veja Tabela 2).

Tabela 2 - Valores de área específica, volume de poro, diâmetro médio de poro e distribuição de poros para as ferritas investigadas nesse estudo

\begin{tabular}{|c|c|c|c|c|}
\hline Sistema & $\begin{array}{c}\text { Área Específica } \\
(\mathrm{m} 2 \mathrm{~g}-1)\end{array}$ & $\begin{array}{c}\text { Volume Total de Poro } \\
(\mathrm{cm} 3 \mathrm{~g}-1)\end{array}$ & $\begin{array}{c}\text { Diâmetro Médio de Poro } \\
(\mathrm{nm})\end{array}$ & $\begin{array}{c}\text { Distribuição do Diâmetro de Poro } \\
(\mathrm{nm})\end{array}$ \\
\hline FNi & 63 & 0,13 & 7,2 & $3-19$ \\
\hline FNiZn & 33 & 0,11 & 12,1 & $3-25$ \\
\hline FNiCu & 77 & 0,07 & 2,5 & $2-12$ \\
\hline FNiCo & 84 & 0,09 & 2,3 & $2-9$ \\
\hline
\end{tabular}

Nota-se também que a ferrita dopada com ions $\mathrm{Zn}^{2+}$ apresenta diminuição cerca de $50 \%$ da área superficial frente à ferrita de níquel pura, fato que pode ser respaldado pela menor temperatura de combustão atingida cerca de $646^{\circ} \mathrm{C}$. Entretanto, para essa amostra foi obtido o maior diâmetro médio de poro, devido ao aumento da porosidade interpartícula. No entanto, não houve variação significativa no volume de poros em relação à ferrita de níquel pura. Contudo, a dopagem com íons $\mathrm{Cu}^{2+} \mathrm{e} \mathrm{Co}^{2+}$ promoveu aumento de área superficial de $22 \%$ e $32 \%$ respectivamente, quando comparada com a cerâmica 
magnética de níquel pura. Isto pode ser justificado pela maior temperatura atingida durante a combustão cerca de 954ํㅡ, para ambas cerâmicas magnéticas $\mathrm{FNiCu}$ e FNiCo, comparada à temperatura de combustão alçancada para ferrita de níquel pura e a ferrita dopada com $\mathrm{Zn}^{2+}$. Para essas mesmas composições de cerâmicas houve diminuição considerável do volume do poro e também do diâmetro do poro.

\subsection{MICROSCOPIA ELETRÔNICA DE VARREDURA (MEV)}

As Figuras 6, 7, 8 e 9 ilustram as análises morfológicas para as amostras: FNi, FNZn, FNCu e FNCo obtidas por microscopia eletrônica de varredura (MEV). Mediante a Figura 6(a) verificou-se que a amostra FNi possui morfologia formada pela presença de aglomerados de formato irregular, com aspecto de novelos e distribuição de tamanho larga. Na Figura 6(b) verifica-se que estes aglomerados são constituídos por partículas finas menores que $100 \mathrm{~nm}$ e que as partículas estão unidas por forças fracas (não se observa partículas com formação de empescoçamento, ou seja, não a indício de pré-sinterização) com porosidade intrapartícula.

Figura 6 - Análise morfológica para a ferrita de FNi: (a) $5 \mu \mathrm{m}$ e (b) $500 \mathrm{~nm}$.
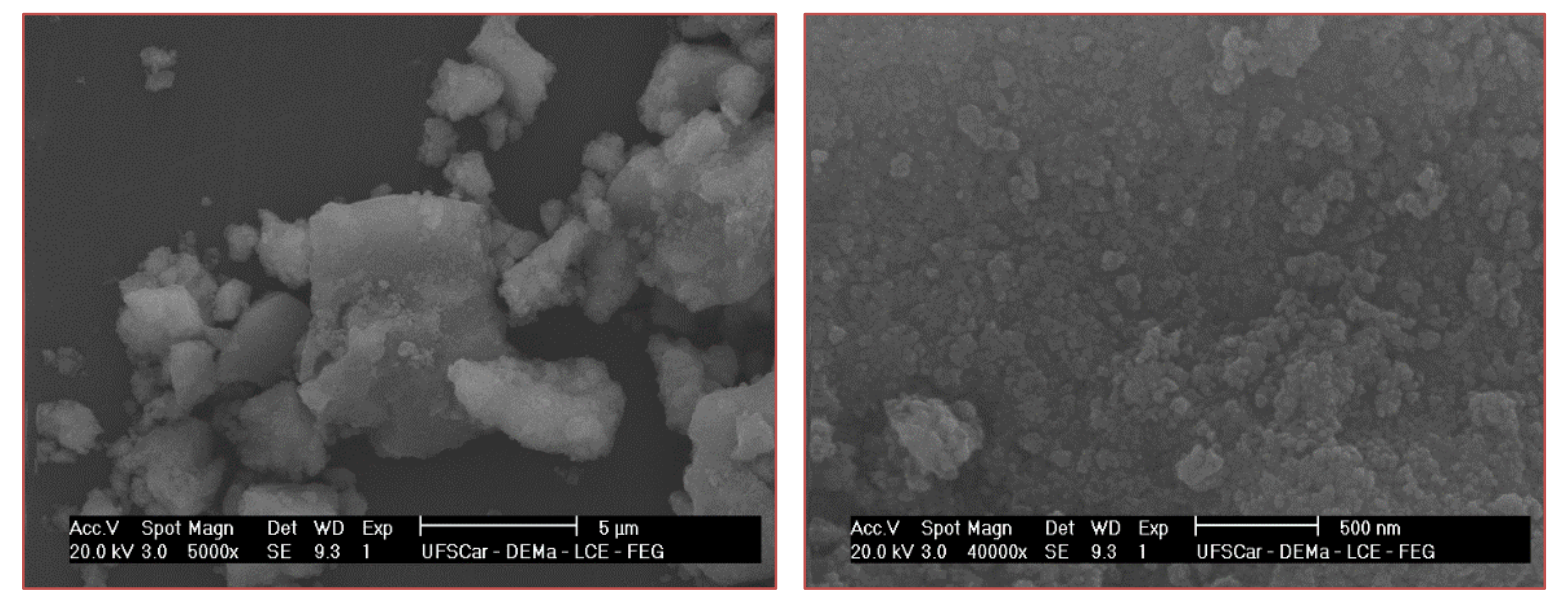

De acordo com as micrografias apresentadas na Figura 7(a) para a amostra FNiZn observa-se formação de aglomerado grande maior que $5 \mu \mathrm{m}$, com formato irregular e aparência de esponja constituída de outros pequenos aglomerados. Tal aspecto é típico da combustão, pois durante a síntese ocorre liberação de gás e isso induz à formação de poros, o que gera a característica esponjosa. Na Figura 7(b) observa-se que estes aglomerados são constituídos por partículas pequenas menores que $100 \mathrm{~nm}$ e que elas estão interligadas por interações fortes (regiões em que se observa pré-sinterização sem porosidade intrapartícula) e outras regiões que elas estão interligadas apenas por interação física, porém com baixa porosidade interpartícula. A baixa porosidade intrapartícula conduz a baixos valores de área superficial, devido à dificuldade de penetração do gás N2 durante a análise, justificando a baixa área superficial observada (ver Tabela 4). 
Figura 7 - Análise morfológica para a ferrita de FNZn: (a) $5 \mu \mathrm{m}$ e (b) $500 \mathrm{~nm}$.
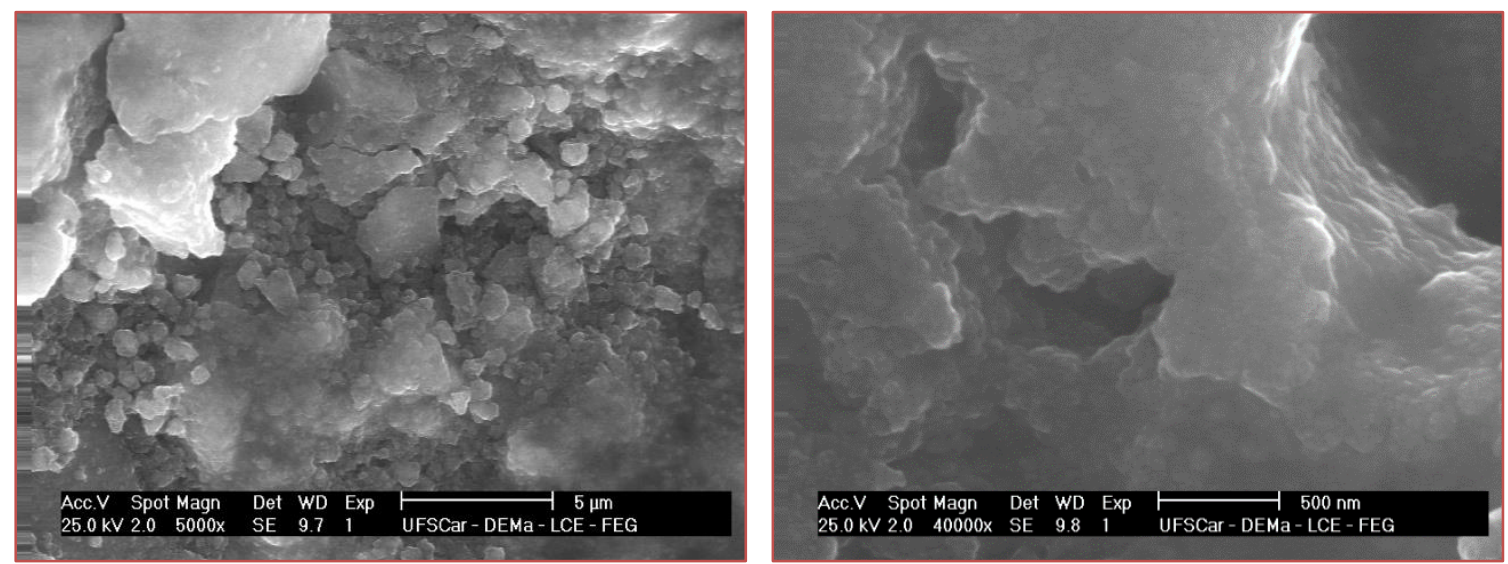

Pela análise das micrografias da amostra FNiCu apresentadas na Figura 8(a) nota-se formação de aglomerado também grande, com característica de partículas menores que $100 \mathrm{~nm}$ e com alta porosidade intrapartícula, indicando um aspecto frágil (fácil desaglomeração) e que as partículas estão interligadas por interações fracas. A dopagem com cobre na ferrita de níquel promoveu uma aparência esponjosa mais marcante como pode ser visto na Figura 8(b).

Figura 8 - Análise morfológica para a ferrita de FNiCu: (a) $200 \mathrm{~nm}$ e (b) $500 \mathrm{~nm}$
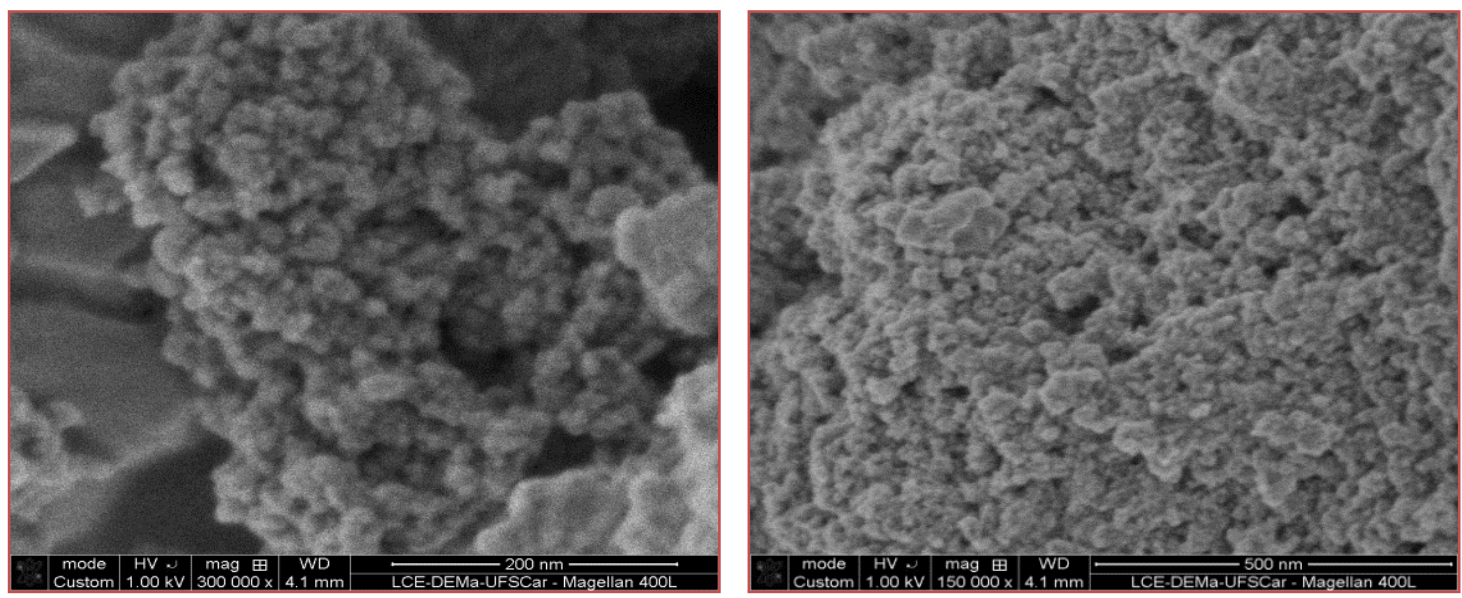

Na Figura 9(a) observa-se na morfologia da amostra FNiCo a presença de aglomerado na forma de bloco irregular e com característica de esponja com alta porosidade no próprio aglomerado. Isso mostra que a dopagem com cobalto conduziu a um aumento de poros, possivelmente formados da liberação de gases de combustão durante a síntese. Na Figura 9(b) verifica-se que estes aglomerados são formados por partículas pequenas e que aparentemente possui alta porosidade intrapartícula. Esta característica possivelmente favorecerá a penetração do gás N2 durante as análises de fissorção o que promove alta área superficial, como demonstrado por tal valor apresentado na Tabela 4. 
Figura 9 - Análise morfológica para a cerâmica FNiCo: (a) $5 \mu \mathrm{m}$ e (b) $1 \mu \mathrm{m}$
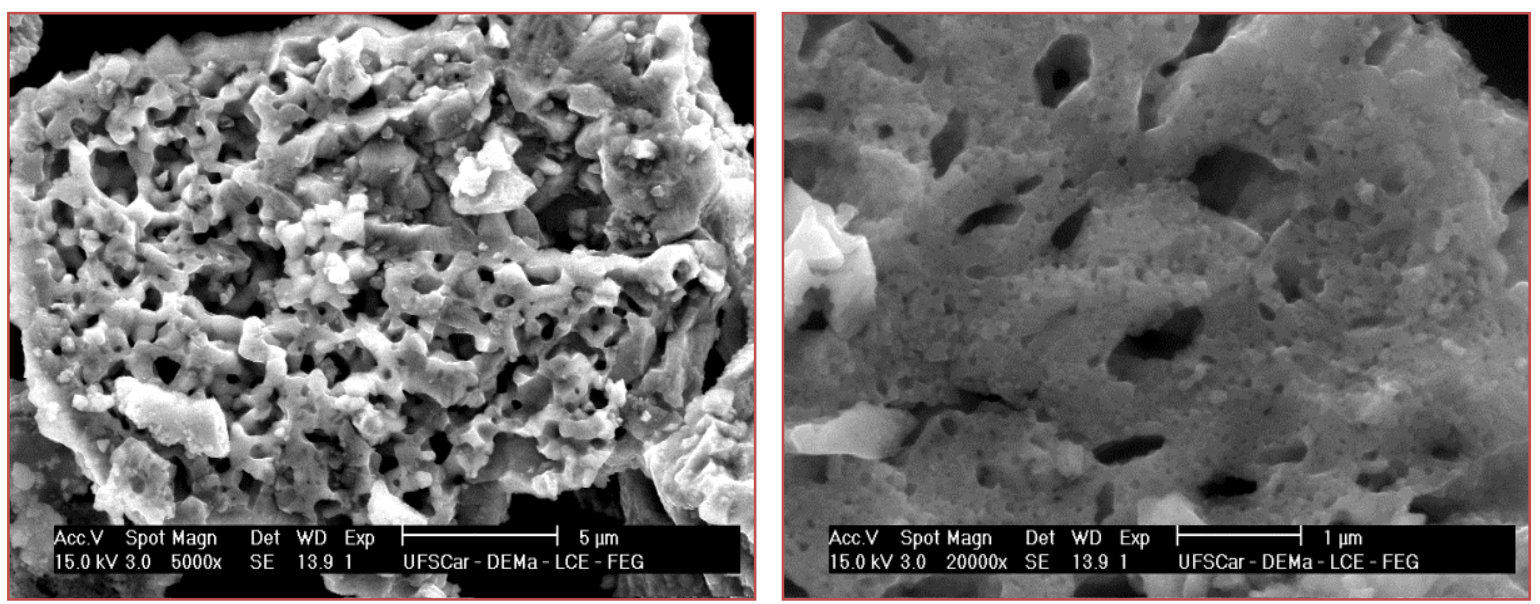

\subsection{AVALIAÇÃO CATALÍTICA DAS CERÂMICAS EM ESTERIFICAÇÃo}

Inicialmente, o desempenho catalítico dos sistemas FNi, FNiZn, FNiCu e FNiCo em comparação à reação autocatalítica, foi avalidao em reator com agitação magnética, em tempos reacionais de 1, 2 e 4 h (Figura 11).

Figura 11 - Conversão na esterificação do ácido oleico com metanol (razão molar metanol: ácido graxo de $4: 1,1 \%$ de catalisador, $160^{\circ} \mathrm{C}$ ), empregando agitação magnética.

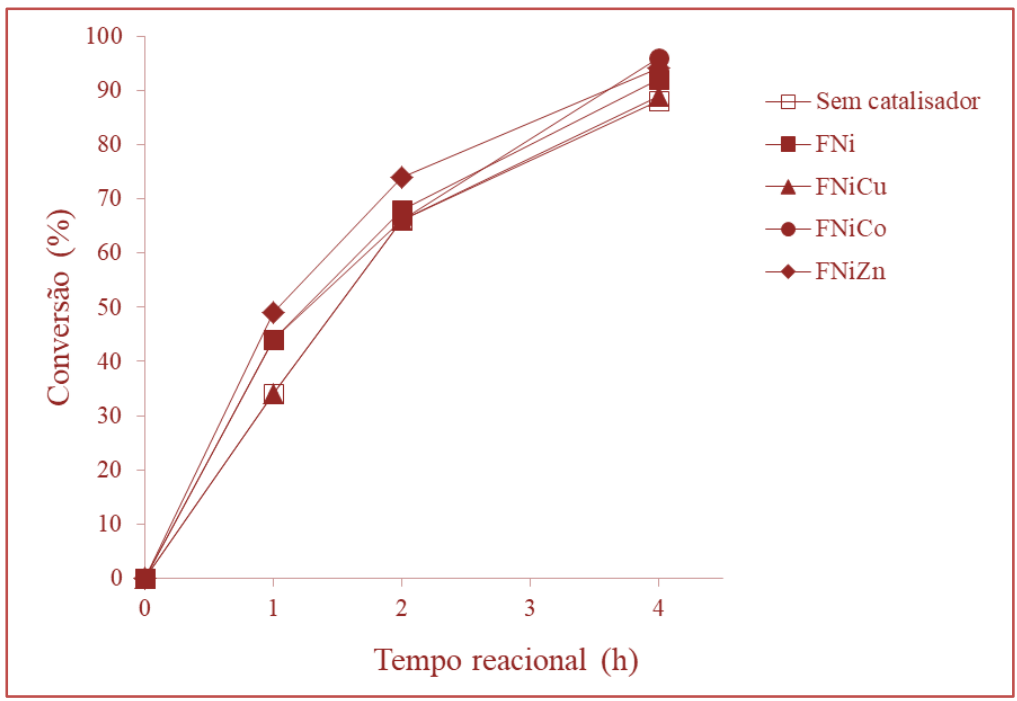

De acordo com o observado na Figura 11, todos os catalisadores exibiram atividade catalítica, no entanto, quando comparados à reação autocatalítica, a atividade dos mesmos revela uma pequena tendência a uma maior conversão. Em 1 hora, com o emprego do FNiCu, foi obtida uma conversão de 34\%, já com o emprego de FNi e FNiCo foi observada uma conversão de 44\%. Porém, para a reação conduzida na presença do sistema FNiZn a conversão foi de 49\% em 1 hora de reação. Tais resultados mostram uma tendência a uma maior atividade do sistema FNiZn e, por essa razão, o mesmo foi testado em condições mais severas, utilizando reator em batelada com agitação mecânica, como será apresentado a seguir.

Nessa etapa do trabalho, foi realizado um estudo cinético durante 8 horas de reação, testando apenas o catalisador FNiZn por este ser mais promissor conforme os resultados das reações de esterificação apresentadas na Figura 11, em consonância com dados de literatura (Sankaranarayanan, et al, 2013, Dantas et al 2014, Dantas et al 2012c). 
Os resultados do estudo cinético na esterificação metílica do ácido oleico, realizados à temperatura de $160^{\circ} \mathrm{C}$, estão apresentados na Figura 12a. A fim de explorar o potencial catalítico desse material, o seu desempenho também foi avaliado em condições mais severas de reação, variando a massa de catalisador FNiZn em 1, 5 e 10\% em relação à massa de ácido oleico e aumentando do teor de álcool presente no meio reacional em condições de razão molar 10:1 de metanol: ácido oleico e os resultados estão ilustrados na Figura 12b.

Figura 12 - Estudo cinético do catalisador FNiZn na esterificação com agitação mecânica utilizando: (a) razão molar metanol: ácido oleico de 4:1,1\% de catalisador; (b) razão molar 10:1 de metanol: ácido oleico e variando a porcentagem do catalisador (1, 5 e 10\%).
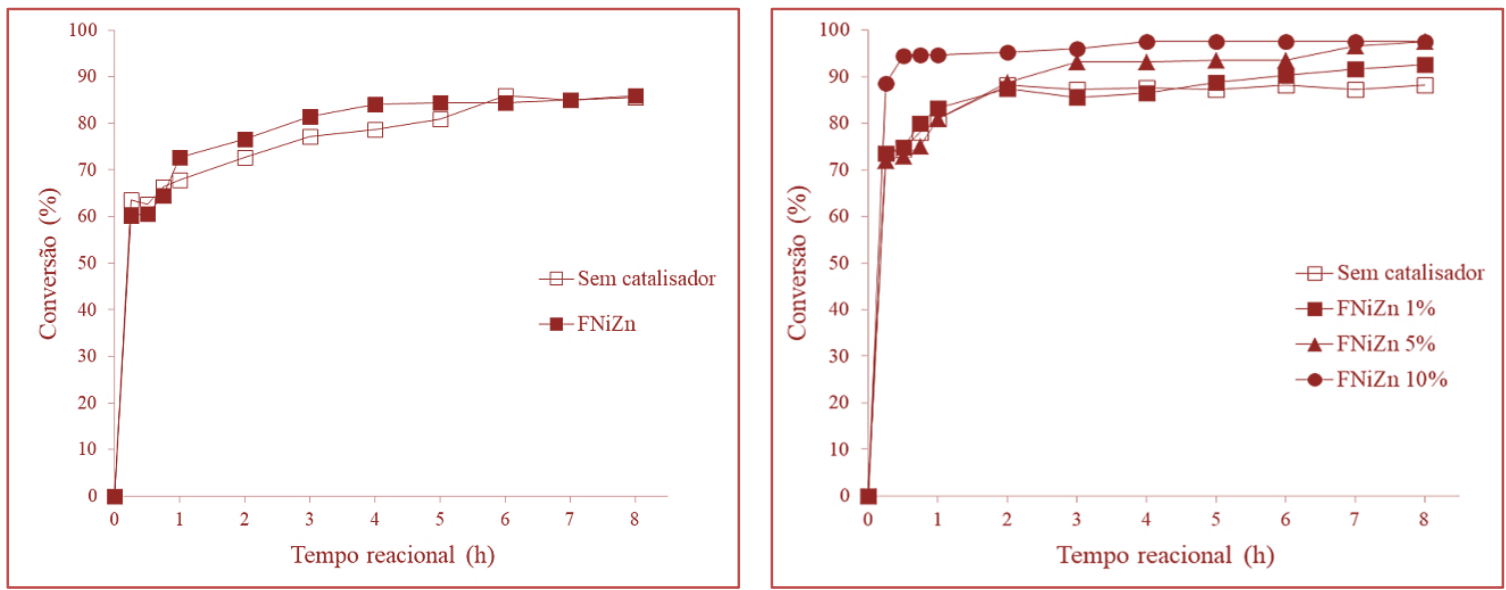

A partir dos resultados apresentados na Figura 12a observa-se uma tendência ao aumento na conversão de ácido oleico, na presença do catalisador FNiZn entre 1 e 6 horas de reação. Após esse tempo, o sistema tende ao equilíbrio atingindo conversão em ésteres de cerca de 86\%. Podemos sugerir que a agitação mecânica resultou em melhores resultados, uma vez que em apenas $1 \mathrm{~h}$ de reação o catalisador promoveu 73\% conversão em ésteres quando comparada a reação com agitação magnética (50\% a 1 h).

Analisando os resultados da Figura 12b observa-se um efeito significativo do aumento do teor de catalisador associado ao aumento da quantidade de álcool presente no meio reacional, principalmente com 10\% de catalisador. Quando comparado aos resultados da reação utilizando 1 e $5 \%$ de FeNiZn, observa-se também a importância do tempo reacional, pois já em 30 minutos de reação uma conversão de 95\% foi obtida e a partir desse tempo o sistema já entrou em equilíbrio. Para os demais sistemas, nesse mesmo tempo reacional, conversões de cerca de 74\% foram atingidas e o equilíbrio foi observado somente a partir de 2 horas. Cabe destacar que com o emprego de 10\% de FeNiZn, já em 15 min de reação, 89\% de conversão foi obtida, demostrando a eficiência desse sistema em reações de esterificação. Tal fato é corroborado pela literatura, pois em trabalho de Dantas et al., 2012a foi apresentado um estudo da síntese, caracterização e aplicação da ferrita Ni0,5Zn0,5Fe204 em esterificação metílica, nas quais foram obtidas conversões de 78,0 \%, usando razão molar óleo:álcool de 1:3 e temperatura de $180^{\circ} \mathrm{C}$, durante 2 horas de reação com 2 \% de catalisador. Resultados semelhantemente satisfatórios do uso de ferritas com sistema Ni0,5-xCuxZn0,5Fe204 pura e dopada com 0,1 mol de íons $\mathrm{Cu}^{2+}$ testadas em reação de transesterificação para biodiesel também foram reportados por Santos et al. (2010), à 160C, com razão molar de 1:9 (óleo:álcool), 2\% de catalisador e tempo reacional de 1 hora, apresentando percentual de conversão superior a 82,0\%.

\section{CONSIDERAÇÕES FINAIS}

A dopagem na amostra $\mathrm{NiFe} 204$ com os íons de $\mathrm{Zn}^{2+}, \mathrm{Cu}^{2+}$ e $\mathrm{Co}^{2+}$ mostram a mesma característica estrutural, pois todas as amostras formaram a fase principal do espinélio com presença de segunda fase. Quanto a morfologia todas as amostras mostraram ser formadas por aglomerados grandes, irregulares, composto de partículas menores que $100 \mathrm{~nm}$, porém a amostra dopada com $\mathrm{Zn}^{2+}$ foi a formada com menor porosidade intrapatícula, o que resultou no menor valor de área superficial $(32,60 \mathrm{~m} 2 / \mathrm{g})$ porém com o diâmetro de poro $12,06 \mathrm{~nm}$. A dopagem com $\mathrm{Cu}^{2+} \mathrm{e} \mathrm{Co}^{2+}$ favoreceu aos maiores valores de área superficial 21,9 e $32,4 \%$ respectivamente, em relação a amostra NiFe204. 
Os testes catalíticos revelaram que as cerâmicas magnéticas apresentaram atividade catalítica satisfatória na esterificação em condições reacionais brandas utilizando agitação magnética, porém o estudo cinético em condições reacionais mais severas em reator de agitação mecânica revelou a efetividade do catalisador dopada com $\mathrm{Zn}^{2+}$ que conduziram a bons resultados, 95\% de conversão com apenas 30 min de reação. Assim, mais uma vez diante destes fatores a amostra Ni0,5Zn0,5Fe204 constitui o catalisador mais promissor para reação de esterificação metílica.

\section{REFERÊNCIAS}

[1] AHLAWAT, A.; SATHE , V. G.; REDDY, V. R.; GUPTA, A. Mossbauer, Raman and X-ray diffraction studies of super paramagnetic NiFe204 nanoparticles prepared by sol-gel auto-combustion method, Journal of Magnetism and Magnetic Materials, v. 323, p. 2049-2054, 2011.

[2] AKHTAR, M. N.; YAHYA, N.; HUSSAIN, P. B.; Structural and Magnetic Characterizations of Nano Structured Ni0.8Zn0.2 Fe204 Prepared By Self Combustion Method, International Journal of Basic \& Applied Sciences IJBAS-IJENS Vol09 N 09, 2009.

[3] BARBOSA, D. C. SANTOS, P. T. A.; SOUZA, F. T. C. de; COSTA, A. C. F. M.; MENEGHETTI, S. M. P. MENEGHETTI, M. R. Síntese, Caracterização e Aplicação da Ferrita Ni0,4Cu0,1Zn0,5Fe204 na Transesterificação e Esterificação. In: 16ํㅡㅁNGRESSO BRASILEIRO DE CATALISE (CBCAT), 2011, Campos do Jordão, 2011.

[4] BARBosA, D. C.; MENEGHETTI, S. M. P.; MENEGHETTI, M. R.; DANTAS, J.; CUNHA, R. B. L.; COSTA, A. C. F. M. Desenvolvimento de novos sistemas catalíticos a base de óxidos ternários com propriedades magnéticas, para produção de biodiesel por esterificação. In: XXIII CONGRESSO IBERO AMERICANO DE CATÁLISES, 2012, Santa Fé, 2012.

[5] BELO, M. D. C, WALLS M, HAKIKI, N. E.; Corset J, Picquenard E, Sagon G, et al. Corros Sci,;40:447-63, 1988.

[6] DANTAS, J.; SANTOS, J. R. D.; SILVA, F. N.; SILVA, A. S.; COSTA, A. C. F. M., Study of Nanoferrites $\mathrm{Ni} 0,5 \mathrm{Zn} 0,5 \mathrm{Fe} 2 \mathrm{O} 4$ and Ni0,1Cu0,4Zn0,5Fe2O4 as Catalysts in the Methyl Transesterification of Soybean oil, Materials Science Forum Vols. 775-776 p. 705-711, 2014.

[7] DANTAS, J.; SANTOS, J. R. D.; SILVA, F. N.; SILVA, A. S.; COSTA, A. C. F. M., Study of Nanoferrites $\mathrm{Ni0}, 5 \mathrm{Zn} 0,5 \mathrm{Fe} 2 \mathrm{O} 4$ and Ni0,1Cu0,4Zn0,5Fe2O4 as Catalysts in the Methyl Transesterification of Soybean oil, Materials Science Forum Vols. 775-776 p. 705-711, 2014.

[8] DANTAS, J.; SILVA, A. S.; COSTA, A. C. F. M.; FREITAS, N. L. Síntese, Caracterização dos Espinélios NiFe204 e CoFe204 e Avaliação do Desempenho na Transesterificação e Esterificação do Óleo de Algodão. Revista Eletrônica de Materiais e Processos, vol. 7.3, p. 174-179, ISSN 1809-8797, 2012(a).

[9] DANTAS, J.; Síntese de catalisadores a base de ferritas Ni-Zn dopada com cobre e avaliação do seu desempenho na reação de transesterificação de óleo vegetal em biodiesel. Dissertação de Mestrado, Universidade Federal de Campina Grande, Campina Grande, 2012(b).

[10] DIAS, J. de C.; REZENDE, MIRABEL CERQUEIRA; MARTIN, INÁCIO MALMONGE. Absorvedores de radiação eletromagnética aplicados no setor aeronáutico. Revista de Ciência \& Tecnologia, noo, p. 33-42, 2000.

[11] GABAL, M. A.; EL-SHISHTAWY, R. M.; ALANGARI, Y. M. Structural and magnetic properties ofnano-crystalline $\mathrm{Ni}-\mathrm{Zn}$ ferrites synthesized using egg-white precursor, Journal of Magnetism and Magnetic Materials, v. 324, p. 2258$2264,2012$.

[12] GALEMBECK, F.; BARBOSA, C. A. S.; SOUZA, R. A. Aproveitamento sustentável de biomassa e de recursos naturais na inovação química. Química Nova, São Paulo, v. 32, n. 3, p. 571-581, 2009.

[13] Gwag, J.; S.; Sohn, Y.; Interfacial Natures and Controlling Morphology of Co Oxide Nanocrystal Structures by Adding Spectator Ni Ions Bull, Korean Chem. Soc. v. 33, N. 2, 2012.

[14] HOUSHIAR, M.; ZEBHI, F.; RAZI, Z. J.; ALIDOUST, A.; ASKARI, Z, Synthesis of cobalto ferrite (CoFe204) nanoparticles using combustion, coprecipitation, and precipitation methods: A comparison study of size, structural, and magnetic properties. Journal of Magnetism and Magnetic Materials, v.371, p. 43-48, 2014.

[15] JACOBS, J. P.; H. Journal of Catalysis, 147, p. 294-300, 1994

[16] JOHN JACOB, J.; KHADAR M. A.; Investigation of mixed spinel structure of nanostructured nickel ferrite, JOURNAL OF APPLIED PHYSICS 107, 114310, 2010.

[17] KÖSEOGLU, Y.; M. SERTKOL, M.; BAYKAL, A, KAVAS, H.; BOZKURT, A.; TOPRAK, M.S.; Microwave synthesis and characterization of Zn-doped nickel ferrite nanoparticles, Journal of Alloys and Compounds, 486, 325-329, 2009.

[18] LI, Y.; CHEN, X.; HOU, C.; ZHANG Q.; WANG, H.; One-step synthesis of Co-Ni ferrite/graphene nanocomposites with controllable magnetic and electrical properties, Materials Science and Engineering B 177, 1067-1072, 2012. 
[19] LÓPEZ, D. E. et al. Esterification and Transesterification Using Modified-zirconia Catalysts. Applied Catalysis A: General, v. 339, p. 76-83, 2008.

[20] MACCURRIE, R. A. Ferromagnetic Materials - Structure and Properties. Academic Press, United State, 1994.

[21] MOUSTAFA, A. M.; SALAH, L. M.; AHMED FARAG, I. S.; Structural characteristics and electrical properties of copper doped manganese ferrite, Ceramics International 38 5605-5611, 2012.

[22] NAVROTSKY, A.; KLEPA, O. J. Thermodynamics of Formation of Simple Spineles. Journal Inorganic and Nuclear Chemistry, v. 30, p. 479, 1968.

[23] PINTO, A. C.; GUARIEIRO, L. L. N.; REZENDE, M. J. C.; RIBEIRO, N. M.; TORRES, E. A.; LOPES, W. A.; PEREIRA, P. A.; de ANDRADE, J. B. J. Braz. Chem. Soc., v. 16, p. 1313, 2005.

[24] RANE, K. S.; VERENKAR, V. S. M.; SWANT, P. Y. Hidrazine Method of Synthesis of g-Fe2O3 Useful in Ferrites Preparation. Part IV - preparation abd charaterization of magnesium ferrite, MgFe204 from g-Fe2O3 obtained from hidrazinated iron oxyhydroxides and iron (II) carboxylato-hidrazinates. Journal of Materials Science Materials Eletronics, vol. 10, p. 133-140, 1994.

[25] REN, Y.; FENG, Q. D. J.; MA, J.; WEN, Q.; ZHANG, M.; Magnetic porous ferrospinel NiFe204: A novel ozonation catalyst with Strong catalytic property for degradation of di-n-butyl phthalate and conveniente separation from water, Journal of Colloid and Interface Science, v. 382, p.90-96, 2012.

[26] SANKARANARAYANAN, T. M., SHANTHI, R. V.; THIRUNAVUKKARASU, K.; PANDURANGAN, A.; SIVASANKER, S., Catalytic properties of spinel-type mixed oxides in transesterification of vegetable oils, Journal of Molecular Catalysis A: Chemical, v. 379, p. 234-242, 2013.

[27] SANTOS, P. T. A; LIRA, H. L; GAMA, L.; ARGOLO, F; ANDRADE, H. M. C; COSTA, A. C. F. M; Evaluation of NiFe204 Spinel, Synthesized by Combustion Reaction, as a Catalyst for Selective CO Oxidation, Materials Science Forum, v.660-661, p. 771-776, 2010.

[28] SANTOS, P.T.A; COSTA, A.C.F.M; KIMINAMI, R.H.G.A; ANDRADE, H.M.C; LIRA, H.L; GAMA, L; Synthesis of a NiFe204 catalyst for the preferential oxidation of carbon monoxide (PROX), Journal of Alloys and Compounds, v.483, p. 399-401, 2009.

[29] SHIRSATH, S. E; PATANGE, S. M; JADHAV, S.S.; LOHAR,K.S; MANE, D.R; JADHAV, K.M. Rietveld refinement ands witching properties of Cr3+substituted NiFe204ferrites. Materials Letters, v. 64, n. 6, p. 722-724, 2010.

[30] SHOBANA, M. K.; RAJENDRAN, V.; JEYASUBRAMANIAN, K.; KUMAR, N. S.; Preparation and characterisation of NiCo ferrite nanoparticles, Materials Letters 61, 2616-2619, 2007.

[31] SINDHU, Raveendran et al. Dilute acid pretreatment and enzymatic saccharification of sugarcane tops for bioethanol production. Bioresource Technology, v. 102, n. 23, p. 10915-10921, 2011.

[32] SIVAKUMAR, P.; RAMESH, R.; RAMANAND, A.; PONNUSAMY, S.; MUTHAMIZHCHELVAN, C.; Preparation and properties of NiFe204 nanowires, Materials Letters, v. 66, p. 314-317, $2012 \mathrm{a}$.

[33] SIVAKUMAR, P.; RAMESH, R.; RAMANAND, A.; PONNUSAMY, S.; MUTHAMIZHCHELVAN, C.; Synthesis, studies and growth mechanism of ferromagnetic NiFe204 nanowires, Applied Surface Science, v. 258, p.6648-6652, 2012b.

[34] SIVAKUMAR, P.; RAMESH, R.; RAMANAND, A.; PONNUSAMY, S.; MUTHAMIZHCHELVAN, C.; Structural, thermal, dielectric and magnetic properties of NiFe204 nanoleaf, Journal of Alloys and Compounds, v. 537, p.203-207, 2012(c).

[35] SRIVASTAVA, M.; OJHA, A. K.; CHAUBEY, S.; SHARMA, P. K.; PANDEY, A. C. Structural study of glasses in the binary system NaPO3-MoO3 by X-ray absorption spectroscopy at the MoK and L3 edges. Materials Chemistry and Physics, v. 120, p. 493, 2010.

[36] VIEIRA, D. A. Sintese por energia de microondas de ferritas Ni-Zn. Dissertação (Ciencia e Engenharia de Materiais) - Universidade Federal de Campina Grande. Campina Grande, PB. 2009.

[37] XIONG, A. L., Synthesis and electrochemical characterization of multi-cations doped spinel. Journal of Power Sources, 199 (1), 214 - 219, 2012.

[38] ZAKI, H. M., Structure, analysis and some magnetic properties for low temperature fired Ni-Cu ferrite. Physica B, v. 407, p. 2025-2031, 2012.

[39] ZAKI, H. M., Structure, analysis and some magnetic properties for low temperature fired Ni-Cu ferrite. Physica B, v. 407, p. 2025-2031, 2012. 


\section{Capítulo 25}

Síntese de ferrita do tipo nio,5 $\mathrm{Zno,5}_{0,5} \mathrm{Fe}_{2} \mathrm{O}_{4}$ e utilização como catalisador em reação de esterificação do óleo de soja para obtenção de biodiesel

Joelda Dantas

Elvia Leal

Nathalia Oliveira Araújo

Kleberson Ricardo de Oliveira Pereira

Pollyana Caetano Ribeiro Fernandes

Ana Cristina Figueiredo de Melo Costa

Resumo: 0 contemporâneo avanço científico e tecnológico associado ao desenvolvimento da sociedade contribuem significativamente para deterioração ambiental e aumento da poluição, o que torna os problemas ambientais uma questão bastante preocupante em todo o mundo. Atualmente, os biocombustíveis têm recebido crescente destaque no mercado nacional e global como componentes de mistura ou substituição direta promissora em motores do ciclo diesel, também devido à constante preocupação com as emissões nocivas de NOx e com o aquecimento global provenientes da poluição do ar com $\mathrm{CO} 2$ ocasionada pela queima dos combustíveis fósseis. Neste ponto, não há outras opções a não ser viabilizar ações para combater os impactos ambientais negativos. Assim, há um interesse crescente em fazer a transição para combustíveis alternativos renováveis, sustentáveis e ecologicamente corretos. Atrasar as ações com oposições a essa tendência poderá trazer significativos impactos destrutivos a nível mundial. Entre os biocombustíveis está o biodiesel, que pode ser obtido por diferentes processos a partir de diversas fontes lipídicas renováveis que reagem com um álcool de baixo peso molecular na presença de um catalisador. Como tal, este trabalho tem como objetivo contribuir nas discussões dos desafios encontrados nessa área, além de oferecer opções possíveis para tornar esse combustível numa realidade mais sustentável em um escopo muito mais amplo. Descreve-se a obtenção de biodiesel proveniente das reações químicas simultâneas de esterificação/transesterificação do óleo de soja acidificado, matéria-prima cuidadosamente preparada com as mesmas características dos óleos e gorduras residuais (OGRs), por catálise heterogênea via metanólise, utilizando as nanopartículas magnéticas (NPMs) de $\mathrm{Ni}_{0,5} \mathrm{Zn}_{0,5} \mathrm{Fe}_{2} \mathrm{O}_{4}$, sintetizadas com o importante diferencial do método de combustão em escala piloto de $200 \mathrm{~g} /$ batelada. As NPMs foram caracterizadas segundo propriedades estruturais e texturais. 0 biodiesel foi analisado por cromatografia gasosa, espectrometria. As NPMs atenderam os requisitos que validam um catalisador em potencial e consequentemente foram obtidas excelentes conversões dos OGRs em biodiesel, de até 99,42\%, além de apresentar as propriedades que foram analisadas dentro dos critérios regidos por Normas. Portanto, essa contribuição na área é bastante pertinente, pois o biodiesel é uma das principais alternativas de cumprimento dos acordos internacionais para minorar as emissões nocivas.

Palavras-chave: Energia renovável, biodiesel, OGRs, nanopartículas magnéticas, reação de combustão. 


\section{INTRODUÇÃO}

A acelerada globalização vivenciada nos dias atuais expande as atividades econômicas mediante a rápida progagação de conhecimento e transferência de tecnologia que influenciam a demanda de energia. 0 setor de transportes se configura como um dos principais agentes do consumo de energia, em vista disso, existe um exponencial esgotamento dos combustíveis fósseis por causa do aumento da demanda de óleo diesel, o qual caracteriza o maior impacto na economia.

Dentre as problemáticas que giram em torno disso, as preocupações mais críticas em relação aos motores movidos a diesel são os óxidos de nitrogênio (NOx) e as emissões de fumaça. Dessa maneira, as crescentes preocupações com o meio ambiente, principalmente com o aquecimento global proveniente da poluição do ar ocasionada pela queima dos combustíveis fósseis e as previsões de que as reservas de energias fósseis diminuem consideravelmente num futuro próximo, têm incentivado a busca por novas fontes de combustíveis alternativos, tais como os biocombustíveis.

A utilização de combustíveis fósseis gera emissões ao longo de seu ciclo de vida, as quais são responsáveis por uma das mais relevantes categorias de impacto ambiental, o aquecimento global, devido ao efeito estufa. Segundo Ribeiro et al. (2015), essa categoria de impacto está relacionada à emissão de gases de efeito estufa GEE. Conforme a literatura enfatiza, o uso contínuo de combustível fóssil, especialmente para transporte, há muito tempo é identificado como principal contribuinte de poluentes atmosféricos. As emissões de hidrocarbonetos não queimados, monóxido de carbono e óxidos de nitrogênio podem tirar anos da vida das pessoas (Goh et al., 2019; Sundus, Fazal e Masjuki, 2017).

Diante do cenário de que o crescimento econômico e a urbanização estimulam o consumo de energia, é possível afirmar que a chamada energia limpa, que é a energia oriunda de fontes renováveis, é uma proposta que se enquadra perfeitamente como solução para diversos problemas relacionados ao meio ambiente e consequentemente de toda a humanidade. Outrossim, esse fato leva a uma maior abertura aos recursos energéticos renováveis, de forma que em face das necessidades e perspectivas do comércio mundial, tais fatores impulsionam a expansão de alternativas para produção e geração de bioenergia.

Dentre os biocombustíveis existentes, o biodiesel tem alcançado grande destaque econômico e tecnológico, devido ao seu potencial em substituir o diesel de petróleo e devido as características intrínsecas, como ser biodegradável, possuir uma baixa emissão de gases poluentes e ser proveniente de fontes renováveis. Nesta questão, a nação brasileira pode ser um referencial global na redução de emissões proporcionada pelo uso de biodiesel, atingindo sua meta de redução de emissões nacionais de GEE em $36,1 \%$ a $38,9 \%$ até 2020 , compromisso voluntário firmado em 2009 , durante a Conferência do Clima.

O Programa Nacional de Produção e Uso de Biodiesel (PNPB) tem o objetivo de estimular a cadeia de produção de biodiesel, garantindo a produção e o consumo interno de biodiesel. A utilização de biocombustíveis como o biodiesel, além de contribuir significativamente para reduzir as emissões de GEE, por ser isento de enxofre $(\mathrm{S})$, atende à Agenda do Conselho Nacional do Meio Ambiente (Conama/MMA), que prevê a redução do teor de enxofre no óleo diesel (Resolução 403/08).

Dados da Agência Nacional do Petróleo, Gás Natural e Biocombustíveis (ANP) dão conta de que na atualidade existem no Brasil 51 plantas produtoras de biodiesel autorizadas para operação, correspondendo a uma capacidade total autorizada de 23.475,02 m3/dia. Essa agência brasileira ainda informa que existem 2 novas plantas de biodiesel autorizadas para construção, e que finalizadas as obras e posterior autorização para operação, a capacidade total de produção de biodiesel poderá ser aumentada em $1.850 \mathrm{~m} 3 /$ dia, que representa um acréscimo de 7,88\% na capacidade atual (ANP, 2019).

Em relação a expansão da mistura do biodiesel ao diesel no país, a Associação dos Produtores de Biodiesel no Brasil (APROBIO) divulgou a estimativa do Conselho Nacional de Política Energética (CNPE), que esse processo continua sucessivamente e que todo o biodiesel comercializado ao consumidor final conterá $15 \%$ de biodiesel até 2023. A estimativa é que a produção do biodiesel brasileira passe de 5,4 para mais de 10 bilhões de litros anuais, entre 2018 e 2023, representando um aumento de 85\% da demanda doméstica. Conforme Moreno et al. (2019), o número de fábricas de produção de biodiesel está crescendo rapidamente em todo o mundo e as tecnologias "verdes" relacionadas estão se desenvolvendo em completa escala industrial em um breve período.

A biomassa vem sendo intensamente investigada e os resultados obtidos indicam que o consumo de energia de biomassa se comporta como uma fonte de energia limpa na redução da poluição ambiental. Essas pesquisas podem ajudar os formuladores de políticas a considerar a energia da biomassa como uma fonte limpa de energia, no esforço para alcançar segurança energética e sustentabilidade ambiental 
(Danish e Wang et al., 2019; Dantas et 2018a). 0 Brasil é um produtor de expressão em produtos agrícolas que geram grandes quantidades de biomassa, que por sua vez, é conceituada a partir do ponto de vista energético, como sendo todo recurso renovável oriundo de matéria orgânica, tanto vegetal como animal, que pode ser utilizada na produção de energia (Vaz, 2012; Fontoura, Brandão e Gomes, 2015). Desta forma, as fontes renováveis de energia da biomassa podem ser facilmente armazenadas e fornecem uma alternativa de combustível líquido para uso no sistema de transporte atual. No entanto, apesar do grande potencial edafoclimático do país, que favorece as condições ideais para diversificação de matérias-primas oleaginosas, inclusive as que não são comestíveis, a soja é a principal fonte na cadeia de produção de biodiesel, ajudando a fortalecer o desenvolvimento regional, promover a inclusão social e a gerar emprego e renda apoiando a agricultura familiar.

O biodiesel então, muito embora seja uma alternativa já consolidada, tem sido alvo de inúmeras pesquisas a nível mundial, tanto na academia quanto no setor industrial, devido ao seu grande potencial e as suas importantes vantagens como ser biodegradável, mitigar as emissões dos GEE e possuir uma boa lubrificação. As pesquisas levam em consideração o aprimoramento e o desenvolvimento de fatores como métodos de obtenção, fontes de matérias-primas, tecnologias para produção, viabilidade técnica, econômica e social, bem como a preocupação em relação a conservação do biodiesel para que se mantenha isento de oxidação durante o tempo de estocagem. Como exemplo, cita-se os estudos de Nagavekar et al. (2021); Ghosh et al. (2021); César et al. (2019); Arcigni et al. (2019); Dantas et al. (2018b); Ribeiro et al. (2018); Gebremariam e Marchetti (2018); Dantas et al (2017).

Em relação as grandes demandas por tecnologias de produção, devido ao rápido avanço da inserção do biodiesel na matriz de transportes, devem ser levadas em consideração uma séria questão, a dos acidentes de trabalho, que por sua vez comprometem a integridade física do trabalhador. Tanto é assim, que alguns estudos são voltados para esse importante foco, como destacado por Moreno et al. (2019), que alertam sobre que a exploração dessas tecnologias relativamente novas, com baixa experiência operacional, está levando a um aumento no número de acidentes nesse setor industrial.

No que diz respeito aos métodos de obtenção do biodiesel, várias são as alternativas visando melhorar o uso dos óleos vegetais em motores do ciclo diesel. Dentre elas, a reação química de esterificação é largamente reportada.

\subsection{ESTERIFICAÇ̃̃O}

O biodiesel é um combustível limpo, biodegradável e atóxico produzido a partir de recursos domésticos e renováveis, como óleos vegetais comestíveis, não comestíveis, gorduras animais, óleos microbianos e óleos de algas por processos químicos simples, como a esterificação e transesterificação.

A esterificação consiste na reação de uma fonte lipídica com um álcool em presença de um catalisador e sua condução deve ser em meio preferencialmente ácido. Essa reação origina éster alcoólico e água como produto final, onde os ésteres são obtidos a partir de ácidos graxos livres. Então, esterificação é a denominação dada à reação que envolve a obtenção de ésteres (biodiesel) a partir de álcoois e ácidos graxos ou seus derivados. Conforme ilustrada na Figura 1, esterificação é a obtenção de ésteres, a partir da substituição de uma hidroxila $(-\mathrm{OH})$ de um ácido (ácido graxo) por um radical alcoxíla (-OR) de um álcool de cadeia curta em presença de catalisador, dando origem a monoésteres de ácidos graxos (Suarez et al., 2009).

Figura 1: Ilustração da reação de esterificação. Fonte: Autoria própria.

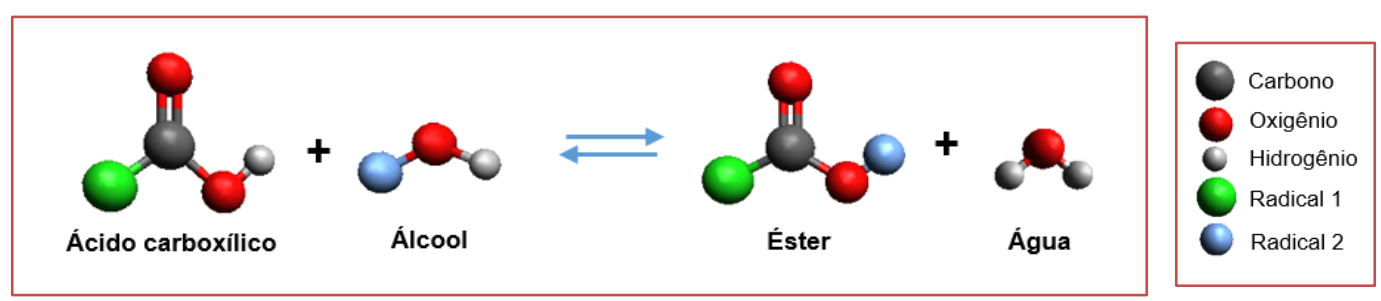

Comercialmente, o biodiesel é produzido por meio da reação de transesterificação ou esterificação de óleos vegetais ou gordura animal. Estas reações são conduzidas na presença de catalisadores alcalinos ou ácidos, no caso da transesterificação, e de catalisadores ácidos, no caso da esterificação. Basicamente, a 
diferença entre as reações de esterificação e transesterificação, reside na qualidade da fonte lipídica a ser utilizada. A transesterificação exige fontes lipídicas refinadas (Ong et al., 2014; Ramos et al., 2014), de alto custo agregado, o que encarece o produto final. Por outro lado, a reação de esterificação permite o uso de fontes lipídicas de baixo valor econômico e de elevada acidez, tais como, óleo de fritura e gordura animal. Quando o teor de ácidos graxos da matéria-prima é elevado pode-se proceder com a neutralização dos ácidos graxos ou com a reação de esterificação seguida de transesterificação numa só etapa (Dantas 2016; Chai et al., 2014).

Os autores Boz, Degirmenbasi e Kalyon (2015) quando utilizaram reações simultâneas de esterificação e transesterificação do óleo de cozinha usado, na presença de metanol para produção de biodiesel, relataram que a água gerada a partir da esterificação dos ácidos graxos livres levou à hidrólise de triglicerídeos e reduziu a produção de biodiesel, enfatizando assim a necessidade para a remoção da água durante a esterificação, concomitantemente ocorreu a transesterificação dos triglicerídeos dos ácidos graxos livres em excesso presentes, para a produção de biodiesel.

Em virtude disto, triacilglicerídeos residuais podem constituir uma matéria-prima alternativa para processos industriais de geração de biocombustíveis, em função do baixo custo e pela sua sustentabilidade, ao minimizar o potencial de poluir o meio ambiente. A esterificação além de agregar valor a fontes lipídicas de baixo valor econômico e, em alguns casos, considerados resíduos contaminantes do meio ambiente, permite a inserção de novas matérias-primas na cadeia produtiva do biodiesel que representarão uma nova fonte de renda para cooperativas, comunidades carentes, pequenos e médios empresários (Oliveira et al., 2014).

Tanto a reação de esterificação quanto a de transesterificação, são controladas por diversas variáveis, tais como, temperatura, razão molar óleo:álcool, tipo e quantidade de catalisador, tempo de reação, agitação, qualidade da matéria-prima, entre outras, influenciam a obtenção do produto final que é o biodiesel. A temperatura, razão molar e o catalisador, geralmente, são as variáveis de maior influência nessas reações (Dantas et al., 2016).

Os autores Thiruvengadaravi et al. (2012) estudaram as reações de esterificação e transesterificação metílica do óleo de karanja a $60{ }^{\circ} \mathrm{C}$ com razões molares de 1:3 a 1:15 na presença da zircônia sulfatada, por 2 horas. No estudo os autores verificaram a dependência direta da reação com a razão molar e a quantidade de catalisador. Os autores concluíram que o aumento da razão molar até 1:15 resultava em mais de $90 \%$ de conversão dos ácidos graxos em ésteres na reação de esterificação. Com relação ao tempo e quantidade dos catalisadores foi observado que o incremente destes promovia, também, elevadas conversões.

Assim, as reações de esterificação e transesterificação são estremamente relevantes na obtenção de muitos insumos necessários à sociedade contemporânea, como biocombustíveis. Existem muitas outras aplicações para essas reações químicas extremamente versáteis, de forma que os estudos científicos ou técnicos dos processos que as envolvam, são sempre de grande valor. Estes podem abranger, além do desenvolvimento de catalisadores, a investigação de matérias-primas alternativas que garantam à sustentabilidade dos processos industriais e permitam a obtenção de produtos feitos especialmente para atender às exigências mercadológicas e às especificações técnicas requeridas.

\subsection{CATALISADORES NA PRODUÇÃO DE BIODIESEL}

Industrialmente, a produção de biodiesel resulta de um processo catalítico homogêneo realizado com metanol e, em geral, na presença de hidróxido de sódio ou potássio como catalisador. Estes catalisadores possuem baixo custo e fornecem altos níveis de conversão do triacilglicerídeo ao éster metílico correspondente (Ma e Hanna, 1999). Por outro lado, possuem várias desvantagens (Tang et al., 2018), entre as quais, pode-se destacar a formação de sabão tanto pela neutralização de ácidos graxos livres presentes no óleo quanto pela saponificação do triacilglicerídeo, a corrosão, a difícil remoção destes catalisadores, que encarece o produto final, a impossibilidade de reciclagem, a geração de grande quantidade de rejeito, a dificuldade de recuperação da glicerina e a presença de água e ácidos graxos livres, que interferem na reação.

Daí o interesse em substituir esses catalisadores por catalisadores heterogêneos, uma vez que estes são de procedimentos operacionais mais fáceis e reduzem significantemente a poluição ambiental. Desta forma, os catalisadores heterogêneos tem sido alvo de diversas pesquisas desenvolvidas, por causa da melhoria provida ao produto final por não produzirem emulsões, a redução de problema com corrosão, a facilidade na sua remoção e reutilização, gerar menos efluentes químicos, a recuperação do excesso de álcool por 
destilação e permitir o uso de matérias-primas com distintas características Dantas et al., 2013; Ramos et al., 2014).

Então, a catálise da reação pode ser ácida ou básica, e os catalisadores ácidos e básicos podem ser homogêneos (na qual toda reação ocorre numa só fase) e heterogêneos (na qual a reação ocorre em interfaces entre fases). A diferença entre os catalisadores vai definir a quantidade de água a ser utilizada na etapa de purificação do biodiesel. 0 tipo de catalisador empregado é um fator determinante na velocidade da reação, assim como na taxa de conversão e também na possível reação entre o catalisador e os ácidos graxos.

Dos catalisadores heterogêneos citados atualmente na literatura, os materiais cerâmicos representam importantes produtos comerciais para indústrias, que por sua vez tem se destacado, entre outros, para obtenção destes catalisadores. A capacidade do catalisador de adsorver os reagentes em sua superfície tem expressiva importância, do que decorre o emprego de catalisadores com elevada área de superfície, objetivando aumentar a área de contato catalisador/reagentes. Moshfegh (2009) e Ong et al. (2014) relataram que os nanocatalisadores proporcionam um aumento da razão área superficial/volume, levando a elevadas atividades catalíticas, quando comparados aos tradicionais catalisadores com largos cristais, resultando assim em alta reatividade química.

Em particular as nanopartículas magnéticas (NPMs), inseridas no grupo de materiais que possuem elevadas áreas de superfície, têm-se apresentado fortemente promissoras devido suas diversas aplicações, que estão ligadas as suas propriedades e características.

\subsection{NANOFERRITAS PARA OBTENÇÃO DE BIODIESEL}

As ferritas cúbicas com estrutura cristalina do tipo espinélio (por analogia à estrutura do mineral espinélio (MgAl204), tem enorme interesse tecnológico em razão das suas propriedades magnéticas, elétricas, ópticas e catalíticas. O sistema cristalino deste material é cúbico, com arranjo compacto de íons de oxigênio em uma rede cúbica de face centrada (CFC), composto por oito sub-redes gerando uma estrutura cristalina ternária do tipo AB204 (Callister Jr. e Rethwisch, 2016).

Na estrutura AB204, A, representa os íons metálicos divalentes (Me2+), e B representa os íons metálicos trivalentes $(\mathrm{Me} 3+)$. De modo que os átomos são dispostos nos seguintes sítios cristalográficos: sítios tetraédricos com 8 íons metálicos A e/ou B; sítios octaédricos com 16 íons metálicos A e/ou B; e 32 íons de oxigênio que constituem os vértices dos tetraedros e octaedros (Figura 2).

Figura 2 - Célula unitária da estrutura cristalina espinélio AB204 (Tatarchuk et al., 2017).

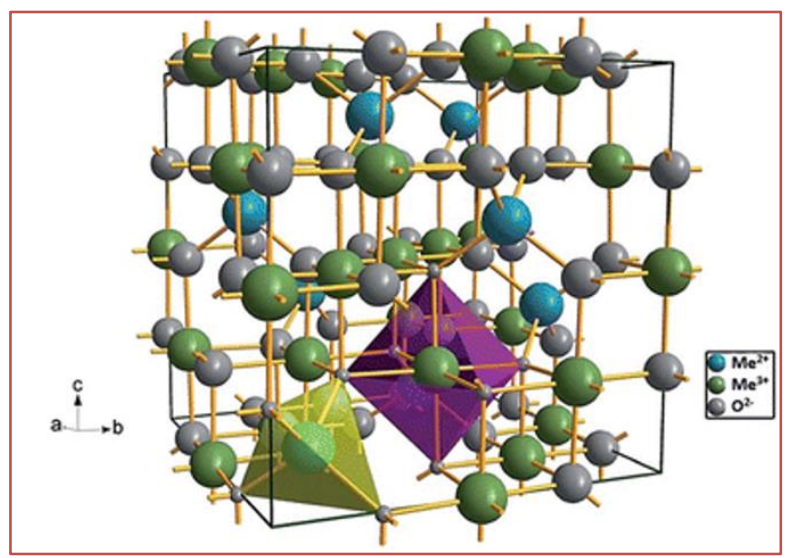

Kumbhar et al. (2015) reportaram em seu estudo sobre a estrutura, morfologia e magnetismo de ferritas $\mathrm{Ni}-\mathrm{Zn}$, que este tipo de material é uma importante classe de óxidos, que apresentam duas treliças sub magnéticas (sítios tetraédricos e sítios octaédricos), e atribuíram as suas propriedades elétricas e magnéticas a dependência da distribuição dos cátions nestes dois locais.

Estas características tornam as nanopartículas magnéticas extremamente atrativas para aplicações em catálise, principalmente pelas elevadas áreas de superfícies que fazem as partículas serem superparamagnéticas, o que segundo Tristão (2010) provoca um aumento significativo na sua reatividade, 
desempenhando um papel fundamental em processos químicos, pelo aumento dos sítios catalíticos na superfície do catalisador.

As ferritas em geral, enquanto catalisadores sólidos nanomagnéticos, podem ser facilmente separados dos reagentes por um campo magnético externo (ímã), o qual pode efetivamente evitar a perda do catalisador e aumentar a sua taxa de recuperação durante o processo de separação, como também ser reutilizado em vários ciclos nas etapas de transesterificação e esterificação. Tais tipos de catalisadores nanomagnéticos tem atraído cada vez mais a atenção dos pesquisadores nos últimos anos. De acordo com Safarik e Safariková (1999) a remoção das nanopartículas em suspensão do meio em que estão, por separação magnética, é relativamente rápida e de fácil operação, requerendo equipamentos simples, eliminando a etapa da centrifugação ou filtração.

Associado a estas vantagens, a ferrita Ni-Zn é facilmente obtida por métodos de processamento economicamente viáveis e com características nanoestruturais. Algumas tecnologias de intensificação de processo têm sido propostas a fim de reduzir o custo final do biodiesel produzido, como um exemplo destaca-se o desenvolvimento inovador de catalisadores nanomagnéticos em escala piloto de produção (Dantas et al. 2018b). As pioneiras pesquisas utilizando diferentes composições de ferritas tipo espinélio foram desenvolvidas avaliando o seu uso nos processos de esterificação e transesterificação via rota metílica e etílica para produção de biodiesel a partir de oleaginosas como a soja e a partir de óleos e gorduras residuais (Dantas, 2012; Dantas, 2016). Os resultados alcançados demonstram potencial viabilidade na utilização destas nanoferritas como catalisadores heterogêneos, sintetizadas via reação de combustão, para produção de biodiesel, além do desenvolvimento de promissores catalisadores que sinalizam a possibilidade de serem utilizados na indústria.

Portanto, nesse presente estudo, buscou-se difundir vantagens como a simplificação dos processos executados nas reações químicas, a possibilidade de separação e possível reutilização de catalisadores, na perspectiva de contribuir para a superação dos desafios dessa área, em particular aqueles relacionados ao meio ambiente.

\section{METODOLOGIA}

\subsection{MATERIAIS}

Os reagentes utilizados na síntese das nanopartículas magnéticas (NPMs) pelo método químico da reação de combustão foram os seguintes:

- $\quad$ Nitrato de ferro nonohidratado - Fe(NO3)3.9H2O 99\%;

- $\quad$ Nitrato de zinco hexahidratado - Zn(NO3)2.6H20 99\%;

- $\quad$ Nitrato de níquel hexahidratado - Ni(NO3)2.6H20 98\%;

- Ureia (combustível) - CO(NH2)2 98\%.

Para a produção do biodiesel pelas reações químicas simultâneas de esterificação/transesterificação foram utilizados:

- $\quad$ Metanol comercial - 98\% PA;
- $\quad$ Ácido oleico;
Óleo de soja comercial.

\subsection{SÍNTESE DAS NPMS POR REAÇÃO DE COMBUSTÃO}

Para a obtenção das nanopatículas magnéticas com composição Ni0,5Zn0,5Fe204, os reagentes metálicos (fonte de cátions $\mathrm{Ni2}+, \mathrm{Zn} 2+$ e Fe3+) e o combustível ureia (agente redutor) foram pesados e misturados diretamente em recipiente de aço inox desenvolvido especificamente para síntese de combustão (Costa e Kiminami, 2012). 0 recipiente foi submetido ao aquecimento em placa com resistência elétrica em espiral até atingir a auto-ignição (combustão).

A composição inicial da solução redox foi calculada com base na valência total dos reagentes oxidantes e redutores, utilizando a teoria dos propelentes e explosivos conforme descrito por Jain et al. (1981). De acordo com a teoria, o carbono, hidrogênio, zinco, níquel e ferro são considerados como elementos redutores com as seguintes valências de $4+, 1+, 2+, 2+$ e $3+$, respectivamente. 0 oxigênio é considerado 
como elemento oxidante com valência de 2- e a valência do nitrogênio não é considerada na reação, devido o mesmo ser eliminado como moléculas de gases de combustão e não como produto. A valência da ureia é considerada como 6+. A reação química proposta para sintetizar a ferrita espinélio Ni0,5Zn0,5Fe204 por reação de combustão segue esquematizada na Equação 1:

$$
C_{1} \text { Niratos Metálicos }+C_{2} \text { Combustível } \stackrel{\Delta}{\rightarrow} P_{1} \operatorname{NiZnFe}_{2} O_{4}+P_{2} \operatorname{Gases}(E q-01)
$$

onde C1, C2, P1 e P2 são coeficientes estequiométricos da reação responsável pelo balanço molar dos componentes químicos. De acordo com Jain et al. (1981), os gases gerados nas reações são N2, H2O e CO2.

A amostra sintetizada, que foi obtida sob a forma de flocos porosos, foi macerada e peneirada em malha 325 mesh (abertura de $45 \mathrm{~mm}$ ) para então ser encaminhada para as caracterizações, como esquematizado no fluxograma da Figura 3.

\subsubsection{AFERIÇÃO DO TEMPO E DA TEMPERATURA}

Durante a síntese, a temperatura da reação de combustão foi medida por um pirômetro de infravermelho (Raytek, modelo RAYR3I $\pm 2^{\circ} \mathrm{C}$ ). 0 tempo de combustão foi medido por um cronômetro digital, marca Technos. A temperatura de reação foi monitorada em um intervalo de tempo de 5 e 5 segundos entre cada medição de forma on-line. 0 início da medição da temperatura da reação foi efetuado após a dissolução total dos reagentes, e o final da medição da temperatura de reação foi estabelecida minutos após a cessão da chama.

Figura 3: Fluxograma da síntese e caracterização das NPMs de Ni0,5Zn0,5Fe204 e sua aplicação na reação de esterificação para produção de biodiesel.

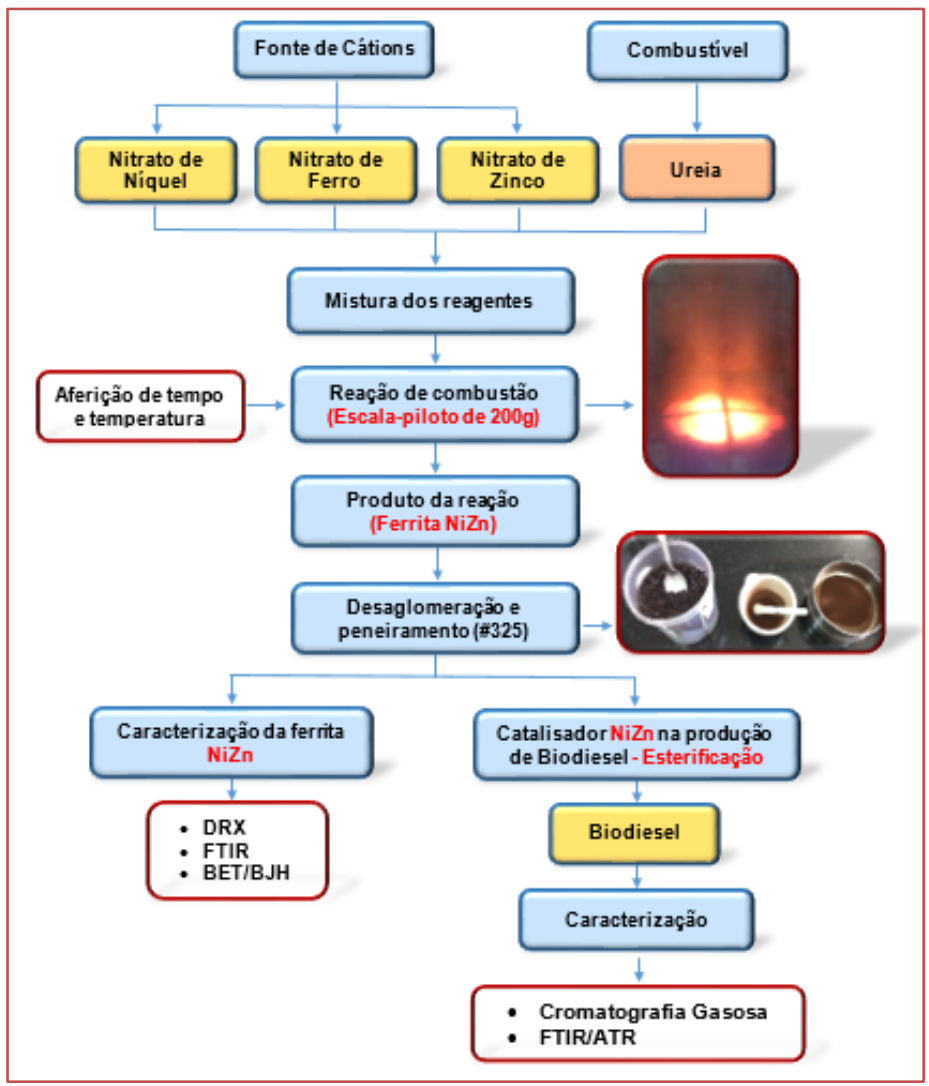

Fonte: Autoria própria. 


\subsection{CARACTERIZAÇÃO DAS NPMS}

\subsubsection{DIFRAÇÃO DE RAIOS X (DRX)}

As NPMs foram caracterizadas por difração de raios $\mathrm{X}$ utilizando um difratômetro de raios X BRUKER modelo D2 Phaser (radiação $\mathrm{Cu}-\mathrm{K} \alpha$ ) e voltagem de $40 \mathrm{kV}$ e $30 \mathrm{~mA}$ de corrente. 0 tamanho de cristalito foi calculado a partir do software DIFFRAC.EVA com base na linha de alargamento de raios X (d311) mediante a deconvolução da linha de difração secundária do cério policristalino (utilizado como padrão) utilizandose a equação de Scherrer (Klung e Alexander, 1962). A cristalinidade foi determinada a partir da razão entre a área integrada do pico referente à fase cristalina e a área referente à fração amorfa.

\subsubsection{ESPECTROMETRIA DE INFRAVERMELHO POR TRANSFORMADA DE FOURIER (FTIR)}

Os espectros de FTIR foram obtidos utilizando-se um espectrômetro modelo Vertex 70 da marca BRUKER, entre 4000 e $200 \mathrm{~cm}-1$, com resolução de $4 \mathrm{~cm}-1$ e 20 varreduras. Esta técnica foi utilizada para observar as bandas características dos materiais avaliados.

\subsubsection{ANÁLISE TEXTURAL POR ADSORÇÃO/DESSORÇÃO DE N2 (BET/BJH)}

A determinação da área superficial das NPMs foi realizada pelo método de adsorção de nitrogênio/hélio desenvolvido por Brunauer, Emmett e Teller (BET) visando determinar a área superficial específica dos pós obtidos na reação de combustão. A partir das isotermas de adsorção de N2 referentes ao sistema de ferrita obtido foi possível obter a característica textual de cada amostra. Foi utilizado um equipamento modelo NOVA 3200. Esta técnica também foi usada para determinar o tamanho médio de aglomerados de partículas (diâmetro esférico equivalente) por meio da Equação 2 (Reed, 1995):

$$
D_{B E T}=\frac{6}{S_{B E T} . \rho}(E q .02)
$$

onde, DBET é diâmetro médio equivalente (nm), SBET é área superficial determinada pelo método BET (m2/g), $\rho$ é densidade teórica ou experimental $(\mathrm{g} / \mathrm{cm} 3)$ e 6 é um fator calculado experimentalmente e adotado para partículas de formato consideradas esféricas e sem rugosidade.

\subsection{PROCESSO CATALÍTICO PARA PRODUÇÃO DE BIODIESEL}

Para as reações de esterificação/transesterificação simultâneas, inicialmente misturou-se 15\% em peso de ácido oleico ao óleo de soja, de forma que foi garantida a acidez característica nos óleos e gorduras residuais. A esta solução foi adicionado álcool metílico na proporção molar óleo:álcool de 1:12 e 1:15, 2 e $3 \%$ de NPMs como nanocatalisador. As reações foram realizadas em reator de aço inox pressurizado (Figura 4a), sob agitação magnética por 1 hora, onde em cada reação variou-se a temperatura, que foram de $140^{\circ} \mathrm{C}$ e $180^{\circ} \mathrm{C}$.

Ao final de cada reação as NPMs que atuaram como nanocatalisadores foram separadas do meio reacional da mistura mediante um campo magnético (ímã) e os demais componentes da mistura (éster metílico, água e pequenas quantidades de glicerol) (Figura 4b) foram colocados em um funil de decantação para separação de fase e lavagem com água destilada aquecida (Figuras 4c e 4d). Finalizada a lavagem, as amostras (biodiesel) foram centrifugadas por 30 minutos a 9000 RPM's, com finalidade de promover uma total separação dos componentes via sedimentação e assim separar resíduos de água e/ou catalisador remanescentes. As amostras de biodiesel foram caracterizadas por cromatografia gasosa e FTIR-ATR para verificação do teor e presença das bandas de éster. 
Figura 4: Fotografias (a) do reator de aço inox, (b) da mistura reacional, (c) e (d) funil de decantação para lavagem e separação dos resíduos do biodiesel.
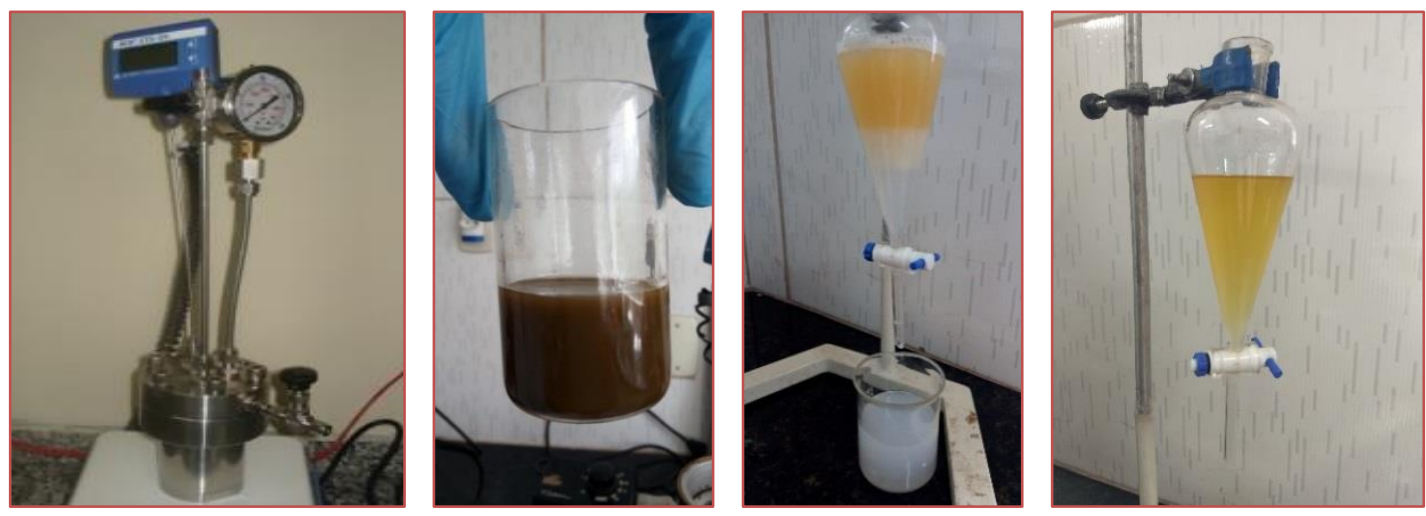

\subsubsection{CROMATOGRAFIA GASOSA}

Os produtos (biodiesel) resultantes das reações foram analisados quanto ao percentual de conversão em éster metílico e também quanto a triacilglicerídeo. Estas análises foram conduzidas em cromatógrafo a gás Varian 450c com detector de ionização de chamas FID (Flame Ionization Detection), em uma coluna capilar curta, de fase estacionária Varian Ultimetal "Select Biodiesel Glycerides + RG" (15m x 0,32mm x $0,45 \mu \mathrm{m})$. A temperatura do detector foi de $250{ }^{\circ} \mathrm{C}$ e a do injetor de $240{ }^{\circ} \mathrm{C}$. A temperatura do forno foi programada de 150 até $260{ }^{\circ} \mathrm{C}$ a uma taxa de aquecimento (rampa) de $10{ }^{\circ} \mathrm{C} / \mathrm{min}$. 0 gás de arraste empregado foi o $\mathrm{H} 2$ de alta pureza. Os resultados foram obtidos em triplicata. Estes ensaios de rendimento da produção do biodiesel, foram um indicativo da eficiência dos nanocatalisadores a partir das NPMs de $\mathrm{Ni0}, 5 \mathrm{Zn} 0,5 \mathrm{Fe} 204$.

\subsubsection{ESPECTROMETRIA DE INFRAVERMELHO POR TRANSFORMADA DE FOURIER (FTIR/ATR)}

Os espectros de FTIR/ATR foram obtidos utilizando-se um espectrômetro modelo Vertex 70 da marca BRUKER, entre 4000 e $200 \mathrm{~cm}-1$, com resolução de $4 \mathrm{~cm}-1$ e 20 varreduras. Esta técnica mostra de forma qualitativa a presença dos grupos orgânicos mais importantes referentes ao biodiesel.

\section{RESULTADOS E DISCUSSÃO}

\subsection{TEMPO E TEMPERATURA DA REAÇÃO DE SÍNTESE DAS NPMS DE NI-ZN}

A curva de temperatura em função do tempo de reação aferidos durante a síntese das nanopartículas magnéticas de Ni0,5Zn0,5Fe2O4 está ilustrada na Figura 5. De acordo com o resultado observa-se pequenas oscilações da temperatura durante todo o intervalo que precede o momento da ignição, o qual acontece no tempo de aproximadamente 16 minutos, e que provavelmente tem relação com a grande evolução dos gases gerados durante a síntese. No momento da ignição, há o surgimento da chama de combustão com forte intensidade e de cor laranja-avermelhada, atingindo uma temperatura máxima de $889^{\circ} \mathrm{C}$ e com duração de aproximadamente 29 segundos. 
Figura 5: Curvas da temperatura em função do tempo de reação aferidos durante a síntese da nanoferrita $\mathrm{Ni}_{0,5} \mathrm{Zn}_{0,5} \mathrm{Fe}_{2} \mathrm{O}_{4}$.

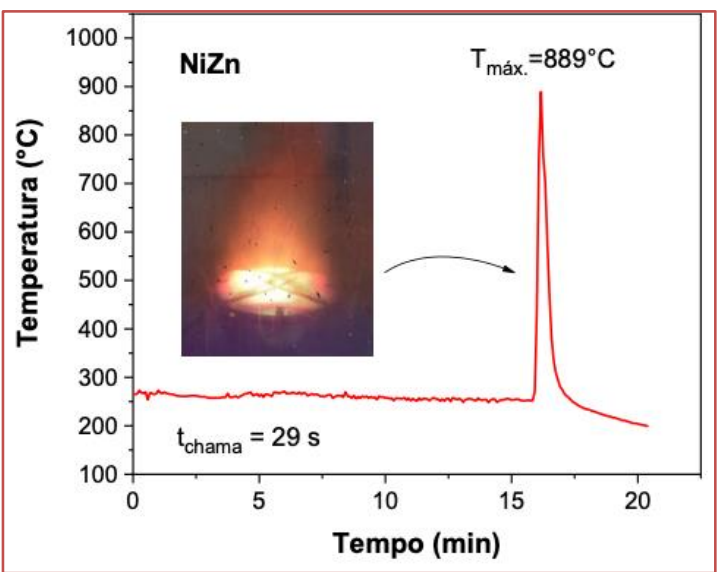

Diante desses resultados experimentais alcançados, de simplicidade do processo aliado ao curto tempo para obter o produto final, pode-se considerer a eficácia do método de síntese por reação de combustão em grandes bateladas do produto. Além disso, em função da temperatura desenvolvida, espera-se um material com elevada área de superfície, pois isso é requesitado como sendo adequado para seu uso na catálise heterogênea, visto que a temperatura impõe alterações diretas na superfície do material.

\subsection{CARACTERIZAÇÃO DAS NPMS POR DIFRAÇÃO DE RAIOS X (DRX)}

A curva de difração de raios X para as nanopartículas magnéticas de NiZn está apresentada na Figura 6. De acordo com o difratograma pode-se dizer que a síntese por reação de combustão foi eficiente na obtenção

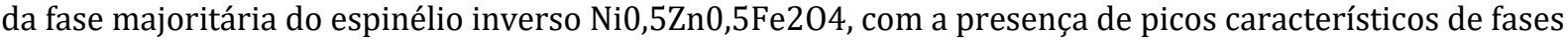
segregadas de hematita (Fe203) e óxido de zinco (ZnO). De modo geral, a obtenção da fase majoritária de interesse indica o sucesso da reação de combustão em bateladas em escala piloto.

Figura 6: Difratograma de raios $\mathrm{X}$ das nanopartículas magnéticas de $\mathrm{Ni}_{0,5} \mathrm{Zn}_{0,5} \mathrm{Fe}_{2} \mathrm{O}_{4}$.

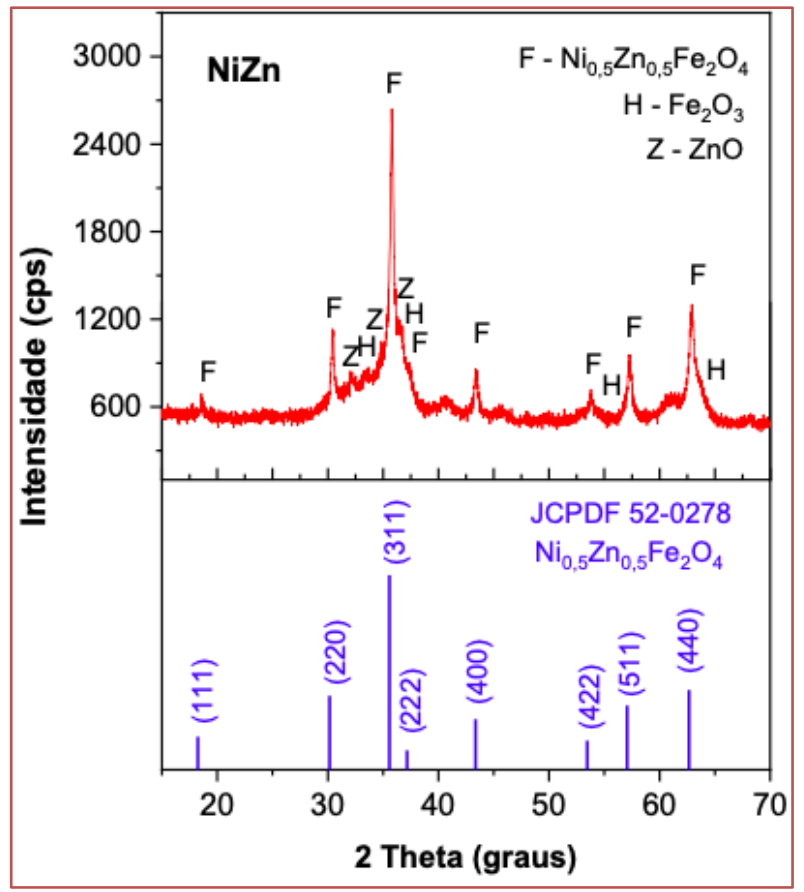


Nota-se a presença dos picos (111), (220), (311), (222), (400), (422), (511) e (440) de acordo com a ficha padrão JCPDS 52-0278 característicos da ferrita Ni-Zn. Este resultado está de acordo com o encontrado por Lazarevic et al. (2015) e Džunuzović et al. (2015) corroborando a eficiência da síntese por reação de combustão na formação do nanomaterial cristalino desejado. 0 tamanho de cristalito obtido pela equação de Scherrer foi de $26 \mathrm{~nm}$ e cristalinidade aproximada de 74\%. Bajorek et al. (2019), sintetizaram a ferrite

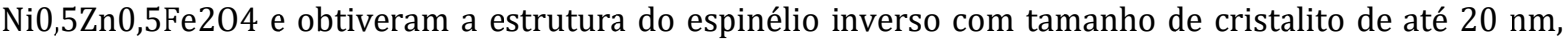
próximo ao alcançado neste estudo. Peng et al. (2005) quando sintetizaram a ferrita NiZn também por reação de combustão e usando a ureia como combustível, obtiveram tamanho de cristalito de $25 \mathrm{~nm}$, próximo ao obtido no presente estudo, mesmo havendo a diferença da pequena escala de produção do autor citado (cadinho de $200 \mathrm{~mL}$ em volume), o que se mostra como um dos indicativos da execelente possibilidade de produção em escala piloto aqui desenvolvida.

\subsection{CARACTERIZAÇÃO DAS NPMS POR ESPECTROSCOPIA NA REGIÃO DO INFRAVERMELHO POR TRANSFORMADA DE FOURIER (FTIR)}

0 espetro de FTIR da nanoferrita magnética NiZn encontra-se ilustrado na Figura 7. Com base nestes resultados verificou-se a presença das bandas vibracionais 586, 1381, 1628, 2352, 2922, 3147 e 3475 cm1. A banda v1 localizada em $586 \mathrm{~cm}-1$ refere-se as vibrações de estiramento da ligação Fe-0- presente nos sítios tetraédricos. A banda v2 localizada abaixo de $500 \mathrm{~cm}-1$ corresponde às vibrações do grupo Fe-O- nos sítios octaédricos (Raghavender et al., 2011; Pathania et al., 2018). Segundo Shirsath et al. (2010), esse valor pode variar conforme às diferentes distâncias da ligação Fe-O- nos sítios tetraédricos e octaédricos. Esta variação pode estar relacionada às condições da reação, tamanho do grão e densidade do material. A banda vibracional $1381 \mathrm{~cm}-1$ é atribuída à presença do íon N03- proveniente possivelmente de nitratos que não reagiram durante a combustão.

A banda $1628 \mathrm{~cm}-1$ refere-se à vibração do grupo 0-H proveniente da água livre ou fisicamente adsorvida na forma de grupos hidroxilas. A banda vibracional localizada em $2352 \mathrm{~cm}-1$ se refere à presença do $\mathrm{CO} 2$ atmosférico. A banda vibracional em $2922 \mathrm{~cm}-1$ corresponde ao resíduo de carbono proveniente do agente complexante (ureia). E a larga banda localizada em 3600 cm-1 é característico de ligações 0-H-O, proveniente da presença de água na amostra, que pode ser atribuída à adsorção superficial pela umidade do ar atmosférico e também devido à característica higroscópica do $\mathrm{KBr}$ utilizado na preparação da amostra. Observou-se também a banda entre 3500 e 3200 cm-1 referente a absorções fracas atribuídas a ligações N-H de aminas primárias.

Figura 7: Espectro de infravermelho das nanopartículas magnéticas Ni0,5Zn0,5Fe204.

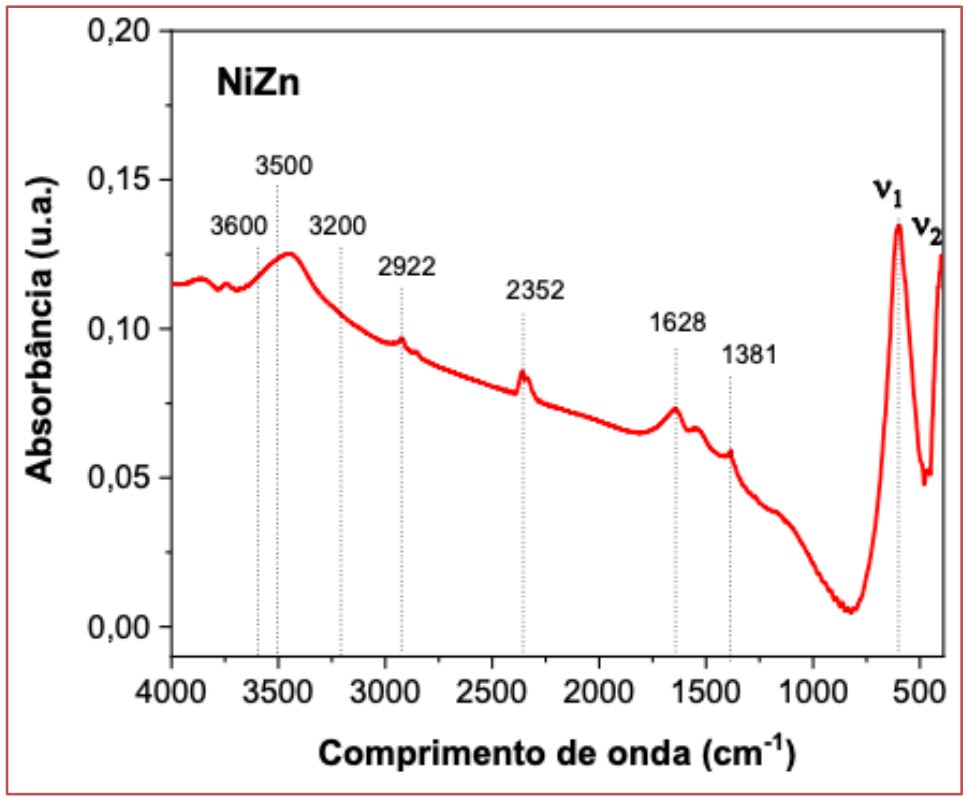




\subsection{CARACTERIZAÇÃO DAS NPMS POR ANÁLISE TEXTURAL POR ADSORÇÃO/DESSORÇÃO DE N2 (BET/BJH)}

A isoterma de adsorção/dessorção de N2 para a nanoferrita NiZn está apresentada na Figura 8a. De acordo com a classificação da International Union of Pure and Applied Chemistry - IUPAC (IUPAC, 1976), a curva sugere um perfil de isoterma do tipo IV mesclada com o tipo $\mathrm{V}$, indicando um material de característica mesoporosa (poros com raios variando entre 10 e $250 \AA ̊$ ), o que pode ser corroborado mediante a Figura 8b, onde se observa a ilustração da evolução crescente do volume do poro em função do raio de poro, que varia de 17 a $123 \AA$, atingindo um volume máximo de poro de $0,144 \mathrm{~cm} 3 / \mathrm{g}$.

Figura 8: (a) Isoterma de adsorção/dessorção de N2 referente as nanopartículas magnéticas de $\mathrm{Ni}_{0,5} \mathrm{Zn}_{0,5} \mathrm{Fe}_{2} \mathrm{O}_{4}$ e (b) a relação volume de poro em função do raio de poro.

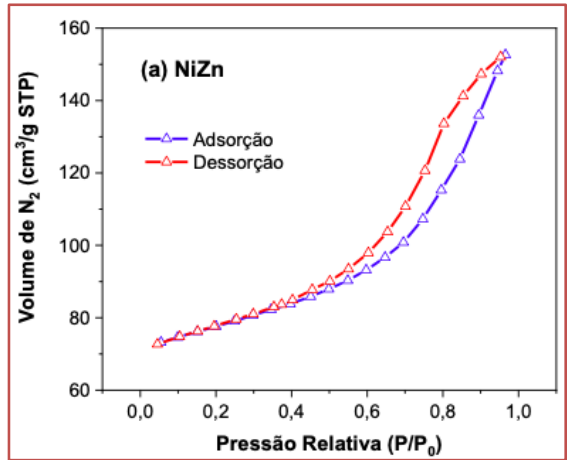

(a)

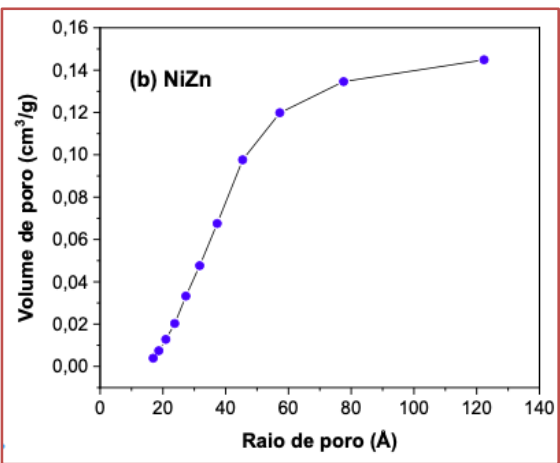

(b)

Esta isoterma é caracterizada por uma região na qual a pressão relativa varia pouco e o volume adsorvido aumenta bruscamente. Quanto menor a inclinação da isoterma, mais homogênea é a distribuição de tamanho de poros. Associado com o processo secundário de condensação capilar está o loop de histerese, que traz como resultado o preenchimento completo dos mesoporos em pressão relativa menor que 1 ( $\mathrm{P} / \mathrm{P} 0<1)$. Neste caso, o loop de histerese é do tipo $\mathrm{H} 3$, que normalmente está associado a agregados nãorígidos de partículas em forma de placa, originando poros em fenda (Fernandes, 2005). Na parte inicial da curva, em torno de uma pressão relativa de 0,2 , há uma pequena inflexão que possivelmente está associada a capacidade de adsorção da monocamada com presença de microporos na estrutura morfológica.

Seguindo o modelo das teorias BET/BJH, as NPMs da ferrita NiZn apresentaram valores de área superficial de $64,171 \mathrm{~m} 2 / \mathrm{g}$, tamanho de partícula de $17,44 \mathrm{~nm}$, volume de poro de $0,152 \mathrm{~cm} 3 / \mathrm{g}$ e raio de poro de 32,630 Å. Ghasemi e Mousavinia (2014) quando sintetizaram partículas magnéticas da ferrita NiZn pelo método sol-gel observaram por meio da análise textural, tamanho de partículas na faixa de 1-4 $\mu \mathrm{m}(1000$ $4000 \mathrm{~nm}$ ), ou seja, bem maiores que o valor reportado no presente estudo. Isso demonstra mais uma vez a eficiência da técnica de reação de combustão na produção de NPMs em escala piloto. Sabe-se que quanto mais nanométrico o material, maior será a sua área superficial, aumentando a acessibilidade dos reagentes químicos aos seus sítios ativos, e consequentemente, aumentando a sua efetividade e/ou atividade no seu desempenho como catalisador heterogêneo em uma determinada reação química, a exemplo, da esterificação e transesterificação de óleos vegetais e/ou gorduras animais para produção de biocombustível.

\subsection{ANÁLISE DAS NPMS NA CATÁLISE HETEROGÊNA PARA PRODUÇÃO DE BIODIESEL}

Na Figura 9 estão ilustrados os resultados da catálise heterogênea para a conversão de biodiesel obtido via esterificação/transesterificação simultâneas do óleo de soja acidificado, semelhantemente a acidez característica presente em óleos e gorduras residuais (OGRs). De forma geral, observam-se ótimas conversões nas condições testadas, implicando no potencial sucesso catalítico das NPMs de

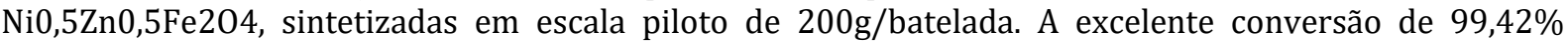
coloca o biodiesel obtido acima do teor de éster mínimo fixado, tanto pelo padrão brasileiro quanto pelo padrão europeu, que é de $96,5 \%$ de éster presente no biodiesel. 
Figura 9: Resultados dos testes catalíticos para as nanopartículas magnéticas Ni0,5Zn0,5Fe204: (a) variação da temperatura e (b) variação da razão molar.
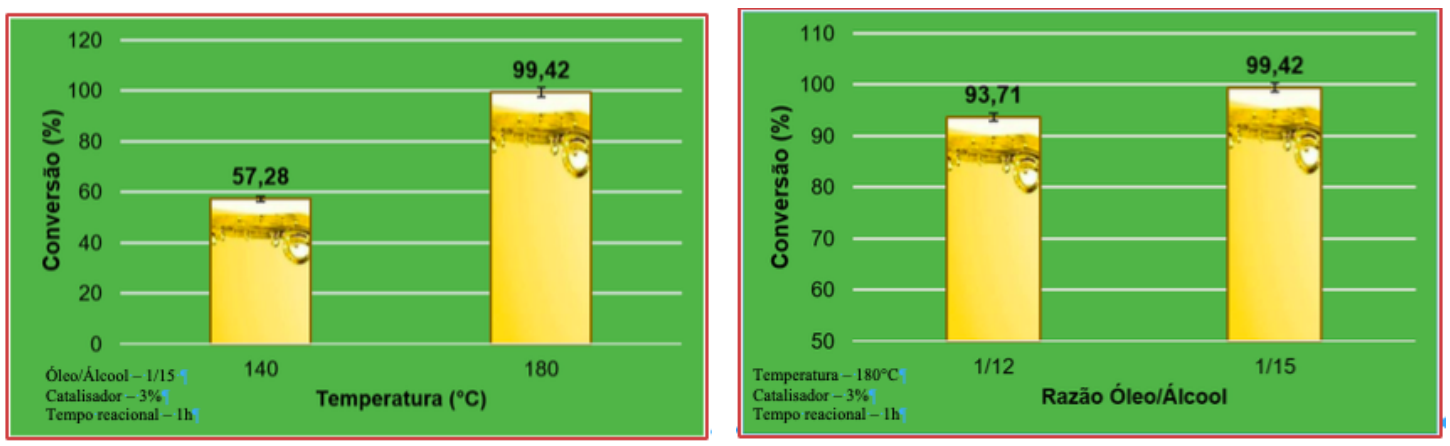

Os resultados de conversões expressam a grande importância e dependência em relação as condições das variáveis reacionais, principalmente a temperatura e a razão molar. Em relação a variável temperatura, observa-se a ocorrência de uma melhora significativa na conversão de ésteres para um incremento de 40 ${ }^{\circ}$ C entre as reações, que propiciou um aumentou 42,14\%. Em relação a variação da razão molar, o resultado de 99,42\% de conversão obtido, quando a razão óleo:álcool foi igual a 1:15, se deve ao aumento da concentração do metanol, que possivelmente promoveu uma maior solubilização do glicerol remanescente devido a uma quantidade mais adequada de álcool.

\subsection{ANÁLISES DO BIODIESEL OBTIDO PELAS NPMS NA CATÁLISE HETEROGÊNA PARA PRODUÇÃO DE BIODIESEL}

Os espectros de infravermelho referentes aos biodieseis metílicos produzidos via esterificação/transesterificação simultâneas dos OGRs constam apresentados na Figura 10. Esta técnica revela de forma qualitativa a presença dos grupos orgânicos mais importantes referentes ao biodiesel. Em $3014 \mathrm{~cm}-1$ ocorre vibrações de estiramento do grupo $\mathrm{CH}$ associado a presença de alcalinos. As bandas localizadas em 2930 e 2851 cm-1 estão associadas com as vibrações de estiramento assimétrico da ligação carbono-carbono (-CH2 assimétrico e - $\mathrm{CH} 2$ simétrico) (Ouanji et al., 2016). Em seguida, nota-se uma banda intensa em $1742 \mathrm{~cm}-1$ referente ao estiramento da carbonila do éster (C=0) que são comuns tanto no óleo refinado ou residual quanto nos ésteres metílicos de ácidos graxos (FAME - Fatty Acids Methyl Esters).

A região principal do espectro que permite a discriminação química entre o óleo de soja e seu respectivo FAME é a região entre 1500 e $900 \mathrm{~cm}-1$, conhecida como a região da "impressão digital". A banda em 1436 cm-1, presente dos espectros 1 e 2, corresponde às vibrações assimétricas do grupo -CH3, característica de espectros de biodiesel, enquanto no espectro 3, referente a reação de menor conversão em biodiesel, esta banda se ausenta, e surge uma banda vizinha em $1462 \mathrm{~cm}-1$, típica do espectro de óleo de soja (Soares et al., 2008), ou seja, demonstra a baixa conversão da reação de esterificação nesta condição. A banda localizada em 1196 cm-1 surgem nos espectros 1 e 2, e está associada à deformação axial da ligação $\mathrm{C}(\mathrm{C}=0)-0$ do éster. A banda localizada em $1169 \mathrm{~cm}-1$ tem relação com a deformação axial assimétrica da ligação C-O do éster. 
Figura 10: Espectros de FTIR/ATR das amostras de biodiesel.

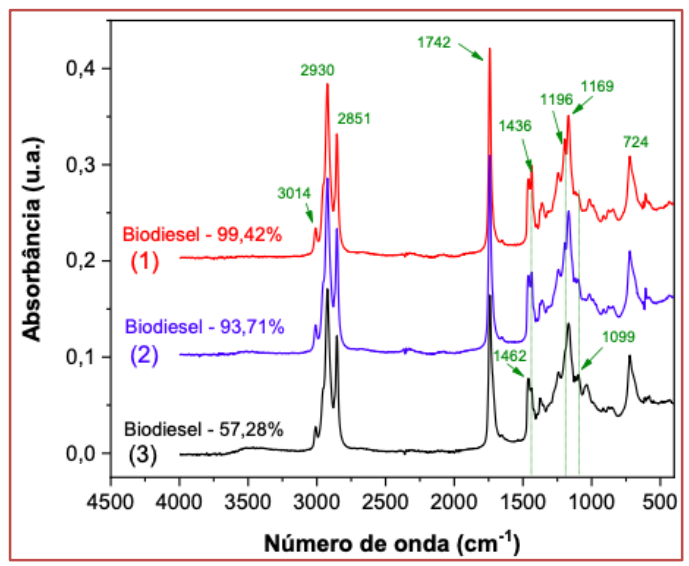

Outra região que permite determinar a presença de FAME e de óleo é a localizada entre 1075 e $1000 \mathrm{~cm}-1$, que representa vibrações axiais assimétricas do grupo - $\mathrm{CH} 2-\mathrm{COOH}$ (Rabelo et al., 2015). Bandas na região de 1300 a $800 \mathrm{~cm}-1$ que indicam sobreposição de bandas presentes tanto no óleo quanto no éster metílico. E por fim, as bandas na região de 1000 a $900 \mathrm{~cm}-1$ e a banda localizada em $724 \mathrm{~cm}-1$ são referentes à deformação angular simétrica fora do plano de ligação do grupo C-H de olefinas (Silverstein et al., 2012). Estas bandas vibracionais identificadas nos espectros dos biodieseis em estudo estão de acordo com os resultados encontrados por Lacerda et al. (2019) e Faraguna et al. (2019).

\section{CONCLUSÕES}

0 método químico por reação de combustão, com o diferencial da produção em escala piloto de $200 \mathrm{~g} /$ batelada foi eficiente na síntese das nanopartículas magnéticas de $\mathrm{Ni0}, 5 \mathrm{Zn} 0,5 \mathrm{Fe} 204$. As caracterizações revelaram a formação do material com características em potencial para promover alta atividade catalítica na obtenção de biodiesel de óleos e gorduras residuais, de forma que se pode garantir requisitos promissores para, associado a outras técnicas, validar a aplicação como nanocatalisador industrial. As variações das condições reacionais influenciaram positivamente nos resultados de ésteres obtidos, chegando na marca dos $99,42 \%$ de conversão em biodiesel metílico. Portanto, considerando as especificações exigidas para se produzir biocombustíveis, essa contribuição na área é bastante promissora, uma vez que o biodiesel se insere como uma alternativa já consolidada para suprir os acordos internacionais de minorar as emissões de gases nocivos.

\section{AGRADECIMENTOS}

Os autores agradecem a CAPES/CNPQ pelo apoio financeiro.

\section{REFERÊNCIAS}

[1] ANP - Agência Nacional do Petróleo, Gás Natural e Biocombustíveis - Boletim mensal do biodiesel - Dezembro 2014 Disponível em: <http://www.anp.gov.br/?pg=73584\&m=\&t1=\&t2=\&t3=\&t4=\&ar=\&ps=\&cachebust=142 $2360133732>$. Acesso em 28/05/2019.

[2] ARCIGNI, F.; FRISO, R.; COLLU, M.; VENTURINI, M. Harmonized and systematic assessment of microalgae energy potential for biodiesel production. Renewable and Sustainable Energy Reviews, v. 101, p. 614-624, 2019.

[3] BAJOREK, A.; BERGER, C.; DULSKI, M.; ŁOPADCZAK, P.; ZUBKO, M.; PRUSIK, K.; WOJTYNIAK, M.; CHROBAK, A.; GRASSET, F.; RANDRIANANTOANDRO, N. Microstructural and magnetic characterization of Ni0,5Zn0,5Fe204 ferrite nanoparticles. Journal of Physics and Chemistry of Solids, v. 129, p. 1-21, 2019.

[4] BOZ, N.; DEGIRMENBASI, N.; KALYON, D. M. Esterification and transesterification of waste cooking oil over Amberlyst 15 and modified Amberlyst 15 catalysts. Applied Catalysis B: Environmental, v. 165, p. 723-730, 2015.

[5] CALliSTER JR., W. D.; RETHWiSCH, D. G. Ciência e Engenharia de Materiais - Uma Introdução. 8a ed., Rio de Janeiro: LTC, 2016. 
[6] CÉSAR, A. S.; CONEJERO, M. A.; RIBEIRO, E. C. B.; BATALHA, M. O. Competitiveness analysis of "social soybeans" in biodiesel production in Brazil. Renewable Energy, v. 133, p. 1147-1157, 2019.

[7] CHAI, M.; TU, Q.; LU, M.; YANG, Y. J. Esterification pretreatment of free fatty acid in biodiesel production, from laboratory to industry. Fuel Processing Technology, v. 125, p. 106-113, 2014.

[8] COSTA, A. C. F. M.; KIMINAMI, R. H. G. A. Dispositivo para produção de nanomateriais cerâmicos em larga escala por reação de combustão e processo contínuo de produção dos nanomateriais. Brasil. Depósito de Patente. Revista de Propriedade Industrial - RPI, BR 102012 002181-3, 2012.

[9] DANISH; WANG, Z. Does biomass energy consumption help to control environmental pollution? Evidence from BRICS countries. Science of The Total Environment, v. 670, p. 1075-1083, 2019.

[10] DANTAS, J. Avaliação do desempenho e reuso do catalisador nanomagnético Ni0,5Zn0,5Fe204 na produção de biodiesel. 192f, [Tese de Doutorado]. Campina Grande-PB: Universidade Federal de Campina Grande, 2016.

[11] DANTAS, J. Síntese e avaliação do desempenho de catalisadores a base de ferritas Ni-Zn dopada com cobre na reação de transesterificação de óleo vegetal em biodiesel. 127p. Dissertação de Mestrado, Universidade Federal de Campina Grande, Programa de Pós-Graduação em Ciência e Engenharia de Materiais, Campina Grande-PB, 2012.

[12] DANTAS, J.; LEAL, E., MAPOSSA, A. B.; SILVA, A. S.; COSTA, A. C. F. M. Síntese, caracterização e performance catalítica de nanoferritas mistas submetidas a reação de transesterificação e esterificação via rota metílica e etílica para biodiesel. Revista Matéria (Rio de Janeiro), v. 21, n. 4, p. 1080-1093, 2016.

[13] DANTAS, J.; LEAL, E.; CORNEJO, D. R.; KIMINAMI, R.H.G.A.; COSTA, A.C.F.M. Biodiesel production evaluating the use and reuse of magnetic nanocatalysts Ni0.5Zn0.5Fe204 synthesized in pilot-scale. Arabian Journal of Chemistry, 2018b.

[14] DANTAS, J.; LEAL, E.; FEITOSA, A. C.; VASCONCELOS, E. V.; COSTA, A. C. F. M. Biodiesel from fatty acids found in brazilian native cultures as soybean and cotton using the nanocatalyst Ni0.5Zn0.5Fe204. Materials Science Forum, v. 912, p.274-279, 2018a.

[15] DANTAS, J.; LEAL, E.; MAPOSSA, A. B.; CORNEJO, D. R.; COSTA, A. C. F. M. Magnetic nanocatalysts of $\mathrm{Ni} 0.5 \mathrm{Zn} 0.5 \mathrm{Fe} 204$ doped with $\mathrm{Cu}$ and performance evaluation in transesterification reaction for biodiesel production. Fuel, v. 191, p. 463-471, 2017.

[16] DŽUnUZOVIĆ, A. S.; ILIĆ, N. I.; VIJATOVIĆ PETROVIĆ, M. M.; BOBIĆ, J. D.; STOJADINOVIĆ, B.; DOHČEVIĆMITROVIĆ, Z.; STOJANOVIĆ, B. D. Structure and properties of Ni-Zn ferrite obtained by auto-combustion method. Journal of Magnetism and Magnetic Materials, v. 374, p.245-251, 2015.

[17] FARAGUNA, F.; RACAR, M.; JUKIĆ, A. Test method for determination of diferente biodiesel (fatty acid alkyl esters) content in diesel fuel using FTIR-ATR. Renewable Energy, v. 133, p. 1231-1235, 2019.

[18] FERNANDES, R. Adsorventes alternativos para remoção de fenol em solução aquosa. Dissertação de Mestrado. Universidade Federal de Santa Catarina, 2005.

[19] FONTOURA, C. F.; BRANDÃO, L. E.; GOMES, L. L. Elephant grass biorefineries: Towards a cleaner Brazilian energy matrix? Journal of Cleaner Production, v. 96, p. 85-93, 2015.

[20] GEBREMARIAM, S. N.; MARCHETTI, J. M. Economics of biodiesel production: Review. Energy Conversion and Management, v. 168, p. 74-84, 2018.

[21] GHASEMI, A.; MOUSAVINIA, M. Structural and magnetic evaluation of substituted NiZnFe204 particles synthesized by conventional sol-gel method. Ceramics International, v. 40, n. 2, p. 2825-2834, 2014.

[22] GHOSH, P. K.; GHOSH, P.; GHOSH, P. K.; GHOSH, N. Intervention of Supercritical Fluids as Reaction Media and Chromatography Tool. Reference Module in Food Science, 2021.

[23] GOH, B. H. H.; ONG, H.C.; CHEAH, M.Y.; CHEN, W.-H.; YU, K. L.; MAHLIA, T. M. I. Sustainability of direct biodiesel synthesis from microalgae biomass: A critical review. Renewable and Sustainable Energy Reviews, v. 107, p. 59-74, 2019.

[24] IUPAC, International Union of Pure and Applied Chemistry, v. 48, p. 127-132, 1976.

[25] JAIN, S. R.; ADIGA, K. C. A new approach to thermochemical calculations of condensed fuel-oxidizer mixture. Combustion and Flame, v.40, p. 71- 79, 1981.

[26] KLUNG, H.; ALEXANDER, L. X-Ray Diffraction Procedures, Wiley, New York, EUA, p. 491, 1962.

[27] KUMBHAR, S. S.; MAHADIK, M. A.; MOHITE, V. S.; HUNGE, Y. M.; RAJPURE, K. Y.; BHOSALE, C. H. Effect of Ni content on the structural, morphological and magnetic properties of spray deposited Ni-Zn ferrite thin films. Materials Research Bulletin, v. 67, p. 47-54, 2015. 
[28] LACERDA, J. G. P.; CANDEIA, R. A.; SALES, L. L. M.; ARAÚJO, A. S.; CUNHA, A. F. P.; WANDERLEY, A. F.; CAMPOS, A. F. Characterization of biodiesel from frying oil obtained by hydro-esterification using vermiculite as heterogeneous catalyst. Journal of Thermal Analysis and Calorimetry, p. 1-8, 2019.

[29] LAZAREVIC, Z. Z.; MILUTINOVIC, A. N.; JOVALEKIC, C. D.; IVANOVSKI, V. N.; DANEU, N.; MADAREVIC, I.; ROMCEVIC, N. Z. Spectroscopy investigation of nanostructured nickel-zinc ferrite obtained by mechanochemical synthesis. Materials Research Bulletin, v. 63, p.239-247, 2015.

[30] MA, F.; HANNA, M. A. Biodiesel Production: A Review. Bioresource Technology, v. 70, p. 1-15, 1999.

[31] MORENO, V. C.; DANZI, E.; MARMO, L.; SALZANO, E.; COZZANI, V. Major accident hazard in biodiesel production processes. Safety Science, v. 113, p. 490-503, 2019.

[32] MOSHFEGH, A. Z. Nanoparticle catalysts. Journal of Physics D: Applied Physics, v. 42, n. 23, p. 233001, 2009.

[33] NAGAVEKAR, N.; DUBEY, K.; SHARMA, A.; SINGHAL, R. S. Supercritical extraction of valued components from animals parts. Reference Module in Food Science, 2021.

[34] OLIVEIRA, J. P.; ANTUNES, P. W. P.; PINOTTI, L. M.; CASSINI, S. T. A. Caracterização físico-química de resíduos oleosos do saneamento e dos óleos e graxas extraídos visando a conversão em biocombustíveis. Química Nova, v. 37, n. 4, p. 597-602, 2014.

[35] ONG, H. R.; KHAN, M. R.; CHOWDHURY, M. N. K.; YOUSUF, A.; CHENG, C. K. Synthesis and characterization of $\mathrm{CuO} / \mathrm{C}$ catalyst for the esterification of free fatty acid in rubber seed oil. Fuel, v. 120, p. 195-201, 2014.

[36] OUANJI, F.; NACHID, M.; KACIMI, M.; LIOTTA, L.F.; PULEO, F.; ZIYAD, M. Small scale biodiesel synthesis from waste frying oil and crude metanol in Morocco. Chinese Journal of Chemical Engineering, v. 24, n. 9, p. 1178-1185, 2016.

[37] PATHANIA, A.; BHARDWAJ, S.; THAKUR, S. S.; MATTEI, J.-L.; QUEFFELEC, P.; PANINA, L. V.; THAKUR, P.; THAKUR, A. Investigation of structural, optical, magnetic and electrical properties of tungsten doped Ni-Zn nanoferrites. Physica B: Condensed Matter, v. 531, p. 45-50, 2018.

[38] PENG, C.-H.; HWANG, C.-C.; WAN, J.; JIH-SHENG TSAI, J.-S.; CHEN, S.-Y. Microwave-absorbing characteristics for the composites of thermal-plastic polyurethane (TPU)-bonded NiZn-ferrites prepared by combustion synthesis method. Materials Science and Engineering B, v. 117, p. 27-36, 2005.

[39] RABELO, S. N.; FERRAZ, V. P.; OLIVEIRA, L. S.; FRANCA, A. S. FTIR Analysis for quantification of fatty acid methyl esters in biodiesel produced by microwave-assisted transesterification. International Journal of Environmental Science and Development, v. 6, n. 12, p. 964-969, 2015.

[40] RAGHAVENDER, A. T.; BILIŠKOV, N.; SKOKO, Ž. XRD and IR analysis of nanocrystalline Ni-Zn ferrite synthesized by the sol-gel method. Letters, v. 65, p. 677-680, 2011.

[41] RAMOS, L. P.; CORDEIRO, C. S.; CESAR-OLIVEIRA, M. A. F.; WYPYCH, F.; NAKAGAKI, S. Applications of heterogeneous catalysts in the production of biodiesel by esterification and transesterification. In: Bioenergy Research: Advances and Applications. 1st. ed., Chap. 17, p. 255-276, 2014.

[42] REED, J. S. Density, Pore Structure, and Specific Surface Area. In: Principles of Ceramics Processing, 2nd Ed., Wiley-Interscience, New York, EUA, Chap. 8, p.127, 1995.

[43] RIBEIRO, E. C. B.; MOREIRA, A. C.; FERREIRA, L. M. D. F.; CÉSAR, A. S. Biodiesel and social inclusion: An analysis of institutional pressures between biodiesel plants and family farmers in southern Brazil. Journal of Cleaner Production, v. 204, p. 726-734, 2018.

[44] RIBEIRO, E. L. F.; MARANDUBA, H. L.; OLIVEIRA, L. B.; ALMEIDA NETO, J. A.; OLIVEIRA, F. B. S. Relação energética e emissão de GEE do biodiesel de pinhão manso: análise sob uma perspectiva dinâmica. Revista de Produção e Desenvolvimento, v. 1, n. 2, p. 79-89, 2015.

[45] SAFARIK, I.; SAFARIKOVÁ, M. Use of magnetic techniques for isolation of cells. Journal of Chromatography B, v.722, p.33-35, 1999.

[46] SHIRSATH, S. E.; TOKSHA, B. G.; KADAM, R. H.; PATANGE, S. M.; MANE, D. R.; JANGAM, G. S.; GHASEMI, A. Doping effect of $\mathrm{Mn} 2+$ on the magnetic behavior in $\mathrm{Ni}-\mathrm{Zn}$ ferrite nanoparticles prepared by sol-gel auto-combustion. Journal of Physics and Chemistry of Solids, v. 71, p.1669-1675, 2010.

[47] SILVERSTEIN, R. M.; WEBSTER, F. X.; KIEMLE, D. J. Identificação Espectrométrica de Compostos Orgânicos. 7a Ed. Tradução de Ricardo Bicca de Alencastro, Rio de Janeiro: LTC; 2012.

[48] SOARES, I. P.; REZENDE, T. F.; SILVA, R. C.; CASTRO, E. V. R.; FORTE, I. C. P. Multivariate calibration by variable selection for blends of raw soybean oil/biodiesel from different sources using Fourier Transform Infrared spectroscopy (FTIR) spectra data. Energy Fuels, v. 22, p.2079-2083, 2008.

[49] SUAREZ, P.; MENEGHETTI, S. Transformation of triglycerides into fulels, polymers and chemicals: Some applications of catalysis in oleochemistry. Química Nova, v. 30, n. 3, p. 667-676, 2009. 
[50] SUNDUS, F.; FAZAL, M.A.; MASJUKI, H.H. Tribology with biodiesel: A study on enhancing biodiesel stability and its fuel properties. Renewable and Sustainable Energy Reviews, v.70, p. 399-412, 2017.

[51] TANG, Z.-E.; LIM, S.; PANG, Y.-L.; ONG, H.-C.; LEE, K.-T. Synthesis of biomass as heterogeneous catalyst for application in biodiesel production: State of the art and fundamental review. Renewable and Sustainable Energy Reviews, v. 92, p. 235-253, 2018.

[52] TATARCHUK, T.; BOUOUDINA, M.; JUDITH VIJAYA, J.; JOHN KENNEDY, L. Spinel ferrite nanoparticles: synthesis, crystal structure, properties, and perspective applications. Nanophysics, Nanomaterials, Interface Studies, and Applications, Chap. 22, p. 305-325, 2017.

[53] THIRUVENGADARAVI, K. V.; NANDAGOPAL, J.; BASKARALINGAM, P.; SATHYA SELVA BALA, V.; SIVANESAN, S. Acid-catalyzed esterification of karanja (Pongamia pinnata) oil with high free fatty acids for biodiesel production. Fuel, v. 98, p. 1-4, 2012.

[54] TRISTÃO, J. C. Materiais nanoestruturados magnéticos à base de ferro recobertos por carbono: síntese, caracterização e aplicações. 200p. Tese de Doutorado, UFMG, Programa de Pós-Graduação em Química. Belo Horizonte/MG, 2010.

[55] VAZ JR., S. As biorrefinarias como oportunidade de agregar valor à biomassa. Agroenergia em Revista, p. 11$12,2012$. 


\section{Capítulo 26}

\section{Produção de hidrogênio a partir da eletrólise do resíduo de frutas tropicais}

\section{Adriana Carla de Oliveira Lopes \\ Fabiane Caxico de Abreu Galdino}

Resumo: 0 uso de combustíveis fósseis, especialmente petróleo e gás, tem acelerado nos últimos anos, o que resultou na crise energética que se observa a nível global. 0 processo biológico fermentativo é uma forma sustentável de produzir hidrogênio, pois pode utilizar como substrato diversos tipos de resíduos industriais e domésticos ricos em carboidratos, tais como as frutas, minimizando os problemas causados pelo descarte inadequado desse material. Dentro de uma perspectiva de conservação de energia e de aproveitamento de fontes renováveis para a geração de energia, este trabalho pretende contribuir para a identificação de aproveitamento de uma parcela de energia, hoje não utilizada, otimizando a produção de hidrogênio a partir de uma célula de combustível microbiana, a qual constitui um sistema bioeletroquímico que espontaneamente converte um substrato em eletricidade por meio da atividade metabólica de microrganismos. 0 principal nanomaterial eletródico analisado na eletrossíntese foi o Feltro de carbono (FC) incorporado aos nanotubos de carbono (NTC) obtidos comercialmente. Estudos de voltametria cíclica também foram realizados em sistemas de três eletrodos: eletrodo de carbono vítreo como eletrodo de trabalho, eletrodo de platina como eletrodo auxiliar e $\mathrm{Ag} / \mathrm{AgCl} / \mathrm{Cl}$ - como eletrodo de referência. Foi construída uma célula eletroquímica formada de dois compartimentos (anódico e catódico) separados por uma membrana de troca iônica. Antes de iniciar os experimentos de eletrólise, foi feito um planejamento experimental usando a técnica do planejamento fatorial completo para analisar a influência das variáveis selecionadas para este estudo. As variáveis independentes selecionadas foram: Concentração do licor de frutas tropicais em $\% \mathrm{v} / \mathrm{v}$, tipo de eletrodo de trabalho, tempo de eletrólise e $\mathrm{pH}$ do meio eletrolítico. A variável dependente observada foi a concentração em \%v/v do gás hidrogênio obtido nas eletrólises. Após os resultados dos testes foi concluído que os nanotubos de carbono podem ser usados como eletrodo de trabalho apresentando grande êxito no processo de produção do hidrogênio e que o pH do meio eletrolítico exerce forte influência neste processo. 0 presente trabalho foi concluído apresentando uma rota alternativa na produção de uma fonte renovável de energia.

Palavras-Chave: Eletrólise, Frutas Tropicais, Hidrogênio. 


\section{INTRODUÇÃO}

A crescente demanda de energia promove uma busca por tecnologias mais eficientes na geração de energia, economicamente viável e sem gerar impacto ambiental. Com isso, fontes de energias renováveis como eólica, solar, hidráulica e biomassa, se tornam o alvo das pesquisas para geração de energia limpa. Neste contexto, o hidrogênio é apontado como o combustível do futuro, sendo que é o vetor energético de maior potencial de energia, várias rotas para obtenção de hidrogênio estão sendo desenvolvidas, isto inclui eletrólise da água, reforma de hidrocarboneto, gaseificação e separação termoquímica (ROTTAVA, 2016). A reforma de hidrocarboneto é a mais utilizada, sendo obtida de vária fontes como gás natural, etanol, biogás, etc. 0 biogás tem como principal componente o metano, quando aplicado na reforma a vapor do metano, produz gás de síntese com alta razão de $\mathrm{H}_{2} / \mathrm{CO}$, sendo o hidrogênio puro aplicado em célula a combustível. A célula a combustível ou pilha a combustível são células galvânicas que geram corrente elétrica através da energia química dos combustíveis, convertendo o $\mathrm{H}_{2}$ e $\mathrm{O}_{2}$ em água, calor e energia elétrica. 0 desenvolvimento da tecnologia das células promovem uma alta eficiência na geração de energia, sem causar impacto ambiental, comparando com motores a combustão ou motogeradores que utilizam a combustão para gerar energia e com isso emitem poluentes nocivos a atmosfera, as células ganham importância na geração de energia limpa (ROTTAVA, 2016).

O processo biológico fermentativo é uma forma sustentável de produzir hidrogênio, pois pode utilizar como substrato diversos tipos de resíduos industriais e domésticos ricos em carboidratos, minimizando os problemas causados pelo descarte inadequado desse material. Diante disso, a utilização de resíduos agroindustriais na produção biológica de hidrogênio vem sendo investigada (GUO et al., 2015).

Dentro de uma perspectiva de conservação de energia e de aproveitamento de fontes renováveis para a geração de energia, este trabalho pretende produzir biohidrogênio utilizando nanotubos de carbono a partir da fermentação de frutas tropicais.

As frutas tropicais vermelhas são ricas em ácidos tais como o ácido ascórbico (vitamina C) - $\mathrm{C}_{6} \mathrm{H}_{8} \mathrm{O}_{6}$ e o ácido elágico $-\mathrm{C}_{14} \mathrm{H}_{6} \mathrm{O}_{8}$. Estes ácidos possuem um grande potencial para produção de hidrogênio para células combustíveis, pois oferecem alta densidade de energia, não são tóxicos e podem ser manuseados com segurança em soluções aquosas (TEDSREE et al., 2014). Soluções de ácidos podem ser utilizadas para a produção de gás hidrogênio eletroquimicamente empregando eletrodos metálicos sólidos, a energia empregada é relativamente baixa quando comparada a eletrólise da água, ou seja, uma interessante economia, tanto financeira quanto ambiental. (GUO et al., 2015; JUNHUA, 2014; RAHIMNEJAD et al., 2014).

Estudos de resíduos do processamento de polpa de frutas utilizados para a produção de hidrogênio são ainda escassos e essa biomassa pode torna-se uma boa alternativa no desenvolvimento de células combustíveis microbianas. Desta forma, o presente trabalho propõe o uso da biomassa como agente da fermentação das frutas tropicais, acelerando assim os processos enzimáticos existentes no meio eletrolítico através da formação de novos compostos capazes de otimizar a produção de gás hidrogênio por meio da oxidação.

0 processo fermentativa, que foi o ponto de partida para a produção de hidrogênio, ocorre iniciando o processo da glicólise. Esta por sua vez é a via central do catabolismo da glicose, sendo que o piruvato é o produto final desse processo, o qual pode seguir diferentes vias metabólicas: fermentação alcoólica, láctea e respiração no ciclo de Krebs e cadeia respiratória. A glicólise é uma sequência metabólica composta por um conjunto de dez reações catalisadas por enzimas livres no citosol, na qual a glicose é oxidada produzindo duas moléculas de piruvato, duas moléculas de ATP e dois equivalentes reduzidos de $\mathrm{NADH}^{+}$, que serão introduzidos na cadeia respiratória ou na fermentação. A glicólise é uma das principais rotas para geração de ATP nas células e está presente em todos os tipos de tecidos (LEHNINGER, 2014). A fermentação é um termo geral para a degradação anaeróbica de glicose (glicólise anaeróbica) ou outros nutrientes orgânicos para obtenção de energia, conservada como ATP (LEHNINGER, 2014).

Neste trabalho os nanotubos de carbono foram usados como eletrodos de trabalho na eletrossíntese do gás hidrogênio. Os nanotubos de carbono vem sendo alvo de estudos dos cientistas, pois representa uma grande revolução graças às suas dimensões, leveza e às suas extraordinárias propriedades elétricas, mecânicas e térmicas que superam as de qualquer material até então conhecido (GOMES, 2010).

Para estudar a influência das principais variáveis de processo de produção do hidrogênio e também otimizar o rendimento desta produção, foi realizado um planejamento fatorial de quatro variáveis, as quais foram concentração de licor de frutas (\% v/v), tipo de eletrodo de trabalho, tempo de eletrólise e pH do meio eletrolítico. 


\section{EXPERIMENTAL}

Os resíduos de frutas tropicais de agroindústrias (figura 1) contendo $100 \mathrm{~g}$ de morango, $100 \mathrm{~g}$ de acerola e $100 \mathrm{~g}$ de pitanga, na proporção de 1:2 em volume (frutas tropicais/água), foi submetida a um processo de fermentação alcoólica (Figura 2) durante nove dias. Durante o processo de fermentação foram realizadas medidas de $\mathrm{pH}$ e condutividade elétrica, a tabela 1 apresenta tais medidas. A partir do sexto dia de fermentação foi observado que os valores de tais medidas foram diminuindo até que se mantiveram constantes com o tempo indicando a presença de etanol, principal produto da fermentação alcoólica. Sendo assim, a fermentação foi finalizada visto que a presença de etanol não é o interesse do presente trabalho. Então, após esta observação, pôde-se concluir que a fermentação deve ser interrompida após cinco dias de início da mesma, pois após este tempo a condutividade decai indicando a formação do etanol o qual possui baixa condutividade elétrica. A condutividade elétrica na amostra de frutas fermentadas atinge seu valor máximo no quinto dia de fermentação, o que indica que nesta fase a amostra está rica em espécies $\mathrm{H}^{+}$produzidas pela oxidação dos compostos piruvato e NADH produzidos durante o processo de glicólise, além de outras espécies ácidas tais como o ácido ascórpico encontrado nas frutas tropicais utilizadas.

Após a interrupção do processo fermentativo, a amostra foi filtrada, se transformando em um licor de frutas, e congelada para então ser submetida aos estudos eletroquímicos.

Figura 1 - Resíduo de frutas tropicais utilizado no processo de fermentação anaeróbia.

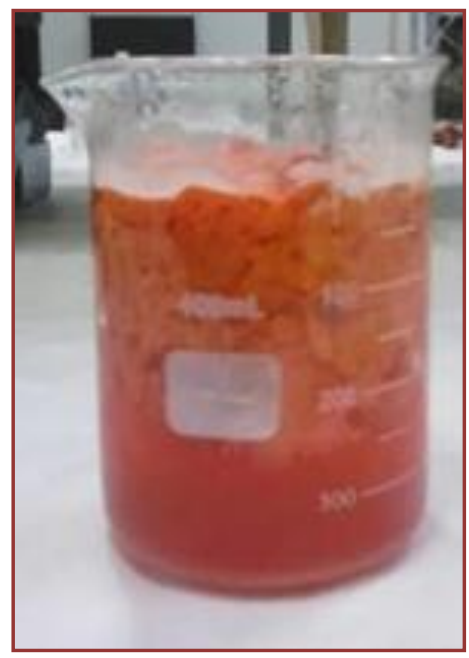

Fonte: AUTORA, 2018.

Figura 2 - Fermentação anaeróbicdo resíduo de frutas tropicais.

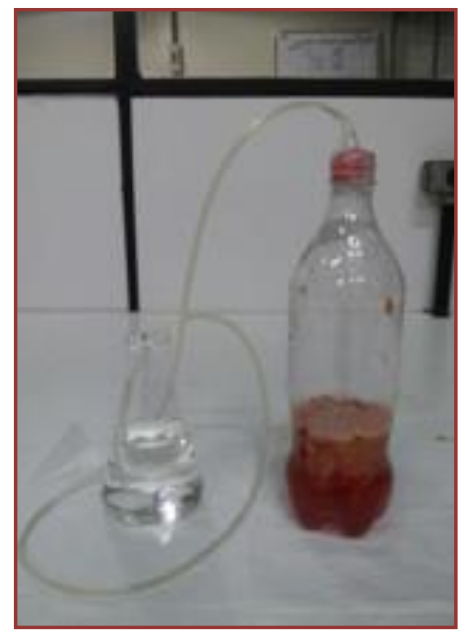

Fonte: AUTORA, 2018. 
Tabela 1 - Medidas de pH e condutividade durante o processo de fermentação anaeróbica das frutas.

\begin{tabular}{|c|c|c|}
\hline Tempo & $\mathbf{p H}$ & Condutividade $(\boldsymbol{\mu S} / \mathbf{c m})$ \\
\hline 0 & 3,2 & 649,2 \\
\hline $24 \mathrm{~h}$ & 3,0 & 692,7 \\
\hline $48 \mathrm{~h}$ & 3,15 & 700,1 \\
\hline $72 \mathrm{~h}$ & 3,14 & 1397 \\
\hline $120 \mathrm{~h}(5$ dias $)$ & 3,15 & 1401 \\
\hline 6 dias & 3,06 & 1378 \\
\hline 7 dias & 3,1 & 1361 \\
\hline 8 dias & 3,1 & 1360 \\
\hline 9 dias & 3,1 & 1360 \\
\hline \multicolumn{3}{|c|}{ Fonte: AUTORA, 2018. } \\
\hline
\end{tabular}

Antes de submeter o licor aos processos de eletrólises, foram realizados estudos de voltamentria ciclíca. Estes estudos foram realizados em sistemas de três eletrodos: eletrodo de carbono vítreo como eletrodo de trabalho, eletrodo de platina como eletrodo auxiliar e $\mathrm{Ag} / \mathrm{AgCl} / \mathrm{Cl}$ - como eletrodo de referência.

As medidas voltamétricas foram realizadas com o auxílio de um potenciostato galvanostato Autolab PGSTAT 302 (Eco Chemic, Utrecht, Holanda) acoplado a um microcomputador dotado de uma interface GPES para controle de potencial, aquisição e tratamento de dados. A partir dos picos obtidos nos voltamogramas iniciais, fixou-se um potencial ótimo para a realização das eletrólises, variando, então, as concentrações da amostra. Foram realizadas eletrólises com diferentes eletrólitos de suporte, fornecendo ao meio diferentes $\mathrm{pH}$. Tais eletrólitos foram: cloreto de potássio $(\mathrm{KCl})$ em ácido clorídrico $(\mathrm{HCl})-\mathrm{pH}=$ 2,5; Acetato de sódio $\left(\mathrm{CH}_{3} \mathrm{COONa}\right)$ em ácido acético $\left(\mathrm{CH}_{3} \mathrm{COOH}\right)-\mathrm{pH}=4,5$ e fosfato de sódio monobásico $\left(\mathrm{NaH}_{2} \mathrm{PO}_{4}\right)$ em ácido fosfórico $\left(\mathrm{H}_{3} \mathrm{PO}_{4}\right)-\mathrm{pH}=7$.

Os testes de voltametria cíclica comprovaram a passagem de corrente elétrica no circuito e que possui grupos funcionais em moléculas capazes de sofrer processos redox. Após os estudos voltamétricos iniciais, foram realizadas as primeiras eletrólises com eletrodo de feltro de carbono como eletrodo de trabalho, eletrodo de platina como eletrodo auxiliar e $\mathrm{Ag} / \mathrm{AgCl} / \mathrm{Cl}^{-}$como eletrodo de referência.

A área do eletrodo utilizado foi de $1,53 \mathrm{~cm}^{2}$. Os gases foram coletados nas buretas de gás e seus volumes foram medidos diretamente e corrigidos considerando-se a temperatura e a contribuição da pressão parcial da água. Estes valores foram usados para calcular a eficiência do sistema eletrolítico.

Visando uma otimização na produção de corrente e transferência de elétrons, o eletrodo de feltro de carbono (FC) sofreu uma modificação através da incorporação com nanotubos de carbono (NTC). Desta forma, foram realizadas eletrólises com o eletrodo de feltro de carbono modificado.

A célula eletrolítica foi fabricada por um vidreiro, em forma de $U$, acoplada a duas buretas e dois funis de decantação, com duas passagens para a saída dos gases produzidos, conforme figura 3. A capacidade total da célula é de $85 \mathrm{~mL}$, porém o volume do eletrólito usado foi de $50 \mathrm{~mL}$, sendo este o licor fermentado das frutas tropicais em diferentes concentrações, diluídas em soluções tampão de KCl, acetato e fosfato para avaliação da eficiência de produção em diferentes faixas de pH.

Figura 3: Sistema para a produção do gás hidrogênio via eletrólise.

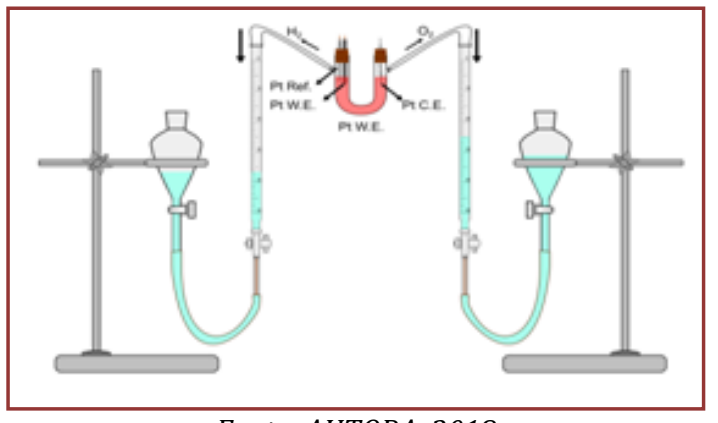

Fonte: AUTORA, 2018. 
As quantidades em volume de gás hidrogênio produzido foram calculadas pelas cargas das eletrólisese realizadas. Para se certificar que o gás produzido era realmente o hidrogênio, amostras do licor de frutas após as eletrólises foram submetidas a análises de cromatografia gasosa.

A concentração $\left(\mathrm{R}_{\%}\right)$ do gás hidrogênio em $\% \mathrm{v} / \mathrm{v}$ foi calculada em relação à quantidade em volume de hidrogênio produzida durante a eletrólise, conforme o valor da carga obtido, e a quantidade total em volume de biogás produzida, como mostra a equação 1:

$$
R_{\%}=\frac{V_{H 2}}{V_{T}} \times 100
$$

Onde:

$\mathrm{V}_{\mathrm{H} 2}$ é a quantidade de hidrogênio produzida durante a eletrólise;

$\mathrm{V}_{\mathrm{T}}$ é a a quantidade total de biogás produzida, obtida pela visualização do deslocamento de água contida nas buretas acopladas ao sistema. (1)

O cálculo do volume de hidrogênio, na CNTP a partir da redução de H+ no catodo, ocorre com:

$$
2 H^{+}+2 e^{-} \rightarrow=H_{2}
$$

Como um mol de $\mathrm{H}_{2}$ gasoso corresponde, nas condições normais de temperatura e pressão - CNTP, a um volume de 22,4 L e, se um mol de H2 é produzido pela carga de 2n x 96500 C, então o volume V desprendido por uma carga q é dado pela equação 2 abaixo:

$$
V_{(2)} \times \frac{22,4}{96500 \times 2 n}
$$

Onde:

q é a carga obtida através do processo de eletrólise;

n corresponde a 1 mol de elétrons;

22,4 L é o volume molar do gás na CNTP;

96500 C é a carga elétrica relativa a 1 mol de elétrons.

Para determinação das condições experimentais que maximizassem a produção de hidrogênio, foi realizado um planejamento experimental fatorial saturado com 2 níveis e 4 variáveis do processo da eletrólise. As variáveis estudadas nesta etapa foram: concentração do licor de frutas tropicais (\% em volume), tipo de eletrodo de trabalho, tempo de eletrólise e pH do meio eletrolítico (solução tampão de $\mathrm{KCl}, \mathrm{pH}=2$ e solução tampão fosfato, $\mathrm{pH}=7$ ). 0 intervalo de estudo das variáveis é apresentado na tabela 2. 
Tabela 2 - Intervalo de estudo das variáveis: Produção de Hidrogênio via eletrólise.

\begin{tabular}{|l|c|}
\multicolumn{1}{c|}{ Variável } & Intervalo \\
\hline Concentração do licor de frutas vermelhas (\%v/v) & $20-50$ \\
\hline Tipo de eletrodo de trabalho & FC - FC+CNT \\
\hline Tempo de eletrólise (h) & $0,5-2$ \\
\hline pH do meio eletrolítico & $2-7$ \\
\hline
\end{tabular}

Fonte: AUTORA, 2018.

\section{RESULTADOS E DISCUSSÕES}

Os estudos eletroquímicos do licor de frutas tropicais em concentração de $50 \%$ v/v (rico em espécies H+ produzidas no processo de glicólise durante a fermentação das frutas) foram realizados em tampões $\mathrm{KCl}$ $0,2 \mathrm{~mol} \mathrm{~L}-1, \mathrm{pH}=2$, acetato $0,2 \mathrm{~mol} \mathrm{~L}^{-1}, \mathrm{pH}=4,5$ e fosfato $0,2 \mathrm{~mol} \mathrm{~L}^{-1}, \mathrm{pH} \mathrm{7,0} \mathrm{em} \mathrm{um} \mathrm{eletrodo} \mathrm{de} \mathrm{carbono}$ vítreo $(\mathrm{CV})$ estático.

Os voltamogramas cíclicos apresentaram uma única onda anódica em Epa +0,9 V (Figura 4), de natureza irreversível. Além da ausência de onda catódica referente à redução do produto da oxidação das espécies presentes no licor de frutas tropicais, o deslocamento do potencial de pico anódico para valores mais positivos em função da velocidade de varredura corrobora a irreversibilidade do sistema.

Figura 4: Voltamogramas cíclicos antes e após eletrólise com eletrodo de Feltro de Carbono a 0,1 V/s e 0,9 V.

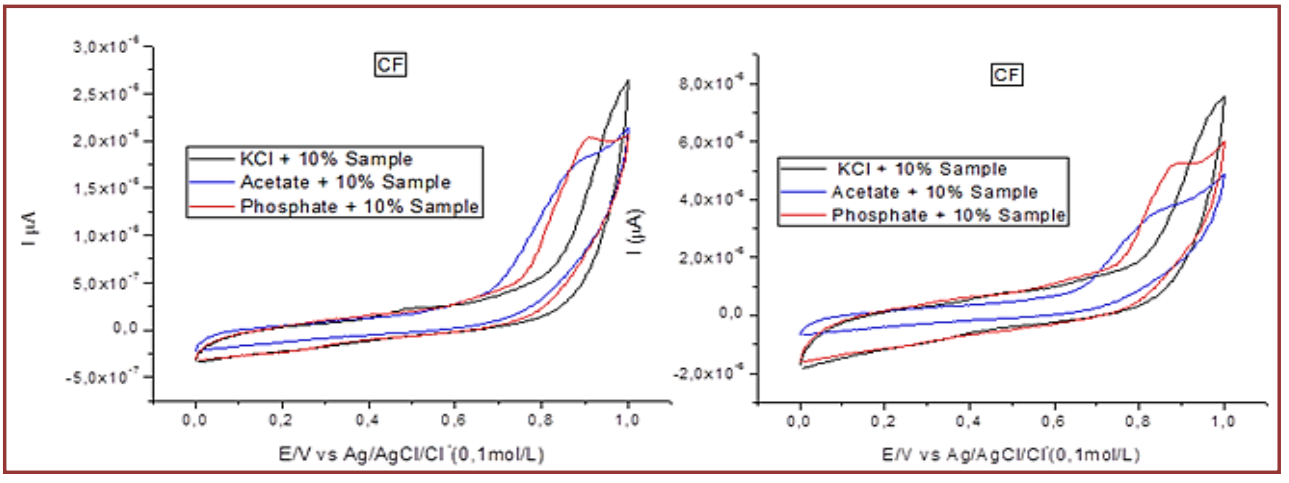

Fonte: AUTORA, 2018

O registro de duas ondas anódicas nos voltamogramas após a eletrólise utilizando FC+CNT (figura 5) indica a oxidação de espécies ácidas como moléculas de piruvato, de NADH e do ácido ascórbico presentes nas frutas. 0 surgimento de uma segunda onda anódica reversível, evidencia a otimização da transferência de elétrons ocorrida pela presença dos nanotubos de carbono no eletrodo de trabalho.

Figura 5: Voltamogramas cíclicos antes e após eletrólise com eletrodo de Feltro de Carbono modificado com Nanotubos de Carbono a $0,1 \mathrm{~V} / \mathrm{s}$ e $0,9 \mathrm{~V}$.

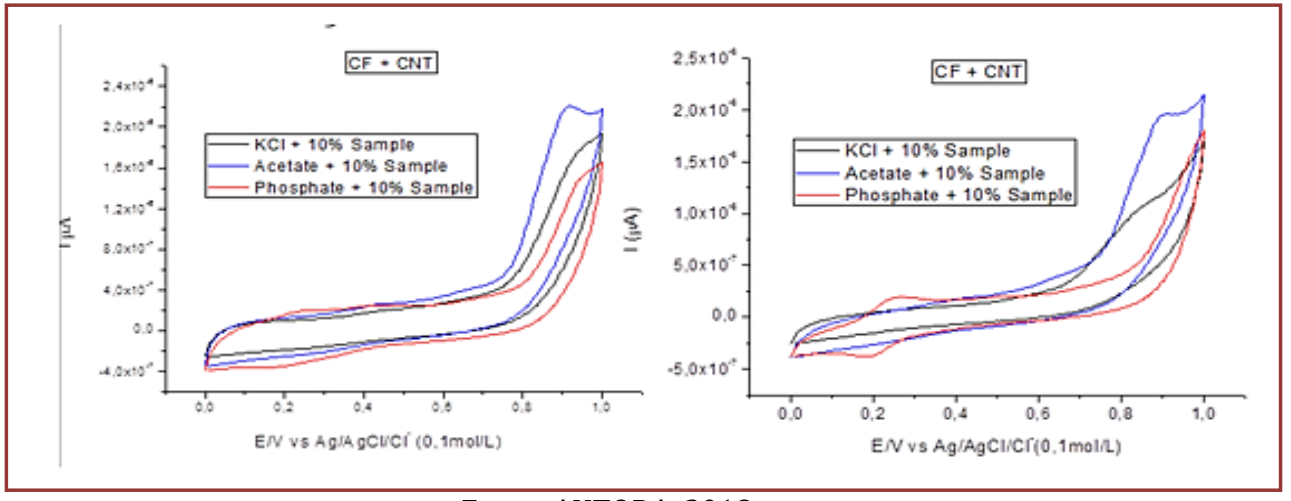

Fonte: AUTORA, 2018. 
A Tabela 3 apresenta os resultados do planejamento fatorial $2^{4}$, nela estão registradas as respostas observadas (rendimento do gás hidrogênio para cada eletrólise) em todas as dezesseis possíveis combinações dos níveis escolhidos: concentração do licor de células em \%v/v (20 e 50 \%), Tipo de eletrodo de trabalho (FC e FC+CNT), Tempo de eletrólise em h $(0,5$ e 2 h) e pH do meio eletrolítico (2 e 7). Todos os ensaios foram feitos em duplicada produzindo trinta e duas respostas no total, às respostas, rendimento do gás hidrogênio, estão apresentadas na tabela abaixo.

Tabela 3 - Resultados de um planejamento fatorial $2^{4}$ para estudar o efeito de cada fator selecionado sobre o rendimento de gás hidrogênio obtido.

\begin{tabular}{|c|c|c|c|c|c|c|c|}
\hline Ensaio & $\begin{array}{c}\text { Conc. do licor } \\
(\% v / v)\end{array}$ & $\begin{array}{l}\text { Tipo de } \\
\text { eletrodo de } \\
\text { trabalho }\end{array}$ & $\begin{array}{l}\text { Tempo de } \\
\text { eletrólise } \\
\text { (h) }\end{array}$ & $\begin{array}{l}\text { pH do meio } \\
\text { eletrolítico }\end{array}$ & \multicolumn{2}{|c|}{$\begin{array}{l}\text { Rendimento do gás } \\
\text { hidrogênio (\%) }\end{array}$} & Média \\
\hline 1 & 20 & $\mathrm{FC}$ & 0,5 & 2 & 35,72 & 36,00 & 35,86 \\
\hline 2 & 50 & $\mathrm{FC}$ & 0,5 & 2 & 43,23 & 41,20 & 42,21 \\
\hline 3 & 20 & $\mathrm{FC}+\mathrm{CNT}$ & 0,5 & 2 & 65,56 & 64,93 & 65,24 \\
\hline 4 & 50 & $\mathrm{FC}+\mathrm{CNT}$ & 0,5 & 2 & 82,13 & 82,45 & 82,29 \\
\hline 5 & 20 & $\mathrm{FC}$ & 2 & 2 & 36,34 & 35,87 & 36,10 \\
\hline 6 & 50 & $\mathrm{FC}$ & 2 & 2 & 46,45 & 44,89 & 45,67 \\
\hline 7 & 20 & $\mathrm{FC}+\mathrm{CNT}$ & 2 & 2 & 87,68 & 87,59 & 87,63 \\
\hline 8 & 50 & $\mathrm{FC}+\mathrm{CNT}$ & 2 & 2 & 88,21 & 88,73 & 88,47 \\
\hline 9 & 20 & $\mathrm{FC}$ & 0,5 & 7 & 78,54 & 78,12 & 78,33 \\
\hline 10 & 50 & $\mathrm{FC}$ & 0,5 & 7 & 89,67 & 90,00 & 90,83 \\
\hline 11 & 20 & $\mathrm{FC}+\mathrm{CNT}$ & 0,5 & 7 & 75,65 & 76,43 & 76,04 \\
\hline 12 & 50 & $\mathrm{FC}+\mathrm{CNT}$ & 0,5 & 7 & 86,51 & 85,94 & 86,22 \\
\hline 13 & 20 & $\mathrm{FC}$ & 2 & 7 & 57,89 & 57,61 & 57,75 \\
\hline 14 & 50 & $\mathrm{FC}$ & 2 & 7 & 89,55 & 88,95 & 89,25 \\
\hline 15 & 20 & $\mathrm{FC}+\mathrm{CNT}$ & 2 & 7 & 90,45 & 91,32 & 90,88 \\
\hline 16 & 50 & $\mathrm{FC}+\mathrm{CNT}$ & 2 & 7 & 94,52 & 93,97 & 94,24 \\
\hline
\end{tabular}

Fonte: AUTORA, 2018.

O diagrama de pareto (figura 6) apresenta graficamente os efeitos das variáveis estudadas assim como seus efeitos da interação das mesmas.

Figura 6 - Diagrama de pareto para os efeitos das variáveis.

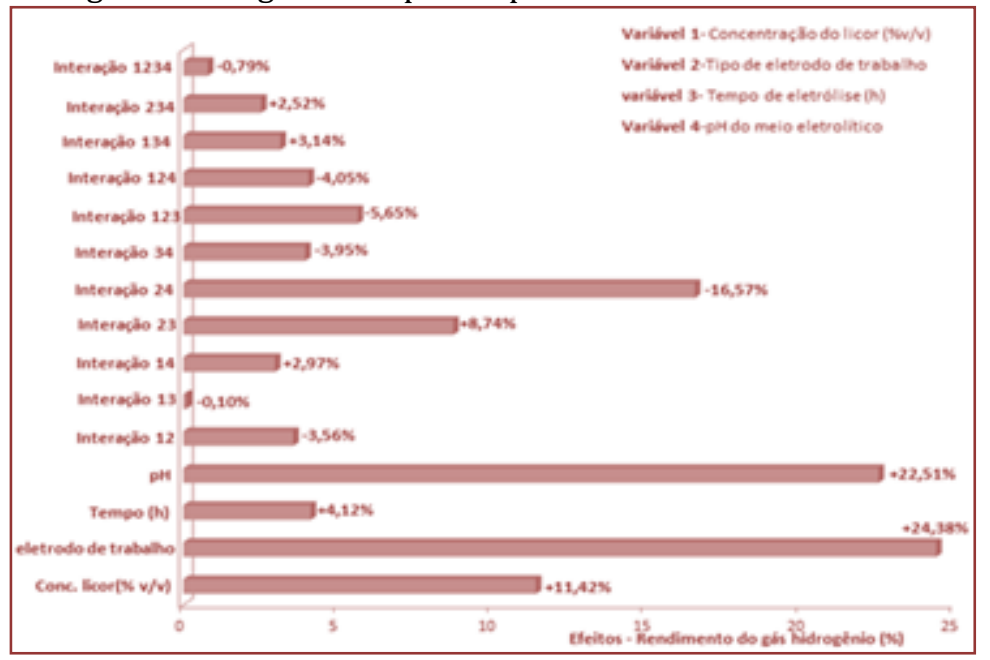

Fonte: AUTORA, 2018.

Analisando o diagrama de pareto pode-se concluir que as variáveis: tipo de eletrodo de trabalho e pH do meio eletrolítico foram as que apresentaram maiores efeitos, assim como interação dessas variáveis recebe maior destaque. Isso se deve ao aumento na transferência de elétrons do meio provocada pelos nanotubos de carbono. $\mathrm{O}$ pH neutro do meio eletrolítico também proporcionou excelentes condições para o aumento do rendimento do gás hidrogênio. 


\section{CONCLUSÕES}

A técnica do planejamento experimental utilizada no presente trabalho aprimorou a metodologia analítica e possibilitou a melhora das análises dos resultados após o término dos ensaios realizados. A metodologia do planejamento fatorial foi uma ferramenta fundamental no estudo estatístico, fornecendo informações seguras sobre o processo estudado.

Após o estudo estatístico, utilizando a técnica do planejamento fatorial completo, percebe-se que os efeitos principais 2, 4 e 1 que correspondem ao tipo de eletrodo de trabalho, $\mathrm{pH}$ do meio eletrolítico, e a concentração do licor de frutas, respectivamente, assim como as interações dos dois fatores 24 (interação entre o tipo de eletrodo de trabalho e pH do meio eletrolítico) e 23 (interação entre tipo de eletrodo de trabalho e o tempo de eletrólise), apresentaram efeitos significativos em relação a resposta desejada que foi o rendimento do gás hidrogênio.

Conforme a análise dos resultados obtidos após a realização dos testes em bancada, pode-se concluir que o eletrodo de trabalho nanotubo de carbono aumentou de forma bastante significativa o rendimento do gás hidrogênio, comprovando suas excelentes propriedades eletroquímicas apresentadas na literatura.

\section{AGRADECIMENTOS}

A todos do laboratório de eletroquímica e Microssistemas de análise - LEMAN do Instituto de Química e Biotecnologia- IQB da UFAL;

A CAPES pelo apoio financeiro.

\section{REFERÊNCIAS}

[1] Gomes, a. H.a., Comportamento eletroquímico de nanotubos de carbon suportados sobre diferentes substrados. Dissertação (Mestrado em Física Aplicada) - Universidade Federal de Viçosa, Viçosa, 2010.

[2] Guo, w.l., li, l., li,ll.., tian, s., liu, s.l., wu, y.p. Hydrogen production via

[3] electrolysis of aqueous formic acid solutions. International Journal of Hydrogen Energy, v. 36, p. 9415-9419, 2015.

[4] Gupta, g., sikarwar, b., vasudevan, v., boopathi, m., kumar, o., singh, b.; vijayaraghavan, r. Microbial fuel cell technology: a review on electricity generation. Journal of cell and tissue research, 11(1): 2631-2654, 2014.

[5] Izadi p., rahimnejad $\mathrm{m}$., Simultaneous electricity generation and sulfide removal via a dual chamber microbial fuel cell Biofuel Research J., 1, pp. 34-38, 2013.

[6] Junhua j.; kucernak, A. Nanostructured platinum as an electrocatalyst for the electrooxidation of formic acid. Journal of Electroanalytical Chemistry, v. 520, p. 64-70, 2014.

[7] Lehniger, A. L. Princípios de bioquímica. 6a edição. São Paulo: Edgard Bluncher, 2014.

[8] Medeiros, e. F., Hidrogênio energético no Brasil: subsídios para políticas de competitividade Centro de Gestão e Estudos Energéticos (CGEE), Ministério de Ciência, Tecnologia e Inovação, CGEE: Brasília, 2015.

[9] PARK, I.h., M. Christy, P. Kim, K.S. Nahma Enhanced electrical contact of microbes using Fe3 04/CNT nanocomposite anode in mediator-less microbial fuel cell Biosens Bioelectron., 58, pp. 75-80, 2014.

[10] Rabaey, k.; verstraete, W. Microbial fuel cells: novel biotechnology for energy generation. Trends in Biotechnology, 23(6): 291-298, 2015.

[11] Rahimnejad m., a. Ghoreyshi, G. Najafpour, H. Younesi, M. Shakeri A novel microbial fuel cell stack for continuous production of clean energy Int. J. Hydrogen Energy, 37, pp. 5992-6000, 2014.

[12] Reddy, l.v., kumar, s.p. e Wee, Y-J. Microbial fuel cells (MFCs) - a novel source of energy for new millennium in Méndez-Vilas, A. (Ed.) Current Research, Technology and Education Toipcs in Applied Microbiology and Microbial Biotechnology, p. 956-964, 2013.

[13] Rottava, w., Estimativa de produção de hidrogênio para aplicação em célula a combustível - Estudo de caso: Granja Colombari. Dissertação (Mestrado em Energias renováveis) - Universidade Federal do Paraná, Palotina, 2013.

[14] Tardast, a., m. Rahimnejad, G. Najafpour, A.A. Ghoreyshi, H. Zare Fabrication and operation of a novel membrane-less microbial fuel cell as a bioelectricity generator Int. J. Environ. Eng., 3, pp. 1-5, 2015. 
[15] Tedsree, k.; li,t.; jones, s.; chan, c.w.a.; yu, k. M.k.; bagot, p.a.j.; marquis, e.a.; smith, g.d.w.; tsang, s .c.e. Hydrogen production from formic acid decomposition at room temperature using a Ag-Pd core-shell nanocatalyst. Nature Nanotechonology, v. 6, p. $302-307,2014$.

[16] Wang, c.; chang, c.; chu, c.; lee, d.; chang, b.; LIAO, C. Using filtrate of waste biosolids to effectively produce bio-hydrogen by anaerobic fermentation. Water Research, v. 37, p. 2789-2793, 2014.

[17] Zhou, m., j. Yang, h. Wang, t. Jin, d.j. Hassett, T. Gu Bioelectrochemistry of microbial fuel cells and their potential applications in bioenergy Bioenergy Research: Adv. Appl., pp. 131-153, 2014. 


\section{Capítulo 27}

\section{Análise de risco associada aos desafios da exploração do gás natural liquefeito em ambiente offshore por plantas FLNG.}

\section{Kaique Moreira Matos Magalhães \\ Geraldo José Belmonte dos Santos \\ Armando Sá Ribeiro Junior}

Resumo: 0 gás natural liquefeito (GNL) têm atraído grande atenção das matrizes energéticas em função das crescentes preocupações com a poluição ambiental, produzida por combustíveis fósseis clássicos e usinas nucleares. No entanto, a maioria das reservas de gás estão localizadas em áreas offshore, dificultando assim a sua exploração, principalmente em função dos problemas ambientais e da sua segurança operacional. Portanto, o desenvolvimento da tecnologia de GNL embarcado (FLNG) está se tornando cada vez mais importante. Embora as tecnologias FLNG tenham vantagens sobre as tecnologias convencionais de GNL, ainda existem vários obstáculos. Para superar os desafios, os projetos modulares relacionados às etapas principais e típicas do processo FLNG devem ser aprimorados. Neste artigo são descritos os principais desafios da tecnologia empregada durante a exploração do GNL.

Palavras-chave: Gás natural liquefeito; FLNG; Análise de risco; Estruturas offshore. 


\section{INTRODUÇÃO}

A busca de novos poços de exploração do petróleo tem gerado pesquisas e desenvolvimento tecnológico com o aporte de muitos recursos financeiros. Neste contexto, a descoberta de petróleo na camada de présal foi sem dúvida um marco. A exploração do óleo e gás em águas profundas, no entanto, exigirá um grande avanço tecnológico para ser viabilizado. Sendo assim, faz-se necessário buscar alternativas para explorar todo o potencial desta riqueza, mitigando os efeitos deletérios sobre o meio ambiente oriundo de tal exploração.

Também, em função das possíveis descobertas de gás natural não convencional (shale gas) em bacias terrestres no Brasil, ganha força o uso do gás natural como uma fonte de energia alternativa ou complementar ao petróleo. 0 gás natural é uma energia carente de enxofre e a sua combustão é completa, liberando como produtos da mesma apenas o dióxido de carbono $\left(\mathrm{CO}_{2}\right)$ e vapor de água, sendo dois componentes não tóxicos (o dióxido de carbono é considerado ligeiramente tóxico), o que faz do gás natural uma energia ecológica e pouco poluente se comparado à outros combustíveis fósseis. Outra vantagem é a facilidade de adaptação dos equipamentos que utilizam outro tipo de combustível fóssil para o uso de gás natural.

A produção de gás natural em poços offshore é atualmente muito limitada devido aos altos custos de montagem de sistema de tubulações para escoamento do produto em longas distâncias.

0 interesse crescente na comercialização de gás natural, juntamente com as previsões da indústria indicando que a demanda mundial por gás natural aumentará, tem crescido significativamente o interesse no desenvolvimento de plantas de produção de gás natural liquefeito (GNL) ou GNL embarcado (FLNG). A produção offshore de GNL é uma tecnologia emergente e, portanto, há uma falta de experiência em serviço e a necessidade de uma estrutura regulatória sólida para os requisitos de segurança (Patel et al. (2011)).

Desde que o primeiro terminal comercial de GNL foi construído em Arzew, na Argélia, em 1964, a produção de GNL expandiu-se continuamente. De acordo com relatórios publicados, o consumo global de GNL aumentou rapidamente. Nos $E U A$, antes de 2005, seu consumo aumentou 6,4\% ao ano e, entre 2005 e 2010 , aumentou $12,6 \%$ ao ano, enquanto, mesmo após 2010 , espera-se um aumento anual de $8,5 \%$. Na Europa, especialmente em países como Inglaterra, França, Itália e Espanha, o consumo de GNL dobrou depois de 2010. Na Ásia, o consumo de GNL de países importadores de GNL convencionais como Coréia, Japão e Taiwan aumentou rapidamente. Nos últimos 40 anos, o negócio de GNL cresceu rapidamente e é responsável por mais de $29 \%$ do comércio global de gás. (Kumar et al. (2011)).

0 interesse da indústria do petróleo e gás no processo $F L N G$ pode ser evidenciado pelo projeto desenvolvido por um consórcio de empresas liderado pela Shell BP. Para uma análise da dimensão do projeto, a planta de refrigeração terá uma capacidade de armazenamento de GNL com um volume equivalente a 175 piscinas olímpicas e o sistema de refrigeração irá bombear cerca de 50 milhões de litros de água do oceano por hora para auxiliar a liquefação do gás natural. Sua operação teve início em 2017 (Shell (2012)).

Em todo o mundo existem muitas reservas de gás natural offshore, isoladas de infraestrutura terrestre e muitas vezes situado em águas muito profundas. Consequentemente, o transporte econômico de gás natural entre as plantas de liquefação e regaseificação são sempre desafiadoras. Isto é de grande preocupação para a indústria naval. Já foram relatados 158 acidentes com transportadores de GNL desde o seu início (Vanem et al. (2008).

No Brasil, houve uma iniciativa da Petrobrás na criação de um consórcio para exploração de gás natural na camada de pré-sal utilizando o processo FLNG. As informações disponíveis mostram que, após discussões internas dos técnicos da empresa, o processo foi interrompido devido à insegurança relativa a pouca confiabilidade que ainda existe sobre a técnica FLNG.

Diante do exposto anteriormente e dada a importância do tema apresentado, serão apresentados nas próximas seções os principais desafios da tecnologia, empregada para exploração do GNL, trazendo uma visão de como esses desafios poderão ser superados.

\section{CADEIA DE FORNECIMENTO DE GNL POR PLANTAS FLNG}

Com o volume reduzido de GN, tornou-se viável a entrega de GNL a mercados distantes. De fato, a forte demanda de gás e a descoberta de grandes reservatórios de gás disponíveis resultaram em maior atenção à liquefação do GN. Entre vários tipos de comércio de GN, a FLNG tem sido um setor de crescimento principal na indústria de GNL desde sua primeira instalação na Gulf Gateway, localizada no Golfo do 
México dos EUA em 2005. No entanto, grande parte das reservas de gás natural estão localizadas em poços offshore, exigindo assim muitos esforços para explorar e monetizar essas reservas com instalações flutuantes, onde é possível realizar a liquefação do GN. Embora as tecnologias FLNG tenham vantagens em relação às tecnologias convencionais de GNL, ainda existem vários processos que precisam ser melhorados, pincipalmente os aspectos relacionados à segurança operacional.

Os diagramas da cadeia de fornecimento para GNL e FLNG são mostrados na

Figura 1, onde a sigla $R V$ refere-se ao vaso de regaseificação e $F R S U$ as unidades de produção e armazenagem flutuantes. Ambas as tecnologias, GNL e $F L N G$, são compostas por quatro processos principais:

(i) Produção de gás e transporte até o terminal de liquefação;

(ii) Liquefação, armazenamento e carregamento em transportadores de GNL;

(iii) Transporte e descarga;

(iv) Armazenamento, regaseificação e distribuição.

Figura 1 - Diagramas da cadeia de fornecimento para GNL e FLNG. Fonte: adaptado de Won et al., (2014).

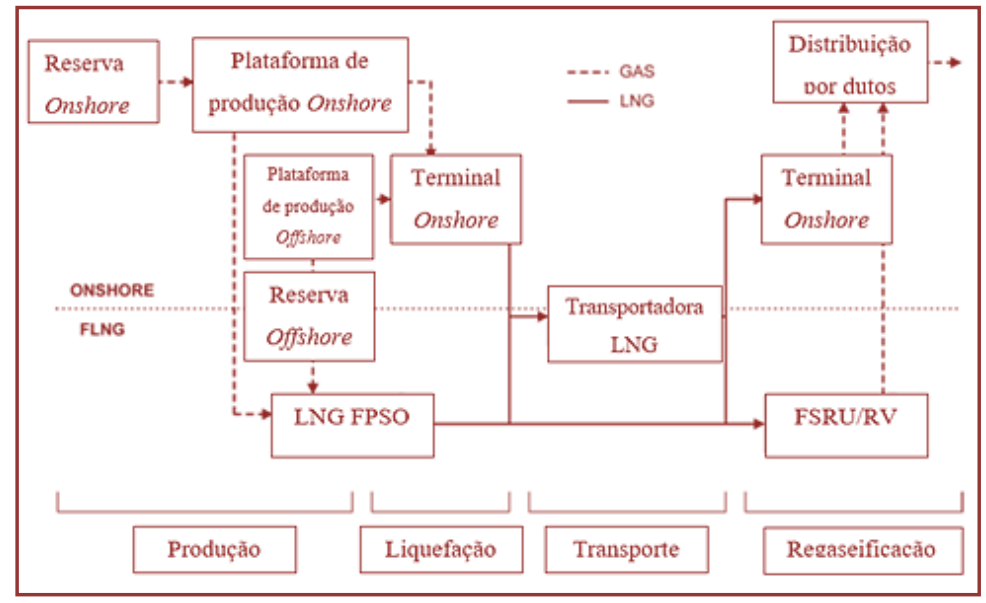

Existem vários pré-requisitos para instalar um terminal de GNL no mar. 0 mais importante é construir uma plataforma apropriada que seja grande o suficiente para acomodar as estruturas relevantes. 0 próximo requisito é um sistema de contenção que ofereça uma área de convés plano. Um aspecto atraente do atual projeto de $F L N G$ são os navios de casco de aço que são simples em projetos para transportadores de GNL e bem adaptados para liquefazer ou regaseificar o GN. Essas embarcações podem mover o GNL facilmente entre os campos sempre que necessário, em comparação com outros tipos de plataformas flutuantes. Para instalar um terminal de GNL no mar, as seguintes partes devem ser construídas (Westwood (2011)):

(i) Produção flutuante;

(ii) Embarcação de armazenamento e transferência (FPSO);

(iii) Barcaça de liquefação e unidade flutuante de armazenamento e regaseificação (FSRU).

Ao contrário dos FPSO's produtores de óleo convencionais, os navios FPSO de GNL contêm instalações de liquefação de GNL a bordo. 0 elemento fixo recebe o gás não tratado por tubulação. Todos os utilitários e instrumentação estão posicionados na plataforma fixa. Os terminais $F L N G$ devem ser operados mesmo em condições climáticas severas. Para garantir uma operação segura e eficaz do terminal. A apresenta um diagrama esquemático, mostrando o sistema flutuante de produção, armazenamento e descarregamento (FPSO). 
Figura 2 - Diagrama esquemático, mostrando o sistema flutuante de produção, armazenamento e descarregamento (FPSO) da cadeia de fornecimento para GNL e FLNG.

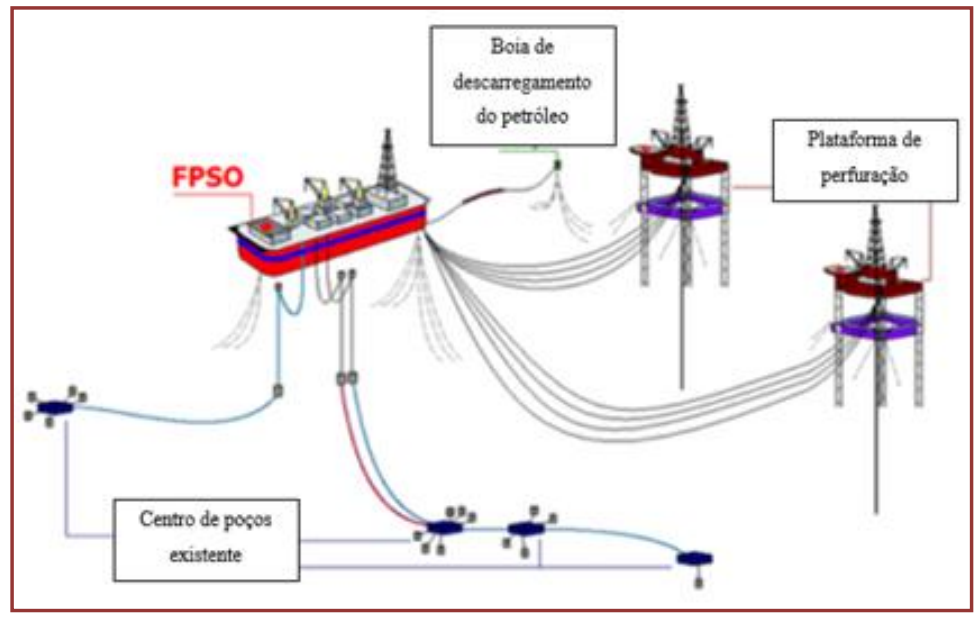

Fonte: adaptado de Won et al., (2014).

O descarregamento de GNL e gás entre dois navios no mar é uma operação desafiadora e difícil em condições climáticas adversas. Equipamentos específicos que fornecem descarregamento seguro e eficiente são, portanto, importantes para os operadores sendo uma das tecnologias não comprovadas na indústria de FLNG. Existem muitos tipos de equipamentos de descarregamento e métodos de descarregamento. Na Figura 3 é apresentado o método de descarregamento do liquido através de mangueiras criogênicas.

Figura 3 - Método de descarregamento do líquido através de mangueiras criogênicas.

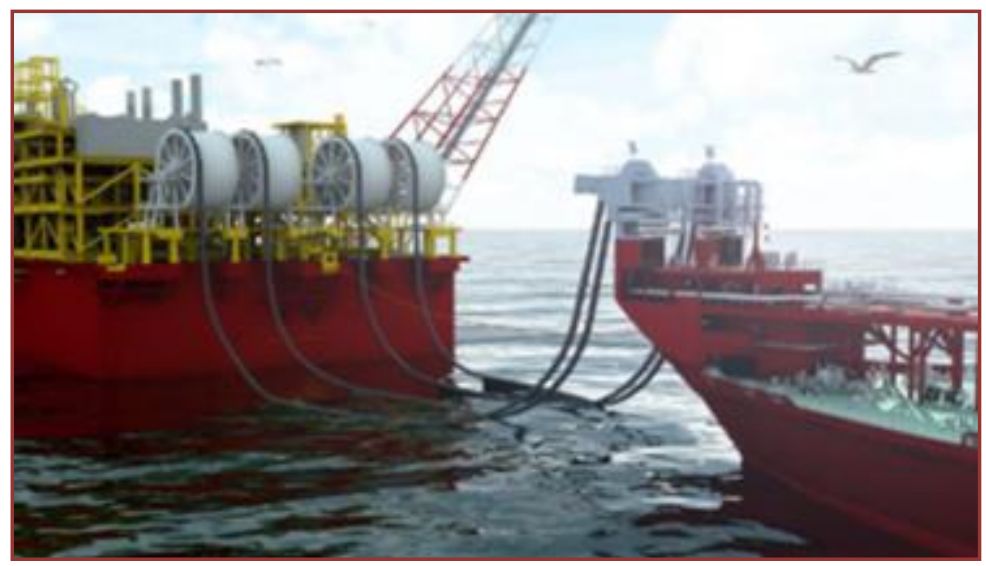

Fonte: (Won et al., 2014)

\section{ANÁLISE DE RISCO EM ESTRUTURAS FLNG}

Paltrinieri, Tugnoli e Cozzani (2015) fizeram um estudo para identificação dos perigos referentes a tecnologia inovadora de regaseificação de GNL, desenvolvendo novas metodologias para análise de risco durante o processo. De acordo com estes autores, a cadeia de fornecimento de gás natural liquefeito pode ser dividida em 5 passos, que são mostrados na 
Figura 4 - Etapas da cadeia de fornecimento de gás natural liquefeito.

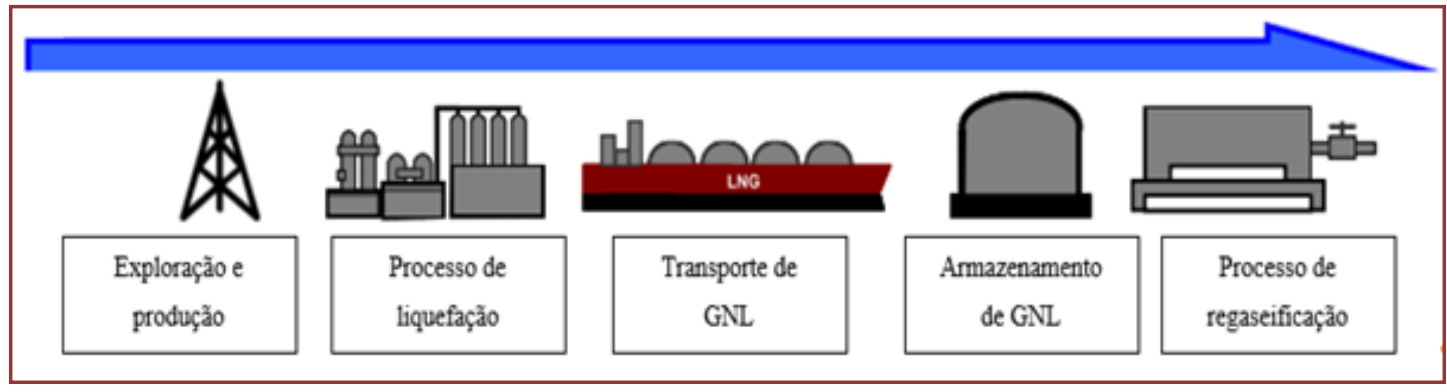

Fonte: (Paltrinieri; Tugnoli; Cozzani, (2015)

Devido à relativa falta de experiência com essa tecnologia, empresas podem encontrar sérios problemas ao tentar identificar os perigos relacionados a tecnologias novas e alternativas, como no setor de GNL. Um exemplo representativo desta questão pode ser identificado no desenvolvimento do aproveitamento de dióxido de carbono $\left(\mathrm{CO}_{2}\right) .0 \mathrm{CO}_{2}$ já é tratado em muitas aplicações industriais. No entanto, a escala de manuseio deve aumentar drasticamente e os riscos que foram parcialmente ignorados, como asfixia e intoxicação, devem agora ser levados em consideração (Paltrinieri, Tugnoli e Cozzani (2015)).

Em uma das análises realizadas pelos autores estabeleceu-se uma visão geral dos principais riscos relacionados ao tipo de equipamento considerado (tanques de armazenagem, compressores, bombas, colunas e tubulações). Para cada categoria de equipamento foram identificados vários tipos de problemas como quebra de casco do navio, vazamento de gás e ruptura catastrófica além do colapso dos vasos. Esta análise introduz todos os cenários de acidentes atípicos importantes que foram identificados para a regaseificação de GNL. Um dos riscos mais impactantes identificado neste estudo é referente aos possíveis danos causados pelo liquido criogênico, por exemplo, durante um vazamento acidental. Este tipo de carga poderá ocasionar a falha de alguns componentes estruturais.

Em um estudo proposto por Patel et al. (2011) na OTC (Offshore Tecnology Conference), definiu-se aspectos relativos à segurança operacional e algumas perspectivas regulatórias para plantas $F L N G$, em função principalmente da crescente procura na comercialização de campos de gás offshore acoplados às previsões da indústria indicando que a demanda mundial de GN aumentará, levando a um interesse significativo no desenvolvimento de plantas de produção de gás natural liquefeito. Foram apresentadas pelos autores algumas questões adicionais a serem avaliadas, em comparação as preocupações da técnica usual de produção de GNL (aplicações terrestres), para a produção em ambiente offshore:

1) Planta de produção de GNL (offshore);

2) Método para manuseio da carga criogênica;

3) Extensão do equipamento de manuseio e produção de gás a bordo;

4) Equipamentos existentes no convés e nos tanques de armazenamento de GNL;

5) Manutenção e inspeção;

6) Multiplicidade de operações e complexidade;

7) Múltiplos produtos para armazenamento e capacidade de armazenamento no interior;

Nos últimos anos, vários proponentes da tecnologia GNL, desenvolvedores e grandes empresas de petróleo, solicitaram fornecer requisitos de classificação para a tecnologia a ser utilizada em uma aplicação offshore de uma instalação de produção de GNL. Ao desenvolver requisitos de classificação para uma nova tecnologia, a $A B S$ (American Bureau of Shipping) adota a seguinte metodologia de avaliação:

a) Desenvolver uma compreensão da concepção;

b) Identificar os novos aspectos do projeto proposto;

c) Identificar os perigos e preocupações de segurança decorrentes da concepção e dos novos recursos específicos;

d) Identificar os requisitos e padrões marinhos e offshore existentes; 
e) Utilizar a análise para identificar as áreas do projeto para as quais não existem atualmente normas marítimas relevantes;

f) Aplicar os princípios e metodologia de risco para identificação de riscos.

Vários conceitos de FLNG propostos até hoje têm vários elementos comuns de perspectivas de tecnologia e aplicação. Todos os conceitos propuseram o uso de várias tecnologias existentes que possuem ampla experiência em aplicações terrestres ou marítimas. 0 processamento de gás, a liquefação e a tecnologia de fracionamento selecionada são baseadas na experiência terrestre. A tecnologia de armazenamento de carga (GNL, GPL e condensado) baseia-se no transporte de gases de petróleo liquefeitos a granel num ambiente marinho, como transportadores de GNL e GPL. A tecnologia para casco, amarração, acomodação, produção submarina, integração de instalações de processo, etc. vem da experiência de FPSO offshore. Considera-se que a nova tecnologia inclui a transferência de carga criogênica em ambiente offshore (Patel et al. (2011).

O desafio para a $F L N G$ é determinar a aplicabilidade e a segurança da tecnologia selecionada para aplicação offshore. Os regimes regulatórios de segurança offshore para a indústria marítima provêm de várias camadas de regulamentação e supervisão, incluindo a Organização Marítima Internacional (OMI) e a jurisdição local. As equipes técnicas desenvolvem e estabelecem requisitos técnicos para a integridade estrutural e mecânica das estruturas marinhas com base em sua própria experiência. Os códigos e padrões da indústria que fornecem requisitos técnicos também podem ser uma base para a integridade estrutural e mecânica de equipamentos ou componentes específicos. A classificação em função da segurança ocorre da maneira apresentada pela Figura 5

Figura 5 - Fluxograma da classificação das etapas para garantia da segurança.

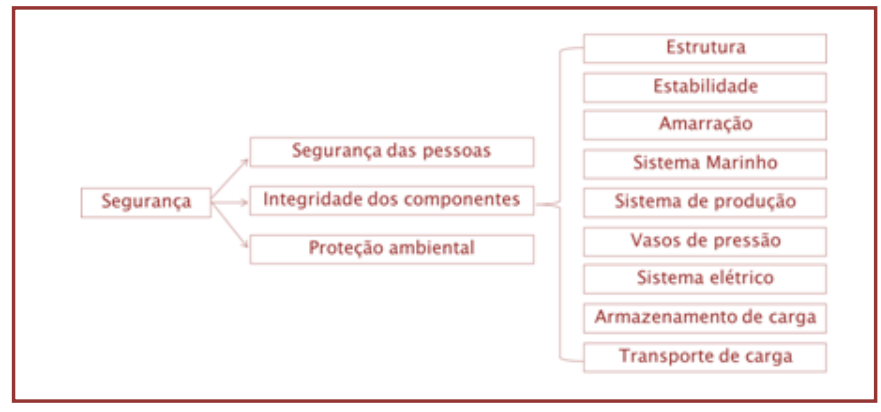

Fonte: Adaptado de Patel et al., (2011).

Um FPSO de GNL, é uma combinação de liquefação, armazenamento e descarga de GNL, foi avaliada pela $A B S$ como uma nova tecnologia, em relação aos novos desafios dos requisitos de segurança, a listagem de identificação dos principais riscos envolvidos foram:

1) Risco de derramamento do líquido criogênico (GNL), incêndio e explosão.

2) Restrições em relação aos equipamentos.

3) Perigo para as pessoas referentes as baixas temperaturas.

4) Rotas de fuga e alojamento para as pessoas envolvidas nos processos.

Segundo Patel et al. (2011) o derramamento de GNL e a dispersão de vapor após a liberação acidental dos tanques de armazenamento tem sido um assunto desafiador. Muitas experiências e teorias foram estabelecidas para modelar tais cenários nas plantas de liquefação de GNL. Os perigos do vapor de GNL incluem o fogo, explosão, toxicidade, corrosão, reatividade e baixa temperatura. Os derramamentos de GNL e a dispersão envolvem os riscos de danos no casco e no convés do navio.

\section{RESULTADOS E DISCUSSÃO}

Pelo fato do FLNG ser uma tecnologia emergente, seu estudo e produção vem sendo rapidamente ampliados em diversos países. Visto que ainda há um déficit em relação à eficiência total de todo o processo empregado nessa exploração, seus riscos são identificados para constatar-se soluções. No desenvolvimento de normas, a grande preocupação para a $A B S$ é a promoção da segurança da vida e do 
meio ambiente. Portanto, o foco principal destas análises é a aplicação segura desta tecnologia em unidades flutuantes offshore e não a otimização do projeto com relação à eficiência.

Verificados os processos, as adversidades preponderantes detectadas pelos autores referem-se às singularidades de cada equipamento utilizado, quebra de casco do navio, vazamento de gás, rupturas dos equipamentos e aos prováveis malefícios gerados pelo líquido criogênico durante um vazamento acidental.

A integridade dos componentes deve ser considerada no projeto, para garantia da segurança global da estrutura. Os principais riscos para este tipo de elemento são referentes à amarração da estrutura, estabilidade dos componentes, armazenamento de carga, vasos de pressão, sistema elétrico e transporte de carga.

Uma das maneiras para prever esses ricos são as análises feitas com modelos reduzidos (protótipos) para simular os efeitos gerados pelas situações identificadas nas análises de riscos. Com este tipo de estudo é possível prever o comportamento dos elementos sob tais condições podendo-se avaliar à garantia da segurança. Portanto, mais recursos deverão ser dispostos para que as empresas ou instituições de pesquisa tenham condições mais adequadas para realização deste tipo de estudo. Atualmente o Grupo de Inovação Tecnológica (GITEC) da UFBA-Universidade Federal da Bahia em cooperação com o Departamento de Tecnologias Marinhas da NTNU - Norwegian University of Science and Technology têm desenvolvido pesquisas que envolvem a avaliação de cargas acidentais em elementos submetidos à vazamentos criogênicos com objetivo de prever o comportamento dos materiais sob tais condições para, enfim, avaliar a integridade desses componentes.

\section{CONCLUSÕES}

Diante das informações apresentadas anteriormente pode-se destacar que a maioria dos riscos, envolvidos no processo de obtenção do GNL, são gerados pela temperatura criogênica que é um fator determinante na integridade tanto operacional como pessoal de todos os envolvidos. Portanto, é de suma importância o estudo do efeito produzido pela temperatura criogênica quando entra em contato com os elementos estruturais não projetados para este fim.

\section{REFERÊNCIAS}

[1] Kumar, s.;kwon, h.;choi, k.;cho, j. H.;lim, w.; moon, i.. Current status and future projections of LNG demand and supplies : A global prospective. Energy Policy, v. 39, n. 7, p. 4097-4104, 2011.

[2] Paltrinieri, n.; tugnoli, a.; cozzani, v. Hazard identification for innovative LNG regasification technologies. Reliability Engineering and System Safety, v. 137, p. 18-28, 2015.

[3] Patel, h. N; rynn p.; wang x.; das b.; pham m. Safety and Regulatory Perspective for Floating LNG plant Offshore (FLNG). Proceedings of OTC Brasil, 2011.

[4] Won, w; lee, s. K.; choi, k.; kwon y. Current trends for the floating liquefied natural gas (FLNG) technologies. Korean Journal of Chemical Engineering, v. 31, n. 5, p. 732-743, 2014.

[5] Abs. Guide for Building and Classing Floating Offshore Liquefied Gas Terminals. Houston: American. Bureau of Shipping, 2015.

[6] Liquefied Natural Gas: Understanding the Basic Facts; DOE NETL, 2005.

[7] LNG Technology. Disponivel em <http://www.airproducts.com/ /media/Files/ PDF/industries/energy-lngbrochure-0408.ashx> Accesso, 3 de maio de 2018.

[8] Kirillov, N. G. Analysis of Modern Natural Gas Liquefaction Technologies. Chem. Pet. Eng. 2004, 40 (7-8), $401-406$

[9] Abegás redação. Nova chance para o FLNG. Disponível em: <http://www.abegas.org.br/Site/?p=48391> . Acesso em: 10 março de 2018.

[10] International energy agency. Key world energy statistics. Disponível em: http://www.enecho.meti.go.jp/statistics/total energy/results.html> Acesso em 12 de maio de 2018.

[11] Vanem, E., Antão, P., Ostvik, I., de Comas, F.D.C., 2008. Analysing the risk of LNG carrier operations. Reliability Engineering \& System Safety 93, 1328-1344.

[12] Shell's Prelude FLNG Project, Browse Basin, Australia. Offshore Technology. Outubro 2014. 


\section{Capítulo 28}

\section{Energia eólica: Perspectivas no Brasil e no mundo}

\section{Erica Werneck Duarte Melo}

\section{Isabela Pessanha Vilaça}

João José de Assis Rangel

Resumo: Este trabalho tem como foco analisar as perspectivas e os avanços da energia eólica no Brasil e no mundo, avaliando desde o seu surgimento até os dias atuais, em especial como diferentes países estão no ranking quanto ao uso dessa fonte de energia renovável e a tecnologia utilizada. É apresentado, diante de um cenário de mudança climática, como esta fonte pode ser significativamente mais limpa e economicamente viável, ainda que seja apenas o início para que se estabeleça. Mostra como deu-se sua consolidação e quais são os principais desafios enfrentados para que alcance, a longo prazo, a sua sustentabilidade. Com base em fontes nacionais e internacionais, destaca o crescente potencial competitivo dessa fonte energética e a necessidade de investimentos governamentais para o alcance de resultados satisfatórios.

Palavras-chave: Energia Eólica, perspectivas, sustentabilidade. 


\section{INTRODUÇÃO}

A dependência da humanidade por recursos energéticos e fatores como poluição e mudança climática, por exemplo, estimularam investimentos em fontes energéticas renováveis, dentre as quais a energia eólica se destaca [JUNFENG et al., 2006]. Esta é produzida através da força dos ventos, que transforma energia cinética em energia elétrica. Em meio às inúmeras opções de energias renováveis, a eólica tem destaque no que diz respeito à segurança de fornecimento, sustentabilidade ambiental e produção [GWEC, 2008; EWEA, 2010].

Para Junfeng et al., [2006] e Pengfei e Hu [2010], a energia eólica ganha destaque como uma das mais promissoras e competitivas fontes de energia renovável, além de produzir efeitos ambientais inferiores se comparada a outras fontes energéticas.

Considerando e analisando o passado recente da humanidade, resgata-se a primeira crise do petróleo como um acontecimento de significativa importância para o setor elétrico e para o início do movimento ambiental atual. A dependência mundial de combustíveis fósseis e os impactos gerados por essa dependência, acentuados com uma nova crise do petróleo na década de 1980, forçou governos ao redor do mundo a darem início a políticas de incentivo ao desenvolvimento de tecnologias alternativas de energia, tendo como embasamento a capacidade de renovação dos insumos [JUNFENG et al., 2006].

Dentro desse cenário, a indústria de energia eólica ganhou maior destaque como exemplo de produção de energia limpa e a disponibilidade gratuita de seu combustível - o vento. Esse fato trouxe consequências positivas, fazendo com que em 2005 o setor obtivesse mais de US\$ 10 bilhões em investimentos e empregasse mais de 150 mil pessoas [JUNFENG et al., 2006]. Essa realidade contribuiu para estimular investimentos de várias formas ao setor e tornar esta modalidade de energia mais interessante economicamente.

Ao longo deste trabalho serão feitas comparações entre o Brasil e outros países, em especial como estão no ranking quanto ao uso dessa fonte de energia renovável, apresentando o processo de consolidação e os principais desafios enfrentados para que a energia eólica alcance, a longo prazo, a sua sustentabilidade.

\subsection{AEROGERADORES}

Um aerogerador (turbina eólica ou Sistema de Geração Eólica) é um equipamento que usa a energia cinética do vento transformando-a em energia elétrica. Como no processo é utilizado uma fonte de energia infinita, denomina-se fonte de energia renovável, e também de energia eólica por utilizar o vento no processo.

Dois tipos de aerogeradores podem ser diferenciados de acordo com o tipo de rotor. Com rotor de eixo vertical, como mostra a Figura 1, normalmente possuem preços mais elevados que os de eixo horizontal, pois o gerador não gira seguindo a direção do vento, apenas o rotor gira enquanto o gerador fica fixo. Devido a isso, o de eixo horizontal possui desempenho inferior.

Os aerogeradores com rotor de eixo horizontal, Figura 2, são os mais conhecidos e os mais utilizados pela sua maior eficiência, compensando o seu custo mais elevado. Nesta categoria encontram-se os rotores multipás e os de 2 ou 3 pás. Os rotores constituídos por 3 pás são os mais usados para geração de energia elétrica em larga escala. São utilizadas como fonte de energia renovável, estes são impulsionados apenas pela força de sustentação. Estes apresentam também maior eficácia pela sua menor resistência ao ar.

A gama de potências dos aerogeradores estende-se desde os $100 \mathrm{~W}$ (comprimento das pás da ordem de 1 metro) até cerca de $8 \mathrm{MW}$ (longitude das pás que supera os 80 metros). 
Figura 1: Aerogerador Vertical

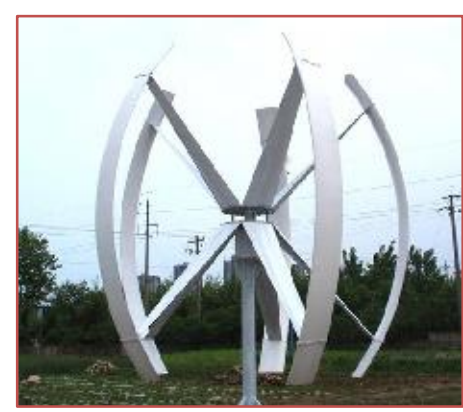

Fonte:

https://evolucaoenergiaeolica.wordpress.com/aerogeradorde-eixo-horizontal/gerador-eolico-de-eixo-vertical/

Figura 2: Aerogerador Horizontal

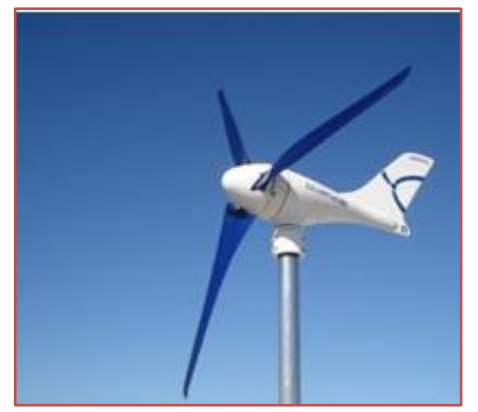

Fonte: http://www.portalenergia.com/funcionamento-deum-aerogerador

\subsection{PERSPECTIVAS SOBRE A GERAÇÃO EÓLICA NO BRASIL}

De acordo com Melo [2014], ainda muito recente no Brasil, a energia eólica tem experimentado um virtuoso e exponencial crescimento no país. Esta fonte de energia já vem colaborando em elevado grau para o desenvolvimento, abastecendo nos dias atuais cerca de quatro milhões de casas brasileiras, ou doze milhões de indivíduos, o que é equivalente a uma cidade do tamanho de São Paulo.

O desenvolvimento da fonte eólica no Brasil foi marcado pela instalação da primeira turbina eólica em 1992, em Fernando de Noronha, seguindo com a criação do Programa de Incentivo às Fontes Alternativas de Energia Elétrica (PROINFA). Fundamentado em um estruturado modelo de financiamento e políticas regionais e lançado em 2004, o PROINFA foi responsável pela contratação de 1.422,9 MW (megawatts), por meio de preços subsidiados [MELO, 2014].

Segundo Melo [2014], o Brasil se destaca com geração de energia elétrica renovável e limpa, preponderantemente hídrica, na qual a eólica é complementar. Quarenta e cinco por cento (45\%) de sua matriz energética deriva de fontes que não emitem C02, contra menos de $20 \%$ da média mundial. A Figura 3 apresenta a evolução da produção de energia eólica no Brasil no período de 1990 a 2013. 
Figura 3: Geração de Energia Eólica - Brasil

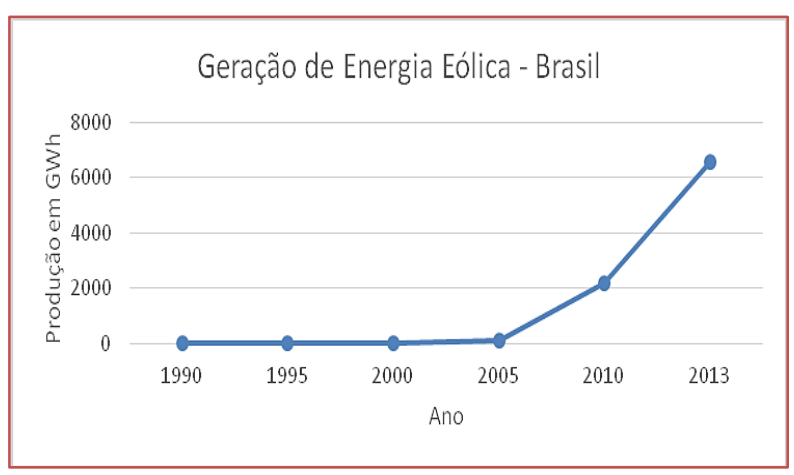

Fonte: Adaptado do IEA

Segundo dados da IEA - International Energy Agency, em português - Agência Internacional de Energia, como mostra a figura acima, nos anos 90 não havia produção de energia eólica, sendo no ano 2000 o seu aparcimento, de uma forma ainda não expressiva. A partir de 2010 já começa tornar-se significativa.

O Brasil possui uma vantagem competitiva única, frente aos demais, devido a trajetória tecnológica, que é o principal fator de competitividade desta indústria. A exemplo disso pode-se citar o aumento na altura dos aerogeradores, de $50 \mathrm{~m}$ para $100 \mathrm{~m}$, e o diâmetro das pás e dos rotores, somados a especificidades dos ventos brasileiros. Unindo esses fatores a uma conjuntura de crise internacional, com grande choque nos anos 2009 a 2012, o Brasil tornou-se, junto a Índia e a China, um importante foco de investimento para este setor.

Europa e EUA reduziram e, em alguns casos, cortaram seus investimentos em fontes renováveis subsidiadas. Esses fatores fazem com que a competição se torne ainda maior, de forma que os investidores, para ganhar mercado, tendem a aceitar uma remuneração menor para entrar e continuar no País [MELO, 2014].

Segundo o mesmo autor, a energia eólica é uma fonte renovável e limpa, que gera renda e empregos para o Brasil. Até 2013, foram criados 120 mil empregos diretos e, neste ano, está sendo investidos no setor em torno de R\$ 14 bilhões, com projeção de chegar a mais R\$ 60 bilhões até 2018.

Diante dos fatos apresentados, registra-se, especialmente a partir do ano de 2009, a chegada de muitos fabricantes interessados no mercado brasileiro e uma forte redução nos preços de venda. A estratégia destas empresas deu-se com a entrada agressiva no mercado brasileiro, com baixos preços, e com a oferta dos equipamentos em estoque e, no futuro, a instalação de fábricas no país. Por essa razão, no início houve uma tendência à entrada de equipamentos de tecnologia secundária para atender a demanda por equipamentos a preços menores, não representando, assim, equipamentos com tecnologia de ponta [MELO, 2014].

A partir dos leilões de 2010 e 2011, principalmente, houve modificação no cenário. Os últimos equipamentos instalados refletem a tecnologia de ponta dos fabricantes. 0 Brasil atrai hoje o investimento em aerogeradores de última geração com potência de $3 \mathrm{MW}$, torres com 120 metros de altura e pás com mais de 60 metros [MELO, 2014].

Essas tecnologias referem-se a geração de energia eólica on-shore, uma vez que os parques off-shore estão tendendo para máquinas maiores, acima de $6 \mathrm{MW}$ e, atualmente de $9 \mathrm{MW}$, em P\&D. Em contrapartida, essa tecnologia de ponta ainda possui elevados custos no Brasil e ainda há muito o que se explorar em áreas on-shore no país.

O grau de evolução tecnológica e a estrutura do mercado mundial de equipamentos eólicos, demonstra que essa indústria encontra-se em seu estado inicial, no Brasil e no mundo, permitindo concluir que esse setor tem um grande potencial de crescimento [MELO, 2014].

Para Melo [2014], o Brasil ainda tem um extenso caminho visando melhorar a competitividade e garantir a sustentabilidade de longo prazo da fonte de energia eólica. Essa fonte passa essencialmente pela melhora da competitividade nos valores de produção das turbinas eólicas e nos demais custos do país, uma vez que essas turbinas são influenciadas densamente pela aquisição dos insumos no país. Dessa forma, a diminuição nos preços das turbinas ainda é um dos maiores entraves para redução do custo total de produção de energia eólica. Isso monstra a necessidade de fortes incentivos ao progresso tecnológico, seja 
em investimentos em P\&D e Inovação, ou no sentido de manutenção de uma relativa abertura do país para ganhar investimentos externos.

A possibilidade de produção de energia eólica no Brasil é quase infinita, tem-se potencias eólicos de altíssima qualidade no Sul e Nordeste do país, e, mais recentemente, os estudos eólicos têm apresentado potenciais em São Paulo, Minas Gerais, Espirito Santo, entre outros estados que ainda estavam fora da rota da energia dos ventos no passado. Com esse crescimento em alta velocidade, logo, o país estará entre os líderes mundiais no investimento e na produção em energia eólica [MELO, 2014].

O Brasil concluiu o ano de 2013 como 13o colocado no ranking mundial de parques eólicos construídos, sendo em 2014, o sétimo país que mais instalou novos parques de energia eólica, estando abaixo apenas, da China, Alemanha, Reino Unido, Índia, Canadá e EUA [MELO, 2014].

A indústria eólica hoje, em processo de consolidação, embora esteja enfrentando grandes desafios, ainda precisa superar alguns obstáculos, como os problemas de logística para o transporte de equipamentos. Esses desafios podem ser considerados bons, pois serão a fim de desenvolver para desempenhar uma próxima etapa desta indústria virtuosa, alcançando, no longo prazo, a sua sustentabilidade [MELO, 2014].

\subsection{PERSPECTIVAS SOBRE A GERAÇÃO EÓLICA NO MUNDO}

Segundo relatórios da Associação Mundial de Energia Eólica (WWEA - Word Wind Energy Association), dados de 2010, mais de 80 países utilizam a energia eólica como fonte de energia elétrica, sendo esta energia renovável disponível que tem levado os países a investirem em grande escala, estabelecendo incentivos e conduzindo investimentos financeiros para estimular essa geração limpa. A figura 4 mostra a evolução dessa fonte alternativa no mundo.

Figura 4: Geração de Energia Eólica - Mundo

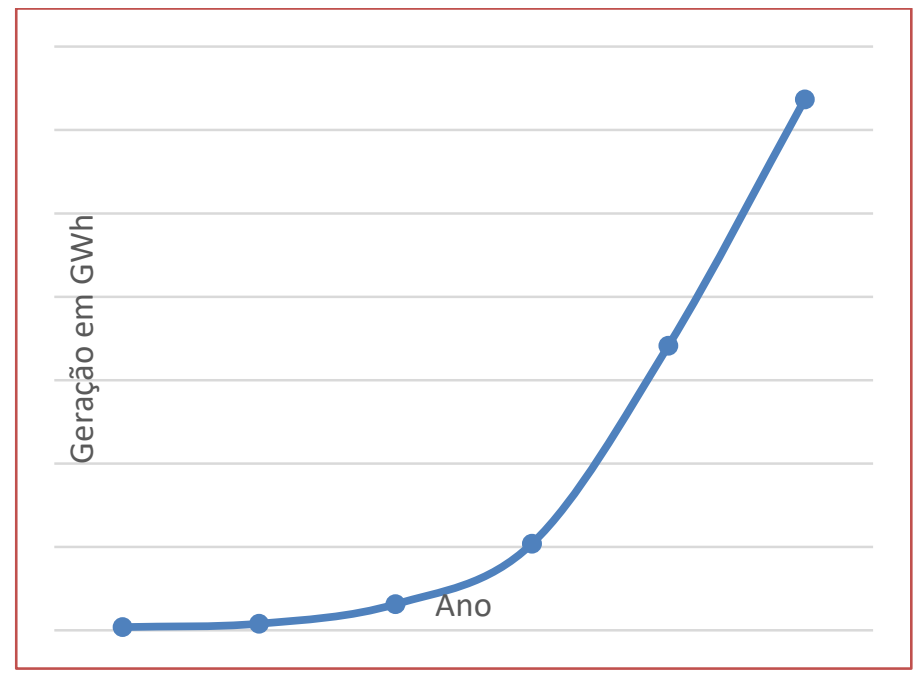

Fonte: Adaptado do IEA

Como é possível observar na imagem acima, o aumento da geração de energia eólica dá-se pelo expressivo avanço tecnológico dos parques eólicos e pela queda dos preços de implementação. Esse rápido crescimento do setor eólico no mundo é estimulado pela nova orientação para a transferência dos combustíveis fósseis como fundamental fonte energética [CORREA, 2016].

A Alemanha, até 2005, estava no ranking como o país líder em produção de energia eólica, sendo superada pelos Estados Unidos no ano de 2008. A China tem se mostrado, desde 2010, o maior produtor, com um aumento significativo de 41\%, com um total de $62.000 \mathrm{MW}$ (62 GW).

Na Dinamarca, segundo ainda a WWEA, a demanda por energia eólica, no ano de 2007, representava 23\% da produção, enquanto essa parcela era de $6 \%$ e $8 \%$ na Alemanha e Portugal respectivamente. 
Conforme tabela abaixo, enquanto o Canadá teve um bom desempenho, subindo no ranking, a Espanha apresentou com $0 \mathrm{MW}$ de capacidade adicionada. Algo jamais visto em se tratando de um país que já teve um papel de liderança e que não tinha se colocado ainda em posição de paralisação completa.

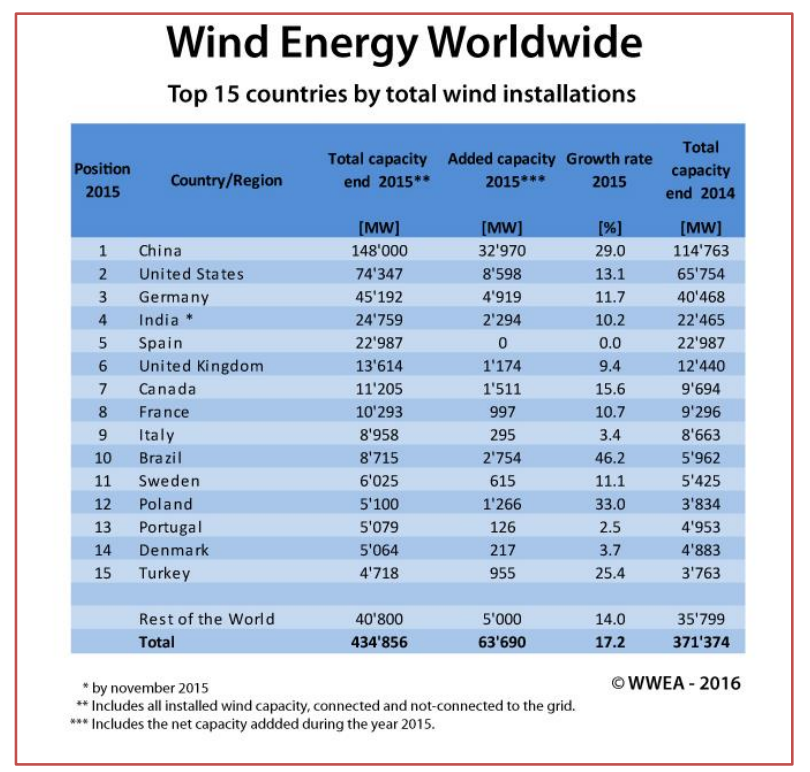

A IEA - International Energy Agency, em português - Agência Internacional de Energia, considera as energias renováveis um leque de opções para estabelecer um potencial energético seguro e sustentável. Apresentando em recente Relatório de Mercado de Energia Renovável de Médio Prazo, uma quota de geração de poder global superior a 26\% de energias renováveis até 2020, contra 22\% em 2013.

Continuando a análise, dados do Conselho Global de Energia Eólica (GWEC, na sigla em inglês), ratificam que a capacidade instalada de geração de energia eólica mundial passou de 6,1 GW para 282,4 GW nos últimos 16 anos, dados de 2012. Considerando essas informações, o mundo teria capacidade de produzir o correspondente a 20 hidrelétricas de Itaipu em energia a partir do poder do vento.

A China, líder do grupo, prevê, segundo matéria exibida pela BBC NEWS, em 9 de janeiro de 2014, dobrar o número de turbinas eólicas no país ao longo dos próximos seis anos, pretendendo atingir a marca de 200 GW até 2020, sendo sua capacidade atual instalada de energia eólica de cerca de 75 gigawatts (GW). Perspectiva esta bem provável, uma vez que foram os chineses que deram início ao maior impulso que as energias renováveis já receberam em todo o mundo.

O caminho para o crescimento dessa fonte renovável tem se mostrado tão significativo no país, que hoje duas usinas são instaladas por dia na região de Xinjiang. Dados de 2016 da WWEA apontam a China com uma quota de 51,8\% do mercado de geração de energia eólica no mundo, somando 33 GW de nova capacidade.

Ainda segundo a mesma fonte citada anteriormente, o mundo assiste um recorde em novas instalações eólicas, acrescentando 63'690 MW no ano de 2015. A capacidade total de vento do mundo chegou a 435 GW.

A IEA considera as energias renováveis um leque de opções para estabelecer um potencial energético seguro e sustentável, apresentando em recente Relatório de Mercado de Energia Renovável de Médio Prazo, uma quota de geração de poder global superior a 26\% de energias renováveis até 2020, contra 22\% em 2013.

Segundo dados do Ministério Minas e Energia, quanto as emissões de CO2, o indicador brasileiro é de 1,59 tonelada para cada mil quilos de energia consumida (tCO2/tep). Com esse número, o país está muito abaixo da média mundial, como mostra a Figura 5. 
Figura 5: Emissão CO2 Brasil versus Mundo

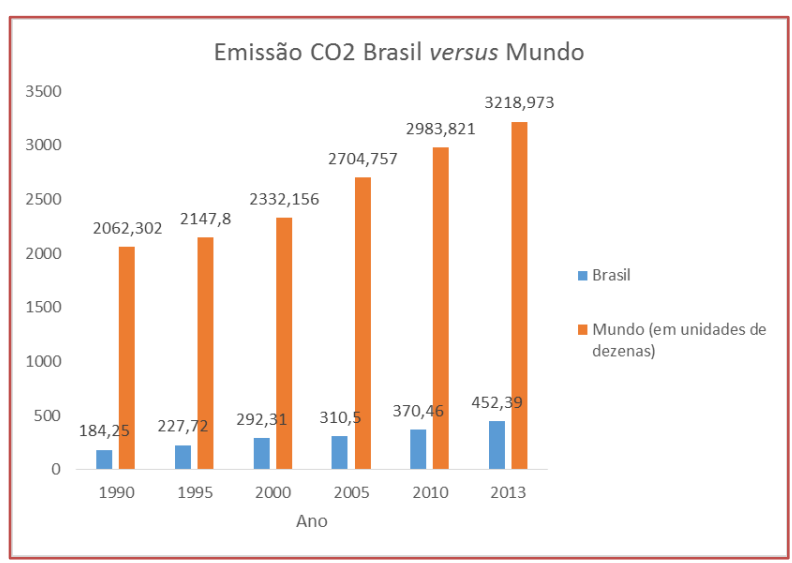

Fonte: Adaptado do IEA

O sucesso da COP21 eleva as expectativas dos esforços globais em combater as alterações climáticas, o que afeta de forma positiva a dinâmica para a implantação de tecnologias renováveis e eficientes, fazendo com que as perspectivas em relação a um progressivo aumento da geração de energia eólica torne-se cada mais mais expressivo.

Segundo informações do portal ABE Eólica, do crescimento esperado das renováveis, $52 \%$ serão feitos por hidrelétricas e 28\% por energia eólica. Grande parte do crescimento das hidrelétricas será nos países fora da OCDE, enquanto da energia eólica será nos países da organização.

\section{METODOLOGIA}

Para elaboração deste trabalho foram feitas revisões bibliográficas, utilizando dados de agências nacionais e internacionais especializadas no estudo das fontes renováveis de energia, neste caso com ênfase na energia eólica, objeto de estudo e comparação, o que possibilitou a consistência das informações e elaboração dos gráficos apresentados.

\section{RESULTADOS E DISCUSSÃO}

Conforme apresentado neste trabalho, o Brasil e o mundo, nos últimos anos, têm demostrado expressivo interesse na expansão de energias renováveis. A energia eólica tem se destacado como exemplo de produção de energia limpa e a disponibilidade gratuita de seu combustível - o vento. Tendo impactos ambientais relativamente baixos e sofrido grande evolução tecnológica nos últimos tempos, seu custo de implantação e operação tem caído, tornando-a uma fonte alternativa cada vez mais competitiva em relação as outras.

No Brasil o trajeto ainda é longo na busca por se tornar um país mais sustentável e melhorar a competitividade nos custos com produção das turbinas eólicas. Estas são consideradas um dos agentes dificultadores mais relevantes para a redução do custo total de produção de energia eólica. No ano de 2013 o país foi o 13ํㅡㄹ colocado no ranking mundial de parques eólicos construídos, sendo em 2014, o sétimo país que mais instalou novos parques.

Estudos revelam um aumento do uso de energia eólica no mundo, com destaque para a China, que tornouse o país com maior capacidade instalada, bem como o centro da indústria eólica internacional, ultrapassando $41 \%$ o total instalado, de 2010 a 2011. Estima-se que até o ano de 2050, a energia eólica seja responsável por uma parcela relevante no abastecimento mundial, cerca de $25 \%$ a $30 \%$, segundo o Conselho Global de Energia Eólica.

O melhor aproveitamento da energia eólica será de vital importância no futuro, pois espera-se que esta supra a necessidade de populações. A implantação do uso de energia eólica é uma premissa para aqueles que desejam uma indústria consolidada e um setor forte e sustentável, que depende unicamente do crescimento tecnológico da humanidade. 


\section{CONCLUSÕES}

Diante do exposto, verificou-se o significativo papel da evolução da energia eólica nos cenários brasileiro e mundial, com benefícios ambientais, contribuindo não apenas para a redução de gases poluentes, como também para a diminuição da dependência de combustíveis fósseis. Os custos de implantação e operação têm sofrido uma diminuição, o que torna essa fonte renovável ainda mais atrativa. No que se refere ao Brasil, em 2014 foi o sétimo país na instalação de novos parques de energia eólica, enquanto a China prevê dobrar o número, segundo Conselho Global de Energia Eólica. As estimativas positivas não desconsideram o fato dos projetos terem um custo elevado e com retorno em longo prazo, o que ratifica a necessidade de apoio governamental para que esta fonte renovável de energia evolua e revolucione.

\section{REFERÊNCIAS}

[1] Como funciona um Aerogerador. Disponível em: <http://www.portalenergia.com/funcionamento-de-um-aerogerador/>. Acesso em: 24 maio 2016.

[2] CORREA, Paula Machado. Energia Eólica: Análise teórica e sua aplicação no mundo. Disponível em: <http://www.lume.ufrgs.br/bitstream/handle/10183/26101/000755238.pdf?sequence=1>. Acesso em: 01 jun. 2016.

[3] Ministério de Minas e Energia. Disponível em: <http://www.mme.gov.br/>. Acesso em: 01 jun. 2016.

[4] Geração de energia elétrica deve crescer 93\% até 2040 no mundo, segundo EUA. Disponível em: <http://www.portalabeeolica.org.br/index.php/noticias/865-geração-de-energia-elétrica-deve-crescer93-até-2040-no-mundo,-segundo-eua.html>. Acesso em: 02 maio 2016.

[5] GLOBAL WIND ENERGY COUNCIL - GWEC. Global wind energy outlook 2008. Brussels: GWEC, 2008. Global Wind report: annual market update 2010. Brussels: GWEC, 2010.

[6] IEA to receive Spanish Wind Energy Association's Annual Award for emphasis on renewables: Recognition welcomed as sign that IEA increasingly seen as global clean energy hub. Disponível em: $<$ https://www.iea.org/newsroomandevents/agencyannouncements/iea-to-receive-spanish-wind-energyassociations-annual-award-for-emphasis-on-renewables.html>. Acesso em: 03 maio 2016.

[7] Investimentos em energia eólica no Brasil: aspectos de inserção, tecnologia e competitividade. Disponível em: <http://www.wwindea.org/the-world-sets-new-wind-installations-record-637-gw-newcapacity-in-2015/>. Acesso em: 03 maio 2016.

[8] JUNFENG, L. et al. A study on the pricing policy of wind power in China. Brussels: GWEC, 2006.

[9] PENGFEI, S.; HU, G. China wind power outlook 2010. Bélgica: GWEC, 2010.

[10] MELO, Elbia. Brasil um potencial gigante de produção de energia eólica. Disponível em: <http://www.portalabeeolica.org.br/index.php/artigos/2478-brasil-um-potencial-gigante-de-produçãode-energia-eólica.html>. Acesso em: 03 maio 2016.

[11] MELO, Elbia. Investimentos em energia eólica no Brasil: aspectos de inserção, tecnologia e competitividade. Disponível em: <http://www.portalabeeolica.org.br/index.php/artigos/2476investimentos-em-energia-eólica-no-brasil-aspectos-de-inserção,-tecnologia-e-competitividade.html>. Acesso em: 03 maio 2016.

[12] World Wind Energy Association. Disponível em: <http://www.wwindea.org>. Acesso em: 02 maio 2016. 


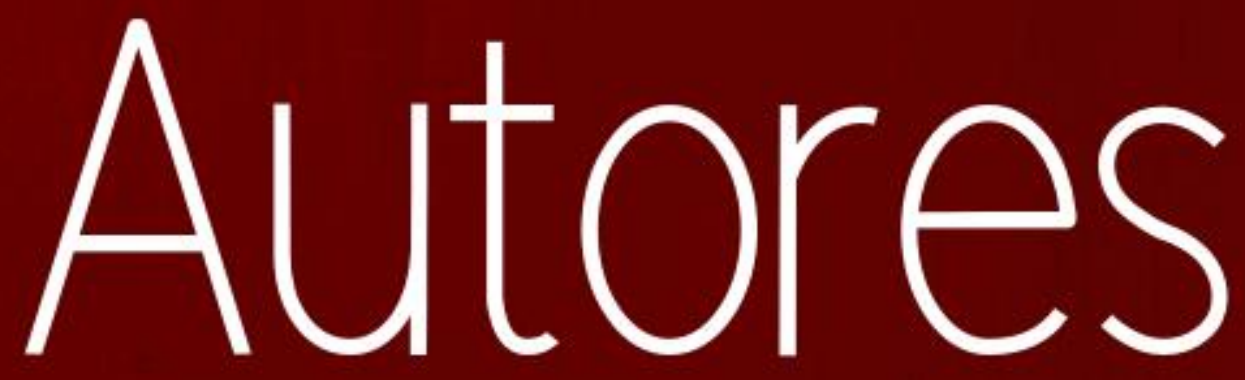




\section{ADRIANA CARLA DE OLIVEIRA LOPES}

Adriana Carla de Oliveira Lopes nasceu na cidade de Maceió, no Estado de Alagoas, em 16 de maio de 1980. Em 1998 ingressou no curso de Engenharia Química da Universidade Federal de Alagoas (UFAL), concluindo o mesmo em março de 2004. No segundo ano da graduação, foi contemplada com uma bolsa do Programa Institucional de Bolsas de Iniciação Científica, PIBIC/CNPq. Em 2004, foi aprovada no curso de Mestrado no Programa de Pós- graduação em Engenharia Química da Universidade Federal de Campina Grande (UFCG), na área de Operações e Processos. Em dezembro de 2007, defendeu a dissertação intitulada "Estudo da degradação do Hipoclorito de Sódio com Níquel Metálico". Entre 2005 à 2016 lecionou em todas as Engenharias de faculdades particulares do Estado de Alagoas. Em Abril de 2006, concluiu sua segunda graduação no curso de Física da Universidade Federal de Alagoas (UFAL), tendo seu trabalho de conclusão de curso intitulado "Fontes de Energia" . Neste mesmo ano foi aprovada, em primeiro lugar, no curso de Mestrado no Programa de Pós- graduação em Engenharia Química da Universidade Federal de Alagoas (UFAL), na área de Desenvolvimento e Pesquisa de Processos Regionais. Em Agosto de 2008, defendeu sua segunda dissertação intitulada "Estudo das variáveis de processo na produção e na purificação do biodiesel de soja via rota etílica". Em 2009 começou a coordenar diversos projetos de pesquisa e extensão sobre Energias Renováveis, os quais geraram artigos publicados em revistas e eventos científicos nas áreas de Engenharia. Em Agosto de 2015 foi aprovada, em primeiro lugar, no curso de Doutorado no Programa de Pósgraduação em Materiais da mesma instituição (UFAL), iniciando o trabalho de sua tese intitulada "Utilização de nanotubos de carbono na eletrossíntese de hidrogênio a partir da fermentação de frutas tropicais", sob orientação da professora doutora Fabiane Caxico de Abreu Galdino. Em fevereiro de 2017 foi nomeada professora efetiva da Universidade Federal de Alagoas (UFAL), compondo o quadro de docentes dos cursos de Engenharia de Produção, Engenharia de Pesca e Sistemas de Informação da Unidade Educacional de Penedo. Em 2019 recebeu o título de Doutora em Ciência dos Materiais pela Universidade Federal de Alagoas

\section{ADRIANO LIMA DA SILVA}

Possui Graduação em Engenharia de Materiais (UFCG, 2016), Mestre em Ciência e Engenharia de Materiais (UFCG, 2018), Especialista em Engenharia da Qualidade pela FUNIP (2019) e Doutorando do Programa de Pós-Graduação em Ciência e Engenharia de Materiais, da Universidade Federal de Campina Grande, Membro Atuante do Laboratório de Síntese de Materiais Cerâmicos, Desenvolvendo Pesquisas no Âmbito de Catalisadores Cerâmicos Magnéticos Avançados para Obtenção de Biodiesel.

\section{ALMIR MARIANO DE SOUSA JUNIOR}

Possui graduação em Engenharia de Produção pela Universidade Federal Rural do Semi-Árido, Especialista em Engenharia de Segurança do Trabalho, Especialista em Geografia e Gestão Ambiental, Mestrado em Engenharia de Petróleo e Gás Natural e Doutor em Ciência e Engenharia de Petróleo (UFRN). Atualmente é professor Efetivo da Universidade Federal Rural do SemiÁrido, professor do Mestrado Acadêmico em Planejamento e Dinâmicas Territoriais da Universidade Estadual do Rio Grande do Norte e Pró-Reitor Adjunto de Extensão e Cultura da UFERSA.

\section{ANA CAROLINA SANTOS DE OLIVEIRA}

Graduando do $9^{\circ}$ período de Engenharia de Petróleo pelo Centro Universitário Tiradentes (UNIT- AL), cursando inglês intermediário (América Language Center ALC), membro do Capítulo Estudantil da Society of Petroleum Engineers - SPE. Participaçã o no VIII Congresso de 
Engenharia, Ciência e Tecnologia CONECTE 2014; Rio Oil \& Gas 2014; I Conepetro 2015; SEMEX - Semana de Extensã o FITS.

\section{ANA CATARINA FERNANDES CORIOLANO}

Possui Graduação em Geologia pela Universidade Federal do Rio Grande do Norte (1997), Graduação em Direito pela Faculdade Natalense para o Desenvolvimento do Rio Grande do Norte (2007), Doutorado em Geologia - Geodinâmica e Geofísica pela Universidade Federal do Rio Grande do Norte (2002), Especialização em Direito Público-Direito Ambiental pela Faculdade de Natal (FAL) e ESMAT/RN (2009) e Pós-Doutorado no Instituto de Química da UFRN.

\section{ANA CRISTINA F. M. COSTA}

Doutora em Ciências dos Materiais pela UFSCar em 2002. Atua desde então, no desenvolvimento de novos materiais via síntese química, atividades relacionadas à nanotecnologia e desenvolvimento de materiais para aplicação em eletro-eletrônica, aplicações em catálise, materiais magnéticos, ópticos, nanocompósitos, biomateriais, membranas cerâmicas e marcadores biológicos. Possui experiência em síntese e caracterização de materiais, desenvolvimento de materiais magnéticos para aplicações em catálise, absorvedores de radiação eletromagnética, marcadores biológicos e dispositivos magnéticos moles. A respectiva pesquisadora participa como membro permanente do Programa de Pós-Graduação em Ciências e Engenharia de Materiais (conceito CAPES 5). Também atua na formação de recursos humanos participando ativamente dos programas de Iniciação Científica PIBIC/CNPq; PIBIT/CNPq e PIVIC/UFCG.

\section{ANA CRISTINA FIGUEIREDO DE MELO COSTA}

Doutora em Ciências dos Materiais pela UFSCar em 2002. Atua desde então, no desenvolvimento de novos materiais via síntese química, atividades relacionadas à nanotecnologia e desenvolvimento de materiais para aplicação em eletro-eletrônica, aplicações em catálise, materiais magnéticos, ópticos, nanocompósitos, biomateriais, membranas cerâmicas e marcadores biológicos. Possui experiência em síntese e caracterização de materiais, desenvolvimento de materiais magnéticos para aplicações em catálise, absorvedores de radiação eletromagnética, marcadores biológicos e dispositivos magnéticos moles. A respectiva pesquisadora participa como membro permanente do Programa de Pós-Graduação em Ciências e Engenharia de Materiais (conceito CAPES 5). Também atua na formação de recursos humanos participando ativamente dos programas de Iniciação Científica PIBIC/CNPq; PIBIT/CNPq e PIVIC/UFCG.

\section{ANA FLÁVIA FELIX FARIAS}

Possui graduação em Licenciatura Plena em Química pela Universidade Estadual da Paraíba (2007). Mestrado em Química pela Universidade Federal da Paraíba (2011). Doutorado em Química pela Universidade Federal da Paraíba (2016). Possui experiência na área de Química, com ênfase em Biocombustíveis, atuando principalmente nos seguintes temas: Produção de biodiesel com diferentes oleaginosas, Caracterização e controle de qualidade de biocombustíveis, Catálise heterogênea para a produção de Biodiesel, Síntese de materiais híbridos inorgânicos a base de bentonitas e óxidos metálicos, com experiência em métodos de sínteses por reações: hidrosolvotermal assistido por micro-ondas e Pechini. Trabalha atualmente em pesquisa com foco no desenvolvimento de catalisadores magnéticos obtidos por reação de combustão para aplicação na produção de Biodiesel. Atualmente é pesquisadora PNPD vinculada ao LabSMaC/UAEMa/CCT/UFCG. 


\section{ANDERSON ALMEIDA DA PIEDADE}

Estudante de Doutorado em Geofísica ( 2015 ) e Mestre em Geofísica (2014) do programa de pós- graduação em Geofísica da Universidade Federal do Pará. Licenciado pleno em Física pela Universidade Federal do Pará (2012). Tem experiência na área de Física bem como Geofísica, com ênfase em Física aplicada às ciências da Terra, atuando principalmente nos seguintes temas: Métodos Eletromagnéticos e Inversão Eletromagnética.

\section{ANDRÉ FELIPE SIMOES}

Livre docente da USP. Engenheiro Metalúrgico com Mestrado em Engenharia Metalúrgica com ênfase em Ciência dos Materiais. Doutor em Planejamento Energético pela UFRJ (2003) e PósDoutor em Planejamento de Sistemas Energéticos pela UNICAMP (2006). Revisor do 5o Relatório e do 60 Relatório (em curso) de Avaliação do IPCC. Em 2015, conquistou o Prêmio Vale-Capes de Ciência e Sustentabilidade. Docente do Curso de Bacharelado em Gestão Ambiental da Escola de Artes, Ciências e Humanidades da Universidade de São Paulo (EACH/USP), do qual foi Coordenador. Atua também como Prof. Dr. do Programa de Pós-Graduação em Energia - IEE/USP - e do Programa de Pós-Graduação em Sustentabilidade da EACH/USP. Integrante de diversas delegações brasileiras nas COP da UNFCCC.

\section{ANDRÉ KEULLEN DA CUNHA SILVA}

É graduado, mestre e doutor em Física pela Universidade Federal do Rio Grande do Norte. Atualmente é professor de Física na Universidade Federal do Pará (UFPA) em Salinópolis-PA. É membro pesquisador associado do Laboratório de Inovação Interdisciplinar - LabX, da Universidade Federal do Pará. Realiza pesquisa nos seguintes temas: transporte eletrônico em DNA/ RNA, sistemas magnéticos, processos epidêmicos, caminhadas aleatórias, processos estocásticos não-Markovianos e Inteligência Artificial.

\section{ANDRÉA FRANCISCA FERNANDES BARBOSA}

Graduação em Química Bacharelado pela Universidade Federal do Rio Grande do Norte(2001), graduação em Química Licenciatura pela Universidade Federal do Rio Grande do Norte (2005), Mestrado em Química pela Universidade Federal do Rio Grande do Norte (2004) e Doutorado pela Universidade Federal do Rio Grande do Norte (2008). Tem experiência na área de Química, com ênfase em Química, atuando principalmente nos seguintes temas: Extração de amostras, Cromatografia Gasosa, Inibidores de Corrosão e Caracterização de complexos. Foi professora da Universidade Federal do Maranhão (UFMA) e atualmente, professora adjunta da Universidade Federal do Semiárido (UFERSA).

\section{ANTONIO DE SOUZA ARAUJO}

Bacharel em Química pela Universidade Federal do Rio Grande do Norte (1986); mestre em química pela Universidade Federal da Paraíba (1988) e doutor em ciências (Química Inorgânica) pelo Instituto de Química da Universidade de São Paulo (1992). Realizou Pós-Doutoramento em Kent State University, 1999 (Ohio, Estados Unidos). Professor Titular do Instituto de Química da Universidade Federal do Rio Grande do Norte desde 2010. 


\section{ARMANDO SÁ RIBEIRO JÚNIOR}

Possui graduação em Engenharia Mecânica pela Universidade Federal da Bahia (1991), mestrado em Engenharia Mecânica pela Universidade Federal de Santa Catarina (1995), doutorado em Engenharia Mecânica pela Universidade Federal de Santa Catarina (2003) e pós-doutorado na Norwegian University of Science and Technology (2014-2015). Atualmente é professor Associado da Universidade Federal da Bahia e líder do Gitec - Grupo de Inovação Tecnológica da UFBA. Tem experiência na área de Engenharia Mecânica, com ênfase em Análise de Tensões, atuando principalmente nos seguintes temas: análise não-linear utilizando o método dos elementos finitos, desenvolvimento de produtos, mecânica da fratura.

\section{CAROLINA ROCHA LUIZ VIANNA}

Mestre em Engenharia Metalúrgica pela Universidade Federal Fluminense e graduada em Química Industrial pela Universidade Severino Sombra. Atualmente é professora dos cursos de engenharia, além de atuar como pesquisadora.

\section{CLAUDIANA FERREIRA DA SILVA}

Engenheira de Petróleo pelo Centro Universitário Tiradentes (UNIT-AL), foi aluna bolsista no Programa Voluntário de Iniciação Científica (PROVIC) desenvolvendo a pesquisa sobre: "ESTUDO E ANÁLISE DA INTERPRETAÇÃO DOS PERFIS DE PRODUÇÃO ". Tem experiência na área de Engenharia de Petróleo, com ênfase em Engenharia de Reservatórios e Métodos Convencionais de Recuperação Secundária de petróleo.

\section{CRISTIANE LEAL}

Doutoranda em Engenharia de Materiais e Processos Químicos na PUC-RJ. Mestre em Engenharia Química da UFRuralRJ (2015) com ênfase em Biocombustíveis no Laboratório de Termodinâmica Aplicada e Biocombustíveis. Possui graduação em Engenharia Química pela Universidade Federal Rural do Rio de Janeiro (2012). Tem experiência na área de Engenharia Química, com ênfase em Biocombustíveis, Termodinâmica Aplicada, Meio Ambiente e Garantia de Controle de Qualidade.

\section{DANIEL FREIRE ALMEIDA}

Graduado no curso de Engenharia Química da Universidade Salvador (UNIFACS). Graduado no curso de Engenharia Mecânica da Universidade Federal da Bahia (UFBA). Mestre em Engenharia Química pelo Programa de Graduação em Engenharia Química - PPEQ -UFBA. Doutorando em Engenharia Química pelo Programa de Graduação em Engenharia Química - PPEQ -UFBA. Como pesquisador, vem atuando em trabalhos na área de combustíveis, biocombustíveis, análises físico- químicas, catálise heterogênea e processos de dessulfurização.

\section{DANIELA DA COSTA BARBOSA}

Graduada em Licenciatura plena em Química pela Universidade Federal de Alagoas em 2006, Mestre em Química em 2009 atuando com misturas de óleos vegetais para produção de biodiesel via catálise homogênea e Doutora em Química no ano de 2015 trabalhando com catalisadores heterogêneos como cerâmicas magnéticas de NiFe2O4 dopadas com íons $\mathrm{Cu} 2+, \mathrm{Zn} 2+$ e $\mathrm{Co} 2+$ para produção de biodiesel. 


\section{DEBORA ABREU DA SILVA}

Graduanda em Geologia pela Universidade Federal do Amazonas (UFAM), Campus Manaus, com formação prevista para o segundo semestre de 2020. Integrante do Grupo PET-Geologia (Programa de Educação Tutorial). Possui interesse em áreas de pesquisa que envolvem Geofísica, Geologia Ambiental e Sedimentologia.

\section{DIÊGO VINÍCIUS FERNANDES BEZERRA}

Atualmente participa do grupo de pesquisa sobre adsorção direcionado ao estudo referente a remoção de contaminantes metálicos a partir da semente de maracujá tratada com tensoativo aniônico.

\section{DIVANIRA FERREIRA MAIA}

Engenheira de Materiais e Mestre em Engenharia Química pela Universidade Federal da Paraíba, Doutora em Engenharia de Processos com ênfase em Petróleo e Gás pela Universidade Federal de Campina Grande. Atualmente é professora do curso técnico em Petróleo e Gás do Instituto Federal da Paraíba, Campus Campina Grande

\section{EDÍLSON PONCIANO DE LIMA}

Mestrando em Propriedade Intelectual e Transferência Tecnológica para Inovação no programa PROFNIT; Especialista em Automação Industrial e Controle de Processos; Bacharel em Sistemas de Informação. Atua como professor do núcleo das engenharias do Centro Universitário Tiradentes - UNIT-AL e Presta serviço como Téc. Em Automação Industrial Sênior nas unidades da Petrobras em Alagoas pela SGS do Brasil. Experiência de mais de 20 anos em Eletroeletrônica, Robótica e Automação Industrial no segmento de O\&G.

\section{EDMILSON MOUTINHO DOS SANTOS}

É engenheiro e economista formado pela Universidade de São Paulo. Doutor em Economia da Energia pelo IFP Nouvelles Energie (antigo Instituto Francês do Petróleo) da França. Professor Associado e Presidente da Comissão de Pós-Graduação do Instituto de Energia e Ambiente da Universidade de São Paulo; Coordenador do Programa de Economia e Políticas Energéticas do Centro de Pesquisa e Inovação em Gás (projeto da Universidade de São Paulo apoiado pela Fundação de Amparo à Pesquisa do Estado de São Paulo, FAPESP e a SHELL do BRASIL); Coordenador do Projeto GASBRAS, Rede de P\&D para Gases Não Convencionais (projeto apoiado pela agência de fomento Federal: Financiadora de Estudos e Projetos, FINEP).

\section{EDNÍLSON VIANA}

Graduado em Licenciatura em Ciências Biológicas pela UNESP (1992). Mestre em Ciências pelo Instituto de Química de São Carlos-USP (1994). Doutor em Saneamento pela Escola de Engenharia de São Carlos-USP (1999). Pós-doutorado em Saneamento pela Engenharia Civil da Universidade Federal de São Carlos (2001). Pós-doutorado pela Universidade Nova de Lisboa (2014). Pós- doutorado pela University of Wisconsin (2018). É professor Livre Docente na Universidade de São Paulo campus EACH. Orientou mais de 70 trabalhos entre TCC, mestrado, doutorado e pós-doutorado nacional e internacional. Desenvolve trabalhos em Gestão Sustentável de Resíduos Sólidos, com destaque para a valorização de resíduos orgânicos com foco na biometanização e compostagem. 


\section{EDUARDO LINS DE BARROS NETO}

Possui graduação em Engenharia Química pela Universidade Federal do Rio Grande do Norte (1992), mestrado em Engenharia Química pela Universidade Federal do Rio Grande do Norte (1996) e doutorado em Engenharia Química - Ecole National Supérieur Dingenieurs de Genie Chimique Institut National P (1999). Atualmente é professor associado IV da Universidade Federal do Rio Grande do Norte. Tem experiência na área de Engenharia Química, com ênfase em Tecnologia de Tensoativos, Engenharia de Processos, atuando principalmente nos seguintes temas: petróleo e gás, equilíbrio de fases, tratamento de efluentes, extração de metais e compostos orgânicos, novas formulações para combustíveis base diesel.

\section{ELVIA LEAL}

Possui Graduação em Engenharia de Materiais com Ênfase no Setor de Petróleo e Gás (2006) pela Universidade Federal de Campina Grande (UFCG) em parceria com a Agência Nacional do Petróleo (ANP), Mestrado em Ciência e Engenharia de Materiais (2009) pela UFCG também em parceria com a ANP, Doutorado em Ciência e Engenharia de Materiais (2013) pela UFCG e PósDoutorado pelo PNPD da CAPES (2013-2016) na área de materiais magnéticos híbridos e de biomateriais. Possui Especialização em Engenharia e Segurança do Trabalho (2014-2016) pela Faculdade Anglo- Americano. Atualmente participa do Programa Nacional de Pós-Doutorado (PNPD/CAPES) na UFCG, atuando diretamente na área de síntese e caracterização de nanopartículas magnéticas, desenvolvimento de materiais compósitos destinados ao uso como absorvedores eletromagnéticos. Além de possuir experiência nos temas: tecnologias aplicadas aos nanomateriais, síntese de pós-cerâmicos (óxidos metálicos) pelo método da reação por combustão, desenvolvimento de catalisadores para as tecnologias de produção do biodiesel e técnicas de caracterização de materiais.

\section{ÉRICA WERNECK DUARTE MELO}

Mestra em Engenharia de Produção (UCAM/Taxista CAPES); Especialista em Gestão de Pessoas e Estratégias Organizacionais (Faberi); Graduada em Administração (UFF). Professora no curso de Administração da FASAP ministrando as disciplinas Gestão de Logística e Gestão de Pequenas e Médias Empresas; Professora nos cursos de Administração e Ciências Contábeis no Centro Universitário São José de Itaperuna ministrando disciplinas de Marketing, Tópicos Especiais em Administração I e II, Administração Geral e Empreendedorismo; Instrutora nas áreas de Gestão e Logística na Firjan SENAI Itaperuna - Departamento Regional do Rio de Janeiro.

\section{FÁBIO DE MELO RESENDE}

Graduado em Química Industrial pela Universidade Federal de Sergipe. Doutor em Biotecnologia Industrial pela Universidade Estadual do Ceará/UECE/RENORBIO. Com ênfase no desenvolvimento de bioprocessos para produção de biocombustíveis de 2a geração (BIOGÁS) a partir do bagaço de cana. Possui MBA Executivo em Gestão de Projetos. Pós-doutor em biocombustíveis pelo Programa de Pós-doutorado Empresarial PDI/CNPq desde 2011. Na linha de pesquisa que envolveu o desenvolvimento do projeto de uma Planta industrial de Biodiesel com ênfase em biocatalisadores imobilizados em sílica macroporosa. Atualmente está lotado na Universidade Federal de Sergipe no Centro de Ciências Agrárias do Sertão - CAMPUS DO SERTÃO. Departamento de Bacharel em Agroindústria. Cargo de Professor Adjunto Nível III. 


\section{FABIANE CAXICO DE ABREU GALDINO}

Fabiane Caxico de Abreu Galdino nasceu na cidade de Estância, no Estado de Sergipe. Possui graduação em Química Licenciatura pela Universidade Federal de Sergipe (1992), mestrado em Química e Biotecnologia pela Universidade Federal de Alagoas (1996), doutorado em Doutorado Sandwiche pela Universidade de Coimbra (2001), doutorado em Química pela Universidade Federal de Pernambuco (2001). e pós-doutorado na ENS-Paris (2006). Atualmente é professor associado IV da Universidade Federal de Alagoas orientadora os Programas de Posgraduação em Materaiis, PPGQB e RENORBIO. Em maio de 2010, foi pesquisadora visitante no Department of Chemistry of the University of Hull, England em colaboração com o prof. Jay Wadhawan. Realizou estágio pós doutoral no Laboratório de Microanalytical da University of Texas at San Antonio sob a supervisão do prof Dr Carlos D Garcia com bolsa PDE do CNPq na área de microssistemas de análise e Eletroforese Capilar.Tem experiência na área de Química, com ênfase em química analítica e eletroanalítica, atuando principalmente nos seguintes temas: Bioeletroquímica, Biossensores, eletroanálise de poluentes, voltametria cíclica, quitosana, atividade biológica, agentes alquilantes do dna, genotoxicidade em peixes, eletroforese capilar e sistemas microfluidicos. A pesquisadora é Lider do grupo de pesquisa microssistemas de análise da UFAL. De abril de 2014 a agosto de 2015 foi vice-diretora do IQB e desde março de 2015 é coordenadora do Programa de posgraduação em Materiais da UFAL.

\section{FABRÍCIA MEDEIROS SANTANDREA}

Graduanda do nono período do curso de engenharia de petróleo, no Centro Universitário Tiradentes (UNIT-AL).

\section{FERNANDO NUNES DA SILVA}

Possui graduação em Engenharia de Materiais pela UFRN, Mestrado e Doutorado em Engenharia Mecânica pela UFRN. Tem experiência na área de Engenharia de Materiais, com ênfase em Corrosão e Desgaste dos Materiais, atuando principalmente nos seguintes temas: tribologia, inibidores e monitoramento da corrosão, incrustação e caracterização dos materiais.

\section{FRANCISCO ODAIR FILGUEIRA JUNIOR}

Discente do $7^{\circ}$ período de engenharia elétrica na Universidade Potiguar- UNP; Técnico em automação industrial; Atua profissionalmente em projetos, instalações e montagem de usinas solares; realiza intervenções elétricas em redes de média e baixa tensão; realiza instalações e manutenções elétricas industriais e prediais; cursou tecnólogo em engenharia de Petróleo e Gás na UNP.

\section{GERALDO JOSÉ BELMONTE DOS SANTOS}

Possui Doutorado em Modelagem Computacional pelo Laboratório Nacional de Computação Científica - LNCC, mestrado em Engenharia Civil e Ambiental pela Universidade Estadual de Feira de Santana - UEFS e Graduação em Engenharia Mecânica pela Universidade Federal da Bahia UFBA. É, atualmente, professor da Universidade Estadual de Feira de Santana. As áreas de atuação são: Modelagem Matemática e Computacional de Problemas de Engenharia, Método dos Elementos Finitos, Mecânica dos Sólidos e Estrutural, Dinâmica Estrutural, Projeto e Análise de Sistemas Mecânicos e Inovação Tecnológica. 


\section{HIRDAN KATARINA DE MEDEIROS COSTA}

Advogada OAB/SP. Mestre em Energia e Doutora em Ciências pelo PPGE/USP. Mestre em Direito de Energia e de Recursos Naturais pela Faculdade de Direito da Universidade de Oklahoma. PósDoutora em Sustentabilidade pela EACH/USP. Vice-coordenadora do Programa de Políticas de Energia e Economia do Research Center of Gas Innovation (RCGI), Coordenadora do Projeto 21 (RCGILex.com.br) e 42 (Análise do Impacto Ambiental da Captura e Estocagem de Carbono e aspectos legais), que fazem parte do RCGI/SHELL/FAPESP/USP (www.rcgi.poli.usp.br).

\section{HOMERO FONSECA FILHO}

Engenheiro Agrônomo e Mestre pela ESALQ da Universidade de São Paulo - USP, Doutor em Geociências e Meio Ambiente pelo IGCE da Universidade Estadual Paulista - UNESP. Ingressou na USP em 2002, como Professor Doutor do Departamento de Engenharia de Transportes da EP (Área de Informações Espaciais). É professor do Bacharelado em Gestão Ambiental e do Programa de Pós-Graduação em Sustentabilidade da EACH - USP. É membro do Grupo de Pesquisas em Resíduos, Energia, Saúde e Ambiente (RESA) e do Grupo de Estudos e Pesquisas em Infraestrutura de Dados Espaciais (GEPIDE). É coordenador da Rede Internacional de Sustentabilidade Ambiental. Pesquisa em Geoprocessamento para resolução de problemas ambientais e sustentabilidade de áreas costeiras.

\section{ILEAN JOSÉ FERREIRA LIMA VERÇOSA}

Graduando do sétimo período do curso de engenharia de petróleo, no Centro Universitário Tiradentes (UNIT-AL), e atua na iniciação cientifica Provic sobre revestimentos sustentáveis de garrafas PEAD a assoalho.

\section{INGRID ROCHA TEIXEIRA}

Graduanda do curso de Engenharia Química na Universidade Salvador (UNIFACS). Estagiaria do Instituto de Meio Ambiente e Recurso hídricos (INEMA) e integrante do grupo de pesquisa Catálise e Ambiente (CATAM). Como bolsista de iniciação científica da FAPESB, desenvolveu a pesquisa com o seguinte tema: Análise Qualitativa e Quantitativa do Extrato de Alecrim no Biodiesel 80/20\% (m/m) Soja/Sebo. Durante a graduação, vem desempenhando estudos na área de biocombustíveis, análises físico-químicas e catálise enzimática.

\section{IRAN TALIS VIANA SANTOS}

Possui graduação em Química pela Universidade Federal da Bahia (1985) e mestrado em Energia pela Universidade Salvador (2015). Atualmente é sócio do Instituto Brasileiro de Tecnologia e Regulação, pesquisador do Instituto de Pesquisas Aplicadas da UNIFACS e professor assistente i da Universidade Salvador. Conselheiro do Conselho Regional de Química VII Região - BA, atualmente participa da diretoria do CRQ assumindo o cargo de tesoureiro. Experiência como consultor em empresas petroquímica na área de controle de qualidade e desenvolvimento e implantação de metodologias analíticas, e em implantação de metodologias analíticas para análises de controle de qualidade de água potável e esgoto sanitário e agrícolas, para tender a legislação brasileira. Tem experiência na área de Química, com ênfase em Instrumentação Analítica, atuando principalmente nos seguintes temas: automação do laboratório, novas metodologias analíticas e piona. 


\section{ISABELA PESSANHA VILAÇA}

Engenheira e Mestra em Engenharia de Produção pela Universidade Cândido Mendes, Campos dos Goytacazes, RJ (08/2015 - CREA: 2015715304).

\section{ISABELLY CHISTINNE ALVES BEZERRA ALENCAR DOS SANTOS}

Graduada em Engenharia de Petróleo pela Universidade Federal de Campina Grande (UFCG). Foi pesquisadora voluntária do Grupo de Estudo em Exploração Petrolífera (GEEP), em seguida bolsista Petrobras com ênfase em Geologia Estrutural. Foi bolsista pelo programa de Monitoria da Universidade Federal de Campina Grande, disciplina Introdução à Estatística, vinculado ao Departamento de Estatística. Trabalhou como voluntária na empresa AIESEC em Campina Grande, exercendo o cargo de Diretora de Intercâmbios Sociais para Organizações (VP iGV) em 2018, membro desde 2017. Atualmente é mestranda no Programa de Engenharia Civil da COPPE/UFRJ, com ênfase em Sistemas Petrolíferos.

\section{JACEGUAI SOARES DA SILVA}

Doutor e mestre pelo Instituto de Química e Biotecnologia (IQB) da Universidade Federal de Alagoas (UFAL), possui especialização em Gestão Ambiental e graduação em Licenciatura em Química pela Universidade Estadual de Alagoas (UNEAL), com atuação no Ensino de Química e pesquisa nas áreas de Eletroquímica (ênfase nas técnicas de Polarização Linear e Impedância Eletroquímica), Química Ambiental e Tratamento de Resíduos da Indústria do Petróleo. Atuou como Estagiário do Laboratório de Pesquisa em Química Ambiental (LPQA), no Campus III da UNEAL no período da graduação, e como Professor Substituto no Instituto Federal de Educação, Ciência e Tecnologia de Alagoas (IFAL), no Campus Maceió, de 2011 a 2013. Atualmente, é Professor Assistente, regime horista, do Centro Universitário Tiradentes-UNIT nos cursos de Engenharias (Ambiental, Mecatrônica e Petróleo) e Nutrição, bem como atua, desde 2017, como membro do Núcleo Docente Estruturante (NDE) do curso de Engenharia de Petróleo.

\section{JAIR RODRIGUES NEYRA}

Está fazendo graduação em Engenharia de Exploração e Produção de Petróleo na Universidade Federal do Pará, em Salinópolis-PA. É aluno de Iniciação Científica, orientado pelo professor Dr. Thiago Moura, com o foco da pesquisa em Caminhadas Aleatórias e Redes Neurais.

\section{JARDEL DANTAS DA CUNHA}

Doutor em Ciências e Engenharia do Petróleo pela Universidade Federal do Rio Grande do Norte (UFRN) em 2013, Mestre em Ciências e Engenharia dos Materiais pela Universidade Federal do Rio Grande do Norte (UFRN) em 2008 e Engenheiro de Materiais pela Universidade Federal do Rio Grande do Norte (UFRN) em 2004. Docente do curso de Engenharia do Petróleo da Universidade Federal do Semiárido (UFERSA). Tem experiência na área de Engenharia dos Materiais, com ênfase em Corrosão de Dutos e Equipamentos onde atuou como Engenheiro pela Fundação Norte-Rio- Grandense de Pesquisa e Cultura (FUNPEC) em contratos com a Petrobras e Transpetro dos anos de 2004 a 2010. Possui atuação nas áreas: Síntese de precursores poliméricos, pigmentos cerâmicos, corrosão induzida por microorganismos (CIM), pintura industrial e Monitoramento da Corrosão. 


\section{JOÃO JOSÉ DE ASSIS RANGEL}

Possui doutorado em Engenharia e Ciência dos Materiais pela Universidade Estadual do Norte Fluminense Darcy Ribeiro - UENF (1998), mestrado em Engenharia Mecânica pelo Instituto Militar de Engenharia - IME (1994) e graduação em Engenharia Mecânica pela Universidade Gama Filho - UGF (1991). Atualmente é Professor Titular da Universidade Candido Mendes (UCAM-Campos) e Professor Titular do Instituto Federal Fluminense (IFF). Tem experiência nas áreas de Engenharia da Sustentabilidade e Pesquisa Operacional, com ênfase em Modelos Analíticos e de Simulação, atuando principalmente nos seguintes temas: simulação computacional, desenvolvimento sustentável e produção de diamantes e ferramentas diamantadas.

\section{JOELDA DANTAS}

Doutora em Ciência e Engenharia de Materiais pela Universidade Federal de Campina Grande (UFCG), Especialista em Engenharia de Segurança do Trabalho pela Master Educacional, Pósdoutorado PNPD/CAPES e Professora externa no Programa de Pós-Graduação em Energias Renováveis (PPGER), do Centro de Energias Alternativas e Renováveis (CEAR) da Universidade Federal da Paraíba (UFPB), onde desenvolve pesquisas com ênfase em Materiais Aplicados às Energias Renováveis e Conversão da Biomassa em Biocombustíveis. Possui experiência na área de Engenharia de Materiais, com ênfase em Engenharia de Materiais e Metalúrgica (área de concentração em estrutura, processamento e propriedades de materiais), catálise, boas práticas de segurança laboratorial, sinalização de segurança e Normas técnicas ABNT. Atuação principal na área de síntese e caracterização de materiais cerâmicos, desenvolvimento de novos catalisadores via síntese química, desde pequena escala até escala piloto de produção, materiais magnéticos, ópticos, nanocatalisadores mistos para fotocatálise solar, atividades relacionadas à nanotecnologia e desenvolvimento de novos catalisadores de Biomassa para produção de Biocombustíveis.

\section{JOSÉ ANTONIO DE PADUA NETO}

Formado em Engenharia de Petróleo pela Universidade de Barra Mansa período no qual se dedicou também a pesquisa no NUPIDE - Núcleo de Pesquisa, Inovação e Difusão das Engenharias. Em 2019 entrou na COPPE-UFRJ para cursar o mestrado em Engenharia Naval e Oceânica com a previsão de termino em 2021.

\section{KAIQUE MOREIRA MATOS MAGALHÃES}

Possui graduação em Engenharia Civil e é aluno do Programa de Mestrado em Engenharia de Estruturas da Universidade Federal da Bahia (UFBA), faz parte do GITEC - Grupo de Inovação Tecnológica da UFBA, desenvolvendo projetos de pesquisa e extensão. Tem experiência na área de Engenharia Civil, com ênfase em Engenharia de Estruturas, Projeto Estrutural, Análise Estrutural, Análise de Tensões, Mecânica dos Sólidos e Mecânica Experimental. Atualmente é Professor Substituto do departamento de construção e estruturas da Universidade Federal da Bahia ministrando disciplinas relacionadas à teoria das estruturas.

\section{KELSON CARVALHO LOPES}

Graduado em Química Industrial (UFPB), mestrado (UFPB), Doutorado (UFPB) Pós-doutorado (UFPB), Professor Efetivo da UFPB no Departamento de Tecnologia Sucroalcooleira (DTS). 


\section{KLEBERSON RICARDO DE OLIVEIRA PEREIRA}

Possui graduação em Química Industrial pela Universidade Estadual da Paraíba (2000), mestrado em Engenharia Química pela Universidade Federal de Campina Grande (2003) e doutorado pela Universidade de São Paulo (2008). Atualmente é coordenador e professor do curso de Gestão e Especialização em Petróleo e Gás do Instituto Brasileiro de Engenharia de Custos (IBEC) e pesquisador na Universidade Federal de Campina Grande, Unidade Acadêmica de Engenharia de Materiais, atuando na área de síntese e caracterização de nanopartículas magnéticas, silicoaluminofosfatos, aluminofosfatos e zeólitas, reação de hidrocraqueamento e catalisadores para biocombustíveis. Tem experiência na área de Engenharia de Materiais, com ênfase em Transformação de Materiais, atuando principalmente nos seguintes temas: síntese e caracterização de catalisadores, caracterização de argilas, tratamento químico de argilas, obtenção de argilas organofílicas, nanocompósitos polímero-argila e desenvolvimento de novos materiais e atua na formação de recursos humanos participando ativamente dos programas de Iniciação Científica PIBIC/CNPq/UFCG e PIVIC/UFCG.

\section{KLISMERYANE COSTA DE MELO}

Possui graduação em Engenharia Química pela Universidade Federal do Rio Grande do Norte (2006) e mestrado em Engenharia Química pela Universidade Federal do Rio Grande do Norte (2008) E doutorado em Engenharia Química (2013)

\section{LAÍSE RAMONNY NUNES DE OLIVEIRA}

Estudante de engenharia de petróleo e gás pela Universidade Federal de Campina Grande.

\section{LARISSA FREITAS FARIAS}

Engenheira civil pela UFCG, especialista em engenharia ambiental e saneamento. Atuante a área de tratamento de água.

\section{LAUANDA ALBUQUERQUE QUEIROZ}

Técnica em Petróleo e Gás pelo Instituto Federal da Paraíba, Campus Campina Grande e atualmente é graduanda do curso de Arquitetura da Universidade Federal de Campina Grande. Tem experiência em desenho e materiais aplicados ao setor de Petróleo e Gás.

\section{LEILA MARIA AGUILERA CAMPOS}

Possuo graduação em Engenharia Química pela Universidade Federal do Rio de Janeiro (1981) e, em Licenciatura em Química pela Universidade do Estado do Rio de Janeiro (1990). Tenho especialização em Didática do Ensino Superior pela Faculdade Montenegro. Sou mestre e doutora em Engenharia Química pela Universidade Federal da Bahia (2010 e 2017) Atualmente sou sócia do Instituto Brasileiro de Tecnologia e Regulação, professora do curso de engenharia da Universidade Salvador e oriento no Programa de Pós-graduação da UNIFACS, no Mestrado em Energia. Tenho experiência na área de Engenharia Química, com ênfase em transformação de biomassa, meio ambiente e energia, atuando com diversas biomassas, a saber: bagaço de cana de açúcar, cana energia, mesocarpo do coco, sisal folha da bananeira, desde o pré-tratamento até a produção de etanol de $2^{\text {a }}$ geração. 


\section{LEONARDO ALCÂNTARA ALVES}

Possui Graduação em Química Industrial (2007), Mestrado (2009) e Doutorado em Química (2013) pela Universidade Federal do Ceará com trabalhos desenvolvidos nas áreas de Produtos Naturais e Biocátalise. Atualmente é professor Instituto Federal do Rio Grande do Norte Campus Apodi. Orienta projetos nas áreas de Ensino de Ciências Naturais, Química Orgânica, Química de Produtos Naturais e Biocatálise nos níveis de graduação e pós-graduação.

\section{LUCAS MOTA DE LIMA}

Graduado em Engenharia de Petróleo pela Universidade Federal de Campina Grande (UFCG). Foi Assessor Financeiro da Empresa Rifte Engenharia Júnior durante um ano, na qual logo depois foi promovido Diretor Administrativo Financeiro desta mesma empresa. Foi bolsista por duas vezes do programa de Monitoria da Universidade Federal de Campina Grande - UFCG, onde foi vinculado, em sua primeira participação, ao Departamento de Matemática, e posteriormente, ao Departamento de Engenharia de Petróleo. Participou do Programa Ciências sem Fronteiras, pela

CAPES, nos Estados Unidos, cursando ESL na University of Maryland, e posteriormente, um ano acadêmico na Wayne State University. Foi pesquisador na University of Oklahoma, com atuação na área de Fraturamento Ácido. Foi Presidente do Capítulo Estudantil SPE/UFCG entre 2016 e 2018. Foi estagiário no Departamento de Política Pública de Exploração e Produção de Petróleo e Gás Natural (DEPG) do Ministério de Minas e Energia (MME). Atualmente é assistente técnico na área de petróleo e gás natural no DEPG do MME onde trata de assessoramento superior para os temas de marco regulatório, institucional e normativo do setor de exploração e produção de petróleo e gás natural; elaboração de pareceres sobre proposições legislativas, atos normativos do executivo e avaliação de projetos da indústria do petróleo.

\section{LUCIANA ROCHA ALVES}

Graduada em Tecnologia em Petróleo e Gás pela UNIRB - Faculdade Regional da Bahia. Atualmente Desenvolve pesquisa na área de escoamento de petróleo em linhas de produção, métodos de recuperação de reservatório de petróleo, desparafinação de linhas de produção e meio ambiente e petróleo.

\section{LUIZ ANTONIO PIMENTEL CAVALCANTI}

Doutor em Engenharia Química pela Universidade Federal de Pernambuco (2013), Atualmente Professor EBTT do Curso de Biocombustíveis e do Mestrado Profissional de Engenharia de Materiais do Instituto Federal de Educação, Ciência e Tecnologia da Bahia (IFBA) e Coordenador Institucional de Iniciação Científica e Tecnológica do IFBA, atuou como coordenador do curso de Biocombustíveis do IFBA de 2015 a 2018, no campus Paulo Afonso. Foi Coordenador do Curso de Engenharia Ambiental do Centro Universitário ASCES-UNITA (Caruaru-Pe).

\section{LUZIA APARECIDA TOFANELI}

Possui graduação em Licenciatura Plena Em Matemática pela Universidade Estadual Paulista Júlio de Mesquita Filho (1999), mestrado em Engenharia Aeronáutica e Mecânica pelo Instituto Tecnológico de Aeronáutica (2003) e doutorado em Engenharia Aeronáutica e Mecânica pelo Instituto Tecnológico de Aeronáutica (2009). Atualmente é professora adjunto e pesquisadora da Faculdade de Tecnologia SENAI CIMATEC. Tem experiência na área de Engenharia Mecânica, 
com ênfase em Mecânica dos Fluidos, atuando principalmente nos seguintes temas: meios porosos, simulação numérica, energias renováveis.

\section{LYCIA CAROLINNE SANTOS DE OLIVEIRA}

Graduanda do nono período do curso de engenharia de petróleo, no Centro Universitário Tiradentes (UNIT-AL).

\section{MÁRCIO ROBERTO DE ANDRADE ARAUJO}

Graduando do $10^{\circ}$ período de Engenharia de Petróleo pelo Centro Universitário Tiradentes (UNIT- AL), foi aluno bolsista no Programa Voluntário de Iniciação Científica (PROVIC) desenvolvendo a pesquisa sobre "ESTUDO E ANÁLISE DA INTERPRETAÇÃO DOS PERFIS DE PRODUÇÃO", Vice-Presidente do Capítulo Estudantil da Society of Petroleum Engineers - SPE.

\section{MARCOS ALEXANDRE LOPES SILVA}

Graduando do nono período do curso de engenharia de Petróleo, no Centro Universitário Tiradentes (UNIT AL), é diretor de eventos da Society of Petroleum Engineers Unit-AL, já foi Auxiliar de eventos da Society of Petroleum Engineers Unit-AL.

\section{MARCOS MESQUITA DA SILVA}

Possui graduação em Engenharia Mecânica pela Universidade Federal de Campina Grande, UFCG (2007), mestrado (2009) e doutorado (2013) pelo Programa de Pós-Graduação em Ciências e Engenharia de Materiais da UFCG, PPGCEMat/UFCG, com ênfase no Setor de Petróleo e gás. Atualmente é Professor do Instituto Federal de Educação, Ciência e Tecnologia da Paraíba (IFPB) no curso de Petróleo e Gás. Tem experiência na área de Engenharia de Materiais e Metalúrgica, com ênfase em Soldagem, atuando principalmente nos seguintes temas: Microestrutura, Propriedades Mecânicas e Revestimento. Também possui experiência em materiais tais como as ligas com memória de forma.

\section{MARIA GABRIELA DA SILVA CAVALCANTI}

Graduanda em Engenharia pelo Instituto Federal de Educação, Ciência e Tecnologia da Bahia

\section{MARIA LIDUÍNA DAS CHAGAS}

Possui graduação em Física Licenciatura pela Universidade do Estado do Rio Grande do Norte (2008), mestrado em Física pela Universidade Federal do Rio Grande do Norte (2010) e doutorado em Física pela mesma Universidade (2014), com período de estágio sanduíche no observatório Astrofísico de Catania (2012). Atualmente é professora Adjunta, com Dedicação Exclusiva, da Universidade Federal do Sul e Sudeste do Pará. Atua como Membro Permanente no Programa de Mestrado Nacional Profissional em Ensino de Física (2016-Atual). Desenvolve pesquisa em Astronomia e Astrofísica Estelar. Tem experiência na área de Astrofísica, atuando principalmente nos seguintes temas: fotometria estelar, evolução estelar, rotação diferencial, atividade cromosférica e coronal. 


\section{MARIA ROSIMAR DE SOUSA}

Possui graduação em Engenharia Mecânica pela Universidade Federal do Rio Grande do Norte (1990), mestrado em Engenharia Mecânica pela Universidade Federal do Rio Grande do Norte (1999) e doutorado em Ciência e Engenharia de Materiais pela Universidade Federal do Rio Grande do Norte (2005). Atualmente é professora do Instituto Federal do Rio Grande do Norte . Tem experiência na área de Engenharia Mecânica, com ênfase em Processos de Fabricação, Seleção Econômica, atuando principalmente nos seguintes temas: caracterização, diatomita, propriedade, revestimento e cera de carnaúba.

\section{MÁRIO AUGUSTO LOPES DE ALMEIDA}

Graduado em Engenharia de Minas pela Universidade Católica de Salvador e especialista em Engenharia de Petróleo pela Petrobras/Sepes/Diven/Senba (atual Universidade CoorporativaBA). Atualmente, trabalha na Carioca Oil \& Gas, no estudo preliminar para remoção de mercaptanas do Butano e remoção de H2S do gás da BANAGAS (Bahrein). Além disso, ele trabalhou como Engenheiro Consultor na PETROLAB SA Aracaju-SE (2014-2017), no estudo da aplicação de surfactantes em operações de perfuração de poços de petróleo e também no estudo de tratamento de gás em Manifa (Arábia Saudita) e Abu Dhabi, Campos do Emirado, com o objetivo de remover o H2S. Engenheiro de Processos e Coordenador Técnico de Projetos na WBS Gestão e Empreendimentos Ltda (2011-2013); Consultor da disciplina de Engenharia de Processos da Advance Consultoria \& Projetos (2009-2010); Supervisor e Consultor da disciplina de Engenharia de Processos da GENPRO Engenharia S.A. Salvador-BA (2007-2009); Engenheiro Consultor na UTCAM Engenharia de Petróleo Ltda. Salvador-BA (2006-2007); Engenheiro Consultor na MANA Engenharia S.A. Salvador-BA (2002-2006); Engenheiro Consultor na PETROLAB S.A. Aracaju-SE (2001-2002); Engenheiro Consultor na PETROBRAS / UN-BA (atual OU-BA), Salvador-BA (1975-1994). Tem domínio intermediário nos idiomas inglês e espanhol.

\section{MARIO HERMES DE MOURA NETO}

Ex-bolsista de Iniciação Científica do Programa Federal de Recursos Humanos (PFRH-ANP). Concluinte do curso técnico em Eletrônica no Instituto Federal de Educação, Ciência e Tecnologia do Rio Grande do Norte (IFRN), bacharelando em Engenharia Química pela Universidade Federal do Rio Grande do Norte (UFRN). Possui experiência na área de Eletrônica, com ênfase em Sensores Eletrônicos e Plataformas de Prototipagem (Arduino/PIC), e em Química, com ênfase em Processos de Adsorção, Instrumentação para Química Analítica e Síntese de Biodiesel.

\section{MATEUS FERNANDES MONTEIRO}

Atualmente é pesquisador da Universidade Federal do Rio Grande do Norte. Tem experiência na área de Engenharia Química, com ênfase em Termodinâmica Química, atuando principalmente nos seguintes temas: solubilidade de dióxido de carbono em altas pressões, solubilidade de sais e modelagem termodinâmica de processos.

\section{NATHALIA OLIVEIRA ARAÚJO}

Formada em Engenharia de Petróleo pela Universidade Federal de Campina Grande desde 2016. Realizou pesquisas na área de tratamento de efluentes da indústria com argilas organofílicas entre 2012 e 2013 e na área de biocombustíveis entre 2013 e 2015. 


\section{OSVALDO CHIAVONE FILHO}

Possui graduação em Engenharia Química pelo Centro Universitário da FEI (1985), mestrado em Engenharia Química pela Universidade Federal do Rio de Janeiro no PEQ-COPPE (1988) e doutorado em Engenharia Química pela Universidade Técnica da Dinamarca-DTU-IKT (1993). Atualmente é professor titular da Universidade Federal do Rio Grande do Norte. Tem ativa experiência em pesquisa em Termodinâmica Química Aplicada para o Projeto de Processos e em Tratamento de Efluentes e Resíduos com Técnicas Avançadas de Oxidação. Os seguintes temas têm sido estudados: equilíbrio de fases, fotodegradação, propriedades físico-químicas, desenvolvimento de dispositivos experimentais, como célula PVTx, flotação, floculação, absorção, remediação de solos, destilação solar, e para o tratamento de resíduos com oxidação avançada. A análise, modelagem e cálculo de dados de bancada e de processos também são aplicadas com ajuda de ferramentas computacionais.

\section{PAULA FABIANE PINHEIRO DO NASCIMENTO}

Doutoranda do Programa de Pós Graduação em Engenharia Química, da Universidade Federal do Rio Grande do Norte (PPGEQ/UFRN), na área de Engenharia Ambiental, Mestre e Graduada em Engenharia Química (UFRN). Possui experiência no desenvolvimento/tratamento de materiais sólidos visando sua aplicação nas Tecnologias de Adsorção, direcionadas para a mitigação de contaminantes ao meio ambiente.

\section{PAULO SANTOS DE ALMEIDA}

Doutor em Direito (PUC/SP); Mestre e Graduado em Direito (Mackenzie/SP); Pós doutorado (Visiting Scholar) pela University of California in San Diego. Professor de Direito Ambiental no curso de Gestão Ambiental (graduação) no Programa de Pós-graduação em Sustentabilidade (onde também é orientador), ambos na EACH/USP. Consultor Jurídico e Advogado. Ex-diretor Executivo e Presidente da Fundação para a Conservação e a Produção Florestal do Estado de São Paulo (Fundação Florestal). Assessor Técnico da Superintendência de Gestão Ambiental da Universidade de São Paulo (SGA-USP).

\section{PEDRO VICTOR BOMFIM BAHIA}

Graduado em Química Bacharelado pela Universidade Federal da Bahia (2019). Atualmente, é discente do Programa de Pós-Graduação em Química (UFBA). Tem experiência em processos de sorção utilizando biomassas na remoção de óleo cru presente em águas oleosas. Atualmente, estuda compostos sulfurados de origem petroquímica nos sedimentos da Baía de todos os Santos por GC-MS.

\section{POLLYANA CAETANO RIBEIRO FERNANDES}

Possui Graduação em Engenharia de Materiais (2005), Mestrado (2007) e Doutorado em Engenharia de Materiais (2011), todos pela Universidade Federal de Campina Grande (UFCG). Professora adjunta IV do Departamento de Engenharia de Energia Renováveis da UFPB. Tem experiência na área de obtenção e caracterização de materiais aplicados a Energias Renováveis, tais como células solares não convencionais, com ênfase em Nanotecnologia. Atua também na obtenção de nanocatalisadores mistos para fotocatálise solar e para produção de biocombustíveis. 


\section{RAFAEL SANTOS DA COSTA}

Atualmente é graduando de Licenciatura em Matemática pela Universidade Federal do Pará (UFPA). É aluno de iniciação científica, realiza pesquisas nos seguintes temas: nanomagnetismo aplicado à hipertermia magnética.

\section{RAFAELY ANGÉLICA FONSECA BANDEIRA}

Possui graduação em Engenharia Civil pela Universidade Potiguar (2014). Especialista em engenharia de segurança do trabalho (2017). Mestre em engenharia de petróleo e gás (2015). Doutora em engenharia de petróleo e gás na UFRN (2019). Tecnica de segurança do trabalho da Universidade Federal Rural do Semi-Árido de 2008 a 2019. Atuou como professora substituta na UFERSA. Atuou como Professora DNSII na Universidade Potiguar. Ministrou aula na pós graduação de gerenciamento de resíduos sólidos e de Engenharia de Segurança do trabalho. Realizou perícias técnicas para a Justiça Federal e o Ministério Público do Rio Grande do Norte. Tem experiência na área de Engenharia Civil, com ênfase em Engenharia Civil, atuando principalmente nos seguintes temas: resíduos e grupo de trabalho.

\section{RAYANNE SAMARA DE SOUSA REINALDO}

Formação técnica em Biocombustível (2013) pelo Instituto Federal de Educação Ciência e Tecnologia do Rio Grande do Norte campus Apodi. Bacharela em Ciência e Tecnologia (2017) pela Universidade Federal do Rio Grande do Norte. Atualmente, é graduanda em Engenharia Mecânica pela Universidade Federal do Rio Grande do Norte. Áreas de maior interesse: Biocombustíveis e materiais compósitos.

\section{REGINA CÉLIA PEREIRA MARQUES}

Possui graduação em Ciências Biológicas pela Universidade do Estado do Rio Grande do Norte (1999), mestrado em Genética e Biologia Molecular pela Universidade Federal do Rio Grande do Norte(2001) e doutorado em Ciências Biológicas (Microbiologia) pela Universidade de São Paulo(2008). Atualmente é Docente da Universidade Potiguar, Docente da Universidade do Estado do Rio Grande do Norte, Revisor de periódico da Holos (Natal. Online), Membro de comitê assessor da (CNPq) Conselho Nacional de Desenvolvimento Científico e Tecnológico, do Centro de Oncologia e Hematologia de Mossoró e Revisor de periódico da Runpetro. Tem experiência na área de Microbiologia. Atuando principalmente nos seguintes temas: Caulobacter crescentus, Alquiltransferência, Genômica Funcional, Lesão no DNA, Reparo por excisão de nucleotídeo.

\section{ROGÉRIO NAVARRO CORREIA DE SIQUEIRA}

Graduou-se no ano de 2002 em Engenharia Química pela Pontifícia Universidade Católica do Rio de Janeiro (PUC-Rio). Obteve o título de mestre em Engenharia de Materiais e de Processos Químicos e Metalúrgicos pelo Departamento de Engenharia de Materiais (DEMa) da PUC-Rio em 2005. No mesmo departamento obteve o título de doutor em Engenharia de Materiais e Processos Químicos e Metalúrgicos em 2009. Atualmente se encontra vinculado ao Departamento de Engenharia Química e Materiais da PUC-Rio, onde atua como professor assistente, participando do desenvolvimento de pesquisas voltadas à cloração, redução seletiva de misturas de óxidos com hidrogênio, e catálise aplicada à gaseificação da biomassa. É Coordenador do Curso de Engenharia Química da PUC-Rio. 


\section{ROSANGELA REGIA LIMA VIDAL}

Docente do Departamento de Físico-Química do Instituto de Química da Universidade Federal da Bahia, desde 2010. Graduada em Engenharia Química (1998), mestre em Química (2001) e doutora em Química (2006) pela Universidade Federal do Rio Grande do Norte. Fez PósDoutorado, em 2010 na UFRN, financiado pela CAPES, e em 2015-2016 na École Nationale Supérieuse des Techniques Insdustrielles et des Mines d'Alès, em Alès, França, financiado pelo CNPq. Tem atuado nos últimos anos na utilização de biomassas e biopolímeros na remoção de óleo cru derramado e presente em águas oleosas emulsionadas.

\section{ROSANNE GRAZIELE VIEIRA DE MELO SANTOS}

Graduated in Oil \& Gas Technology - UNIT, Chemical Technician - IFS, Drilling, Stimulation and Well Completion Specialist - UFRN and accredited PMP® / PMI. Areas of interest are basically focused on best practices for project / team management with a focus on chemical development with application in petroleum systems. The process of development of new technologies encompasses several activities: identification of demand, critical analysis, identification of possibilities of action, chemical analysis, commercial analysis, planning / execution of laboratory and field tests, analysis of results, application of new technology in the field and customer validation. During such activities, the application of good management practices is of paramount importance for success. Worked for 6 years at Petrolab Industrial and Comercial LTDA, where I was responsible for the technical and commercial development of the Petrobras Northeast oil basins.

\section{SANDRO LUIS DA COSTA ALVES}

Possui Mestrado em Gestão e Tecnologia Industrial, especialização em Engenharia de Petróleo, graduação em Engenharia Agrícola e graduação em Engenharia de Petróleo. Atualmente é Professor EBTT e coordenador dos cursos técnicos em Eletromecânica e Petróleo e Gás do IFMA - Campus Pedreiras, foi professor no Centro Estadual de Educação Profissional Pedro Ribeiro Pessoa lecionando disciplinas específicas do curso técnico em Petróleo e Gás, também foi professor especialista da Faculdade Regional da Bahia nos cursos de Tecnologia de Petróleo e Gás, Engenharia de Petróleo e Engenharia Civil, foi professor horista no SENAI - Departamento Regional da Bahia na área de petróleo e gás. Tem experiência na área de Petróleo e gás, quando atuou na SOTEP - Sociedade Técnica de Perfuração, tendo experiência em Avaliação de reservatórios de petróleo, perfuração e completação de poços de petróleo, bem como estimulação e equipagem de poços de petróleo. Atualmente Desenvolve pesquisa na área de escoamento de petróleo em linhas de produção, métodos de recuperação de reservatório de petróleo, desparafinação de linhas de produção e meio ambiente e petróleo.

\section{SCARLLET O'HARA DE OLIVEIRA MORAES}

Tecnóloga em Produção Sucroalcooleira e mestre em Energias Alternativas e Renováveis com ênfase em cogeração de bioenergia no setor sucroalcooleiro a partir de resíduos agroindustriais pela Universidade Federal da Paraíba. Atualmente integrante Grupo de Pesquisa em Gestão, Bioenergia e Sustentabilidade Ambiental pela Universidade Federal de Sergipe.

\section{SEBASTIÃO HENRIQUE CAMILO DA SILVA}

Graduando do $10^{\circ}$ período de Engenharia de Petróleo pelo Centro Universitário Tiradentes (UNIT- AL), curso profissional em Petróleo e Gás (MICROLINS), membro do Capítulo Estudantil da Society of Petroleum Engineers - SPE. Atuando na área de petróleo como assistente de encarregado. 


\section{SELMO QUEIROZ ALMEIDA}

Possui graduação em Química Industrial pela Universidade Federal da Bahia (1999), Mestrado em Regulação da Indústria de Energia pela Universidade Salvador (2002) e Doutor Química Analítica na UFBA (2018) e Professor Adjunto e Coordenador Laboratórios Engenharias Campus Federação da Universidade Salvador - UNIFACS. Gerente de Qualidade do Laboratório de Combustíveis do IBTR (UNIGEL-Camaçari-BA). Tem experiência em Química dos Combustíveis e Biocombustíveis. Cursos EAD: Competências para o Ciclo de Desenvolvimento de Inovações (UFSC), Curso Geral de Propriedade Intelectual (INPI) e Laureate Certificate in Teaching and Learning in Higher Education.

\section{SIMONI MARGARETI PLENTZ MENEGHETTI}

Bacharel em Química (1992) pela Universidade Luterana do Brasil, Mestre em Química ? Ênfase em Catálise pela Universidade Federal do Rio Grande do Sul (sob a supervisão de Profa. Dra. Michele Oberson de Souza, em 1996) e Doutora em Físico-Química de Materiais Macromoleculares (sob a supervisão do. Dr. Pierre J. Lutz e Dr. Jacky Kress, na Université Louis Pasteur? Strasbourg I, França, em 2000). Atualmente é Professora Associada e Pesquisadora da Universidade Federal de Alagoas. Tem pós-doutorado na Université Louis Pasteur Strasbourg, ULP, Strasbourg, França e na UFAL, ambos envolvendo aspectos de catálise e oleoquímica.

\section{THAÍS DA SOLVA BITENCOURT}

Discente do Curso de Engenharia Química pela Universidade Federal da Bahia. Tem experiência em processos de sorção utilizando biomassas na remoção de óleo cru derramado e em águas oleosas. Atualmente, é estagiária na área de processos e análises químicas e tem interesse em seguir carreira na área industrial.

\section{THAIS MENDONÇA DE CARVALHO}

Estudante de Engenharia Química na Pontifícia Universidade Católica do Rio de Janeiro (PUCRio) (2015-2020) e bolsista CNPQ pela PUC-Rio.

\section{THIAGO RAFAEL DA SILVA MOURA}

É graduado, mestre e doutor em Física pela Universidade Federal do Rio Grande do Norte. Atualmente é professor de Física na Universidade Federal do Pará (UFPA) em Salinópolis-PA. É membro pesquisador associado do Laboratório de Inovação Interdisciplinar - LabX, da Universidade Federal do Pará. Realiza pesquisa nos seguintes temas: transporte eletrônico em DNA/ RNA, sistemas magnéticos, processos epidêmicos, caminhadas aleatórias, processos estocásticos não-Markovianos e Inteligência Artificial.

\section{TURAN DIAS OLIVEIRA}

Mestre em modelagem computacional pela Faculdade de Tecnologia SENAI CIMATEC. Graduação em Engenharia Mecânica pela Universidade Federal da Bahia (UFBA). Tem especial interesse em aplicações computacionais para a engenharia de energia. Trabalha hoje com a análise de desempenho de equipamentos via Dinâmica dos Fluidos Computacional (CFD) e com tecnologias para energias renováveis. 


\section{VICTOR HENRIQUE ROCHA SALES}

Formato em engenharia de Petróleo pela Universidade de Barra Mansa, atualmente trabalhando na empresa Bimbo do Brasil.

\section{VITÓRIA CAMILA PAIXÃO DOS SANTOS}

Graduanda no Sétimo período em Engenharia de Petróleo pelo Centro Universitário Tiradentes (UNIT), em Alagoas, estudante do quarto período de Controle e Processos Industriais na área habilitação em Química pelo Instituto Federal de Educação, Ciência e Tecnologia de Alagoas (IFAL), no Campus Maceió. Estagiaria na COPRA Alimentos, no setor de Controle de Produção e Qualidade. É auxiliar da secretaria da Society of Petroleum Engineers Unit-AL

\section{WELLINGTON DA SILVA RODRIGUES}

Professor licenciado na disciplina de geografia, pela Universidade Estadual do Ceará. Atuou durante cinco anos em escolas públicas e privadas da Paraíba. Formado também no curso Superior de Tecnologia em Produção Sucroalcooleira, pela Universidade Federal da Paraíba. Atualmente trabalha como encarregado de laboratório de controle industrial e microbiológico

\section{WELLINGTON DOS SANTOS DE ARAÚJO}

Graduando do $10^{\circ}$ período de Engenharia de Petróleo pelo Centro Universitário Tiradentes (UNIT- AL), Cursando Técnico em Eletrotécnica pela escola Técnica Residência- AL, membro do Capítulo Estudantil da Society of Petroleum Engineers - SPE.

\section{YASMIN GEISSIANA MARINHO DE MENEZES}

Técnica em Petróleo e Gás pelo Instituto Federal da Paraíba, Campus Campina Grande

\section{ZORAIDA ROXANA TEJADA DA PIEDADE}

Possui graduação em Engenharia Geofísica na Universidade Nacional de San Agustin em 2008. Trabalhou Na CGG-Véritas no período de 2010 a 2012, em Controle de Qualidade, suporte de Operações em Aquisições Sísmicas terrestre 2D e 3D, selamento de poços de adquisição, e prestou serviços de consultoria em processamento sísmico $2 \mathrm{D}$, também possui experiência na modelagem, processamento e interpretação de dados GPR. Atualmente, trabalha na Universidade Federal do Amazonas, no Departamento de Geociências como professora na área de Geofísica. 
Agência Brasileira do ISBN ISBN 978-85-7042-113-5

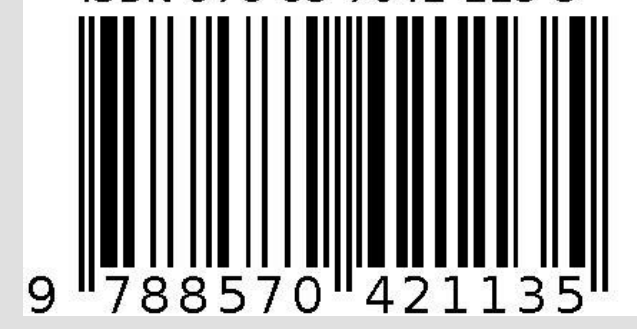

